\title{
Impacts Analyses Supporting the National Environmental Policy Act Environmental Assessment for the Resumption of Transient Testing Program
}

November 2013

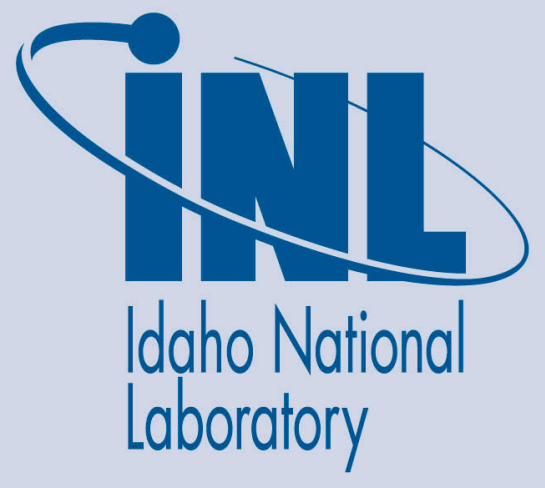

The INL is a U.S. Department of Energy National Laboratory operated by Battelle Energy Alliance 


\section{DISCLAIMER}

This information was prepared as an account of work sponsored by an agency of the U.S. Government. Neither the U.S. Government nor any agency thereof, nor any of their employees, makes any warranty, expressed or implied, or assumes any legal liability or responsibility for the accuracy, completeness, or usefulness, of any information, apparatus, product, or process disclosed, or represents that its use would not infringe privately owned rights. References herein to any specific commercial product,

process, or service by trade name, trade mark, manufacturer, or otherwise, does not necessarily constitute or imply its endorsement, recommendation, or favoring by the U.S. Government or any agency thereof. The views and opinions of authors expressed herein do not necessarily state or reflect those of the U.S. Government or any agency thereof. 


\section{Impacts Analyses Supporting the National Environmental Policy Act Environmental Assessment for the Resumption of Transient Testing Program}

November 2013

Idaho National Laboratory Idaho Falls, Idaho 83415

http://www.inl.gov

Prepared for the

U.S. Department of Energy

Office of Nuclear Energy

Under DOE Idaho Operations Office

Contract DE-AC07-05ID14517 



\begin{abstract}
This document contains the analysis details and summary of analyses conducted to evaluate the environmental impacts for the Resumption of Transient Fuel and Materials Testing Program. It provides an assessment of the impacts for the two action alternatives being evaluated in the environmental assessment. These alternatives are (1) resumption of transient testing using the Transient Reactor Test Facility (TREAT) at Idaho National Laboratory (INL) and (2) conducting transient testing using the Annular Core Research Reactor (ACRR) at Sandia National Laboratory in New Mexico (SNL/NM). Analyses are provided for radiologic emissions, other air emissions, soil contamination, and groundwater contamination that could occur (1) during normal operations, (2) as a result of accidents in one of the facilities, and (3) during transport. It does not include an assessment of the biotic, cultural resources, waste generation, or other impacts that could result from the resumption of transient testing.

Analyses were conducted by technical professionals at INL and SNL/NM as noted throughout this report. The analyses are based on bounding radionuclide inventories, with the same inventories used for test materials by both alternatives and different inventories for the TREAT Reactor and ACRR. An upper value on the number of tests was assumed, with a test frequency determined by the realistic turn-around times required between experiments. The estimates provided for impacts during normal operations are based on historical emission rates and projected usage rates; therefore, they are bounding. Estimated doses for members of the public, collocated workers, and facility workers that could be incurred as a result of an accident are very conservative. They do not credit safety systems or administrative procedures (such as evacuation plans or use of personal protective equipment) that could be used to limit worker doses. Doses estimated for transportation are conservative and are based on transport of the bounding radiologic inventory that will be contained in any given test. The transportation analysis assumes all transports will contain the bounding inventory.
\end{abstract}




\section{CONTRIBUTORS}

The following people have either contributed to creation of this document or have supplied key technical analyses:

Annette L. Schafer, Idaho National Laboratory

Lloyd C. Brown, Idaho National Laboratory

David C. Carathers, Sandia National Laboratory

Boyd D. Christensen, Idaho National Laboratory

James J. Dahl, Sandia National Laboratory

Mark L. Miller, Sandia National Laboratory

Cathy Ottinger Farnum, Sandia National Laboratories

Steven Peterson, Oak Ridge National Laboratory

A. Jeffrey Sondrup, Idaho National Laboratory

Peter V. Subaiya, Sandia National Laboratory

Daniel M. Wachs, Idaho National Laboratory

Ruth F. Weiner, Sandia National Laboratories 


\section{CONTENTS}

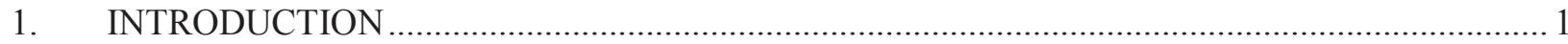

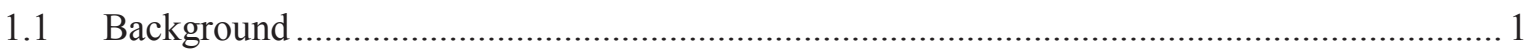

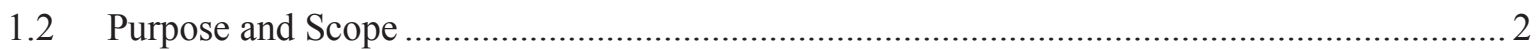

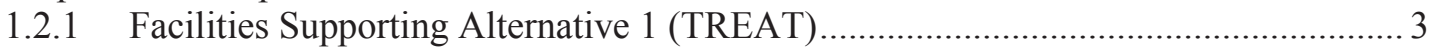

1.2.2 Facilities Supporting Alternative 2 (ACRR) ........................................................ 4

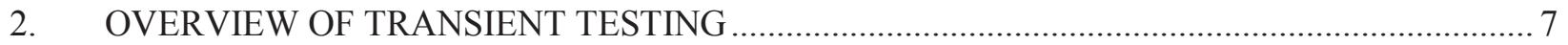

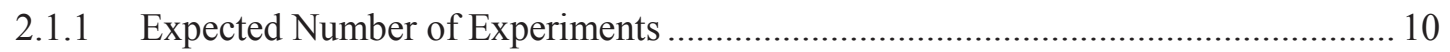

2.2 Overview of Transient Testing using the Transient Reactor Test Facility.......................... 10

2.2.1 Transient Reactor Test Facility Background Information........................................ 10

2.2.2 Experimental Sequence using the Transient Reactor Test Facility ........................... 11

2.3 Overview of Transient Testing Using the Annular Core Research Reactor ........................ 13

2.3.1 Annular Core Research Reactor Background Information ..................................... 13

2.3.2 Experimental Sequence using the Annular Core Research Reactor.......................... 14

3. ENVIRONMENTAL IMPACTS DURING NORMAL OPERATIONS ...................................... 14

3.1 Impacts of the Experiment Fuel During Transient Testing ............................................... 15

3.2 Impacts of Normal Operations using the Transient Reactor Test Facility ........................... 16

3.2.1 Diesel Generator Emissions .................................................................................. 17

3.2.2 Non-Radiologic Emissions from the Transient Reactor Test Facility Stack.............. 18

3.2.3 Radiologic Emissions from the Transient Reactor Test Facility Stack..................... 18

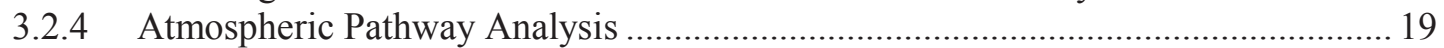

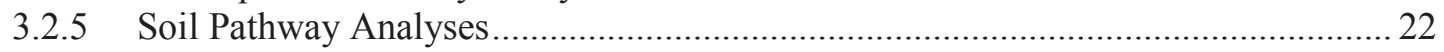

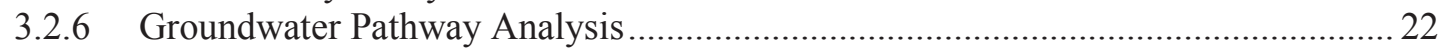

3.3 Impacts of Normal Test Reactor Operations using the Annular Core Research

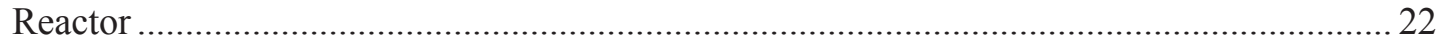

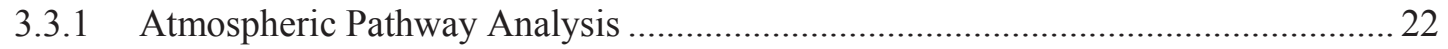

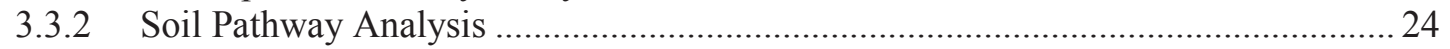

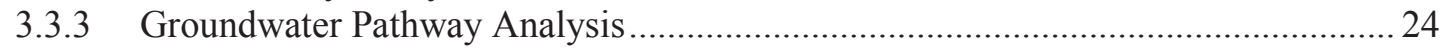

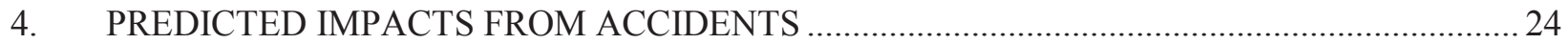

4.1 Accident Consequences for Alternative 1 (Use of the Transient Reactor Test Facility

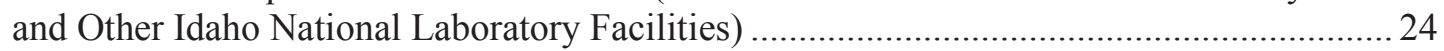

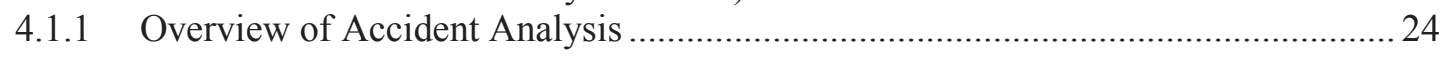

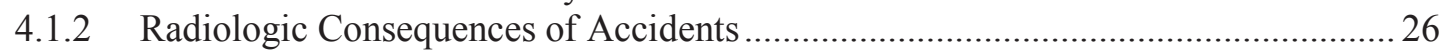

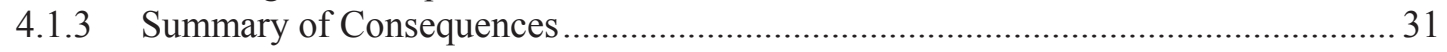

4.1.4 Incorporation into the Environmental Assessment ................................................ 31

4.2 Accident Consequences for Alternative 2 (Use of the Annular Core Research

Reactor and Idaho National Laboratory Facilities) ........................................................... 31

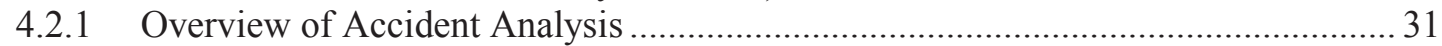

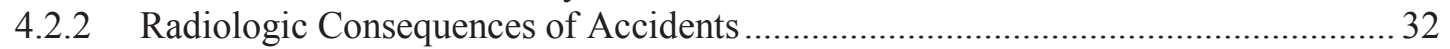

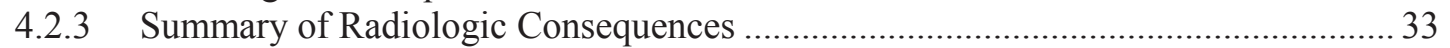

4.2.4 Incorporation into the Environmental Assessment .................................................... 33

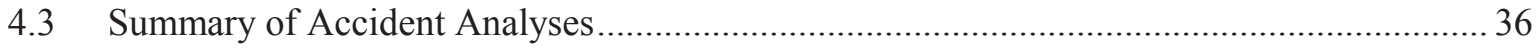

5. IMPACTS OF TRANSPORTING THE EXPERIMENT COMPONENTS …............................. 36 
5.1 Summary of the Analysis of Transportation at the Idaho National Laboratory ................... 39

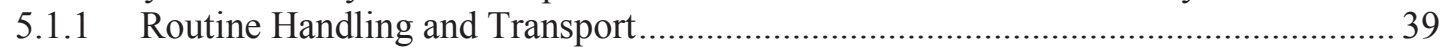

5.1.2 Transportation Accidents at Idaho National Laboratory ......................................... 41

5.2 Summary of Analysis of Transportation between the Materials and Fuels Complex and Annular Core Research Reactor ....................................................................................... 41

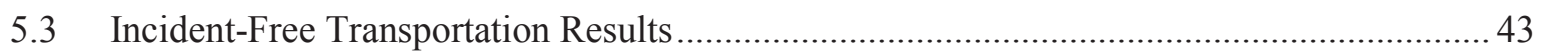

5.3.1 Transport between Idaho National Laboratory Facilities Required by Alternative 2 (ACRR) .

5.3.2 Transportation between the Materials and Fuels Complex and Sandia National Laboratory New Mexico ………........................................................... 44

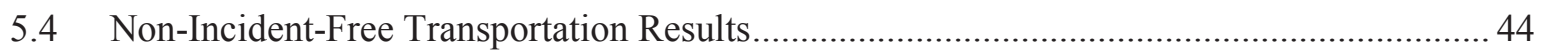

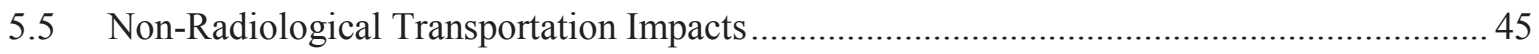

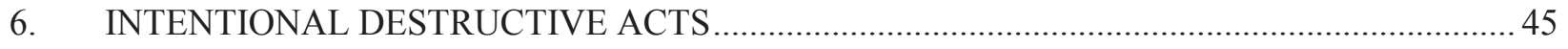

7. QUALITY ASSURANCE FOR SOFTWARE AND CALCULATIONS …............................... 46

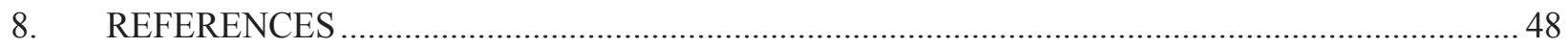

Appendix A Near-Field Environment Affected by Resumption of Transient Testing at the

Transient Reactor Test Facility............................................................................................ 1

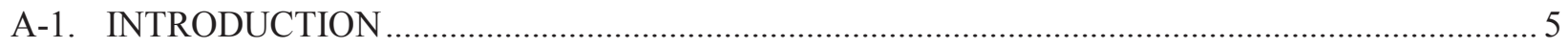

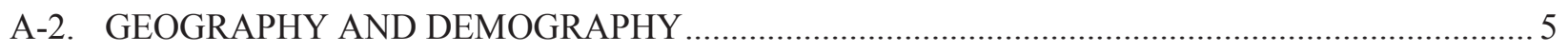

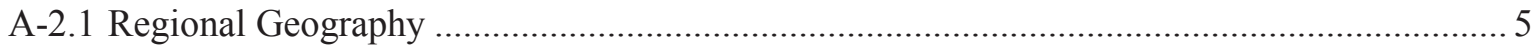

A-2.2 Geography of the Materials and Fuels Complex and the Transient Reactor Test

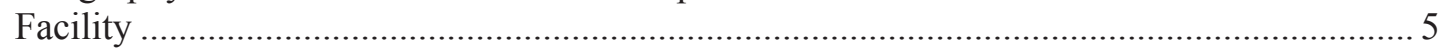

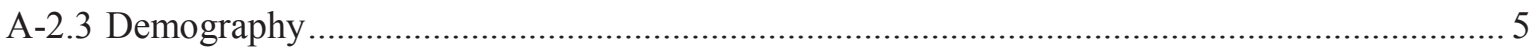

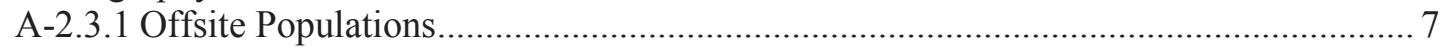

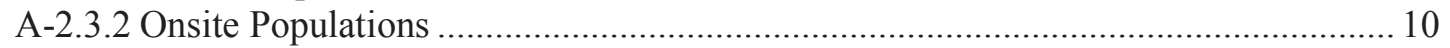

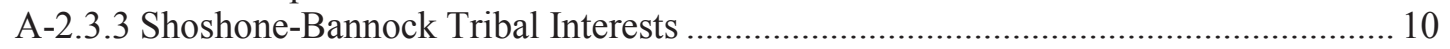

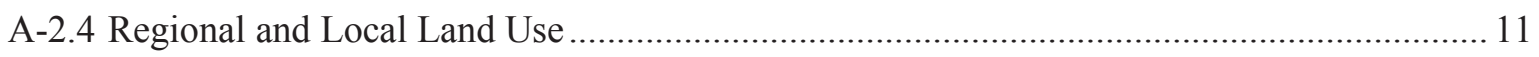

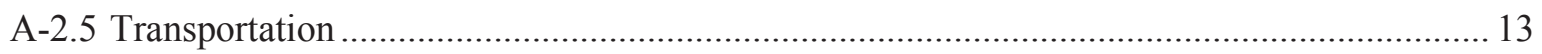

A-3. TRANSIENT REACTOR TEST FACILITY SITE CHARACTERISTICS .................................. 14

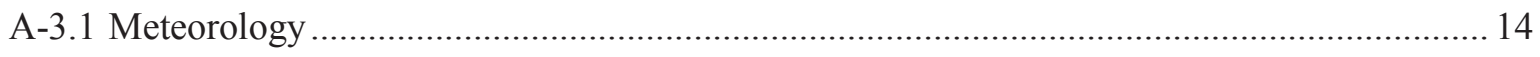

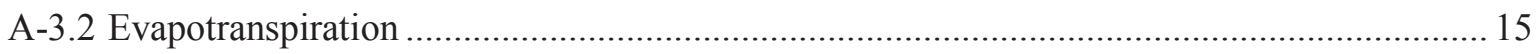

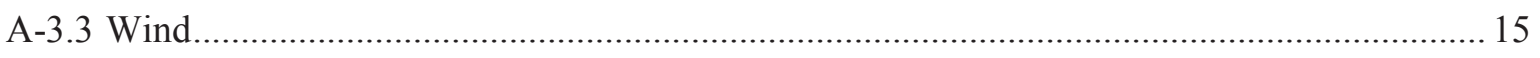

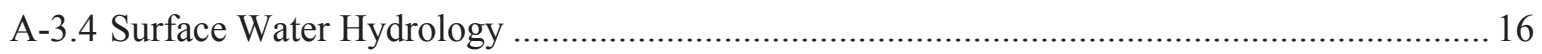

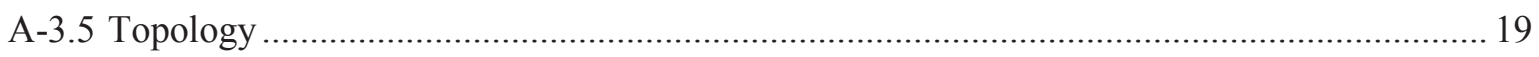

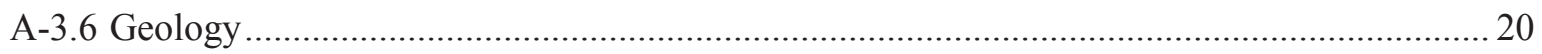

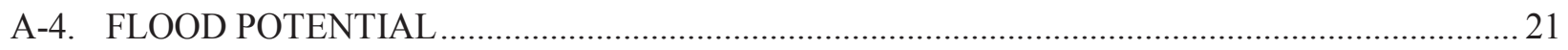

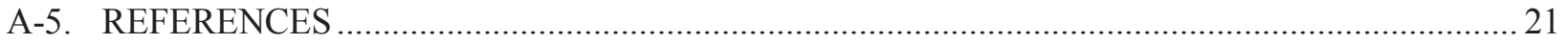


Appendix B Near-Field Environment Affected by Resumption of Transient Testing at the ACRR Facility.....

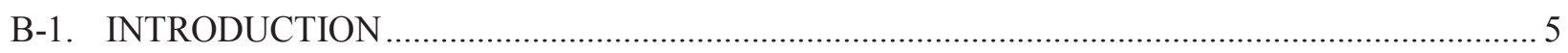

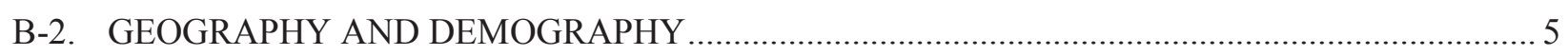

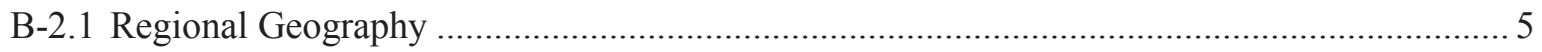

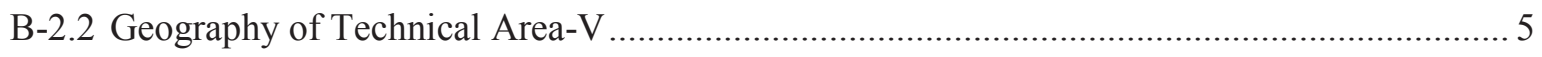

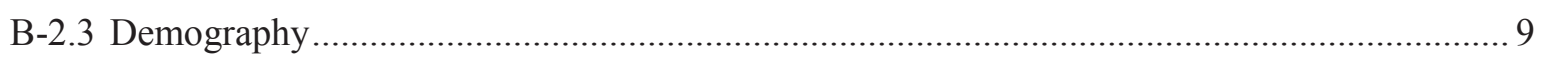

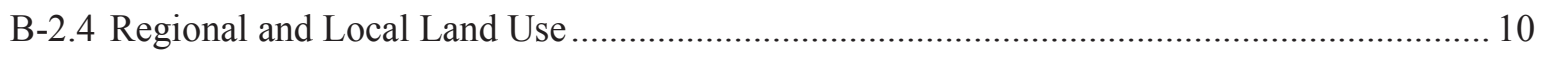

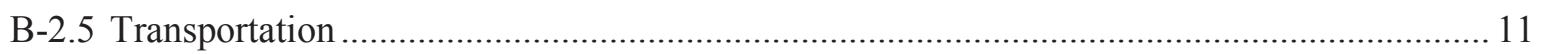

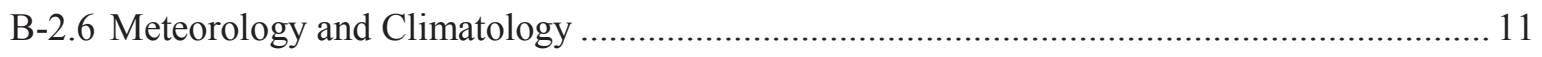

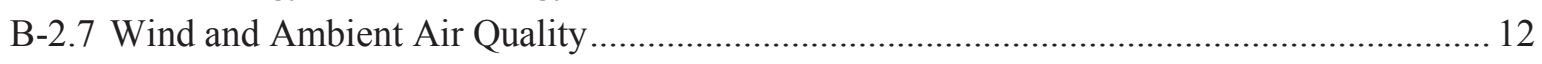

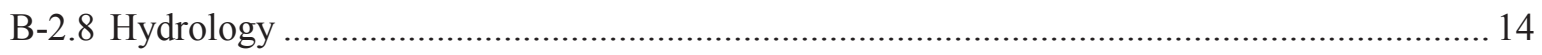

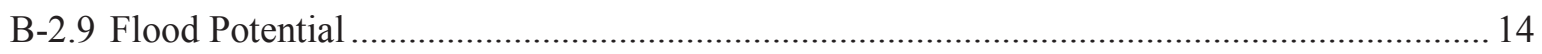

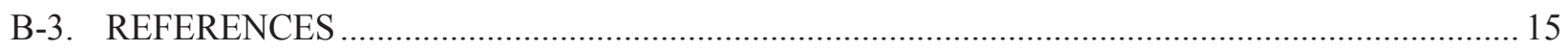

Appendix C Evaluation of the Air and Soil Pathway Doses During Normal Operations......................... 1

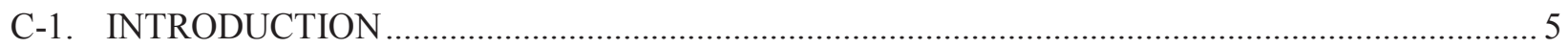

C-2. MODEL OVERVIEW AND RECEPTOR LOCATIONS .......................................................... 5

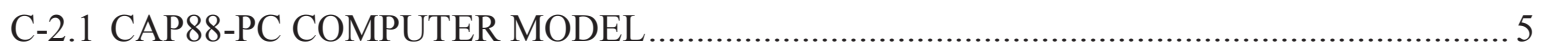

C-2.2 SELECTION OF RECEPTOR LOCATIONS ................................................................ 5

C-3. AIR PATHWAY ASSESSEMENT FOR THE TRANSIENT REACTOR TEST

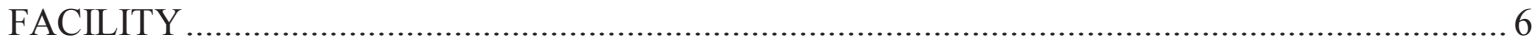

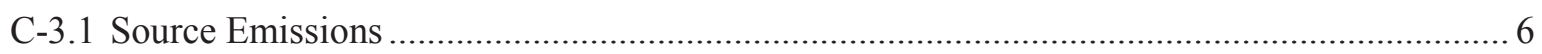

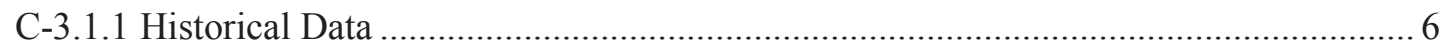

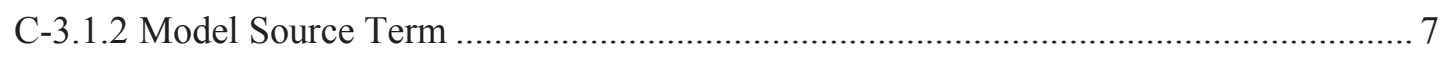

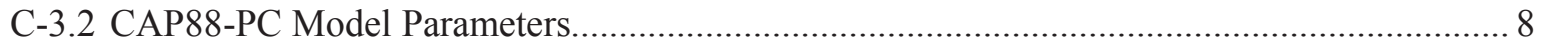

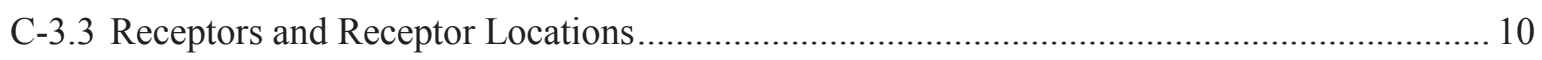

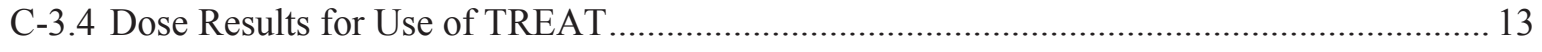

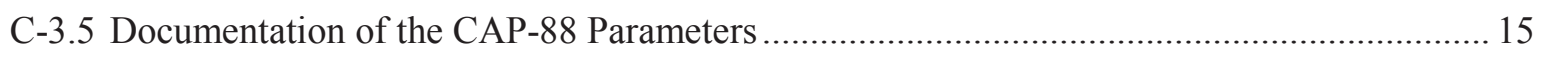

C-4. SOIL PATHWAY ASSESSEMENT FOR THE TRANSIENT REACTOR TEST

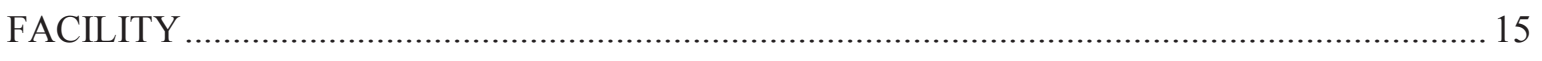

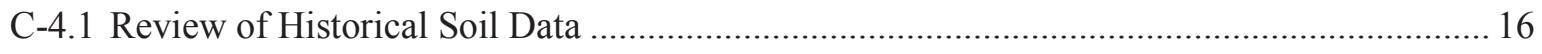

C-4.2 Projected Particulate Radionuclide Releases ................................................................ 17

C-5. AIR PATHWAY ASSESSEMENT USING THE ANNULAR CORE RESEARCH

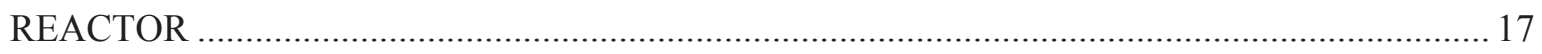

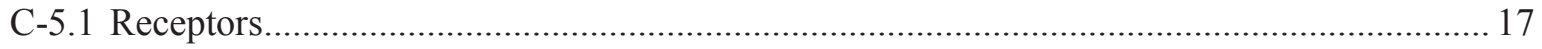

C-5.2 Source Emissions for Use of the Annual Core Research Reactor........................................ 17

C-5.3 CAP88-PC Model Parameters...................................................................................... 17 
C-5.4 Dose Results for Use of the Annular Core Research Reactor............................................ 19

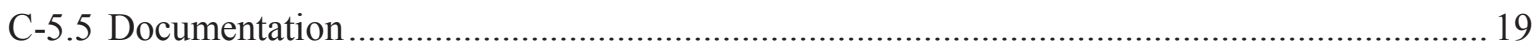

C-6. SOIL PATHWAY ASSESSEMENT USING THE ANNULAR CORE RESEARCH

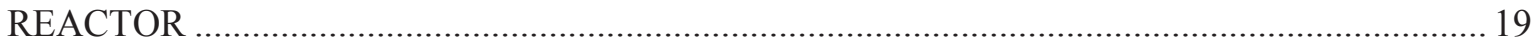

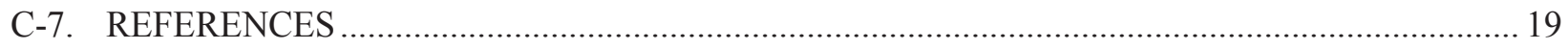

Appendix D Impacts from Operation of Diesel Generators at the Transient Reactor Test Facility ........... 1

D-1. STANDBY POWER SYSTEM (30-kw DIESEL GENERATOR) .............................................. 5

D-2. REDUNDANT POWER SYSTEM (130-kw DIESEL GENERATOR) ........................................ 5

D-3. ESTIMATED GENERATOR USAGE DURING TRANSIENT TESTING ............................... 5

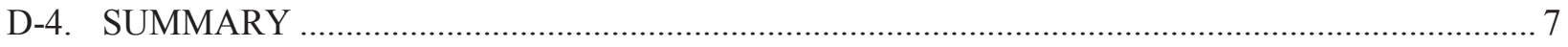

Appendix E Inventory Development for Accident and Handling Scenarios .......................................... 1

E-1. IDENTIFICATION OF THE BOUNDING EXPERIMENT RADIONUCLIDE

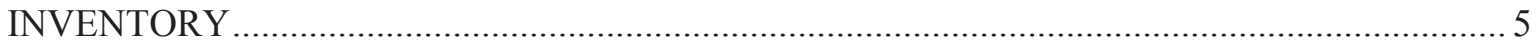

E-1.1 Dose Assessment Methodology and Parameters.............................................................. 5

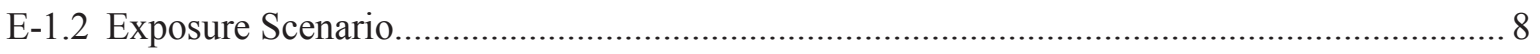

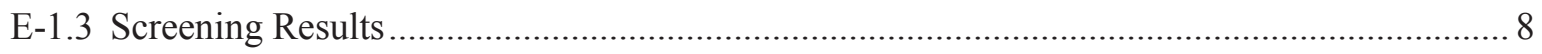

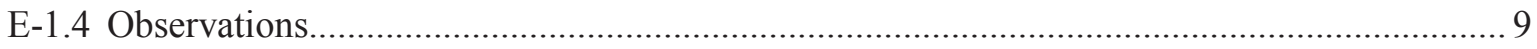

E-2. DISCUSSION OF THE BOUNDING CORE INVENTORY FOR THE REACTOR AT

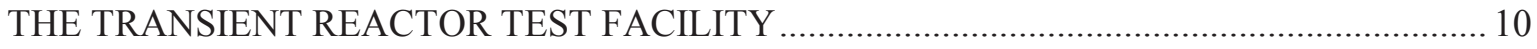

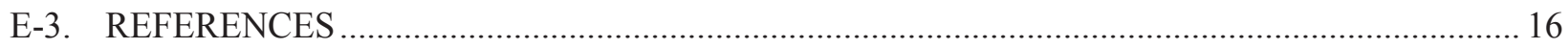

Appendix F Accident Impact Assessment for the TREAT and ACRR Facilities.................................... 1

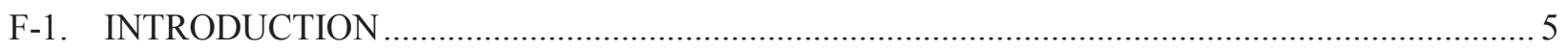

F-1.1 Accident Scenarios Identified for the Transient Reactor Test Facility ............................... 5

F-1.2 Accident Scenarios Identified for Idaho National Laboratory Facilities other than

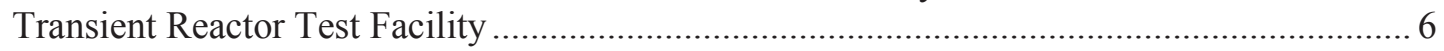

F-1.3 Accident Scenarios Identified for the Annular Core Research Reactor Facility .................... 8

F-2. DOSE ASSESSMENT METHODOLOGY AND ASSUMPTIONS …..................................... 9

F-2.1 Idaho National Laboratory Facilities …..................................................................... 9

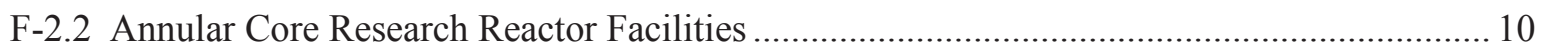

F-2.3 Differences in Dose Assessment Assumptions ............................................................ 12

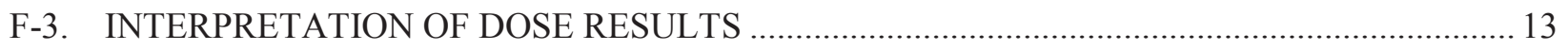

F-4. PREDICTED DOSE IMPACTS FOR ACCIDENTS AT TRANSIENT REACTOR TEST

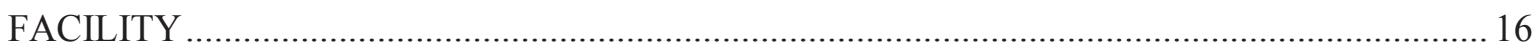




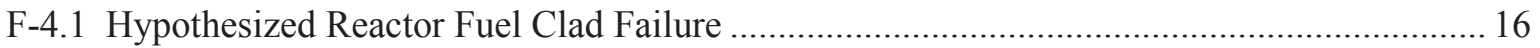

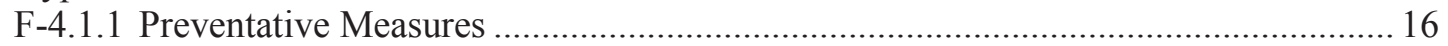

F-4.1.2 Probability of this Type of Accident Occurring ....................................................... 19

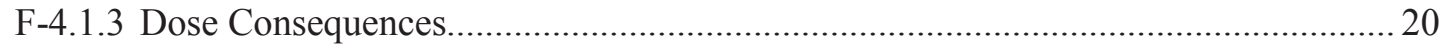

F-4.2 Hypothesized Experiment Impact/Drop Accident ........................................................... 23

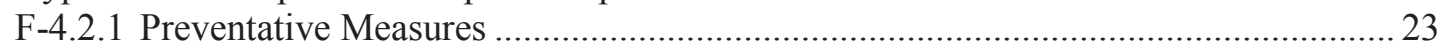

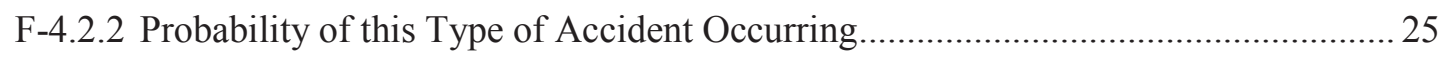

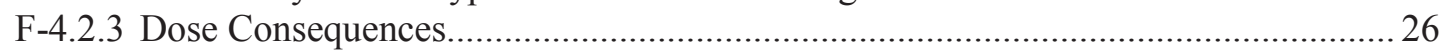

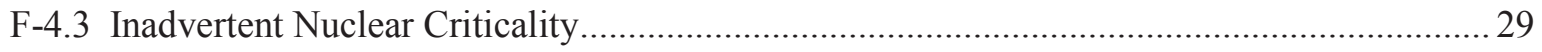

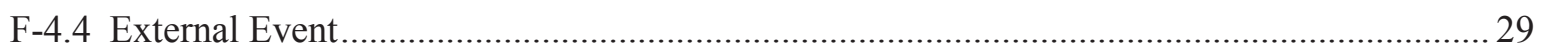

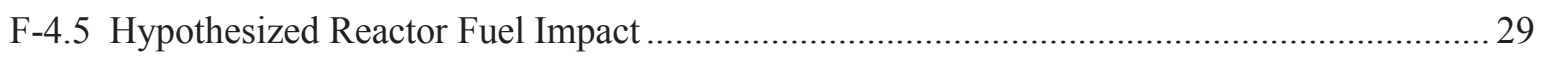

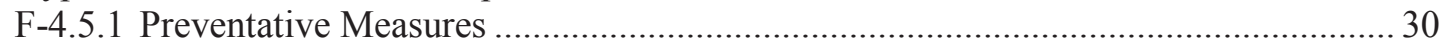

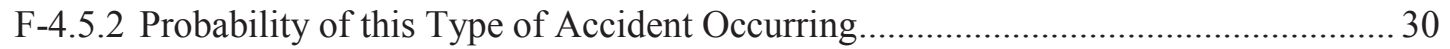

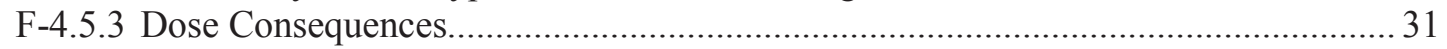

F-4.6 Hypothesized Drop of Experiment into the TREAT Reactor ........................................... 32

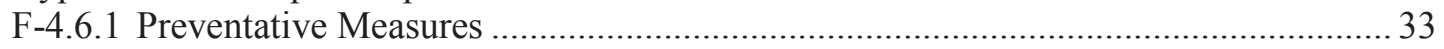

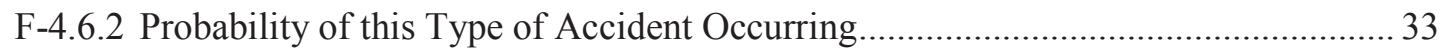

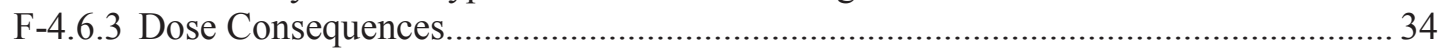

F-4.7 Hypothesized Sodium Fire Impacting the Core and Experiment...................................... 35

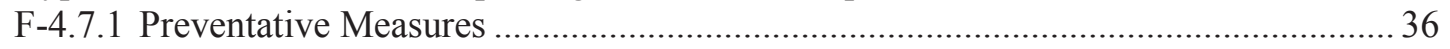

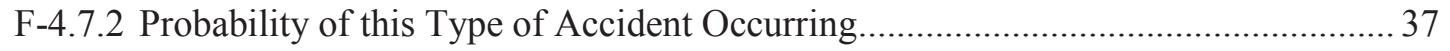

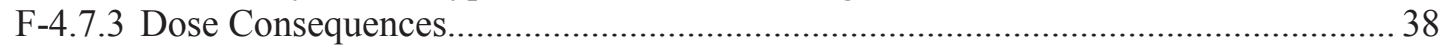

F-4.8 Cask Handling Operations at the Hot Fuel Examination Facility ........................................ 39

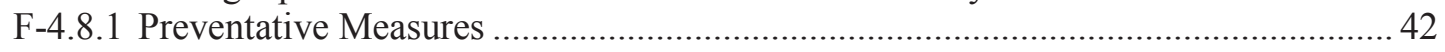

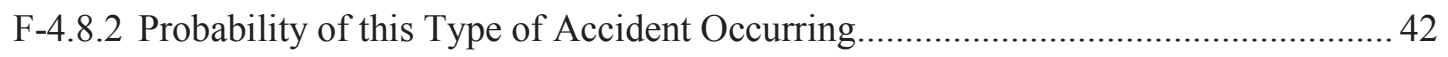

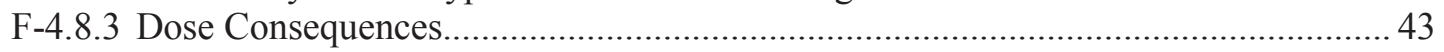

F-4.9 Overview of Accident Analysis for Alternative 1 (TREAT) ............................................ 46

F-4.9.1 Summary of Radiologic Consequences for Alternative 1 (TREAT) ....................... 47

F-5. PREDICTED DOSE IMPACTS FOR ACCIDENTS IN ALTERNATIVE 2 (ACRR) .................. 50

F-5.1 Experiment Drop or Impact Accident at the Annular Core Research Reactor .................... 50

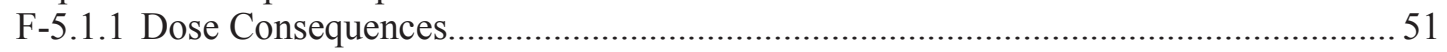

F-5.2 Rapid Over-Pressurization of the Sodium-Cooled Experiment ......................................... 52

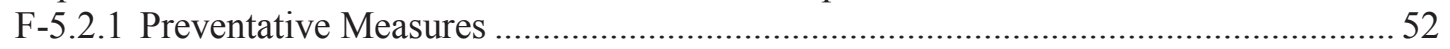

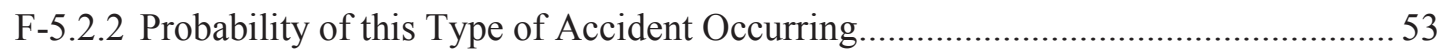

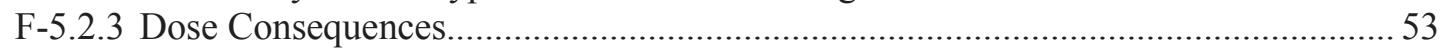

F-5.3 Releasing Melted Fuel into the Annular Core Research Reactor Central Cavity ................. 54

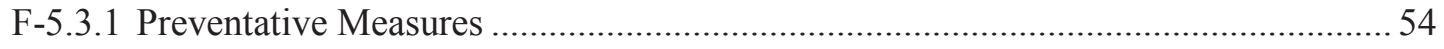

F-5.3.2 Probability of this Type of Accident Occurring ....................................................... 55

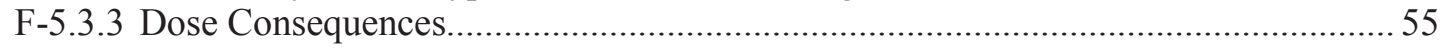

F-5.4 Summary of Impacts Using the Annular Core Research Reactor Facility ........................... 57

F-5.4.1 Overview of Accident Analysis for the Annular Core Research Reactor................. 57

F-5.4.2 Summary of Radiologic Consequences for Alternative 2 (ACRR) .......................... 57

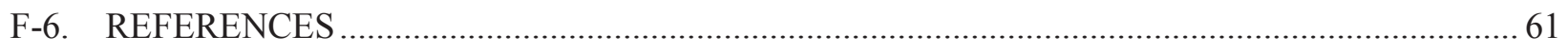

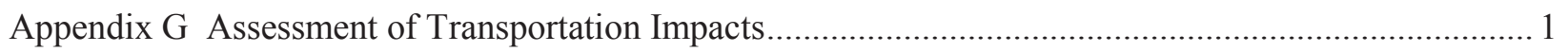




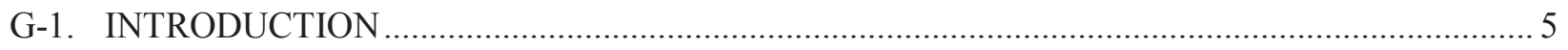

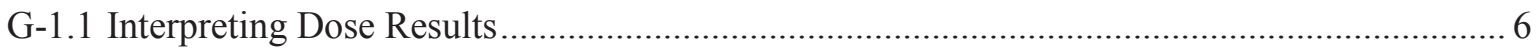

G-2. MODELS USED IN THE TRANSPORTATION ANALYSIS …............................................. 8

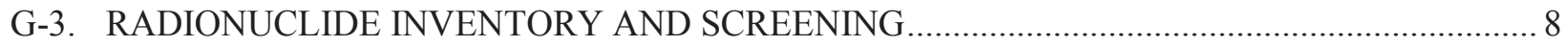

G-4. TRANSPORATION CASKS AND CASK-SPECIFIC PARAMETERS ….................................. 9

G-5. ANALYSIS OF TRANSPORTATION AT THE IDAHO NATIONAL LABORATORY ............. 10

G-5.1 Routine or Incident-Free Transportation..................................................................... 10

G-5.1.1 Transportation Routes and Route-Specific Parameters............................................ 10

G-5.1.2 Results for Routine Transportation at Idaho National Laboratory ........................... 12

G-5.2 Transportation Accidents at Idaho National Laboratory .................................................... 12

G-6. ANALYSIS OF IMPACTS FOR TRANSPORTATION BETWEEN THE MATERIALS

AND FUELS COMPLEX AND THE ANNULAR CORE RESEARCH REACTOR ................... 14

G-6.1 Transportation Routes and Route-Specific Parameters....................................................... 14

G-6.2 Transportation Casks and Cask-Specific Parameters.......................................................... 17

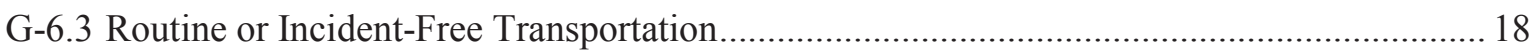

G-6.3.1 Summary of Incident-Free Transportation Impacts ............................................. 28

G-6.4 Transportation Impacts Involving an Accident Enroute between the Materials and Fuels Complex and the Annular Core Research Reactor .................................................... 30

G-6.4.1 Summary of Transportation Impacts Involving an Accident Enroute between the Material and Fuels Complex and Annular Core Research Reactor..................... 40

G-7. NON-RADIOLOGICAL TRANSPORTATION IMPACTS …................................................. 41

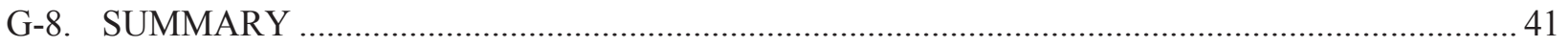

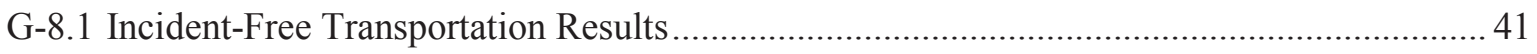

G-8.2 Non-Incident-Free Transportation Results...................................................................... 42

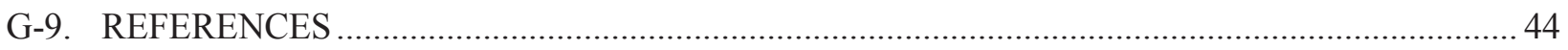

\section{FIGURES}

1. Map of the Idaho National Laboratory showing the locations of major facilities ...................... 3

2. Aerial photograph of the Materials and Fuels Complex area, including TREAT and the TREAT Reactor control building .................................................................................. 4

3. Map of facilities at the Materials and Fuels Complex …...................................................... 5

4. Location of Sandia National Laboratory, Kirtland Air Force Base, and surrounding area .......... 6

5. Location of key points of interest adjacent to Technical Area V at Sandia National

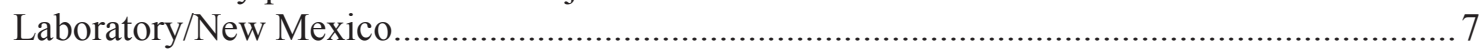


6. Photograph of the top of TREAT at the Idaho National Laboratory, showing the circular top of the fuel elements supported by the rectangular fuel plate; the experiments are usually placed in the center of the reactor.

7. Schematic diagram of a transient test reactor with an experiment inserted into the center of the reactor core

8. Mark-III and single-pin test loop, showing primary containment of the fuel pins in stainless steel tubes and secondary containment of the loop by stainless steel liners (from Guide 1991) 16

9. Public receptor locations for the air pathway analysis, showing distance and direction from TREAT (base map courtesy of Google Earth)...

10. Public receptor locations for the air pathway analysis, showing distance and direction from the ACRR (base map courtesy of Google Earth).

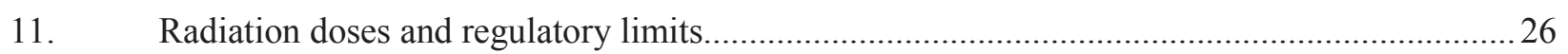

12. Transport pathways followed by the experiment fuel and assemblies ...................................... 38

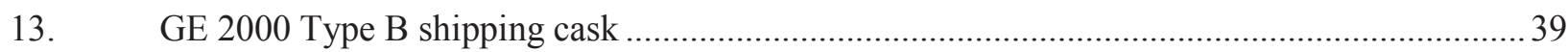

14. Transportation route between ATR and HFEF and between HFEF and TREAT Facility

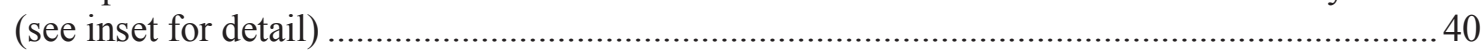

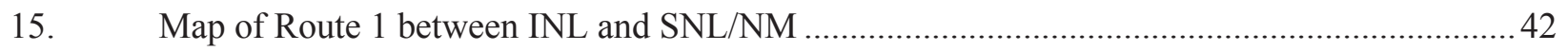

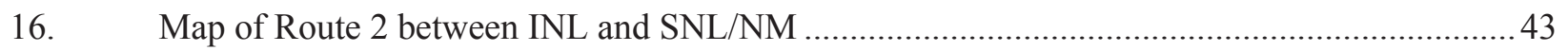

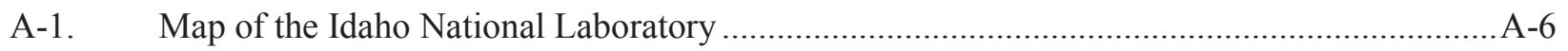

A-2. Aerial photograph of the Materials and Fuels Complex and TREAT areas .............................

A-3. 2010 population within $80 \mathrm{~km}(50 \mathrm{mi})$ of the Materials and Fuels Complex...........................

A-4. Incorporated cities within $80 \mathrm{~km}(50 \mathrm{mi})$ of the Idaho National Laboratory........................... A-9

A-5. Land ownership distribution in the vicinity of the Idaho National Laboratory Site...............A-12

A-6. Location of the Idaho National Laboratory site on the Snake River Plain aquifer in Idaho ......

A-7. Materials and Fuels Complex wind rose for the 15-m height for the period April 1993 through March 2013 A-16

A-8. Idaho National Laboratory-related watersheds (United States Geological Survey 8digit "cataloging units") (from INL 2010a).

A-9. Topographic map of the Materials and Fuels Complex and TREAT in the Medicine Lodge cataloging unit (from INL 2010a) A-18 
A-10. General topography of Materials and Fuels Complex and TREAT watersheds (from INL 2010a) .

A-11. Aerial photo of TREAT, with the Materials and Fuels Complex in the background

B-1. Sandia National Laboratory, Kirtland Air Force Base, and surrounding area.....

B-2. Technical Areas at Sandia National Laboratory (corresponding to inset area shown in Figure B-1)

B-3. Location of the Annular Core Research Reactor in Technical Area V at Sandia National Laboratory B-8

B-4. State of New Mexico Map showing major roads, cities, and county lines

B-5. Normal operational onsite and core receptor locations (from DOE 1999) B-10

B-6. Road access to SNL/NM Technical Areas and the U.S. Forest Service Land withdrawn area

B-7. 2011 annual wind roses for daytime and nighttime wind frequency at the A36 tower B-13

B-8. Arroyos, floodplains, and springs at Kirtland Air Force Base (from SNL-SWEIS 1999) ..... B-15

C-1. Public receptor locations for the air pathway analysis showing distance and direction from TREAT (base map courtesy of Google Earth)

C-2. Worker receptor location for the air pathway analysis showing the distance and direction of building MFC-721 from TREAT (base map courtesy of Google Earth)

C-3. Total dose (mrem/year) by sector at the maximally exposed individual distance of $20.85 \mathrm{~km}$ from TREAT

C-4. Public receptor locations for the air pathway analysis, showing distance and direction from the Annular Core Research Reactor (base map courtesy of Google Earth) C-18

F-1. Hot Fuel Examination Facility elevation view facing north .............................................. F-7

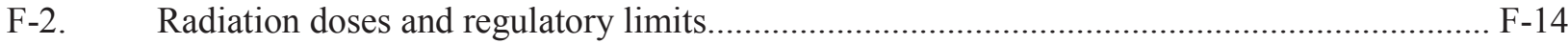

F-3. TREAT Reactor building main floor layout ................................................................. F-18

F-4. Fault tree for determining reactor design basis accident probability ................................ F-21

F-5. Mark-III and single-pin test loop showing primary containment of the fuel pins in stainless steel tubes and secondary containment of the loop by stainless steel liners

F-6. Fault tree for a sodium loop experiment, resulting in rapid oxidation and damage to the reactor fuel elements.

F-7. Hot Fuel Examination Facility service floor layout 
F-8. Cask tunnel and cask cart used to transfer the cask from the transport vehicle to the main hot cells

F-9. $\quad$ Fault tree for an inadvertent fuel melt contained in a sodium-cooled experiment while in the ACRR central cavity

G-1. Transport pathways followed by the experiment fuel and assemblies ...................................

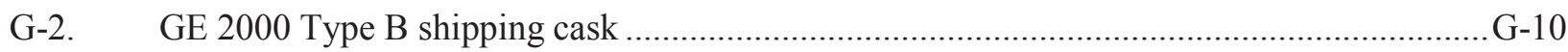

G-3. Transportation route between ATR and HFEF and between HFEF and TREAT Facility (see inset for detail) .....................................................................................................

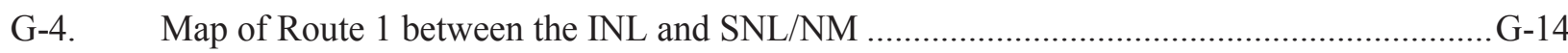

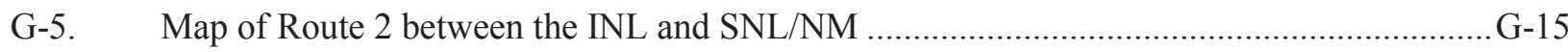

G-6. Basic RADTRAN model for routine transportation (from NRC 2013, Chapter 2)...............G-18

G-7. Truck stop model (from NRC 2013, Appendix B) ...........................................................

\section{TABLES}

1. Bounding number of experiments expected to be conducted ................................................... 10

2. Summary of typical sequence of experiment-related operations at TREAT ........................... 12

3. Radionuclide emissions of noble gasses from the TREAT stack ......................................... 19

4. Radionuclide emissions at the top of the TREAT stack for two air flow rates ........................ 19

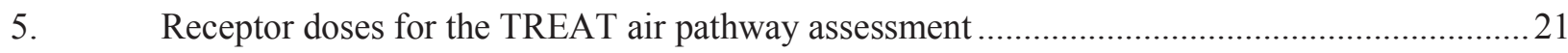

6. Pathway effective dose summary from particulate releases for a collocated worker ................22

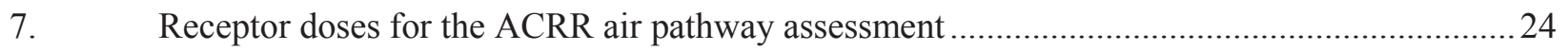

8. Summary of consequences for each accident scenario for Alternative 1, use of TREAT ..........28

9. Summary of dose impacts for highest consequence events for Alternative 1, use of TREAT

10. Table for use in the Environmental Assessment for Alternative 1 ..........................................30

11. Summary of consequences for each accident scenario for Alternative 2, use of ACRR ............34

12. Summary of dose impacts for highest consequence events for Alternative 2, use of ACRR 35

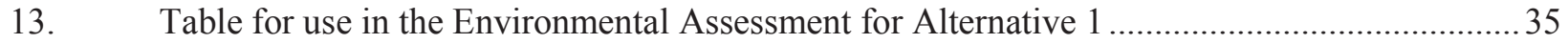


14. Dose summary for routine transportation of 34 roundtrips from the Advanced Test Reactor Complex and TREAT.

15. Summary of analysis results for routine transportation of 34 roundtrips from the Advanced Test Reactor to TREAT.

16. Summary of analysis results for routine transportation for 34 roundtrips from the Advanced Test Reactor to the Materials and Fuels Complex.

17. Summary of the analysis results for routine transportation of 34 roundtrips from the Materials and Fuels Complex to ACRR

18. Summary of dose and latent cancer fatality for non-incident free transportation for 34 roundtrips from the Materials and Fuels Complex to ACRR

19. Summary of dose and latent cancer fatality risk accounting for the probability of occurrence for non-incident free transportation for 34 roundtrips from the Materials and Fuels Complex to ACRR.

20. Estimated annual emissions and fatalities resulting from on-Idaho National Laboratory and off-Idaho National Laboratory shipments.

21. Quality assurance summary table for software and code input/output used for the Resumption of Transient Testing environmental assessment.

A-1. Population estimates for counties and selected communities surrounding the Idaho National Laboratory (U.S. Census Bureau 2012)....

C-1. Radionuclide emissions at the top of the TREAT stack for two air flow rates ........................ C-6

C-2. Radionuclide independent parameters for the rural receptor.............................................. C-8

C-3. Fraction of particulate radionuclides for time ranges of interest ....................................... C-12

C-4. Activity of particulates released per year and per week and activity remaining after 1, 7, 14 , and 21 days C-13

C-5. Receptor doses for the air pathway assessment C-14

C-6. Pathway effective dose summary from particulate releases for a collocated worker ............. C-14

C-7. Dose by radionuclide for the maximally exposed individual receptor at Atomic City........... C-14

C-8. Background upper tolerance limit and maximum concentrations measured in the windblown area near TREAT C-16

C-9. Receptor doses for the Annular Core Research Reactor air pathway assessment .................. C-19

D-1. Diesel fuel usage for key INL facilities from 2007 through 2012 _...................................... D-6

E-1. Summary of fuel pins and experiment configurations evaluated to determine bounding experimental inventory 
E-2. INL $\chi / \mathrm{Q}$ values at various separation distances..................................................................... E-7

E-3. Release factors for test loop drop airborne releases ...................................................... E-8

E-4. Screening dose consequences to determine the bounding inventory for experiments............. E-9

E-5. Bounding inventory used to represent the TREAT Reactor core ...................................... E-11

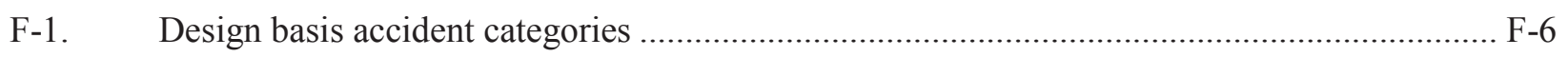

F-2. Accident scenarios evaluated by the Annular Core Research Reactor documented safety

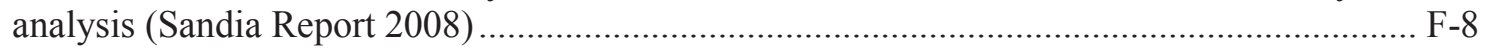

F-3. Net adjustment to the material at risk for scenarios releasing radionuclides from a fire,

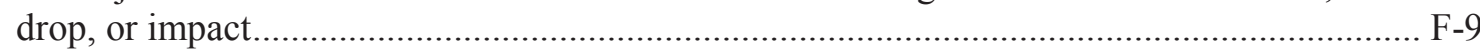

F-4. Regulatory Guide 1.183 matrix release fractions for boiling and pressurized water

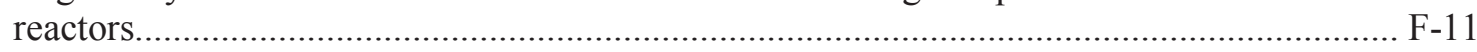

F-5. Likelihood categories assigned to the hazards identified in the preliminary hazards

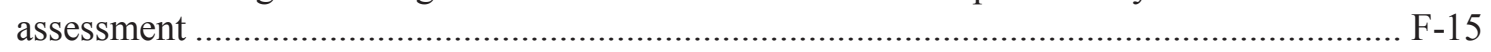

F-6. Idaho National Laboratory dose evaluation guidelines (from GDE-10820)........................ F-15

F-7. Dose consequences for reactor fuel clad failure ......................................................... F-21

F-8. Dose and latent cancer fatality summary for reactor fuel clad failure................................ F-22

F-9. Estimated loop handling accident frequencies of occurrence .......................................... F-26

F-10. Dose consequences for experiment assembly drop …................................................ F-27

F-11. Dose and latent cancer fatality summary for experiment assembly drop .......................... F-28

F-12. Dose consequences for reactor fuel impact ................................................................ F-31

F-13. Dose and latent cancer fatality summary for reactor fuel impact ........................................ F-32

F-14. Dose consequences for the scenario dropping the experiment into the reactor core ............. F-34

F-15. Dose and latent cancer fatality summary for the scenario of dropping the experiment

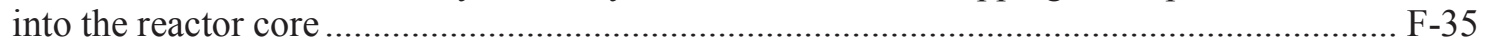

F-16. Dose consequences for a sodium fire in the TREAT Reactor ............................................. F-39

F-17. Dose and latent cancer fatality summary for sodium fire in the TREAT Reactor................. F-39

F-18. Dose consequences for experiment assembly drop …................................................. F-45

F-19. Dose and latent cancer fatality summary for experiment assembly drop .......................... F-46

F-20. Summary of consequences for each accident scenario for Alternative 1 (TREAT).............. F-48 
F-21. Summary of dose impacts for highest consequence events ............................................ F-49

F-22. Dose consequences for an experiment drop or impact release at SNL/NM ........................ F-52

F-23. Dose and latent cancel fatality summary for experiment assembly drop ........................... F-52

F-24. Estimated dose consequences for an over-pressurization of the sodium-bearing experiment loop in the ACRR (from SNL/NM 2013) ..................................................... F-54

F-25. Dose and latent cancer fatality summary for sodium fire in the ACRR ............................. F-54

F-26. Estimated dose consequences for a fuel melt in the ACRR central cavity (from

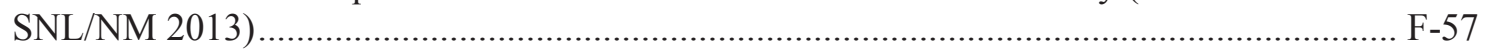

F-27. Dose and latent cancer fatality summary for a fuel melt in the ACRR central cavity........... F-57

F-28. Summary of consequences for each accident scenario for Alternative 2 (ACRR)................ F-59

F-29. Summary of dose impacts for the highest consequence events ......................................... F-60

G-1. Radionuclides used in the transportation analysis ...............................................................

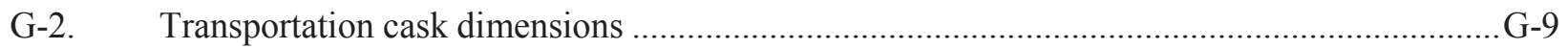

G-3. RADTRAN route-dependent input parameters for transport at Idaho National Laboratory G-11

G-4. RADTRAN route-independent input parameters for transport at Idaho National Laboratory

G-5. Radiation doses (person-rem) to various receptors during routine transportation, oneway from the Advanced Test Reactor to TREAT.

G-6. RADTRAN route-dependent input values for Route 1 .....................................................

G-7. RADTRAN route-dependent input values for Route 2 ..................................................... G-17

G-8. RADTRAN route-independent input values.......................................................................

G-9. Radiation doses (person-rem) to various receptors during routine transportation, oneway from the Materials and Fuels Complex to the Annular Core Research Reactor along Route 1

G-10. Radiation doses (person-Sv) to various receptors during routine transportation, one-way from the Materials and Fuels Complex to the Annular Core Research Reactor along Route 1

G-11. Latent cancer fatalities to various receptors during routine transportation, one-way from the Materials and Fuels Complex to the Annular Core Research Reactor along Route 1 ......G-22 
G-12. Radiation doses (person-rem) to various receptors during routine transportation, oneway from the Materials and Fuels Complex to the Annular Core Research Reactor along Route 2 .

G-13. Radiation doses (person-Sv) to various receptors during routine transportation, one-way the Materials and Fuels Complex to the Annular Core Research Reactor along Route 2 ......G-25

G-14. Latent cancer fatality to various receptors during routine transportation, one-way from the Materials and Fuels Complex to the Annular Core Research Reactor along Route 2 ......G-26

G-15. Summary of analysis results for routine transportation for a one-way trip from the Materials and Fuels Complex to the Annular Core Research Reactor

G-16. RADTRAN input for no-release accidents.

G-17. RADTRAN input for release accident analysis.

G-18. Conditional probabilities and associated release fractions

G-19. Population dose risk for two different accident types occurring between the Materials and Fuels Complex and Annular Core Research Reactor along Route 1 using the GE 2000 package

G-20. Population dose for two different accident types occurring between the Materials and Fuels Complex and Annular Core Research Reactor along Route 1 using the GE 2000 package

G-21. Population dose risk for two different accident types occurring between the Materials and Fuels Complex and Annular Core Research Reactor along Route 1 using the Battelle Energy Alliance research reactor package

G-22. Population dose for two different accident types occurring between the Materials and Fuels Complex and Annular Core Research Reactor along Route 1 using the Battelle Energy Alliance research reactor package

G-23. Population dose-risk for two different accident types occurring between the Materials and Fuels Complex and Annular Core Research Reactor along Route 2 using the GE 2000 package G-36

G-24. Population dose for two different accident types occurring between the Materials and Fuels Complex and Annular Core Research Reactor along Route 2 using the GE 2000 package G-37

G-25. Population dose risk for two different accident types occurring between the Materials and Fuels Complex and Annular Core Research Reactor along Route 2 using the Battelle Energy Alliance research reactor package G-38

G-26. Population dose for two different accident types occurring between the Materials and Fuels Complex and Annular Core Research Reactor along Route 2 using the Battelle Energy Alliance research reactor package. G-39 
G-27. Summary of accident doses during transport from the Materials and Fuels Complex to the Annular Core Research Reactor

G-28. Estimated annual emissions and fatalities resulting from shipments.

G-29. Dose summary for routine transportation for 34 roundtrips between the Advanced Test Reactor Complex and TREAT

G-30. Summary of analysis results for routine transportation for 34 roundtrips between the Advanced Test Reactor to TREAT.

G-31. Route and cask summary results for routine transportation for 34 roundtrips from the Materials and Fuels Complex to the Annular Core Research Reactor ...

G-32. Summary of analysis results for routine transportation for 34 roundtrips from the Materials and Fuels Complex to the Annular Core Research Reactor

G-33. Summary results for transportation accidents occurring between the Materials and Fuels Complex and Annular Core Research Reactor 


\section{ACRONYMS}

ACRR Annular Core Research Reactor

ANL Argonne National Laboratory

ATL Advanced Test Loop

ATR Advanced Test Reactor

BRR Battelle Energy Alliance research reactor

CED committed effective dose

CFA Central Facilities Area

CFR Code of Federal Regulations

DBA design basis accident

DOE U.S. Department of Energy

DSA documented safety analysis

EA environmental assessment

ED effective dose

EPA U.S. Environmental Protection Agency

F/CS filtration/cooling system

HEPA high-efficiency particulate air

HFEF Hot Fuel Examination Facility

INL Idaho National Laboratory

INTEC Idaho Nuclear Technology and Engineering Center

KAFB Kirtland Air Force Base

LCF latent cancer fatality

LWR light water reactors

MAR material at risk

MEI maximally exposed individual

MFC Materials and Fuels Complex

MOX mixed oxide

MRF matrix release fraction

NE Office of Nuclear Energy

NEPA National Environmental Policy Act

NEPA-HA hazards analysis (conducted to support the NEPA EA)

NESHAP National Emissions Standard for Hazardous Air Pollutants

NPH natural phenomena hazard

NRC U.S. Nuclear Regulatory Commission 


$\begin{array}{ll}\text { PC } & \text { performance category } \\ \text { RSAC } & \text { Radiological Safety Analysis Computer } \\ \text { RCS } & \text { Reactor Control System } \\ \text { RTS } & \text { Reactor Trip System } \\ \text { RTT } & \text { resumption of transient testing } \\ \text { SNL } & \text { Sandia National Laboratories } \\ \text { SNL/NM } & \text { Sandia National Laboratories/New Mexico } \\ \text { SSC } & \text { systems, structures, and components } \\ \text { TA-V } & \text { Technical Area V } \\ \text { TED } & \text { total effective dose } \\ \text { TLHC } & \text { TREAT loop handling cask } \\ \text { TREAT } & \text { Transient Reactor Test Facility } \\ \text { TRU } & \text { transuranic }\end{array}$




\section{Impacts Analyses Supporting the National Environmental Policy Act Environmental Assessment for the Resumption of Transient Testing Program}

\section{INTRODUCTION}

Environmental and health impacts are presented for activities associated with transient testing of nuclear fuel and material using two candidate test reactors. Transient testing involves irradiation of nuclear fuel or materials for short time periods under high neutron flux rates. The transient testing process includes transportation of nuclear fuel or materials inside a robust shipping cask to a hot cell, removal from the shipping cask, pre-irradiation examination of the nuclear materials, assembly of an experiment test train, transportation of the experiment assembly to the test reactor, irradiation in the test reactor, transport back to the hot cell, and post-irradiation examination of the nuclear fuel or material.

The potential for environmental or health consequences during the transportation, examination, and irradiation actions are assessed for normal operations, off-normal (accident) scenarios, and transportation. Impacts to the environment (i.e., air, soil, and groundwater) are assessed during each phase of the transient testing process. This report documents the evaluation of potential consequences to the general public and to workers. This document supports the Environmental Assessment (EA) required by the U.S. National Environmental Policy Act (NEPA) (42 USC § 4321 et seq.).

\subsection{Background}

The primary mission of the U.S. Department of Energy (DOE) Office of Nuclear Energy (NE) is to advance nuclear power as a resource capable of making major contributions to meeting the nation's energy supply, environmental, and energy security needs. This is accomplished by resolving technical, cost, safety, security, and proliferation-resistance barriers through research, development, and demonstration, as appropriate. NE's research and development activities will help address mission challenges, thereby enabling the development of new reactor technologies that will support the current fleet of reactors and facilitate the construction of new ones.

NE organizes its research and development activities along the following four main objectives that address challenges to expanding the use of nuclear power:

1. Develop technologies and other solutions that can improve the reliability, sustain the safety, and extend the life of current reactors

2. Develop improvements in the affordability of new reactors to enable nuclear energy to help meet the Administration's energy security and climate change goals

3. Develop sustainable nuclear fuel cycles

4. Understand and minimize the risks of nuclear proliferation and terrorism.

Development and licensing of improved and new forms of fuel for nuclear power production requires testing of nuclear fuels under anticipated reactor transient conditions. Significant transient testing of nuclear fuels has not been conducted in the United States in over a decade, and there are very few test facilities in the world where transient testing of prototype-scale fuel pins could take place.

Transient test reactors must have the ability to induce specific phenomenological changes to nuclear fuel systems. The phenomenological changes of interest are induced by short bursts of intense, high-power radiation. Nuclear fuel systems in this context are comprised of nuclear fuel, coolant, pumps to circulate the coolant past the nuclear fuel, and onboard instrumentation. The nuclear fuel system being tested is contained in an experiment assembly. The test reactor must be able to accommodate the 
experiment assembly in the reactor core. Requirements of transient test reactors also include in-situ real-time imaging technology (using a radiation detection system such as a hodoscope). This technology provides the time evolution of fuel damage, which is key to developing a thorough understanding of the underlying science of fuel behavior. In-situ imaging is augmented by post-irradiation examination to confirm the condition of the fuel during and after testing.

Two alternatives are being considered for use by the Resumption of Transient Testing (RTT) Program and are being assessed by the program EA: (1) restart and use of the Transient Reactor Test Facility (TREAT) at Idaho National Laboratory's (INL's) Materials and Fuels Complex (MFC) and (2) use of the operational Annular Core Research Reactor (ACRR) Facility at Sandia National Laboratory in New Mexico (SNL/NM). Both alternatives involve the use of existing facilities and capabilities with current missions at INL, in addition to the scope specifically addressed by the EA, namely activities enabling the restart and use of TREAT and use of ACRR to support the specific objectives of the transient testing program. Facilities that would be involved with the proposed actions are discussed in Sections 1.2.1 and 1.2.2.

\subsection{Purpose and Scope}

The purpose of this report is to document the analyses assessing the environmental and human health impacts that could result during the transient testing alternatives being considered. Analyses are provided for radiologic emissions, other air emissions, soil contamination, and groundwater contamination that could occur (1) during normal operations, (2) as a result of accidents in one of the facilities, and (3) during transport. This report does not include an assessment of biotic, cultural resources, waste generation, or other impacts that could result from the resumption of transient testing.

The scope of the following assessments is limited to the two alternatives being evaluated by the EA for the RTT Program (DOE/EA 2013). Both alternatives involve use of facilities at INL with current missions. Primary missions that could contribute an interacting human health or environmental impact are those at TREAT, hot cells at MFC primarily including the hot fuel examination facility (HFEF), Advanced Test Reactor (ATR) Complex, and facilities at the Idaho Nuclear Engineering and Technology Center (INTEC) (discussed in the following subsections). The activities that will be conducted under the RTT Program are bounded by the current scope and safety basis for those facilities. To further ensure the safety of workers and the public, activities associated with the transient experiments will be verified to meet the safety basis of the specific facilities receiving the radiologic materials from the program, given the material in each facility at the time of receipt. INL facilities at MFC, the ATR Complex, and INTEC used to support the RTT Program would not be modified and would remain within their current operating requirements and limitations; therefore, their use is not addressed in this assessment of impacts.

This allows refinement of the scope of this analysis to assess the human health and environmental impacts that specifically involve the experiments and reactors proposed for use by the RTT Program. The analyses provide (1) the general process that will be followed during transient testing, which is contained in Section 2.0, and, more specifically for the two different test reactors, in Sections 2.1 and 2.2 for normal operations; (2) normal operations impacts discussed in Section 3, which are different for each alternative being considered because of the processes discussed in Sections 2.1 and 2.2, (3) impacts that could occur for bounding facility accident scenarios summarized in Section 4 for each alternative; (4) transportation impacts that are different for the use of the two reactor facilities as summarized in Section 5; and (5) consequences of potential intentional destructive acts. The detailed supporting information for the summaries provided in Sections 2 through 4 is contained in Appendices A through G as noted throughout the text. Conclusions drawn in Section 5 are based on information provided in Sections 3 and 4. 


\subsubsection{Facilities Supporting Alternative 1 (TREAT)}

Facilities that could be used to support Alternative 1 are located at TREAT, MFC, the ATR Complex, and INTEC (Figures 1 and 2).

TREAT is located approximately $1.3 \mathrm{~km}(0.8$ mile) northwest of MFC (Figures 1 and 2). It is considered to be a part of MFC, but it is not located within the MFC fenced area. The TREAT Reactor building includes the TREAT Reactor, high bays, pre and post-irradiation test equipment, and fuel storage. The TREAT Reactor was specifically designed and built to test prototypic-sized reactor fuel pins and bundles under transient overpower accident conditions. It has the capability to obtain in-situ, time-resolved, real-time images of fuel behavior under prototypic neutron irradiation.

TREAT has been maintained in good condition since it last operated in 1994; however, the data acquisition system, reactor control system electronics, and the electronics components of the time-resolved imaging system (i.e., hodoscope) are likely to be replaced or updated if use of TREAT is the selected alternative following the EA review required by NEPA (DOE/EA 2013). If Alternative 1 is selected, transportation of nuclear materials to and from TREAT would be required as discussed and evaluated in Section 4. The current mission of TREAT includes storage of TREAT Reactor fuel and other nuclear materials. If use of TREAT is the selected alternative, current activities conducted at TREAT would be relocated.

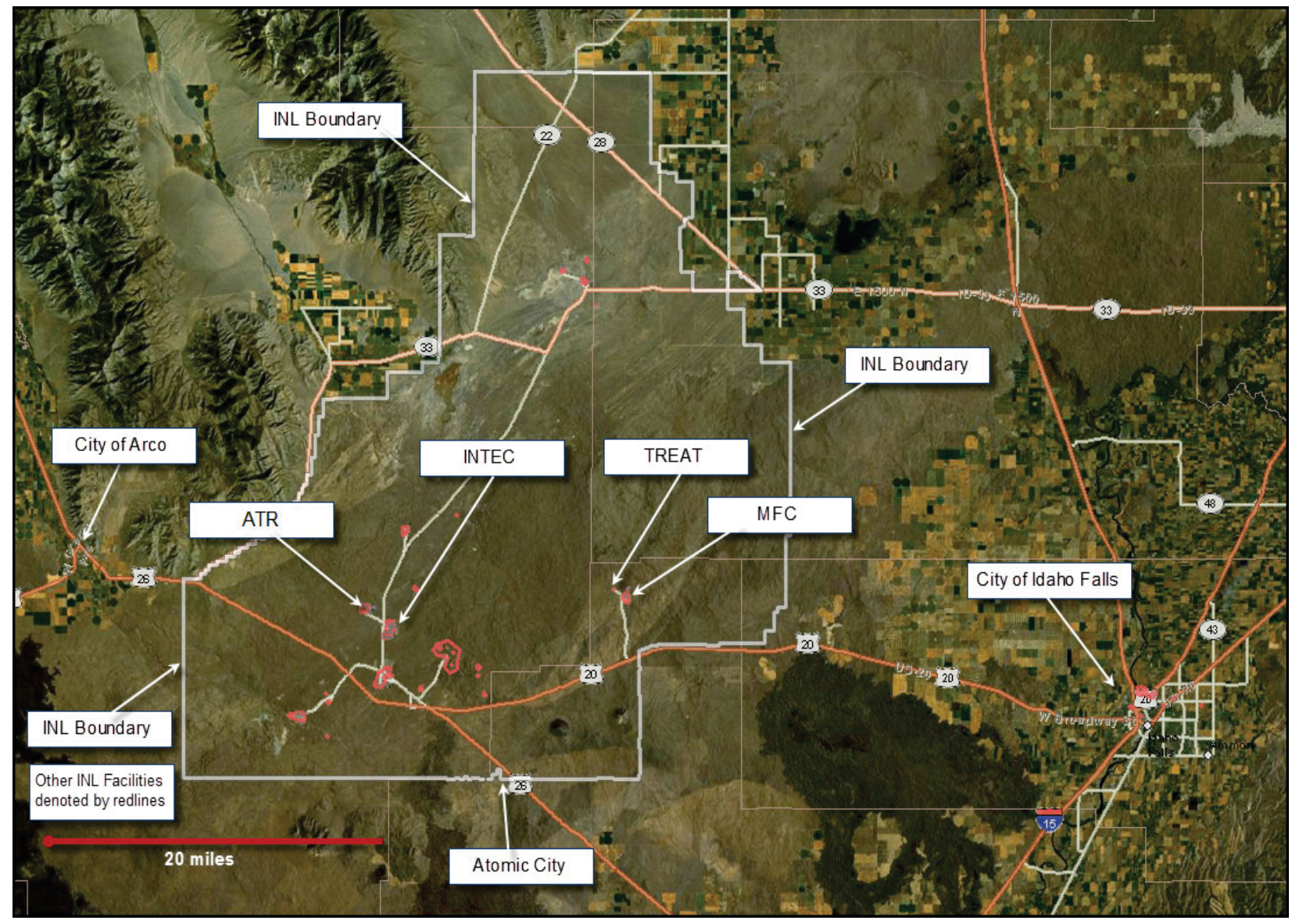

Figure 1. Map of the Idaho National Laboratory showing the locations of major facilities. 


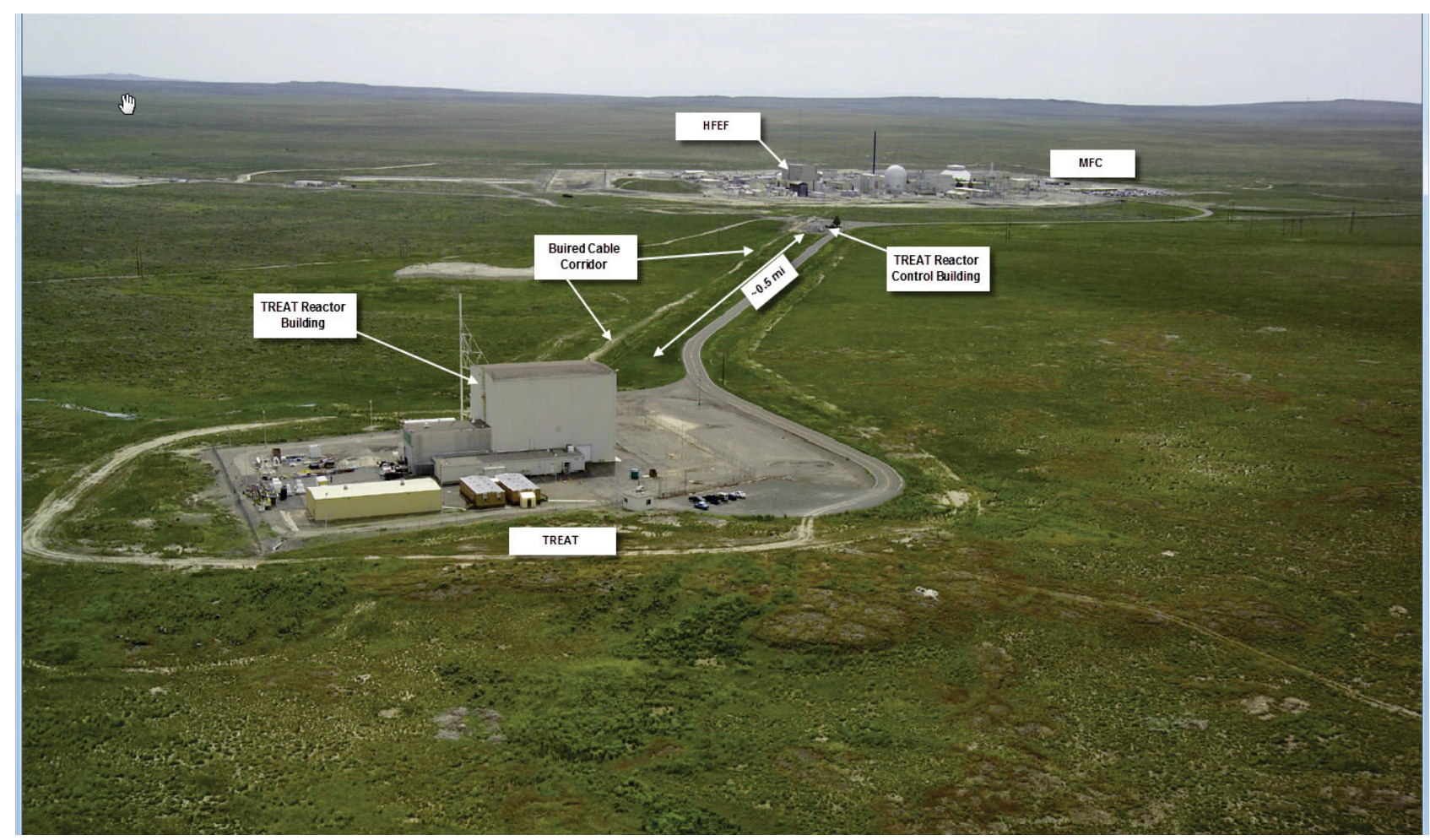

Figure 2. Aerial photograph of the Materials and Fuels Complex area, including TREAT and the TREAT Reactor control building.

MFC was established by Argonne National Laboratory-West in 1949. For the next half century, its primary mission was to take nuclear reactor power stations through the steps from design to demonstration. The design of every major reactor type can be traced back to Argonne National Laboratory-West. Capabilities at MFC currently are focused on the research and development of nuclear fuels and advanced technologies in nuclear power systems supporting the Global Nuclear Energy Partnership, DOE-NE's Advanced Fuel Cycle Initiative, and the Radioisotope Power Systems Program.

The primary MFC facility that will be used by the RTT Program is HFEF (Figure 3). Additional facilities at MFC may be utilized as necessary. HFEF began fully operating on March 31, 1975, to support the Liquid Metal Light Breeder Reactor through post-irradiation and interim-irradiation examination. Advanced ceramic and metallic fuels have been developed at HFEF and it is equipped with two adjacent highly shielded hot cells, a main argon cell, and a decontamination air cell. The operating HFEF hot cells are designed to receive, handle, and process irradiated nuclear fuel assemblies, construct test experiment assemblies with either fresh or irradiated fuels, receive the tested transient experiments containing irradiated fuel, and perform post-irradiation examination on the fuel. HFEF also has machining equipment for destructive and nondestructive testing to characterize highly irradiated fuel and structural materials.

Pre-irradiation of fuels and materials could occur at the ATR Complex (TRA-670). Facilities at INTEC, including CPP-666, could be used for storing and preparing materials for disposition.

\subsubsection{Facilities Supporting Alternative 2 (ACRR)}

Facilities that would be used to support Alternative 2 (ACRR) include ACRR, a new hot cell at SNL/NM, and facilities within the ATR Complex, INTEC, and MFC at INL. 


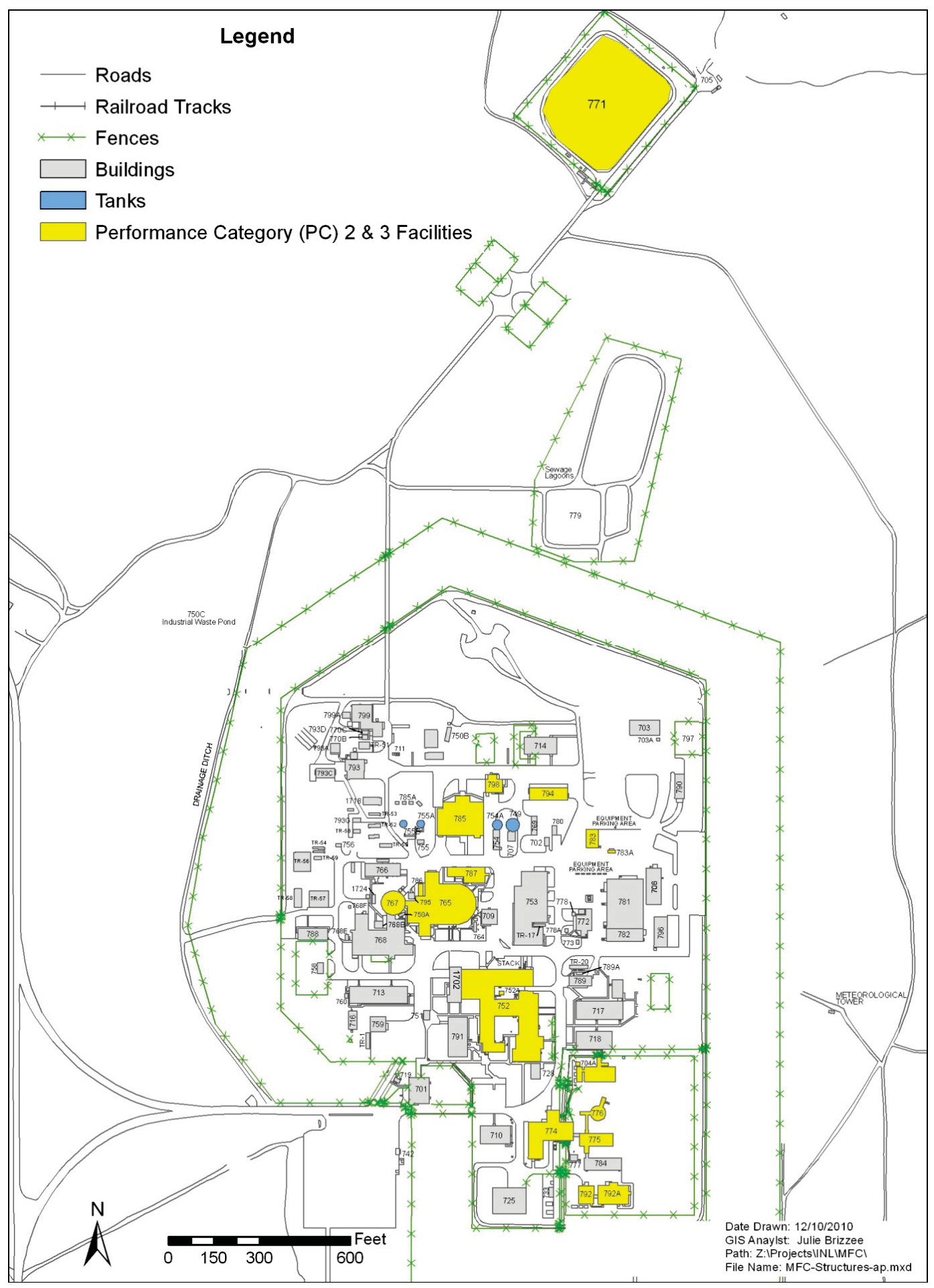

Figure 3. Map of facilities at the Materials and Fuels Complex.

ACRR is located in Technical Area V (TA-V) at SNL, south of Albuquerque, New Mexico (Figures 4 and 5). ACRR currently is used to primarily support the pulsed neutron testing of materials, components, and equipment designed for use in high neutron pulse conditions. ACRR was used to conduct severe fuel damage experiments for the U.S. Nuclear Regulatory Commission (NRC) in the 1980s and for DOE's New Production Reactor fuel testing and other experiments. The ACRR can support power pulses of 
milliseconds to provide specific power versus time responses (power shaping) over seconds using its transient rod withdrawal operations capability. It currently does not support visual imaging of tests and components during irradiation; this capability would be added if this alternative is selected.

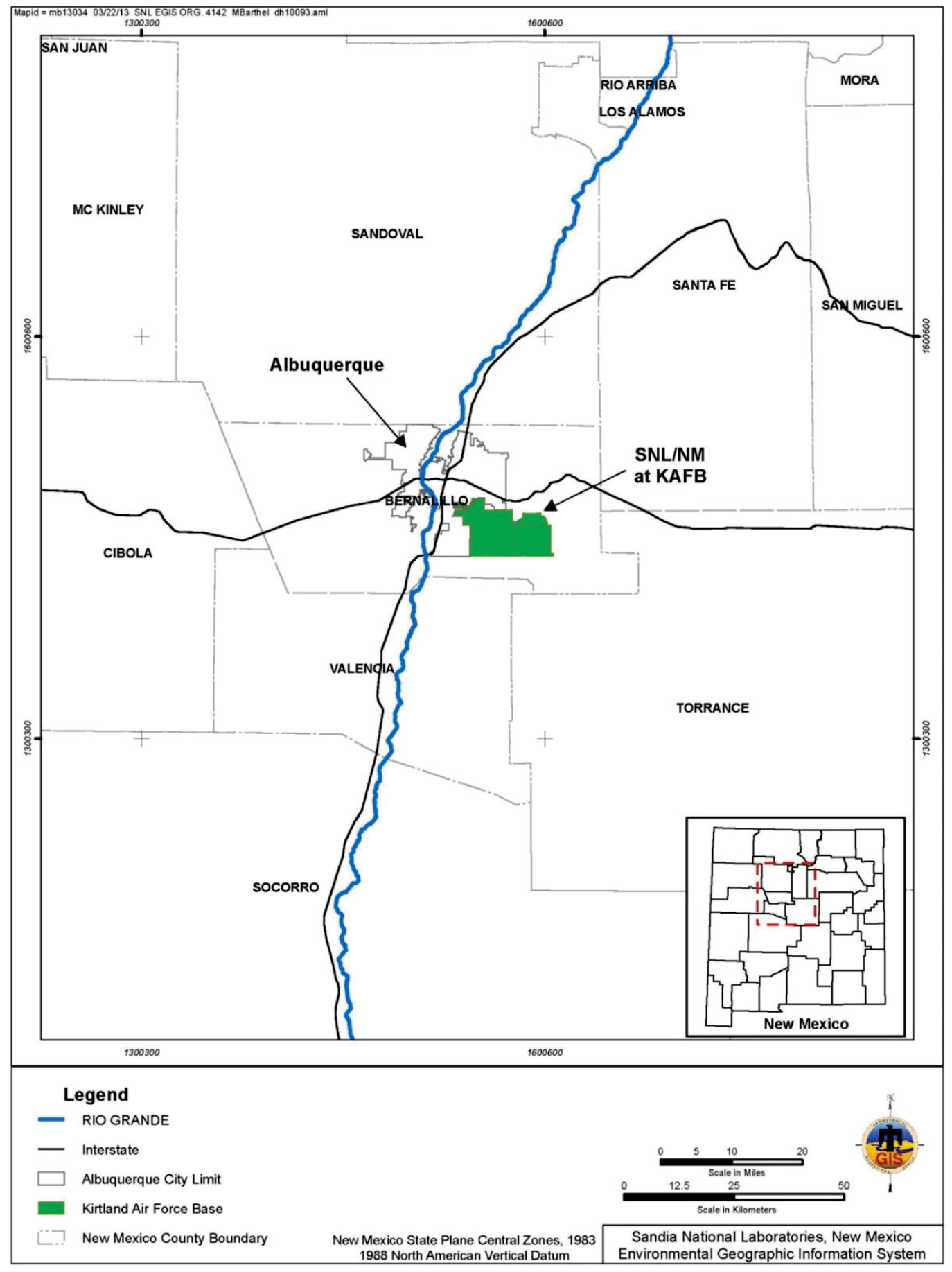

Figure 4. Location of Sandia National Laboratory, Kirtland Air Force Base, and surrounding area. 


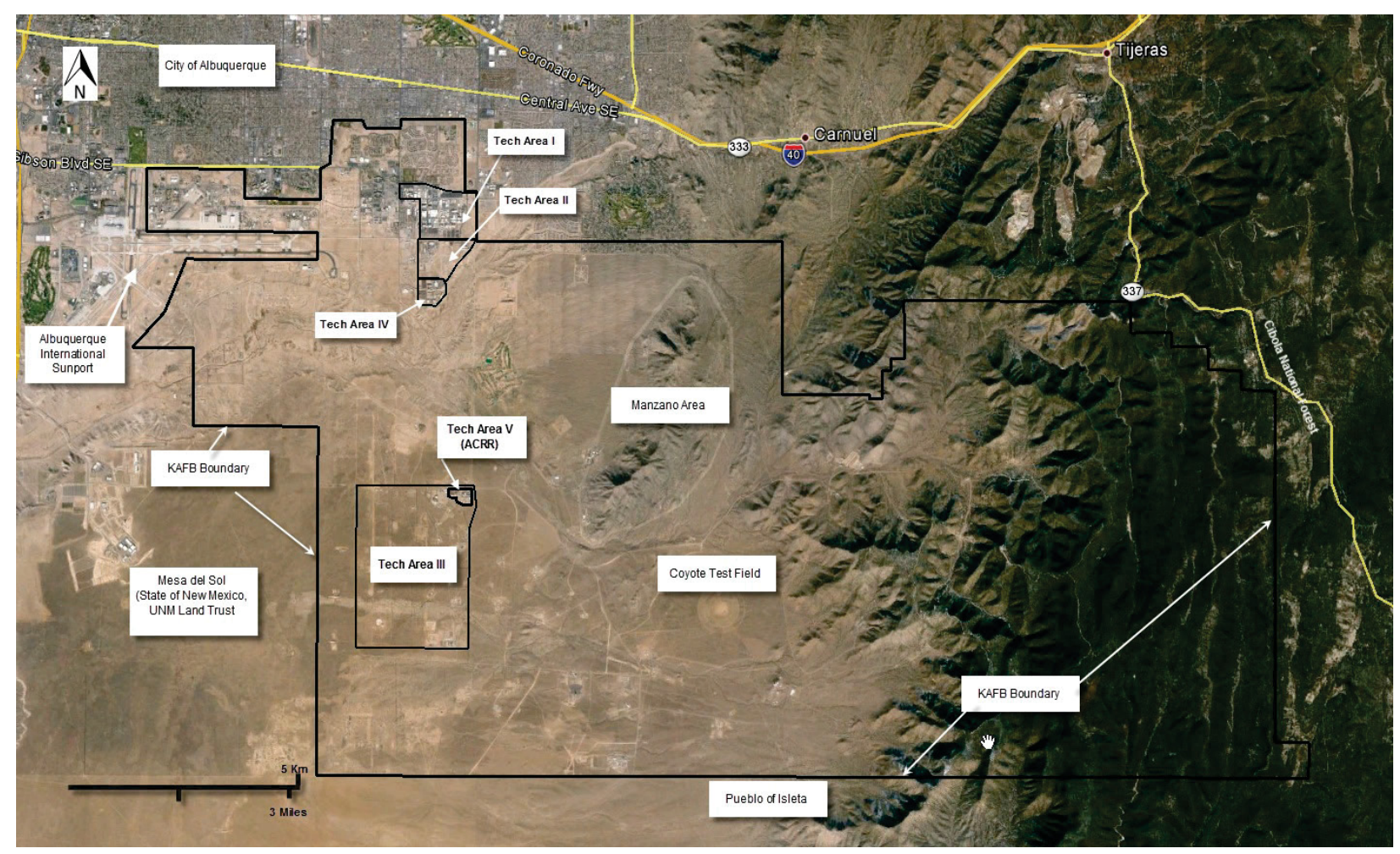

Figure 5. Location of key points of interest adjacent to Technical Area V at Sandia National Laboratory/New Mexico.

ACRR is not located near operating facilities designed to receive, handle, and process irradiated nuclear fuel assemblies. This alternative would require a new hot cell to be constructed at ACRR to allow receipt and repackaging of fuel and experiment components as discussed in the following sections (DOE/EA 2013). The new hot cell would not provide pre and post-irradiation examination capability.

In this alternative, facilities at INL's MFC, primarily HFEF, would be used for pre-irradiation examination, packaging materials for shipment to ACRR, receipt of irradiated test assemblies from ACRR, and post-irradiation examination. Pre-irradiation of fuels and materials could occur at the ATR Complex (TRA-670). Facilities at INTEC, including CPP-666, could be used for storing and preparing materials for disposition at INTEC. If the use of ACRR is selected as the preferred alternative, transportation between INL facilities and to and from MFC at INL to SNL would occur as discussed in Section 5.

\section{OVERVIEW OF TRANSIENT TESTING}

In general, there are two types of transient experiments: static tests and closed loop tests. Static tests evaluate the impact of transient conditions on the physical and chemical configuration of nuclear fuel in the presence of static or non-flowing coolant. Closed loop tests evaluate the impact of transient conditions on the physical and chemical configuration of nuclear fuel in the presence of flowing coolant.

Static test assemblies are relatively simple, consisting of nuclear fuel or material sealed inside a capsule with water, helium, or another coolant. The size of a static experiment can be as small as a single test piece (or sample of nuclear fuel) that is contained in a test assembly, with nominal outside dimensions of 1-in. in diameter and 6-in. in height. Larger static experiments also may be performed with test assembly dimensions of about 6-in. in diameter and 93-in. in length. Closed loop test assemblies are more complex and include single rods, rodlets, or a bundle of fuel pin/fuel rods sealed inside a larger test vessel 
that is charged with coolant and contains all pumps and other equipment needed to circulate coolant past the nuclear fuel or materials. Closed loop test assemblies have dimensions of up to 6-in. in diameter and 200 -in. in length.

The steps performed prior to, during, and after a transient test include the following:

1. Selecting a nuclear fuel system to be tested. The nuclear fuel system will include the nuclear fuel or material, its cladding, and a coolant system. Prior to being subjected to transient testing, nuclear fuel or materials may be pre-irradiated at ATR or at an NRC-licensed domestic commercial nuclear reactor, depending on customer needs and interests.

2. Transporting the nuclear fuel and test assemblies to a hot cell for pre-examination and assembly. The nuclear fuel and experiment assembly components will be transported to a hot cell at INL for pre-examination of the nuclear fuel or material using scientific instruments such as scanning electron microscopes, an x-ray diffractometer, and gas chromatographs.

3. Placing the nuclear fuel or material in an experiment loop assembly. The experiment (test) assembly acts as a containment structure to isolate the test specimen from its surroundings before, during, and after the transient test. In addition, the experiment assembly is placed into a robust metal transportation cask, which is sealed for transport. At this stage, the nuclear fuel is double contained for safety during transport operations.

4. Transporting the test assembly from the hot cell to the test reactor. The complete experiment assembly will be transported to the specially designed transient test reactor and the experiment assembly will be emplaced into the transient test reactor. A photo of the top of a transient test reactor is shown in Figure 6.

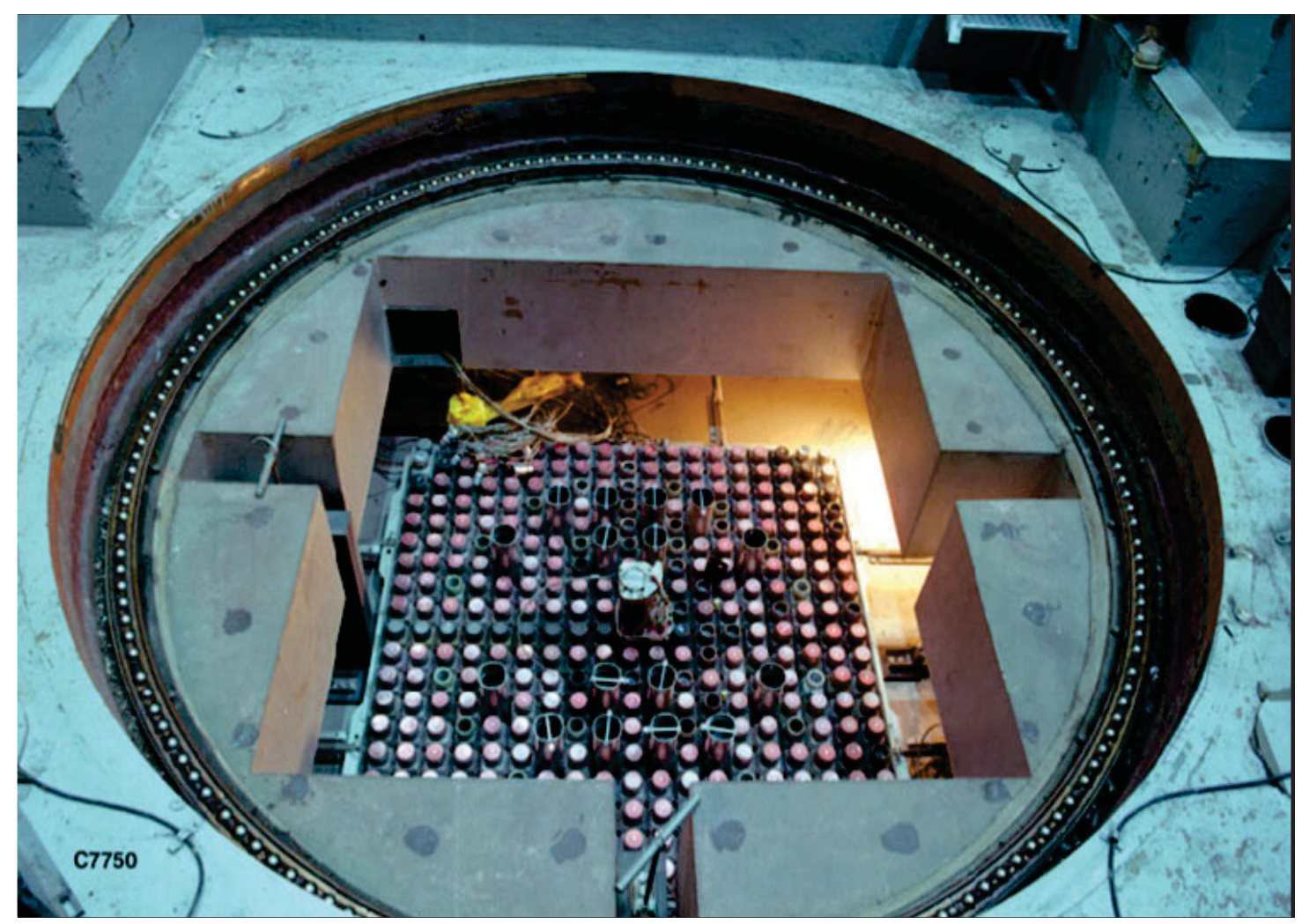

Figure 6. Photograph of the top of TREAT at the Idaho National Laboratory, showing the circular top of the fuel elements supported by the rectangular fuel plate; the experiments are usually placed in the center of the reactor. The rotating shield plug is not present in the picture. 
5. Irradiating the experiment loop with neutrons. The burst of neutrons from the transient test reactor causes the nuclear fuel or materials (test materials) to heat rapidly. During irradiation, information is collected using instrumentation that is attached to the transient test reactor and experiment assembly. Figure 7 shows a schematic diagram of the transient test reactor shown in Figure 6, with an experiment inserted into the test section of the reactor core.

6. Measuring important parameters during the test. During the transient tests, researchers measure as many parameters as possible. Typically, the parameters of most interest to experimenters include motion and chemistry, the temperature, and the pressure of the fuel at selected locations within the experiment.

7. Removing the experiment assembly and transporting the irradiated experiment assembly back to a hot cell. Following the experiment, the experiment assemblies are placed back into the robust transportation casks, sealed, and transported back to a hot cell for post-irradiation examination.

8. Conducting post-irradiation examination of the fuel and materials. In the hot cell, technicians open the transport cask and experiment assembly in order to examine the nuclear fuel and materials.

9. Disposing of all waste generated following approved disposal practices finishes the activity.

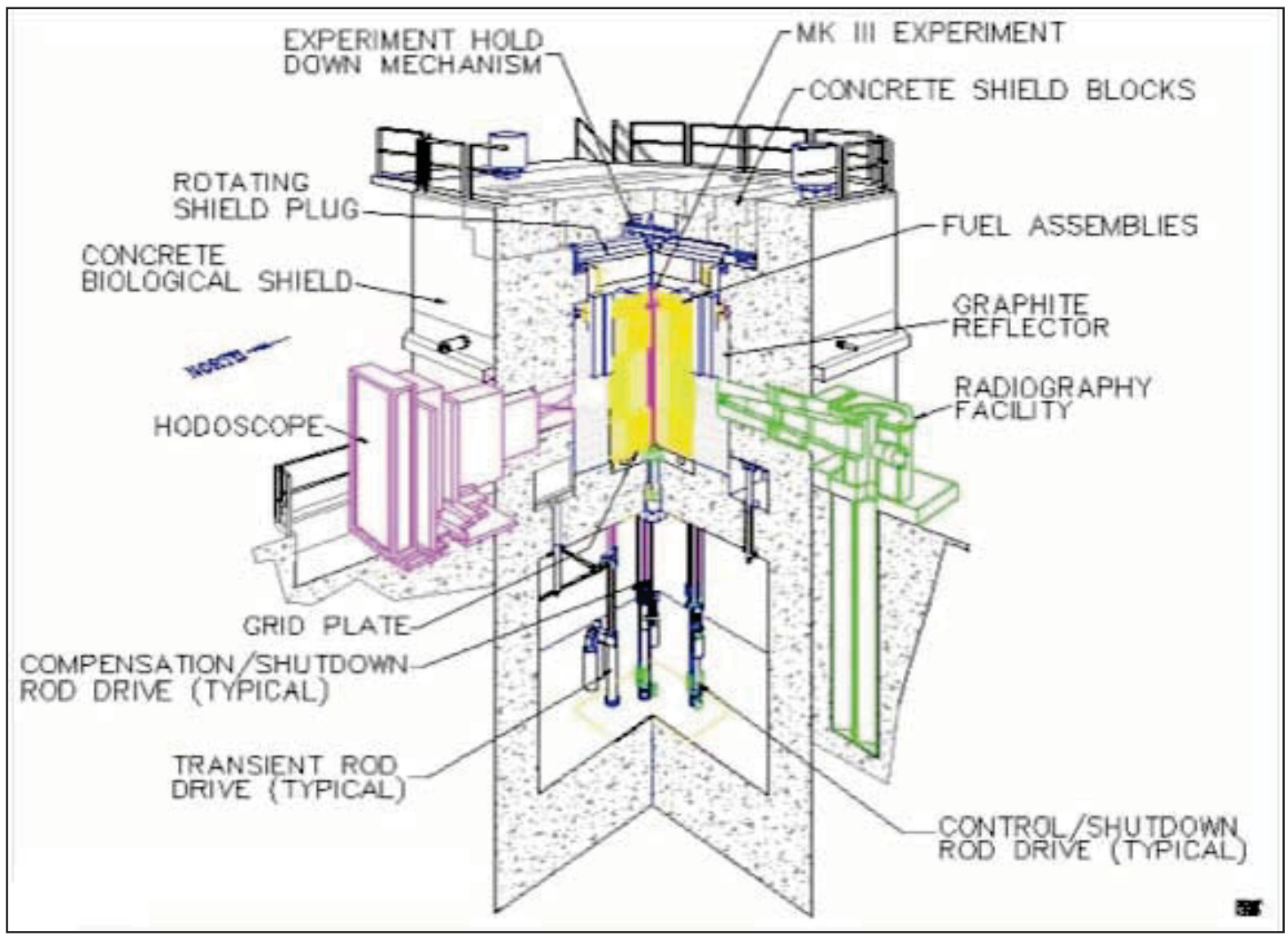

Figure 7. Schematic diagram of a transient test reactor with an experiment inserted into the center of the reactor core.

Following a transient experiment, researchers use the collected information to support development of safer fuels and extension of nuclear fuel use in power reactors. The data collected also are used in development of computer models used to predict nuclear fuel and material behavior. These models allow simulation of fuel responses that could occur during transient conditions that could be slightly different 
from the conditions used in the transient test. For example, these data are used by NRC, who compares model predictions to the results of the transient test to verify that the computer models are accurate and to qualify nuclear fuel systems. The essential facilities required to conduct transient testing include the following:

- A hot cell to be used for pre-test assembly and examination and post-irradiation examination with capabilities of the following:

- Placing nuclear fuel and materials into experiment assemblies and sealing them for safe transport to and from the test reactor.

- Examination of highly radioactive nuclear fuel and materials using specialized scientific instruments such as scanning electron microscopes, an x-ray diffractometer, and gas chromatographs.

- A transient test reactor capable of operating in steady-state and providing short bursts of high-intensity neutrons to the sealed experiment. Power level requirements include the ability to deposit 100 to 1,670 cal/g of energy into the nuclear fuel test samples. Required transient power shapes range from short pulses $(100 \mathrm{msec})$ and complex-shaped transients matching experimenter defined profiles.

\subsubsection{Expected Number of Experiments}

Transient tests (experiments) are expected to be conducted at the frequencies shown in Table 1. The experiment frequency is restricted by the time necessary to perform pre-irradiation and post-irradiation examinations, calibrations prior to testing, and the actual tests. The maximum number of experiments would be higher for the smaller capsule tests and the more complicated loop tests would be conducted less frequently. Of these, it is expected that six to eight loop tests will be conducted by DOE per year, with the remaining tests funded by other potential customers.

Table 1. Bounding number of experiments expected to be conducted.

Transient

Experiment Type
Fuel Type
Bounding Number of Experiment Assemblies/Year

Static (Capule) Tests Fresh/Irradiated LWR, Liquid Metal Reactor or HighTemperature Gas-Cooled Reactor Fuel

Loop Test

Fresh/Irradiated LWR Fuel

20

14

\subsection{Overview of Transient Testing using the Transient Reactor Test Facility}

This section provides an overview of TREAT and the steps that would be taken during transient testing using TREAT.

\subsubsection{Transient Reactor Test Facility Background Information}

Original construction of TREAT began in February 1958 and was completed in early November 1958. The facility includes a high bay for receipt of test assemblies, a reactor control room that contains computer consoles, the TREAT Reactor, and the TREAT Reactor control building. The TREAT Reactor is an air-cooled, graphite-moderated thermal reactor, designed primarily for operation in a transient, or pulsed mode for destructive testing of prototypic fast reactor fuel pins. The reactor achieved initial criticality on February 23, 1959. For the next 35 years, it was one of the principal reactor safety transient testing facilities in the United States, performing more than 600 experiments on thermal and fast reactor fuels. 
In addition to the power response of the TREAT Reactor, use as a test rector is provided by flexibility in the core configuration that allows the reactor to accommodate a variety of experiments, including loops containing sodium. Because the core is air cooled, it is easy to access core assemblies, remove core assemblies, insert experiment hardware into the core, and observe/monitor the experiments during testing. Horizontal access to the core is possible by removing shielding blocks along the sides of the reactor.

A key requirement of transient testing is to allow experimenters to "see" how large energy inputs affect the test fuel pins. To accommodate this requirement, "Open" viewing slots are provided in the core through which an experimental apparatus at the core center can be observed with special instruments during transient tests. The TREAT Reactor building also includes other key experiment support capabilities. Most notable is the unique TREAT fast neutron hodoscope, which provides two-dimensional, space-time monitoring of experimental fuel motion during power transients, as well as mapping of the test fuel spatial distribution before and after transients. This is a critical capability during many tests performed on fast reactor fuel. The TREAT radiography facility is adjacent to the reactor, inside the TREAT Reactor building, allowing radiography of experiment equipment before the experiment is inserted into the core and after experiment removal from the core (thus, before any appreciable handling or transport occurs). There is additional space external to the reactor for experimental equipment as needed.

During 35 years of operation, TREAT has undergone several facility upgrades to enhance reactor capability and safety. During the latest upgrade, the TREAT Reactor was configured to primarily produce short-duration, high-power bursts of neutrons. Upgrades included (1) modifications to the reactor site and building to upgrade security, electrical, and fire systems, (2) reactor physics and core-related changes to enable reliable safe control during the transient experiments, and (3) major modifications to the reactor's air filtration/cooling system (F/CS), including new blowers, a 140-ft coolant exhaust stack, and a 2-in-series, high-efficiency particulate air (HEPA) filter assembly that historically had provisions for monitoring.

\subsubsection{Experimental Sequence using the Transient Reactor Test Facility}

Specific steps, facilities, and transport processes involved during transient testing using TREAT are described in the following list, which is expanded from Section 2:

1. Select the nuclear fuel to be tested. In some experiments, the nuclear fuel would be fuel that has not been previously irradiated (i.e., "un-irradiated fuel"), while in other tests, the fuel may have been irradiated. In the case of pre-irradiated fuel, the irradiation could occur at the INL ATR Complex or at an NRC-licensed domestic commercial nuclear reactor (under its operating conditions) and transported to MFC.

2. Transport the research fuel to MFC. Transport of fuels from the ATR complex to MFC would occur on roads with access controlled by INL security. MFC is located 4.5 miles north of Highway 20 (Figures 1 and 2), which crosses the southern portion of the INL Site. Transport of research fuels to MFC from commercial facilities would occur on public roadways using commercial, NRC-certified, U.S. Department of Transportation-compliant transport casks.

3. Perform non-destructive examinations of the pre-experiment fuel while at MFC. Samples of pre-experiment fuel would be archived for comparison purposes (if required); the test fuel would be loaded into the test assembly with the coolant, coolant circulation equipment (for closed loop tests), and instrumentation; and preliminary checks of the loaded test equipment would be performed.

4. Transport the test assembly to TREAT from MFC. This would occur by first transferring the loaded test assembly into an onsite transfer cask. The transfer cask containing the loaded test assembly would be delivered to TREAT using an approved transport vehicle. The road between HFEF and TREAT is entirely on the INL Site. The road distance between HFEF and TREAT is 3/4 mile. 
5. Perform pre-irradiation radiography while at TREAT and insert the test assembly into the core, connect it to supporting equipment, and subject it to the planned TREAT Reactor irradiation(s). During irradiation, information will be collected using the instrumentation that is attached to the transient test reactor and test assembly, including real-time fuel motion monitoring.

6. Remove the test assembly from the TREAT Reactor, re-radiograph it (if requested by the experimenter), and transfer the assembly back to MFC in the onsite transfer cask over the controlled access road connecting TREAT and MFC.

7. Conduct post-irradiation examination at HFEF or other MFC facilities, depending on the outcome of the test. Undamaged fuel pins generally would be removed from the test assembly vehicle and non-destructively examined. Dissection of disrupted fuel remains and destructive examinations of transient-tested fuel samples would be performed mostly at MFC facilities or they could be shipped offsite to another facility. In-cell operations may be conducted to preserve and refurbish contaminated experiment assemblies for reuse. If reuse is not desired, the experiment assembly might be stripped of external equipment to allow better neutron radiography of its contents.

8. Preparing the waste for disposition and transferring the waste to a suitable (most likely on-site) facility would conclude the activity.

A summary of the typical sequence of experiment-related operations at TREAT is provided in Table 2. It includes a calibration step to determine a reactor-to-fuel coupling factor, pre-experiment assembly of the experiment loop assembly, steps conducted during the experiment, and steps conducted after the experiment is completed. These collective steps inform the time-at-risk used to estimate accident frequencies provided in Appendix D and are not meant to be exhaustive or exclusive.

Table 2. Summary of typical sequence of experiment-related operations at TREAT.

Calibrations (to determine the coupling factor)

Receive fresh calibration fuel.

Load calibration fuel rods into a calibration assembly.

Adjust core loading as required, includes removing top shielding, transferring TREAT fuel assemblies between storage and core, using the TREAT fuel handling cask, and replacing top shielding.

Load calibration assembly.

Perform fresh fuel calibration runs at low-power steady state.

Reload calibration assembly with wires/foils instead of fuel.

Perform runs (steady-state and transient) with wires/foils in calibration assembly.

Pre-experiment (trial transient stage)

Receive and inspect experiment fuel rods and loop hardware.

Perform final assembly of experiment loop and loading of test train into loop.

Radiograph final assembly.

Perform out-of-pile operational checks.

Return core loading to above configuration if a different core loading has been used between calibration and the pre-experiment stage, includes removing top shielding, transferring fuel between storage and core, using the TREAT fuel handling cask, and replacing top shielding.

Load calibration assembly or other nuclear mockup of loop (no test fuel).

Perform trial transient(s) with nuclear mockup (containing no test fuel) of experiment in core until transient is satisfactory. 
Experiment

Transfer experiment loop, loaded with the experiment fuel, into the core.

Perform pre-transient operations, including hodoscope scan at low-power steady state.

Perform an operational simulation if required by the complexity of the experimental apparatus; includes running the experimental apparatus without running the reactor.

Perform low-power, steady-state heat balance with experimental loop.

Perform experiment.

Perform post-transient operations, including hodoscope scan at low-power steady state.

Post-Experiment

Transfer experiment loop from core.

Perform post-experiment disassembly operations as required.

Radiograph.

Transfer experiment loop from TREAT.

\subsection{Overview of Transient Testing Using the Annular Core Research Reactor}

\subsubsection{Annular Core Research Reactor Background Information}

The ACRR is located within the boundary of Kirtland Air Force Base (KAFB) southeast of the city of Albuquerque, New Mexico, and within SNL's Technical Area (TA)-V (see Figures 4 and 5). ACRR is a pulse-type research reactor that has been in continuous operation since 1979, logging more than 10,000 operations. The water-moderated and cooled $\mathrm{UO}_{2}-\mathrm{BeO}$ fueled core is capable of producing pulses as short as 6 milliseconds full-width at half maximum, with a maximum energy of $350 \mathrm{MJ}$. The reactor also can run in programmed transient, as well as steady-state mode, producing up to 4 MWth of constant power. Although ACRR is water moderated, there is a large, dry central cavity that extends through the center of the core. This cavity can hold test articles up to $23 \mathrm{~cm}$ in diameter and nearly $5 \mathrm{~m}$ high, extending below and above the active core. The active core height is $51 \mathrm{~cm}$ and the effective length can be increased to approximately $1 \mathrm{~m}$ with flux shaping. In addition to the 236-element ACRR core, there is an auxiliary core that can be coupled to the main system. This Fuel Ringed External Cavity, Version II core contains Training, Research, Isotopes, General Atomics-type UZrH fuel and a much larger, 51-cm dry central cavity, but pulse energies are more restrictive.

ACRR has historically been used for a wide array of research. Although the current mission is focused on supporting the DOE National Nuclear Security Administration's nuclear security and weapons mission, past missions have served NRC and DOE-NE for fuels, safety, and isotope production missions. ACRR was transitioned from the Annular Core Pulsed Reactor with the new $\mathrm{UO}_{2}-\mathrm{BeO}$ fuel, the purpose was to enable larger pulses and enable the ability for the driving core to bring the test specimen fuel to complete failure without failure of the core's fuel. In addition, a fuel motion monitoring device, the Coded Aperture Imaging System, was successfully installed and used in the reactor to monitor these fuel safety studies that included flowing steam over an array of light water reactor (LWR) fuel (Kelley and Stalker 1981). The fuel motion monitoring has since been removed due to lack of need.

For the RTT Program, ACRR's current facilities would have to be expanded by adding an adjacent hot cell and a fuel motion monitoring device. The new hot cell would enable the potential repackaging of large experiments for transport to and from MFC at INL, where small experiments would not require such a facility. Installing a fuel motion monitoring device would involve removal of a row of fuel from the 
ACRR core and insertion of a new Coded Aperture Imaging System in its place. Transient testing at ACRR would rely on pre-irradiation of test materials from INL or commercial reactors and for pre and post-test examination at INL's MFC (as described in the following subsection).

\subsubsection{Experimental Sequence using the Annular Core Research Reactor}

Specific steps, facilities, and transport processes involved during transient testing using ACRR are described in the following list, which is expanded from Section 2:

1. Select the nuclear fuel to be tested. As with Alternative 1, the nuclear fuel could either be un-irradiated or pre-irradiated fuel. Fuel would either be pre-irradiated at the INL ATR Complex or at an NRC-licensed domestic commercial nuclear reactor under their operating conditions and transported to HFEF.

2. Transport the research fuel to MFC. Transport from the ATR Complex to MFC would occur on roads with access controlled by INL security. Transport of research fuels to MFC from commercial facilities would occur on public roadways using commercial, Department of Transportation-compliant transport casks.

3. Perform non-destructive examinations of the pre-experiment fuel while at MFC. For comparison of post-irradiated fuel conditions, samples could be taken from the pre-experiment fuel for non-destructive and destructive examinations. The test fuel and experiment assembly with the coolant, coolant circulation equipment (for loop type tests), and instrumentation would be packaged for transport, and the fuel would be loaded into a Department of Transportation-approved transportation cask for shipment to TA-V at SNL/NM.

4. Transport test specimens to the ACRR hot cell at SNL from MFC using commercially available, Department of Transportation- approved transport casks (see Section 4).

5. Assemble test components at SNL/NM in the new ACRR hot cell. While at ACRR, the test components would be assembled and the assembly would generally be neutron radiographed and functionally checked. Thereafter, it would be connected to supporting equipment, inserted into the central cavity of the core, and subjected to the planned ACRR irradiation(s).

6. Perform post-irradiation radiography (if requested by the experimenter) and transfer the assembly back to the ACRR hot cell for packaging into Department of Transportation-approved transportation casks for transport back to MFC at INL.

7. Step 7 is the same as the sequence of experiments in Alternative 1 and would occur at INL.

8. Preparing waste for disposition would occur at SNL/NM and INL with the majority of the waste generated at INL.

\section{ENVIRONMENTAL IMPACTS DURING NORMAL OPERATIONS}

The assessment of environmental and human health impacts that could be incurred during normal operations is provided in this section for the two alternatives being considered. Normal operations in this context include operation of the reactors during transient testing, handling the test material, and irradiation of the test material. Environmental impacts expected during normal operations would be a function of irradiation time and mode of operation used for each particular experiment and of the specific test reactor being used. The potential for releases from the experiment loops is the same for both alternatives during normal operations and are not expected to be significant (as discussed in Section 3.1). Potential impacts of operating the two reactors would not be the same (as discussed in Subsections 3.2 and 3.3). 
The assessment that follows assumes that controls will be used to ensure safety and to minimize the potential for environmental consequences under both alternatives. The controls common to both alternatives are provided as follows:

- All required safety analyses for the selected test reactor will be conducted and implemented in accordance with the requirements of 10 CFR 830, Subpart B. These safety analyses are driven by the need to carefully establish the safe operating envelope. This will ensure the following:

- All safety systems are identified and verified to be functional

- Technical safety requirements and administrative controls are developed for reactor operations to minimize the impacts of normal operating and accident conditions (e.g., locations of facility workers and collocated workers during testing)

- A maintenance and surveillance program is in place for continued verification

- The operating parameters of the reactor will not be exceeded during steady-state or transient testing conditions

- Operations and experiment personnel are extensively trained.

- All required safety analyses for the test assemblies will be conducted in accordance with the requirements of 10 CFR 830, Subpart B. Test procedures will be developed that clearly identify the limits and requirements of the test conditions and components, ensuring the following:

- Test assemblies will not contain radiologic materials that exceed the radiologic inventory analyzed in this EA.

- Test assembly containment systems will be designed and used that will withstand the transient test conditions under all foreseeable accident conditions.

- Nuclear fuels will be contained to minimize the potential for release of material under all credible accident conditions. Fresh cladded fuels (unirradiated) will be in sealed containment. Irradiated fissile materials or fission products will be sealed and will have single or double containment, as appropriate, with the containment designed to retain its integrity during all planned tests and credible accident conditions.

- Pre-experiment evaluation and analysis of experiments will be conducted to ensure the tests are within established operating parameters.

- Transportation and security training procedures will be developed and enforced, ensuring the following:

- Casks are being used that have been designed and constructed to withstand credible accident conditions.

- Identified routes are followed during transportation.

- Security is provided as necessary to ensure safe transport.

\subsection{Impacts of the Experiment Fuel During Transient Testing}

Prior to testing in the reactor, the nuclear fuel or material is placed in the experiment assembly; it is then brought to the transient test reactor in a robust transport cask designed to limit worker exposure during normal operating conditions and during accidents. After removal from the transport cask, the experiment assembly is inserted into the core of the transient test reactor and irradiated with neutrons; it is then reinserted into the handling casks and removed from the reactor. Potential impacts during transport and handling are considered in Section 5. Potential impacts during irradiation are considered here.

Environmental impacts during normal transient tests related to the experiment assembly are not expected to occur. The experiment designs (i.e., experiment assembly, experiment loop, test loop, or test train assembly) will include containment requirements. For example, as specified in the Guide for 
Irradiation Experiments in TREAT (1991), the first requirement is for fresh fuels (unirradiated) to be in sealed containment in addition to the test specimen fuel cladding and the second is for any hardware containing irradiated fissile materials or fission products to be sealed and have double containment. Historically, primary containment of the fuel pins is provided by stainless steel tubes in the Mark-III and Single Pin Test Loops, with secondary containment of the loop provided by a stainless steel liner as shown in Figure 8. Additional requirements are placed on the corrosivity of all materials in the test loop to Zircaloy, stainless steel, aluminum, or graphite and for the containment to be designed to retain its integrity during all planned test and credible accident conditions. Similar requirements for test loops used in either TREAT or ACRR are likely to be required if transient testing is resumed. In combination, the design requirements for the experiment assemblies ensure that all radioactive materials will remain contained in the experiment loops themselves, with no emissions to the environment during normal operations. If the restart of transient testing is selected as the preferred alternative during the process required by NEPA, requirements and procedures for experiment designs will be developed to ensure containment of all nuclear materials during normal operating conditions. Therefore, releases to the environment during transient testing would only occur as a function of the operation of the reactor itself. This applies to use of either the INL TREAT Reactor or the ACRR at SNL/NM as discussed in the following subsections.

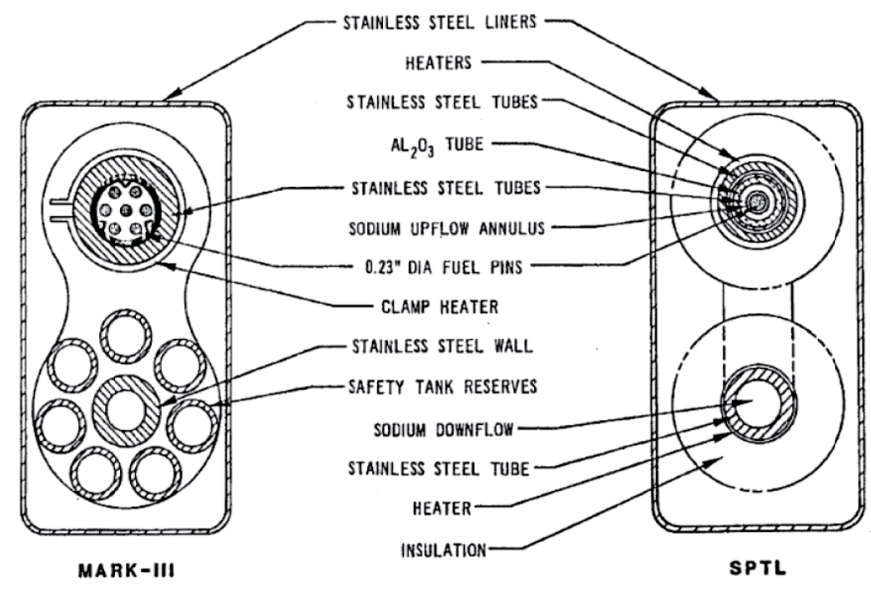

Figure 8. Mark-III and single-pin test loop, showing primary containment of the fuel pins in stainless steel tubes and secondary containment of the loop by stainless steel liners (from Guide 1991).

\subsection{Impacts of Normal Operations using the Transient Reactor Test Facility}

During the sequence of events that will take place under normal operating conditions (shown in Table 2), the TREAT Reactor is operated under steady-state and transient conditions and heat is generated in the reactor and experiment. As previously described, the air-cooled TREAT Reactor is a small test reactor, and the heat generation rate is low enough for heat to be removed using an air F/CS as opposed to 
using liquid coolant as required by most commercial reactors. Two blowers operating in parallel, located downstream of the reactor, pull coolant air from the reactor high bay into the reactor core and reflector regions through two fiberglass-filtered openings at the top of the reactor shield. After passing through the core, the cooling air passes through two banks of eight HEPA filters before being discharged out the reactor coolant exhaust stack (discussed in Section 3.2.2).

The air F/CS for TREAT is designed to be highly reliable through use of redundant active components and conservatively designed passive components. The F/CS is designed to entrain and remove radioactive material by first providing subatmospheric pressure in the reactor cavity. Second, the F/CS deposits radioactive aerosols on HEPA filters before discharging the filtered effluent up the stack (discussed in Section 3.2.3).

Under normal operating conditions, the reactor can be shut down safely if both blowers fail. To ensure the reliability of the F/CS system, the blowers can be powered from independent power sources. One power source is the normal site electric power; the other is an onsite diesel generator. To maximize reliability, the diesel generator can be started and operating before transient testing is initiated. The NEPA Hazards Analysis (NEPA-HA; NEPA-HA 2013) indicates that neither the cooling function nor the filtration function is required to prevent abnormal operation. Therefore, the diesel generator is not required for safe operation, but is used to ensure safe transient testing. Emissions related to diesel generators are discussed in Section 3.2.1.

\subsubsection{Diesel Generator Emissions}

Currently, two diesel generators are employed at TREAT to supply redundant and standby power. Redundant power used during transient testing was historically supplied by a $130-\mathrm{kW}$ diesel generator, and standby power for electrical components was supplied by a $30-\mathrm{kW}$ diesel generator. Both diesel generators were located in the reactor building and vented to the outside. Emissions from these diesel generators were typical products of internal combustion of diesel fuel and include $\mathrm{NO}_{\mathrm{x}}, \mathrm{CO}, \mathrm{SO}_{\mathrm{x}}, \mathrm{PM}$, PM-10 and volatile organic compounds. Emissions from the generators currently are regulated by the U.S. Environmental Protection Agency's (EPA's) Clean Air Act Requirements, specifically "Control of Emissions of Air Pollution From Nonroad Diesel Engines and Fuel" (40 CFR Parts 9, 69 et al. 2004), the Idaho Administrative Procedures Act (IDAPA) 58.01.01, "Rules for the Control of Air Pollution in Idaho", and 40 CFR 63, Subpart ZZZ, "National Emissions Standards for Hazardous Air Pollutants for Reciprocating Internal Combustion Engines."

Potential impacts from diesel generator emissions are detailed in Appendix D and are summarized here. The $30-\mathrm{kW}$ generator is operated approximately 2 hours/month and 1 hour/month for preventative maintenance and load testing for a total of about 37 hour/year, consuming approximately 66 gal/year of diesel fuel. The 130-kW unit currently is operated approximately 1 hour/month for preventative maintenance. If TREAT is the selected alternative, the $130-\mathrm{kW}$ unit will be operated during transient operations, powering one of the two reactor filtration/cooling system blowers to help ensure that the reactor and experiments are cooled after a transient test, thus minimizing the amount of cladding oxidation. The estimated diesel fuel usage for the $130-\mathrm{kW}$ generator is approximately 2,433 gal/year.

Cumulative diesel fuel usage for the two generators would be less than $0.006(0.6 \%)$ of the average diesel fuel usage for all emergency diesel generators and boilers at MFC during the 2007 through 2011 time period $(449,563 \mathrm{gal})$ and less than $0.3 \%$ of the total INL usage of $1,114,995$ gal.

Emissions from operation of diesel generators at TREAT as a result of transient testing are not expected to be a significant contributor to diesel emissions from MFC or INL. If this option of resuming transient testing using the TREAT facilities is selected as a result of the NEPA process, the permitting status and requirements will be addressed to ensure the generators meet all regulatory requirements prior to beginning operations. 


\subsubsection{Non-Radiologic Emissions from the Transient Reactor Test Facility Stack}

Warm air will be emitted from the TREAT stack. Stack emissions will contain trace levels of volatile radionuclides as discussed in Section 3.2.3; the warm air will contain very little moisture as humidity; the air reactor cooling function will preclude it from carrying other volatile chemical pollutants; and the HEPA filters will preclude all but extremely low trace emissions of particulates. Air emitted from the TREAT Stack will vary in temperature depending on whether the F/CS system is being used to cool the experiment assembly. Air flow rates during cooling will range from 3,000 to 6,000 cfm. Cool air will be drawn from the high-bay area through the 2-in-series banks of HEPA filters and then through the blowers prior to being emitted up the 140-ft high stack. The HEPA filters and filter housing are designed to accept $260^{\circ} \mathrm{C}$ air. After passing through the HEPA filters, the air will reach the blowers. By design, the air temperature at the blower inlet is limited to $170^{\circ} \mathrm{C}\left(338^{\circ} \mathrm{F}\right)$ by a valve that is set to open automatically, introducing clean moist cool air from the subpile room if $170^{\circ} \mathrm{C}$ exhaust air temperature is exceeded. The air temperature will decrease as it is exhausted up the stack because of the cooler outside ambient air and will further decrease as it enters the ambient air. The air would be relatively dry and should not form steam condensate at the top of the stack. If steam is formed, it should dissipate very near the stack.

Warm air emissions are regulated by IDAPA Section 58.01.01.625.03, which states that "Provisions of this section (Visible Emission Regulation) shall not apply when the presence of uncombined water, nitrogen oxides and/or chlorine gas are the only reason(s) for the failure of the emission to comply with the requirements of this rule."

\subsubsection{Radiologic Emissions from the Transient Reactor Test Facility Stack}

The air F/CS system used to cool the reactor removes radioactive aerosols from the cooling system that have been released to the reactor cavity by depositing them on HEPA filters before discharging the filtered effluent up the stack. These emissions are generated during the high-energy transient tests, which are expected to occur at a rate of less than one experiment per week (Table 1). Radioactive emissions released from the TREAT stack are the result of activation of naturally occurring argon that is present in the cooling air and fission of uranium impurities in the Zircaloy cladding of the TREAT Reactor fuel.

The annual radioactive nuclide emissions from the TREAT stack were reported in an intra-laboratory memo (ANL memo 1992), based on a total annual energy release of 350,000 MJ (Mw-s). The average annual energy release over 32 years of TREAT operation and 20 tests per year is under 82,000 MJ; therefore, the values provided were conservative by about a factor of 4 . If 34 test per year are conducted (Table 1), the value provided should still be conservative by a factor of 2 . The emission rates for the dominant isotopes Ar-41, Kr-88, Xe-133, and Xe-135 referenced in the memo and evaluated in the 1990 report of National Emissions Standards for Hazardous Air Pollutants not Including Radon (NESHAPS) for TREAT during operations are shown in Table 3.

Emissions rates for all activation and fission products are shown in Table 4 and include $\mathrm{Kr}-85 \mathrm{~m}$, $\mathrm{Kr}-87 \mathrm{~m}, \mathrm{Rb}-88$, Xe-140, Cs-140, Ba-140, and La-140. Emissions rates for these isotopes were reported in the intra-laboratory memo (ANL memo 1992), and were determined through a series of calculations performed using the computer code, ORIGEN, to simulate the irradiation of uranium impurities in the Zircaloy cladding. ORIGEN is a standard point-depletion code that is widely used to compute isotopic buildup and depletion as a result of irradiation and subsequent radioactive decay. The simulation parameters were calibrated to the measured Ar- 41 to $\mathrm{Kr}-88$ ratio. Emission rates for these additional isotopes were generated by applying the calculated ratio of emission rates to the observed value of $\mathrm{Kr}-88$. During calibration, an irradiation time of one second was used in the ORIGEN calculations. The time required to reach the top of the TREAT Stack (i.e., the point of emission) is approximately 14 seconds at a flow rate of $6,000 \mathrm{cfm}$ and 28 seconds at a flow rate of $3,000 \mathrm{cfm}$. The radionuclide emissions at the top of the TREAT Stack for these two flow rates are shown in Table 4. 
Table 3. Radionuclide emissions of noble gasses from the TREAT stack.

\begin{tabular}{lccc}
\hline Radionuclide & Half-Life & Release Factor & Release $(\mathrm{Ci})^{\mathrm{a}}$ \\
\hline Ar-41 & $1.82 \mathrm{~h}$ & 1 milliCi/MW-s & 350 \\
$\mathrm{Kr}-88$ & $2.80 \mathrm{~h}$ & 16 microCi/MW-s & 5.6 \\
Xe-133 & $5.27 \mathrm{~d}$ & 2 microCi/MW-s & 0.7 \\
Xe-135 & $9.00 \mathrm{~h}$ & 4 microCi/MW-s & 1.4 \\
\hline \multicolumn{2}{l}{ a. Based on conservative estimate of 350,000 MW-s annual energy release. }
\end{tabular}

Table 4. Radionuclide emissions at the top of the TREAT stack for two air flow rates.

\begin{tabular}{|c|c|c|c|c|c|c|}
\hline \multirow{2}{*}{$\begin{array}{c}\text { Parent } \\
\text { Isotope }\end{array}$} & \multirow{2}{*}{$\begin{array}{c}\text { Parent } \\
\text { Half-Life }\end{array}$} & \multirow[b]{2}{*}{ Progeny } & \multirow{2}{*}{$\begin{array}{l}\text { Progeny } \\
\text { Half-Life }\end{array}$} & \multirow{2}{*}{$\begin{array}{l}\text { Parent } \\
\text { Phase }\end{array}$} & \multicolumn{2}{|c|}{ Annual Activity (Ci) } \\
\hline & & & & & $6,000 \mathrm{cfm}^{\mathrm{b}}$ & $3,000 \mathrm{cfm}^{\mathrm{b}}$ \\
\hline Ar-41 & $1.82 \mathrm{~h}$ & & & Gas & 350.0 & 350.0 \\
\hline $\mathrm{Kr}-85 \mathrm{~m}$ & $4.48 \mathrm{~h}$ & $\mathrm{Kr}-85$ & $10.73 \mathrm{yr}$ & Gas & 1.40 & 1.40 \\
\hline $\mathrm{Kr}-87$ & $1.27 \mathrm{~h}$ & $\mathrm{Rb}-87$ & $4.8 \mathrm{E}+10 \mathrm{yr}$ & Gas & 8.00 & 8.00 \\
\hline $\mathrm{Kr}-88$ & $2.84 \mathrm{~h}$ & $\mathrm{Rb}-88$ & $17.7 \mathrm{~m}$ & Gas & 5.60 & 5.60 \\
\hline $\mathrm{Rb}-88^{\mathrm{a}}$ & $17.7 \mathrm{~m}$ & & & Solid & 0.03 & 0.05 \\
\hline Xe-133 & $5.24 \mathrm{~d}$ & & & Gas & 0.70 & 0.70 \\
\hline $\mathrm{Xe}-135$ & $9.1 \mathrm{~h}$ & Cs-135 & $2.3 \mathrm{E}+06 \mathrm{yr}$ & Gas & 1.40 & 1.40 \\
\hline $\mathrm{Xe}-140^{\mathrm{a}}$ & $13.6 \mathrm{~s}$ & Cs-140 & $1.06 \mathrm{~m}$ & Gas & $2,375.0$ & $1,163.0$ \\
\hline Cs- $140^{\mathrm{a}}$ & $1.06 \mathrm{~m}$ & Ba-140 & $12.75 \mathrm{~d}$ & Solid & $1,028.0$ & $1,120.0$ \\
\hline Ba-140 & $12.75 \mathrm{~d}$ & La-140 & $1.68 \mathrm{~d}$ & Solid & 0.01 & 0.02 \\
\hline La-140 & $1.68 \mathrm{~d}$ & & & Solid & $6 \mathrm{E}-07$ & $2 \mathrm{E}-06$ \\
\hline
\end{tabular}

\subsubsection{Atmospheric Pathway Analysis}

Appendix C provides an assessment of the release and transport of gas-phase and particulate (solid-phase) radionuclides from the TREAT stack to actual and hypothetical receptor locations via the air pathway. Results are summarized in this section.

The analysis methodology and determination of the locations for evaluation were based on the need to meet the requirements of 40 CFR 61, Subpart $\mathrm{H}$ in addition to allowing comparison of emissions consequences between the two RTT-EA alternatives. Federal regulation 40 CFR 61, Subpart H requires determination of the effective dose (ED) for a "Maximally Exposed Individual," or MEI. This federal regulation defines the MEI to mean any member of the public (real or hypothetical) who abides or resides in an unrestricted area, and may receive the highest ED from the emission unit(s) under consideration, taking into account all exposure pathways affected by the radioactive air emissions. To determine the location of the MEI, the ED is calculated at any potential public receptor location. The highest predicted dose at public receptor locations with permanent residents is denoted the MEI dose. To meet the annual reporting requirements of NESHAPS, the INL has historically calculated the cumulative dose from all sitewide radiological air emissions, and therefore, the INL-wide MEI location is known. Similarly, the MEI locations are known for releases at SNL/NM based on historical NESHAPS evaluations. Cumulative MEI doses are required to be less than $10 \mathrm{mrem} / \mathrm{yr}$. 
Three potential public receptor locations were evaluated for transient testing using the TREAT Reactor. The three potential public receptor locations are located off the INL Site (see Figure 9) as follows:

- Frenchman's Cabin. This location is just south of the southern boundary, $36.75 \mathrm{~km}$ west-southwest of TREAT. No member of the public resides at Frenchman's Cabin; therefore, it represents a hypothetical receptor location. The annual INL NESHAPs assessment has reported atmospheric doses at this location since 1995 (DOE-ID 2012). It is the INL-wide MEI location for cumulative radiologic air emissions at INL because it is aligned with the predominant nocturnal air movement (from north-northeast) passing by most major INL facilities. If Alternative 1 (TREAT) is selected, the INL MEI location will remain at Frenchman's Cabin, as shown by the analysis for TREAT, because of the relatively low emissions from TREAT compared to other INL sources.

- Atomic City. Permanent residents here will receive the highest dose from TREAT stack emissions. Atomic City is $20.85 \mathrm{~km}$ south-southwest of the TREAT facility; therefore, the predominant transport path is parallel to that for atmospheric transport to Frenchman's Cabin. There is a closer permanent residence located $10 \mathrm{~km}$ southeast of TREAT and $3 \mathrm{~km}$ south of Highway 20, but it is not aligned with the predominant nocturnal wind direction. Doses at the closer location would be lower than those predicted at Atomic City.

- Nearest INL boundary. Doses are reported at the nearest INL boundary because during the 40-year operating period, a residence could be established here. There currently are no permanent residents at this location, but it was included in the assessment for completeness. The closest point on the INL boundary to TREAT is $6.15 \mathrm{~km}$ south-southeast of TREAT, just north of U.S. Highway 20.

Worker dose was calculated at TREAT and at the TREAT Reactor control building (see Figure 9) based on the following assumptions:

- Collocated workers at the TREAT Reactor control building. Workers at the TREAT Reactor control building could be stationed there full time or could be workers arriving from TREAT during a transient test. These workers would receive the dose from the gaseous and particulate emissions (see Table 4 and Appendix C) after dispersive transport. Doses for these workers were computed using the entire source term shown in Table 4.

- Collocated workers at TREAT. TREAT is assumed to be occupied by workers during a normal work day. During transient testing, the TREAT workers are relocated to the TREAT Reactor control building or beyond. Workers stationed at TREAT would not be exposed to the gaseous emissions shown in Table 4 during or shortly after transient testing. Instead, they would be exposed to the gases after they had migrated the separation distance between TREAT and the TREAT Reactor control building. However, workers stationed at TREAT would be exposed to the particulates generated by the gases as discussed in Appendix C.

Table 5 contains the computed dose results for both public and worker receptors. The total ED at the public MEI location (Atomic City) is $2.1 \mathrm{E}-03 \mathrm{mrem} / \mathrm{year}$. The total ED for the nearest worker at the TREAT Reactor control building is 3.6E-03 mrem/year. For each receptor, the total dose is dominated by the external dose from air immersion. Internal doses from ingestion (public only) and inhalation and external doses from direct radiation (ground surface) are negligible in comparison. In addition, the total dose is mostly from Ar-41 (as shown in Appendix C). These doses are well below the 10-mrem/year dose limit. 


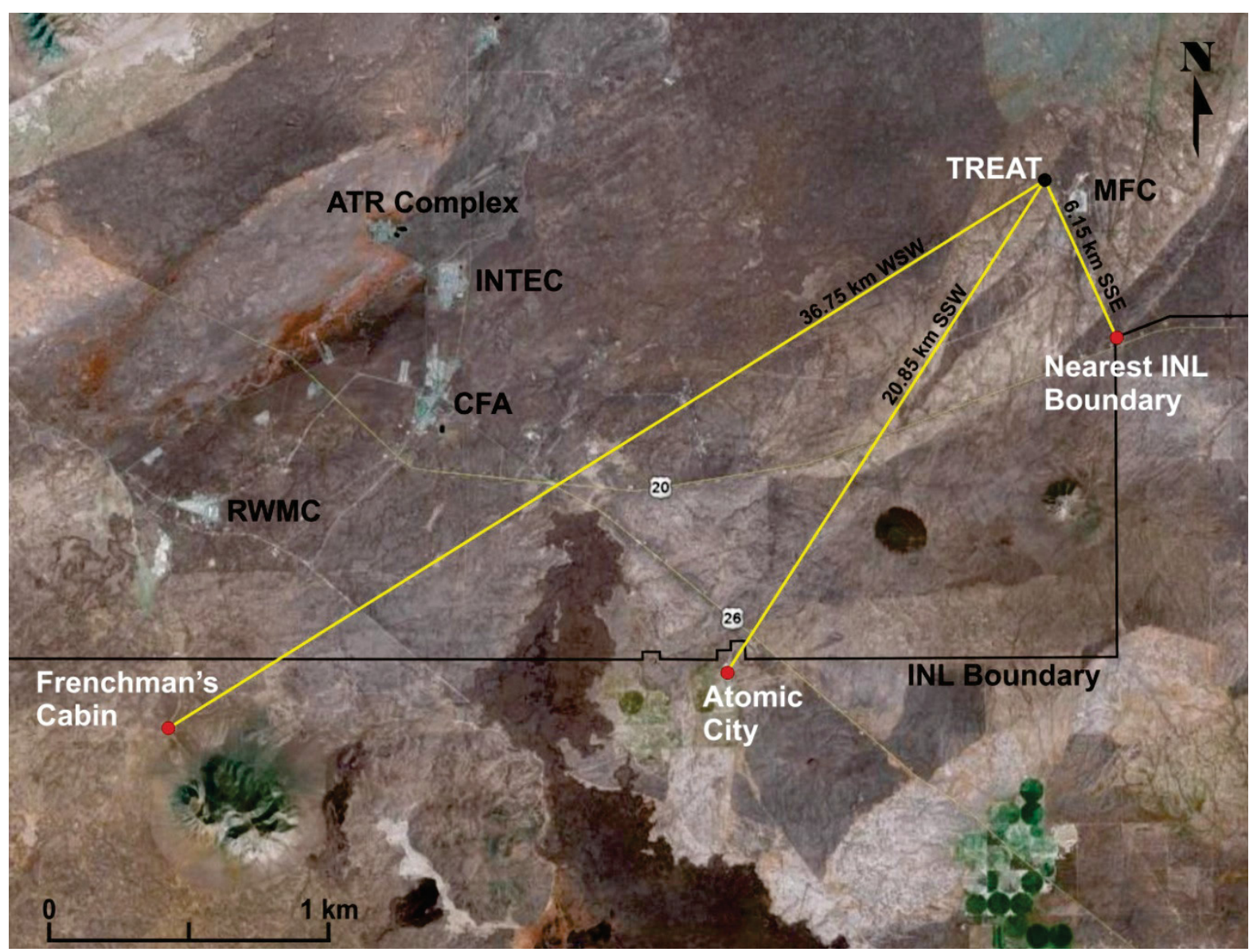

Figure 9. Public receptor locations for the air pathway analysis, showing distance and direction from TREAT (base map courtesy of Google Earth).

Table 5. Receptor doses for the TREAT air pathway assessment.

\begin{tabular}{|c|c|c|c|}
\hline Receptor & $\begin{array}{c}\text { Internal ED } \\
(\mathrm{mrem} / \text { year })^{\mathrm{a}}\end{array}$ & $\begin{array}{l}\text { External ED } \\
(\mathrm{mrem} / \text { year })^{\mathrm{b}}\end{array}$ & $\begin{array}{c}\text { Total ED } \\
\text { (mrem/year) }\end{array}$ \\
\hline Frenchman's Cabin (public) $^{\mathrm{c}}$ & $1.4 \mathrm{E}-06$ & $1.1 \mathrm{E}-03$ & $1.1 \mathrm{E}-03$ \\
\hline Atomic City (public MEI) & $5.5 \mathrm{E}-06$ & $2.1 \mathrm{E}-03$ & $2.1 \mathrm{E}-03$ \\
\hline Nearest INL Boundary (public) & $4.8 \mathrm{E}-05$ & $2.5 \mathrm{E}-02$ & $2.5 \mathrm{E}-02$ \\
\hline TREAT Reactor control building (worker) & $5.1 \mathrm{E}-06^{\mathrm{a}}$ & $3.6 \mathrm{E}-03^{\mathrm{b}}$ & $3.6 \mathrm{E}-03$ \\
\hline TREAT (collocated worker) & $2.2 \mathrm{E}-02^{\mathrm{a}}$ & $4.2 \mathrm{E}-02^{\mathrm{b}}$ & 6.4E-02 \\
\hline $\begin{array}{l}\text { a. Internal dose for workers includes only inhalatior } \\
\text { takes into account the higher breathing rate of wo } \\
\text { b. External dose for workers is scaled (reduced) by }\end{array}$ & $\begin{array}{l}\text { and is scaled (r } \\
\text { eed time onsite. }\end{array}$ & & \\
\hline
\end{tabular}

As reported in Table 5, the ED at the INL-wide MEI location (Frenchman's cabin) is estimated to be 1.1E-3 mrem/year. The estimated dose at Frenchman's cabin reported in the 2012 NESHAPs report (DOE-ID 2013) was 3.57 E-02 mrem/year (3.57 E-07 sievert/year), calculated using all sources that emitted radionuclides to the environment from the INL Site. Combined with the TREAT Reactor emissions the total air emissions are approximately $0.37 \%$ of the 10 -mrem/year federal standard. 


\subsubsection{Soil Pathway Analyses}

The potential for exposure via contaminated soils as a result of transient testing using the TREAT Reactor is negligible based on a review of historical data and projected particulate releases from the TREAT stack during normal reactor operations (see Appendix C, Section C-4).

The doses resulting from accumulated particulates are shown in Table 6 for a hypothetical worker inhaling suspended dust, being immersed in contaminated air, and being exposed to ground-surface contamination. These doses indicate that within $125 \mathrm{~m}$ of the stack, the impacts by the particulates decrease by an order of magnitude and are negligible.

Table 6. Pathway effective dose summary from particulate releases for a collocated worker.

$\mathrm{ED}^{\mathrm{b}}$ (mrem/year) as a function of distance from the ground source at TREAT

\begin{tabular}{lrrr}
\multicolumn{1}{c}{ Pathway $^{\mathrm{a}}$} & $38 \mathrm{~m}$ & $125 \mathrm{~m}$ & $250 \mathrm{~m}$ \\
\hline Inhalation (Internal) & $2.2 \mathrm{E}-02$ & $2.3 \mathrm{E}-03$ & $6.1 \mathrm{E}-04$ \\
Air Immersion (External) & $1.1 \mathrm{E}-04$ & $1.1 \mathrm{E}-05$ & $3.0 \mathrm{E}-06$ \\
Ground Surface (External) & $4.2 \mathrm{E}-02$ & $4.4 \mathrm{E}-03$ & $1.2 \mathrm{E}-03$ \\
\hline Total & $6.4 \mathrm{E}-02$ & $6.7 \mathrm{E}-03$ & $1.8 \mathrm{E}-03$ \\
\hline
\end{tabular}

a. In all cases, the ingestion dose for collocated workers is assumed to be zero.

b. Doses account for worker time onsite and breathing rate.

\subsubsection{Groundwater Pathway Analysis}

Radionuclide transport from potentially contaminated soils is improbable given the short half-lives of the TREAT Stack effluents discussed in Section 3.2.2 and the time necessary to travel from land surface to the aquifer. The travel time from land surface to the aquifer is equal to the distance to the aquifer, divided by the pore-velocity. The distance to the groundwater at TREAT is approximately $195 \mathrm{~m}(640 \mathrm{ft})$ below land surface (Section A-3.6). The pore-velocity is determined as the infiltration rate divided by an average porosity. In regions at INL where native vegetation and undisturbed soil conditions persist, the infiltration rate is approximately $1 \mathrm{~cm} /$ year. If it assumed that the average porosity for basalt is on the order of $5 \%$, the average pore velocity is $0.2 \mathrm{~m}$ /year and it would take a conservative tracer unaffected by chemical sorption to porous media about 1,000 years to reach the aquifer. The longest lived particulate radionuclide, Ba-140, has a half-life of 12.8 days. During the time necessary to travel to the aquifer, negligible activity would remain and there would be no dose impact via the groundwater pathway.

\subsection{Impacts of Normal Test Reactor Operations using the Annular Core Research Reactor}

To support the EA for RTT, impacts expected during normal testing using the ACRR need only consider the additional use of the existing operating reactor. The ACRR is a water-cooled reactor instead of being air cooled. Radioactive emissions from the ACRR stack are the result of activation of air surrounding and adjacent to the reactor. All other fission products are contained in the cooling water.

\subsubsection{Atmospheric Pathway Analysis}

An assessment was performed for the release and transport of gas-phase radionuclides from the ACRR stack to actual and hypothetical receptor locations via the air pathway and is presented in Appendix C, Section C-5. Using CAP 88-PC (EPA 2007), EDs were calculated for the following three receptor locations (shown in Figure 10): 
1. Kirtland Storage Site. This location is occupied by workers 24 hours per day, 7 days per week; therefore, it represents an important worker location. It is the nearest Air Force personnel receptor to the ACRR facility and the location of highest reported offsite impact by ACRR. There are no permanent residents at Kirtland Storage Site, which is located 1,783 m west-northwest of ACRR.

2. Chestnut Site. This location was selected for this analysis because it also is occupied by Air Force personnel. The Chestnut site is 4,172 $\mathrm{m}$ south-southwest of ACRR. There are no permanent residents at Chestnut Site.

3. Eubank Gate. This location was selected for this analysis because it is the location of a frequently occupied public location nearest ACRR. The Eubank Gate is located 5,984 m north of ACRR.

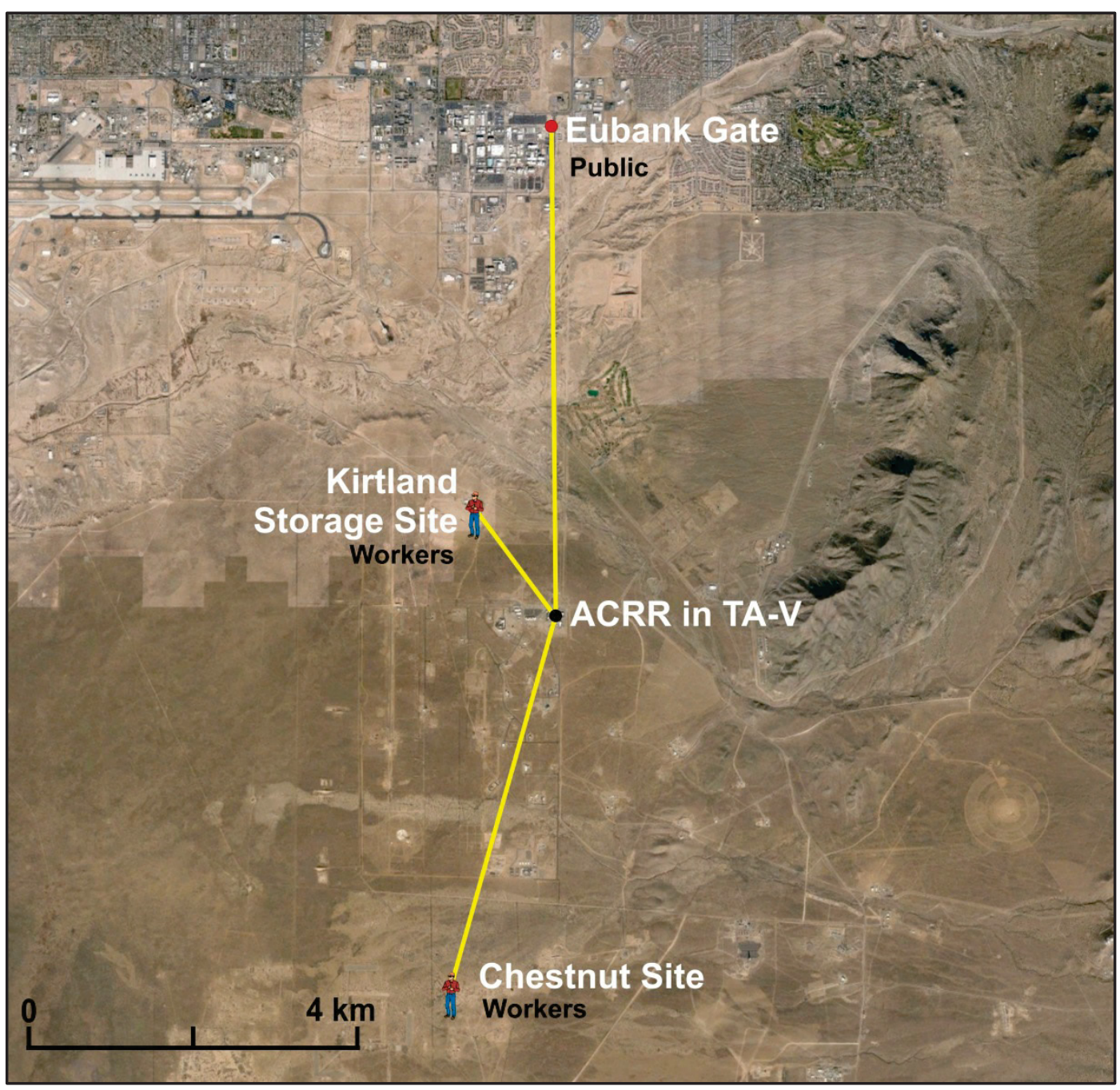

Figure 10. Public receptor locations for the air pathway analysis, showing distance and direction from the ACRR (base map courtesy of Google Earth).

Under Alternative 2 (ACRR), the total dose for receptors is exclusively due to external dose from air immersion from Ar-41, a noble gas that is neither deposited on plant or soil surfaces nor subject to bioaccumulation by biota. The projected total ED at each of the three designated receptor locations resulting from air immersion and inhalation are provided in Table 7. 
Table 7. Receptor doses for the ACRR air pathway assessment.

\begin{tabular}{lcc}
\hline \multicolumn{1}{c}{ Receptor } & $\begin{array}{c}\text { Total ED } \\
\text { (mrem/year) }\end{array}$ & $\begin{array}{c}\text { NESHAPS } \\
\text { Reported Dose }{ }^{\mathrm{a}}(2011) \\
\text { (mrem/year) }\end{array}$ \\
\hline Kirtland Storage Site & $4.8 \mathrm{E}-04$ & $8.6 \mathrm{E}-04$ \\
Chestnut Site & $1.1 \mathrm{E}-04$ & $8.2 \mathrm{E}-04$ \\
Eubank Gate (public receptor) & $4.8 \mathrm{E}-05$ & Not reported \\
\hline a. & Sandia National Laboratories/New Mexico (SNL/NM), 2012, Calendar Year 2011 Annual Site Environmental Report for Sandia National \\
& Laboratories, New Mexico, SAND2012-7340P, Sandia National Laboratories, Albuquerque, NM, September.
\end{tabular}

\subsubsection{Soil Pathway Analysis}

Atmospheric releases during normal operations from the ACRR are limited to Ar-41. The ED is the sum of the internal and external doses. Internal dose is comprised of inhalation and ingestion doses. External dose is comprised of air immersion and direct radiation from deposition on the ground. Under Alternative 2 (ACRR), the total dose for receptors is exclusively due to external dose from air immersion from Ar-41, a noble gas that is neither deposited on plant or soil surfaces nor subject to bioaccumulation by biota. Therefore, there no ingestion or biotic exposure pathways from contaminated soil that needs to be considered by this analysis.

\subsubsection{Groundwater Pathway Analysis}

There is no soil contamination and there are no groundwater releases during normal operations of ACRR. Therefore, there are no groundwater pathways that need to be considered by this analysis.

\section{PREDICTED IMPACTS FROM ACCIDENTS}

\subsection{Accident Consequences for Alternative 1 (Use of the Transient Reactor Test Facility and Other Idaho National Laboratory Facilities)}

Accident consequences for Alternative 1 were evaluated for events related to operation of the TREAT Reactor, including refueling; handling the experiments; and irradiating the experiments using the TREAT Reactor (transportation is covered in Section 5).

\subsubsection{Overview of Accident Analysis}

Results of the accident analysis conducted for RTT Program operations at INL are summarized in Table 8, with a full explanation provided in Appendix F. The analysis was conducted by doing the following:

1. Identifying bounding inventories that would be contained in the experiment assembly and the bounding inventory contained in the TREAT Reactor core with the bounding inventories determined by radiologic dose potential (as opposed to fission potential). This is provided in Appendix E.

2. Identifying potential accident scenarios that could involve operation of the TREAT Reactor, handling the TREAT Reactor fuel and experiment assembly, and accident scenarios that could occur during the process of transient testing using the TREAT Reactor. This is provided in the hazards analysis conducted for operations at TREAT (INL 2013a). 
3. Identifying the chain of events necessary to result in a radiologic release for each accident scenario; determining the probability of occurrence for each event in the chain and the time-at-risk for each event; calculating the annual frequency of occurrence for each accident scenario; and calculating the probability of each accident scenario occurring during the 40-year RTT Program lifetime. This is provided in Appendix F, Section F-4. As required by the DOE guidance for analyzing accidents for NEPA (DOE 2002), the probability that at least one accident occurs over the lifetime of the project also is provided. The lifetime of the RTT Program is expected to be 40 years. The probability that at least one accident occurs for each scenario analyzed is computed in Appendix F, assuming an inhomogeneous Poisson process as:

$P=1-(1-f)^{N W * N Y}$

where:

$\mathrm{P} \quad=$ probability of at least one failure from the nw items over a period of ny years

$\mathrm{F} \quad=$ frequency of failure over a particular period of time (a year in this case)

$\mathrm{NW}=$ number of items that may fail with frequency "f" (assumed to be one in this case)

$\mathrm{NY}=$ number of time periods over which failures can occur (years) (40-year lifecycle).

4. Identifying receptor locations for dose calculations. Receptor locations included those for facility workers, collocated workers, and members of the public. This is discussed in Appendix F, Section F-4.

5. Calculating the acute dose from gamma cloud exposure and inhalation at the receptor locations. Ingestion doses were not computed, because, in the event of an accident, contaminated areas would be secured and remediated to prevent food product ingestion. Dose calculations are discussed in Appendix E and in Appendix F, Sections F-2.1 and F-4.

To put the doses provided by the accident analysis into perspective, annual dose limits and annual radiation doses received by average Americans are summarized in Figure 11. On average, Americans receive a radiation dose of about $0.62 \mathrm{rem}(620 \mathrm{mrem})$ each year. During normal operations, the annual dose limit allowable by DOE for radiation workers is $5 \mathrm{rem}(5,000 \mathrm{mrem})$, and the annual dose limit for members of the public is $0.1 \mathrm{rem}(100 \mathrm{mrem})$.

According to the Health Physics Society's Radiation Benefit and Risk Assessment and International Commission on Radiological Protection (Publication No. 103, 2007):

- The average natural lifetime incidence of cancer in the U.S. is $42 \%$ (i.e., 42 out of 100 people will get cancer in their lifetime). Radiation exposure increases this risk at the estimated rate of $0.17 \%$ per rem of radiation dose based on the effects observable at high doses.

- A dose of 5 rem increases the chance of getting a cancer by $0.85 \%$. For a dose of 5 rem, 43 people out of 100 will get cancer in their lifetime. This is an additional one person getting cancer relative to the average natural lifetime incidence of cancer.

- A dose of 25 rem increases the chance of getting a cancer by $4.25 \%$. For a dose of 25 rem, 46 out of 100 people will get cancer in their lifetime. This is an additional 4 people getting cancer relative to the average natural lifetime incidence of cancer.

- A dose of 100 rem increases the chance of getting cancer by $17 \%$. For a dose of $100 \mathrm{rem}, 59$ out of 100 people will get cancer in their lifetime. This is an additional 17 people getting cancer relative to the average natural lifetime incidence of cancer.

According to the Interagency Steering Committee on Radiation Standards (ISCORS 2002), latent cancer fatality (LCF) is a measure of deaths resulting from cancer that became active after a latent period following exposure to radiation. The LCF value corresponds to the risk that cancer will result from the 
dose sustained. The dose is the consequence. The numbers of radiation-induced LCFs are estimated by multiplying the dose (rem) by health risk conversion factors. The factors most commonly used in recent assessments are 6E-04 LCF per rem (ISCORS 2002). The same factor applies for facility workers, collocated workers, and members of the public.

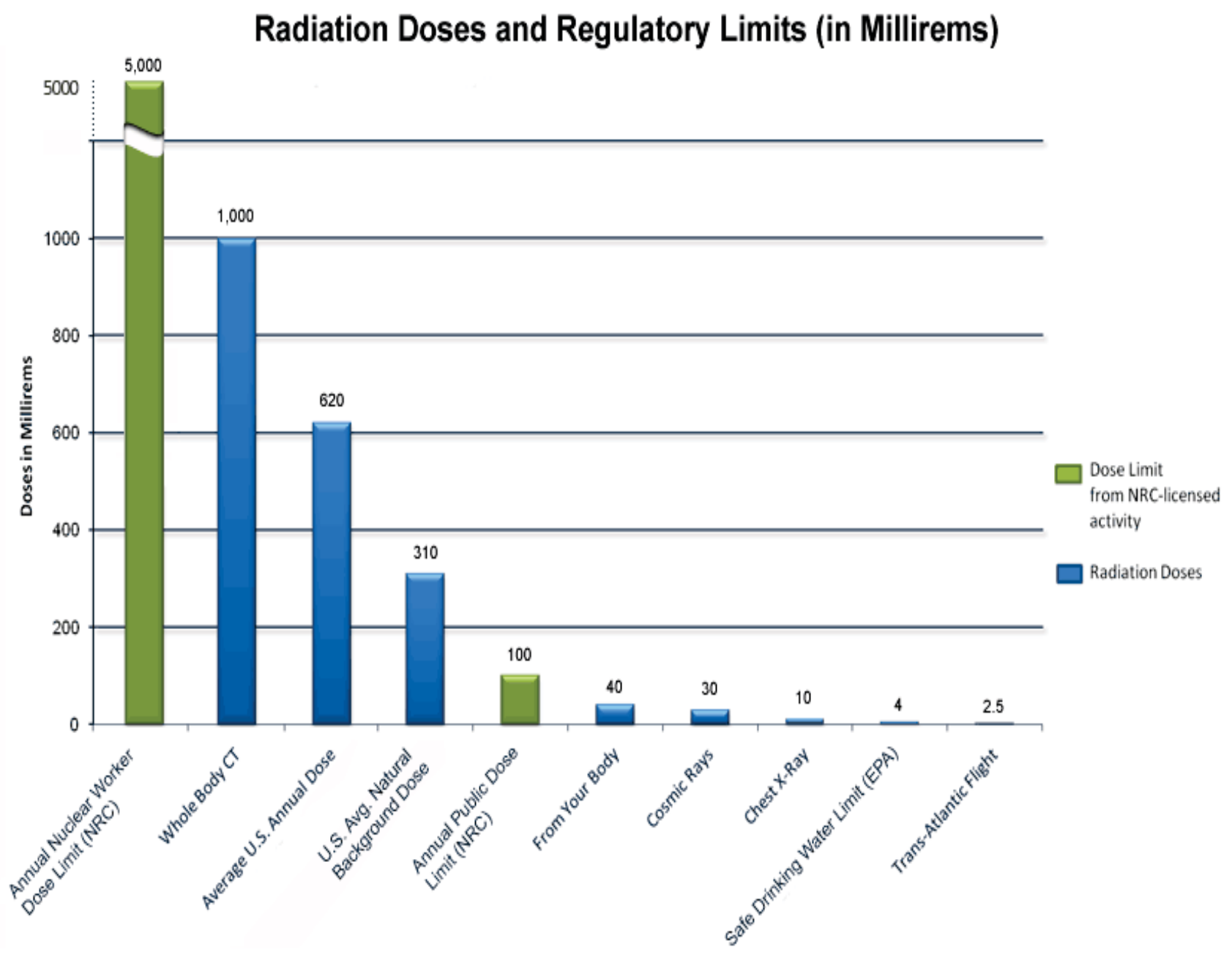

Figure 11. Radiation doses and regulatory limits.

\subsubsection{Radiologic Consequences of Accidents}

The analysis of accident scenarios looked at events that could be caused by a range of natural phenomena hazards (NPHs; e.g., seismic, wind, and flood), operator errors, and equipment failure. The only credible NPH with the potential of impacting the TREAT Reactor or experiments is an earthquake. The probability that an earthquake could result in damage to key structural features sufficient to cause a radiologic release is on the order of one in 32,000 years. The more likely accident scenarios would be initiated by operator error or equipment failure. The probability that an operator error or equipment failure could cause a radiologic release ranges between 1 chance in 100 years to 1 chance in 25,000 years. The results of the two highest consequence events are shown in Table 9. The consequences of these events can be summarized as follows: 
- Experiment handling event impacting the TREAT Reactor. Higher accident-related doses for workers at TREAT are expected to occur as a result of routine equipment failure or operator error as opposed to being a function of irradiation in the TREAT Reactor. Transient testing requires moving the experiment assembly above the reactor. If the experiment assembly is dropped, there is a remote chance that fuel from the experiment and from damaged reactor fuel assemblies could be released into the building. A handling accident involving the experiment above the TREAT Reactor has a one in 25,000 chance of occurring in any given year. The probability of this type of accident occurring once during the 40 -year program lifetime is 0.002 .

During this event, the reactor is not active. It is improbable that dropping an experiment assembly into the reactor would result in a fire or an inability to safely shutdown the reactor. If the drop resulted in a release of gas or particulates from the fuel, facility workers in the building would receive a radiologic dose from the release. In addition, it is assumed that a release occurring in the building would be immediately available to be dispersed and transported downwind from the building. The downwind transport of released radionuclides would first affect workers outside of the building (collocated workers). Eventually, the transported plume would reach the INL boundary, where members of the public could be affected. The predicted doses, dose risk, and risk of a latent cancer fatality are shown in Tables 9 and F-19.

Members of the public exposed to this dose would receive $0.077 \mathrm{rem}$. They would have a $0.01 \%$ chance of getting a cancer from this dose, and the probability of a latent cancer fatality occurring is about 1 in 22,000. This dose is calculated for a point on the INL boundary closest to the TREAT Reactor building. Persons located further from the accident site would receive a lower dose.

Collocated workers $300 \mathrm{~m}$ from the TREAT Reactor building could receive a dose of $2.2 \mathrm{rem}$. This could increase their chance of getting a cancer by $0.4 \%$. For every 750 workers exposed, one latent cancer fatality would be expected.

Workers in the building during the accident would receive an estimated dose of $6.4 \mathrm{rem} / \mathrm{minute}$. These workers could remain in the building about 4 minutes before they received a dose of 25 rem. Twenty-five rem is the EPA protective action guide value for response persons. At 25 rem, there is a $4.25 \%$ increased chance of a facility worker getting cancer and for every 200 facility workers exposed, 3 latent cancer fatalities would be expected.

- TREAT Reactor fuel clad failure: The highest dose, increased occurrence of cancer, or risk of latent cancer fatality (dose consequence) for members of the public could occur if the TREAT Reactor fuel cladding is compromised. The probability that the redundant reactor safety features would fail in any given year is one in 270,000 . The probability that the safety features fail once during the 40 -year transient testing program is 0.00015 . Therefore, this accident is extremely unlikely to occur.

Members of the public at the closest INL boundary could receive a dose of $0.24 \mathrm{rem}$. This could increase the probability of getting cancer by $0.04 \%$. One latent cancer fatality in 7,000 exposed persons would be expected.

During transient testing, facility workers and collocated workers are located in the TREAT Reactor control building, approximately $770 \mathrm{~m}$ from the TREAT Reactor building. At this distance, they could be exposed to $6.5 \mathrm{rem}$, resulting in an increased chance of getting cancer of $1.1 \%$. One latent cancer fatality out of 250 exposed persons could be expected. 


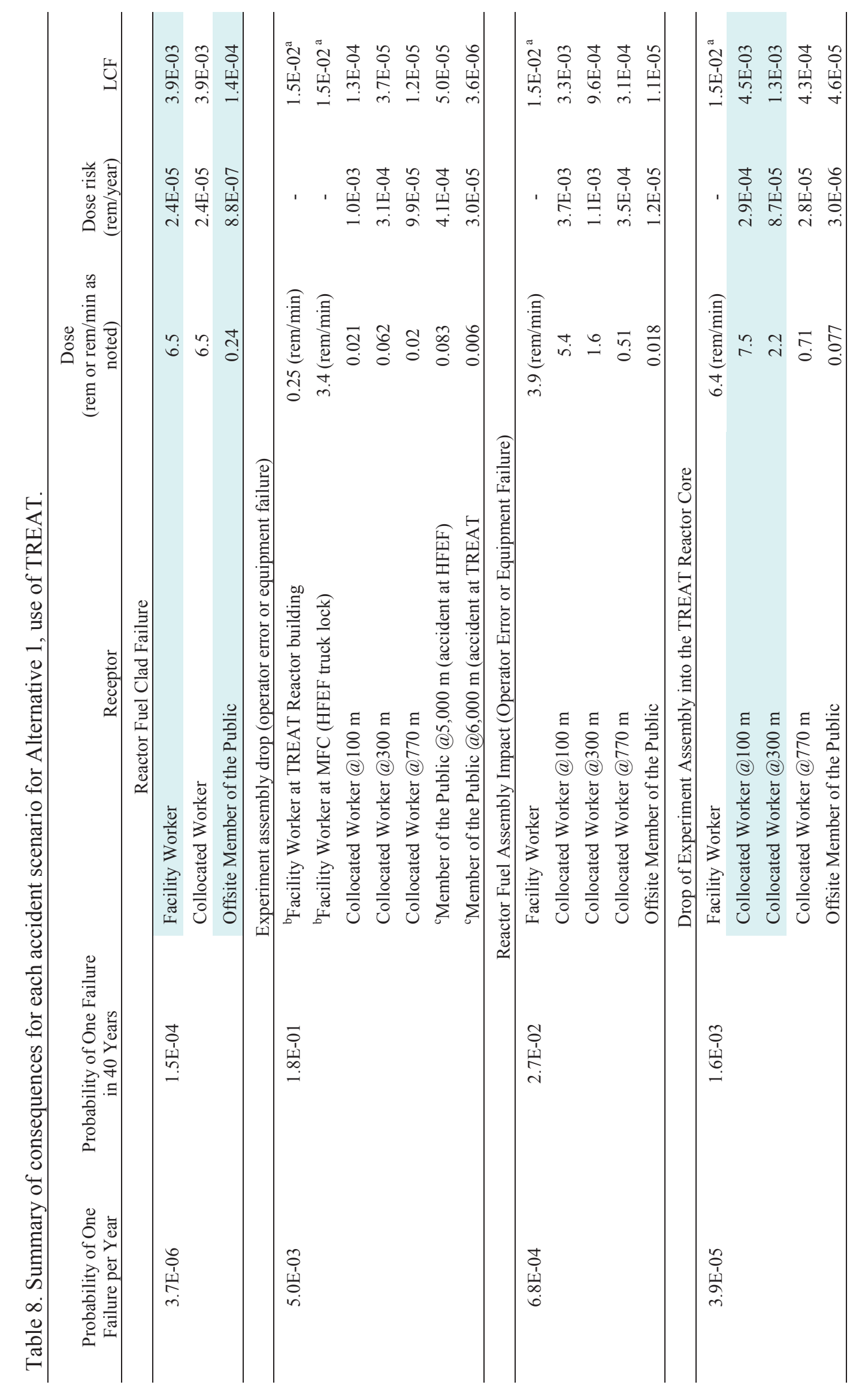




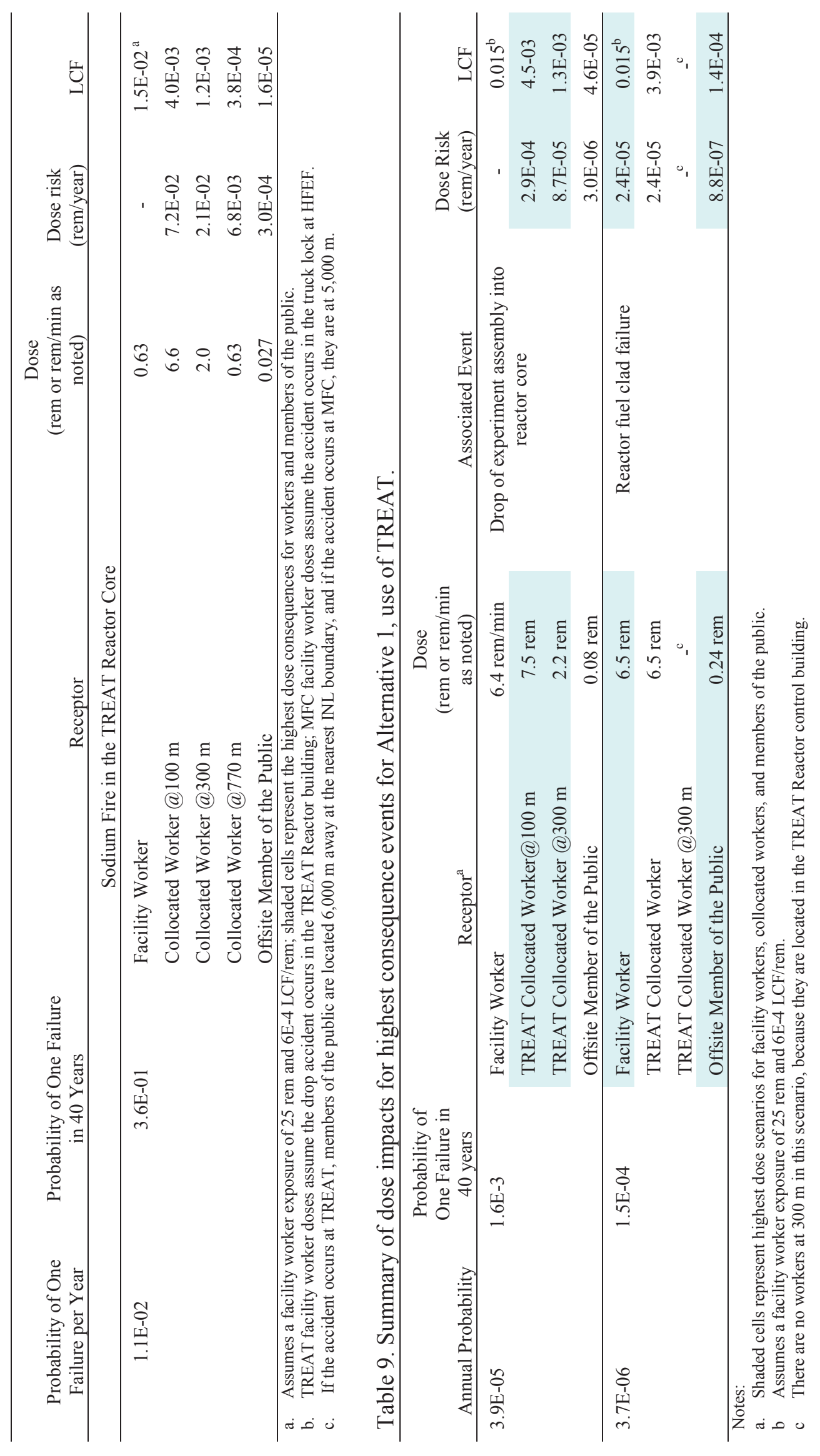




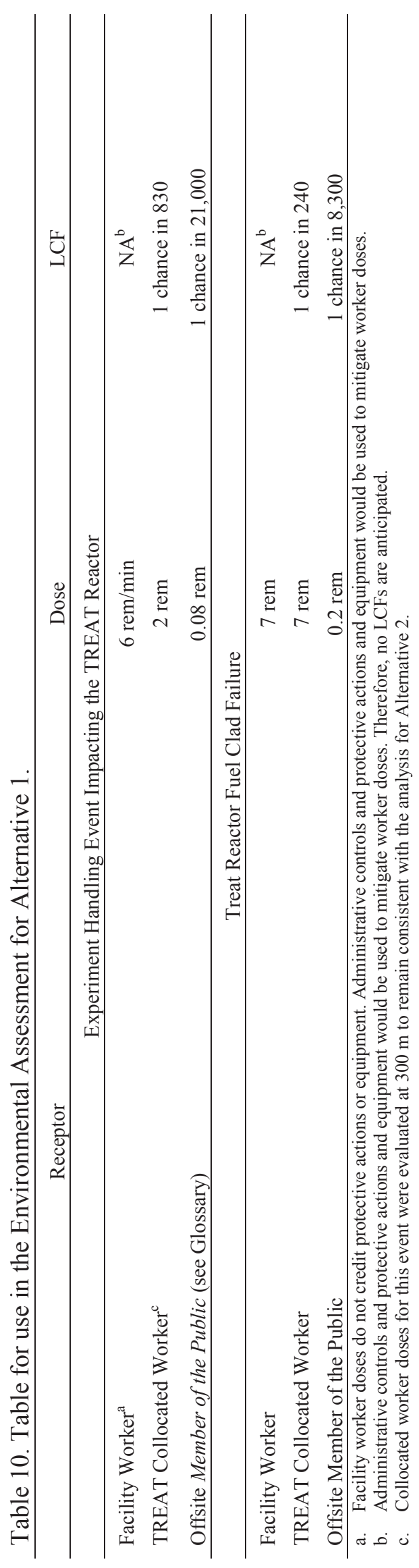




\subsubsection{Summary of Consequences}

The estimated doses and resultant health risks provided in the analysis of accidents are conservative. They are based on a bounding radiologic inventory for the experiments and a very conservative estimate of the TREAT Reactor core radiologic inventory. The dose calculations essentially assume accidents occur outside of a structure (e.g., TREAT Reactor building or HFEF); therefore, they do not credit reductions in radionuclide concentrations that could occur during transport from the site of an accident to the outside environment. Applicable reductions would include particulate filtering by the HEPA filters for some scenarios and adherence to equipment or the facility structure itself for others. The estimated doses do not assume receptors are evacuated. Facility workers and collocated workers are assumed to be unprotected by shielding, respirators, or other personal protective equipment. Additional conservatisms in the dose calculation are discussed for each accident as applicable in Appendix F.

Dose, LCF, and cancer consequences for members of the public are negligible for all scenarios. Protection of facility workers and collocated workers would be provided to limit dose consequences. Based on a 25-rem exposure, there is ample time for workers to be evacuated. At 25 rem, there is $4.25 \%$ chance of an exposed worker getting cancer and 1.5E-2 chance of a latent cancer fatality. Therefore, the accident consequences for workers also are considered to be negligible.

\subsubsection{Incorporation into the Environmental Assessment}

The EA provides a high-level overview of the results summarized in this section and provided in detail in Appendix F. The first difference occurs in calculation of the probability of one accident occurring in 40 years. According to the NEPA preparation guidance (DOE 2002), the probability should be calculated assuming a homogeneous Poisson process. This essentially is equivalent to assuming a uniform distribution of failure over the lifetime of the facility. Probability in this model is computed from:

$P=f / n y$

where:

$\mathrm{P}=$ probability of at least one failure over a period of ny years

$\mathrm{F} \quad=$ frequency of failure over a particular period of time (a year in this case)

$\mathrm{NY}=$ number of time periods over which failures can occur (years) (40-year lifecycle).

This model is recommended for use simply because it is easier for the public to understand.

Table 10 provides the dose summary for use in the EA. It was derived by rounding the doses in Table 9 to one non-zero figure. LCFs were calculated using a dose-to-LCF conversion factor of 6E-4 and the rounded dose values. This approach was taken for ease in presentation to the public.

\subsection{Accident Consequences for Alternative 2 (Use of the Annular Core Research Reactor and Idaho National Laboratory Facilities)}

\subsubsection{Overview of Accident Analysis}

Results of the accident analysis conducted for Alternative 2 are provided in Appendix F, Section F-5 and are summarized in Table 11. The analysis generally followed the approach used for accidents at INL (summarized in Section 4.1.1) and was conducted by doing the following:

1. Using the bounding inventories for the experiments identified in Appendix $\mathrm{E}$ and the inventory for the ACRR (SNL/NM 2013).

2. Identifying potential accident scenarios that could involve the following: 
- Experiment assembly and material handling operations at INL (discussed in Section F-4.2). In Alternative 2 (ACRR), facilities at INL will be used to pre-irradiate the fuels (ATR), to conduct pre-irradiation and post-irradiation examination (MFC), and for waste packaging for dispensation (INTEC). The radiologic inventories allowed in those facilities exceed the bounding inventory being evaluated by the RTT Program. However, in order to provide a basis of comparison for the two alternatives being evaluated by the EA, an analysis of accidents specific to experiment handling was conducted to support the RTT Program's EA. This assessment determined that a drop/impact accident involving the experiment assembly would represent the worst-case scenario for accidents occurring at INL in Alternative 2. For the purposes of determining the highest public dose, the accident was assumed to occur at HFEF. This location was selected because (1) most activities related to examination, packaging, and shipping will occur at HFEF and (2) it is the facility that will be used that is closest to the INL boundary.

- Experiment assembly and material handling operations at SNL/NM. At SNL/NM (discussed in Section F-5.1), the experiment components will be received, irradiated, and re-packaged for transport back to INL. Experiment handling operations will be similar to those expected at INL. Therefore, the bounding accident was assumed to be similar.

- Irradiation of the experiment assembly in ACRR (discussed in Sections F-5.2 and F-5.3).

Accidents that could occur at ACRR are a function of the experiment design, reactor design, and reactor operation. The differences between operations at TREAT and ACRR required identification of scenarios specific to ACRR.

3. Identifying the chain of events necessary to result in a radiologic release for each accident scenario; determining the probability of occurrence for each event in the chain and the time-at-risk for each event; calculating the annual frequency of occurrence for each accident scenario; and calculating the probability of each accident scenario occurring during the 40-year RTT Program lifetime.

4. Identifying receptor locations for dose calculations. Receptor locations included those for facility workers, collocated workers, and members of the public. This is discussed in Section F-5.

5. Calculating the acute doses at the receptor locations using the methodologies discussed in Sections F-2.2 and F-5.

\subsubsection{Radiologic Consequences of Accidents}

The results of the highest consequence events expected to occur either on INL or SNL/NM are shown in Table 12. The consequences of these events can be summarized as follows:

- Experiment assembly and material handling operations at INL. Accidents occurring at INL under Alternative 2 (ACRR) would be bounded by the experiment drop/impact events occurring at MFC, which is located about 5,000 $\mathrm{m}$ from the nearest INL boundary. The chance of an experiment drop is one in 200 per year. The probability of one drop occurring in the 40 -year project lifetime is 0.018 .

Members of the public exposed to this dose could receive $0.007 \mathrm{rem}$. They would have a $0.001 \%$ chance of getting cancer from this dose and the risk of a latent cancer fatality occurring is about 1 in 225,000 . This dose is calculated for a point on the INL boundary closest to MFC. Persons located further from the accident site would receive a lower dose.

Collocated workers $300 \mathrm{~m}$ from the accident site could receive a dose of $0.062 \mathrm{rem}$. This could increase their chance of getting cancer by $0.01 \%$. One latent cancer fatality in 27,000 exposed workers would be expected.

Workers in the facility could receive a dose of $3.4 \mathrm{rem} /$ minute. To put this into perspective, a dose of $25 \mathrm{rem}$ is considered. For a dose of $25 \mathrm{rem}$, they could remain in the building for about 7 minutes before they received a dose of $25 \mathrm{rem}$. At $25 \mathrm{rem}$, the increased probability of a worker getting cancer is $4.25 \%$. At 25 rem, the rate of latent cancer occurrence is 0.015 or 1.5 people in 100 . 
- Irradiation of the experiment assembly in the ACRR. The worst-case accident identified at SNL/NM would occur if the experiment assembly failed while in the ACRR central cavity. The engineering design requirements of an experiment assembly make it unlikely that a failure would occur. The probability of an experiment assembly failure is 0.002 , or about one chance in 500 . The probability that the experiment assembly fails once during the 40 -year project lifetime is equal to 0.08 .

Members of the public could be exposed to a dose of 0.4 rem. This dose would increase the probability of a member of the public getting cancer by $0.07 \%$. The risk of a latent cancer fatality is one in 4,000 exposed persons.

Collocated workers outside of the ACRR building could receive a dose of $3.7 \mathrm{rem}$. This would increase the chance of exposed workers getting cancer by $0.6 \%$. The risk of a latent cancer fatality is one in 450 exposed persons.

Facility workers located in the ACRR building at the time of an accident could receive a dose of $74.7 \mathrm{rem} / \mathrm{min}$. This dose rate assumes the facility worker is not protected by safety equipment. At the estimated dose rate, an unprotected (unshielded) facility worker would likely receive at least 25 rem. However, at the estimated dose rate, an unprotected (unshielded) facility worker would have 1.3 minutes prior to exceeding a 100 -rem dose. At $100 \mathrm{rem}$, the increased probability of a worker getting cancer is $17 \%$. At 100 rem, the risk of a latent cancer fatality occurring is about 1 in 16 . To minimize this potential, activities leading to this dose rate would be administratively controlled, safety systems would be used, and safety equipment would be provided to the workers.

\subsubsection{Summary of Radiologic Consequences}

The estimated doses and resultant health risks provided in this analysis are conservative. They are based on a bounding radiologic inventory for the experiments and a conservative estimate of the ACRR core radiologic inventory. The dose calculations take credit for the filtering capacity of the ACRR pool, but do not credit HEPA filters. The estimated doses assume receptors are evacuated after 2 hours. Facility workers and collocated workers are assumed to be unprotected by shielding, respirators, or other personal protective equipment. Additional assumptions made in the dose calculation are discussed for each accident as applicable in Appendix F. Consequences for members of the public and for collocated workers would be negligible without additional protective measures. Administrative controls and protective actions and equipment would be used to mitigate worker doses. Administrative procedures that could be implemented at ACRR have not been factored into the dose estimates provided in Tables 11 or 12.

\subsubsection{Incorporation into the Environmental Assessment}

The EA provides a high-level overview of the results summarized in this section and provided in detail in Appendix F. The probability of one accident occurring in 40 years was calculated using Equation 2 instead of Equation F-5. This was used simply because it is easier for the public to understand.

Table 13 provides the dose summary for use in the EA. It was derived by rounding the doses in Table 12 to one non-zero figure. LCFs were calculated using a dose-to-LCF conversion factor of 6E-4 and the rounded dose values. This approach was taken for ease in presentation to the public. 


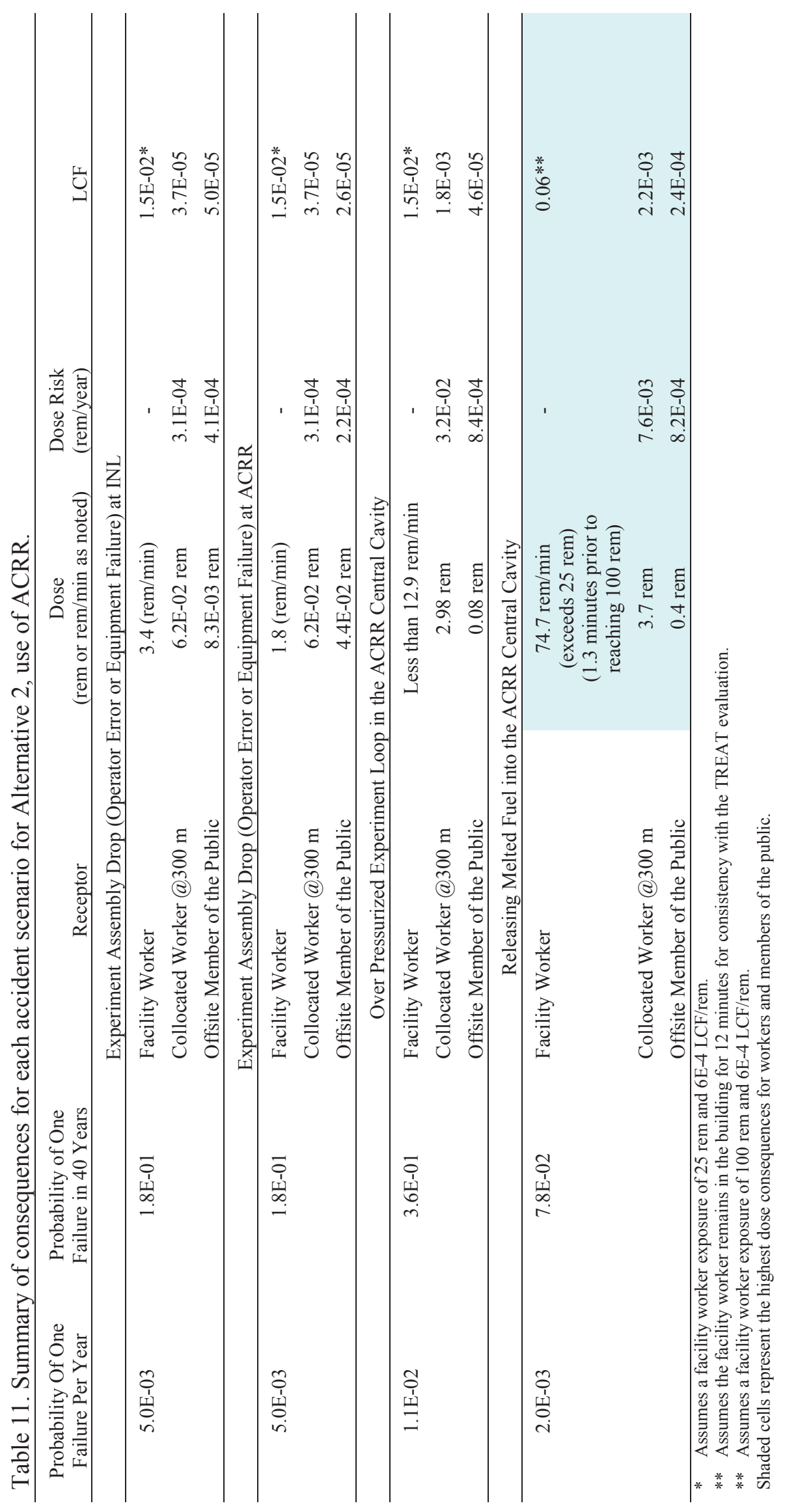




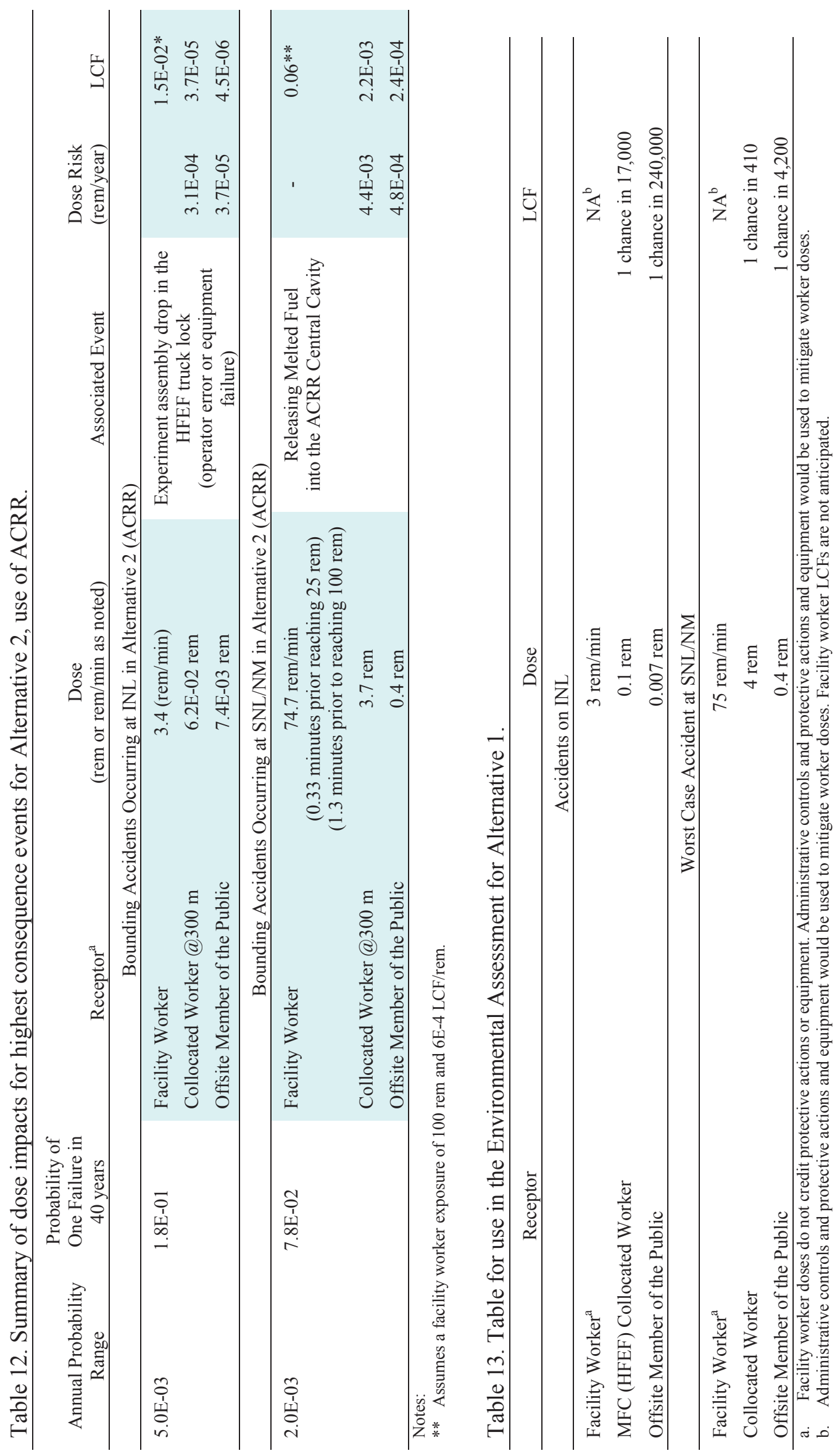




\subsection{Summary of Accident Analyses}

Based on assumptions made in development of the radiologic inventories, development of accident scenarios, and dose assessment methodology:

- Estimated doses incorporate a comparable level of conservatism. Because of differences between operation of the TREAT Reactor and ACRR and differences in dose assessment methodology (as discussed in Section F-2.3), the differences that were introduced are either appropriate or would result in negligible differences in dose. Therefore, the provided dose estimates are not biased toward either alternative.

- Estimated doses are conservative. The provided doses and health consequences are bounding for members of the public. They are very conservative for collocated workers and facility workers because they take no credit for training, evacuation, or emergency response plans that would limit either the accident occurrence or exposure in the event of an accident.

Consequences for members of the public and for collocated workers would be negligible without additional protective measures. Administrative controls and protective actions and equipment would be used to mitigate worker doses. With additional protection for facility workers, their dose consequences also would be negligible.

\section{IMPACTS OF TRANSPORTING THE EXPERIMENT COMPONENTS}

An assessment of the potential impacts from transport of the radiological inventory in the experiments that will be used in RTT are detailed in Appendix G. For this analysis, incident-free transportation and transportation accidents have been evaluated.

Transportation and handling of the experiment assemblies were assessed for (1) transportation at INL and (2) between MFC at INL and ACRR at SNL/NM (as explained in Section 2). These paths are illustrated conceptually in Figure 12. At INL, the transport path includes the routes between INL facilities, including ATR, INTEC, and MFC, as indicated by the red arrows. For Alternative 2 (ACRR), the transport will occur between INL facilities, then will proceed from MFC to the SNL hot cell, to ACRR, back to the SNL hot cell, and finally back to MFC, as shown by the green connecting arrows. The blue and orange connecting arrows are provided to indicate a transport pathway for experimental components originating at NRC-licensed facilities. Transport of research fuels to MFC from commercial facilities would occur on public roadways pursuant to NRC's authority for the commercial reactor.

For transport between the ATR and MFC at INL and between MFC and TREAT, either the GE 2000 cask (Figure 13), Battelle Energy Alliance research reactor (BRR) cask (package), or the TREAT loop handling cask (HFEF-15) will be used. The radiological material will be transported between MFC and ACRR using either the GE 2000 or BRR cask (package).

In this report, transportation and routine handling risks are evaluated in terms of collective population dose risk and collective population LCF risk. Collective population risk is defined as the radiological risk resulting from the potential exposure of people to ionizing radiation and is the result of integrating the radiation risk over the area occupied by the population. In the analyses contained in Appendix G, the source of the radiation is through exposure that could occur (1) during incident-free transportation to external radiation from the loaded casks, (2) following an incident to external radiation from the loaded cask, or (3) following a severe accident to radioactive material potentially released from the cask. In the case of transportation accidents involving a release of radioactive material, the population in question is those within the dispersion plume footprint. As outlined in the handbook, for routine transportation, all

major groups of potentially exposed persons were considered. For transportation-related accidents, dose 
risk is provided for the general population. The calculations of risk for routine highway transportation include exposures of the following population groups:

- Persons along the route (offlink population). Collective doses are calculated for all persons living or working on each side of a transportation route. The width of this band is assumed to be $800 \mathrm{~m}$ (about $1 / 2$ mile).

- Persons sharing the route (onlink population). Collective doses are calculated for persons in vehicles sharing the transportation route. This group includes persons traveling in the same and in the opposite direction of the shipment.

- Persons at stops. Collective doses are calculated for people who share the stop and may be exposed while a shipment is stopped en route. For truck transportation, these stops include those for refueling, food, and rest. Residents who live within a half mile of the stop also are assumed to be exposed and doses for them are calculated.

- Inspectors of the transport. Collective doses are calculated for workers that would inspect the transport initially and that could accompany the transport along the route. Inspectors are assumed to be occupational radiation workers, are shielded, and would be monitored by a dosimetry program. Therefore, the maximum allowable dose would be $5 \mathrm{rem} /$ year.

- Crew members. Collective doses are calculated for truck transportation crew members. Truck crew members are assumed to be occupational radiation workers, are shielded, and would be monitored by a dosimetry program. Therefore, during routine transport, the maximum allowable dose would be $5 \mathrm{rem} /$ year.

The dose model considered direct external exposure and exposure from radiation scattered from the soil and air. The doses calculated for the first three population groups were added to yield the collective dose to the public for transport to SNL/NM and to onsite workers for transport on INL; the dose calculated for the fourth and fifth groups represents the collective dose to workers. The calculation of routine doses for each exposed population group depends on parameters such as the radiation field strength, source-receptor distance, duration of exposure, vehicular speed, stopping time, traffic density; and route characteristics (such as population density) discussed in Appendix G.

Dose risk and LCF risk were computed assuming transport of the bounding radionuclide inventory for the experiments discussed in Appendix E. The radioactivity of this inventory represents the highest dose potential of any package that would be contained in any of the transient test experiments. It is likely that many of the experiment packages transported in support of transient testing would be smaller in size and would contain less radioactivity.

In addition to providing dose risk and LCF risk, Appendix G provides estimated vehicle-related health risks that result from routine transportation that might be associated with transporting vehicles that generate air pollutants during shipment, independent of the nature of the shipment.

Models used in the analysis include the following:

- TRAGIS. TRAGIS sets routes for the shipment and designates route segments as urban, suburban, or rural so that population densities within $50 \mathrm{mi}(80 \mathrm{~km})$ of the route can be estimated. Two potential transport routes for off-INL transport have been identified for this alternative, each of which may be taken depending on the conditions at the time of transport. The two routes between MFC and ACRR are shown in Figure 14. Route segment data generated from TRAGIS for the two routes are discussed in Section G-5.1. The length of Route 1 is $1,346 \mathrm{~km}$ (836 miles) with 117,660 residents while Route 2 is $1,914 \mathrm{~km}$ (1,190 miles) with 131,905 residents (assuming a bandwidth of $800 \mathrm{~m}$ ). Route 2 has more interstate miles, but RADTRAN treats interstate and U.S. primary highways the same way. Route 1 could be preferred because it passes through the least populated areas and is shorter than Route 2 . TRAGIS was not used to define the on-INL transport route shown in Figure G-3. 
- RADTRAN. The RADTRAN program calculates individual and collective doses and risks to workers and the public along each route based on radiological and physical properties of the material being transported. Output from TRAGIS is used as input to RADTRAN to determine the route segment lengths and associated population densities along each route. The dose to crew members along the route, inspectors, employees at stops, and other specific receptors are calculated. The exposures to members of the public along the route, usually, but not necessarily, within 2,625 $\mathrm{ft}(800 \mathrm{~m})$ of the transport link (offlink); occupants of vehicles sharing the transport link (onlink); and at stops are calculated.

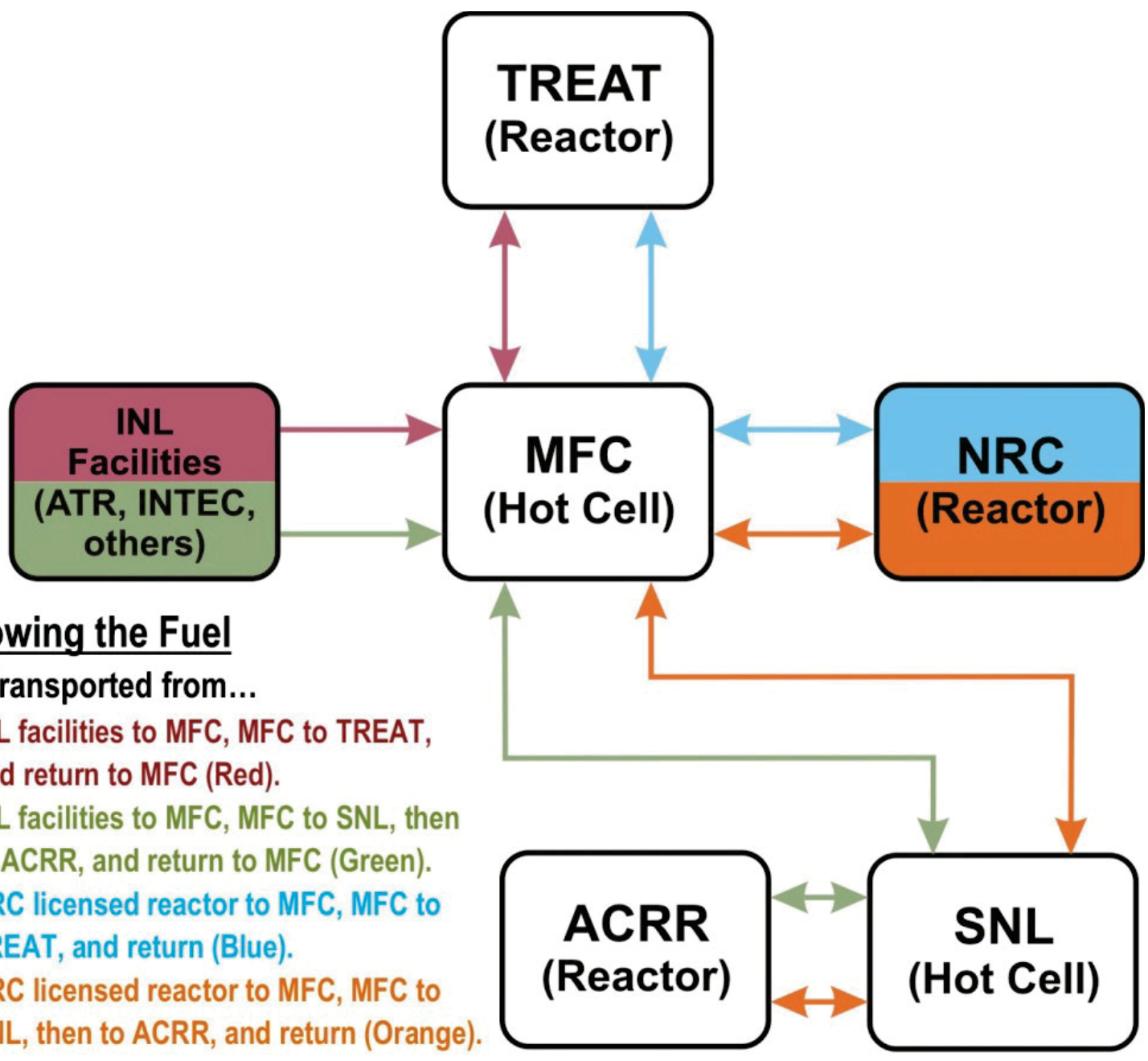

Figure 12. Transport pathways followed by the experiment fuel and assemblies. 


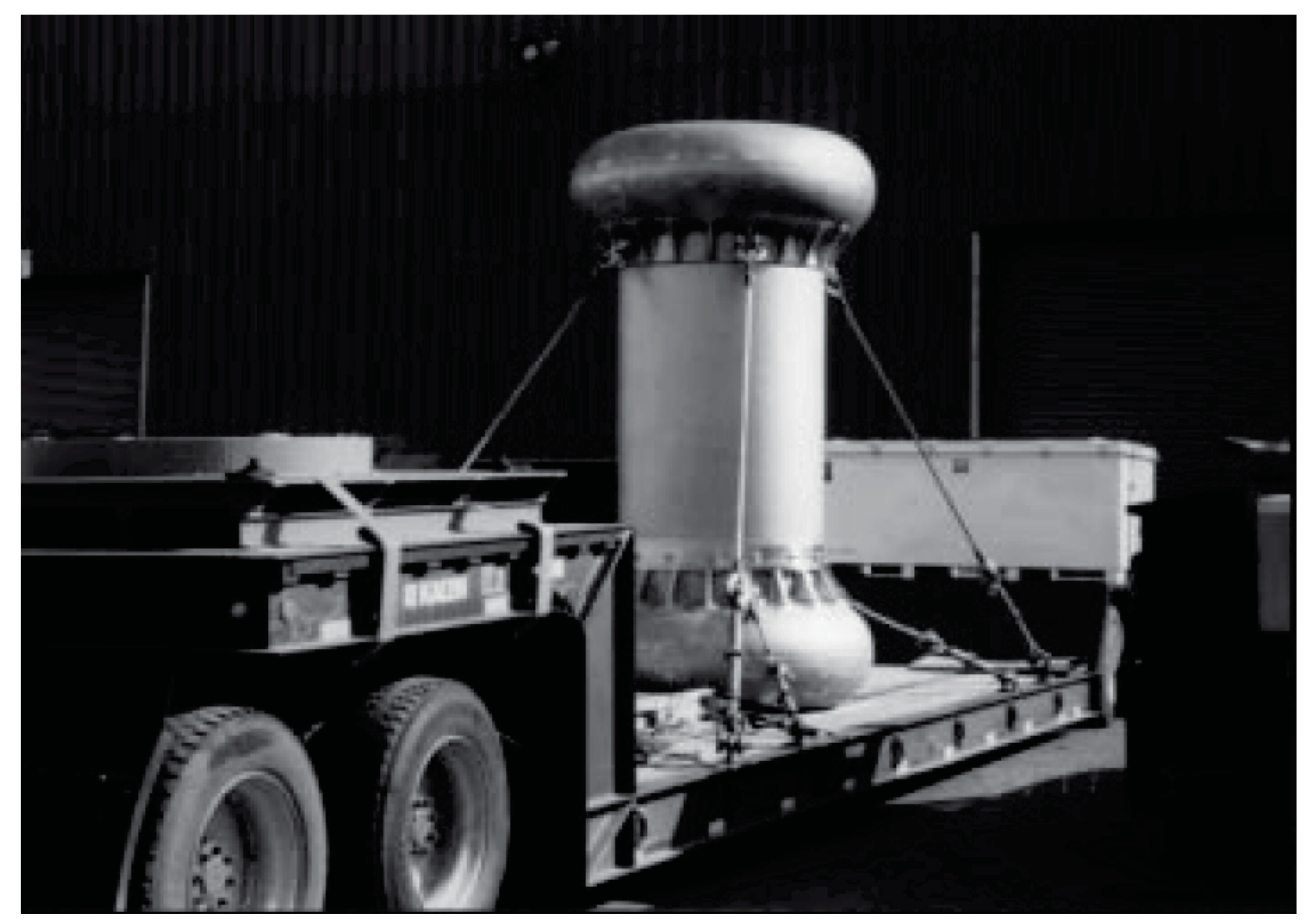

Figure 13. GE 2000 Type B shipping cask.

\subsection{Summary of the Analysis of Transportation at the Idaho National Laboratory}

Transportation of the research quantities of fuel contained in the experiment assemblies will occur between facilities at INL as shown in Figure 14. The following subsections summarize the impacts that could occur during routine handling and transport at INL and during potential accident conditions.

\subsubsection{Routine Handling and Transport}

Transportation at INL would involve "out of commerce" shipments on controlled access roads located solely on INL. As the test materials are being transported between facilities at INL, access to the route by members of the public and non-involved workers will be restricted and a transportation-related dose would not be received. However, the crew (i.e., 2 drivers), inspectors of the shipment, and populations along the route (people in facilities) could be impacted. Doses for persons sharing the route (other drivers) are provided to show that restriction of the route is not required by transportation exposure.

Cask-specific exposure doses are provided in Table 14. The values shown in Table 14 represent doses and LCF for 34 roundtrip shipments; therefore, they represent an annual dose. For transport between ATR and MFC (the longest distance), an unlicensed cask or licensed cask similar to the GE-2000 or BRR cask would be used. For transport between MFC and TREAT, the HFEF-15 cask will likely be used.

Radiological exposure for the GE-2000 and BRR casks are shown in Table 14, because those casks would be used on the links potentially affecting worker populations along the route, persons sharing the routes between those facilities, and they would be used for the longest distance traveled by the crew. Persons not associated with the cask transport would not be exposed to the HFEF-15 cask on the route link between MFC and TREAT. Doses for those crew members would be maintained within the administrative limits for DOE workers (5 rem/year) (DOE 1994). The maximum radiologic exposure regardless of cask or route link is summarized in Table 15. 


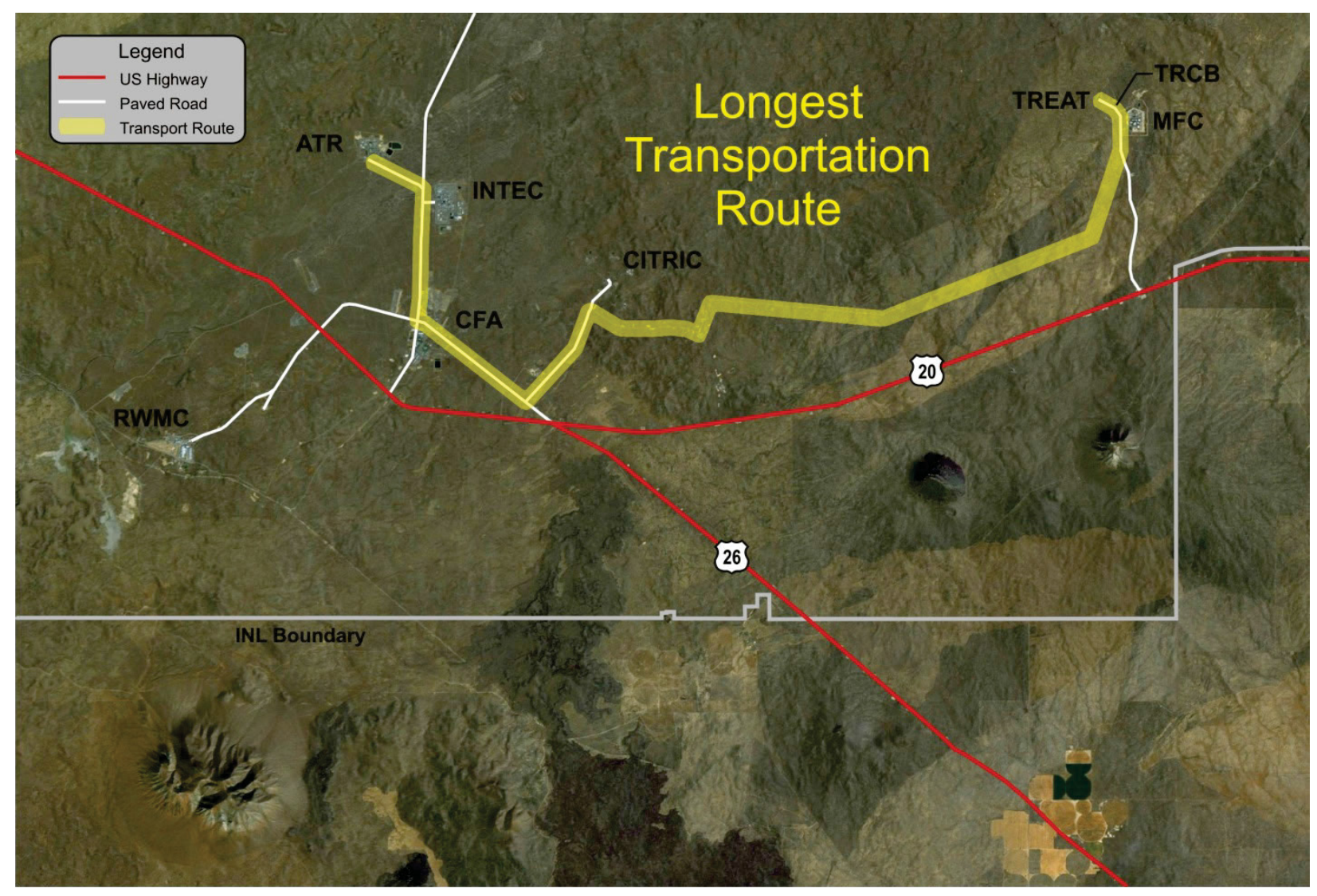

Figure 14. Transportation route between ATR and HFEF and between HFEF and TREAT Facility (see inset for detail). (All routes are on INL controlled access roads.)

Table 14. Dose summary for routine transportation of 34 roundtrips from the Advanced Test Reactor Complex and TREAT.

\begin{tabular}{|c|c|c|c|c|c|c|}
\hline \multirow[t]{2}{*}{ Link } & \multicolumn{3}{|c|}{ BRR Cask } & \multicolumn{3}{|c|}{ GE-2000 Cask } \\
\hline & Crew & $\begin{array}{c}\text { People Along } \\
\text { Route }\end{array}$ & $\begin{array}{c}\text { People Sharing } \\
\text { Route }\end{array}$ & Crew & $\begin{array}{l}\text { People Along } \\
\text { Route }\end{array}$ & $\begin{array}{c}\text { People Sharing } \\
\text { Route }\end{array}$ \\
\hline ATR-INTEC & $2.41 \mathrm{E}-02$ & $7.00 \mathrm{E}-03$ & $5.24 \mathrm{E}-03$ & $2.70 \mathrm{E}-02$ & $7.89 \mathrm{E}-03$ & $5.88 \mathrm{E}-03$ \\
\hline INTEC-CFA & $3.33 \mathrm{E}-02$ & $2.88 \mathrm{E}-03$ & $7.28 \mathrm{E}-03$ & $3.74 \mathrm{E}-02$ & $3.24 \mathrm{E}-03$ & $8.16 \mathrm{E}-03$ \\
\hline CFA-MFC & $2.51 \mathrm{E}-01$ & 2.84E-02 & $5.47 \mathrm{E}-02$ & $2.82 \mathrm{E}-01$ & $3.19 \mathrm{E}-02$ & $6.14 \mathrm{E}-02$ \\
\hline MFC-TREAT & $9.86 \mathrm{E}-03$ & $2.28 \mathrm{E}-03$ & $2.15 \mathrm{E}-03$ & $1.11 \mathrm{E}-02$ & $2.56 \mathrm{E}-03$ & $2.41 \mathrm{E}-03$ \\
\hline Totals & $3.18 \mathrm{E}-01$ & $4.06 \mathrm{E}-02$ & $6.94 \mathrm{E}-02$ & $3.21 \mathrm{E}-01$ & $4.15 \mathrm{E}-02$ & $7.00 \mathrm{E}-02$ \\
\hline $\begin{array}{l}\text { Maximum individual dose } \\
\text { (rem) }\end{array}$ & & $2.31 \mathrm{E}-05$ & & & $2.58 \mathrm{E}-05$ & \\
\hline $\begin{array}{l}\text { Inspector/escort (rem) } \\
\text { ( } 3 \mathrm{~m} \text { from cask) }\end{array}$ & & $6.23 \mathrm{E}-01$ & & & $5.88 \mathrm{E}-01$ & \\
\hline
\end{tabular}


Table 15. Summary of analysis results for routine transportation of 34 roundtrips from the Advanced Test Reactor to TREAT.

\begin{tabular}{lcc}
\hline \multicolumn{1}{c}{ Receptor } & Dose & LCF \\
\hline Crew (transportation worker) & 0.32 (person-rem) & $1.9 \mathrm{E}-04$ \\
Collocated workers along route & 0.04 (person-rem) & $2.5 \mathrm{E}-05$ \\
Collocated workers sharing the route ${ }^{\mathrm{a}}$ & 0.07 (person-rem) & $4.2 \mathrm{E}-05$ \\
Maximum collocated worker dose & $2.6 \mathrm{E}-05(\mathrm{rem})$ & $1.6 \mathrm{E}-08$ \\
Inspector/escort (3 m from cask) & $6.2 \mathrm{E}-01(\mathrm{rem})$ & $3.7 \mathrm{E}-04$ \\
\hline a. Calculations assume other vehicles could share the route. During most transports, the routes would be closed and there would be no dose for \\
$\quad$
\end{tabular}

It is unlikely that the crew or inspectors would be the same for every shipment; therefore, the doses provided are conservative. If longer inspection times or drive times are encountered, their doses will be maintained within the administrative limits for DOE workers of 5 rem/year (DOE 1994).

\subsubsection{Transportation Accidents at Idaho National Laboratory}

Onsite shipments containing radiological materials undergo an extensive safety analysis and review process to ensure proper safety plans are developed and implemented. After a review of the design criteria used for the shipping casks and of the potential transportation accident scenarios that could occur on INL, it was determined that an accident that would result in the release of radioactive material from a shipping cask is not credible. Based on data for truck accident rates from 1996 through 2007, there are 0.0013 accidents per thousand large truck miles (one per 760,000 miles) (NRC 2012). Accidents, including minor accidents, are not likely to occur more than once in every 100,000 miles on public roadways (NRC 2012). Minor accidents are more unlikely to occur at INL because of the low transport speeds. The total number of miles traveled on INL per year is expected to be less than 1,000. Based on mileage alone, there is very little chance that even a minor accident would occur in any year.

Type B casks such as the GE-2000 or BRR cask are licensed for highway speeds over public roads and certified to withstand a $9 \mathrm{~m}$ drop onto a solid surface with impact at the most damaging point, followed by a 1-m drop onto a steel bar (10 CFR 71.73). To withstand a potential accident involving a fire, they also are designed to withstand an $800^{\circ} \mathrm{C}$ fire for 30 minutes. These design criteria are in place to minimize the release of radionuclides during potential traffic accidents. The unlicensed casks that could be used at INL are similarly designed, but are not certified for highway use.

The HFEF-15 cask has undergone an extensive safety analysis and review process to ensure it is capable of safely transporting the test loops between the HFEF and TREAT facilities. It was specifically designed to carry the MARK-III loops. It is designed to protect the MARK-III loops under credible drop or impact conditions. On that route, there are no combustible materials that would result in a fire of sufficient duration and intensity to release materials from the cask.

\subsection{Summary of Analysis of Transportation between the Materials and Fuels Complex and Annular Core Research Reactor}

Alternative 2 requires transport of experiments from MFC to ACRR (via the SNL hot cell) (as shown in Figure 14), in addition to transport between facilities at INL (discussed in Section 5.1). Potential impacts to the public and the crew from routine transport from MFC to ACRR and potential accidents along the route are provided in Appendix G. The offsite transportation impacts were analyzed in accordance with the 2002 Resource Handbook on DOE Transportation Risk Assessment (DOE 2002). 
Transportation impacts were analyzed along two routes running between MFC and ACRR: the most direct route, which goes through Idaho, Utah, Colorado, and New Mexico; and a longer route, which bypasses Utah. These routes are shown in Figures 15 and 16. Appendix E contains the details of the analysis and model parameters. These include the route-dependent RADTRAN input values. The routes, distances, population densities, and rural, suburban, and urban designations were data developed using the code TRAGIS. Re-fueling stops were included in the analysis to account for potential impacts during the long-distance transport and were based on heavy trucks refueling approximately every $800 \mathrm{~km}$.

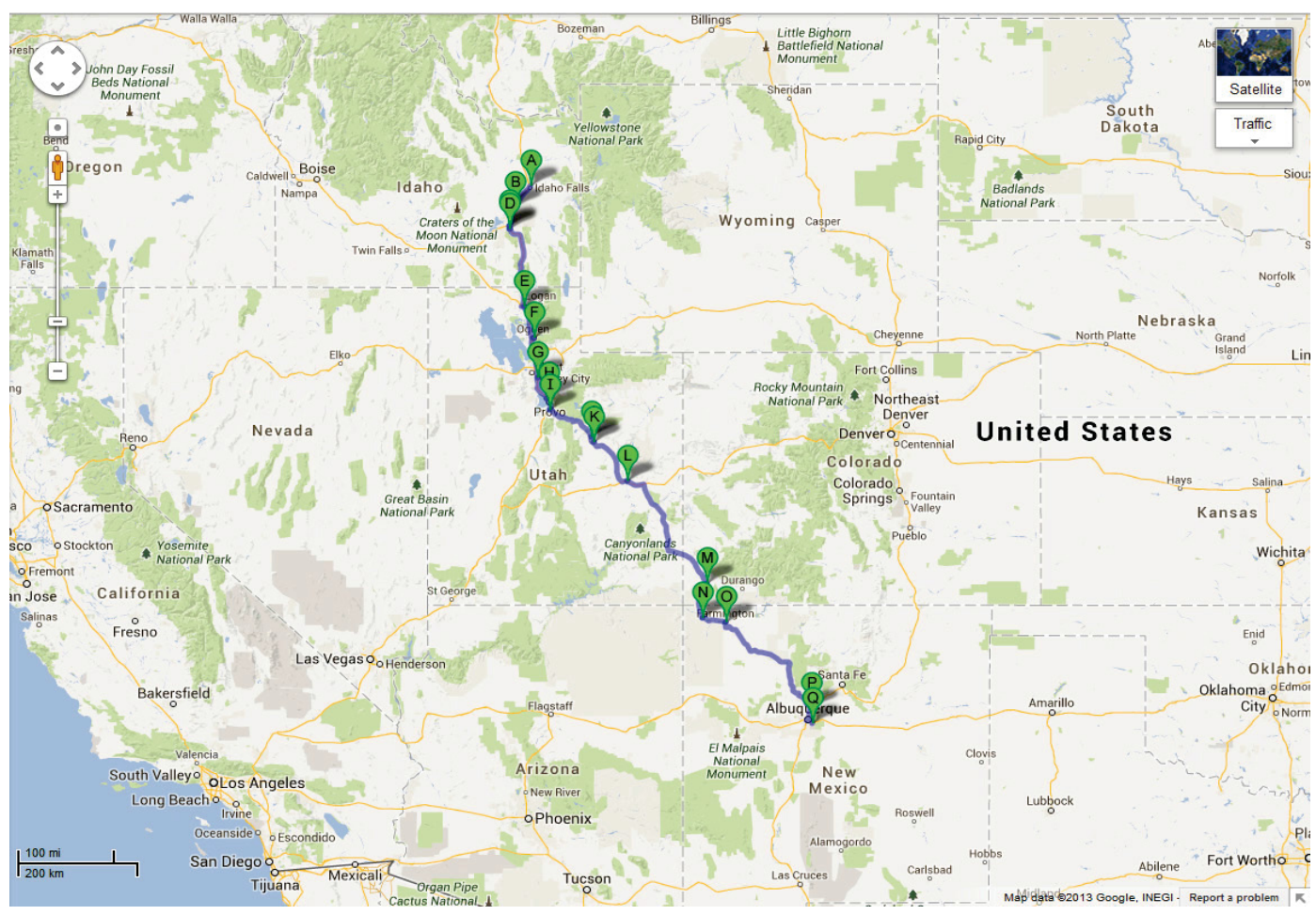

Figure 15. Map of Route 1 between INL and SNL/NM. 


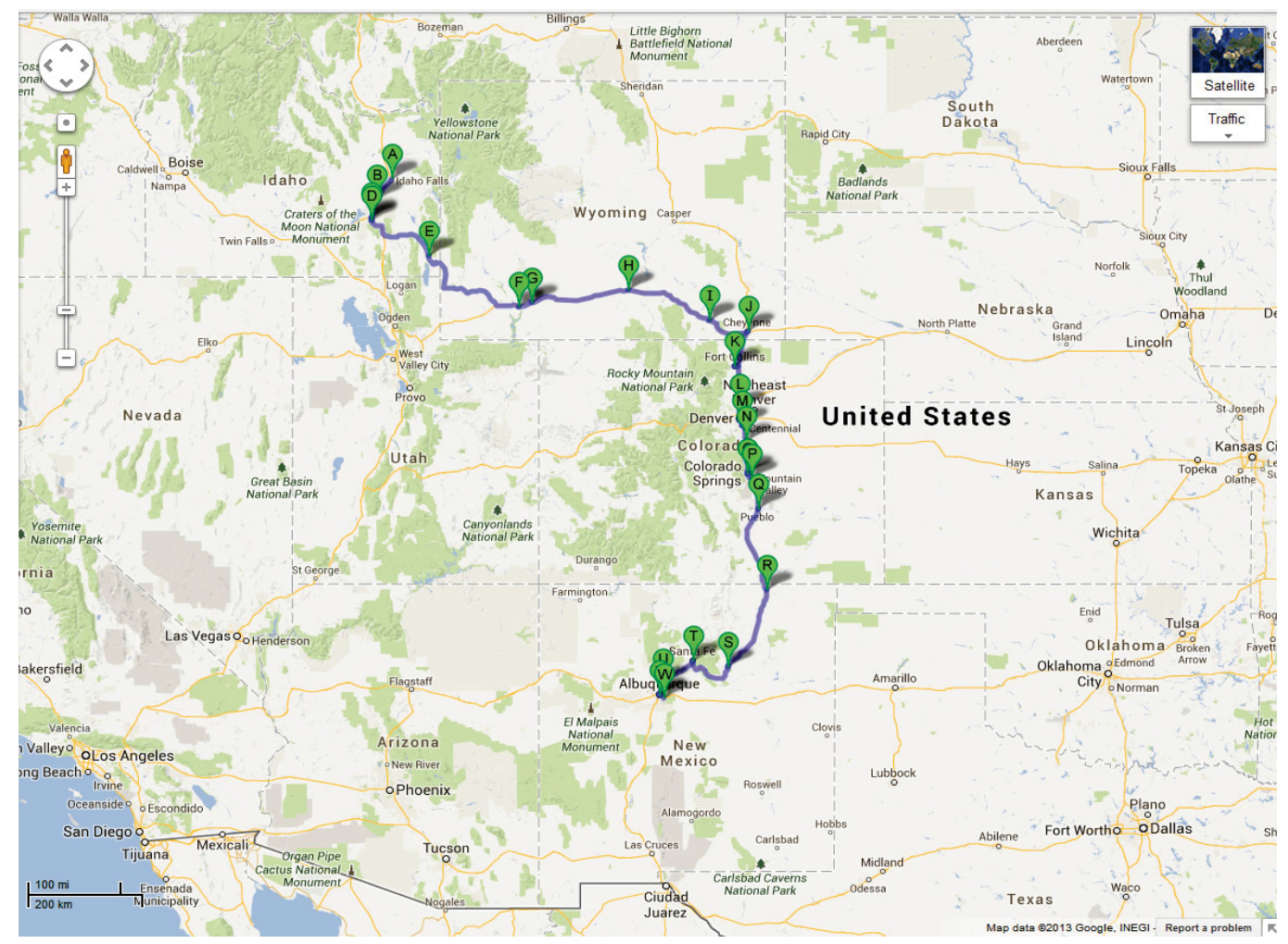

Figure 16. Map of Route 2 between INL and SNL/NM.

\subsection{Incident-Free Transportation Results}

\subsubsection{Transport between Idaho National Laboratory Facilities Required by Alternative 2 (ACRR)}

For transport at INL, no exposure to the general public from incident-free transport is expected. Radiologic exposure for transport between INL facilities is summarized in Table 14. The link between MFC and TREAT would not be included in the total exposure. Therefore, the total doses would be slightly less than shown in Table 15. Doses excluding the MFC-TREAT link are summarized in Table 16.

Table 16. Summary of analysis results for routine transportation for 34 roundtrips from the Advanced Test Reactor to the Materials and Fuels Complex.

\begin{tabular}{lcc}
\hline \multicolumn{1}{c}{ Receptor } & Dose (person-rem) & LCF \\
\hline Crew & 0.31 & $1.9 \mathrm{E}-04$ \\
Population Along Route & 0.04 & $2.5 \mathrm{E}-05$ \\
Vehicle Occupants Sharing Route & 0.07 & $4.2 \mathrm{E}-05$ \\
Maximum Individual Dose (rem) & $2.6 \mathrm{E}-05$ & $1.6 \mathrm{E}-08$ \\
Inspector/Escort (rem) (3 m from cask) & $6.2 \mathrm{E}-01$ & $3.7 \mathrm{E}-04$ \\
\hline
\end{tabular}




\subsubsection{Transportation between the Materials and Fuels Complex and Sandia National Laboratory New Mexico}

For 34 roundtrip transports from MFC to ACRR, incident-free radiological exposure is provided in Table 17. These values represent the highest doses for the two casks evaluated. Doses are compared to the percent of natural background radiation an average individual would be exposed to $(311 \mathrm{mrem} / \mathrm{year})$. The percent of background calculation considers the actual time on each transportation route; therefore, it is not a straight percentage of a peak dose. The risk of an LCF occurring as a result of making 34 roundtrip shipments from MFC to ACRR also is provided. Exposure to drivers would be maintained within the administrative limits of $5 \mathrm{rem} /$ year for DOE workers (DOE 1994).

Table 17. Summary of the analysis results for routine transportation of 34 roundtrips from the Materials and Fuels Complex to ACRR.

\begin{tabular}{lccc}
\hline \multicolumn{1}{c}{ Receptor } & Dose (person-rem) & Percent of Background $^{\mathrm{a}}$ & LCF $^{-}$ \\
\hline Two-member crew & 10.9 & 10.8 & $5.09 \mathrm{E}-03$ \\
Population along route & 0.1 & 0.1 & $6.13 \mathrm{E}-05$ \\
Vehicle occupants sharing route & 1.5 & 2.2 & $7.50 \mathrm{E}-03$ \\
Persons at a stop & 0.5 & 0.8 & $1.61 \mathrm{E}-04$ \\
\hline
\end{tabular}

a. Calculation shown in Appendix G, based on population and exposure time.

\subsection{Non-Incident-Free Transportation Results}

Table 18 provides a summary of the estimated annual dose and LCF for non-incident free transportation between MFC and ACRR based on 34 roundtrips per year. Table 19 provides the summary of estimated annual dose risk and LCF risk. It is extremely unlikely that an LCF would occur as a result of any incident involving an accident during transport of the materials that will comprise the transient testing experiments that will be conducted.

Table 18. Summary of dose and latent cancer fatality for non-incident free transportation for 34 roundtrips from the Materials and Fuels Complex to ACRR.

Accidents Not Involving a Release or Loss of Lead Shield ${ }^{\mathrm{a}}$

Dose

\begin{tabular}{ccccc} 
& (person-rem) & LCF & (person-rem) & LCF \\
\hline & $1.68 \mathrm{E}-02$ & $1.01 \mathrm{E}-05$ & $2.83 \mathrm{E}-01$ & $1.70 \mathrm{E}-04$ \\
\hline a. & $\begin{array}{l}\text { No release, no loss of lead shield accidents are accidents (including flat tires, fender benders, etc.) that require a stop of the transport and } \\
\text { involve assistance from someone else. These accident types are expected to occur. }\end{array}$ \\
b. Severe accidents could involve a release of radiologic material from a cask. These accident types are very unlikely to occur.
\end{tabular}

Dose
Accident Involving a Release ${ }^{\mathrm{b}}$

Table 19. Summary of dose and latent cancer fatality risk accounting for the probability of occurrence for non-incident free transportation for 34 roundtrips from the Materials and Fuels Complex to ACRR.

\begin{tabular}{|c|c|c|c|}
\hline \multicolumn{2}{|c|}{ Accidents Not Involving a Release or Loss of Lead Shield ${ }^{\mathrm{a}}$} & \multicolumn{2}{|c|}{ Accident Involving a Release ${ }^{b}$} \\
\hline $\begin{array}{c}\text { Dose Risk } \\
\text { (person-rem) }\end{array}$ & LCF Risk & $\begin{array}{c}\text { Dose Risk } \\
\text { (person-rem) }\end{array}$ & LCF Risk \\
\hline $1.00 \mathrm{E}-06$ & $6.02 \mathrm{E}-10$ & $1.16 \mathrm{E}-14$ & $6.96 \mathrm{E}-18$ \\
\hline
\end{tabular}




\subsection{Non-Radiological Transportation Impacts}

Non-radiological impacts related to transportation for the alternatives using the TREAT Reactor, or ACRR, result simply from transporting any material from one location to another independent of the characteristics of the cargo. The presence or absence of cargo is not a factor in the assessment of these risks. Non-radiological risks are directly related to vehicle emissions (greenhouse gases) and the probability of an accident-related fatality. Table 20 identifies the transportation characteristics for the onsite and offsite alternatives and applies documented rates of occurrence or risk factors as appropriate.

Table 20. Estimated annual emissions and fatalities resulting from on-Idaho National Laboratory and off-Idaho National Laboratory shipments.

\begin{tabular}{|c|c|c|c|c|}
\hline Impact Type & Factor & $\begin{array}{c}\text { ATR-MFC-TREAT- } \\
\text { MFC }^{1}\end{array}$ & $\begin{array}{c}\text { ATR-MFC-ACRR } \\
\text { Route } 1^{2} \\
\end{array}$ & $\begin{array}{c}\text { ATR-MFC-ACRR } \\
\text { Route } 2^{2} \\
\end{array}$ \\
\hline $\begin{array}{l}\text { Miles/one-way trip } \\
\text { (MFC-ACRR) }\end{array}$ & & 25.2 & $1,346.5$ & 1,914 \\
\hline Miles/roundtrip & & 23.6 & 2,720 & 3,853 \\
\hline Trips/year & & 34 & 34 & 34 \\
\hline Distance/year & & $\begin{array}{r}857 \mathrm{mi} \\
1,379 \mathrm{~km}\end{array}$ & $\begin{array}{r}92,419 \\
148,730\end{array}$ & $\begin{array}{l}131,010 \\
210,832\end{array}$ \\
\hline Gallons/year & $6.6 \mathrm{mi} /$ gallon $^{3}$ & 128.65 & $13,876.70$ & $19,670.99$ \\
\hline Greenhouse gases & $22.2 \mathrm{lb} / \mathrm{gal}^{4}$ & 1.43 ton & 154.03 ton & 218.35 ton \\
\hline Accident fatality ${ }^{5}$ & $\begin{array}{r}3.53 \mathrm{E}-3 \\
\text { fatalities/accident }\end{array}$ & 0 & $1.25 \mathrm{E}-05$ & 2.3E-05 \\
\hline $\begin{array}{l}\text { 1. ATR to } \mathrm{MFC}=23.6 \\
\text { 2. ATR to } \mathrm{MFC}=23.6 \\
\text { total miles/trip }=2, \\
\text { 3. State Transportation } \\
\text { 4. www.eia.gov/tools } / \mathrm{f} \\
\text { 5. ATR-MFC-ACRR } \mathrm{f}\end{array}$ & $\begin{array}{l}\text { to TREAT }=0.8 \mathrm{mi} \text {, tota } \\
\text { to TA-V at } \mathrm{SNL}-1346 \\
\text { ute } 1,3,853 \text { for Route } 2 \\
011 . \\
\text { ?id }=307 \& \mathrm{t}=11 \text {. } \\
\text { imated for each link (Ap }\end{array}$ & $\begin{array}{l}\text { miles/trip }=25.2 \mathrm{mi} \\
\text { Route } 1,1914 \text { Route } 2 \text {, }\end{array}$ & & \\
\hline
\end{tabular}

\section{INTENTIONAL DESTRUCTIVE ACTS}

- Alternative 1. The impacts of intentional acts of destruction occurring at an INL facility or during transport at INL were considered. The potential for an act of sabotage occurring onsite is mitigated by protective services. INL routinely employs a variety of measures to mitigate the likelihood and consequences of intentional destructive acts. DOE maintains a highly trained and equipped protective force that is intended to prevent attacks against and entry into the facilities. The site perimeters are monitored and patrolled to prevent unauthorized entry.

Access to INL roads will be restricted during transport of radioactive materials. Security measures will be in place to mitigate the likelihood and consequences of sabotage. Transportation crew members would be screened for behavioral and substance abuse issues and would receive safety and security training. Crew members would conduct a thorough inspection of their vehicle and load prior to transport. During transport, crew members would always have in their possession a working means of communication and would be trained to immediately report suspicious activity encountered en route.

An act of sabotage for Alternative 1 would result in dose consequences similar to the bounding accident scenarios evaluated for TREAT. 
- Alternative 2. The potential for an act of sabotage occurring at SNL/NM will be mitigated by protective services. SNL/NM routinely employs a variety of measures to mitigate the likelihood and consequences of intentional destructive acts. DOE maintains a highly trained and equipped protective force that is intended to prevent attacks against and entry into the facilities. Access to facilities on SNL/NM is controlled, with only those persons performing official business and presenting the proper credentials being allowed onsite. The site perimeters are monitored and patrolled to prevent unauthorized entry.

Transport of radioactive materials would routinely employ a variety of measures to mitigate the likelihood and consequences of sabotage. Crew members would be screened for behavioral and substance abuse issues and would receive safety and security training. Crew members would conduct a thorough inspection of their vehicle and load prior to transport. During transport, crew members would always have in their possession a working means of communication and would be trained to immediately report suspicious activity encountered en route.

\section{QUALITY ASSURANCE FOR SOFTWARE AND CALCULATIONS}

Calculations used to support the EA are bounding estimates that are viewed as scoping in nature; they are not used to support environmental permitting or radiological safety analyses. As a result, the EA work is being performed at a Quality Level-3 level of rigor. Separate analyses will be completed for environmental permitting and for all nuclear safety determinations and analyses.

Quality assurance strategies for environmental reviews and assessments fall under GDE-8400, "National Environmental Policy Act: Environmental Review and Assessment Guide," Appendix E. The quality assurance strategies identified in Appendix E are being followed for the EA.

Software used for the EA includes the computer codes: CAP88-PC, RSAC-7, TRAGIS, RADTRAN, and Microsoft Excel spreadsheet calculations. The following is a description of each computer code and its use:

- CAP88-PC is a mature computer code that EPA requires for demonstration of compliance with 40 CFR Part 61, "National Emission Standards for Hazardous Air Pollutants (NESHAPs)," Subpart H, "National Emission Standards for Emissions of Radionuclides Other than Radon from Department of Energy Facilities." The code is maintained and distributed by EPA and validation is performed by EPA (http://www.epa.gov/radiation/assessment/CAP88/aboutcap88.html). Upon installation at INL, sample test problems provided with the code are executed and output compared with sample output. The latest release of Version 3 (2-9-2013) was verified prior to conducting the INL NESHAPS analysis (DOE-ID 2013).

- $\quad$ RSAC-7 is the newest version of the Radiological Safety Analysis Computer (RSAC) Program used to calculate consequences from radionuclides released to the atmosphere (http://www.inl.gov/technicalpublications/Documents/4192226.pdf). It can be used as a tool to evaluate accident conditions in emergency response scenarios, radiological sabotage events, and to evaluate safety basis accident consequences. The RSAC-7 code was developed by and is maintained by INL. It is fully verified and validated per NQA-1 2000 for Quality Level 1 applications. The pedigree and validation for RSAC-7 is documented in PLN-2223, "Software Quality Assurance Plan for the Radiological Safety Analysis Computer (RSAC) Program Version 7.0," and provides the software quality assurance activities completed for RSAC-7. The current release (7.2) was used for the EA. 
- TRAGIS is the national standard (mandated) code providing transportation routing analysis based on a geographic information system. It was developed by and is maintained by Oak Ridge National Laboratory (ORNL/TM-2000/86). WEBTRAGIS is used to provide population density information along transportation routes. WEBTRAGIS currently is being updated by Oak Ridge National Laboratory. To provide the RTT EA the necessary route information, the database is being queried by Oak Ridge National Laboratory. Information is being provided directly to SNL for use by RADTRAN.

- RADTRAN is the national and international standard for transportation risk assessment for radioactive materials. The code was developed at SNL. RADTRAN combines user-determined demographic, routing, transportation, packaging, and materials data, with meteorological data (partly user-determined) and health physics data to calculate expected radiological consequences of incident-free radioactive materials transportation and associated accident risks. It is verified and validated by SNL (https://radtran.sandia.gov). Calculations using RADTRAN were performed for this EA by the code author/steward (Ruth Weiner at SNL).

- Microsoft Excel is commercial software and used for spreadsheet calculations for accident dose analysis.

Because these computer codes are national standard codes, the quality assurance focuses on correct code usage and complete documentation of all input and output used to support the conclusions of the EA. This report provides the discussion and justification of all input parameters used by the codes and includes a detailed analysis of the results. Code input and output is provided in INL (2013b). If code input and/or output is extensive, it will be provided electronically. Table 21 provides a summary of the quality assurance information for software and code input/output for the EA.

Table 21. Quality assurance summary table for software and code input/output used for the Resumption of Transient Testing environmental assessment.

\begin{tabular}{|c|c|c|c|c|}
\hline $\begin{array}{l}\text { Environmental } \\
\text { Assessment } \\
\text { Application }\end{array}$ & $\begin{array}{c}\text { Computer } \\
\text { Code(s) }\end{array}$ & $\begin{array}{c}\text { Results } \\
\text { Summary }\end{array}$ & $\begin{array}{c}\text { Analysis } \\
\text { Details }\end{array}$ & Code Verification/Validation Information \\
\hline \multirow{2}{*}{$\begin{array}{l}\text { Atmospheric } \\
\text { Transport and } \\
\text { Dose Analysis } \\
\text { from } \\
\text { Operational } \\
\text { Releases }\end{array}$} & $\begin{array}{l}\text { CAP88-PC } \\
\text { (TREAT) }\end{array}$ & $\begin{array}{l}\text { Sections } \\
3.2 .4 \text { (air) } \\
\text { and } 3.2 .5 \\
\quad \text { (soil) }\end{array}$ & Appendix C-3 & $\begin{array}{l}\text { CAP88-PC is validated by the developer/distributor (U.S. EPA). } \\
\text { Verification is accomplished by duplicating test problem file } \\
\text { output distributed with code. Verification test problem } \\
\text { input/output included in quality assurance document. }\end{array}$ \\
\hline & $\begin{array}{l}\text { CAP88-PC } \\
\text { (ACRR) }\end{array}$ & $\begin{array}{l}\text { Sections } \\
3.3 .1 \text { (air) } \\
\text { and } 3.3 .2 \\
\quad \text { (soil) }\end{array}$ & Appendix C-4 & $\begin{array}{l}\text { CAP88-PC code is validated by the developer/distributor (U.S. } \\
\text { EPA). CAP88-PC verification at SNL accomplished through } \\
\text { generation and acceptance of annual NESHAPs results. }\end{array}$ \\
\hline \multirow[t]{3}{*}{$\begin{array}{l}\text { Accident Dose } \\
\text { Analysis }\end{array}$} & RSAC-7 & Section 4 & $\begin{array}{l}\text { Appendices } \mathrm{E} \\
\text { and } \mathrm{F}\end{array}$ & RSAC validated and verified by developer (TEV-1455). \\
\hline & & Section 4.1 & Appendix F-4 & $\begin{array}{l}\text { Spreadsheet formulas for all calculation cells were visually } \\
\text { checked for accuracy and a sample of all calculations were } \\
\text { checked by hand. }\end{array}$ \\
\hline & & Section 4.2 & Appendix F-5 & $\begin{array}{l}\text { Spreadsheet formulas for all calculation cells were visually } \\
\text { checked for accuracy and a sample of all calculations were } \\
\text { checked by hand. }\end{array}$ \\
\hline \multirow{2}{*}{$\begin{array}{l}\text { Transportation } \\
\text { Dose Analysis }\end{array}$} & WEBTRAGIS & Section 5 & Appendix G & WEBTRAGIS validated and verified by developer. \\
\hline & RADTRAN & Section 5 & Appendix G & RADTRAN validated and verified by developer \\
\hline
\end{tabular}




\section{REFERENCES}

10 CFR 71.73, “Hypothetical Accident Conditions," Code of Federal Regulations, Office of the Federal Register.

10 CFR 830, Subpart B, "Nuclear Safety Management," Code of Federal Regulations, Office of the Federal Register.

40 CFR Parts 9, 69, 2004, "Control of Emissions of Air Pollution From Nonroad Diesel Engines and Fuel," Code of Federal Regulations, Office of the Federal Register, 2004.

40 CFR 61, 2010, "National Emission Standards for Hazardous Air Pollutants," Code of Federal Regulations, Office of the Federal Register, April 2010.

40 CFR 61, Subpart H, 2010, "National Emission Standards for Emissions of Radionuclides Other than Radon from Department of Energy Facilities," Code of Federal Regulations, Office of the Federal Register, April 2010.

40 CFR 63, Subpart ZZZ, "National Emissions Standards for Hazardous Air Pollutants for Reciprocating Internal Combustion Engines," Code of Federal Regulations, Office of the Federal Register

42 USC § 4321 et seq., "National Environmental Policy Act of 1969 (NEPA)," United States Code, January 1970.

ANL memo, 1992, Intra-Laboratory Memo from R. M. Bradford to R. W. Swanson, "Annual Radioactive Nuclide Emissions from the TREAT Stack," April 3, 1992.

DOE, 1994, DOE Radiological Control Manual, DOE/EH-0256T, Revision 1, U.S. Department of Energy, April 1994.

DOE, 2002, A Resource Handbook on DOE Transportation Risk Assessment, U.S. DOE National Transportation Program, DOE/EM/NTP/HB-01, July 2002.

DOE-ID, 2012, National Emission Standards for Hazardous Air Pollutants - CY 2011 INL Report for Radionuclides, DOE/ID-11441, U.S. Department of Energy Idaho Operations Office.

DOE-ID 2013, National Emission Standards for Hazardous Air Pollutants-Calendar Year 2012 INL Report for Radionuclides, DOE/ID-11441 (2013), U.S. Department of Energy Idaho Operations Office, June 2013.

DOE/EA, 2013, Environmental Assessment for the Resumption of Transient Testing of Nuclear Fuels and Materials, DOE/EA-1954.

EPA, 2007, “Updated User's Guide For CAP88-PC Version 3.0,” EPA 402-R-00-004, U.S.

Environmental Protection Agency, December 2007 (currently available at http://www.epa.gov/radiation/assessment/CAP88/index.html, web site last updated February 2009, web site last visited November 30, 2009).

Guide, 1991, "Guide for Irradiation Experiments in Treat," Z0004-0001-OR, Argonne National Laboratory. 
GDE-8400, "National Environmental Policy Act: Environmental Review and Assessment Guide,” Idaho National Laboratory.

IDAPA 58.01.01, "Rules for the Control of Air Pollution in Idaho," Idaho Administrative Procedures Act, Idaho Department of Environmental Quality.

INL, 2013a, National Environmental Policy Act Hazards Assessment of the TREAT Alternative, INL/EXT-13-29496, Revision 0, Idaho National Laboratory.

INL, 2013b, Compilation of Quality Assurance Documentation for Impact Analyses Supporting the Environmental Assessment for the Resumption of Transient Testing Program,"

INL/EXT-13-29515, Idaho National Laboratory.

ISCORS, 2002, "ISCORS Technical Report No. 1, A Method for Estimating Radiation Risk from TED," Interagency Steering Committee on Radiation Standards, July 2002.

Kelley, J. G. and K. T. Stalker, 1981, "The CAIS Fuel Motion Monitoring Detection System Development, System Design and Proof Tests," NUREG/CR-2140 and SAND81-1112, Albuquerque, New Mexico, Kirtland Air Force Base (KAFB), 2006, Final Predator Survey Report for Kirtland Air Force Base, New Mexico.

NRC, 2003, “Interim Safety Guide-5,” Nuclear Regulatory Commission.

NRC, 2012, "Spent Fuel Transportation Risk Assessment," draft report for comment, NUREG-2125, Nuclear Regulatory Commission.

ORNL/TM-2000/86, 2000, “Transportation Routing Analysis Geographic Information System (WeTRAGIS) User's Manual,” Oak Ridge National Laboratory, April 2000.

PLN-2223, "Software Quality Assurance Plan for the Radiological Safety Analysis Computer (RSAC) Program Version 7.0," Idaho National Laboratory.

Sandia Report, 2008, Documented Safety Analysis (DSA) for the Annular Core Research Reactor Facility (ACRRF), SAND2008-5636, Annual Update/CN4, 2001, SER January 11, 2012, IVR April 18, 2012, Sandia National Laboratory, Albuquerque, NM.

SNL/NM, 2013, National Environmental Policy Act Hazards Assessment for the Alternative to Conduct Sodium Cooled Experiments in the Annular Core Research Reactor (ACRR), September 2013, Sandia National Laboratory, Albuquerque, NM. 


\section{Appendix A}

\section{Near-Field Environment Affected by Resumption of Transient Testing at the Transient Reactor Test Facility}


A-2 


\section{CONTENTS}

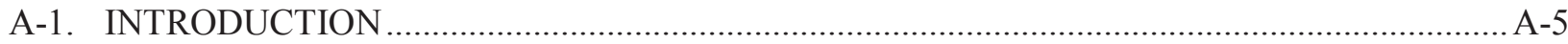

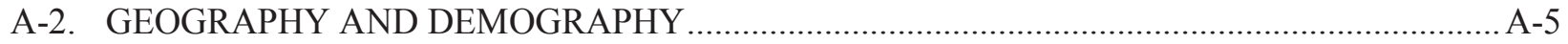

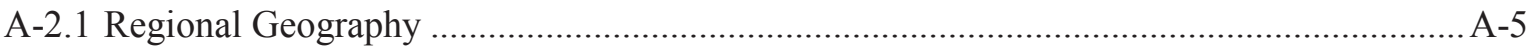

A-2.2 Geography of the Materials and Fuels Complex and the Transient Reactor Test

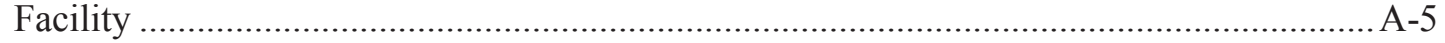

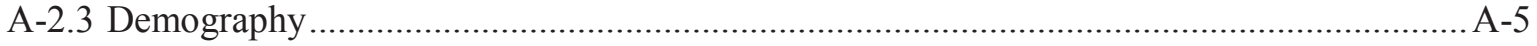

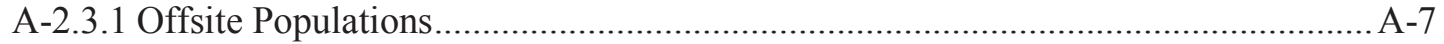

A-2.3.2 Onsite Populations ..........................................................................................

A-2.3.3 Shoshone-Bannock Tribal Interests ................................................................ A-10

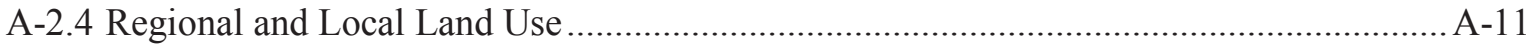

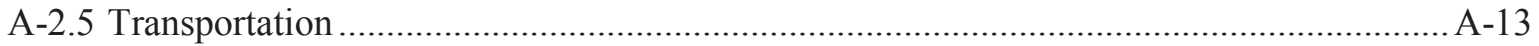

A-3. TRANSIENT REACTOR TEST FACILITY SITE CHARACTERISTICS ............................... A-14

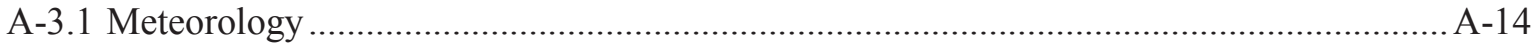

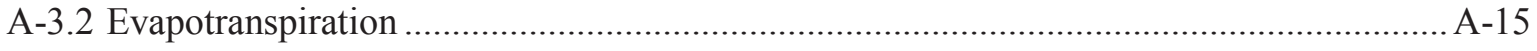

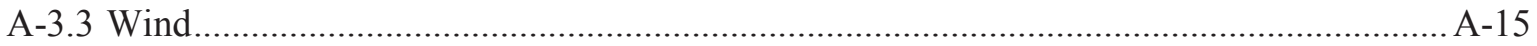

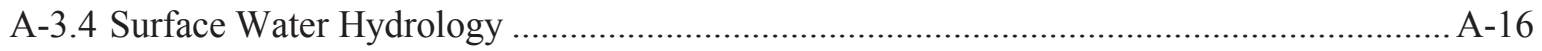

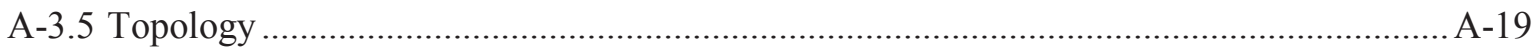

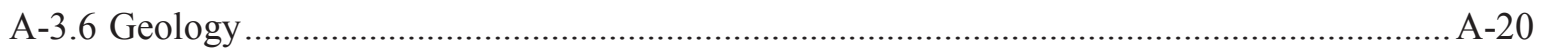

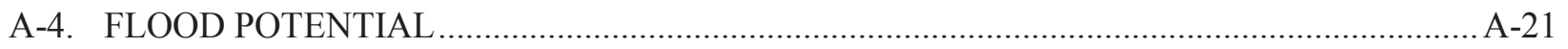

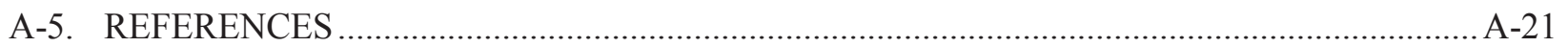




\section{Appendix A \\ Near-Field Environment Affected by Resumption of Transient Testing at the Transient Reactor Test Facility}

\section{A-1. INTRODUCTION}

This section provides an overview of meteorology, topography, geology, surface water, and groundwater resources of the region surrounding TREAT. It includes the physical characteristics of the MFC and TREAT areas and is representative of the general southeastern portion of INL. This information is used to support the assessment of human health impacts.

\section{A-2. GEOGRAPHY AND DEMOGRAPHY}

The geography and demography of the INL, MFC, and TREAT areas are provided in the following subsections to give context to the selection of receptor locations used in the evaluation of human health impacts.

\section{A-2.1 Regional Geography}

INL lies along the eastern edge of the Snake River Plain in southeastern Idaho at the foot of the Lost River, Lemhi, and Bitterroot mountain ranges (shown in Figure A-1). The Snake River Plain, which extends across southern Idaho, is a broad, low-relief, sagebrush-covered basin floored with basaltic lava flows and terrestrial sediment, contrasting sharply with mountainous terrain to the north and south. The Snake River Plain is approximately 80 to $97 \mathrm{~km}$ (50 to $60 \mathrm{mi}$ ) wide and $600 \mathrm{~km}$ (375 mi) long, extending in a broad arc from the Idaho-Oregon border in the west to the Yellowstone Plateau in the east. Surface elevations on the Snake River Plain decrease gradually, from over 1,980 m (6,500 ft) near the Yellowstone Plateau to approximately $640 \mathrm{~m}$ (2,100 ft) near the Idaho-Oregon border.

The Eastern Snake River Plain covers approximately $27,972 \mathrm{~km}^{2}\left(10,800 \mathrm{mi}^{2}\right)$ of southern Idaho. The land surface contains little topographic relief, except for a number of buttes and volcanic scablands. Overall, the surface of the area slopes westward to approximately $975 \mathrm{~m}(3,200 \mathrm{ft})$, where the eastern and western parts of the Snake River Plain meet.

\section{A-2.2 Geography of the Materials and Fuels Complex and the Transient Reactor Test Facility}

The fenced area containing MFC is a roughly rectangular-shaped administrative area encompassing approximately 890 acres in the south-central portion of INL (Figures A-1 and A-2). A double security fence, with the largest east-west and north-south dimensions of $580 \mathrm{~m}$ and $765 \mathrm{~m}(1,902 \mathrm{ft}$ and 2,512 ft), surrounds the major portion of MFC, respectively. Located inside the fenced area are more than 60 structures. Located outside the MFC security fence are six buildings that support TREAT, three sanitary sewage lagoons, the radioactive scrap waste facility, and a parking lot. Outside the perimeter of MFC are unpaved roads, groundwater monitoring wells, an interceptor canal, and an industrial waste pond.

\section{A-2.3 Demography}

Populations potentially affected by INL Site activities include INL Site employees, ranchers who graze livestock in areas on or near the INL Site, hunters on or near the INL Site, residential populations in 
neighboring communities, travelers along U.S. Highway 20/26, and visitors at EBR-I. The population distribution within 50 miles of MFC is shown in Figure A-3.

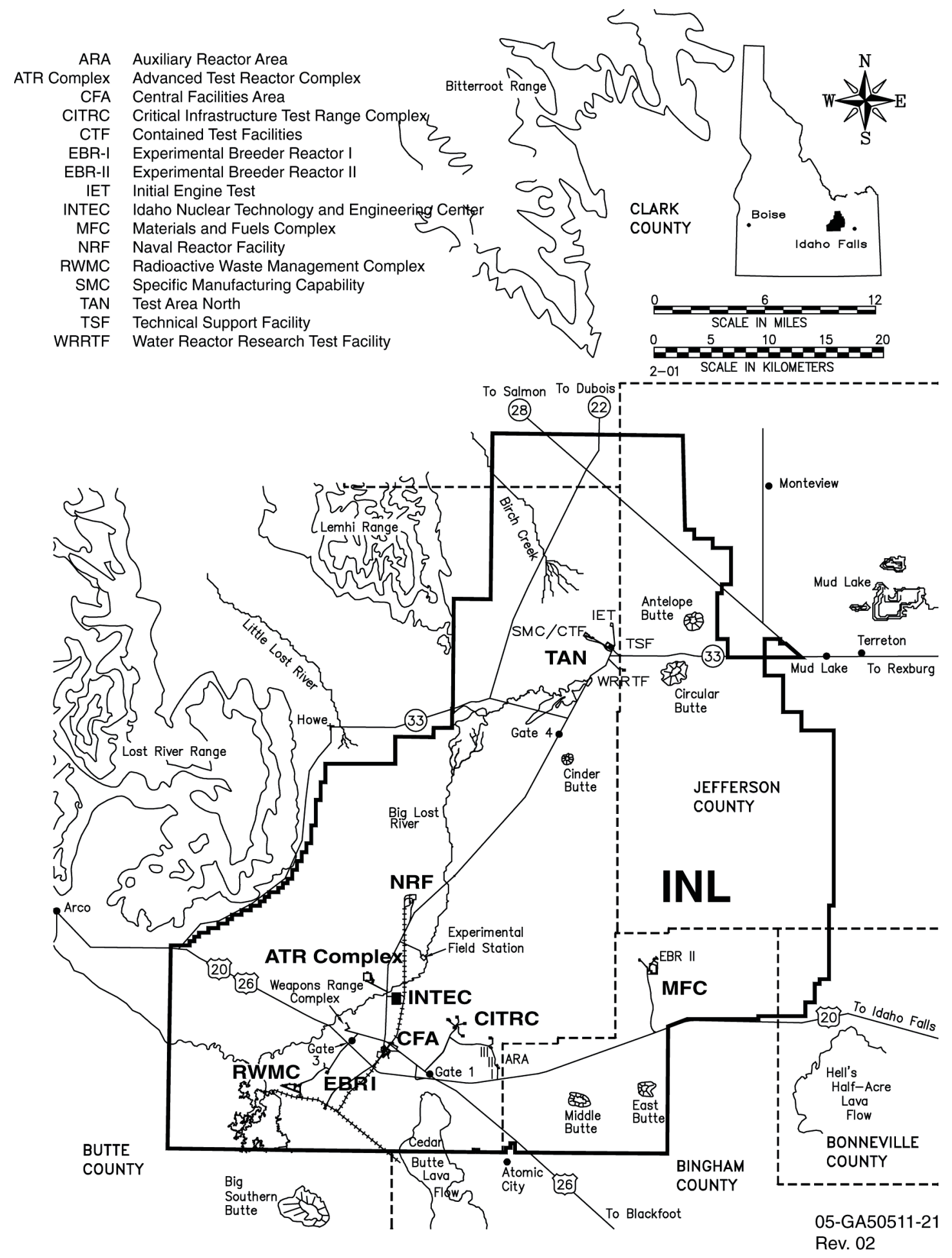

Figure A-1. Map of the Idaho National Laboratory. 


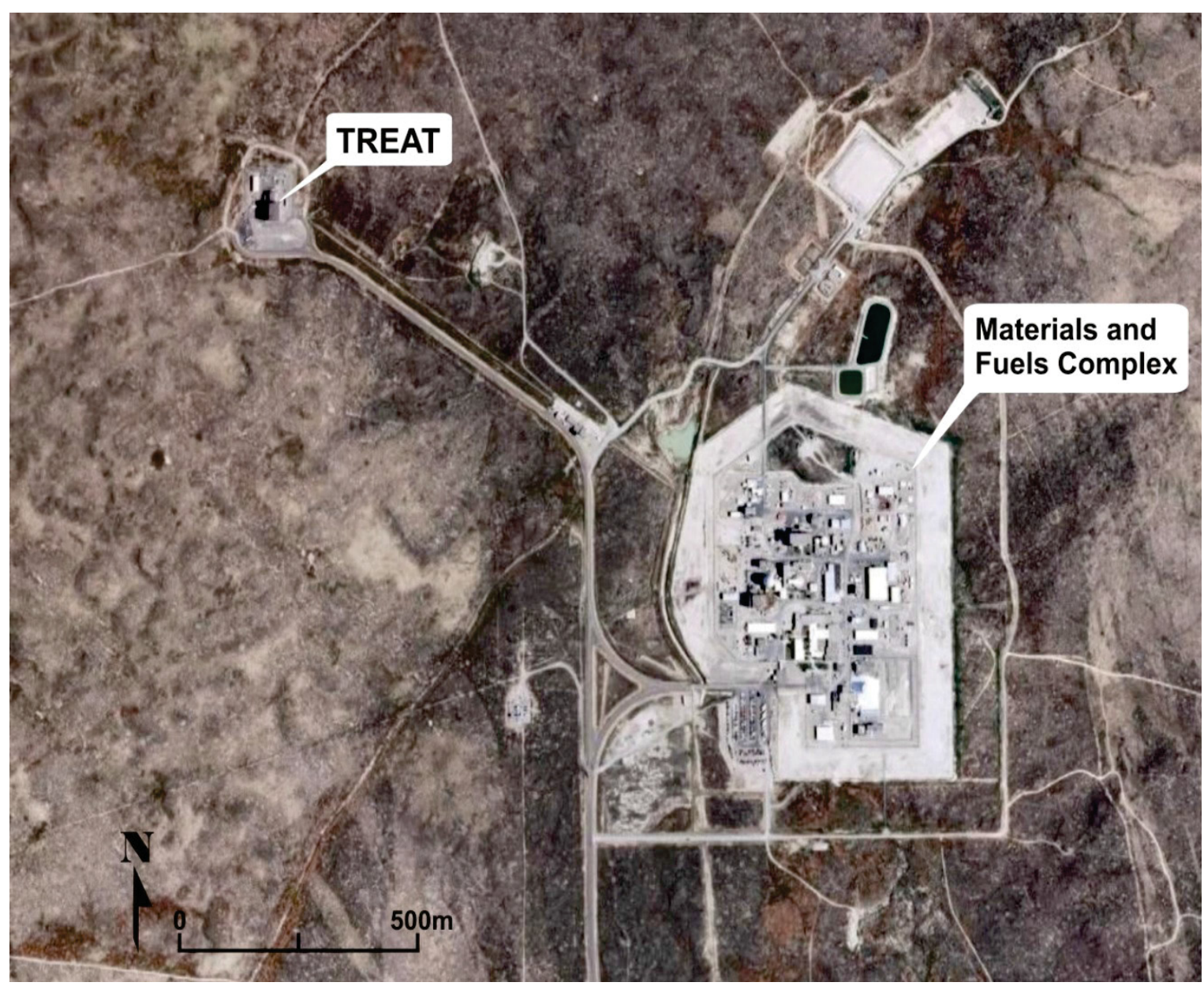

Figure A-2. Aerial photograph of the Materials and Fuels Complex and TREAT areas.

\section{A-2.3.1 Offsite Populations}

The INL Site is bordered by five Idaho counties: Bingham, Bonneville, Butte, Clark, and Jefferson (see Figure A-4). Major communities include Blackfoot and Shelley in Bingham County, Idaho Falls and Ammon in Bonneville County, Arco in Butte County, and Rigby in Jefferson County. Population estimates for the counties surrounding the INL Site and the largest population centers in these counties are shown in Table A-1 (U.S. Census Bureau 2012). The community nearest to TREAT and INL Site is Atomic City, Idaho, located south of the INL boundary on U.S. Highway 20/26 (Figure A-1). Other population centers near the INL Site include Arco, $11 \mathrm{~km}(7 \mathrm{mi})$ west of the INL Site; Howe, west of the INL Site on U.S. Highway 22/33; and Mud Lake and Terreton on the northeast border of the INL Site. The INL Site supports no permanent residents. 


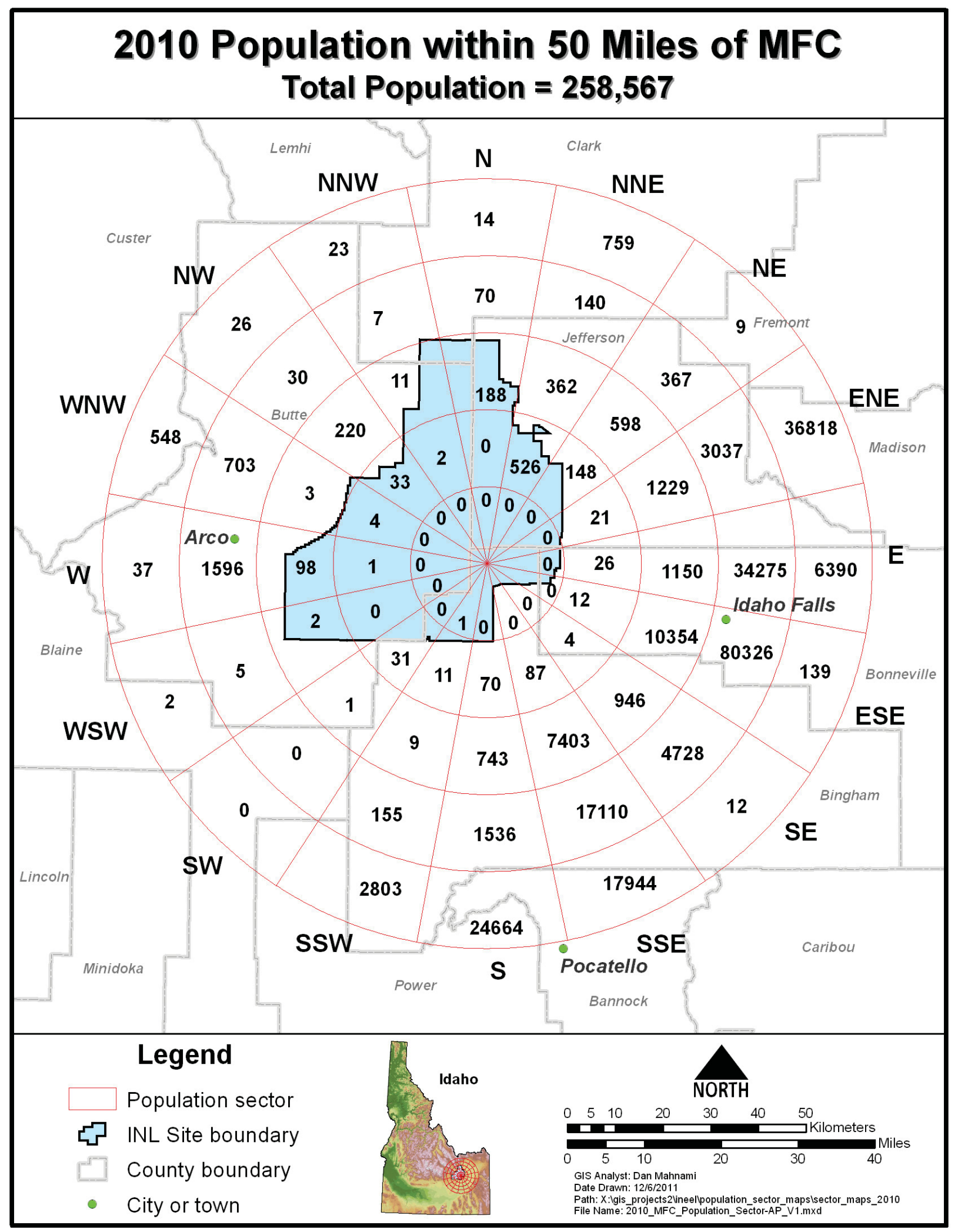

Figure A-3. 2010 population within $80 \mathrm{~km}$ (50 mi) of the Materials and Fuels Complex. 


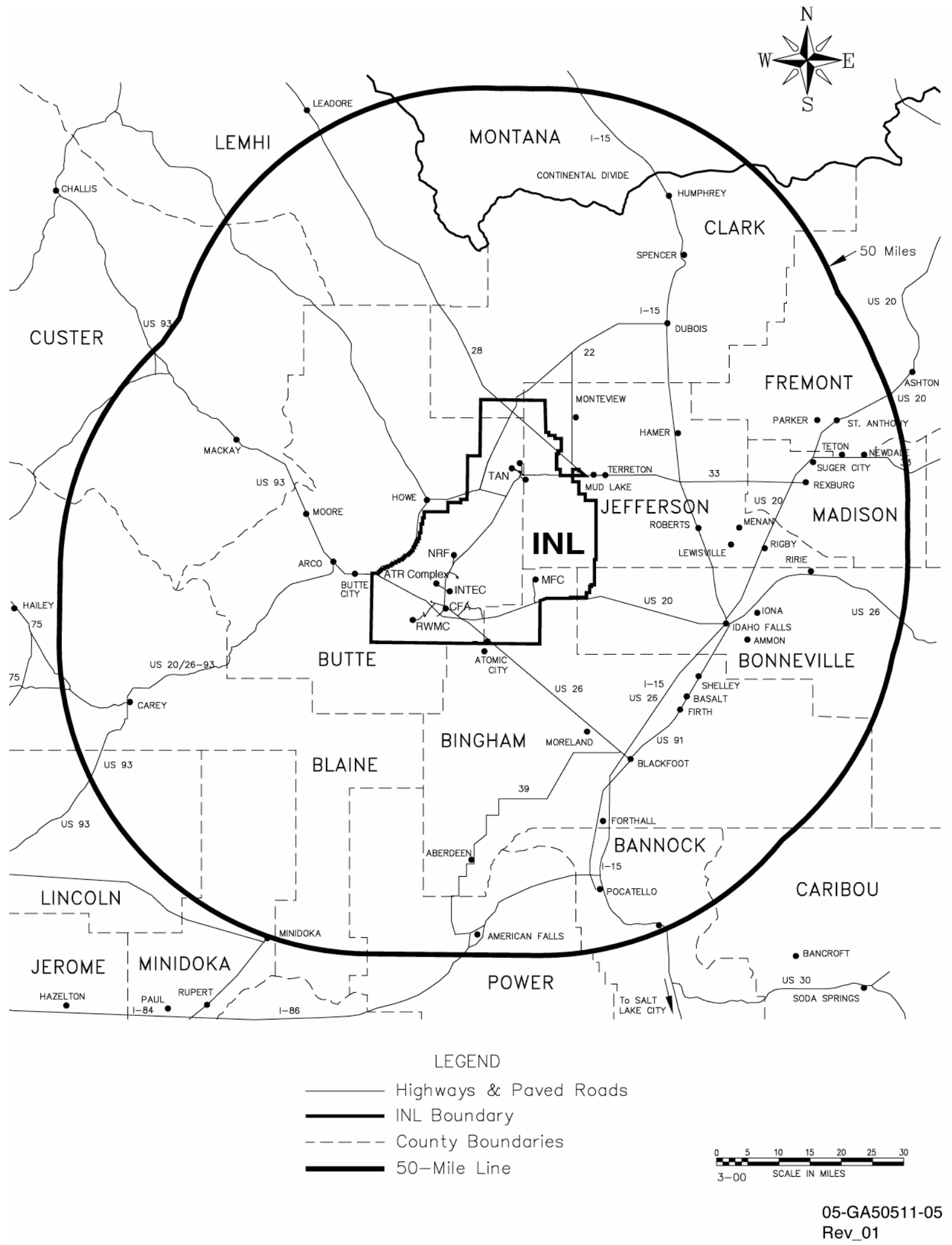

Figure A-4. Incorporated cities within $80 \mathrm{~km}(50 \mathrm{mi})$ of the Idaho National Laboratory. 
Table A-1. Population estimates for counties and selected communities surrounding the Idaho National Laboratory (U.S. Census Bureau 2012).

\begin{tabular}{ll}
\hline Location & Population Estimate \\
\hline Bingham County & 45,474 \\
Blackfoot & 11,852 \\
Shelley & 4,413 \\
Clark County & 869 \\
Bonneville County & 106,684 \\
Ammon & 14,199 \\
Idaho Falls & 57,899 \\
Butte County & 2,740 \\
Arco & 942 \\
Jefferson County & 26,684 \\
Rigby & 4,016 \\
\hline
\end{tabular}

\section{A-2.3.2 Onsite Populations}

Separate facilities at the INL Site include a total of more than 550 buildings and trailers and more than 500 smaller support facilities. As of October 2013, the total INL/Idaho Cleanup Project workforce included approximately 7,000 employees at INL Site locations (with about 1,400 employees at the Naval Reactors Facility; 900 at MFC; 750 at INTEC; 450 at CFA; 500 at the ATR Complex; 200 at Test Area North/Specific Manufacturing Capability; 380 at the Radioactive Waste Management Complex; 10 at the Critical Infrastructure Test Range Complex; 35 at EBR-I and unspecified areas) and 2,400 employees in Idaho Falls occupying numerous offices, research laboratories, and support facilities or other offsite locations. Authorized groups and visitors occasionally are escorted at the INL Site. Subcontracted employees and personnel from the Idaho Department of Environmental Quality and EPA oversight programs also visit the area.

\section{A-2.3.3 Shoshone-Bannock Tribal Interests}

The Shoshone-Bannock Tribes of the Fort Hall Indian Reservation are a federally recognized Indian tribe and a sovereign government. The Fort Bridger Treaty of July 3, 1868, Stat. 673, secured the Fort Hall Reservation as the permanent homeland of the Shoshone-Bannock peoples (15 Stat. 673). The 1868 Treaty also reserved aboriginal rights to these peoples that extend to areas of unoccupied land in Idaho and surrounding states, allowing access for cultural, political, and economic activities essential to the Tribes' survival. Though the INL Site is occupied land, the DOE Idaho Operations Office protects cultural resources and allows tribal members access to areas of cultural and religious significance at the INL Site. In 1994, the DOE Idaho Operations Office entered into a memorandum of agreement that provides the tribes free access to the Middle Butte area of the INL Site (Figure A-1). Although the tribes have free access to the Middle Butte area, it is not a viable receptor location in this analysis because there are no permanent structures or residents, and the distance is much farther than the hypothetical receptor locations analyzed for maximally exposed offsite members of the public. Other INL Site areas may be identified for access in the future for cultural, religious, and educational activities. The Agreement-InPrinciple (DOE-ID 2007) with the tribes ensures that activities being conducted at the INL Site protect health, safety, environment, and cultural resources of the tribes and address tribal interests in DOE-administered programs. From its inception, the Agreement-In-Principle has been updated periodically to reflect the working relationship between the tribes and the DOE Idaho Operations Office. Therefore, it is likely that future INL Site activities will include tribal support to avoid endangering the 
tribes' environment or impairing their ability to protect the health, welfare, and safety of tribal members, others within the tribes' jurisdiction, and the environment and cultural resources of the tribes.

\section{A-2.4 Regional and Local Land Use}

Because the INL Site is remotely located from most developed areas, INL Site lands and adjacent areas are not likely to experience residential and commercial development. No residential development will be allowed to occur within the INL Site boundaries while the land is under DOE control. Land use on INL is associated with facility operations, agriculture, and recreation. Land use adjacent to INL is primarily agricultural and recreational.

INL operations are performed within the INL Site's primary facility areas. A 345,000-acre security and safety buffer surrounds the developed areas. Approximately $6 \%$ of INL (i.e., 34,000 acres) is devoted to utility rights of way and public roads. Up to 340,000 acres of INL are leased for cattle and sheep grazing; grazing permits are administered by the Bureau of Land Management. However, grazing is not permitted within $1 / 2$ mile of any primary facility boundary or within 2 miles of any nuclear facility. In addition, 900 acres located at the junction of Idaho State Highways 28 and 33 are used by the U.S. Sheep Experiment Station as a winter feedlot for sheep.

The dominant land uses in the area surrounding INL are agriculture and open land, each type accounting for $45 \%$ of the area, with the remaining $10 \%$ occupied by urban/built land and water. Land ownership around the INL Site is illustrated in Figure A-5. About $75 \%$ of the land immediately adjacent to the INL Site is owned by the federal government and is administered by the Bureau of Land Management. Uses of the federally owned land consist of grazing, wildlife management, mineral and energy production, and recreation. The State of Idaho owns approximately $1 \%$ of the adjacent land. These state-owned lands are used for grazing, wildlife management, and recreation. Private lands near the INL Site are used primarily for grazing and farming. Irrigated farmlands make up the remaining $24 \%$ of the land bordering the INL Site. Livestock produced on land surrounding the INL Site includes sheep, beef cattle, dairy cattle, hogs, and poultry. The major crops produced on the surrounding lands include wheat, alfalfa, barley, potatoes, oats, corn, and sugar beets.

Recreational uses of INL include public tours of the general facility areas and EBR-I (a national historic landmark). Controlled hunting also is permitted on INL, but it is restricted to specific locations. These restricted hunts are intended to assist the Idaho Department of Fish and Game in reducing crop damage caused by wild game on adjacent private agricultural lands. INL is a designated national environmental research park, functioning as a field laboratory set aside for ecological research and evaluation of the environmental impacts from nuclear energy development.

The INL is bordered on the north and west by the Bitterroot, Lemhi, and Lost River mountain ranges, and on the south by the Big Southern, Middle, and Eastern Buttes (Figure A-1). Significant portions of these largely federally owned lands are used for recreational purposes such as hunting, fishing, boating, hiking, cross-country skiing, and camping. Specific recreational and tourism sites are nearby at the Craters of the Moon National Monument, Hell's Half-Acre Wilderness Study Area, Black Canyon Wilderness Study Area, Camas National Wildlife Refuge, Market Lake State Wildlife Management Area, Mud Lake Wildlife Management Area, and the Birch Creek Camping Area. In addition, there are two national forests, Challis-Salmon and Targhee-Caribou, within $80 \mathrm{~km}(50 \mathrm{mi})$ of the north and west INL boundaries, respectively. 


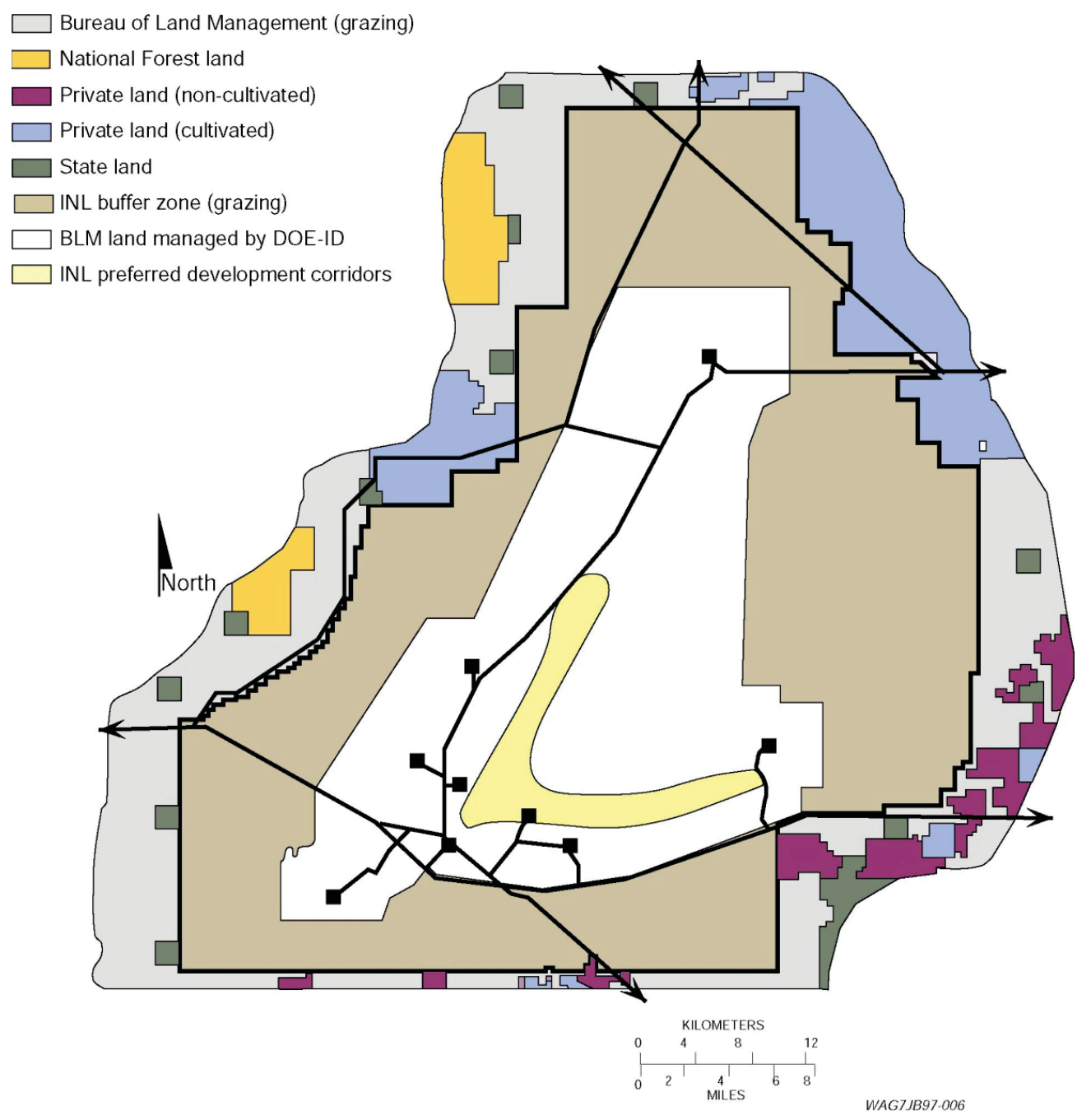

Figure A-5. Land ownership distribution in the vicinity of the Idaho National Laboratory Site.

The Snake River Plain aquifer underlies about $10,000 \mathrm{mi}^{2}$ of the Eastern Snake River Plain (Figure A-6). Irrigated agriculture provides the economic base for people of southern Idaho, and the Snake River Plain aquifer makes a significant percentage of that base possible. It is a remarkable water resource to the area. Pumping for irrigation during a typical year averages 1.6 million acre-ft. Springs from the aquifer provide clean, safe water at just the right temperature for raising more than 25 million $\mathrm{lb}$ of rainbow trout, about $75 \%$ of the entire United States' annual production. It is estimated that over 127,000 people depend on the aquifer for domestic and municipal water needs (Hackett, Pelton, and Brockway 1986). 


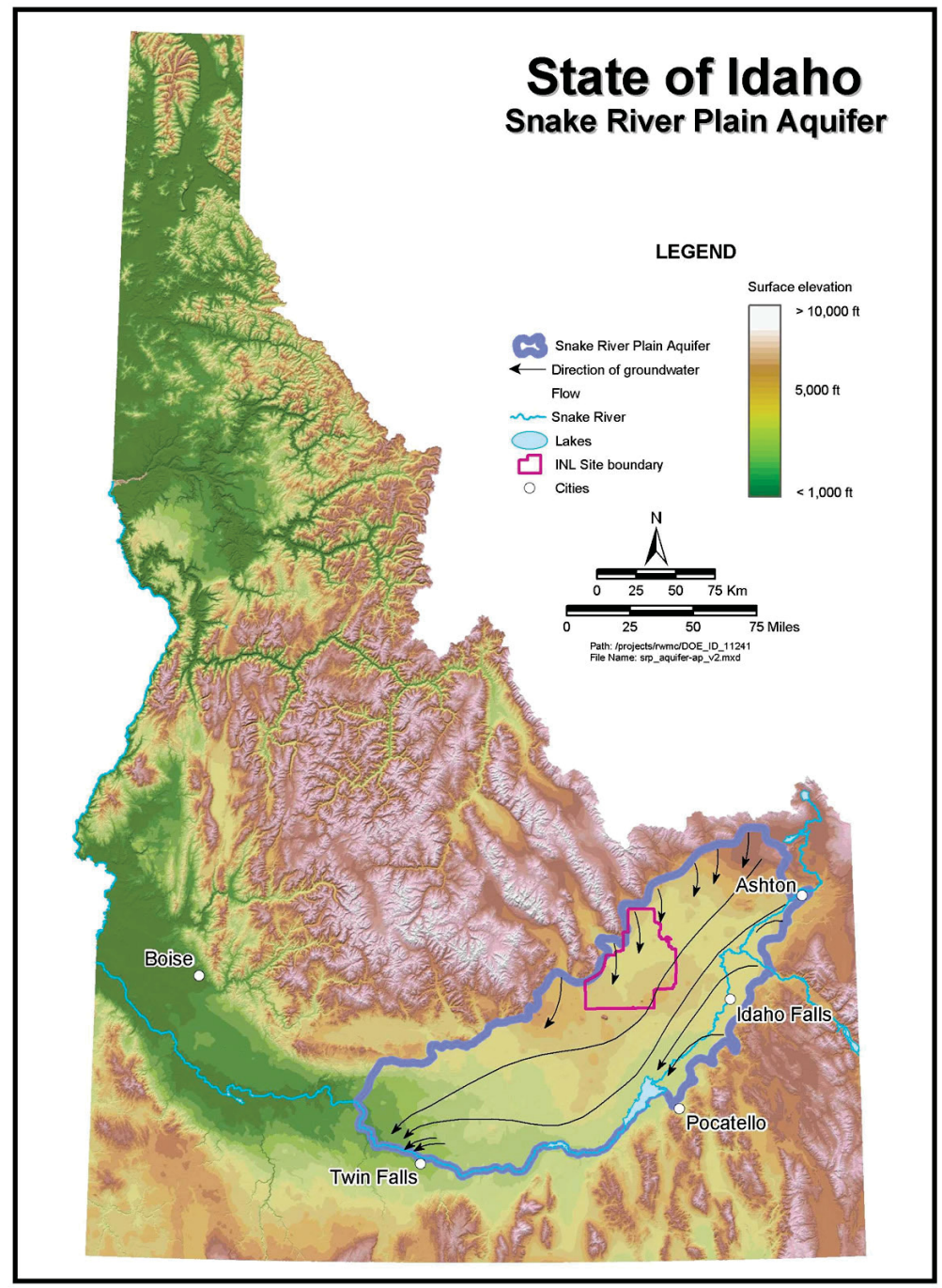

Figure A-6. Location of the Idaho National Laboratory site on the Snake River Plain aquifer in Idaho.

\section{A-2.5 Transportation}

The INL and commercial transportation systems include road and highway systems, railroad systems, and airports. Approximately 6\% of INL land (approximately 34,000 acres) is devoted to public road and utility rights of way crossing the INL Site. The INL Site has $140 \mathrm{~km}(87 \mathrm{mi})$ of paved roads within its boundaries, approximately $29 \mathrm{~km}(18 \mathrm{mi})$ of which are considered service roads. Road use is restricted to employees and visitors on official business. An additional $145 \mathrm{~km}(90 \mathrm{mi})$ of paved public highways run through INL. U.S. Highways 20 and 26 cross the southern portion and Idaho State Highways 22, 28, and 33 cross the northern portion of the Site (see Figure A-1). Over $161 \mathrm{~km}(100 \mathrm{mi})$ of unpaved roads and trails provide additional access for emergency, security, and service vehicles.

The Union Pacific Railroad's Mackay Branch Line services the southern portion of INL through the Scoville Spur. Freight services are received from the Union Pacific Railroad's main lines from Butte, Montana, on the north, and Pocatello, Idaho, and Salt Lake City, Utah, on the south. Interconnections are made from these locations throughout the United States. The INL freight comes through Blackfoot, Idaho, from the Union Pacific's north-south track over the Mackay Branch Line. There are $23 \mathrm{~km}$ (14 mi) of Mackay Branch Line traversing the southern part of the INL Site (see Figure A-1). 
A DOE-owned railroad track passes north at Scoville Siding from the Mackay Branch through CFA, past the east side of INTEC, and terminates within the Naval Reactors Facility. The cities of Idaho Falls and Pocatello both have airports with passenger and cargo service. There is a helicopter pad at each of the major facilities, and a main helicopter pad is located at the CFA-608 security facility. These pads were built to support INL security helicopter operations from 1984 to 1996. Use of security helicopters at INL has been discontinued. One low-altitude airway crosses the southwest portion of INL in a northwestwardly direction. The Federal Aviation Administration requests that pilots avoid flights below $1.8 \mathrm{~km}(6,000 \mathrm{ft})$ above mean sea level when crossing INL.

\section{A-3. TRANSIENT REACTOR TEST FACILITY SITE CHARACTERISTICS}

TREAT site characteristics are summarized in the following subsections to provide context to the assessment of impacts via the air, soil, and water exposure pathways. Characteristics also include those important to the assessment of flood potential discussed in Section A-4.

\section{A-3.1 Meteorology}

Climate data from the CFA (see Figure A-1) and MFC meteorological stations are available from the National Ocean Atmospheric Administration. The CFA meteorological station is located at latitude 43.533 degrees north and longitude 112.948 degrees west at an elevation of 4,950 ft. Its tower is north of building CF-690. The CFA period of record extends from March 1, 1950, to the present (over 60 years) and contains a daily record of precipitation, snowfall, and snowpack thickness. The MFC meteorological station (tower code EBR) is located at latitude 43.594 degrees north and longitude 112.652 degrees west at an elevation of 5,143 ft. Its $250-\mathrm{ft}$ tower is located just outside the east security fence of the MFC area. The MFC period of record extends from April 1, 1993, to the present (about 20 years) and contains daily precipitation. The combination of information from the two meteorological stations was summarized in the NPHs flood assessment for MFC (INL 2010a). From the NPH flood assessment, the important meteorological data includes the following:

- Average daily temperatures at INL range from a low of -11 C (13 F) in early January to a high of $21 \mathrm{C}(70 \mathrm{~F})$ in late July. The average frost-free period at CFA is 88 days and the shortest recorded frost-free period is 40 days. An average of $42 \%$ of the days contains a freeze/thaw cycle. Based on data from November 1956 to August 1963, the average maximum depth of freezing temperatures in the soil is approximately $1 \mathrm{~m}(3 \mathrm{ft})$. Freezing temperatures have been recorded to a maximum depth of $1.5 \mathrm{~m}(5 \mathrm{ft})$.

- Precipitation across INL is variable. Although the total amount is relatively light, precipitation can be expected in any month of the year. There also have been several months when no precipitation has been recorded. The type of precipitation also varies, depending on the season. The average annual precipitation (water equivalent) between 1950 through 2006 at CFA is $21.6 \mathrm{~cm}(8.51 \mathrm{in}$.). The monthly averages for the same periods show a peak in May and June, with 3.09 and $3.00 \mathrm{~cm}$ (1.22 and 1.18 in.), respectively. The highest total annual precipitation recorded was $36.6 \mathrm{~cm}$ (14.4 in.). Based on data from January 1994 to December 2006, the greatest 1-hour precipitation recorded was $1.80 \mathrm{~cm}(0.71 \mathrm{in}$.) in June and the greatest 24-hour precipitation recorded was $4.55 \mathrm{~cm}$ (1.79 in.), also in June. The highest monthly average snowfall (measured at CFA) is $15.7 \mathrm{~cm}(6.2 \mathrm{in}$.), which occurred during January. The maximum-recorded snowfall during any 24-hour period is $22.9 \mathrm{~cm}$ (9.0 in.), which occurred during January. The greatest average monthly snow depth was $63.8 \mathrm{~cm}$ (25.1 in.) in February. Snowfall as late as May and as early as September has been recorded at the INL Site. 
A statistical analysis of precipitation data from 18 stations in the Upper Snake River Plain indicates 4.3 and $5.6 \mathrm{~cm}$ (1.7 and 2.2 in.) for the 25 and 100-year, 24-hour summertime precipitation events (SAR-400). For wintertime 25 and 100-year precipitation events, the amounts are 2.6 and $3.2 \mathrm{~cm}$ (1.0 and 1.3 in.), respectively (INL 2010a).

\section{A-3.2 Evapotranspiration}

Natural recharge through disturbed sediment across INL is approximately $10 \mathrm{~cm} /$ year. The $10-\mathrm{cm} /$ year value also is the default value used for assessing groundwater impacts at low probability hazard (Track 2) sites (DOE-ID 1994). To put the 10-cm/year Track 2 value into perspective, background infiltration rates outside the Subsurface Disposal Area at the Radioactive Waste Management Complex in undisturbed sediment have been estimated to be on the order of $1.0 \mathrm{~cm} /$ year (Cecil et al. 1992) or as low as $0.1 \mathrm{~cm} /$ year based on Mattson et al. (2004). Site-specific estimates under disturbed conditions inside facilities have been determined using inverse modeling of meteorological time histories and measured soil moisture profiles obtained with neutron logging for monitoring locations around the Subsurface Disposal Area (Martian and Magnuson 1994; Martian 1995). These inverse modeling estimates were used in combination with surface topography to assign a distribution of three infiltration rates across the Subsurface Disposal Area (Martian 1995). The three rates applied were $1 \mathrm{~cm} /$ year (0.4 in./year), which is the same as the background infiltration rate traditionally assumed for undisturbed soil outside the Subsurface Disposal Area; $3.7 \mathrm{~cm} /$ year (1.5 in./year), representing a medium value; and $10.0 \mathrm{~cm} /$ year (4 in./year), representing infiltration obtained near drainage ditches where water and snow are intentionally diverted (DOE-ID 2006a). For a more direct comparison to the single-rate infiltration values assigned in the Naval Reactors Facility and ATR Complex evaluation, the spatial average inside the Subsurface Disposal Area of the spatially varying rates (although the spatial average was never explicitly used for the Radioactive Waste Management Complex remedial investigation and baseline risk assessment) was $5 \mathrm{~cm} /$ year.

Similarly, inverse modeling at INTEC was performed for the Operable Unit 3-14 tank farm soil and groundwater remedial investigation and baseline risk assessment (DOE-ID 2006b) to determine infiltration rates. This study indicated net infiltration across disturbed INTEC soils was $18 \mathrm{~cm} /$ year. This value is representative of highly disturbed gravels in the tank farm where infiltration is enhanced by leaks through a temporary cover and evapotranspiration is eliminated by the cover. As with the Subsurface Disposal Area model, disturbed conditions were accounted for explicitly. In the INTEC model, infiltration through undisturbed areas at INTEC was assigned a value of $1 \mathrm{~cm} /$ year and disturbed areas were assigned the higher rate of $18 \mathrm{~cm} /$ year (DOE-ID 2006b), which constitutes $85 \%$ of the average annual precipitation.

\section{A-3.3 Wind}

Wind measurements at MFC are made at $10 \mathrm{~m}$ and $250 \mathrm{ft}$ above the ground surface. From the data, MFC is subject to the same southwest and northeast winds typical of INL. Winds tend to be diurnal with up-slope winds (those out of the southwest) occurring during the day and down-slope winds (those out of the northeast) occurring at night. During the time of record at MFC, the mean 5-minute average wind speed and gusts were $9.4 \mathrm{mph}(4.2 \mathrm{~meters} / \mathrm{sec})$ and $12.7 \mathrm{mph}$, respectively, at the $15-\mathrm{m}$ (49-ft) height and $13.6 \mathrm{mph}$ and $16.3 \mathrm{mph}$, respectively, at the $76-\mathrm{m}(250-\mathrm{ft})$ height. The maximum 5-minute average wind speed and gusts during the 21 -year period were $49.1 \mathrm{mph}$ and $73.8 \mathrm{mph}$, respectively, at the 15-m (49-ft) height and $68.2 \mathrm{mph}$ and $84.7 \mathrm{mph}$, respectively, at the $76-\mathrm{m}(250-\mathrm{ft})$ height. 


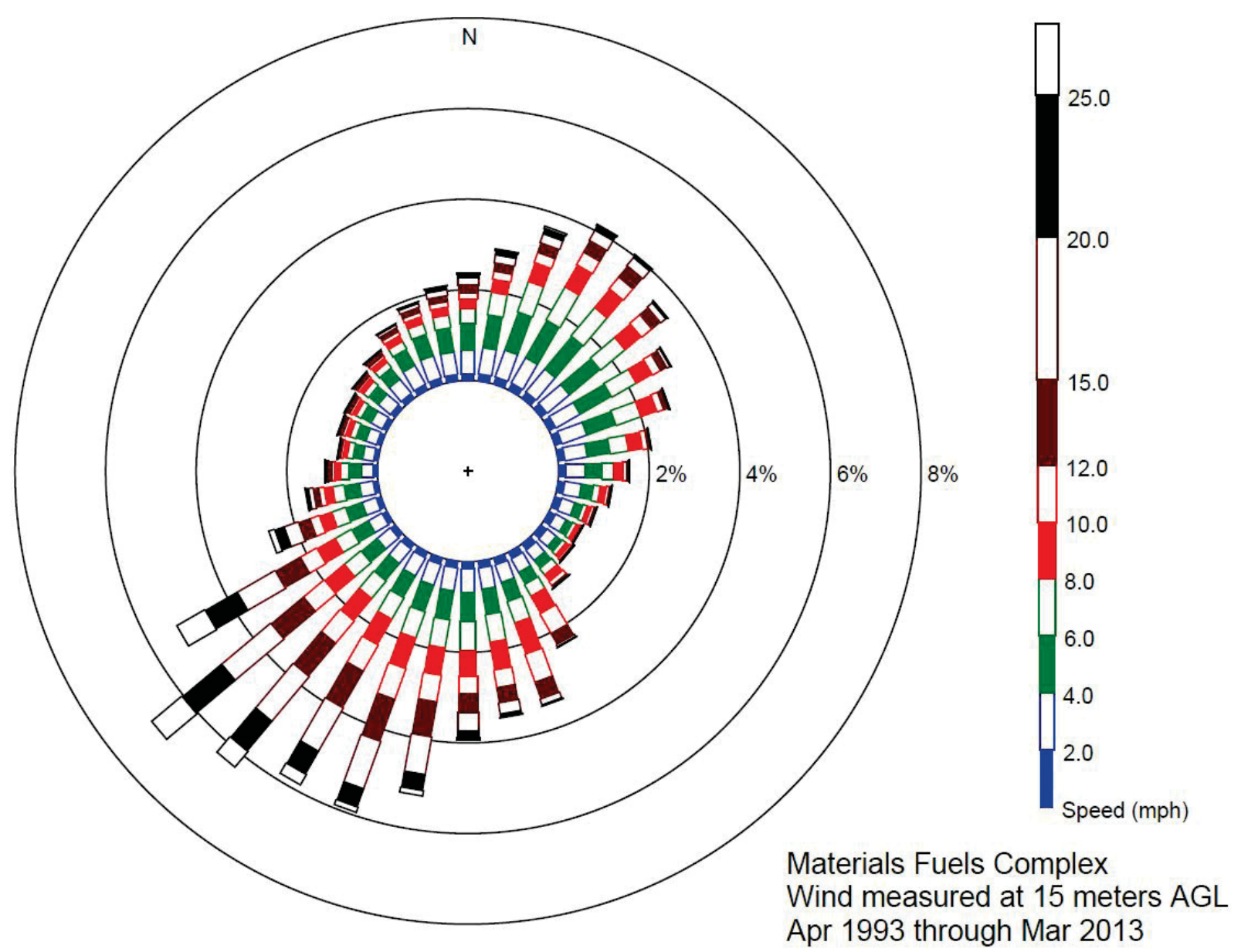

Figure A-7. Materials and Fuels Complex wind rose for the 15-m height for the period April 1993 through March 2013.

\section{A-3.4 Surface Water Hydrology}

There are no perennial surface water bodies near MFC. Using the United States Geological Survey's surface water hydrologic unit code classification scheme, INL is located in the Upper Snake River Basin Accounting Unit (170402). Portions of six "watersheds" (United States Geological Survey 8-digit "Cataloging Units") either drain surface water to or from the INL Site. These units include American Falls (17040206), Big Lost (17040218), Birch Creek (17040216), Idaho Falls (17040201), Little Lost (17040217), and Medicine Lodge (17040215) (Figure A-8). The Big Lost River, Birch Creek, Little Lost River, and Medicine Lodge are all part of the northern "closed basins." Each of these streams flows near or onto the INL Site and terminates on or near the northern portion of the INL boundary by a combination of infiltration and evapotranspiration. MFC and TREAT are both located at the southern portion of the Medicine Lodge cataloging unit (Figure A-9). 


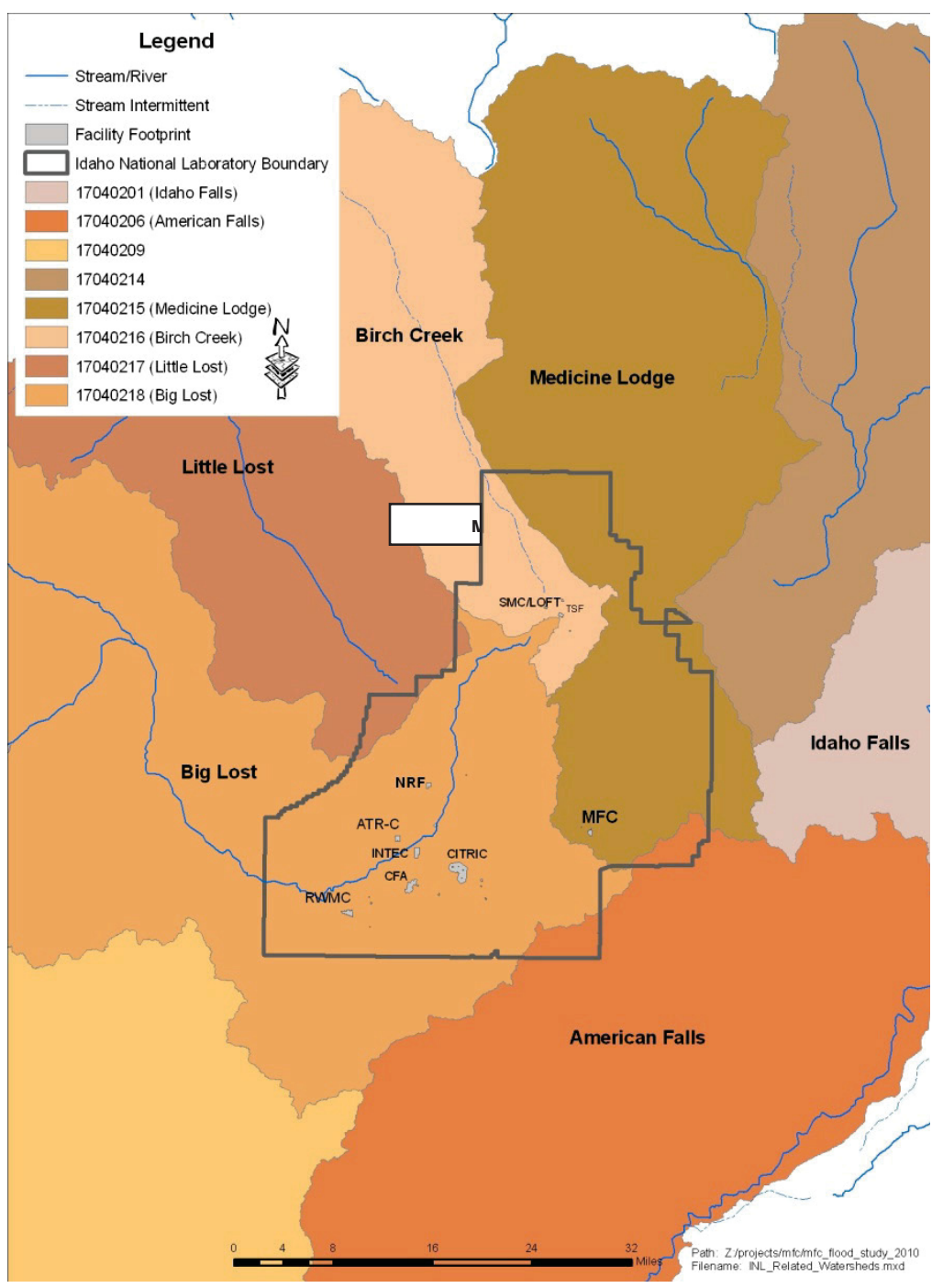

Figure A-8. Idaho National Laboratory-related watersheds (United States Geological Survey 8digit “cataloging units") (from INL 2010a). 


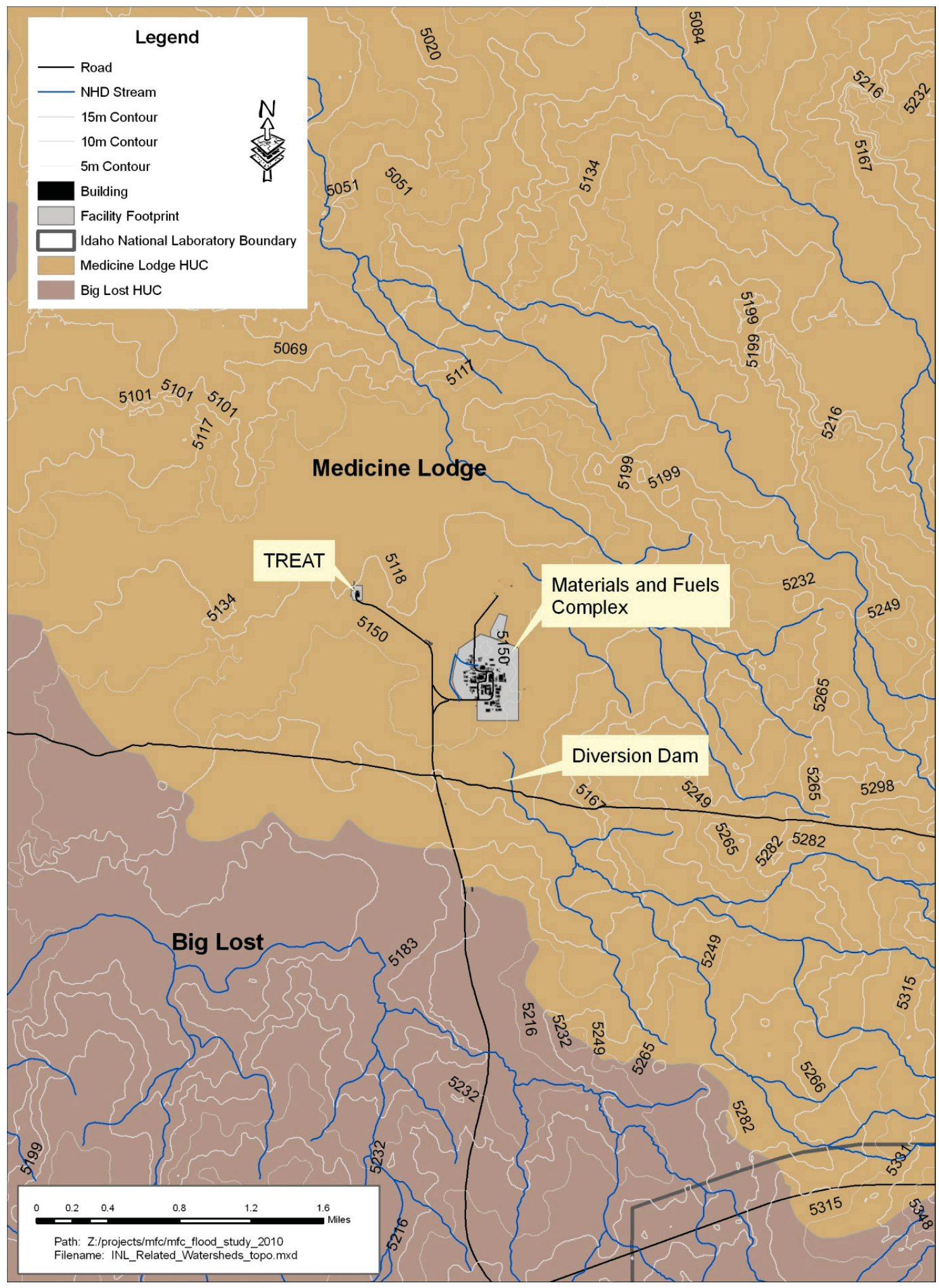

Figure A-9. Topographic map of the Materials and Fuels Complex and TREAT in the Medicine Lodge cataloging unit (from INL 2010a). 
All MFC facilities within the MFC fence are within a single "local" (12-digit hydrologic unit code) topographically closed watershed (Figure A-10). The MFC watershed contains natural drainage channels, which can concentrate overland flow during periods of high precipitation or heavy spring runoff; however, it contains no perennial, natural surface water features. TREAT is located in an adjacent local topographically closed watershed, which also contains no identifiable perennial, natural surface water features. The MFC and TREAT watersheds are separated by a low-lying topographic ridge that passes just north of the TREAT Reactor control building.

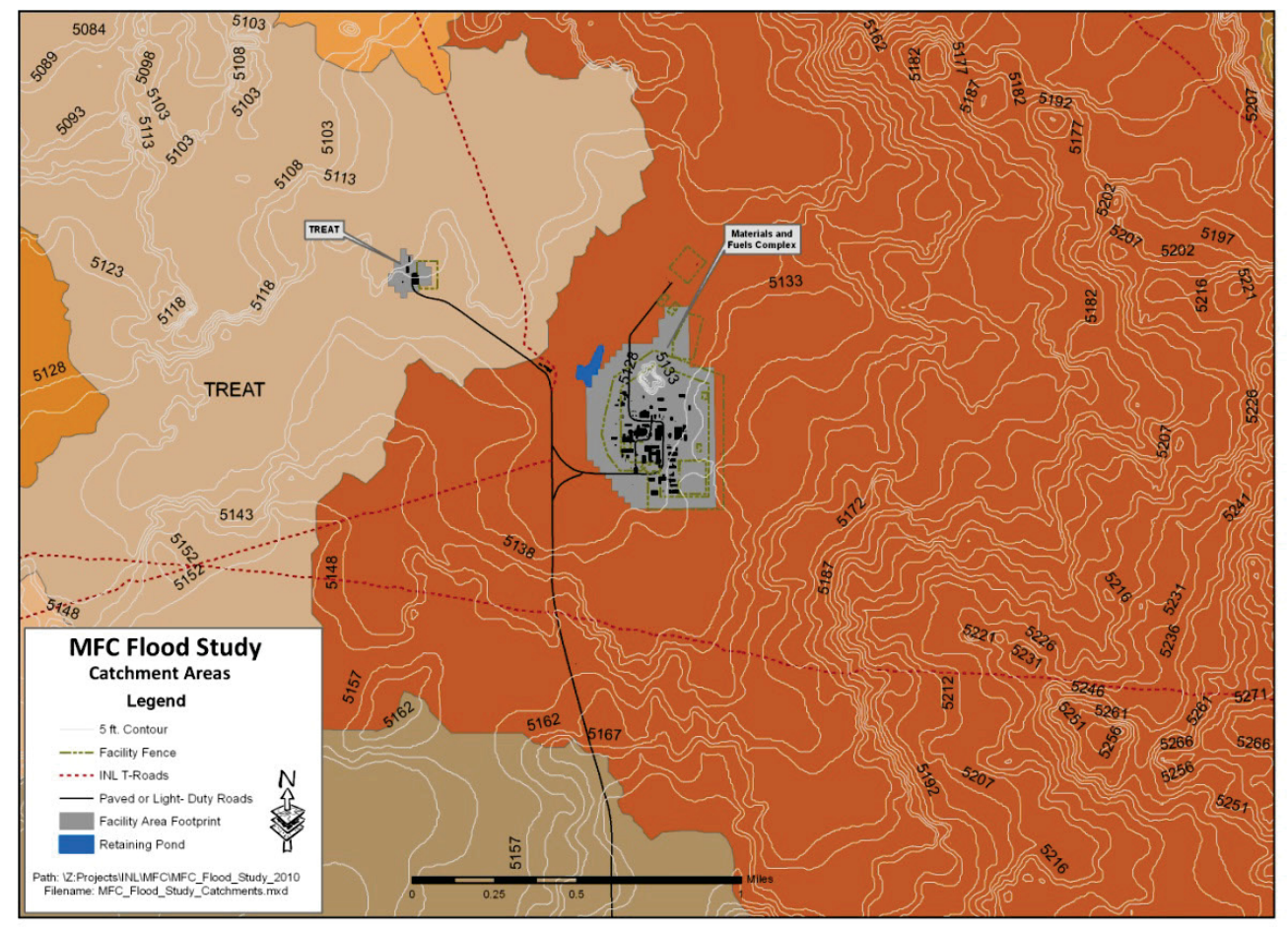

Figure A-10. General topography of Materials and Fuels Complex and TREAT watersheds (from INL 2010a).

\section{A-3.5 Topology}

Topographical relief in the MFC watershed (CH2M Hill 1978) is about $50 \mathrm{ft}$, ranging from 5,110 ft above mean sea level on the north boundary to $5,160 \mathrm{ft}$ on a basalt ridge to the southeast (Figure A-10). This report is substantiated by geographical information system evaluations conducted for the natural phenomena flood evaluation (INL 2010a), which indicates that the MFC watershed slopes from the cinder cone in the southeast to the northwest portion of the watershed (Figure A-11), approximately 6.3 miles at a slope of $66 \mathrm{ft}$ per mile. Facilities at MFC lie near the northern portion of the watershed with elevations within the fenced area between 5,120 and 5,130 ft above sea level (CH2M Hill 1978). 


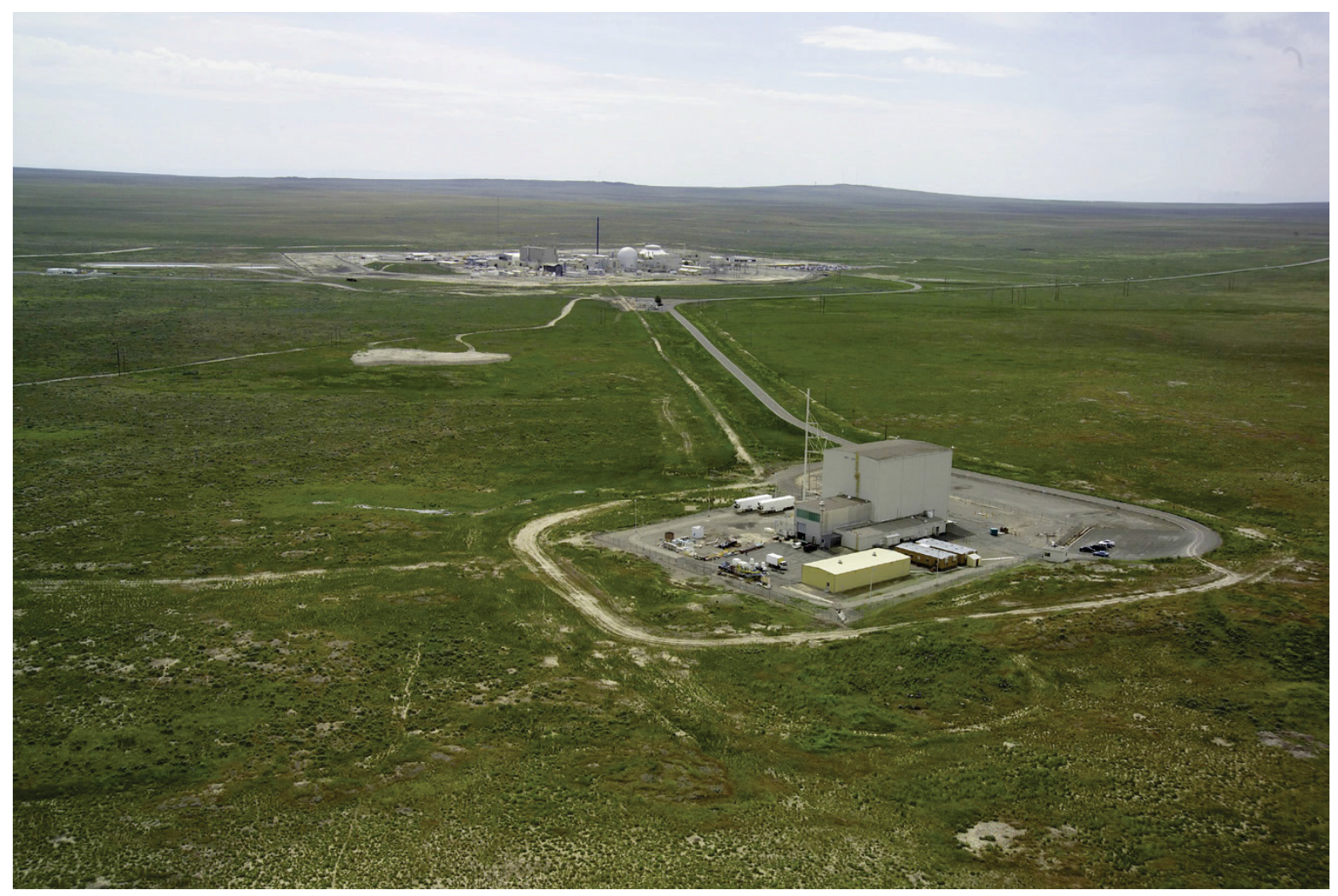

Figure A-11. Aerial photo of TREAT, with the Materials and Fuels Complex in the background.

\section{A-3.6 Geology}

Much of INL's surface is covered by Pleistocene and Holocene basalt flows. Alluvial sediment of Quaternary age occurs in a band that extends across INL from the southwest to the northeast. These define the flood plain of the Big Lost River. Paleozoic sedimentary rocks make up a very small area of INL along the northwest boundary.

MFC and TREAT are isolated from the flood plain of the Big Lost River by the topographically closed basins in which they reside. Surficial sediment near MFC and TREAT were either derived from upland erosion of the surrounding highlands or windblown loess. The thickness of surficial sediment near MFC ranges from $0 \mathrm{ft}$, associated with outcroppings at the surface, to $14 \mathrm{ft}$ in depth. In general, the depths of the surface soils tend to increase from approximately $2 \mathrm{ft}$ deep on the east side of the facility to a depth of $14 \mathrm{ft}$ near the west side of the security fence. The permeability of soils at MFC is moderately rapid to rapid. The hazard of erosion is slight or moderate.

Subsurface geology near MFC is similar to that on the rest of the INL Site, with the exception of a lack of continuous sedimentary interbeds beneath the facility. The sedimentary interbeds appear to be discontinuous stringers, deposited in low areas on basalt surfaces. They are generally composed of calcareous silt, sand, or cinders. Rubble layers between individual basalt flows are composed of sand and gravel to boulder-sized material. The interbeds range in thickness from less than $1 \mathrm{in}$. to $15 \mathrm{ft}$. Areally extensive interbeds have been identified above the regional water table, at approximately 400, 550, and $600 \mathrm{ft}$ below land surface (Northern Engineering and Testing, Inc. 1988). The depth to the Snake River Plain aquifer below MFC is approximately $640 \mathrm{ft}$ below land surface. 


\section{A-4. FLOOD POTENTIAL}

Surface hydrology and flood potential at MFC were the focus of a natural phenomena flood hazards study performed in 2010 (INL 2010a). The study determined that because MFC and TREAT are not located near a river or a large body of surface water that could cause a tsunami, seiche, storm surge, or large waves, the only potential source of flooding would be overland flow from the surrounding higher topographic areas.

During times of high precipitation when the ground is not frozen, surface water will first infiltrate into the soils, then pond in low-lying areas, and then eventually may become overland flow. Under colder conditions, precipitation or snowmelt may be unable to infiltrate into the ground and may immediately become overland flow. Runoff can occur as overland sheet flow and/or become concentrated in normally dry depressions and channels. Excess flows will seek the lowest point in the watershed.

To estimate the probable maximum flood impact from overland flooding, a probable maximum precipitation (PMP) event was used. The PMP event assumed a 10,000-year event storm consisting of 2.2 in. of total rainfall over the first hour, with a total of $4.65 \mathrm{in}$. of rain falling in 24 hours. The assumed PMP was approximately equal to half of the total annual average rainfall at INL ( 8.51 in. per year) based on the 56-year period of record at CFA. For comparison to the PMP, a statistical analysis of meteorological data from CFA for the period of 1950 through 1995 provides estimates of $1.7 \mathrm{in}$. of precipitation for a 25-year (3.9\% annual exceedance probability), 24-hour storm event and $2.2 \mathrm{in}$. of precipitation for a 100-year (1\% annual exceedance probability), 24-hour storm event (INL 2010b and Sagendorf 1996). Therefore, the probability of a 4.65-in., 24-hour local PMP is much less likely than 1\%.

The PMP and 10,000-year precipitation events were transformed into a watershed outflow using the USACE HEC-HMS software. In the analysis, the synthetic Soil Conservation Service unit hydrograph option within HEC-HMS was used as the transformation method to convert the design storm hyetographs to stream flow hydrographs. Losses due to surface ponding, infiltration, and evaporation were assumed to be zero to provide the most conservative (highest) runoff for the probable maximum flood analysis. Therefore, the runoff volumes equaled the precipitation over the watersheds.

The $0.22-\mathrm{mi}^{2}$ (140 acre) TREAT fenced area was treated as a single watershed. Applying the PMP to this area, the probable maximum flood estimated for runoff at the TREAT buildings (MFC-720 and MFC-723) was 2,161 cfs; however, the flood analysis was bracketed (200 to 5,000 cfs) for modeling to provide a conservative estimate. At 5,000 cfs, which is more than double the runoff rate estimated to be generated by the PMP, the maximum predicted flood water elevation at TREAT buildings (MFC-720 and MFC-723) was determined to be 5,114.82 ft. The elevation of critical facilities at TREAT is 5,121.85 ft, more than $7 \mathrm{ft}$ above the predicted flood level. Therefore, the TREAT Reactor building (MFC-720) and support facility (MFC-723) are not at risk of flooding even under the conservative assumptions modeled.

\section{A-5. REFERENCES}

15 Stat. 673, Fort Bridger Treaty of July 3, 1868.

Cecil, L. D., J. R. Pittman, T. M. Beasley, R. L. Michel, P. W. Kubik, P. Sharma, U. Fehn, and H. Gove, 1992, "Water Infiltration Rates in the Unsaturated Zone at the Idaho National Engineering Laboratory Estimated by Chlorine-36 and Tritium Profiles, and Neutron Logging," in Proceedings of the $7^{\text {th }}$ International Symposium on Water-Rock Interactions, WRI-7, Y. K. Kharaka and A. S. Meest, eds., Park City, Utah, July 13-18, 1992.

CH2M Hill, 1978, Argonne National Laboratory Site Drainage Study, W7500-4J07-ES-00, CH2M Hill, Boise, Idaho, 1978. 
DOE-ID, 1994, Track 2 Sites: Guidance for Assessing Low Probability Hazard Sites at the INEL, DOE/ID-10389, U.S. Department of Energy Idaho Operations Office, January 1994.

DOE-ID, 2006a, Remedial Investigation and Baseline Risk Assessment for Operable Unit 7-13/14, DOE/ID-11241, U.S. Department of Energy Idaho Operations Office.

DOE-ID, 2006b, Operable Unit 3-14 Tank Farm Soil and Groundwater Remedial Investigation/Baseline Risk Assessment, DOE/NE-ID-11227, U.S. Department of Energy Idaho Operations Office, April 2006.

DOE-ID, 2007, Agreement in Principle Between the Shoshone-Bannock Tribes and the United States Department of Energy, AR-25223, U.S. Department of Energy Idaho Operations Office, December 2007.

Hackett, W. R., J. Pelton, and C. Brockway, 1986, Geohydrologic Story of the eastern Snake River Plain and the Idaho National Engineering Laboratory, Administrative Record No. 8405, Idaho National Engineering Laboratory.

INL, 2010a, Idaho National Laboratory Materials and Fuels Complex Natural Phenomena Hazards Flood Assessment, INL/EXT-10-20572, Idaho National Laboratory, December 2010.

INL, 2010b, Assessment of Potential Flood Events and Impacts at INL's Proposed Remote-Handled Low-Level Waste Disposal Facility Sites, INL/EXT-10-18191, Idaho National Laboratory.

Martian, P., 1995, UNSAT-H Infiltration Model Calibration at the Subsurface Disposal Area, INEL-95/0596, Idaho National Engineering Laboratory.

Martian, P. and S. O. Magnuson, 1994, A Simulation Study of Infiltration Into Surficial Sediments at the Subsurface Disposal Area, Idaho National Engineering Laboratory, EGG-WM-11250, Idaho National Engineering and Environmental Laboratory.

Mattson, E., M. Ankeny, S. Dwyer, N. Hampton, G. Matthern, B. Pace, A. Parsons, M. Plummer, S. Reese, and J. Waugh, 2004, Preliminary Design for an Engineered Surface Barrier at the Subsurface Disposal Area, ICP/EXT-04-00216, Idaho National Engineering and Environmental Laboratory.

Northern Engineering and Testing, Inc., 1988, Final Report Geohydrologic Investigation of Industrial Waste Pond at Argonne National Laboratories-West Idaho Falls, Idaho, NE497.HG.

Sagendorf, J., 1996, Precipitation Frequency and Intensity at the Idaho National Engineering Laboratory, ARLFRD 94-100, U.S. Department of Commerce, National Oceanic Atmospheric Administration, Environmental Research Laboratories, Air Resources Laboratory Field Research Division, Idaho Falls, ID, 1996.

SAR-400, 2013, "Chapter 1-Site Characteristics - INL Standardized Safety Analysis Report," SAR-400, Revision 6, May 2013.

U.S. Census Bureau, 2012, 2012 Population Estimates, U.S. Department of Commerce, Economics, and Statistics Administration, and United States Census Bureau. 
Appendix B

\section{Near-Field Environment Affected by Resumption of Transient Testing at the ACRR Facility}


B-2 


\section{CONTENTS}

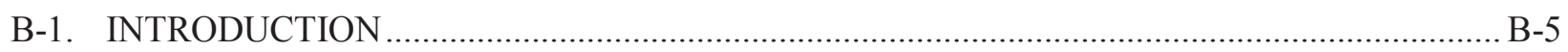

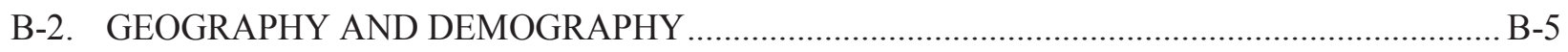

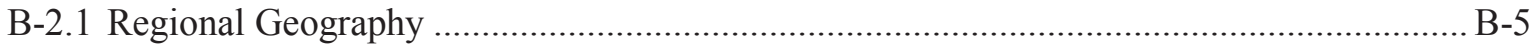

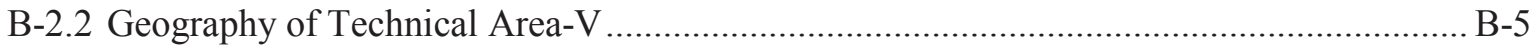

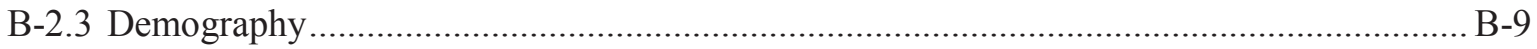

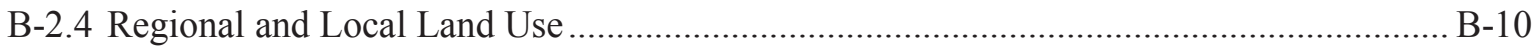

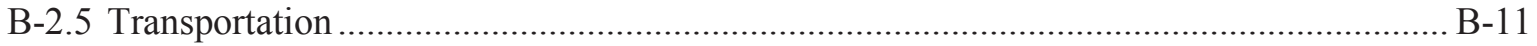

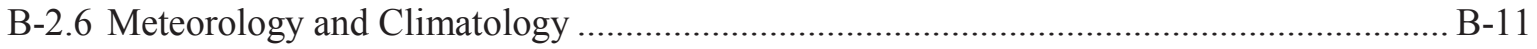

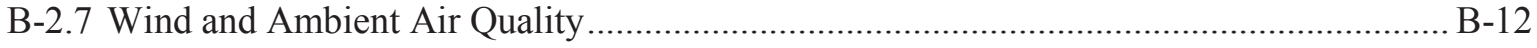

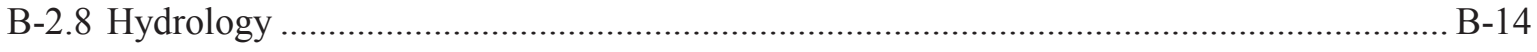

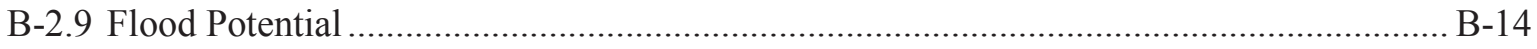

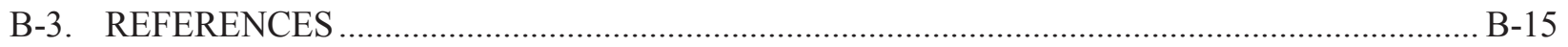


B-4 


\section{Appendix B \\ Near-Field Environment Affected by Resumption of Transient Testing at the ACRR Facility}

\section{B-1. INTRODUCTION}

This section provides an overview of the meteorology, topography, geology, surface water, and groundwater resources of the region surrounding TA-V at SNL/NM. It includes the physical characteristics of KAFB, SNL/NM, and general area surrounding Albuquerque, New Mexico. This information is used to support the assessment of human health impacts.

\section{B-2. GEOGRAPHY AND DEMOGRAPHY}

The geography and demography of the areas adjacent to KAFB and TA-V at SNL/NM are provided in the following subsections to give context to the selection of receptor locations used in the evaluation of human health impacts.

\section{B-2.1 Regional Geography}

SNL/NM is a multi-program national security laboratory. Sandia Corporation (Sandia), a wholly owned subsidiary of Lockheed Martin Corporation, manages and operates SNL/NM for the DOE National Nuclear Security Administration. The DOE National Nuclear Security Administration's Sandia Site Office administers the contract and oversees contractor operations at the site. SNL/NM operations are conducted on approximately 8,800 acres of federal land on KAFB (SNL/NM 2011). KAFB is approximately 7 miles southeast of downtown Albuquerque, New Mexico (Figure B-1). Albuquerque is located in Bernalillo County, in north-central New Mexico.

The local topology of the Albuquerque area is dominated by the Sandia Mountains and Rio Grande River. The Sandia Mountains rise steeply immediately north and east of the city, with the Manzanita Mountains extending to the southeast. The Rio Grande River runs southward through Albuquerque and is the primary river traversing central New Mexico.

\section{B-2.2 Geography of Technical Area-V}

TA-V is an area occupying approximately 33 acres in the north-central portion of KAFB (Figure B-2). TA-V, located adjacent to the northeast section of TA-III, includes facilities that routinely handle radioactive materials used in experimental research and development programs. TA-V houses the Gamma Irradiation Facility, ACRR, the Hot Cell Facility, and the Auxiliary Hot Cell Facility. In addition to DOE-owned lands within the boundaries of TA-V, approximately six acres are permitted to DOE by the U.S. Air Force to provide additional security. TA-V is a relatively small research area consisting of about 35 closely grouped structures where experimental and engineering research reactors are located. Approximately 150 personnel work in the area. TA-V is widely developed, with some planned landscaping, but predominantly consists of paved ("hard-scaped") roads and parking areas and has been deemed an urban/landscaped area.

Although TA-V is predominately an urban area, a biological standard conservation area has been proposed for the area within TA-V and adjacent Technical Area III. The standard conservation area was established due to heavy use of this habitat and to a higher amount of incidental use by the following bird species: eastern meadowlark, western meadowlark, loggerhead shrike, sage sparrow, and Cassin's sparrow. No federally listed threatened or endangered species are associated with TA-V. 


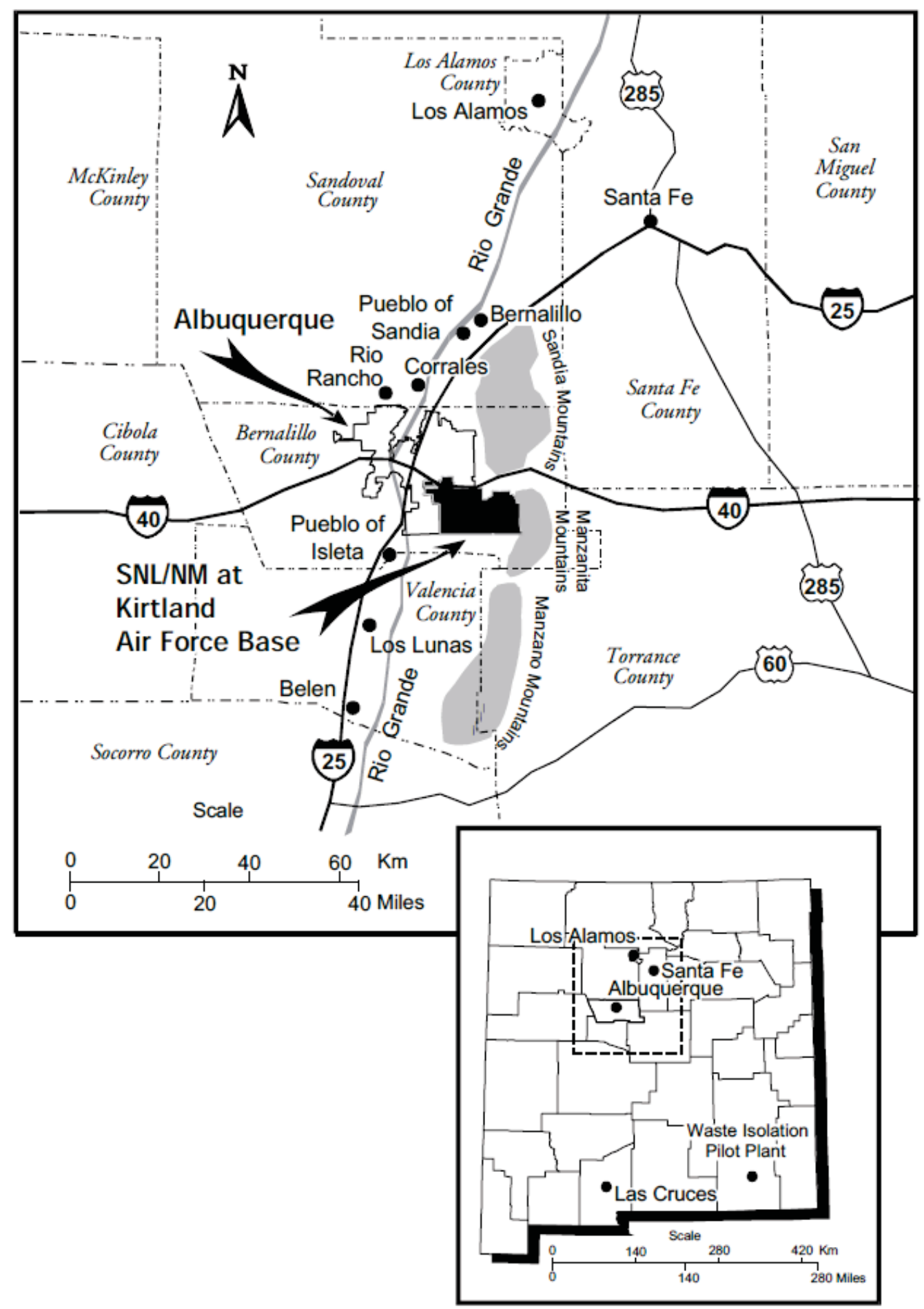

Figure B-1. Sandia National Laboratory, Kirtland Air Force Base, and surrounding area. 


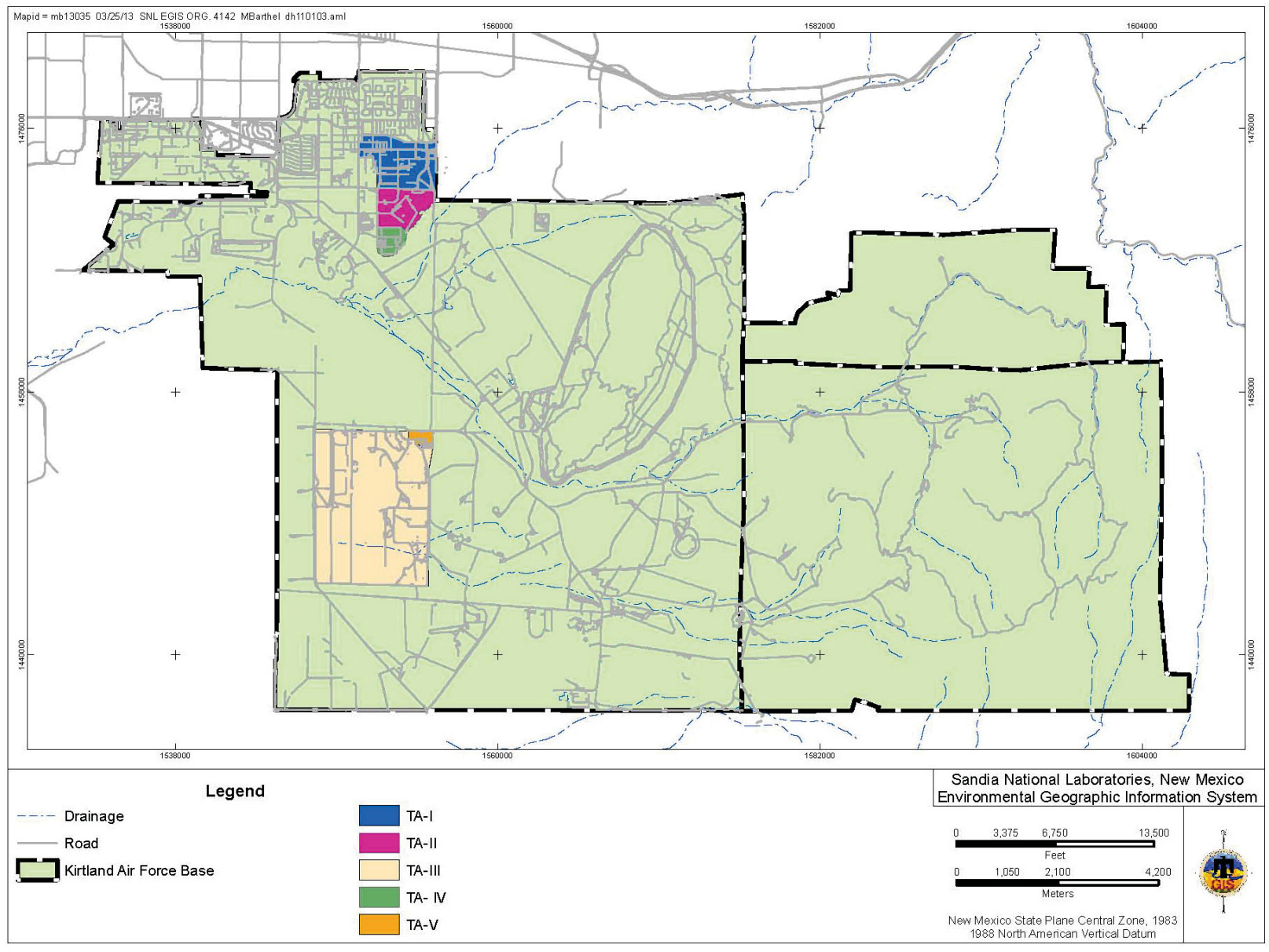

Figure B-2. Technical Areas at Sandia National Laboratory (corresponding to inset area shown in Figure B-1).

Cultural resources include archaeological, traditional, and built environmental resources, including district sites, buildings, structures, or objects from both the prehistoric and historic eras of human history. TA-V has been surveyed for archeological sites (both prehistoric and historic) (DOE 1999). Aside from isolated occurrences of artifacts, no prehistoric or historic archeological sites have been identified (DOE 2006). Currently, nine buildings (including ACRR) or structures in TA-V (referred to as the "Reactor Complex Historic District") are recommended as eligible for the National Register of Historic Places (SNL/NM 2011).

ACRR (Figure B-3) is one of two facilities in TA-V that is required by NESHAPs to monitor radionuclide source emissions that have the potential to produce a specific dose. 


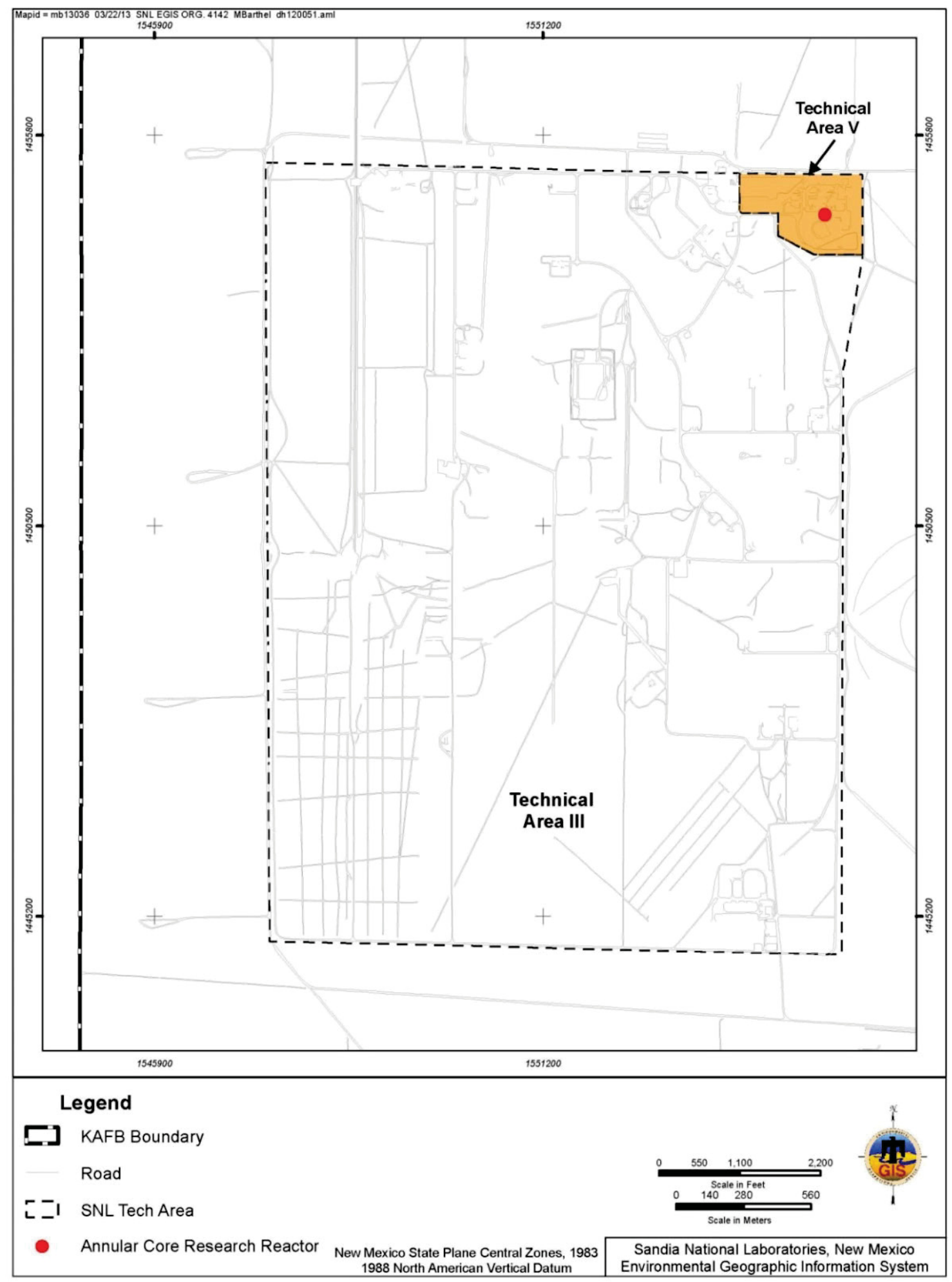

Figure B-3. Location of the Annular Core Research Reactor in Technical Area V at Sandia National Laboratory. 


\section{B-2.3 Demography}

New Mexico has an estimated population of 2 million residents. The largest city is Albuquerque with about 552,804 metro-area residents; other neighboring metro areas include the City of Rio Rancho with 89,320 residents and Bernalillo with 8,480 residents. The population within a 50-mile radius of SNL/NM is over 685,000 residents; nine counties are contained or partially included in that radius (SNL/NM 2012). The nine counties include: Cibola, McKinley, Sandoval, Bernalillo, Santa Fe, San Miguel, Torrance, Socorro, and Valencia (Figure B-4).

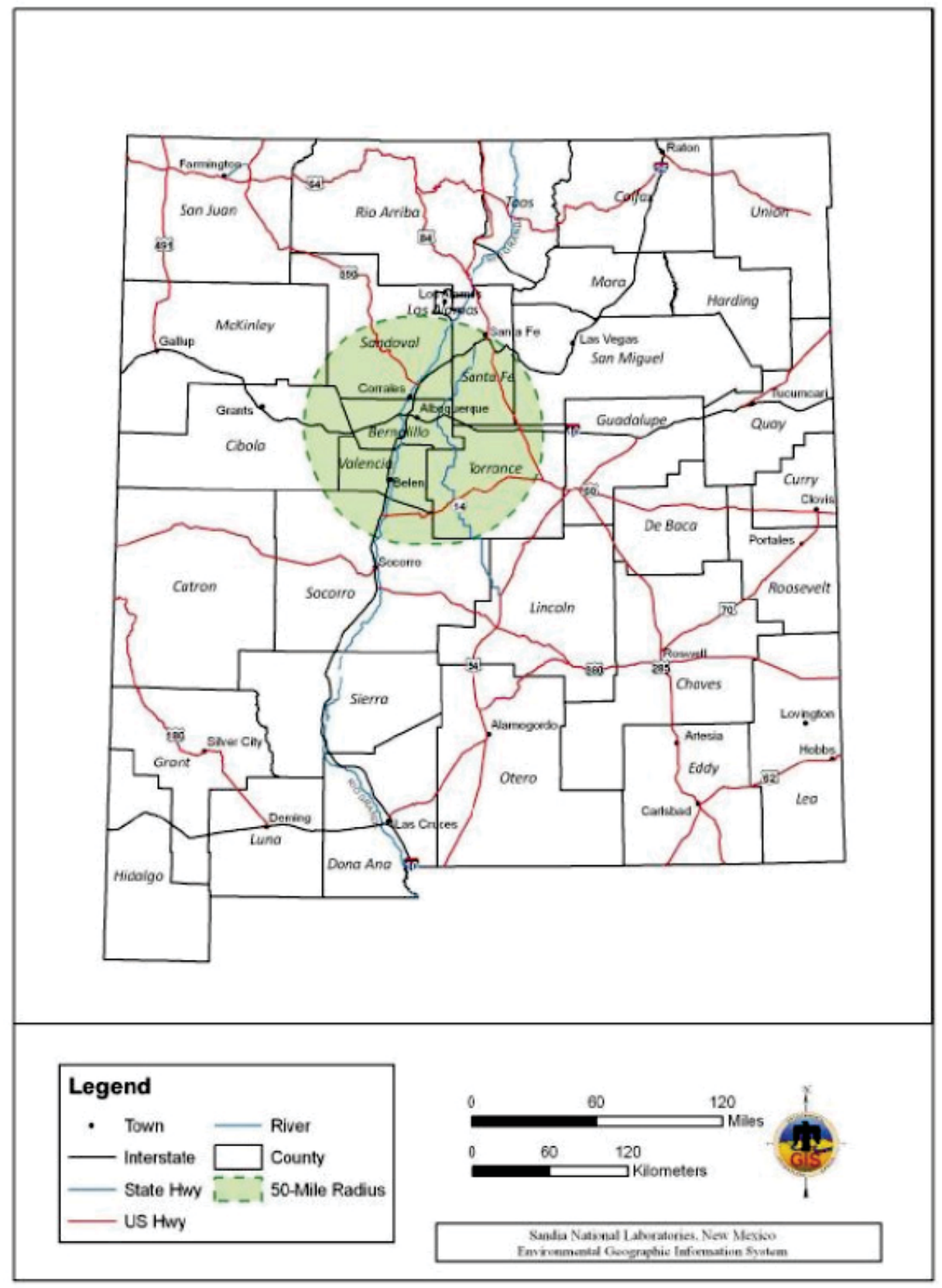

Figure B-4. State of New Mexico Map showing major roads, cities, and county lines. The dashed circle encompasses a 50-mile radius from SNL/NM facilities. 


\section{B-2.4 Regional and Local Land Use}

KAFB is an Air Force Materiel Command Base southeast of Albuquerque, New Mexico. KAFB shares facilities and infrastructure with several associates, including DOE and its affiliates (e.g., SNL/NM). Although the area within the boundaries of KAFB is federally owned, ownership and administrative responsibilities of the area and adjacent land are complex. KAFB shares facilities and infrastructure with several associates, including DOE. It is comprised of approximately 51,560 acres of land, including portions of Cibola National Forest withdrawn in cooperation with the U.S. Forest Service. It is geographically bounded by the Pueblo of Isleta to the south, the Albuquerque International Sunport (airport) and lands held in trust by the state of New Mexico to the west, and the city of Albuquerque to the north. The eastern boundary lies within the Manzanita Mountains (Figure B-5). The western portion of KAFB contains both DOE land and U.S. Air Force land, with areas permitted for DOE/Sandia use.

SNL/NM is comprised of TAs I through V on DOE land, numerous facilities on Department of Defense-owned/DOE-leased land, and several facilities off KAFB on non-government-owned lands (see Figure 5) (SNL/NM 2012).

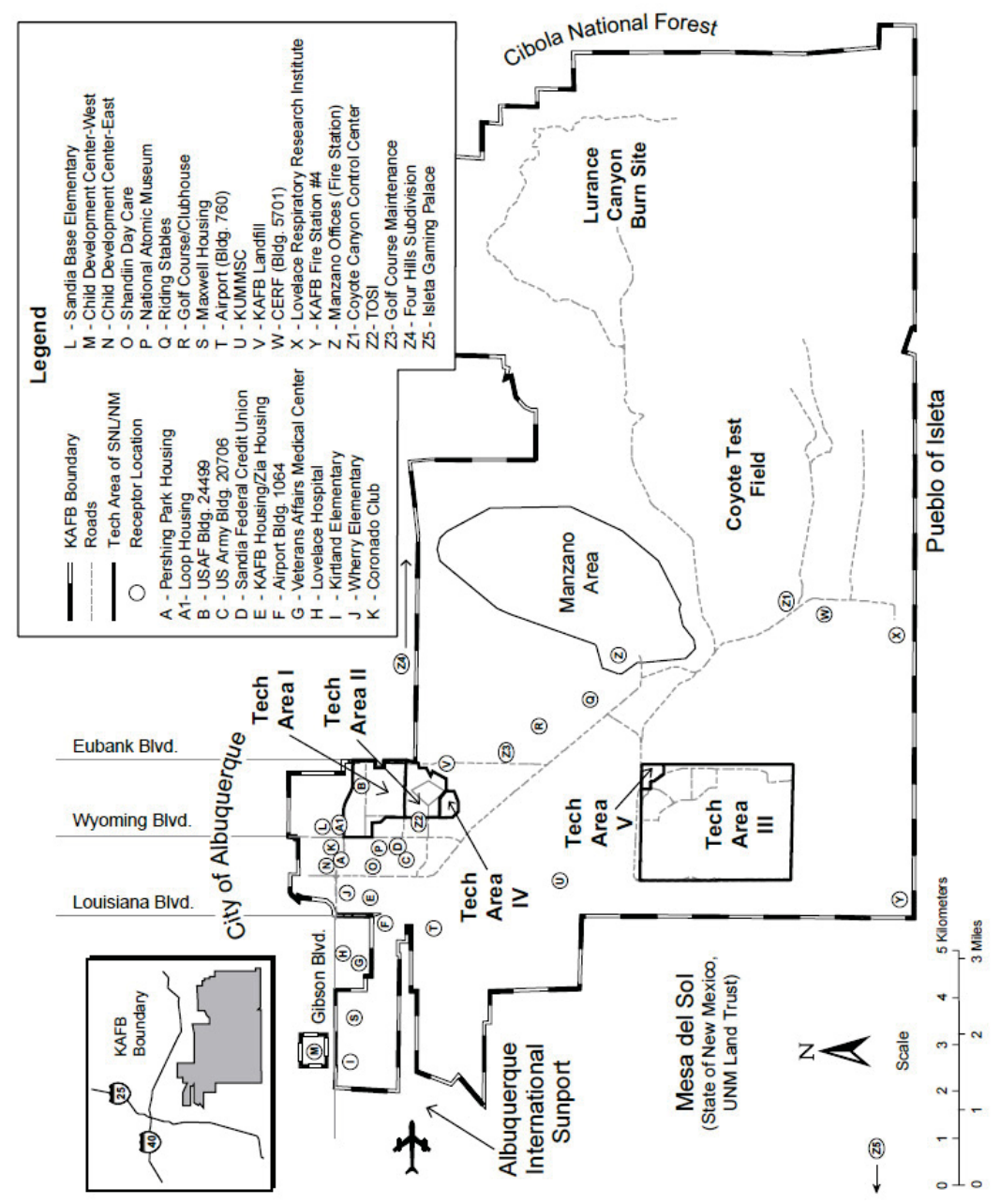

Source: SNLNM 1996u

Figure B-5. Normal operational onsite and core receptor locations (from DOE 1999). 


\section{B-2.5 Transportation}

The general road network leading to KAFB includes Interstates 25 and 40 shown in Figure B-4. Interstate 25 runs north-south and is approximately 1.5 miles west of the KAFB boundary at its nearest point. Interstate 40 runs east-west through Albuquerque and is approximately 1 mile north of the KAFB boundary at its nearest point.

Access to KAFB and SNL/NM consists of an urban road network maintained by the city of Albuquerque, the gates and roadways of KAFB, and SNL/NM-maintained roads (Figure B-6). Traffic enters SNL/NM through three principal gates: Wyoming, Gibson, and Eubank. Most commercial traffic enters through the Eubank gate, because it provides direct access to the SNL/NM shipping and receiving facilities located in TA-II. An additional entrance to KAFB (i.e., the Truman gate) serves KAFB's western areas.

SNL/NM maintains approximately 20 miles of paved roads, 25 miles of unpaved roads, approximately 80 acres of paved service areas, and approximately 80 acres of paved parking (SNL/NM 1997). The roads near SNL/NM experience heavy traffic in the early morning and late afternoon. The principal contributors are SNL/NM staff and other civilian and military personnel commuting to and from KAFB. SNL/NM and DOE commuters represent approximately $36 \%$ of commuter traffic at KAFB (SNL/NM 1997).

Rail facilities are not available at KAFB. Primary air service is provided for the entire region by the Albuquerque International Sunport, which is located immediately northwest of KAFB. Runways and other flight facilities are shared with KAFB.

\section{B-2.6 Meteorology and Climatology}

The climate at SNL/NM and in the surrounding region is semiarid. The ambient temperatures in the region are characteristic of high-altitude, dry continental climates. Winter daytime temperatures average approximately $50^{\circ} \mathrm{F}$, with nighttime temperatures often dropping into the low teens. Summer daytime temperatures generally do not exceed $90^{\circ} \mathrm{F}$, except in July, when average maximum temperatures reach $93^{\circ} \mathrm{F}$. The Albuquerque basin is characterized by low precipitation, averaging between 7.5 and $10 \mathrm{in}$. a year. Most of this precipitation falls from July through September and usually occurs from thunderstorm activities and the intrusion of warm, moist tropical air from the Pacific Ocean. The storms are accompanied by localized heavy wind gusts. Winter months are typically dry, with less than 2 in. of precipitation and limited snowfall. The average annual relative humidity is about $43 \%$. New Mexico has one of the greatest frequencies of lightning in the United States. Tornadoes are uncommon in the Albuquerque basin (SNL/NM 1997).

Temperature, relative humidity, and precipitation do not vary dramatically across the region. Daily and seasonal wind patterns occur near the mountains and plateau. Daytime upslope flows are usually coupled with downslope flows during the night. Strong springtime, easterly winds occur near canyons and light north-south flows occur in the Rio Grande valley. In general, areas closer to the mountains or canyons experience more frequent winds from an easterly direction at night. Daytime wind patterns are not as pronounced, but generally flow toward the mountains or along the Rio Grande valley. The Rio Grande valley experiences the most frequent calm conditions and the lowest average wind speed. In most areas, the nighttime wind direction frequency produces the most dominant average annual direction. 


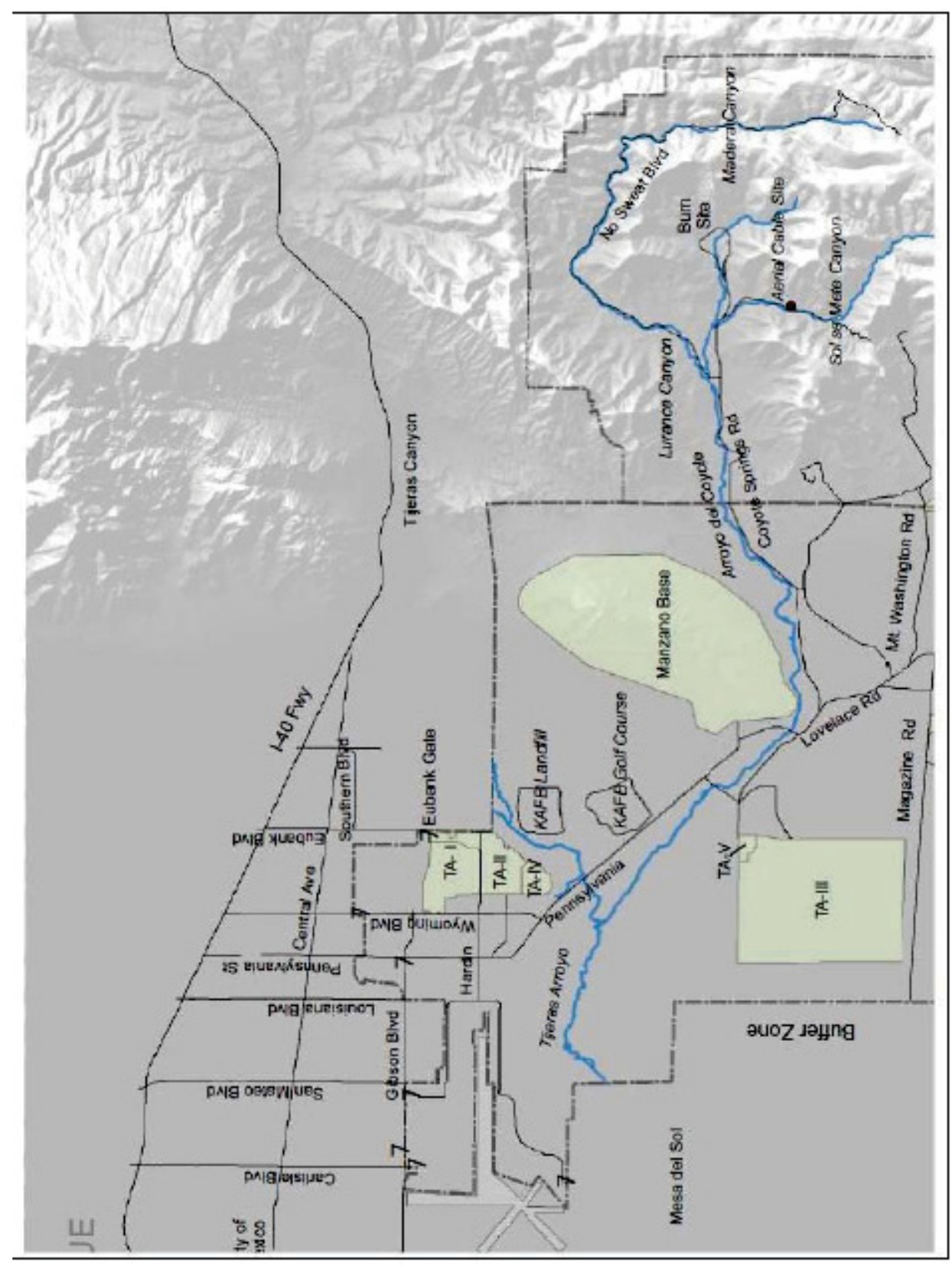

Figure B-6. Road access to SNL/NM Technical Areas and the U.S. Forest Service Land withdrawn area.

\section{B-2.7 Wind and Ambient Air Quality}

Annual wind roses for daytime and nighttime for the tower nearest ACRR are provided in Figure B-7. The wind roses show the variation in wind speed and direction frequency distribution.

SNL/NM is in the Albuquerque Middle Rio Grande Intrastate Air Quality Control Region, which is referred to as Region 152 (SNL 2011). EPA has classified Air Quality Control Region 152 as follows in Title 40 CFR Section 81.332 (SNL/NM 2011):

- $\quad$ Sulfur dioxides - better than national standards

- Ozone - unclassifiable/attainment 
- Total suspended particulate matter - not meeting the primary standards or better than national standards

- Nitrogen dioxide - cannot be classified or better than national standards

- Carbon monoxide - unclassifiable/attainment

- $\quad$ Lead - not designated.

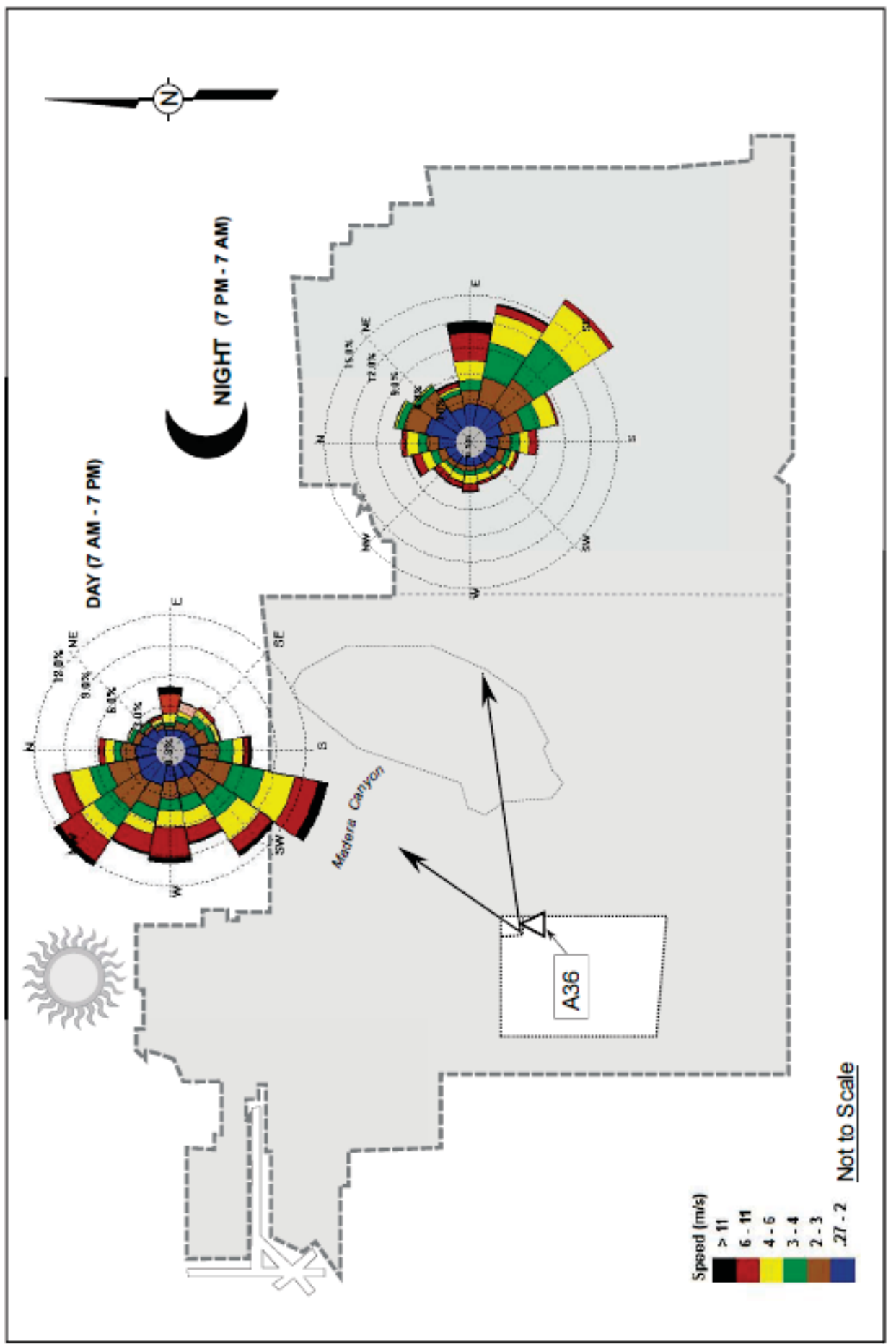

Figure B-7. 2011 annual wind roses for daytime and nighttime wind frequency at the A36 tower. 


\section{B-2.8 Hydrology}

Groundwater in the KAFB area occurs within saturated unconsolidated geologic material and fractured and porous bedrock. Aquifers are subsurface layers of rock or unconsolidated material that are capable of yielding usable amounts of water to wells or springs.

The groundwater beneath the western portion of KAFB is part of an interconnected series of water-bearing geologic units within the Albuquerque Basin that form the Albuquerque-Belen Basin aquifer. Groundwater beneath the eastern portion of KAFB occurs in limited quantities in fractured bedrock.

The principal sedimentary fill of the Albuquerque-Belen Basin is the Santa Fe Group, consisting of gravels, sands, silts, and clays. The local (SNL/NM area) groundwater system has three hydrogeologic regions, which are delineated by their locations in relation to the geologic fault system that bisects KAFB.

The hydrologic region where the SNL/NM TAs are located is to the west of the fault system. It consists of thick unconsolidated sedimentary deposits overlying bedrock. The Albuquerque-Belen Basin aquifer occurs in this unit of unconsolidated sediment and is the source of Albuquerque's municipal water. Groundwater flow generally is north to northwest in the northwestern portion of KAFB, where TAs-I, II, and IV are located. Hydraulic conductivities range from less than $0.1 \mathrm{ft}$ to more than $100 \mathrm{ft}$ per day. The depth of the unsaturated zone, from ground surface to the aquifer, increases toward the west and is approximately $500 \mathrm{ft}$ at the western edge of KAFB.

\section{B-2.9 Flood Potential}

The surface water system on KAFB is a reflection of the dry high-desert climate of the area. Surface water flows through several major and many small unnamed arroyos (Figure B-5), primarily during summer thunderstorms (July through September). With the exception of flow from two springs, there are no perennial streams or other surface water bodies at KAFB.

The major surface drainages at SNL/NM are Tijeras Arroyo and Arroyo del Coyote (Figure B-8). With the exception of two short sections of channel with intermittent flow (fed by springs), these drainages flow only during storm events.

Tijeras Arroyo is the primary drainage feature on KAFB. Above the point where Tijeras Arroyo enters KAFB, it drains approximately $80 \mathrm{mi}^{2}$; at the point where it exits, the drainage area encompasses approximately $122 \mathrm{mi}^{2}$. Tijeras Arroyo is the only substantial outlet for surface water exiting KAFB; this arroyo joins the Rio Grande 4.7 miles downstream of the KAFB boundary.

Arroyo del Coyote joins Tijeras Arroyo approximately 2 miles upstream of where Tijeras Arroyo leaves KAFB and drains approximately $39 \mathrm{mi}^{2}$.

Several unnamed arroyos and drainages to the south of Arroyo del Coyote dissipate as the topographic relief decreases to the west. Storm water in this area either evaporates or infiltrates into the soil; therefore, there is no hydrologic surface connection from these areas to Tijeras Arroyo or the Rio Grande. 


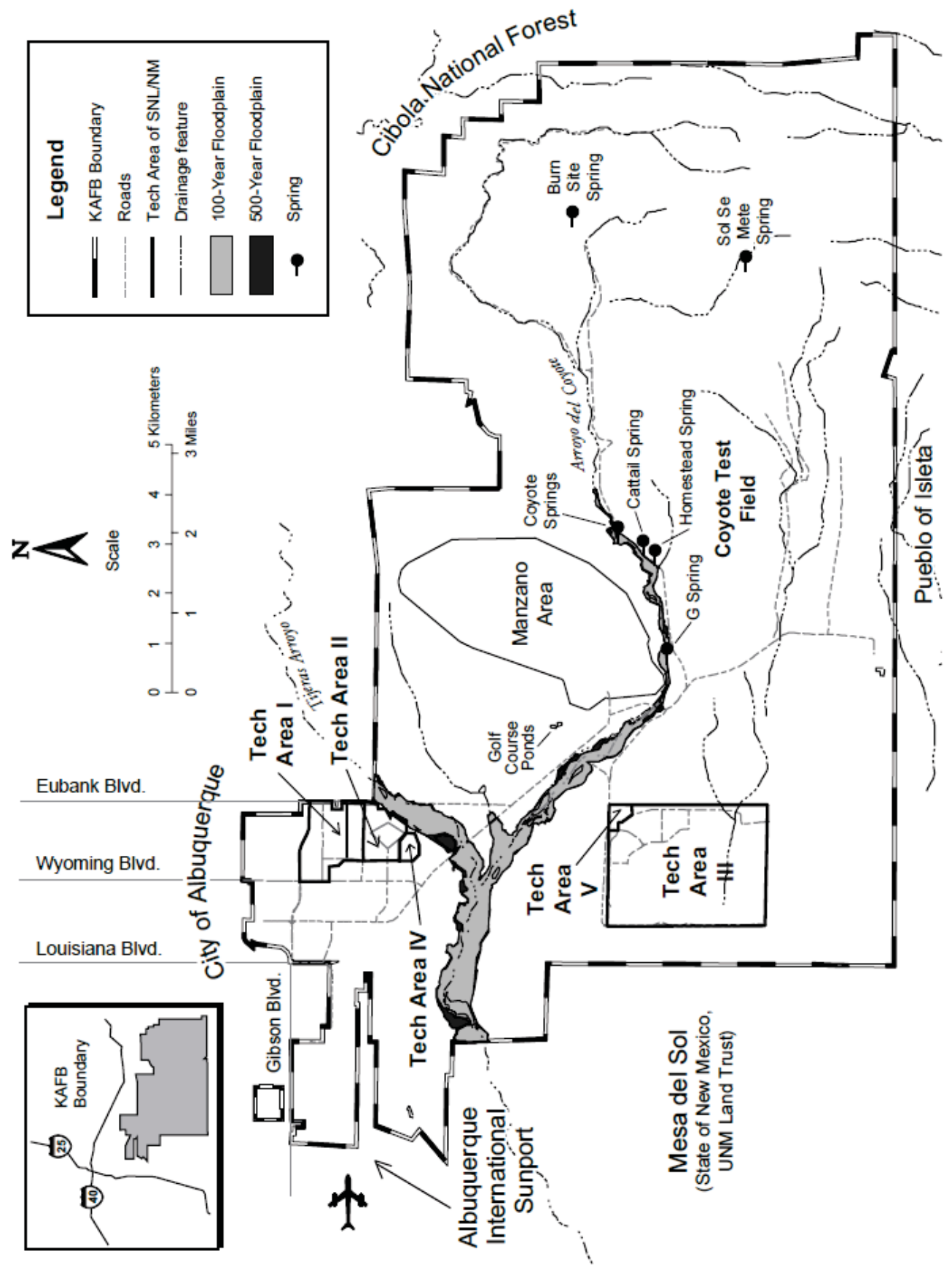

Source: SNLNM 1997]

Figure B-8. Arroyos, floodplains, and springs at Kirtland Air Force Base (from SNL-SWEIS 1999).

\section{B-3. REFERENCES}

DOE, 1999, Final Site-Wide Environmental Impact Statement for Sandia National Laboratories/New Mexico, DOE/EIS-0281. U.S. Department of Energy, Albuquerque Operations Office, Albuquerque, NM, October.

DOE, 2006, Final Supplement Analysis for the Final Site-Wide Environmental Impact Statement for Sandia National Laboratories/New Mexico, Albuquerque, New Mexico, DOE/EIS-0281-SA-04. 
U.S. Department of Energy, National Nuclear Security Administration, Sandia Site Office, Albuquerque, NM, August.

SNL/NM, 1997, Environmental Information Document, SANDXX-XXX, II, Sandia National Laboratories, Albuquerque, New Mexico.

SNL/NM, 2011, Operational Area Environmental Evaluations, SAND2011-6097, Sandia National Laboratories, Albuquerque, New Mexico.

SNL/NM, 2012, Calendar Year 2011 Annual Site Environmental Report for Sandia National Laboratories, New Mexico, SAND2012-7340P, Sandia National Laboratories, Albuquerque, New Mexico. 


\title{
Appendix C
}

\section{Evaluation of the Air and Soil Pathway Doses During Normal Operations}

\author{
Primary Contributors \\ A. Jeffrey Sondrup, Idaho National Laboratory \\ Mark L. Miller, Sandia National Laboratory \\ Annette L. Schafer, Idaho National Laboratory
}




$$
\text { C-2 }
$$




\section{CONTENTS}

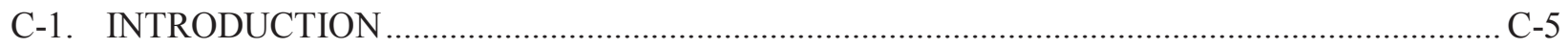

C-2. MODEL OVERVIEW AND RECEPTOR LOCATIONS …........................................................ C-5

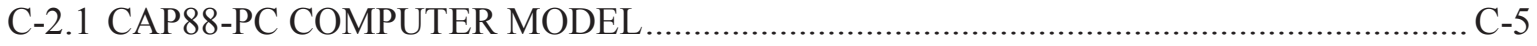

C-2.2 SELECTION OF RECEPTOR LOCATIONS ….............................................................

C-3. AIR PATHWAY ASSESSEMENT FOR THE TRANSIENT REACTOR TEST

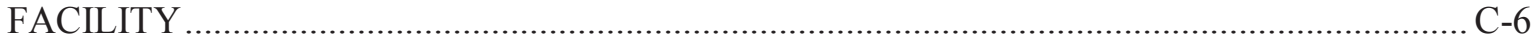

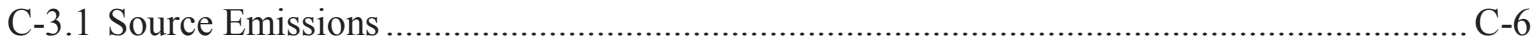

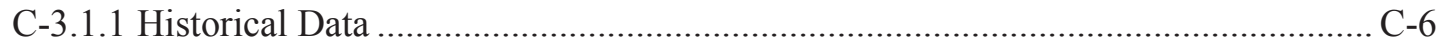

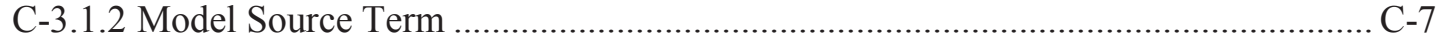

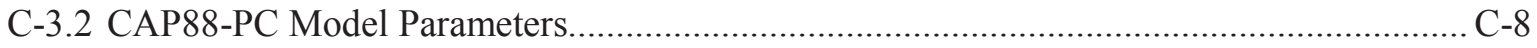

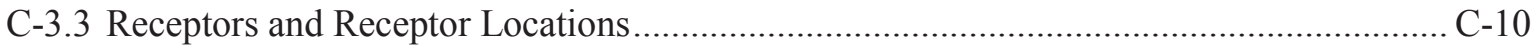

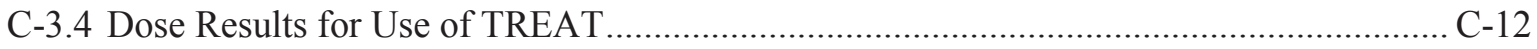

C-3.5 Documentation of the CAP-88 Parameters .................................................................

C-4. SOIL PATHWAY ASSESSEMENT FOR THE TRANSIENT REACTOR TEST

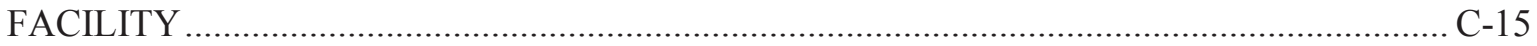

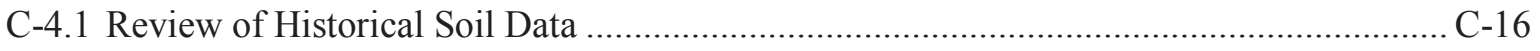

C-4.2 Projected Particulate Radionuclide Releases ................................................................ C-17

C-5. AIR PATHWAY ASSESSEMENT USING THE ANNULAR CORE RESEARCH

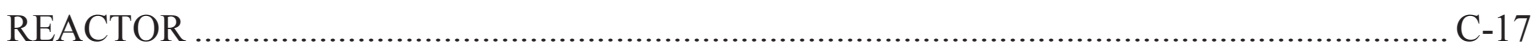

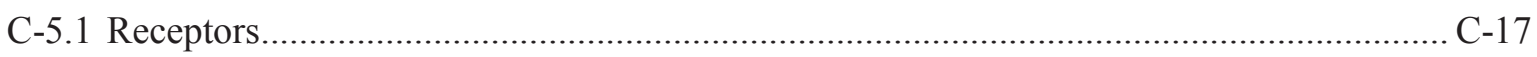

C-5.2 Source Emissions for Use of the Annual Core Research Reactor.................................... C-17

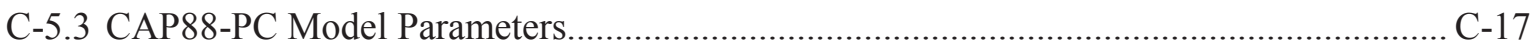

C-5.4 Dose Results for Use of the Annular Core Research Reactor ........................................ C-19

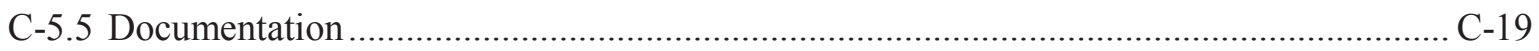

C-6. SOIL PATHWAY ASSESSEMENT USING THE ANNULAR CORE RESEARCH

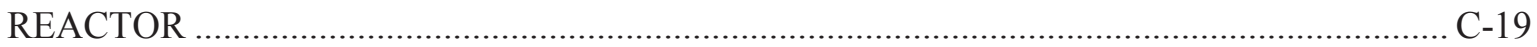

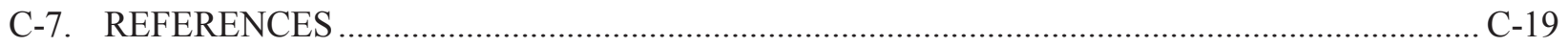




\section{Appendix C \\ Evaluation of the Air and Soil Pathway Doses During Normal Operations}

\section{C-1. INTRODUCTION}

This appendix documents an assessment of releases (emissions) of gaseous and particulate radionuclides from the TREAT Reactor stack at MFC and ACRR, which is located in TA-V at SNL/NM, during presumed normal operations. The analyses include an evaluation of the potential release and transport of gas-phase radionuclides from the TREAT and ACRR reactor stacks to actual and hypothetical receptor locations via the air pathway and compares predictions of effective dose equivalent (ED) to the EPA regulatory limit of 10 mrem/year for the public (40 CFR 61, Subpart H). Releases were estimated from a combination of actual measurements, modeling, and the history of reactor operations. Atmospheric transport and dose calculations were performed using the EPA-approved computer code CAP88-PC (EPA 2007) for both alternatives at public receptor and worker locations as discussed in the following sections.

\section{C-2. MODEL OVERVIEW AND RECEPTOR LOCATIONS}

\section{C-2.1 CAP88-PC COMPUTER MODEL}

The CAP88-PC computer model (EPA 2007) is a set of computer programs, databases, and associated utility programs for estimation of dose and risk from radionuclide emissions to air. CAP88-PC is composed of modified versions of AIRDOS-EPA (Mo79) and DARTAB (ORNL5692). The latest version (Version 3) of CAP88-PC was used for all dose calculations. CAP88-PC is a mature model required by EPA for demonstration of compliance with "National Emission Standards for Emissions of Radionuclides Other Than Radon from Department of Energy Facilities (NESHAPS)" (40 CFR 61, Subpart H). EPA has made comparisons between CAP88-PC predictions of annual, average, ground-level concentration to actual environmental measurements and found very good agreement. This and additional information about CAP88-PC is located at: http://www.epa.gov/radiation/assessment/CAP88/aboutcap88.html.

\section{C-2.2 SELECTION OF RECEPTOR LOCATIONS}

For the alternative where the RTT Program would use the TREAT Reactor, EDs were calculated for three potential public receptor locations and for one worker location. For the alternative using ACRR, EDs were calculated for three public receptor locations. The locations for both alternatives were selected in order to meet the requirements of 40 CFR 61, Subpart $\mathrm{H}$, in addition to allowing comparison of emissions consequences between alternatives.

Federal regulation 40 CFR 61, Subpart H requires determination of the ED for a "maximally exposed individual" (MEI). This federal regulation defines the MEI to mean any member of the public (real or hypothetical) who abides or resides in an unrestricted area and may receive the highest ED from the emission unit(s) under consideration, taking into account all exposure pathways affected by the radioactive air emissions. To determine the location of the MEI, the ED is calculated at any potential public receptor location. The public receptor location corresponding to the highest predicted dose is denoted the MEI dose. To meet the annual reporting requirements of NESHAPS, INL has historically calculated the cumulative dose from all sitewide radiological air emissions; therefore, the INL-wide MEI location is known. Similarly, the MEI locations are known for releases at SNL/NM based on historical NESHAPS evaluations. Cumulative MEI doses are required to be less than $10 \mathrm{mrem} / \mathrm{year}$. 


\section{C-3. AIR PATHWAY ASSESSEMENT FOR THE TRANSIENT REACTOR TEST FACILITY}

The air pathway was assessed following the guidance for performing environmental compliance-driven air modeling of emissions from INL facilities (Staley et al. 2004). The source term, parameters, and receptor locations used in the calculation of ED for TREAT are discussed in the following sections.

\section{C-3.1 Source Emissions}

\section{C-3.1.1 Historical Data}

The annual radioactive nuclide emissions from the TREAT stack were reported in an intra-laboratory memo (ANL memo 1992), based on a total annual energy release of 350,000 MJ (Mw-s). The average annual energy release over 32 years of TREAT operation and 20 tests per year is under 82,000 MJ; therefore, the values provided were conservative by about a factor of 4 . If 34 tests per year are conducted (Table 1), the value provided should still be conservative by a factor of 2 .

The radioactive emissions released from the TREAT stack are the result of activation of naturally occurring Ar-40 present in the cooling air and fission of the uranium impurity in the Zircaloy cladding of the TREAT Reactor fuel (ANL memo 1992). Fission products included in Table C-1 can be produced directly by fissioning or indirectly from decay of parent fission products. These decay products are indicated as progeny. Also as indicated in Table C-1, some of the krypton and xenon isotope decay products include both solids (particulates) formed from parent gasses. For example, from http://periodictable.com/Isotopes/054.140/index2.dm.html, the following decay chains are represented:

$$
\begin{aligned}
& \mathrm{Kr}-88 \text { (gas) } \rightarrow \text { Rb-88 (solid) } \\
& \text { Xe-140 (gas) } \rightarrow \text { Cs-140 (solid) } \rightarrow \text { Ba-140 (solid) } \rightarrow \text { La-140 (solid) }
\end{aligned}
$$

\begin{tabular}{|c|c|c|c|c|c|c|}
\hline \multirow{2}{*}{$\begin{array}{l}\text { Parent } \\
\text { Isotope }\end{array}$} & \multirow{2}{*}{$\begin{array}{c}\text { Parent } \\
\text { Half-Life }\end{array}$} & \multirow{2}{*}{\multicolumn{2}{|c|}{$\begin{array}{l}\text { Progeny } \\
\text { Half-Life }\end{array}$}} & \multirow[b]{2}{*}{ Parent Phase } & \multicolumn{2}{|c|}{ Annual Activity ${ }^{\mathrm{c}}(\mathrm{Ci})$} \\
\hline & & & & & $6,000 \mathrm{cfm}^{\mathrm{c}}$ & $3,000 \mathrm{cfm}^{\mathrm{cc}}$ \\
\hline Ar-41 & $1.82 \mathrm{~h}$ & & & Gas & 350. & 350 \\
\hline $\mathrm{Kr}-85 \mathrm{~m}$ & $4.48 \mathrm{~h}$ & $\mathrm{Kr}-85$ & $10.73 \mathrm{yr}$ & Gas & 1.40 & 1.40 \\
\hline $\mathrm{Kr}-87$ & $1.27 \mathrm{~h}$ & $\mathrm{Rb}-87$ & $4.8 \mathrm{E}+10 \mathrm{yr}$ & Gas & 8.00 & 8.00 \\
\hline $\mathrm{Kr}-88$ & $2.84 \mathrm{~h}$ & $\mathrm{Rb}-88$ & $17.7 \mathrm{~m}$ & Gas & 5.60 & 5.60 \\
\hline $\mathrm{Rb}-88$ & $17.7 \mathrm{~m}$ & & & Solid & 0.03 & 0.05 \\
\hline Xe-133 & $5.24 \mathrm{~d}$ & & & Gas & 0.70 & 0.70 \\
\hline Xe-135 & $9.1 \mathrm{~h}$ & Cs-135 & $2.3 \mathrm{E}+06 \mathrm{yr}$ & Gas & 1.40 & 1.40 \\
\hline Xe- $140^{\mathrm{a}}$ & $13.6 \mathrm{~s}$ & Cs-140 & $1.06 \mathrm{~m}$ & Gas & 2375. & 1,163 \\
\hline Cs- $140^{\mathrm{a}}$ & $1.06 \mathrm{~m}$ & Ba- $-140^{\mathrm{b}}$ & $12.75 \mathrm{~d}$ & Solid & 1028. & 1,120 \\
\hline Ba-140 & $12.75 \mathrm{~d}$ & $\mathrm{La}-140^{\mathrm{b}}$ & $1.68 \mathrm{~d}$ & Solid & 0.01 & 0.02 \\
\hline La-140 & $1.68 \mathrm{~d}$ & & & Solid & $6 \mathrm{E}-07$ & $2 \mathrm{E}-06$ \\
\hline
\end{tabular}

Table C-1. Radionuclide emissions at the top of the TREAT stack for two air flow rates. 
The emission rates for the dominant isotopes Ar-41, Xe-133, Xe-135, and Kr-88 provided by the memo are representative values based on a significant number of actual measurements. The emission rates of these four isotopes provided the basis for the reported rates of the remaining isotopes. The emission rates for $\mathrm{Kr}-85 \mathrm{~m}, \mathrm{Kr}-87 \mathrm{~m}, \mathrm{Rb}-88$, Xe-140, Cs-140, Ba-140, and La-140 were determined through a series of calculations performed using the computer code, ORIGEN, to simulate the irradiation of the uranium impurities in the Zircaloy cladding of the TREAT Reactor fuel. ORIGEN is a standard point-depletion code that is widely used to compute isotopic buildup and depletion as a result of irradiation and subsequent radioactive decay.

To determine the emissions rates for the non-measured isotopes, ORIGEN simulation parameters, including the power history and the quantity of uranium, were adjusted until the ratio of Ar- 41 to $\mathrm{Kr}-88$ emissions rates approximated the reported observed values. Emission rates for the remaining isotopes were generated by applying the calculated ratio of emission rates to the observed value of $\mathrm{Kr}-88$.

During calibration, an irradiation time of 1 second was used in the ORIGEN calculations. The time required to reach the top of the TREAT stack (i.e., the point of emission) is approximately 14 seconds at a flow rate of $6,000 \mathrm{cfm}$ and 28 seconds at a flow rate of 3,000 $\mathrm{cfm}$. The resulting radionuclide emissions rates at the top of the TREAT stack for these two flow rates are shown in Table C-1.

As indicated by the half-life of the isotopes shown in Table $\mathrm{C}-1$, the composition of the stack emissions should change rapidly as they leave the TREAT stack. The memo notes that the historical practice of estimating the Ba-140 and La-140 stack emissions based on the iso-kinetic filter inventory would not provide a clear representation of the actual stack emissions. As noted previously, the $\mathrm{Ba} / \mathrm{La}-140$ ratio, which had been routinely detected on the iso-kinetic filters, is the result of the direct fission product Xe-140 (13.6 s half life) decaying to Cs-140, which is then trapped by the filter. The Cs-140 (63.7s half life) then decays to Ba-140 (12.8 day half life), which in turn decays to La-140. The Cs-140 produced upstream of the HEPA filters would likely be retained in the HEPA filters. Therefore, the $\mathrm{Ba} / \mathrm{La}-140$ activity on the iso-kinetic filters would be the result of the Cs-140 produced between the second HEPA filter and the iso-kinetic filter. The fraction of the total Xe-140 that would decay during this time is small. Because the iso-kinetic filters were historically counted on a monthly basis and the half life of the Ba-140 is 12.8 days, the activity level would be highly dependent on the reactor operating history for the month. Therefore, it was recommended in the memo that the radioactive nuclide emissions resulting from the direct fission product Xe-140 be based on the reactor operating history and not the $\mathrm{Ba} / \mathrm{La}-140$ activity present on the iso-kinetic filters.

\section{C-3.1.2 Model Source Term}

Simulations for the emissions reported in Table C-1 were performed using the source term corresponding to the highest flow rate $(6,000 \mathrm{cfm})$. After viewing the dose results (see Section C-3.4) it was determined that additional modeling using 3,000-cfm flow rate emissions was not warranted. This is because over $99 \%$ of the total dose is from the sum of the dose from $\mathrm{Ar}-41, \mathrm{Kr}-87$ and $\mathrm{Kr}-88$, and the emissions for these three radionuclides were the same for each flow rate.

The emission rates for the non-gaseous radionuclides (i.e., Rb-88, Cs-140, Ba-140, and La-140) were included unabated in the CAP88-PC simulations, with the exception of Cs-140, which was not modeled. The emissions rates for these radionuclides were based on reactor operating history (power). Their activity was not assumed to be reduced by the isokinetic filter, which is downstream from the two HEPA filters. It is likely that these radionuclides would be captured by the HEPA filters and their presence beyond the HEPA filters would be the result of decay of the appropriate parent nuclides (i.e., $\mathrm{Kr}-88$ for Rb-88 and Xe-140 for Cs-140, Ba-140, and La-140). Ba-140 and La-140 were included explicitly in the ST because neither of the two parent nuclides Xe-140 or Cs-140 (excluded from the CAP88-PC database because of short half-life) were included in the simulations. 


\section{C-3.2CAP88-PC Model Parameters}

\section{Facility Parameters}

Gaseous radionuclides released from TREAT exit through the exhaust stack parameterized with the following information:

- $\quad$ Stack height $=42.7 \mathrm{~m}(140 \mathrm{ft})$

- $\quad$ Stack diameter $=0.61 \mathrm{~m}(24 \mathrm{in}$.

- Stack exit velocity $=9.7 \mathrm{~m} / \mathrm{s}$ at 6,000-cfm flow rate, $4.9 \mathrm{~m} / \mathrm{s}$ at 3,000-cfm flow rate.

\section{Meteorological Parameters}

Climate data from meteorological stations at INL are available from the Idaho Falls National Oceanic and Atmospheric Administration Air Resources Laboratory. Ten-year averaged meteorological data (i.e., 1994 through 2003) is available for all INL mesonet stations in Staley (2008). The nearest station to TREAT is the EBR-II station located $1.72 \mathrm{~km}(1.07 \mathrm{mi})$ east-southeast of TREAT (see Figure C-2). The EBR-II station monitors conditions at elevations of $10 \mathrm{~m}$ and $80 \mathrm{~m}$. Although the height of the TREAT Reactor stack $(42.7 \mathrm{~m})$ is nearly in the middle of the two EBR-II station monitoring levels, data from the lower level $(10 \mathrm{~m})$ was used because its use is more conservative (will predict higher doses). The stability array file for the EBR-II lower level (EBRL9403.STR) provided by the National Ocean Atmospheric Administration was input to the WINDGET.EXE program supplied with CAP88-PC to generate the wind file, EBRL9403.WND, used by CAP88-PC. These files are provided in INL (2013).

Other INL Site-specific meteorological parameters shown as follows were obtained from the 2011 INL NESHAPs report (DOE-ID 2012) and represent 10-year average values:

- Annual mean temperature $(280.2 \mathrm{~K})$

- Annual mean precipitation $(20.8 \mathrm{~cm} /$ year $)$

- Absolute humidity $\left(3.54 \mathrm{~g} / \mathrm{m}^{3}\right)$

- Annual mean mixing depth $(800 \mathrm{~m})$.

\section{Agricultural Parameters}

The local food production option was selected to simulate a subsistence farming scenario for the public receptors. This scenario used the CAP88-PC default parameters (EPA 2007) shown in Table C-2.

Table C-2. Radionuclide independent parameters for the rural receptor.

\begin{tabular}{lrr} 
& \multicolumn{1}{c}{ Parameter Description } & Units \\
\hline Inhalation rate & $9.17 \mathrm{E}+05$ & $\mathrm{~cm}^{3} / \mathrm{hour}$ \\
Effective surface density of soil (15-cm plow depth, dry weight) & 215 & $\mathrm{~kg} / \mathrm{m}^{2}$ \\
Build-up time for radionuclides in soil & 100 & year \\
Build-up time for radionuclides deposited on ground/water & 365 & day \\
Delay time, ingestion of pasture grass by animals & 0 & hour \\
Delay time, ingestion of stored feed by animals & 2160 & hour \\
Delay time, ingestion of leafy vegetables by man & 336 & hour \\
Delay time, ingestion of produce by man & 336 & hour \\
Delay time, transport time from animal feed-milk-man & 2 & day
\end{tabular}




\begin{tabular}{|c|c|c|}
\hline Parameter Description & Value & Units \\
\hline Delay time, from animal slaughter to consumption & 20 & day \\
\hline Removal rate constant for physical loss by weathering & $2.90 \mathrm{E}-03$ & $1 /$ hour \\
\hline Crop exposure duration, pasture grass & 720 & hour \\
\hline Crop exposure duration, crops, leafy vegetables & 1440 & hour \\
\hline Ag productivity, grass-cow-milk-man pathway & 0.28 & $\mathrm{~kg} / \mathrm{m}^{2}$ \\
\hline $\mathrm{Ag}$ productivity, produce/leafy vegetables for human consumption & 0.716 & $\mathrm{~kg} / \mathrm{m}^{2}$ \\
\hline Fallout interception fraction, vegetables & 0.2 & --- \\
\hline Fallout interception fraction, pasture & 0.57 & --- \\
\hline Fraction of year animals graze on pasture & 0.4 & --- \\
\hline Fraction of daily feed that is pasture grass (when animal on pasture) & 0.43 & --- \\
\hline Animal consumption rate of contaminated feed/forage (dry weight) & 15.6 & $\mathrm{~kg} / \mathrm{day}$ \\
\hline Milk production of cow & 11 & L/day \\
\hline Muscle mass of animal at slaughter & 200 & $\mathrm{~kg}$ \\
\hline Fraction of animal herd slaughtered per day & $3.81 \mathrm{E}-03$ & --- \\
\hline Fraction of radioactivity retained after washing (leafy vegetable and produce) & 0.5 & --- \\
\hline Fraction of produce ingested grown in garden & 1 & --- \\
\hline Fraction of leafy vegetables ingested grown in garden & 1 & --- \\
\hline Human produce ingestion & 176 & $\mathrm{~kg} /$ year \\
\hline Human milk ingestion & 112 & L/year \\
\hline Human meat ingestion & 85 & $\mathrm{~kg} /$ year \\
\hline Human vegetable ingestion & 18 & $\mathrm{~kg} /$ year \\
\hline Fraction of time spent swimming & 0 & --- \\
\hline Depth of water for dilution for water immersion doses & 1 & $\mathrm{~cm}$ \\
\hline Fraction vegetables home produced & $0.7^{\mathrm{a}}$ & --- \\
\hline Fraction milk home produced & $0.399^{\mathrm{a}}$ & --- \\
\hline Fraction meat home produced & $0.442^{\mathrm{a}}$ & --- \\
\hline Fraction vegetables from assessment area & $0.3^{\mathrm{a}}$ & --- \\
\hline Fraction meat from assessment area & $0.601^{\mathrm{a}}$ & --- \\
\hline Fraction meat from assessment area & $0.558^{\mathrm{a}}$ & --- \\
\hline Minimum ingestion fractions from outside area, vegetables & $0^{\mathrm{a}}$ & --- \\
\hline Minimum ingestion fractions from outside area, meat & $0^{\mathrm{a}}$ & --- \\
\hline Minimum ingestion fractions from outside area, milk & $0^{\mathrm{a}}$ & --- \\
\hline Default beef cattle density & $7.19 \mathrm{E}-02^{\mathrm{a}}$ & $\# / \mathrm{km}^{2}$ \\
\hline Milk cattle density & $8.56 \mathrm{E}-03^{\mathrm{a}}$ & $\# / \mathrm{km}^{2}$ \\
\hline Land fraction cultivated for vegetables & $7.15 \mathrm{E}-02^{\mathrm{a}}$ & --- \\
\hline
\end{tabular}




\section{C-3.3 Receptors and Receptor Locations}

Doses were calculated at three potential public receptor locations and two worker locations. The three potential public receptor locations are located off the INL Site (see Figure C-1) as follows:

1. Frenchman's Cabin. This location has been the MEI for the annual INL NESHAPs assessment since 1995 (DOE-ID 2012). It is the MEI location for cumulative radiologic air emissions resulting from all INL sources. Highest doses are predicted at this location because it is aligned with the predominant nocturnal air movement (from north-northeast) passing by most major INL facilities. This location is a hypothetical receptor location because there are no permanent residents at Frenchman's Cabin, which is located just south of the southern boundary, $36.75 \mathrm{~km}$ west-southwest of TREAT. If Alternative 1 (TREAT) is selected, the INL-wide MEI location will remain at Frenchman's Cabin as shown by the analysis for TREAT because of the relatively low emissions from TREAT compared to other INL sources.

2. Atomic City. Permanent residents outside the INL boundary will receive the highest public receptor dose at this location from operations at TREAT. Atomic City is $20.85 \mathrm{~km}$ south-southwest of the TREAT facility; therefore, the predominant transport path is parallel to that for the MEI location at Frenchman's Cabin. There is a closer permanent residence located $10 \mathrm{~km}$ southeast of TREAT and $3 \mathrm{~km}$ south of Highway 20, but it is not aligned with the predominant nocturnal wind direction. Doses at this location would be lower than those predicted for the third location evaluated (see next).

3. Nearest INL boundary. Although there are no permanent residents at this location, it was included in the assessment for completeness. It is located $6.15 \mathrm{~km}$ south-southeast of TREAT, just north of U.S. Highway 20.

Worker dose was calculated at TREAT and at the TREAT Reactor control building (see Figure C-2) based on the following assumptions:

- Collocated workers at the TREAT Reactor control building. Workers at the TREAT Reactor control building could be stationed there full time or could be workers arriving from TREAT during a transient test. These workers would receive the dose from the gaseous and particulate emissions after the dispersion that would take place between TREAT and the TREAT Reactor control building. Doses for these workers will be computed using the entire source term.

- The resultant doses assume the collocated workers inhale suspended dust, are immersed in contaminated air, and are exposed to contaminated surfaces (e.g., soil and parking lot). An onsite worker would not be expected to ingest food products grown onsite and would be exposed for the time period represented by the actual hours at work. Therefore, the doses shown were reduced from the computed values by the time at work.

- Collocated workers at TREAT. TREAT is assumed to be occupied by workers during a normal work day. During transient testing, the TREAT workers are relocated to the TREAT Reactor control building or to buildings further away from TREAT. Workers stationed at TREAT would not be exposed to the gaseous emissions shown in Table C-1 during or shortly after transient testing. Instead, they would be exposed to the gases after they had migrated the separation distance between TREAT and the TREAT Reactor control building. However, workers stationed at TREAT would be exposed to the particulates generated by the gases.

The concentration of accumulated radionuclides near TREAT will be determined by where the particulate progeny are generated and where they are subsequently deposited on land surface. To determine where the particulates are generated, the residence time of the source air, or cooling air, in the TREAT stack was used. The residence time in the TREAT stack for air containing the parent radionuclides is about 14 and 28 seconds at $6,000 \mathrm{cfm}$ and 3,000 cfm, respectively. The gaseous parent radionuclides are $\mathrm{Kr}-88$ and $\mathrm{Cs}-140$. The half-life of $\mathrm{Kr}-88$ (2.84 h) is much larger than the 
residence time in the stack, suggesting that the bulk of the particulate $\mathrm{Rb}-88$ will be generated after Kr-88 exits the stack. Similarly, the half-life of Xe-140 (13.6 s) is three times longer than the air residence time in the stack, suggesting that although some Cs-140 could be generated prior to passing through the HEPA filter system, the bulk would be generated after Xe-140 gas exits the stack. Given the residence time in the stack, it is conservative to assume that no significant generation of particulates would occur prior to the gasses passing into the HEPA filters (i.e., it is conservative to assume all of the particulates are generated after the parent gases are released to the atmosphere).

Once released to the atmosphere, the gases will migrate away from the stack, where they will decay to produce the particulates that will be deposited on land surface. At low wind speed, it is likely that most of the progeny of Xe-140 will be deposited near the stack, while Rb-88 could be deposited further from the stack. Most of the particulate progeny of Xe-140 have half-lives and inventories sufficiently small enough that dispersion and decay would reduce the activity to insignificant levels between experiments at TREAT. This is based on the time-evolution of activity computed from an elapsed time $(t)$ after deposition and the half-life of each radionuclide $\left(\mathrm{t}_{1 / 2}\right)$ :

$\mathrm{A}(\mathrm{t})=\mathrm{A}_{0} * \mathrm{e}^{-\lambda \mathrm{t}}$ where $\lambda=\frac{\ln (2)}{t_{1 / 2}}$

where $A(t)$ is the activity at time $t, A_{0}$ is the initial activity, and $\lambda$ is the radioactive decay constant. Using Equation $\mathrm{C}-1$, the activity remaining for each of the particulate radionuclides is shown in Table C-3 for different time periods. The time periods shown are relevant for experiments conducted weekly (this is unlikely based on the expected number of experiments shown in Table 1 of this report), every 2 weeks, or every 3 weeks.

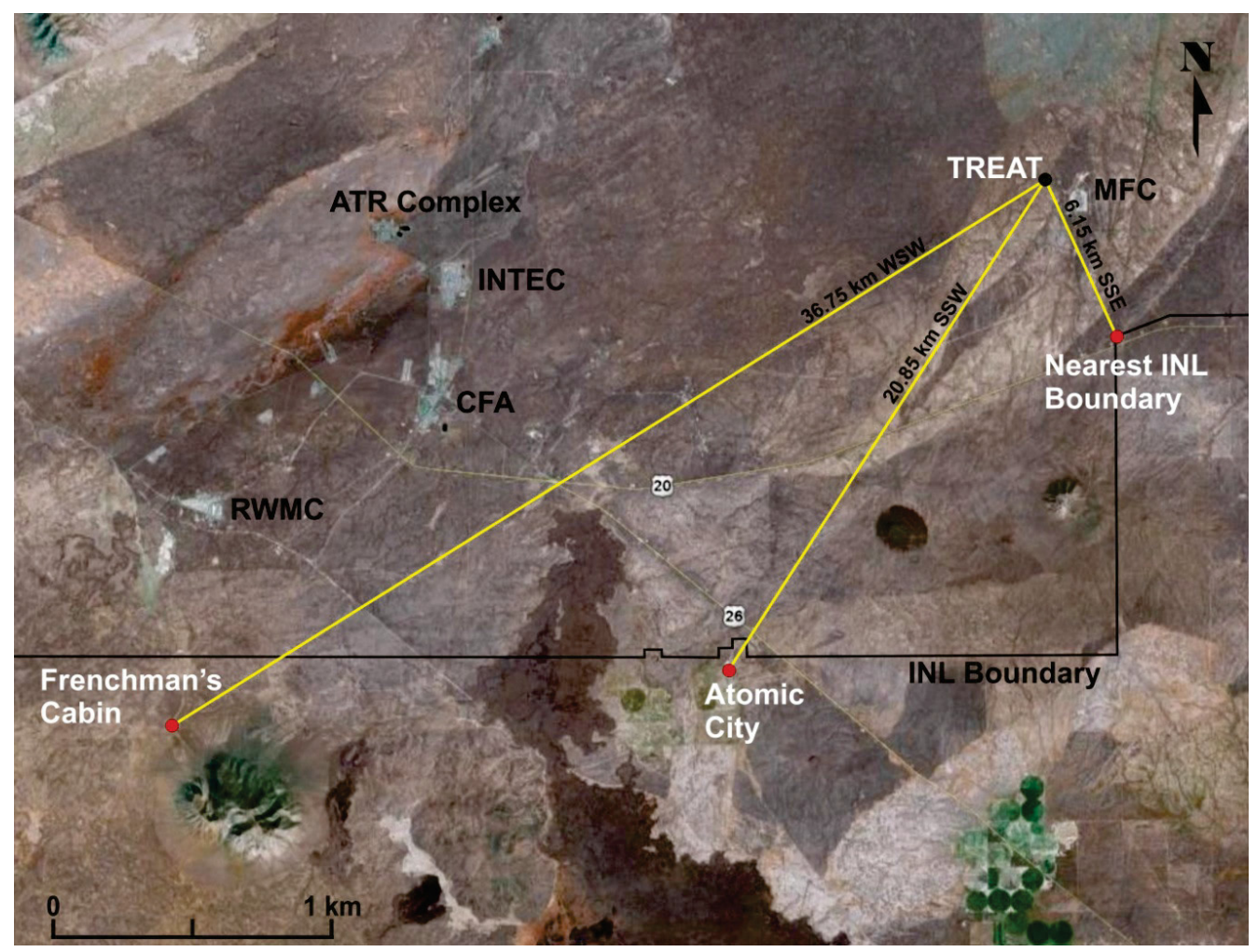

Figure $\mathrm{C}-1$. Public receptor locations for the air pathway analysis showing distance and direction from TREAT (base map courtesy of Google Earth). 


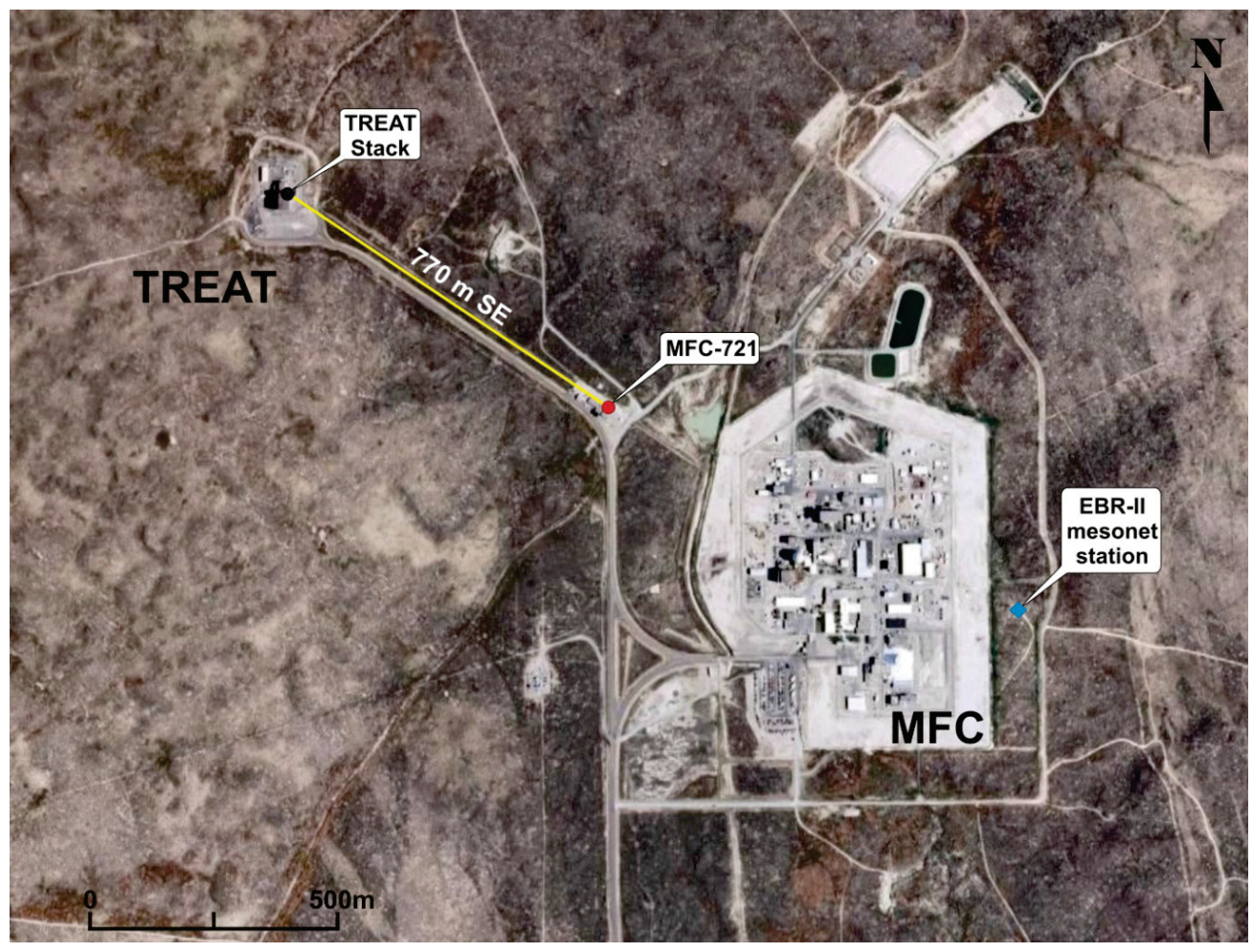

Figure C-2. Worker receptor location for the air pathway analysis showing the distance and direction of building MFC-721 from TREAT (base map courtesy of Google Earth).

Table C-3. Fraction of particulate radionuclides for time ranges of interest.

\begin{tabular}{lccccc}
\hline & & \multicolumn{4}{c}{ Fraction Remaining } \\
\multicolumn{1}{c}{ Isotope } & Half-life & 1 day & 7 days & 14 days & 21 days \\
\hline Rb-88 & $17.78 \mathrm{~m}$ & $9.6 \mathrm{E}-02$ & $7.7 \mathrm{E}-08$ & $6.0 \mathrm{E}-15$ & $4.6 \mathrm{E}-22$ \\
Cs-140* & $1.06 \mathrm{~m}$ & $9.1 \mathrm{E}-18$ & 0 & 0 & 0 \\
Ba-140 & $12.8 \mathrm{~d}$ & $9.5 \mathrm{E}-01$ & $6.8 \mathrm{E}-01$ & $4.7 \mathrm{E}-01$ & $3.2 \mathrm{E}-01$ \\
La-140 & $1.67 \mathrm{~d}$ & $6.6 \mathrm{E}-01$ & $5.5 \mathrm{E}-02$ & $3.0 \mathrm{E}-03$ & $1.6 \mathrm{E}-04$ \\
\hline
\end{tabular}

Based on the remaining fractions shown in Table C-3 and the generation rates shown in Table C-1, the actual accumulation rate can be obtained. For example, Table C-4 contains the average activity released per week, assuming one experiment is performed per week, and the time-decayed activity that would remain after each elapsed time period. For Rb-88, Cs-140, and La-140, during a 1-week elapsed time between experiments, the particulate activity would be reduced to insignificant levels. For Ba-140, the half-life and time between experiments suggests that if all of the Ba-140 activity were deposited near the TREAT stack, accumulation could occur. This could happen because Xe-140 (the gaseous parent radionuclide) decays very rapidly to produce Cs-140 at rates allowing deposition near the stack. Cs-140 also has a very short half-life, making it likely that Ba-140 and/or La-140 would also be deposited near the stack.

- To account for the deposition of Ba-140 and La-140, it was conservatively assumed that the particulate releases occurred at ground level in an area of $100 \mathrm{~m}^{2}(10 \mathrm{~m} \mathrm{x} 10 \mathrm{~m})$. If the releases had been simulated as occurring from the 140-ft high stack, Xe-140 could have been transported somewhat further downgradient prior to the progeny being deposited at land surface. However, 
the $95^{\text {th }}$ percentile wind speed used in the calculations is only about $1 \mathrm{~m} / \mathrm{s}$. By releasing the progeny near land surface, the transported (dispersed) distance is neglected and the source concentration is correspondingly conservative.

- The resultant doses assume the collocated workers inhale suspended dust, are immersed in contaminated air, and are exposed to contaminated surfaces (e.g., soil and parking lot). An onsite worker would not be expected to ingest food products grown onsite and would be exposed for a time period represented by the actual hours at work. Therefore, the doses shown were reduced from the computed values by the time at work. The distance used for calculation purposes corresponds to roughly the extent of the parking lot.

Table C-4. Activity of particulates released per year and per week and activity remaining after 1, 7, 14, and 21 days.

Activity Remaining at 6000 CFM (Curies)

\begin{tabular}{|c|c|c|c|c|c|c|}
\hline Isotope & $\begin{array}{c}\text { Activity } \\
\text { Released per Year } \\
\text { (Curies) }\end{array}$ & $\begin{array}{c}\text { Activity } \\
\text { Released per } \\
\text { Week } \\
\text { (Curies) } \\
\end{array}$ & 1 day & 7 days & 14 days & 21 days \\
\hline $\mathrm{Rb}-88$ & $3.00 \mathrm{E}-02$ & $5.77 \mathrm{E}-04$ & 5.6E-05 & 4.5E-11 & $3.5 \mathrm{E}-18$ & $<1 \mathrm{E}-20$ \\
\hline Cs-140 & $1.03 \mathrm{E}+03$ & $1.98 \mathrm{E}+01$ & $1.8 \mathrm{E}-16$ & $<1 \mathrm{E}-20$ & $<1 \mathrm{E}-20$ & $<1 \mathrm{E}-20$ \\
\hline Ba-140 & $1.00 \mathrm{E}-02$ & $1.92 \mathrm{E}-04$ & $1.8 \mathrm{E}-04$ & $1.3 \mathrm{E}-04$ & $9.0 \mathrm{E}-05$ & $6.2 \mathrm{E}-05$ \\
\hline La-140 & $6.00 \mathrm{E}-07$ & $1.15 \mathrm{E}-08$ & 7.6E-09 & $6.3 \mathrm{E}-10$ & $3.5 \mathrm{E}-11$ & $1.9 \mathrm{E}-12$ \\
\hline
\end{tabular}

Activity Remaining at 3000 CFM (Curies)

\begin{tabular}{lcccccc} 
& $\begin{array}{c}\text { Initial Activity } \\
\text { (Curies) }\end{array}$ & & 1 day & 7 days & 14 days & 21 days \\
\hline $\mathrm{Rb}-88$ & $5.00 \mathrm{E}-02$ & $9.62 \mathrm{E}-04$ & $5.3 \mathrm{E}-08$ & $4.3 \mathrm{E}-14$ & $<1 \mathrm{E}-20$ & $<1 \mathrm{E}-20$ \\
$\mathrm{Cs}-140$ & $1.12 \mathrm{E}+03$ & $2.15 \mathrm{E}+01$ & $3.9 \mathrm{E}-15$ & $<1 \mathrm{E}-20$ & $<1 \mathrm{E}-20$ & $<1 \mathrm{E}-20$ \\
$\mathrm{Ba}-140$ & $2.00 \mathrm{E}-02$ & $3.85 \mathrm{E}-04$ & $7.00 \mathrm{E}-08$ & $5.1 \mathrm{E}-08$ & $3.50 \mathrm{E}-08$ & $2.4 \mathrm{E}-08$ \\
$\mathrm{La}-140$ & $2.00 \mathrm{E}-06$ & $3.85 \mathrm{E}-08$ & $2.9 \mathrm{E}-16$ & $2.4 \mathrm{E}-17$ & $1.3 \mathrm{E}-18$ & $7.3 \mathrm{E}-20$ \\
\hline
\end{tabular}

\section{C-3.4 Dose Results for Use of TREAT}

Table C-5 contains the dose results for both public and worker receptors using the 6,000-cfm activity emissions from Table C-1. This table contains the internal, external, and total ED. The total ED is the sum of the internal and external doses. Internal dose is comprised of inhalation and ingestion doses. External dose is comprised of air immersion and direct radiation from deposition on the ground. For each public receptor the total dose is dominated by the external dose from air immersion. The external dose from ground surface exposure and the internal doses from ingestion and inhalation are negligible in comparison.

For workers, ingestion dose is not included in the total because workers would not consume food grown in the assessment area. External doses for workers are provided assuming a 2,000-hour work year, compared to public resident doses that assume 8,766 hours of exposure. Inhalation doses for workers are also representative of the reduced amount of inhaled air and the higher breathing rate of a worker. The combined adjustment for inhalation is 2,400/8,030 (Staley et al. 2004).

For workers located closer to TREAT, the total dose is dominated by the ground surface (external exposure) component, with a smaller contribution from inhalation of suspended dust as indicated in Table C-6. The differences reflect the influence of particulate deposition and the assumption that TREAT 
workers are located in the TREAT Reactor control building during transient testing. This is further indicated in Table C-7, where the total dose at Atomic City is shown to be associated primarily with Ar-41.

Table C-5. Receptor doses for the air pathway assessment.

\begin{tabular}{|c|c|c|c|}
\hline Receptor & $\begin{array}{l}\text { Internal ED } \\
\text { (mrem/year) }\end{array}$ & $\begin{array}{l}\text { External ED } \\
\text { (mrem/year) }^{\mathrm{a}, \mathrm{b}, \mathrm{c}}\end{array}$ & $\begin{array}{c}\text { Total ED } \\
(\text { mrem/year) }\end{array}$ \\
\hline Frenchman's Cabin (public) & $1.4 \mathrm{E}-06$ & $1.1 \mathrm{E}-03$ & $1.1 \mathrm{E}-03$ \\
\hline Atomic City (public MEI) & $5.5 \mathrm{E}-06$ & $2.1 \mathrm{E}-03$ & $2.1 \mathrm{E}-03$ \\
\hline Nearest INL Boundary (public) & $4.8 \mathrm{E}-05$ & $2.5 \mathrm{E}-02$ & $2.5 \mathrm{E}-02$ \\
\hline $\begin{array}{l}\text { TREAT Reactor control building } \\
\text { (collocated worker) }\end{array}$ & $5.1 \mathrm{E}-06^{\mathrm{a}}$ & $3.6 \mathrm{E}-03^{\mathrm{b}}$ & $3.6 \mathrm{E}-03$ \\
\hline TREAT (collocated worker) & $2.19 \mathrm{E}-02^{\mathrm{a}}$ & $4.21 \mathrm{E}-02^{\mathrm{b}}$ & $6.4 \mathrm{E}-02$ \\
\hline
\end{tabular}

Table C-6. Pathway effective dose summary from particulate releases for a collocated worker.

\begin{tabular}{lrrr} 
& \multicolumn{2}{c}{$\mathrm{ED}^{\mathrm{b}}$ (mrem/year) as a function of distance from the ground source at TREAT } \\
\multicolumn{1}{c}{ Pathway $^{\mathrm{a}}$} & $38 \mathrm{~m}$ & $125 \mathrm{~m}$ & \multicolumn{1}{c}{$250 \mathrm{~m}$} \\
\hline Inhalation (Internal) & $2.19 \mathrm{E}-02$ & $2.28 \mathrm{E}-03$ & $6.07 \mathrm{E}-04$ \\
Air Immersion (External) & $1.08 \mathrm{E}-04$ & $1.12 \mathrm{E}-05$ & $2.99 \mathrm{E}-06$ \\
Ground Surface (External) & $4.20 \mathrm{E}-02$ & $4.38 \mathrm{E}-03$ & $1.17 \mathrm{E}-03$ \\
\hline Total & $6.40 \mathrm{E}-02$ & $6.67 \mathrm{E}-03$ & $1.78 \mathrm{E}-03$ \\
\hline
\end{tabular}

a. In all cases, the ingestion dose for collocated workers is assumed to be zero.

b. Doses are scaled to account for worker time on-site and breathing rate.

Table C-7. Dose by radionuclide for the maximally exposed individual receptor at Atomic City.

\begin{tabular}{ccc}
\hline Radionuclide $^{\mathrm{a}}$ & Dose (mrem/year) & Fraction of Total Dose \\
\hline $\mathrm{Ar}-41$ & $2.01 \mathrm{E}-03$ & $95.5 \%$ \\
$\mathrm{Kr}-85 \mathrm{~m}$ & $9.29 \mathrm{E}-07$ & $0.0 \%$ \\
$\quad \mathrm{Kr}-85$ & $7.08 \mathrm{E}-15$ & $0.0 \%$ \\
$\mathrm{Kr}-87$ & $2.91 \mathrm{E}-05$ & $1.4 \%$ \\
$\quad \mathrm{Rb}-87$ & $0.00 \mathrm{E}+00$ & $0.0 \%$ \\
$\mathrm{Kr}-88$ & $5.18 \mathrm{E}-05$ & $2.5 \%$ \\
$\mathrm{Rb}-88$ & $5.20 \mathrm{E}-06$ & $0.2 \%$ \\
$\mathrm{Xe}-133$ & $9.24 \mathrm{E}-08$ & $0.0 \%$ \\
$\mathrm{Xe}-135$ & $1.51 \mathrm{E}-06$ & $0.1 \%$ \\
$\mathrm{Cs}-135$ & $0.00 \mathrm{E}+00$ & $0.0 \%$ \\
Ba-140 & $2.54 \mathrm{E}-06$ & $0.1 \%$ \\
La-140 & $3.01 \mathrm{E}-06$ & $0.1 \%$ \\
\hline Total & $2.10 \mathrm{E}-03$ & $100 \%$ \\
\hline
\end{tabular}

a. Progeny are shown indented. 


\section{C-3.5 Documentation of the CAP-88 Parameters}

Documentation that can be used to replicate the results for this analysis is contained in INL (2013), including the following:

- CAP-88 input files for the public receptor locations and the worker receptor

- CAP-88 output files for the public receptor locations and the worker receptor

- National Ocean Atmospheric Administration meteorological data files for the EBR-II lower mesonet station.

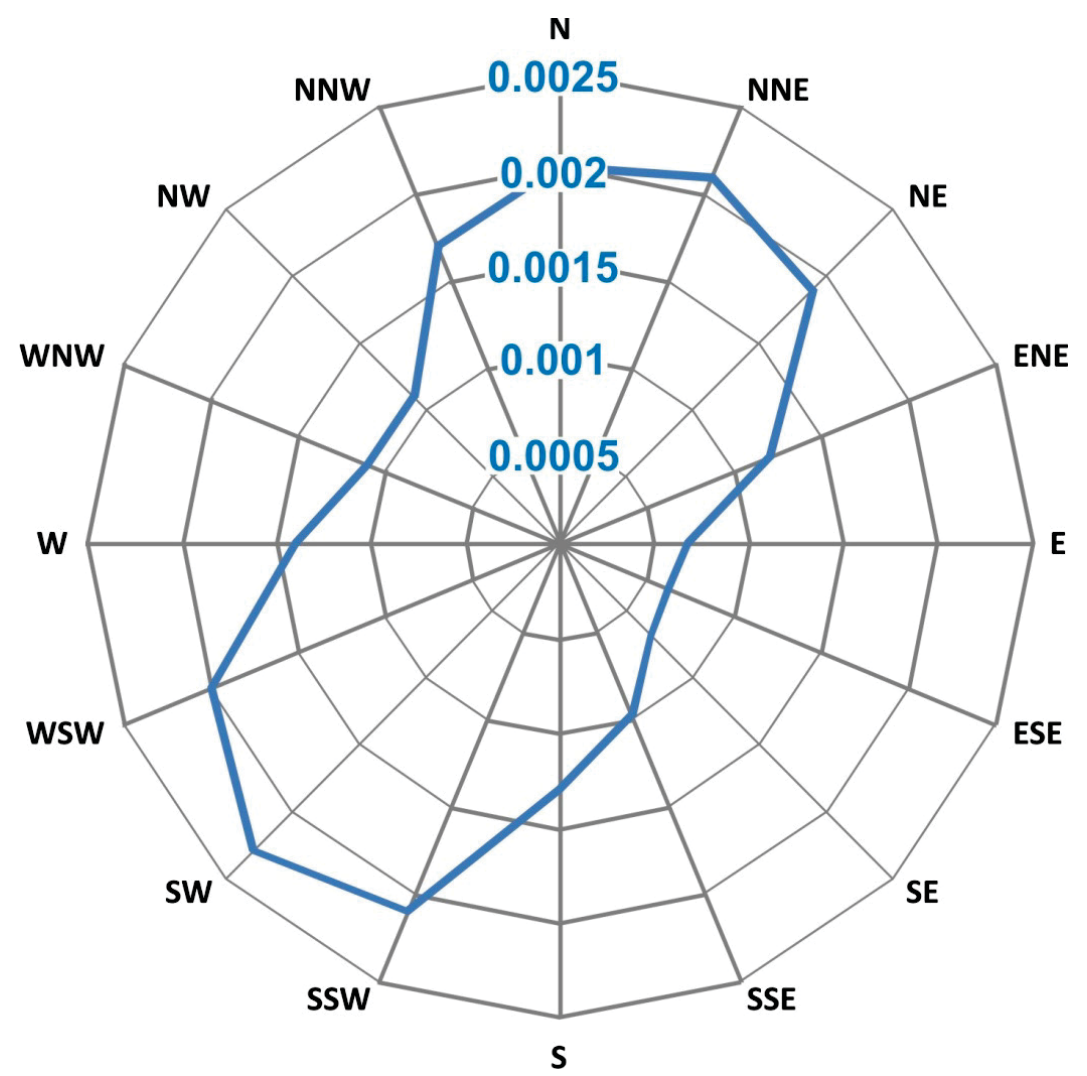

Figure C-3. Total dose (mrem/year) by sector at the maximally exposed individual distance of $20.85 \mathrm{~km}$ from TREAT.

\section{C-4. SOIL PATHWAY ASSESSEMENT FOR THE TRANSIENT REACTOR TEST FACILITY}

Transient testing using the TREAT Reactor was conducted for approximately 35 years prior to placing the reactor in a standby condition in 1992. The air F/CS in the TREAT Reactor building contains a double-bank of HEPA filters in series, with each bank removing $99.97 \%$ of particulates from the air stream passing through each of them. This guarantees that two sets in series will have an efficiency of at least $99.99 \%$. The efficiency of the air F/CS system is reflected in the historical soil data and in the projected particulate releases during normal reactor operations. The historical data and the potential impact of particulate generation resulting from the decay of gaseous emissions are as discussed in the following subsections. 


\section{C-4.1 Review of Historical Soil Data}

INL was listed on the National Priorities List of the Comprehensive Environmental Response, Compensation, and Liability Act of 1980 in November 1989. In response to this listing, DOE, EPA, and the State of Idaho negotiated a Federal Facility Agreement/Consent Order and Action Plan. This agreement describes how DOE, EPA, and the State of Idaho will implement Comprehensive Environmental Response, Compensation, and Liability Act and Resource Conservation and Recovery Act activities at INL release sites. Operable Unit 10-06, Radionuclide-Contaminated Soils, was added to the Federal Facility Agreement/Consent Order as a remedial investigation/feasibility study in 1993.

Operable Unit 10-06 includes windblown contamination areas and other operable units at INL that are identified as primarily radionuclide-contaminated soil areas or non-windblown areas. There are nine windblown areas, which are defined as those areas outside of the perimeter fence(s) (if one exists) at the INL facilities and within the outermost aerial survey isopleths that are potentially contaminated as a result of atmospheric dispersion and deposition of radionuclides. The windblown sites include areas around MFC and TREAT.

Data collected at TREAT includes soil samples obtained during the 1978 to 1985 time period by the Radiological and Environmental Services Laboratory, an aerial survey by EG\&G Energy Measurements Inc. in 1990 (EMI 1992), and during the Operable Unit 10-06 soil investigation conducted in 1993 (INEL 1995). Measured soil concentrations and the upper tolerance limit from Rood et al. (1995) defining the background concentration are shown in Table C-8. Only Cs-137 and Sr-90 were detected above the upper tolerance limit, with Cs-137 detected twice out of 23 samples and Sr-90 found in one of three samples. This list does not include Ba-140 or La-140 identified in the atmospheric releases. The particulates shown in Table C-8 were not included in the list of atmospheric emissions (Table C-1).

The dose equivalent and risk for radionuclides given in Table C-8 were assessed for hypothetical occupational and residential receptors (INEL 1995). Exposure pathways considered ingestion of soil, inhalation of fugitive dust, and ingestion of food crops for 25-year occupational and 30-year residential scenarios. The computed dose rate was $87.7 \mathrm{mrem} / \mathrm{year}$, which can be compared to the upper tolerance limit background dose rate of $175.3 \mathrm{mrem} / \mathrm{year}$. The corresponding peak risk was 4E-6, which is well within the 1E-4 to 1E-6 National Contingency Plan target risk range (55 FR 8665-8865 1990). The corresponding risk for a current occupational scenario was lower and equal to $1 \mathrm{E}-08$. This risk is primarily from soil ingestion.

Table C-8. Background upper tolerance limit and maximum concentrations measured in the windblown area near TREAT.

\begin{tabular}{lccc}
\hline Radionuclide & $\begin{array}{c}\text { Background UTL } \\
\text { (pCi/g) }\end{array}$ & $\begin{array}{c}\text { Maximum Measured } \\
\text { Soil Concentration } \\
(\mathrm{pCi} / \mathrm{g})\end{array}$ & $\begin{array}{c}\text { Number of Detections Above } \\
\text { UTL/Number of Samples Analyzed }\end{array}$ \\
\hline Am-241 & 0.011 & 0.0058 & $0 / 3$ \\
$\mathrm{Cs}-137$ & 0.82 & 0.996 & $2 / 23$ \\
$\mathrm{~K}-40$ & 24 & 21.3 & $0 / 15$ \\
$\mathrm{Pu}-238$ & 0.0049 & 0.0004 & $0 / 3$ \\
$\mathrm{Pu}-239 / 240$ & 0.10 & 0.015 & $0 / 3$ \\
$\mathrm{Sr}-90$ & 0.49 & 0.51 & $1 / 3$ \\
$\mathrm{U}-234$ & 1.44 & 0.809 & $0 / 1$ \\
$\mathrm{U}-238$ & 1.40 & 1.02 & $0 / 1$ \\
\hline
\end{tabular}




\section{C-4.2 Projected Particulate Radionuclide Releases}

Table C-6 provides the dose computed from the particulate emissions for collocated workers as a function of distance. These doses drop off significantly with distance from TREAT. Based on the values shown, particulate emissions from the TREAT stack during transient testing pose an insignificant hazard.

\section{C-5. AIR PATHWAY ASSESSEMENT USING THE ANNULAR CORE RESEARCH REACTOR}

For the alternative using ACRR, EDs were calculated for three potential public receptor locations: a civilian worker at the nearby Kirtland Storage Facility, a civilian worker at the Chestnut Site, and a public receptor at the Eubank Gate, using a similar process as described for the TREAT Reactor but employing site-specific parameters as discussed in the following sections.

\section{C-5.1 Receptors}

Doses were calculated at three potential public receptor locations. Three potential public receptors were located off DOE-controlled property (see Figure C-4) at the following:

1. Kirtland Storage Site. This has frequently been the MEI for the SNL annual NESHAPs assessment for ACRR. It is the nearest U.S. Air Force personnel receptor to the ACRR facility. There are no permanent residents at Kirtland Storage Site, which is located 1,783 m west-northwest of ACRR.

2. Chestnut Site. This location was selected for this analysis because it is another MEI location occupied by U.S. Air Force personnel 4,172 m south-southwest of ACRR. There are no permanent residents at Chestnut Site.

3. Eubank Gate. This location was selected for this analysis because it is a frequently occupied public location nearest ACRR. The Eubank Gate is located 5,984 m north of ACRR.

\section{C-5.2 Source Emissions for Use of the Annual Core Research Reactor}

Source emissions were derived by scaling the annual radioactive nuclide emissions for ACRR by the power requirements to conduct experiments using ACRR. The annual radioactive nuclide emissions from the ACRR stack are based on a typical annual operating history, comprising a total energy release of $25,000 \mathrm{MJ}(\mathrm{MW}-\mathrm{s})$. The Ar-41 generation in ACRR is $1.09 \times 10^{-4} \mathrm{Ci} / \mathrm{MJ}$.

Radioactive emissions from the ACRR stack are the result of activation of naturally occurring Ar-40 present in the cooling. Projected emissions from the ACRR stack for the proposed tests will be about 1.3 $\mathrm{Ci}$ of Ar-41 based on 12,000 MJ of energy released during the tests.

\section{C-5.3 CAP88-PC Model Parameters}

\section{Facility Parameters}

Gaseous radionuclides released from the ACRR facility exit through the exhaust stack with the following parameters:

- $\quad$ Stack height $=16.5 \mathrm{~m}(54 \mathrm{ft})$

- $\quad$ Stack diameter $=0.20 \mathrm{~m}(8 \mathrm{in}$. $)$

- $\quad$ Stack exit velocity $=18.9 \mathrm{~m} / \mathrm{s}$. 


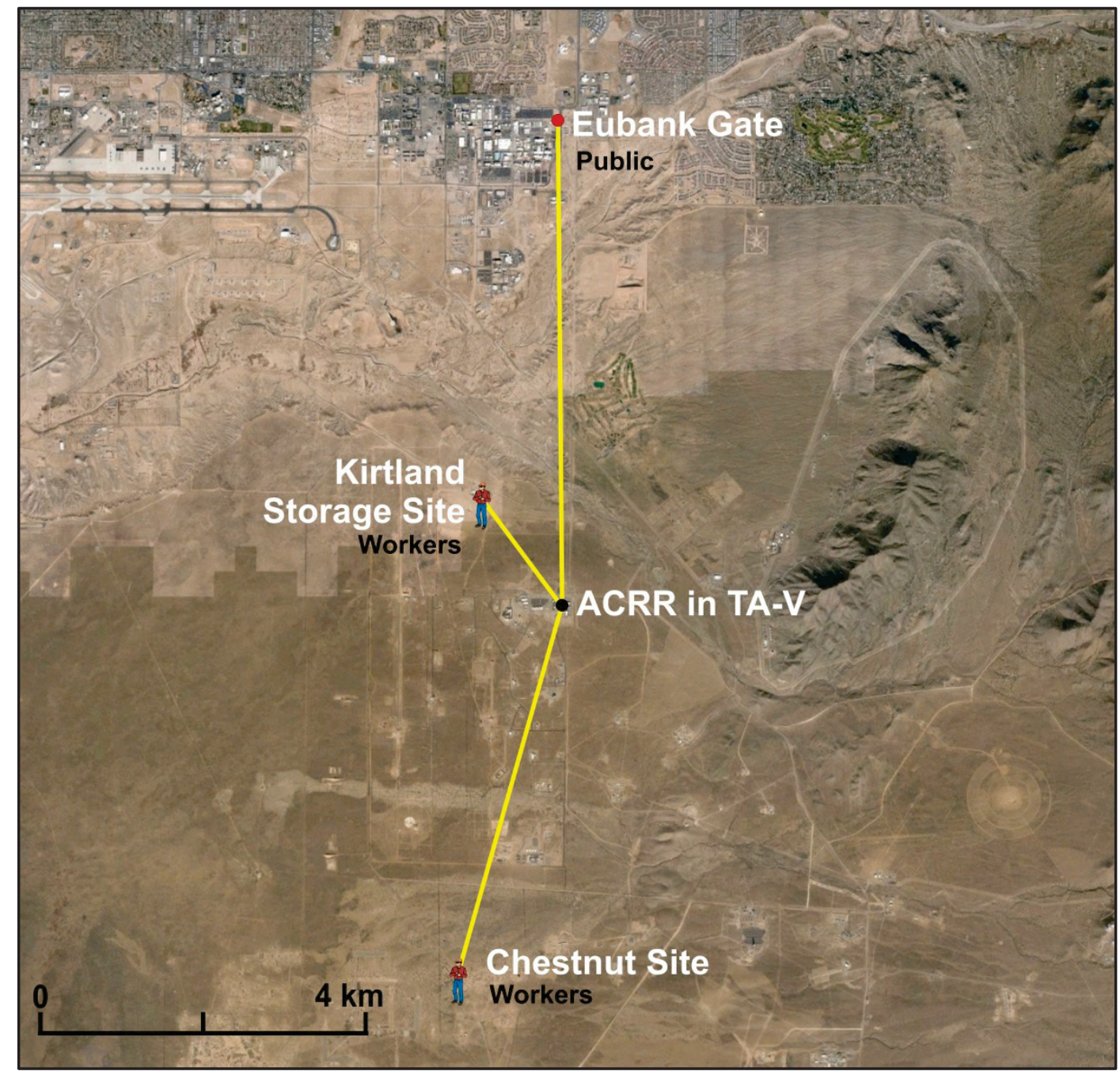

Figure C-4. Public receptor locations for the air pathway analysis, showing distance and direction from the Annular Core Research Reactor (base map courtesy of Google Earth).

\section{Meteorological Parameters}

Climate data from meteorological stations at SNL are compiled by Sandia's meteorologist and provided annually to the NESHAP evaluation staff as part of the annual NESHAP report preparation process. The nearest station to ACRR is meteorological tower "A36" station located 1,000 $\mathrm{m}(0.6 \mathrm{mi})$ south of ACRR. The stability array file for the A36 was input to the WINDGET.EXE program supplied with CAP88-PC to generate the wind file, A36X2012.WND, used by CAP88-PC. These files are provided in INL (2013).

Other SNL site-specific meteorological parameters shown as follows were obtained from the 2012 SNL/NM NESHAPs report:

- Annual mean temperature $\left(15^{\circ} \mathrm{C}\right)$

- Annual mean precipitation (12 cm/year)

- Absolute humidity $\left(5.0 \mathrm{~g} / \mathrm{m}^{3}\right)$

- Annual mean mixing depth (2,055 m). 


\section{C-5.4 Dose Results for Use of the Annular Core Research Reactor}

The total ED is the sum of the internal and external doses. Internal dose is comprised of inhalation and ingestion doses. External dose is comprised of air immersion and direct radiation from deposition on the ground.

The total dose for receptors is exclusively due to external dose from air immersion from Ar-41, a noble gas that is neither deposited on plant or soil surfaces nor is subject to bioaccumulation by biota. The total EDs at each of the three designated receptor locations selected are seen in Table C-9.

Table C-9. Receptor doses for the Annular Core Research Reactor air pathway assessment.

Total ED (mrem/year)

\begin{tabular}{lcc} 
Receptor & 20 tests/year & 34 tests/year $^{\mathrm{a}}$ \\
\hline Kirtland Storage Site & $2.8 \mathrm{E}-04$ & $4.8 \mathrm{E}-04$ \\
Chestnut Site & $6.5 \mathrm{E}-05$ & $1.1 \mathrm{E}-04$ \\
Eubank Gate (public receptor) & $2.8 \mathrm{E}-05$ & $4.8 \mathrm{E}-05$ \\
\hline a. $\quad$ values were calculated for 20 test/year and scaled to obtain results for 34 test/year. & \\
\hline
\end{tabular}

These values can be compared to the 2011 SNL/NM annual NESHAPs dose results for the Kirtland storage site (8.63E-04 mrem/year) and for the Chestnut Site (8.23E-04 mrem/year) (SNL/NM 2011). A value for the Eubank Gate was unavailable in the 2011 NESHAPs report. Based on data from the other two locations, the relative contribution of the RTT Program's experiments to the overall SNL/NM air dose is negligible.

\section{C-5.5 Documentation}

Documentation that can be used to replicate the results for this analysis is contained in INL (2013).

\section{C-6. SOIL PATHWAY ASSESSEMENT USING THE ANNULAR CORE RESEARCH REACTOR}

Atmospheric releases during normal operations from the ACRR are limited to Ar-41. Argon-41 and its progeny do not form particulates and Ar-41 remains in the gaseous phase. Therefore, no ingestion or biotic exposure pathways need to be considered by this analysis.

\section{C-7. REFERENCES}

40 CFR 61, 2010, "National Emission Standards for Hazardous Air Pollutants," Code of Federal Regulations, Office of the Federal Register, April 2010.

40 CFR 61, Subpart H, 2010, "National Emission Standards for Emissions of Radionuclides Other than Radon from Department of Energy Facilities," Code of Federal Regulations, Office of the Federal Register, April 2010.

55 FR 8665-8865, 1990, “1990 National Contingency Plan,” Federal Register, March 8, 1990.

DOE-ID, 2012, National Emission Standards for Hazardous Air Pollutants - CY 2011 INL Report for Radionuclides, DOE/ID-11441, U.S. Department of Energy Idaho Operations Office. 
EMI (EG\&G Energy Measurements, Inc.), 1992, Idaho National Engineering Laboratory (INEL) Aerial Radiological Survey Preliminary Report, NRD-92-419.

EPA, 2007, “Updated User's Guide For CAP88-PC Version 3.0,” EPA 402-R-00-004, U.S. Environmental Protection Agency, December 2007 (currently available at http://www.epa.gov/radiation/assessment/CAP88/index.html, web site last updated February 2009, web site last visited November 30, 2009).

INEL, 1995, Engineering Evaluation/Cost Analysis for Operable Unit 10-06 Radionuclide-Contaminated Soils Removal Action at the Idaho National Engineering Laboratory Volume 1, INEL-95/0259, Revision 0, Idaho National Engineering Laboratory.

INL, 2013, Compilation of Quality Assurance Documentation for Impact Analyses Supporting the Environmental Assessment for the Resumption of Transient Testing Program, INL/EXT-13-29515, Idaho National Laboratory.

NRCP, 2009, "Ionizing Radiation Exposure of the Population of the United States," National Council on Radiation Protection and Measurements, Report No. 160.

Rood, S. M., G. A. Harris, and G. J. White, 1995, Background Dose Equivalent Rates and Surficial Soil Metal and Radionuclide Concentrations for the Idaho National Engineering Laboratory, INEL-94/0250, Revision 0, Lockheed Idaho Technologies Company.

Staley, C. S., M. L. Abbott, and P. D. Ritter, 2004, INEEL Air Modeling Protocol, INEEL-EXT-04-02511, Idaho National Laboratory, December 2004.

Staley, C. S., 2008, "Documentation of 10-year Average Meteorological Data Files for CAP-88 Modeling," EDF-6290, Idaho Cleanup Project.

SNL/NM, 2011, Annual Site Environmental Report for Sandia National Laboratories, New Mexico, Sandia Report SAND2012-340P, Sandia National Laboratories, Albuquerque, New Mexico. 


\section{Appendix D}

\section{Impacts from Operation of Diesel Generators at the Transient Reactor Test Facility}


D-2 


\section{CONTENTS}

D-1. STANDBY POWER SYSTEM (30-kw DIESEL GENERATOR) ............................................ D-5

D-2. REDUNDANT POWER SYSTEM (130-kw DIESEL GENERATOR) ...................................... D-5

D-3. ESTIMATED GENERATOR USAGE DURING TRANSIENT TESTING ............................... D-5

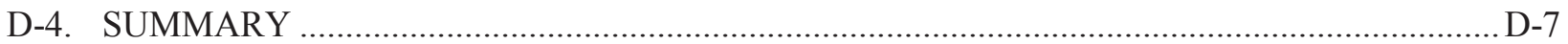


D-4 


\section{Appendix D \\ Impacts from Operation of Diesel Generators at the Transient Reactor Test Facility}

In addition to relying on normal site power, two diesel generators historically have been employed at TREAT. They are analyzed here for the purposes of projecting generation and release of green-house gas emissions and fuel consumption. If Alternative 1 (TREAT) is selected, the permitting requirements for diesel generators will be followed. Historically, redundant power has been supplied by a 130-kW diesel generator and standby power has been supplied by a 30-kW diesel generator. Both diesel generators are located in the Treat Reactor building and they are vented to the outside. Emissions from these diesel generators are typical products of internal combustion of diesel fuel and include $\mathrm{NO}_{\mathrm{x}}, \mathrm{CO}, \mathrm{SO}_{\mathrm{x}}, \mathrm{PM}$, PM-10, and volatile organic compounds. The generators currently are regulated as emergency generators by the EPA Clean Air Act requirements, specifically 40 CFR Part 63, Subpart ZZZZ, "National Emission Standards for Hazardous Air Pollutants for Compression Ignition Stationary Reciprocating Internal Combustion Engines," and the IDAPA 58.01.01, "Rules for the Control of Air Pollution in Idaho."

\section{D-1. STANDBY POWER SYSTEM (30-kw DIESEL GENERATOR)}

The 30-kW diesel generator supplies standby power to selected reactor instrumentation, an uninterruptible power supply unit, selected lighting, security devices, area radiation monitors, diesel-generator auxiliaries, and alarm systems. The standby power system serves as a backup for the normal power system and is designed to come online after a loss of normal power.

\section{D-2. REDUNDANT POWER SYSTEM (130-kw DIESEL GENERATOR)}

The 130-kW diesel generator supplies power to the either one of the two redundant blowers of the $\mathrm{FC} / \mathrm{S}$ and serves as backup for the standby power. The two 4,000-cfm blowers operate in parallel and are capable of supplying $8,000 \mathrm{cfm}$ of air for circulation, but are nominally run at $6,000 \mathrm{cfm}$. Both blowers are operable simultaneously from site power, but only one blower at a time is connected to the diesel generator. It should be noted that safe operation of the TREAT Reactor does not depend on operation of the $\mathrm{F} / \mathrm{CS}$, but cooling is provided because it provides operational benefits.

For experiments containing plutonium, U-233 bearing fuel experiments, or experiments with pre-irradiated fuel, both blowers have been historically operating before the experiment - one being powered from site power, the other by the diesel generator - with the intent of maintaining operation of both blowers throughout the transient. No blower is required to be operating if the quantities of these radioisotopes are equal to or less than the biological equivalent of $5.85 \mathrm{~g}$ of Pu-239. At least one blower has been operating for all other experiments, except for short-time durations (less than or equal to 3 hours), when low-power physics measurements or other operations are in progress that require the blowers to be off or when the natural circulation mode supplies sufficient air cooling and motion. Single blower experiments are usually powered by normal site power. After the transient tests are conducted, both blowers are typically operated using normal site power. Therefore, the $130-\mathrm{kW}$ diesel generator is usually run only for tests that involve plutonium, U-233, or pre-irradiated fuel, and it is only operated before and during the test.

\section{D-3. ESTIMATED GENERATOR USAGE DURING TRANSIENT TESTING}

Since the TREAT Reactor was placed in safe-shutdown mode in 1994, the 30-kW standby generator has been operated during brief periods when normal site power was not available; both generators were operated about 12 hours annually for performance testing and maintenance. Since it was installed in 1980, the 30-kW standby generator has operated 1,215 hours (meter reading April 10, 2013). Subtracting 
12 hour/year for testing and maintenance, the $30-\mathrm{kW}$ generator has operated approximately 25 hour/year to supply standby power during outages ([1215 hours -12 hour/year $\times 33$ years $] / 33$ years $=25$ hour/year). If transient testing resumes, it is expected the $30-\mathrm{kW}$ standby generator usage will be about the same as in the past or about 37 hour/year.

The 130-kW redundant generator has operated 2015 hours since it was installed in 1981 (meter reading April 10, 2013). Subtracting 12 hour/year for maintenance, the 130-kW generator has operated approximately 1,631 hours to run the blower. This is approximately 125 hour/year for the 13-year period from the time the generator was installed in 1981 until the TREAT Reactor was shut down in 1994. Assuming the 130-kW generator was operated for an average of 8 hours for each test that requires two blowers (includes pretest and transient operation time), 125 hours is approximately 16 tests annually. This is nearly half of the bounding number of experiments (34 total, with 20 capsule and 14 loop) that will be run if the reactor is restarted. Therefore, unless the number of experiments that involve plutonium, U-233 bearing fuel, or pre-irradiated fuel and requires two blowers - one run on diesel power - is more than 16 per year, the operation of the $130-\mathrm{kW}$ redundant generator is not expected to be significantly more than 137 hours/year.

From 2007 to 2011, fuel usage for the 30-kW and 130-kW diesel generators used to support TREAT operations averaged 66 and 148 gallons, respectively, of diesel fuel annually. For the 130-kW generator, this equates to a fuel usage rate of about $12.3 \mathrm{gal} / \mathrm{hour}$, assuming annual testing of 12 hours. Assuming a $20 \%$ increase in the operating hours of the $130-\mathrm{kW}$ generator $(137$ hours $\times 1.2=164$ hours) and a $20 \%$ increase in the fuel usage rate $(12.3 \mathrm{gal} /$ hour $\times 1.2=14.8 \mathrm{gal} / \mathrm{hour})$ because of the additional load from running the blowers versus the load used for testing, the $130-\mathrm{kW}$ generator would use approximately $2,433 \mathrm{gal}$ of diesel fuel annually. This combined with the annual fuel usage for the $30-\mathrm{kW}$ generator (66 gal/year) results in an estimated total annual fuel usage of about 2,500 gal for both generators as a result of testing.

Diesel fuel usage for key INL facilities is shown in Table D-1. Using the 2007 through 2011 total fuel usages, the projected TREAT generator usage is less than $0.006(0.6 \%)$ of the average diesel fuel usage for all emergency diesel generators and boilers at MFC during those 5 years (449,563 gal), and less than $0.3 \%$ of the total INL usage $(1,114,995 \mathrm{gal})$. This shows the diesel fuel usage from operation of the two diesel generators at TREAT is an extremely small fraction of the totals for MFC and INL, and they are not a significant contributor to diesel emissions from either MFC or INL.

Table D-1. Diesel fuel usage for key INL facilities from 2007 through 2012.

\begin{tabular}{|c|c|c|c|c|c|c|}
\hline & Facility & ATR Complex & $\begin{array}{l}\text { erials and } \mathrm{F} \\
\text { Complex }\end{array}$ & $\begin{array}{c}\text { wide Facil } \\
\text { Services }\end{array}$ & $\begin{array}{c}\text { fic Manufac } \\
\text { Capability }\end{array}$ & Total \\
\hline & 2007 & 231,557 & 545,045 & 19,707 & 223,039 & $1,119,348$ \\
\hline & 2008 & 253,096 & 562,146 & 593,346 & 253,690 & $1,662,278$ \\
\hline & 2009 & 262,165 & 561,092 & 116,939 & 193,281 & $1,133,477$ \\
\hline & 2010 & 303,968 & 422,761 & 134,921 & 134,921 & 996,571 \\
\hline & 2011 & 193,136 & 156,771 & 116,140 & 197,256 & 663,303 \\
\hline & 2012 & 65,059 & $2,041^{*}$ & 65,289 & 151,354 & 383,743 \\
\hline & Average & 234,830 & 374,976 & 191,057 & 192,257 & 993,120 \\
\hline
\end{tabular}




\section{D-4. SUMMARY}

Emissions from operation of diesel generators at TREAT as a result of transient testing are not expected to be a significant contributor to diesel emissions from MFC or INL. If the option of resuming transient testing using the TREAT Reactor is selected as a result of the NEPA process, the permitting status and requirements will be addressed to ensure that generators used to support TREAT operations will meet all regulatory requirements prior to beginning operations. 
D-8 


\title{
Appendix E
}

\section{Inventory Development for Accident and Handling Scenarios}

\author{
Primary Contributors \\ Daniel M. Wachs, Idaho National Laboratory \\ Annette L. Schafer, Idaho National Laboratory \\ Boyd D. Christensen, Idaho National Laboratory
}


E-2 


\section{CONTENTS}

E-1. IDENTIFICATION OF THE BOUNDING EXPERIMENT RADIONUCLIDE

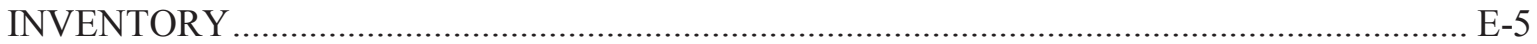

E-1.1 Dose Assessment Methodology and Parameters................................................................ E-5

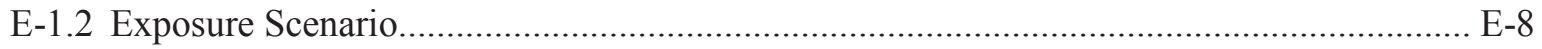

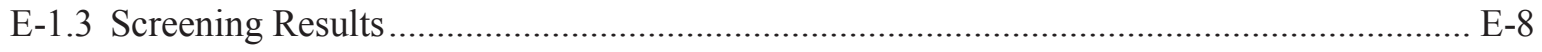

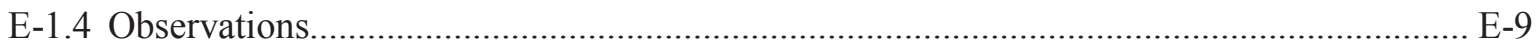

E-2. DISCUSSION OF THE BOUNDING CORE INVENTORY FOR THE TRANSIENT

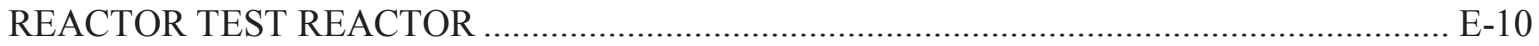

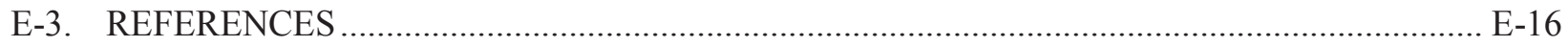


E-4 


\section{Appendix E \\ Inventory Development for Accident and Handling Scenarios}

Assessing potential dose impacts during handling accidents and transportation requires determination of a bounding radiological inventory. This section provides the inventory screening analysis performed to determine the bounding inventory of materials that will be used during transient testing. The bounding inventory determined through this screening evaluation will be used for assessment of dose consequences for both alternatives.

\section{E-1. IDENTIFICATION OF THE BOUNDING EXPERIMENT RADIONUCLIDE INVENTORY}

The radiological inventory is expected to fall within the range of materials discussed in TEV-1832 (2013). The bounding fuel types are shown in Table E-1 and are representative of fuels used or being developed for use in LWR reactors and sodium-cooled fast reactors. This list was developed based on emphasis of the RTT Program and includes a (1) 9-pin array of standard $\mathrm{UO}_{2}$ based LWR fuel pins, (2) 7 pin $\mathrm{MO}_{\mathrm{x}}$ fast reactor fuel, and 3) typical minor actinide burning fast reactor fuel. As discussed in TEV-1832 (2013), the potential dose contribution for each fuel type is dependent on the irradiation state, with inhalation doses due to fission products increasing after irradiation and inhalation doses decreasing for transuranic (TRU) isotopes after irradiation. Therefore, the list contains both the fresh fuel and irradiated fuels for comparison in the screening evaluation.

Table E-1. Summary of fuel pins and experiment configurations evaluated to determine bounding experimental inventory.

Inventory Tables

Case Description Appendix B of TEV-1832 (2013)

\begin{tabular}{lll} 
9-pin array of standard $\mathrm{UO}_{2}$ based $\mathrm{LWR}$ fuel & LWR 9-pin & Table B-1 \\
7-pin array of irradiated MOx fast reactor fuel & ATL 7-pin irradiated & Table B-2 \\
7-pin array of fresh MOx fast reactor fuel & ATL 7-pin fresh & Table B-3 \\
1-pin irradiated TRU-bearing fast reactor fuel & TRU 1-pin irradiated & Table B-4 \\
1-pin fresh TRU-bearing fuel & TRU 1-pin fresh & Table B-5 \\
\hline
\end{tabular}

ATL $=$ Advanced Test Loop

To determine which of the fuels and experimental configurations pose the largest human dose potential, an exposure scenario was assumed corresponding to a drop of the experiment assembly and the total effective dose (TED) was computed. The dose assessment methodology is explained in Section E-1.1 and the exposure scenario assumed for screening is discussed in Section E-1.2.

\section{E-1.1 Dose Assessment Methodology and Parameters}

The dose assessment methodology and parameters used in the inventory screening process are based on a modification of the five-factor formula provided in DOE-HDBK-3010-94. The dose calculation uses a simple Gaussian plume model to represent transport and standard dose factors to convert the source term (ST) to radiologic impacts. Parameters for the transport model are discussed first, followed by those necessary to parameterize the equation for committed effective dose (CED).

The five-factor formula from DOE-HDBK-3010-94 was applied to determine the ST for each candidate experiment inventory. The ST is determined by the inventory (material at risk [MAR]), damage ratio (DR), airborne release fraction (ARF), respirable fraction (RF), and leak path factor (LPF). These 
factors and the values of the factors are explained and presented in DOE-HDBK-3010-94. The five-factor formula from DOE-HDBK-3010-94 for estimating the ST is as follows:

$S T=M A R \times D R \times A R F \times R F \times L P F$

where:

$\mathrm{ST}=$ the airborne ST: the initial ST and initial respirable ST are products of the MAR, DR, ARF, and RF. A depleted ST after a subsequent stage of deposition or filtration is a product of the initial ST multiplied by the leak path factor of the specific stage.

MAR $=$ material at risk: the amount of radioactive materials (in grams or curies of activity for each radionuclide) available to be acted on by a given physical stress.

$\mathrm{DR}=$ damage ratio: As defined by DOE-HDBK-3010-94, the DR is the fraction of the MAR actually affected by a normal operation process or an event sequence. For example, for normal operations involving nuclear fuel, the NRC Interim Safety Guide-5 (NRC 2003, Attachment, p. 7) recommends a value for a fuel rod breakage percentage of $1 \%$, with a corresponding damage ratio during normal operations of 0.01 . During off-normal (i.e., accident conditions), the recommended fuel rod breakage percentage is $10 \%$ and the recommended damage ratio is 0.1 .

$\mathrm{ARF}=$ airborne release fraction: the coefficient used to estimate the amount of a radioactive material that can be suspended in air as an aerosol and made available for airborne transport under a specific set of induced physical stresses. ARF is specific to the series of events and situations that are completed during the course of a potential release.

$\mathrm{RF}=$ respirable fraction: the fraction of airborne radionuclides as particles that can be transported through air and inhaled into the human respiratory system and is assumed to include particles $10-\mu \mathrm{m}$ aerodynamic equivalent diameter and less.

$\mathrm{LPF}=$ leak path factor: the fraction of airborne materials transported from containment or confinement deposition or filtration mechanism (e.g., fraction of airborne material in a glovebox leaving the glovebox under static conditions, fraction of material passing through a HEPA filter).

After the ST is determined, TED is computed using Equation E-2. In this evaluation, TED is considered to be the sum of the 50-year CED from inhalation and the deep dose equivalent from external exposure (cloud gamma). Calculation of the two components of TED considers all radionuclides, including progeny, from the decay of parent radionuclide that are significant with regard to dose consequences and the released radioactivity. As shown in the following section, the gamma exposure component of TED is negligible when compared to the inhalation dose (CED).

$C E D=S T \times \chi / Q \times B R \times D C F \times D C$

where:

$\chi / \mathrm{Q}=$ airborne dispersion values. The $\chi / \mathrm{Q}$ for downwind distances are site specific, but for the purposes of identifying a bounding inventory, the screening analysis assumes the values for INL are representative. The Radiological Safety Analysis Computer (RSAC) Program Version 7.2 (INL 2010) was used to determine the $\chi / \mathrm{Q}$ values for instantaneous releases. The calculations were based on $95^{\text {th }}$ percentile meteorological conditions as described in the RSAC-7 users guide (INL 2010).

For ground level point source releases along the plume centerline, airborne dispersion values are inversely proportional to the wind speed (U) and horizontal and vertical dispersivities $\left(\sigma_{\mathrm{y}}\right.$ and $\left.\sigma_{\mathrm{z}}\right)$. 
$\frac{\chi}{Q}=\frac{1}{\pi u \sigma_{y} \sigma_{z}}$

The $\chi / \mathrm{Q}$ values for INL are given in Table E-2. These were computed assuming the release occurs at ground level and atmospheric stability class F. These locations correspond to those for collocated workers, which are scenario-dependent and for members of the public who are assumed to be located south of the INL boundary.

Table E-2. INL $\chi / \mathrm{Q}$ values at various separation distances.

\begin{tabular}{ccl}
\hline Distance $(\mathrm{m})$ & $\chi / \mathrm{Q}$ value $\left(\mathrm{sec} / \mathrm{m}^{3}\right)$ & \multicolumn{1}{c}{ Potential receptor } \\
\hline 100 & $4.08 \mathrm{E}-03$ & Collocated worker \\
300 & $1.21 \mathrm{E}-03$ & Collocated worker \\
770 & $3.87 \mathrm{E}-04$ & Facility or collocated worker in TREAT Reactor control building \\
1,000 & $2.80 \mathrm{E}-04$ & Collocated worker \\
5,000 & $4.12 \mathrm{E}-05$ & Public (distance from HFEF to INL boundary) \\
6,000 & $3.36 \mathrm{E}-05$ & Public (distance from TREAT to INL boundary) \\
\hline
\end{tabular}

$\mathrm{BR}=$ breathing rate: the assumed breathing rate, described in DOE Order 440.1B, "Worker Protection Program for DOE," is $3.33 \mathrm{E}-4 \mathrm{~m}^{3} / \mathrm{sec}$.

$\mathrm{DCF}=$ dose conversion factor: published in ICRP-68, "Dose Coefficients for Intakes of Radionuclides by Workers," for facility and collocated workers and ICRP-72, "Age-dependent Doses from Intakes of Radionuclides," for use in determining dose to members of the offsite public.

$\mathrm{DC}=$ deposition coefficients: used to include plume fallout. The deposition coefficients are 9.78E-01 at $100 \mathrm{~m}$ and $9.03 \mathrm{E}-01$ at $6,000 \mathrm{~m}$, respectively.

Facility worker inhalation doses are not provided in this inventory screening phase, but in the following accident analyses are estimated based on dispersion of airborne radioactive material into a volume of $16,000 \mathrm{~m}^{3}$, corresponding to the volume of the TREAT (MFC-720) high bay. The 50-year committed effective facility worker doses are determined using:

$\mathrm{CED}=\frac{\mathrm{ST}}{16,000 \mathrm{~m}^{3}} \times 60 \mathrm{sec} / \mathrm{min} \times \mathrm{BR} \times \mathrm{DCF}$

The CED for facility workers located within the TREAT Reactor building is expressed in units of $\mathrm{rem} / \mathrm{min}$. This allows a facility worker inhalation dose to be estimated based on worker stay time, because workers are trained to evacuate the building in the event of a radioactive material release event. Once the workers have evacuated the building, the inhalation doses are significantly lower. In some of the accident scenarios, the facility worker could be located in the TREAT Reactor control building, approximately $770 \mathrm{~m}$ from the TREAT Reactor building. Facility worker doses in these scenarios are computed using Equations E-2 and E-3.

The inhalation and cloud gamma doses are calculated by RSAC using the finite plume model and the RSAC default decay time for the exponential decay function (labeled "Exposure Time" in the RSAC gamma dose output section) of zero seconds. The default time of zero seconds allows RSAC to determine the decay time necessary to result in $100 \%$ release.

Although a fire may be a longer duration event than other radioactive material releases, airborne dispersion is evaluated as discussed above for an instantaneous release. This is conservative because the 
airborne dispersion parameters for longer-duration events, such as fires with significant plume rise, are lower than those for instantaneous releases.

\section{E-1.2 Exposure Scenario}

A screening-level assessment of hazards has been conducted to support the NEPA assessment of RTT Program Alternative 1. This is referred to as the NEPA-HA and is documented in INL (2013). In the NEPA-HA, potential hazards are identified and screening level calculations are provided for unmitigated dose consequences that could be incurred through the use of TREAT facilities. Consequences considered include those related to the use of the TREAT Reactor, experiment assembly handling, and combined events involving both the reactor and experiments. Of these identified events, the test loop drop case included only the experiment inventory and did not include the reactor fuel. Therefore, this exposure scenario was adopted for use in determining the bounding experiment inventory.

In the test loop drop scenario, it is assumed that a radioactive material release could result if a test loop is breached accidentally. This could occur if the test loop were to be severely impacted by an object or if the loop impacted a stationary object during transfer. For the purposes of the screening assessment, it is assumed that the impact is sufficient to cause a total breach of all fuel containment barriers. Other values used to estimate the ST for uptake are shown in Table E-3.

Table E-3. Release factors for test loop drop airborne releases.

\begin{tabular}{lcccccc}
\hline \multicolumn{1}{c}{ Radionuclide } & DR & ARF & RF & LPF & ADJ $_{\text {net }}$ & Applicable Release Scenario \\
\hline $\begin{array}{l}\text { Noble gases and } \\
\text { Halogens }\end{array}$ & $1.00 \mathrm{E}+00$ & $1.00 \mathrm{E}+00$ & $1.00 \mathrm{E}+00$ & $1.00 \mathrm{E}+00$ & $1.00 \mathrm{E}+00$ & $\begin{array}{l}\text { All materials in the gaseous } \\
\text { state can be transported and } \\
\text { inhaled }\end{array}$ \\
$\begin{array}{l}\text { Actinides, } \mathrm{U} \text { and } \\
\text { fission products }\end{array}$ & $1.00 \mathrm{E}+00$ & $2.00 \mathrm{E}-03$ & $3.00 \mathrm{E}-01$ & $1.00 \mathrm{E}+00$ & $6.00 \mathrm{E}-04$ & $\begin{array}{l}\text { Solids exposed to free-fall spill } \\
\text { and impaction stress (DOE- } \\
\text { HDBK-3010-94, p. 4-9) }\end{array}$ \\
\hline
\end{tabular}

$\mathrm{DR}=1.0$ (for the purposes of inventory screening, this assumes all material is damaged as a result of the loop drop).

$\mathrm{ARF}=$ Noble gases and halogens are assumed to be gaseous and available for transport. Values for actinides, uranium, and fission products are taken from DOE-HDBK-3010-94 as applicable to the spill of powders, assuming that the energy of the event is sufficient to generate powder from the solid radioactive material.

$\mathrm{RF}=$ Noble gases and halogens are assumed to be gaseous and available for inhalation. Values for actinides, uranium, and fission products taken from DOE-HDBK-3010-94 as applicable to the spill of powders, assuming that the energy of the event is sufficient to generate powder from the solid radioactive material.

$\mathrm{LPF}=1.0$ (conservative estimate assuming all material is released with no holdup by building materials or HEPA air filters).

$\mathrm{ADJ}_{\text {net }}=$ Net adjustment $=\mathrm{DR} \times \mathrm{ARF} \times \mathrm{RF} \times \mathrm{LPF}$.

\section{E-1.3 Screening Results}

Using the MAR for candidate inventories shown in Table E-1 and the parameters shown in Table E-3, the inhalation (CED), cloud gamma, and TED equivalent were computed. In this case, TED is the sum of the CED and cloud gamma doses. These dose values are shown in Table E-4 for several locations corresponding to a collocated worker or member of the public. 
Table E-4. Screening dose consequences to determine the bounding inventory for experiments.

\begin{tabular}{|c|c|c|c|c|c|}
\hline \multirow[b]{2}{*}{ MAR } & \multirow[b]{2}{*}{ Source } & \multicolumn{3}{|c|}{ Collocated Worker (rem) } & \multirow{2}{*}{$\begin{array}{c}\text { Offsite Public } \\
\text { at } 6,000 \mathrm{~m} \\
(\mathrm{rem})^{\mathrm{b}}\end{array}$} \\
\hline & & at $100 \mathrm{~m}$ & at $770 \mathrm{~m}$ & at $1,000 \mathrm{~m}$ & \\
\hline \multirow{3}{*}{ LWR 9-pin irradiated } & CED & $1.38 \mathrm{E}-02$ & $1.28 \mathrm{E}-03$ & $9.25 \mathrm{E}-04$ & 3.37E-04 \\
\hline & Cloud Gamma & $8.42 \mathrm{E}-08$ & $1.70 \mathrm{E}-08$ & $1.36 \mathrm{E}-08$ & $2.71 \mathrm{E}-09$ \\
\hline & TED & $1.38 \mathrm{E}-02$ & $1.28 \mathrm{E}-03$ & $9.25 \mathrm{E}-04$ & $3.37 \mathrm{E}-04$ \\
\hline \multirow{3}{*}{$\begin{array}{l}\text { ATL 7-pin irradiated } \\
\text { (MARK-III) }\end{array}$} & CED & $8.97 \mathrm{E}+00$ & 8.33E-01 & $6.02 \mathrm{E}-01$ & $2.46 \mathrm{E}-01$ \\
\hline & Cloud Gamma & $3.56 \mathrm{E}-05$ & $7.2 \mathrm{E}-06$ & $5.73 \mathrm{E}-06$ & $1.15 \mathrm{E}-06$ \\
\hline & TED & $8.97 \mathrm{E}+00$ & 8.33E-01 & $6.02 \mathrm{E}-01$ & $2.46 \mathrm{E}-01$ \\
\hline \multirow{3}{*}{$\begin{array}{l}\text { ATL 7-pin fresh } \\
\text { (MARK-III) }\end{array}$} & CED & $2.39 \mathrm{E}+00$ & $2.22 \mathrm{E}-01$ & $1.60 \mathrm{E}-01$ & $-{ }^{c}$ \\
\hline & Cloud Gamma & $2.12 \mathrm{E}-11$ & $4.61 \mathrm{E}-12$ & $3.67 \mathrm{E}-12$ & $-{ }^{c}$ \\
\hline & TED & $2.39 \mathrm{E}+00$ & $2.22 \mathrm{E}-01$ & $1.60 \mathrm{E}-01$ & $-{ }^{c}$ \\
\hline \multirow{3}{*}{ TRU 1-pin irradiated (AFC-2B) } & CED & $5.21 \mathrm{E}-02$ & 4.84E-03 & $3.50 \mathrm{E}-03$ & $-^{c}$ \\
\hline & Cloud Gamma & $5.66 \mathrm{E}-09$ & $1.15 \mathrm{E}-09$ & $9.16 \mathrm{E}-10$ & $-{ }^{c}$ \\
\hline & TED & $5.21 \mathrm{E}-02$ & 4.84E-03 & $3.50 \mathrm{E}-03$ & $-{ }^{c}$ \\
\hline \multirow{3}{*}{$\begin{array}{l}\text { TRU 1-pin fresh } \\
\text { (AFC-2B) }\end{array}$} & CED & 4.27E-01 & 3.97E-02 & $2.87 \mathrm{E}-02$ & $1.44 \mathrm{E}-03$ \\
\hline & Cloud Gamma & $3.78 \mathrm{E}-09$ & $8.35 \mathrm{E}-10$ & $6.61 \mathrm{E}-10$ & $1.83 \mathrm{E}-10$ \\
\hline & TED & 4.27E-01 & $3.97 \mathrm{E}-02$ & $2.87 \mathrm{E}-02$ & $1.44 \mathrm{E}-03$ \\
\hline
\end{tabular}

\section{E-1.4 Observations}

The following observations can be made from the screening results shown in Table E-4.

- Cloudshine (cloud gamma) is a minor (negligible) contributor to the collocated worker doses at $100 \mathrm{~m}, 770 \mathrm{~m}$, and members of the public located at 6,000 $\mathrm{m}$ for all of the materials and configurations subject to this screening dose evaluation. The relative contribution is dominated by the inhalation dose conversion factors, which are orders of magnitude higher than the cloudshine dose conversion factors.

- $\quad$ Highest collocated worker doses were obtained for the ATL (MARK-III) 7-pin irradiated inventory. The dose is predominantly associated with $\mathrm{Pu}-238, \mathrm{Pu}-239, \mathrm{Pu}-240, \mathrm{Pu}-241$, and $\mathrm{Am}-241$, with a small contribution from $\mathrm{Kr}-85$.

- Doses for the ATL 7-pin fuel (which contains both uranium and plutonium) increase after irradiation, suggesting that irradiation of uranium (causing an increase in dose as seen in Figure 1 of TEV-1832) dominates irradiation of plutonium (causing a decrease in dose as seen in Figure 2 of TEV-1832 [2013]).

- Doses for the LWR fuel increase after irradiation. This is consistent with the relative proportions of uranium in the inventory and Figure 1 of TEV-1832 (2013). 
- For dose consequences of the TRU-bearing inventory to approach that of the ATL 7-pin inventory, two pins of fresh TRU-bearing fuel would be required. This is not likely to occur.

- It is not likely that LWR fuel will be contained in experiments irradiated in the TREAT Reactor or ACRR in configurations approaching the dose consequences of the ATL 7-pin irradiated experiment.

Therefore, it is concluded that the irradiated ATL 7-pin provided in Appendix B, Table B-2 represents the bounding radionuclide inventory.

\section{E-2. DISCUSSION OF THE BOUNDING CORE INVENTORY FOR THE REACTOR AT THE TRANSIENT REACTOR TEST FACILITY}

The inventory selected to represent the TREAT core provides an absolute upper bound radionuclide inventory that could be present in the reactor core at any given time. It was selected for use in evaluation of dose consequences for postulated accidents presented in the NEPA-HA (INL 2013) and Appendix F of this document in order to ensure that the calculated dose consequences for postulated accidents are bounding of any credible conditions and configurations that may be encountered during the life of the facility. The inventory is given in Table E-5. This inventory is referred to as the conservative TREAT core inventory and was estimated using the computer code ORIGEN (Bell 1973). ORIGEN is a standard point-depletion code that is widely used to compute isotopic buildup and depletion as a result of irradiation and subsequent radioactive decay. For determination of the final core inventory, it was used to simulate the reactor operating history in preparation of the last TREAT upgrade. For the TREAT Reactor, the simulations were conducted assuming the reactor was operated for a series of steady-state periods, transient testing periods, and a final transient test.

In determining the radiologic composition of the absolutely bounding TREAT core inventory, a number of conservatisms were included in the operating history and resultant inventory calculations. The core radionuclide inventory is based on the following conservative operating history and assumptions:

- For 20 years, the reactor core has been operated weekly, at a steady-state power level of $120 \mathrm{kw}$ for a period of 4 hours and has produced a 5,000-MJ transient. This operation schedule and energy level exceeds the historical operations of the TREAT Reactor. Therefore, the resultant fission product inventory from the steady-state reactor operation period and weekly transient test is conservative.

- For 33 1/3 days preceding each accident, the reactor has produced a 3,500-MJ transient once every 8 hours, for a total of 100 transients conducted for calibrations and short tests. This is conservative with respect to number of transients and energy of each transient. Therefore, the resultant fission product inventory from the transient test periods is conservative.

- At the time of the accident, the reactor produced a 6,000-MJ transient. This transient energy is approximately $46 \%$ in excess of the $100 \%$ design energy transient. Therefore, the resultant fission product inventory from the transient test preceding the accident is conservative.

Because the operating history is simulated as occurring sequentially, the isotopic buildup includes all steady-state, calibrations, and test periods of reactor operations.

The conservatisms introduced in the bounding inventory will not be matched by the future testing program because of the following:

- Currently planned experiments will not include the addition of the TREAT upgraded core.

- Limits are placed on the energy transient by reactor design.

- A range of experiments are planned, including a maximum of 20 capsule tests and 14 loop tests (Table 1). Objectives of each test will vary, with each requiring a different power transient. It is unlikely that a 3,500-MJ transient will be used every 8 hours for $331 / 3$ days for each experiment. 
- The frequency of loop experiments is limited by the availability of the TREAT loop handling cask (TLHC), time required for non-destructive examination of the experiment components, incorporation of fuel into the test vehicle, and preparations for a transient test. It is implausible that the reactor will produce a 5,000-MJ transient every week because of the logistics involved in setting up the experiments.

Therefore, the inventory used to represent the core is thought to be very conservative.

Table E-5. Bounding inventory used to represent the TREAT Reactor core.

\begin{tabular}{|c|c|c|c|c|c|}
\hline Radioisotope & Curies $^{1}$ & WF- $68^{2}$ & $\begin{array}{c}\text { Specific Activity } \\
(\mathrm{Ci} / \mathrm{gm})\end{array}$ & $\begin{array}{c}\begin{array}{c}\text { ICRP-68 DCF } \\
(\mathrm{rem} / \mathrm{Ci})\end{array} \\
\end{array}$ & PEC- $68^{4}$ \\
\hline TE135 & $2.50 \mathrm{E}+06$ & $2.91 \mathrm{E}+05$ & $3.36 \mathrm{E}+07$ & $4.07 \mathrm{E}+02$ & $8.59 \mathrm{E}+00$ \\
\hline SR93 & $4.30 \mathrm{E}+05$ & $9.41 \mathrm{E}+04$ & $1.26 \mathrm{E}+07$ & $1.26 \mathrm{E}+03$ & $4.57 \mathrm{E}+00$ \\
\hline SN131 & $3.80 \mathrm{E}+05$ & $2.13 \mathrm{E}+05$ & $2.49 \mathrm{E}+07$ & $5.55 \mathrm{E}+02$ & $1.78 \mathrm{E}+00$ \\
\hline SN132 & $3.20 \mathrm{E}+05$ & $2.13 \mathrm{E}+05$ & $2.49 \mathrm{E}+07$ & $5.55 \mathrm{E}+02$ & $1.50 \mathrm{E}+00$ \\
\hline AS83 & $3.40 \mathrm{E}+05$ & $2.29 \mathrm{E}+05$ & $2.66 \mathrm{E}+07$ & $5.18 \mathrm{E}+02$ & $1.49 \mathrm{E}+00$ \\
\hline SE87 & $8.50 \mathrm{E}+05$ & $6.04 \mathrm{E}+05$ & $1.02 \mathrm{E}+08$ & $1.96 \mathrm{E}+02$ & $1.41 \mathrm{E}+00$ \\
\hline SB133 & $4.70 \mathrm{E}+05$ & $3.86 \mathrm{E}+05$ & $6.24 \mathrm{E}+07$ & $3.07 \mathrm{E}+02$ & $1.22 \mathrm{E}+00$ \\
\hline TE137 & $3.50 \mathrm{E}+05$ & $2.91 \mathrm{E}+05$ & $3.36 \mathrm{E}+07$ & $4.07 \mathrm{E}+02$ & $1.20 \mathrm{E}+00$ \\
\hline I131 & $2.90 \mathrm{E}+03$ & $2.91 \mathrm{E}+03$ & $1.24 \mathrm{E}+05$ & $4.07 \mathrm{E}+04$ & 9.97E-01 \\
\hline CE144 & $9.40 \mathrm{E}+02$ & $1.10 \mathrm{E}+03$ & $3.18 \mathrm{E}+03$ & $1.07 \mathrm{E}+05$ & 8.52E-01 \\
\hline SB132 & $3.10 \mathrm{E}+05$ & $3.86 \mathrm{E}+05$ & $6.24 \mathrm{E}+07$ & $3.07 \mathrm{E}+02$ & 8.04E-01 \\
\hline SN133 & $1.40 \mathrm{E}+05$ & $2.13 \mathrm{E}+05$ & $2.49 \mathrm{E}+07$ & $5.55 \mathrm{E}+02$ & $6.56 \mathrm{E}-01$ \\
\hline SE85 & $3.60 \mathrm{E}+05$ & $6.04 \mathrm{E}+05$ & $1.02 \mathrm{E}+08$ & $1.96 \mathrm{E}+02$ & $5.96 \mathrm{E}-01$ \\
\hline SE85M & $3.40 \mathrm{E}+05$ & $6.04 \mathrm{E}+05$ & $1.02 \mathrm{E}+08$ & $1.96 \mathrm{E}+02$ & $5.63 \mathrm{E}-01$ \\
\hline SR90 & $2.30 \mathrm{E}+02$ & $4.16 \mathrm{E}+02$ & $1.38 \mathrm{E}+02$ & $2.85 \mathrm{E}+05$ & $5.53 \mathrm{E}-01$ \\
\hline SB134 & $2.00 \mathrm{E}+05$ & $3.86 \mathrm{E}+05$ & $6.24 \mathrm{E}+07$ & $3.07 \mathrm{E}+02$ & 5.19E-01 \\
\hline SB134M & $1.90 \mathrm{E}+05$ & $3.86 \mathrm{E}+05$ & $6.24 \mathrm{E}+07$ & $3.07 \mathrm{E}+02$ & 4.93E-01 \\
\hline SE88 & $2.90 \mathrm{E}+05$ & $6.04 \mathrm{E}+05$ & $1.02 \mathrm{E}+08$ & $1.96 \mathrm{E}+02$ & 4.80E-01 \\
\hline Y91 & $2.50 \mathrm{E}+03$ & $5.25 \mathrm{E}+03$ & $2.45 \mathrm{E}+04$ & $2.26 \mathrm{E}+04$ & 4.77E-01 \\
\hline SB135 & $1.70 \mathrm{E}+05$ & $3.86 \mathrm{E}+05$ & $6.24 \mathrm{E}+07$ & $3.07 \mathrm{E}+02$ & 4.41E-01 \\
\hline TE132 & $4.60 \mathrm{E}+03$ & $1.07 \mathrm{E}+04$ & $3.09 \mathrm{E}+05$ & $1.11 \mathrm{E}+04$ & $4.31 \mathrm{E}-01$ \\
\hline I133 & $6.40 \mathrm{E}+03$ & $1.52 \mathrm{E}+04$ & $1.13 \mathrm{E}+06$ & $7.77 \mathrm{E}+03$ & $4.20 \mathrm{E}-01$ \\
\hline SR89 & $2.20 \mathrm{E}+03$ & $5.71 \mathrm{E}+03$ & $2.91 \mathrm{E}+04$ & $2.07 \mathrm{E}+04$ & $3.85 \mathrm{E}-01$ \\
\hline RB90 & $4.80 \mathrm{E}+05$ & $1.28 \mathrm{E}+06$ & $1.40 \mathrm{E}+08$ & $9.25 \mathrm{E}+01$ & $3.75 \mathrm{E}-01$ \\
\hline ZR97 & $8.50 \mathrm{E}+03$ & $2.29 \mathrm{E}+04$ & $1.93 \mathrm{E}+06$ & $5.18 \mathrm{E}+03$ & $3.72 \mathrm{E}-01$ \\
\hline PR143 & $5.40 \mathrm{E}+03$ & $1.45 \mathrm{E}+04$ & $6.73 E+04$ & $8.14 \mathrm{E}+03$ & $3.71 \mathrm{E}-01$ \\
\hline CE141 & $3.80 \mathrm{E}+03$ & $1.03 \mathrm{E}+04$ & $2.85 \mathrm{E}+04$ & $1.15 \mathrm{E}+04$ & $3.68 \mathrm{E}-01$ \\
\hline SB132M & $1.40 \mathrm{E}+05$ & $3.86 \mathrm{E}+05$ & $6.24 \mathrm{E}+07$ & $3.07 \mathrm{E}+02$ & $3.63 \mathrm{E}-01$ \\
\hline GE83 & $8.20 \mathrm{E}+04$ & $2.29 \mathrm{E}+05$ & $2.74 \mathrm{E}+07$ & $5.18 \mathrm{E}+02$ & $3.59 \mathrm{E}-01$ \\
\hline ZR95 & $2.50 \mathrm{E}+03$ & $7.62 \mathrm{E}+03$ & $2.15 \mathrm{E}+04$ & $1.55 \mathrm{E}+04$ & $3.28 \mathrm{E}-01$ \\
\hline TE134 & $9.30 \mathrm{E}+04$ & $2.91 \mathrm{E}+05$ & $3.36 \mathrm{E}+07$ & $4.07 \mathrm{E}+02$ & $3.20 \mathrm{E}-01$ \\
\hline BA140 & $5.90 \mathrm{E}+03$ & $2.00 \mathrm{E}+04$ & $7.32 \mathrm{E}+04$ & $5.92 \mathrm{E}+03$ & $2.95 \mathrm{E}-01$ \\
\hline NI59 & $4.20 \mathrm{E}+04$ & $1.45 \mathrm{E}+05$ & $7.99 \mathrm{E}-02$ & $8.14 \mathrm{E}+02$ & $2.89 \mathrm{E}-01$ \\
\hline CS139 & $1.90 \mathrm{E}+05$ & $6.96 \mathrm{E}+05$ & $4.69 \mathrm{E}+08$ & $1.70 \mathrm{E}+02$ & $2.73 \mathrm{E}-01$ \\
\hline
\end{tabular}




\begin{tabular}{|c|c|c|c|c|c|}
\hline Radioisotope & Curies $^{1}$ & WF- $68^{2}$ & $\begin{array}{c}\text { Specific Activity } \\
(\mathrm{Ci} / \mathrm{gm})\end{array}$ & $\begin{array}{c}\begin{array}{c}\text { ICRP-68 DCF } \\
(\mathrm{rem} / \mathrm{Ci})\end{array} \\
\end{array}$ & PEC- $68^{4}$ \\
\hline LA140 & $5.80 \mathrm{E}+03$ & $2.13 \mathrm{E}+04$ & $5.56 \mathrm{E}+05$ & $5.55 \mathrm{E}+03$ & $2.72 \mathrm{E}-01$ \\
\hline AS87 & $5.90 \mathrm{E}+04$ & $2.29 \mathrm{E}+05$ & $2.66 \mathrm{E}+07$ & $5.18 \mathrm{E}+02$ & $2.58 \mathrm{E}-01$ \\
\hline TE138 & $7.20 \mathrm{E}+04$ & $2.91 \mathrm{E}+05$ & $3.36 \mathrm{E}+07$ & $4.07 \mathrm{E}+02$ & $2.48 \mathrm{E}-01$ \\
\hline MO99 & $6.80 \mathrm{E}+03$ & $2.91 \mathrm{E}+04$ & $4.80 \mathrm{E}+05$ & $4.07 \mathrm{E}+03$ & $2.34 \mathrm{E}-01$ \\
\hline SR92 & $2.10 \mathrm{E}+04$ & $9.41 \mathrm{E}+04$ & $1.26 \mathrm{E}+07$ & $1.26 \mathrm{E}+03$ & $2.23 \mathrm{E}-01$ \\
\hline TE133M & $3.20 \mathrm{E}+04$ & $1.68 \mathrm{E}+05$ & $1.13 \mathrm{E}+08$ & $7.03 \mathrm{E}+02$ & $1.90 \mathrm{E}-01$ \\
\hline I135 & $1.20 \mathrm{E}+04$ & $6.96 \mathrm{E}+04$ & $3.54 \mathrm{E}+06$ & $1.70 \mathrm{E}+03$ & $1.73 \mathrm{E}-01$ \\
\hline CE143 & $5.30 \mathrm{E}+03$ & $3.20 \mathrm{E}+04$ & $6.64 \mathrm{E}+05$ & $3.70 \mathrm{E}+03$ & $1.66 \mathrm{E}-01$ \\
\hline SE83M & $9.70 \mathrm{E}+04$ & $6.04 \mathrm{E}+05$ & $1.02 \mathrm{E}+08$ & $1.96 \mathrm{E}+02$ & $1.61 \mathrm{E}-01$ \\
\hline ND147 & $2.20 \mathrm{E}+03$ & $1.52 \mathrm{E}+04$ & $8.09 \mathrm{E}+04$ & $7.77 \mathrm{E}+03$ & $1.44 \mathrm{E}-01$ \\
\hline SB131 & $4.60 \mathrm{E}+04$ & $3.86 \mathrm{E}+05$ & $6.24 \mathrm{E}+07$ & $3.07 \mathrm{E}+02$ & $1.19 \mathrm{E}-01$ \\
\hline RU103 & $1.70 \mathrm{E}+03$ & $1.45 \mathrm{E}+04$ & $3.22 \mathrm{E}+04$ & $8.14 \mathrm{E}+03$ & $1.17 \mathrm{E}-01$ \\
\hline SR91 & $6.00 \mathrm{E}+03$ & $5.61 \mathrm{E}+04$ & $3.58 \mathrm{E}+06$ & $2.11 \mathrm{E}+03$ & $1.07 \mathrm{E}-01$ \\
\hline TE133 & $6.90 \mathrm{E}+04$ & $7.27 \mathrm{E}+05$ & $2.55 \mathrm{E}+07$ & $1.63 \mathrm{E}+02$ & $9.49 \mathrm{E}-02$ \\
\hline RU106 & $6.10 \mathrm{E}+01$ & $9.14 \mathrm{E}+02$ & $3.30 \mathrm{E}+03$ & $1.30 \mathrm{E}+05$ & $6.67 \mathrm{E}-02$ \\
\hline NB95 & $1.20 \mathrm{E}+03$ & $2.46 \mathrm{E}+04$ & $3.93 \mathrm{E}+04$ & $4.81 \mathrm{E}+03$ & $4.88 \mathrm{E}-02$ \\
\hline CS137 & $2.30 \mathrm{E}+02$ & $4.78 \mathrm{E}+03$ & $8.69 \mathrm{E}+01$ & $2.48 \mathrm{E}+04$ & $4.82 \mathrm{E}-02$ \\
\hline Y93 & $5.30 \mathrm{E}+03$ & $1.14 \mathrm{E}+05$ & $9.53 \mathrm{E}+06$ & $1.04 \mathrm{E}+03$ & 4.64E-02 \\
\hline PM149 & $1.10 \mathrm{E}+03$ & $3.90 \mathrm{E}+04$ & $3.96 \mathrm{E}+05$ & $3.03 \mathrm{E}+03$ & $2.82 \mathrm{E}-02$ \\
\hline I132 & $4.50 \mathrm{E}+03$ & $1.60 \mathrm{E}+05$ & $1.71 \mathrm{E}+07$ & $7.40 \mathrm{E}+02$ & $2.81 \mathrm{E}-02$ \\
\hline PM147 & $2.50 \mathrm{E}+02$ & $9.14 \mathrm{E}+03$ & $9.28 \mathrm{E}+02$ & $1.30 \mathrm{E}+04$ & $2.73 \mathrm{E}-02$ \\
\hline TE131M & $4.10 \mathrm{E}+02$ & $2.00 \mathrm{E}+04$ & $5.75 \mathrm{E}+07$ & $5.92 \mathrm{E}+03$ & $2.05 \mathrm{E}-02$ \\
\hline U235 & $9.90 \mathrm{E}-02$ & $5.25 \mathrm{E}+00$ & $2.16 \mathrm{E}-06$ & $2.26 \mathrm{E}+07$ & $1.89 \mathrm{E}-02$ \\
\hline RB89 & $2.30 \mathrm{E}+04$ & $1.28 \mathrm{E}+06$ & $1.40 \mathrm{E}+08$ & $9.25 \mathrm{E}+01$ & $1.80 \mathrm{E}-02$ \\
\hline IN131 & $1.90 \mathrm{E}+04$ & $1.10 \mathrm{E}+06$ & $6.59 \mathrm{E}+08$ & $1.07 \mathrm{E}+02$ & $1.72 \mathrm{E}-02$ \\
\hline TE129M & $9.80 \mathrm{E}+01$ & $5.93 \mathrm{E}+03$ & $2.10 \mathrm{E}+07$ & $2.00 \mathrm{E}+04$ & $1.65 \mathrm{E}-02$ \\
\hline NB97M & $7.00 \mathrm{E}+03$ & $4.44 \mathrm{E}+05$ & $2.69 \mathrm{E}+07$ & $2.66 \mathrm{E}+02$ & $1.58 \mathrm{E}-02$ \\
\hline I134 & $6.10 \mathrm{E}+03$ & $4.05 \mathrm{E}+05$ & $3.90 \mathrm{E}+08$ & $2.92 \mathrm{E}+02$ & $1.51 \mathrm{E}-02$ \\
\hline PU239 & $1.40 \mathrm{E}-02$ & $1.00 \mathrm{E}+00$ & $6.21 \mathrm{E}-02$ & $1.18 \mathrm{E}+08$ & $1.40 \mathrm{E}-02$ \\
\hline NB97 & $5.60 \mathrm{E}+03$ & $4.44 \mathrm{E}+05$ & $2.69 \mathrm{E}+07$ & $2.66 \mathrm{E}+02$ & $1.26 \mathrm{E}-02$ \\
\hline Y90 & $2.30 \mathrm{E}+02$ & $1.88 \mathrm{E}+04$ & $5.44 \mathrm{E}+05$ & $6.29 \mathrm{E}+03$ & $1.22 \mathrm{E}-02$ \\
\hline CS138 & $8.10 \mathrm{E}+03$ & $6.96 \mathrm{E}+05$ & $4.69 \mathrm{E}+08$ & $1.70 \mathrm{E}+02$ & $1.16 \mathrm{E}-02$ \\
\hline NP239 & $2.20 \mathrm{E}+02$ & $2.91 \mathrm{E}+04$ & $2.32 \mathrm{E}+05$ & $4.07 \mathrm{E}+03$ & $7.56 \mathrm{E}-03$ \\
\hline SB127 & $1.40 \mathrm{E}+02$ & $1.88 \mathrm{E}+04$ & $2.67 \mathrm{E}+05$ & $6.29 \mathrm{E}+03$ & $7.44 \mathrm{E}-03$ \\
\hline SE83 & $3.80 \mathrm{E}+03$ & $6.04 \mathrm{E}+05$ & $1.02 \mathrm{E}+08$ & $1.96 \mathrm{E}+02$ & $6.29 \mathrm{E}-03$ \\
\hline TE131 & $3.20 \mathrm{E}+03$ & $5.25 \mathrm{E}+05$ & $7.98 \mathrm{E}+05$ & $2.26 \mathrm{E}+02$ & $6.10 \mathrm{E}-03$ \\
\hline RH106 & $4.30 \mathrm{E}+02$ & $7.27 \mathrm{E}+04$ & $8.45 \mathrm{E}+05$ & $1.63 \mathrm{E}+03$ & $5.91 \mathrm{E}-03$ \\
\hline TC99M & $5.60 \mathrm{E}+03$ & $1.10 \mathrm{E}+06$ & $3.62 \mathrm{E}+03$ & $1.07 \mathrm{E}+02$ & $5.08 \mathrm{E}-03$ \\
\hline RU105 & $5.70 \mathrm{E}+02$ & $1.28 \mathrm{E}+05$ & $6.73 \mathrm{E}+06$ & $9.25 \mathrm{E}+02$ & $4.45 \mathrm{E}-03$ \\
\hline BR84 & $1.90 \mathrm{E}+03$ & $5.16 \mathrm{E}+05$ & $7.05 \mathrm{E}+07$ & $2.29 \mathrm{E}+02$ & $3.68 \mathrm{E}-03$ \\
\hline MN56 & $5.10 \mathrm{E}+02$ & $1.60 \mathrm{E}+05$ & $2.17 \mathrm{E}+07$ & $7.40 \mathrm{E}+02$ & $3.19 \mathrm{E}-03$ \\
\hline
\end{tabular}




\begin{tabular}{|c|c|c|c|c|c|}
\hline Radioisotope & Curies $^{1}$ & WF- $68^{2}$ & $\begin{array}{c}\text { Specific Activity } \\
(\mathrm{Ci} / \mathrm{gm})\end{array}$ & $\begin{array}{c}\begin{array}{c}\text { ICRP-68 DCF } \\
(\mathrm{rem} / \mathrm{Ci})\end{array} \\
\end{array}$ & PEC- $68^{4}$ \\
\hline BA139 & $1.70 \mathrm{E}+03$ & $5.82 \mathrm{E}+05$ & $1.63 \mathrm{E}+07$ & $2.04 \mathrm{E}+02$ & $2.92 \mathrm{E}-03$ \\
\hline RM105 & $1.10 \mathrm{E}+03$ & $4.38 \mathrm{E}+05$ & $8.20 \mathrm{E}+04$ & $2.70 \mathrm{E}+02$ & $2.51 \mathrm{E}-03$ \\
\hline Y92 & $4.80 \mathrm{E}+03$ & $2.13 \mathrm{E}+06$ & $2.43 \mathrm{E}+04$ & $5.55 \mathrm{E}+01$ & $2.25 \mathrm{E}-03$ \\
\hline RB88 & $2.50 \mathrm{E}+03$ & $1.14 \mathrm{E}+06$ & $1.20 \mathrm{E}+08$ & $1.04 \mathrm{E}+02$ & $2.19 \mathrm{E}-03$ \\
\hline BA137M & $2.70 \mathrm{E}+02$ & $1.39 \mathrm{E}+05$ & $8.09 \mathrm{E}+05$ & $8.51 \mathrm{E}+02$ & $1.94 \mathrm{E}-03$ \\
\hline Y91M & $2.80 \mathrm{E}+03$ & $2.13 \mathrm{E}+06$ & $4.16 \mathrm{E}+07$ & $5.55 \mathrm{E}+01$ & $1.31 \mathrm{E}-03$ \\
\hline SN125 & $1.40 \mathrm{E}+01$ & $1.14 \mathrm{E}+04$ & $1.58 \mathrm{E}+08$ & $1.04 \mathrm{E}+04$ & $1.23 \mathrm{E}-03$ \\
\hline TE127M & $5.40 \mathrm{E}+00$ & $5.16 \mathrm{E}+03$ & $9.44 \mathrm{E}+03$ & $2.29 \mathrm{E}+04$ & $1.05 \mathrm{E}-03$ \\
\hline AG111 & $2.00 \mathrm{E}+01$ & $2.00 \mathrm{E}+04$ & $1.58 \mathrm{E}+05$ & $5.92 \mathrm{E}+03$ & $1.00 \mathrm{E}-03$ \\
\hline TE129 & $5.00 \mathrm{E}+02$ & $5.61 \mathrm{E}+05$ & $3.01 \mathrm{E}+04$ & $2.11 \mathrm{E}+02$ & 8.91E-04 \\
\hline PR144 & $9.50 \mathrm{E}+02$ & $1.07 \mathrm{E}+06$ & $7.56 \mathrm{E}+07$ & $1.11 \mathrm{E}+02$ & 8.91E-04 \\
\hline BR83 & $3.80 \mathrm{E}+02$ & $4.78 \mathrm{E}+05$ & $1.57 \mathrm{E}+07$ & $2.48 \mathrm{E}+02$ & $7.96 \mathrm{E}-04$ \\
\hline NB95M & $2.80 \mathrm{E}+01$ & $3.76 \mathrm{E}+04$ & $3.93 \mathrm{E}+04$ & $3.15 \mathrm{E}+03$ & $7.44 \mathrm{E}-04$ \\
\hline TE127 & $1.20 \mathrm{E}+02$ & $1.78 \mathrm{E}+05$ & $2.64 \mathrm{E}+06$ & $6.66 \mathrm{E}+02$ & $6.75 \mathrm{E}-04$ \\
\hline SN123 & $2.40 \mathrm{E}+00$ & $5.71 \mathrm{E}+03$ & $8.22 \mathrm{E}+03$ & $2.07 \mathrm{E}+04$ & $4.20 \mathrm{E}-04$ \\
\hline PD109 & $2.50 \mathrm{E}+01$ & $6.40 \mathrm{E}+04$ & $2.10 \mathrm{E}+06$ & $1.85 \mathrm{E}+03$ & $3.91 \mathrm{E}-04$ \\
\hline CD115 & $9.00 \mathrm{E}+00$ & $2.46 \mathrm{E}+04$ & $5.10 \mathrm{E}+05$ & $4.81 \mathrm{E}+03$ & $3.66 \mathrm{E}-04$ \\
\hline SB125 & $3.40 \mathrm{E}+00$ & $9.70 \mathrm{E}+03$ & $1.04 \mathrm{E}+03$ & $1.22 \mathrm{E}+04$ & $3.51 \mathrm{E}-04$ \\
\hline U236 & $1.70 \mathrm{E}-03$ & $5.08 \mathrm{E}+00$ & $6.47 \mathrm{E}-05$ & $2.33 \mathrm{E}+07$ & $3.35 \mathrm{E}-04$ \\
\hline CS136 & $5.20 \mathrm{E}+00$ & $1.68 \mathrm{E}+04$ & $7.30 \mathrm{E}+04$ & $7.03 \mathrm{E}+03$ & $3.09 \mathrm{E}-04$ \\
\hline AC227 & $1.10 \mathrm{E}-05$ & $5.08 \mathrm{E}-02$ & $7.24 \mathrm{E}+01$ & $2.33 \mathrm{E}+09$ & $2.17 \mathrm{E}-04$ \\
\hline U238 & $1.20 \mathrm{E}-03$ & $5.61 \mathrm{E}+00$ & $3.36 \mathrm{E}-07$ & $2.11 \mathrm{E}+07$ & $2.14 \mathrm{E}-04$ \\
\hline CS134 & $6.60 \mathrm{E}-01$ & $3.33 \mathrm{E}+03$ & $1.29 \mathrm{E}+03$ & $3.55 \mathrm{E}+04$ & $1.98 \mathrm{E}-04$ \\
\hline CD115M & $7.00 \mathrm{E}-01$ & $5.00 \mathrm{E}+03$ & $5.10 \mathrm{E}+05$ & $2.37 \mathrm{E}+04$ & $1.40 \mathrm{E}-04$ \\
\hline RH103M & $1.70 \mathrm{E}+03$ & $1.28 \mathrm{E}+07$ & $3.26 \mathrm{E}+07$ & $9.25 \mathrm{E}+00$ & $1.33 \mathrm{E}-04$ \\
\hline PA231 & $4.20 \mathrm{E}-05$ & $3.60 \mathrm{E}-01$ & $4.73 \mathrm{E}-02$ & $3.29 \mathrm{E}+08$ & $1.17 \mathrm{E}-04$ \\
\hline AS77 & $8.50 \mathrm{E}+00$ & $7.62 \mathrm{E}+04$ & $1.05 \mathrm{E}+06$ & $1.55 \mathrm{E}+03$ & $1.12 \mathrm{E}-04$ \\
\hline U237 & $1.70 \mathrm{E}+00$ & $1.88 \mathrm{E}+04$ & $8.16 \mathrm{E}+04$ & $6.29 \mathrm{E}+03$ & $9.03 \mathrm{E}-05$ \\
\hline PU238 & $8.50 \mathrm{E}-05$ & $1.07 \mathrm{E}+00$ & $1.71 \mathrm{E}+01$ & $1.11 \mathrm{E}+08$ & 7.97E-05 \\
\hline CD113M & $1.70 \mathrm{E}-02$ & $2.46 \mathrm{E}+02$ & $2.31 \mathrm{E}+02$ & $4.81 \mathrm{E}+05$ & $6.91 \mathrm{E}-05$ \\
\hline TE125M & $6.60 \mathrm{E}-01$ & $1.10 \mathrm{E}+04$ & $1.82 \mathrm{E}+04$ & $1.07 \mathrm{E}+04$ & $5.98 \mathrm{E}-05$ \\
\hline GE77 & $3.60 \mathrm{E}+00$ & $7.11 \mathrm{E}+04$ & $3.61 \mathrm{E}+06$ & $1.67 \mathrm{E}+03$ & $5.06 \mathrm{E}-05$ \\
\hline PU240 & $4.50 \mathrm{E}-05$ & $1.00 \mathrm{E}+00$ & $2.27 \mathrm{E}-01$ & $1.18 \mathrm{E}+08$ & $4.50 \mathrm{E}-05$ \\
\hline PM148M & 0.2 & $7.44 \mathrm{E}+03$ & $1.64 \mathrm{E}+05$ & $1.59 \mathrm{E}+04$ & $2.69 \mathrm{E}-05$ \\
\hline IN115M & $9.30 \mathrm{E}+00$ & $3.68 \mathrm{E}+05$ & $6.08 \mathrm{E}+06$ & $3.22 \mathrm{E}+02$ & $2.53 \mathrm{E}-05$ \\
\hline PM148 & $3.40 \mathrm{E}-01$ & $1.45 \mathrm{E}+04$ & $2.14 \mathrm{E}+04$ & $8.14 \mathrm{E}+03$ & $2.34 \mathrm{E}-05$ \\
\hline U232 & $1.50 \mathrm{E}-05$ & $1.23 \mathrm{E}+00$ & $2.24 \mathrm{E}+01$ & $9.62 \mathrm{E}+07$ & $1.22 \mathrm{E}-05$ \\
\hline P32 & $1.30 \mathrm{E}-01$ & $1.10 \mathrm{E}+04$ & $2.86 \mathrm{E}+05$ & $1.07 \mathrm{E}+04$ & $1.18 \mathrm{E}-05$ \\
\hline I130 & $3.30 \mathrm{E}-01$ & $3.33 \mathrm{E}+04$ & $1.95 \mathrm{E}+06$ & $3.55 \mathrm{E}+03$ & $9.90 \mathrm{E}-06$ \\
\hline TH228 & $1.10 \mathrm{E}-05$ & $1.28 \mathrm{E}+00$ & $8.21 \mathrm{E}+02$ & $9.25 \mathrm{E}+07$ & $8.59 \mathrm{E}-06$ \\
\hline ZR93 & $9.20 \mathrm{E}-03$ & $1.10 \mathrm{E}+03$ & $2.52 \mathrm{E}-03$ & $1.07 \mathrm{E}+05$ & 8.34E-06 \\
\hline
\end{tabular}




\begin{tabular}{|c|c|c|c|c|c|}
\hline Radioisotope & Curies $^{1}$ & WF- $68^{2}$ & $\begin{array}{c}\text { Specific Activity } \\
(\mathrm{Ci} / \mathrm{gm})\end{array}$ & $\begin{array}{c}\text { ICRP-68 DCF }{ }^{3} \\
(\mathrm{rem} / \mathrm{Ci})\end{array}$ & PEC- $68^{4}$ \\
\hline TC99 & $3.90 \mathrm{E}-02$ & $1.00 \mathrm{E}+04$ & $1.70 \mathrm{E}-02$ & $1.18 \mathrm{E}+04$ & $3.90 \mathrm{E}-06$ \\
\hline BR82 & $1.40 \mathrm{E}-01$ & $3.64 \mathrm{E}+04$ & $1.08 \mathrm{E}+06$ & $3.26 \mathrm{E}+03$ & $3.85 \mathrm{E}-06$ \\
\hline TH227 & $1.10 \mathrm{E}-05$ & $4.21 \mathrm{E}+00$ & $3.08 \mathrm{E}+04$ & $2.81 \mathrm{E}+07$ & $2.61 \mathrm{E}-06$ \\
\hline RB86 & $6.20 \mathrm{E}-02$ & $2.46 \mathrm{E}+04$ & $8.15 \mathrm{E}+04$ & $4.81 \mathrm{E}+03$ & $2.52 \mathrm{E}-06$ \\
\hline U234 & $1.10 \mathrm{E}-05$ & $4.71 \mathrm{E}+00$ & $6.23 \mathrm{E}-03$ & $2.52 \mathrm{E}+07$ & $2.34 \mathrm{E}-06$ \\
\hline NP237 & 4.90E-06 & $2.13 \mathrm{E}+00$ & 7.04E-04 & $5.55 \mathrm{E}+07$ & $2.30 \mathrm{E}-06$ \\
\hline RA223 & $1.10 \mathrm{E}-05$ & $5.61 \mathrm{E}+00$ & $5.12 \mathrm{E}+04$ & $2.11 \mathrm{E}+07$ & $1.96 \mathrm{E}-06$ \\
\hline SN119M & $3.00 \mathrm{E}-02$ & $2.13 \mathrm{E}+04$ & $3.75 \mathrm{E}+03$ & $5.55 \mathrm{E}+03$ & $1.41 \mathrm{E}-06$ \\
\hline SE77M & $2.60 \mathrm{E}-02$ & $1.88 \mathrm{E}+04$ & $1.46 \mathrm{E}+04$ & $6.29 \mathrm{E}+03$ & $1.38 \mathrm{E}-06$ \\
\hline H3 & 7.60E-01 & $7.80 \mathrm{E}+05$ & $9.63 \mathrm{E}+03$ & $1.52 \mathrm{E}+02$ & $9.74 \mathrm{E}-07$ \\
\hline RA224 & $1.10 \mathrm{E}-05$ & $1.33 \mathrm{E}+01$ & $1.59 \mathrm{E}+05$ & $8.88 \mathrm{E}+06$ & $8.25 \mathrm{E}-07$ \\
\hline GA72 & $2.60 \mathrm{E}-02$ & $3.81 \mathrm{E}+04$ & $3.09 \mathrm{E}+06$ & $3.11 \mathrm{E}+03$ & $6.83 \mathrm{E}-07$ \\
\hline PU241 & $3.20 \mathrm{E}-05$ & $5.52 \mathrm{E}+01$ & $1.04 \mathrm{E}+02$ & $2.15 \mathrm{E}+06$ & $5.80 \mathrm{E}-07$ \\
\hline SB124 & $3.30 \mathrm{E}-03$ & $6.81 \mathrm{E}+03$ & $1.75 \mathrm{E}+04$ & $1.74 \mathrm{E}+04$ & $4.85 \mathrm{E}-07$ \\
\hline TH234 & $1.90 \mathrm{E}-03$ & $5.52 \mathrm{E}+03$ & $2.31 \mathrm{E}+04$ & $2.15 \mathrm{E}+04$ & $3.44 \mathrm{E}-07$ \\
\hline NA24 & $1.70 \mathrm{E}-02$ & $6.04 \mathrm{E}+04$ & $2.33 \mathrm{E}+13$ & $1.96 \mathrm{E}+03$ & $2.82 \mathrm{E}-07$ \\
\hline AM241 & $2.60 \mathrm{E}-07$ & $1.19 \mathrm{E}+00$ & $3.43 \mathrm{E}+00$ & $9.99 \mathrm{E}+07$ & $2.19 \mathrm{E}-07$ \\
\hline SI31 & $5.90 \mathrm{E}-02$ & $2.91 \mathrm{E}+05$ & $3.86 \mathrm{E}+07$ & $4.07 \mathrm{E}+02$ & $2.03 \mathrm{E}-07$ \\
\hline TM231 & $2.00 \mathrm{E}-01$ & $1.03 \mathrm{E}+06$ & $7.07 \mathrm{E}+07$ & $1.15 \mathrm{E}+02$ & $1.94 \mathrm{E}-07$ \\
\hline PR142 & $7.00 \mathrm{E}-03$ & $4.32 \mathrm{E}+04$ & $1.15 \mathrm{E}+06$ & $2.74 \mathrm{E}+03$ & $1.62 \mathrm{E}-07$ \\
\hline CS134M & $1.50 \mathrm{E}-01$ & $1.23 \mathrm{E}+06$ & $2.67 \mathrm{E}+03$ & $9.62 \mathrm{E}+01$ & $1.22 \mathrm{E}-07$ \\
\hline CS135 & $3.90 \mathrm{E}-03$ & $3.23 \mathrm{E}+04$ & $1.15 \mathrm{E}-03$ & $3.66 \mathrm{E}+03$ & $1.21 \mathrm{E}-07$ \\
\hline $\mathrm{SC} 48$ & $2.20 \mathrm{E}-03$ & $2.00 \mathrm{E}+04$ & $1.50 \mathrm{E}+06$ & $5.92 \mathrm{E}+03$ & $1.10 \mathrm{E}-07$ \\
\hline NB93M & $3.40 \mathrm{E}-03$ & $3.72 \mathrm{E}+04$ & $2.64 \mathrm{E}+02$ & $3.18 \mathrm{E}+03$ & $9.14 \mathrm{E}-08$ \\
\hline I129 & $5.60 \mathrm{E}-05$ & $6.27 \mathrm{E}+02$ & $1.77 \mathrm{E}-04$ & $1.89 \mathrm{E}+05$ & $8.93 \mathrm{E}-08$ \\
\hline AG110M & $3.80 \mathrm{E}-04$ & $4.38 \mathrm{E}+03$ & $4.76 \mathrm{E}+03$ & $2.70 \mathrm{E}+04$ & $8.67 \mathrm{E}-08$ \\
\hline PA234M & $1.90 \mathrm{E}-03$ & $5.52 \mathrm{E}+04$ & $2.00 \mathrm{E}+06$ & $2.15 \mathrm{E}+03$ & $3.44 \mathrm{E}-08$ \\
\hline FE59 & $3.20 \mathrm{E}-04$ & $1.00 \mathrm{E}+04$ & $4.98 \mathrm{E}+04$ & $1.18 \mathrm{E}+04$ & $3.20 \mathrm{E}-08$ \\
\hline NP238 & $4.50 \mathrm{E}-04$ & $1.88 \mathrm{E}+04$ & $2.59 \mathrm{E}+05$ & $6.29 \mathrm{E}+03$ & $2.39 \mathrm{E}-08$ \\
\hline SB122 & 4.10E-04 & $2.67 \mathrm{E}+04$ & $3.93 \mathrm{E}+05$ & $4.44 \mathrm{E}+03$ & $1.54 \mathrm{E}-08$ \\
\hline $\mathrm{BI} 212$ & $1.10 \mathrm{E}-05$ & $8.21 \mathrm{E}+02$ & $3.55 \mathrm{E}+07$ & $1.44 \mathrm{E}+05$ & $1.34 \mathrm{E}-08$ \\
\hline PB212 & $1.10 \mathrm{E}-05$ & $9.70 \mathrm{E}+02$ & $1.39 \mathrm{E}+06$ & $1.22 \mathrm{E}+05$ & $1.13 \mathrm{E}-08$ \\
\hline U233 & $5.20 \mathrm{E}-08$ & $4.64 \mathrm{E}+00$ & $9.64 \mathrm{E}-03$ & $2.55 \mathrm{E}+07$ & $1.12 \mathrm{E}-08$ \\
\hline BR80 & $1.40 \mathrm{E}-02$ & $1.88 \mathrm{E}+06$ & $1.33 \mathrm{E}+08$ & $6.29 \mathrm{E}+01$ & 7.44E-09 \\
\hline IN114M & $1.60 \mathrm{E}-05$ & $2.91 \mathrm{E}+03$ & $2.32 \mathrm{E}+04$ & $4.07 \mathrm{E}+04$ & $5.50 \mathrm{E}-09$ \\
\hline AS76 & $1.80 \mathrm{E}-04$ & $3.48 \mathrm{E}+04$ & $1.60 \mathrm{E}+06$ & $3.40 \mathrm{E}+03$ & $5.18 \mathrm{E}-09$ \\
\hline CM242 & $3.70 \mathrm{E}-08$ & $8.65 \mathrm{E}+00$ & $3.31 \mathrm{E}+03$ & $1.37 \mathrm{E}+07$ & $4.28 \mathrm{E}-09$ \\
\hline SR87M & $3.80 \mathrm{E}-03$ & $9.14 \mathrm{E}+05$ & $1.29 \mathrm{E}+07$ & $1.30 \mathrm{E}+02$ & 4.16E-09 \\
\hline BR80M & $8.40 \mathrm{E}-04$ & $3.20 \mathrm{E}+05$ & $1.33 \mathrm{E}+08$ & $3.70 \mathrm{E}+02$ & $2.63 \mathrm{E}-09$ \\
\hline CA45 & $2.20 \mathrm{E}-05$ & $1.39 \mathrm{E}+04$ & $1.79 \mathrm{E}+04$ & $8.51 \mathrm{E}+03$ & $1.58 \mathrm{E}-09$ \\
\hline TH230 & $9.00 \mathrm{E}-10$ & $1.14 \mathrm{E}+00$ & $2.06 \mathrm{E}-02$ & $1.04 \mathrm{E}+08$ & $7.88 \mathrm{E}-10$ \\
\hline
\end{tabular}




\begin{tabular}{|c|c|c|c|c|c|}
\hline Radioisotope & Curies $^{1}$ & WF- $68^{2}$ & $\begin{array}{c}\text { Specific Activity } \\
(\mathrm{Ci} / \mathrm{gm})\end{array}$ & $\begin{array}{c}\text { ICRP-68 DCF }{ }^{3} \\
(\mathrm{rem} / \mathrm{Ci})\end{array}$ & PEC- $68^{4}$ \\
\hline PA233 & $5.00 \mathrm{E}-06$ & $1.00 \mathrm{E}+04$ & $2.08 \mathrm{E}+04$ & $1.18 \mathrm{E}+04$ & $5.00 \mathrm{E}-10$ \\
\hline PU236 & $9.10 \mathrm{E}-10$ & $2.46 \mathrm{E}+00$ & $5.30 \mathrm{E}+02$ & $4.81 \mathrm{E}+07$ & $3.70 \mathrm{E}-10$ \\
\hline AM242M & $1.80 \mathrm{E}-10$ & $1.33 \mathrm{E}+00$ & $1.05 \mathrm{E}+01$ & $8.88 \mathrm{E}+07$ & $1.35 \mathrm{E}-10$ \\
\hline TL208 & $4.10 \mathrm{E}-06$ & $5.16 \mathrm{E}+04$ & $4.64 \mathrm{E}+02$ & $2.29 \mathrm{E}+03$ & $7.94 \mathrm{E}-11$ \\
\hline CD111M & $1.80 \mathrm{E}-07$ & $3.33 \mathrm{E}+03$ & $2.60 \mathrm{E}+03$ & $3.55 \mathrm{E}+04$ & $5.40 \mathrm{E}-11$ \\
\hline PA234 & $1.90 \mathrm{E}-06$ & $5.52 \mathrm{E}+04$ & $2.00 \mathrm{E}+06$ & $2.15 \mathrm{E}+03$ & $3.44 \mathrm{E}-11$ \\
\hline IN114 & $2.50 \mathrm{E}-05$ & $1.00 \mathrm{E}+06$ & $1.67 \mathrm{E}+07$ & $1.18 \mathrm{E}+02$ & $2.50 \mathrm{E}-11$ \\
\hline RB87 & $7.40 \mathrm{E}-08$ & $4.21 \mathrm{E}+04$ & 8.56E-08 & $2.81 \mathrm{E}+03$ & $1.76 \mathrm{E}-12$ \\
\hline TE123M & $1.40 \mathrm{E}-08$ & $9.41 \mathrm{E}+03$ & $8.88 \mathrm{E}+03$ & $1.26 \mathrm{E}+04$ & $1.49 \mathrm{E}-12$ \\
\hline TH232 & $8.00 \mathrm{E}-13$ & $1.10 \mathrm{E}+00$ & $1.10 \mathrm{E}-07$ & $1.07 \mathrm{E}+08$ & $7.25 \mathrm{E}-13$ \\
\hline PU242 & $6.00 \mathrm{E}-13$ & $1.03 \mathrm{E}+00$ & $3.94 \mathrm{E}-03$ & $1.15 \mathrm{E}+08$ & $5.81 \mathrm{E}-13$ \\
\hline SC49 & $1.10 \mathrm{E}-07$ & $5.25 \mathrm{E}+05$ & $6.72 \mathrm{E}+07$ & $2.26 \mathrm{E}+02$ & $2.10 \mathrm{E}-13$ \\
\hline PO214 & $2.60 \mathrm{E}-12$ & $1.45 \mathrm{E}+01$ & $4.49 \mathrm{E}+03$ & $8.14 \mathrm{E}+06$ & $1.79 \mathrm{E}-13$ \\
\hline PO218 & $2.60 \mathrm{E}-12$ & $1.45 \mathrm{E}+01$ & $4.49 \mathrm{E}+03$ & $8.14 \mathrm{E}+06$ & $1.79 \mathrm{E}-13$ \\
\hline RA226 & $2.60 \mathrm{E}-12$ & $1.45 \mathrm{E}+01$ & $9.89 \mathrm{E}-01$ & $8.14 \mathrm{E}+06$ & $1.79 \mathrm{E}-13$ \\
\hline AT217 & $4.70 \mathrm{E}-11$ & $2.91 \mathrm{E}+02$ & $2.06 \mathrm{E}+06$ & $4.07 \mathrm{E}+05$ & $1.62 \mathrm{E}-13$ \\
\hline AM242 & $4.20 \mathrm{E}-10$ & $2.67 \mathrm{E}+03$ & $8.08 \mathrm{E}+05$ & $4.44 \mathrm{E}+04$ & $1.58 \mathrm{E}-13$ \\
\hline $\mathrm{C} 14$ & $1.80 \mathrm{E}-09$ & $6.40 \mathrm{E}+04$ & $4.48 \mathrm{E}+00$ & $1.85 \mathrm{E}+03$ & $2.81 \mathrm{E}-14$ \\
\hline PO210 & $3.40 \mathrm{E}-13$ & $1.45 \mathrm{E}+01$ & $4.49 \mathrm{E}+03$ & $8.14 \mathrm{E}+06$ & $2.34 \mathrm{E}-14$ \\
\hline RA228 & $3.50 \mathrm{E}-13$ & $1.88 \mathrm{E}+01$ & $2.73 \mathrm{E}+02$ & $6.29 \mathrm{E}+06$ & $1.86 \mathrm{E}-14$ \\
\hline AM243 & $2.20 \mathrm{E}-14$ & $1.19 \mathrm{E}+00$ & $2.00 \mathrm{E}-01$ & $9.99 \mathrm{E}+07$ & $1.86 \mathrm{E}-14$ \\
\hline $\mathrm{SC} 47$ & $7.10 \mathrm{E}-10$ & $4.38 \mathrm{E}+04$ & $8.30 \mathrm{E}+05$ & $2.70 \mathrm{E}+03$ & $1.62 \mathrm{E}-14$ \\
\hline PB210 & $3.80 \mathrm{E}-13$ & $2.91 \mathrm{E}+01$ & $7.64 \mathrm{E}+01$ & $4.07 \mathrm{E}+06$ & $1.31 \mathrm{E}-14$ \\
\hline CM243 & $7.00 \mathrm{E}-15$ & $1.60 \mathrm{E}+00$ & $5.06 \mathrm{E}+01$ & $7.40 \mathrm{E}+07$ & $4.38 \mathrm{E}-15$ \\
\hline CM244 & $5.30 \mathrm{E}-15$ & $1.88 \mathrm{E}+00$ & $8.10 \mathrm{E}+01$ & $6.29 \mathrm{E}+07$ & $2.82 \mathrm{E}-15$ \\
\hline BI214 & $2.60 \mathrm{E}-12$ & $1.52 \mathrm{E}+03$ & $1.93 \mathrm{E}+07$ & $7.77 \mathrm{E}+04$ & $1.71 \mathrm{E}-15$ \\
\hline BI210 & $3.80 \mathrm{E}-13$ & $5.33 \mathrm{E}+02$ & $5.60 \mathrm{E}-04$ & $2.22 \mathrm{E}+05$ & $7.13 \mathrm{E}-16$ \\
\hline PB214 & $2.60 \mathrm{E}-12$ & $6.67 \mathrm{E}+03$ & $3.28 \mathrm{E}+07$ & $1.78 \mathrm{E}+04$ & $3.90 \mathrm{E}-16$ \\
\hline IN115 & $2.70 \mathrm{E}-14$ & $7.11 \mathrm{E}+01$ & $7.06 \mathrm{E}-12$ & $1.67 \mathrm{E}+06$ & $3.80 \mathrm{E}-16$ \\
\hline AC228 & $3.50 \mathrm{E}-13$ & $1.10 \mathrm{E}+03$ & $2.23 \mathrm{E}+06$ & $1.07 \mathrm{E}+05$ & $3.17 \mathrm{E}-16$ \\
\hline CD109 & $1.10 \mathrm{E}-14$ & $3.33 \mathrm{E}+03$ & $2.60 \mathrm{E}+03$ & $3.55 \mathrm{E}+04$ & $3.30 \mathrm{E}-18$ \\
\hline ND144 & $3.20 \mathrm{E}-12$ & $3.64 \mathrm{E}+06$ & $8.93 \mathrm{E}+06$ & $3.26 \mathrm{E}+01$ & $8.80 \mathrm{E}-19$ \\
\hline CA47 & $2.60 \mathrm{E}-15$ & $1.52 \mathrm{E}+04$ & $6.13 \mathrm{E}+05$ & $7.77 \mathrm{E}+03$ & $1.71 \mathrm{E}-19$ \\
\hline SC47 & $4.10 \mathrm{E}-15$ & $4.38 \mathrm{E}+04$ & $8.30 \mathrm{E}+05$ & $2.70 \mathrm{E}+03$ & $9.35 \mathrm{E}-20$ \\
\hline IN113M & $4.80 \mathrm{E}-14$ & $1.00 \mathrm{E}+06$ & $1.67 \mathrm{E}+07$ & $1.18 \mathrm{E}+02$ & $4.80 \mathrm{E}-20$ \\
\hline PU243 & 4.40E-15 & $2.91 \mathrm{E}+05$ & $2.60 \mathrm{E}+06$ & $4.07 \mathrm{E}+02$ & $1.51 \mathrm{E}-20$ \\
\hline NI63 & $2.80 \mathrm{E}-16$ & $6.15 \mathrm{E}+04$ & $5.68 \mathrm{E}+01$ & $1.92 \mathrm{E}+03$ & $4.55 \mathrm{E}-21$ \\
\hline CM245 & $2.20 \mathrm{E}-21$ & $1.19 \mathrm{E}+00$ & $1.72 \mathrm{E}-01$ & $9.99 \mathrm{E}+07$ & $1.86 \mathrm{E}-21$ \\
\hline K42 & $5.50 \mathrm{E}-19$ & $1.60 \mathrm{E}+05$ & $6.04 \mathrm{E}+06$ & $7.40 \mathrm{E}+02$ & $3.44 \mathrm{E}-24$ \\
\hline AL28 & $1.60 \mathrm{E}+03$ & $0.00 \mathrm{E}+00$ & $3.00 \mathrm{E}+09$ & & \\
\hline BR85 & $1.30 \mathrm{E}+05$ & & $7.71 \mathrm{E}+08$ & & \\
\hline
\end{tabular}




\begin{tabular}{|c|c|c|c|c|c|}
\hline Radioisotope & Curies $^{1}$ & WF- $68^{2}$ & $\begin{array}{c}\text { Specific Activity } \\
(\mathrm{Ci} / \mathrm{gm})\end{array}$ & $\begin{array}{c}\begin{array}{c}\text { ICRP-68 DCF } \\
\text { (rem/Ci) }\end{array} \\
\end{array}$ & PEC- $68^{4}$ \\
\hline BR87 & $9.20 \mathrm{E}+05$ & & $2.34 \mathrm{E}+09$ & & \\
\hline BR88 & $2.00 \mathrm{E}+06$ & & $7.82 \mathrm{E}+09$ & & \\
\hline BR89 & $1.60 \mathrm{E}+06$ & & $2.88 \mathrm{E}+10$ & & \\
\hline BR90 & $1.10 \mathrm{E}+06$ & & $6.96 \mathrm{E}+10$ & & \\
\hline BR91 & $3.60 \mathrm{E}+05$ & & $2.07 \mathrm{E}+11$ & & \\
\hline $\mathrm{I} 133 \mathrm{M}$ & $1.10 \mathrm{E}+05$ & $0.00 \mathrm{E}+00$ & $9.43 \mathrm{E}+09$ & & \\
\hline I134M & $6.30 \mathrm{E}+04$ & $0.00 \mathrm{E}+00$ & $2.67 \mathrm{E}+07$ & & \\
\hline I136 & $7.50 \mathrm{E}+05$ & & $1.84 \mathrm{E}+09$ & & \\
\hline I137 & $2.20 \mathrm{E}+06$ & & $3.36 \mathrm{E}+09$ & & \\
\hline I138 & $1.40 \mathrm{E}+06$ & & $1.26 \mathrm{E}+10$ & & \\
\hline I139 & $6.40 \mathrm{E}+05$ & & $3.38 \mathrm{E}+10$ & & \\
\hline I140 & $1.90 \mathrm{E}+05$ & $0.00 \mathrm{E}+00$ & $9.37 \mathrm{E}+10$ & & \\
\hline KR83M & $3.40 \mathrm{E}+02$ & $0.00 \mathrm{E}+00$ & $2.07 \mathrm{E}+07$ & & \\
\hline KR85 & $2.10 \mathrm{E}+01$ & & $3.94 \mathrm{E}+02$ & & \\
\hline KR85M & $8.60 \mathrm{E}+02$ & & $8.24 \mathrm{E}+06$ & & \\
\hline KR87 & $7.40 \mathrm{E}+03$ & & $2.83 \mathrm{E}+07$ & & \\
\hline KR88 & $1.10 \mathrm{E}+04$ & & $1.26 \mathrm{E}+07$ & & \\
\hline KR89 & $7.40 \mathrm{E}+05$ & & $6.71 \mathrm{E}+07$ & & \\
\hline KR90 & $2.90 \mathrm{E}+06$ & & $3.88 \mathrm{E}+09$ & & \\
\hline KR91 & $3.00 \mathrm{E}+06$ & & $1.41 \mathrm{E}+10$ & & \\
\hline ND149 & $1.10 \mathrm{E}+03$ & $0.00 \mathrm{E}+00$ & $1.22 \mathrm{E}+07$ & & \\
\hline RN220 & $1.10 \mathrm{E}-05$ & & $9.22 \mathrm{E}+08$ & & \\
\hline RN222 & $2.60 \mathrm{E}-12$ & & $1.54 \mathrm{E}+05$ & & \\
\hline XE131M & $1.50 \mathrm{E}+01$ & & $8.42 \mathrm{E}+04$ & & \\
\hline XE133 & $7.30 \mathrm{E}+03$ & & $1.82 \mathrm{E}+05$ & & \\
\hline XE133M & $2.10 \mathrm{E}+02$ & & $4.48 \mathrm{E}+05$ & & \\
\hline XE135 & $6.50 \mathrm{E}+03$ & & $2.55 \mathrm{E}+06$ & & \\
\hline XE135M & $6.70 \mathrm{E}+03$ & & $1.51 \mathrm{E}+06$ & & \\
\hline XE137 & $6.40 \mathrm{E}+05$ & & $3.56 \mathrm{E}+08$ & & \\
\hline XE138 & $2.40 \mathrm{E}+05$ & & $9.64 \mathrm{E}+07$ & & \\
\hline XE139 & $2.80 \mathrm{E}+06$ & & $2.03 \mathrm{E}+09$ & & \\
\hline XE140 & $3.00 \mathrm{E}+06$ & & $5.88 \mathrm{E}+09$ & & \\
\hline Total & $3.41 \mathrm{E}+07$ & $5.62 \mathrm{E}+07$ & $2.38 \mathrm{E}+13$ & $4.39 \mathrm{E}+09$ & $3.72 \mathrm{E}+01$ \\
\hline
\end{tabular}

\section{E-3. REFERENCES}

DOE-HDBK-3010-1994, “Airborne Release Fractions/Rates and Respirable Fractions for Nonreactor Nuclear Facilities," U.S. Department of Energy, Change Notice No. 1, March 2000. 
DOE-HDBK-3010-1994, “Airborne Release Fractions/Rates and Respirable Fractions for Nonreactor Nuclear Facilities," U.S. Department of Energy, Change Notice No. 1, March 2000.

DOE Order 440.1B, “Worker Protection Program for DOE,” U.S. Department of Energy, May 2007.

ECAR-1214, 2011, “Analysis Calculations for Plutonium-239 Equivalent Curies (PEC),” Idaho National Laboratory.

ICRP-68, 1994, "Dose Coefficients for Intakes of Radionuclides by Workers," International Commission on Radiological Protection.

ICRP-72, 1996, “Age-dependent Doses from Intakes of Radionuclides,” International Commission on Radiological Protection.

INL, 2010, Radiological Safety Analysis Comptuer (RSAC) Program Version 7.2 Users' Manual, INL/EXT-09-15275, Revision 1, October 2010.

INL, 2013, National Environmental Policy Act Hazards Assessment of the TREAT Alternative, INL/EXT-13-29496, Revision 0, Idaho National Laboratory.

NRC, 2003, "Interim Staff Guidance - 5, Revision 1, Confinement Evaluation," SFST-ISG-5, Revision 1, Washington, D.C.: U.S. Nuclear Regulatory Commission, accessed June 3, 2013 http://www.nrc.gov/reading-rm/doc-collections/isg/spent-fuel.html.

TEV-1832, 2013, “Overview of Anticipated Transient Test Experiments,” Revision 03, Idaho National Laboratory, March 1, 2013. 


$$
\text { E-18 }
$$




\title{
Appendix F
}

\section{Accident Impact Assessment for the TREAT and ACRR Facilities}

\author{
Primary Contributors \\ Annette L. Schafer, Idaho National Laboratory \\ Boyd D. Christensen, Idaho National Laboratory \\ James J. Dahl, Sandia National Laboratory \\ Peter V. Subaiya, Sandia National Laboratory \\ David C. Carathers, Sandia National Laboratory
}


F-2 


\section{CONTENTS}

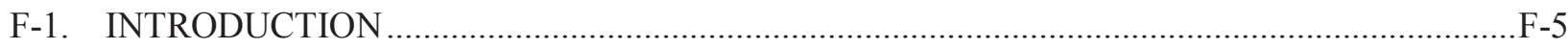

F-1.1 Accident Scenarios Identified for the Transient Reactor Test Facility …...........................F-5

F-1.2 Accident Scenarios Identified for Idaho National Laboratory Facilities other than

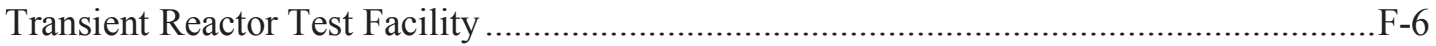

F-1.3 Accident Scenarios Identified for the Annular Core Research Reactor Facility ..................F-8

F-2. DOSE ASSESSMENT METHODOLOGY AND ASSUMPTIONS ….........................................

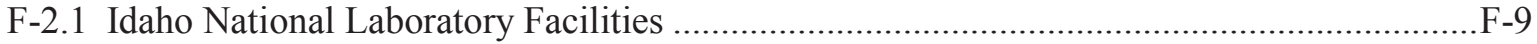

F-2.2 Annular Core Research Reactor Facilities .....................................................................

F-2.3 Differences in Dose Assessment Assumptions ................................................................

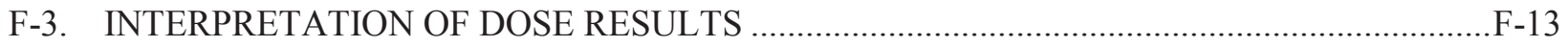

F-4. PREDICTED DOSE IMPACTS FOR ACCIDENTS AT TRANSIENT REACTOR TEST

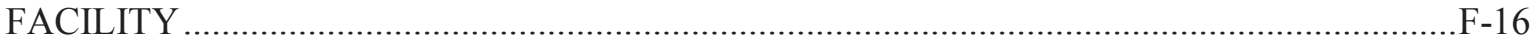

F-4.1 Hypothesized Reactor Fuel Clad Failure ……..............................................................

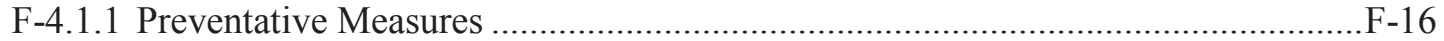

F-4.1.2 Probability of this Type of Accident Occurring..................................................... 19

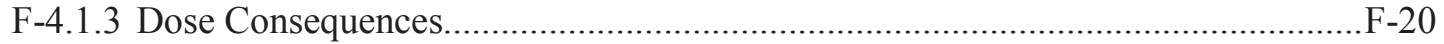

F-4.2 Hypothesized Experiment Impact/Drop Accident ....................................................F-23

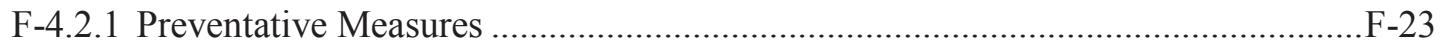

F-4.2.2 Probability of this Type of Accident Occurring .................................................. 25

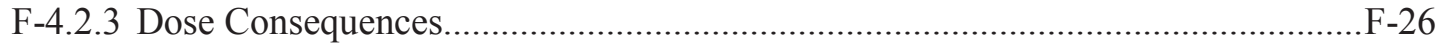

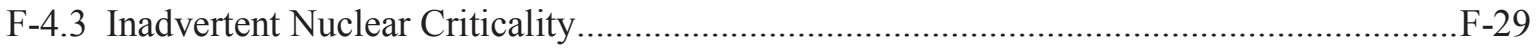

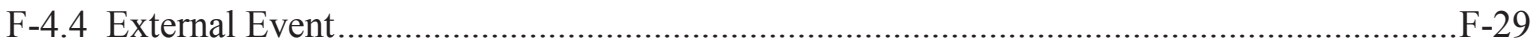

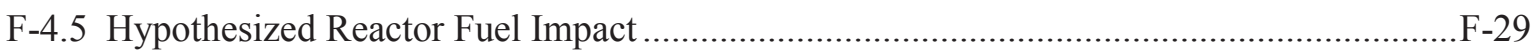

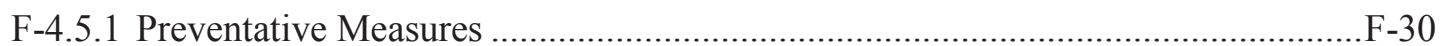

F-4.5.2 Probability of this Type of Accident Occurring .....................................................

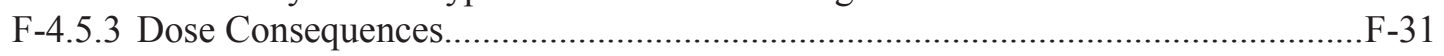

F-4.6 Hypothesized Drop of Experiment into the TREAT Reactor ..............................................

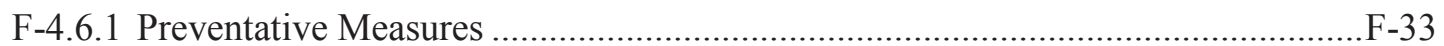

F-4.6.2 Probability of this Type of Accident Occurring.......................................................

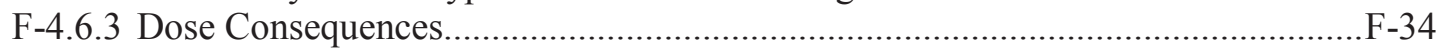


F-4.7 Hypothesized Sodium Fire Impacting the Core and Experiment....................................F-35

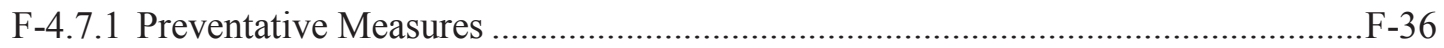

F-4.7.2 Probability of this Type of Accident Occurring................................................. 37

F-4.7.3 Dose Consequences.....................................................................................

F-4.8 Cask Handling Operations at the Hot Fuel Examination Facility ......................................39

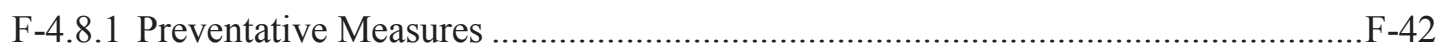

F-4.8.2 Probability of this Type of Accident Occurring ................................................... 42

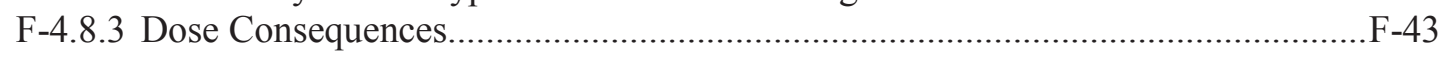

F-4.9 Overview of Accident Analysis for Alternative 1 (TREAT) .............................................4-46

F-4.9.1 Summary of Radiologic Consequences for Alternative 1 (TREAT) ...................... -47

F-5. PREDICTED DOSE IMPACTS FOR ACCIDENTS IN ALTERNATIVE 2 (ACRR)................F-50

F-5.1 Experiment Drop or Impact Accident at the Annular Core Research Reactor ...................F-50

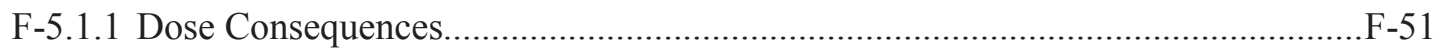

F-5.2 Rapid Over-Pressurization of the Sodium-Cooled Experiment …...................................F-52

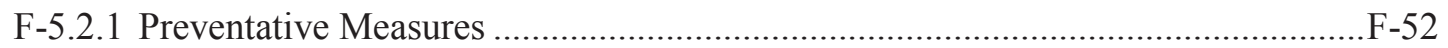

F-5.2.2 Probability of this Type of Accident Occurring ......................................................5-53

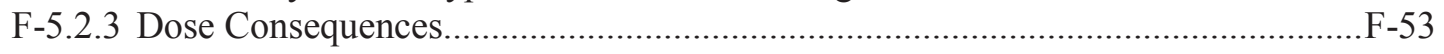

F-5.3 Releasing Melted Fuel into the Annular Core Research Reactor Central Cavity ...............F-54

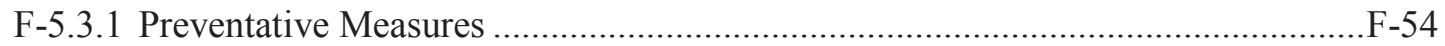

F-5.3.2 Probability of this Type of Accident Occurring......................................................5-55

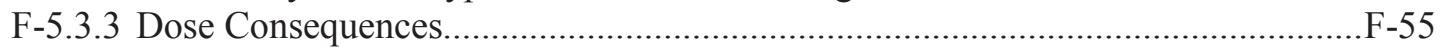

F-5.4 Summary of Impacts Using the Annular Core Research Reactor Facility ........................F-57

F-5.4.1 Overview of Accident Analysis for the Annular Core Research Reactor..............F-57

F-5.4.2 Summary of Radiologic Consequences for Alternative 2 (ACRR) .........................5-57

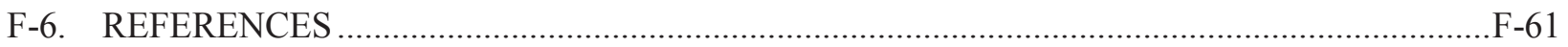




\section{Appendix F Accident Impact Assessment for TREAT and ACRR Facilities}

\section{F-1. INTRODUCTION}

This appendix provides a screening level assessment of human health impacts that could result from the resumption of transient testing. By section, this analysis includes the following:

- Sections F-1.1, F-1.2, and F-1.3 provide an overview of accident scenarios for TREAT, other facilities at INL, and SNL/NM, respectively. Scenarios evaluated are based on those identified in the hazards analyses conducted for both alternatives documented in INL (2013), this document, and SNL/NM (2013).

- Section F-2 provides the dose assessment methodologies for INL and SNL/NM. This section contains an overview of differences in the methodology applied for accidents occurring at INL and ACRR, with an assessment of the relative differences that could be introduced into the resultant doses.

- Section F-3 provides a basis for interpreting dose consequences from accidents. Accident dose consequences are not evaluated using the same dose limits used for normal operations (40 CFR 61, Subpart H) that were provided in Appendix C.

- Section F-4 provides the detailed analyses of bounding accident scenarios and corresponding screening level dose consequences for accidents that could occur as a result of the RTT Program using facilities at INL, including TREAT.

- Section F-5 provides (1) an evaluation of potential dose consequences for accident scenarios evaluated for material handling accidents that could occur at the proposed ACRR hot cell that are derived from the detailed analysis conducted for TREAT and (2) an overview of the analysis conducted for accident scenarios documented in SNL/NM (2013) for scenarios involving the experiment loop and ACRR.

\section{F-1.1 Accident Scenarios Identified for the Transient Reactor Test Facility}

The hazards analysis that was prepared to support the NEPA-HA (INL 2013) identifies bounding scenarios that could lead to radionuclide releases outside normal operations at TREAT. Identification of hazards focused on those that could occur: (1) during use of the TREAT Reactor for normal operations and transient testing, (2) as the TREAT Reactor fuel and experiment assemblies are handled in the TREAT facility, and (3) when the experiment assemblies are being subjected to transient testing. Hazards associated with operation of the TREAT Reactor during normal operations or transient testing would not involve other facilities, and the potential to impact the current storage mission of the TREAT facility was determined to not be credible because of the robust design of the reactor structure and subsurface storage areas (INL 2013).

Potential accident scenarios identified involving operation of the TREAT Reactor, handling of fuel or experiments, and combinations of events involving the TREAT Reactor and experiment loop were evaluated for initiating conditions that included a range of operator errors, equipment failures, external events, and natural phenomena. Examples of operator errors and equipment failure include the following:

- Equipment failure or operator error initiates an electrical fire, resulting in damage to shipping casks/shielded containers and the subsequent release of radioactive material. 
- Equipment failure or operator error initiates a heavy object drop, which impacts a loaded cask that causes a failure in the cask structural integrity or a cask rupture, resulting in a radioactive material release.

Examples of external events or natural phenomena-induced failure modes include the following:

- Range fire damages the reactor facility infrastructure or asset(s), resulting in a radioactive material release.

- $\quad$ NPH exceeds the building design limits (e.g., seismic stability, wind load, or snow load), initiating a facility infrastructure, equipment (e.g., crane), or asset collapse that results in a radioactive material release.

In the NEPA-HA (INL 2013), the postulated events were assessed to identify representative, bounding, or unique events. These design basis accidents (DBAs) were categorized as shown in Table F-1. Experience in other facilities indicates that these DBA events typically represent the highest risk in terms of likelihood and dose consequence. These accident categories are assessed in Section F-4.

Table F-1. Design basis accident categories.

\begin{tabular}{ll}
$\begin{array}{l}\text { Category } \\
\text { Number }\end{array}$ & Hazard Category \\
\hline 1 & Reactor fuel clad failure (bounds all reactivity insertion accidents) \\
2 & $\begin{array}{l}\text { Transport vehicle fire (bounds all fire and explosion events) (analyzed in Appendix G and } \\
\text { summarized in Section 5. }\end{array}$ \\
3 & Experiment drop (bounds all radioactive material release or direct radiation exposure events) \\
4 & Inadvertent nuclear criticality \\
5 & External events (consequences bounded by other events) \\
6 & Severe seismic event (bounds all NPH events) \\
7 & Events involving mechanical failure of the experiment loop while in the TREAT Reactor. \\
\hline
\end{tabular}

\section{F-1.2 Accident Scenarios Identified for Idaho National Laboratory Facilities other than Transient Reactor Test Facility}

Activities associated with use of other facilities at INL, including, but not limited to, ATR, HFEF, other facilities at MFC, and INTEC, will be subject to their respective unreviewed safety question process to ensure each activity associated with the RTT Program is bounded by the facility safety basis. This means that these facilities will operate under their current safety envelope, which bounds the test inventory provided in Appendix E. Activities that will be conducted at these facilities include transportation packing and receipt, pre-irradiation and post-irradiation examination, and waste packaging. Most of these activities will be performed at MFC, with the majority of them occurring at HFEF. MFC is the facility closest to an INL border and to potential members of the public other than TREAT that will be used by the RTT Program. Therefore, the assessment of accident scenarios with the potential of occurring at INL facilities other than TREAT focused on those that could occur at HFEF.

HFEF is a versatile hot-cell facility that consists primarily of two adjacent shielded cells, in a three-story (above ground) building. The facility includes an air-atmosphere decontamination cell (decon cell), an argon-atmosphere main cell (main cell), decontamination areas, repair areas for hot-cell equipment, a radiochemistry laboratory, auxiliary laboratories, offices, and a high-bay area. The facility Safety Analysis Report for HFEF (SAR-405 2013) is being prepared to meet the requirements of the Nuclear Safety Management Rule provided in 10 CFR 830, "Nuclear Safety Management." SAR-405 identifies the hazards that could potentially result in the release of radioactive materials to the 
environment, the material at risk at HFEF, and the resultant risk to facility workers, collocated workers, and members of the public. These are discussed relative to the use of HFEF by the RTT Program in Section F-4.8.

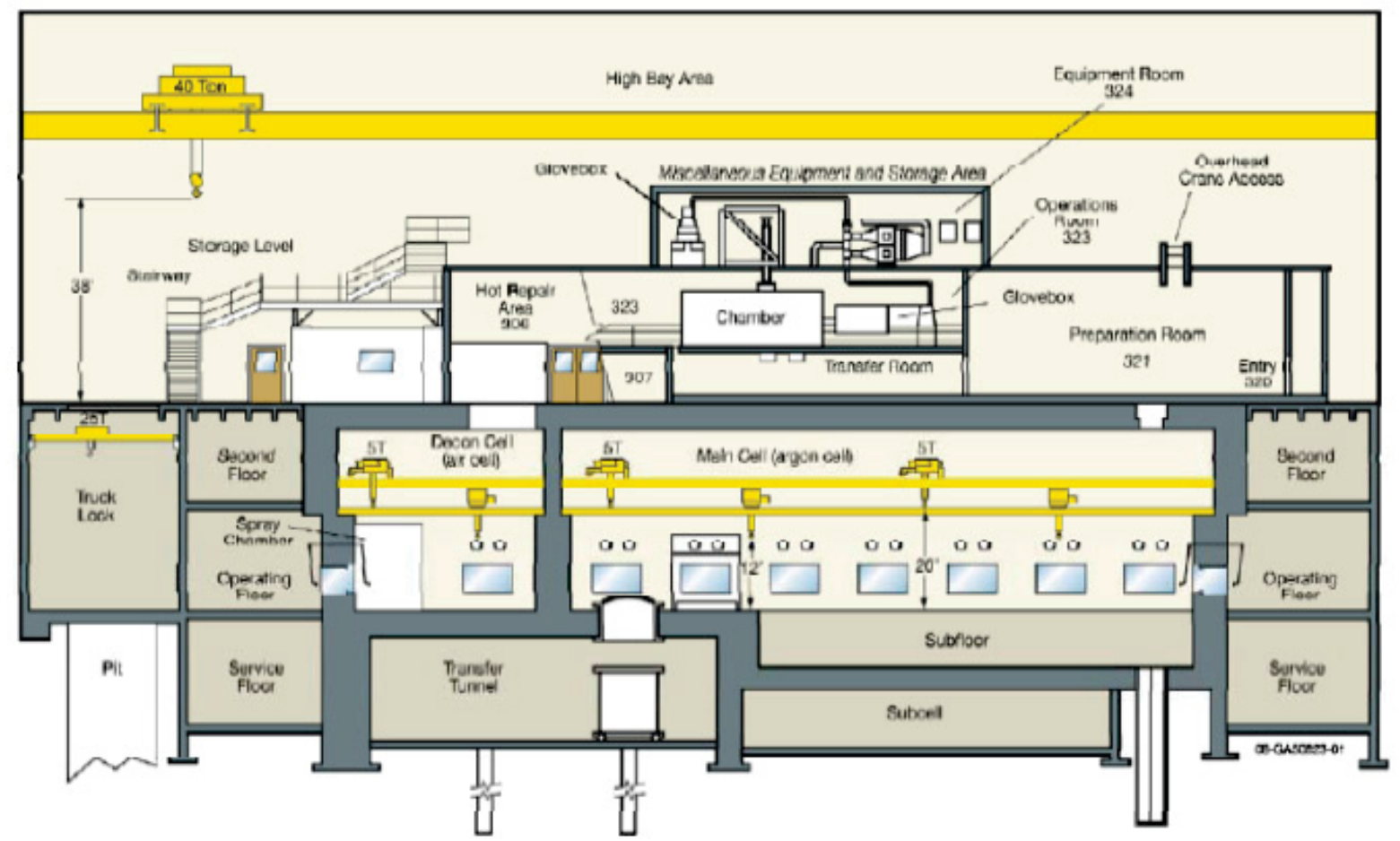

Figure F-1. Hot Fuel Examination Facility elevation view facing north. The truck lock runs the full east-west extent of the facility; the main cells are located within a central corridor.

The safety analysis report for HFEF and its operations (SAR-405 2013) addresses normal operations and the risks of postulated accidents to workers and members of the public. Normal operations associated with the operation of HFEF include handling of radioactive and fissionable material, laboratory chemicals, and hazardous materials. Hazards posing a risk to workers during normal operations are primarily those associated with radioactive material. Application of the INL radiation protection program at HFEF ensures that radiation exposures to workers from normal operations are maintained as low as reasonably achievable and below radiation protection standards and the DOE regulatory limit. The operations that will be conducted at HFEF in support of the RTT Program fall within the currently performed activities at HFEF. The risk of hazardous material exposures and other hazards (such as electrical hazards, high noise levels, and asphyxiant gases) present during normal operations are addressed by the worker safety and health program.

Postulated accident scenarios were evaluated for HFEF that could result in an uncontrolled release of radioactive or hazardous materials or pose a direct radiation exposure. Events that could occur during all phases of cask receipt and handling operations, use of the shielded hot cells, use of examination cells or laboratories, temporary storage of materials, and waste packaging were considered for the HFEF facility radiologic inventory. Of the events analyzed, cask handling operations would pose the greatest hazard for materials used by the RTT Program. Hazards involving cask handling operations include cask drops or impacts and cask tips. Events involving the cask could potentially damage the experiment assembly and its radiologic contents. 


\section{F-1.3 Accident Scenarios Identified for the Annular Core Research Reactor Facility}

The hazards assessment for Alternative 2 (ACRR) must only address the incremental differences introduced by the specific experiments to be conducted under the RTT Program. These hazards include those associated with handling the experiment assembly and those involving the experiment assembly while it is in the ACRR. In this screening analysis, accident scenarios involving the experiment loops were identified and compared to the scenarios currently scoped by the ACRR documented safety analysis (DSA) (Sandia Report 2008). A review of the ACRR DSA determined that accident scenarios shown in Table F-2 involving experiment packages with radioactive and/or fissile materials in the ACRR facility had been previously identified. These postulated accident scenarios generally correspond to those determined for TREAT DBAs shown in Table F-1, with the exception of two that can be eliminated because they are either not relevant or are prevented by specific administrative controls. The eliminated scenarios are as follows:

- Scenarios involving fission foil irradiation, which can be removed from further consideration in this assessment because the transient experiments evaluated in the RTT EA will not involve fission foil irradiations.

- Accident scenarios involving inadvertent nuclear criticality. The ACRR currently is an operating reactor with limits on operations to ensure operations remain within the bounds of the current ACRR DSA. These limits will be enforced for the transient experiments; therefore, there will be no additional releases that need to be evaluated to support the decisions of the RTT EA.

After eliminating these scenarios, the remaining relevant accident categories include those involving (1) a drop or impact to the experiment, (2) an experiment melt, fire, or engulfing fire, and (3) mechanical failure of the experiment assembly while in the ACRR central cavity. Accident consequences for these three remaining categories are provided in Section F-5.

Table F-2. Accident scenarios evaluated by the Annular Core Research Reactor documented safety analysis (Sandia Report 2008).

\begin{tabular}{llc}
\hline \multicolumn{1}{c}{ Accident Scenario } & \multicolumn{1}{c}{ Hazard Category } & Retained for Analysis \\
\hline $\begin{array}{l}\text { Heavy load dropped on } \\
\text { experiment }\end{array}$ & $\begin{array}{l}\text { Experiment drop (bounds all radioactive material } \\
\text { release or direct radiation exposure events) }\end{array}$ & Yes \\
$\begin{array}{l}\text { Experiment malfunction with } \\
\text { reactor operating in pulse mode }\end{array}$ & Melted fuel in experiment assembly & Yes \\
$\begin{array}{l}\text { Experiment malfunction with } \\
\text { reactor operating in steady-state } \\
\text { mode }\end{array}$ & Bounded by melted fuel in experiment assembly & Yes \\
$\begin{array}{l}\text { Overheated plutonium experiment } \\
\text { resulting in fire }\end{array}$ & $\begin{array}{l}\text { Same consequence as melted fuel in experiment } \\
\text { assembly }\end{array}$ & Yes \\
$\begin{array}{l}\text { Facility fire engulfing experiment } \\
\text { packages }\end{array}$ & $\begin{array}{l}\text { Same consequence as melted fuel in experiment } \\
\text { assembly }\end{array}$ & Yes \\
Aircraft crash & Bounded by fuel fire & Yes \\
Earthquake & Bounded by fuel fire & Yes \\
Fission foil vaporization & NA & No \\
$\begin{array}{l}\text { Failure of the test assembly while } \\
\text { in the ACRR central cavity }\end{array}$ & $\begin{array}{l}\text { Mechanical damage of the test assembly resulting } \\
\text { in radiologic release from the ACRR core and } \\
\text { experiment assembly }\end{array}$ & Yes \\
\hline
\end{tabular}




\section{F-2. DOSE ASSESSMENT METHODOLOGY AND ASSUMPTIONS}

This section discusses the dose assessment methodology and assumptions applied to the analysis of accidents for each alternative. Following the discussion for each alternative, an assessment of potential differences is provided.

\section{F-2.1 Idaho National Laboratory Facilities}

The dose assessment methodology applied to the analysis of the TREAT Reactor follows the screening calculations provided to identify the bounding experiment loop inventory in Appendix E. The assumptions in this approach include, but are not limited to, the following:

- ST:

- Appendix E provides the bounding experiment loop ST as the ATL 7-pin (MARK-III) loop inventory.

- Appendix E provides the bounding conservative TREAT core ST.

The net reduction (ADJ ${ }_{\text {net }}$ ) (Equations F-1 and E-1) to the MAR, resulting in the ST for accidents analyzed in the following sections (INL 2013), are shown in Table F-3.

$A D J_{\text {net }}=D R \times A R F \times R F \times L P F$

Table F-3. Net adjustment to the material at risk for scenarios releasing radionuclides from a fire, drop, or impact.

\begin{tabular}{lcccccc}
\hline \multicolumn{1}{c}{$\begin{array}{l}\text { Radionuclide } \\
\text { DR }\end{array}$} & ARF & RF & LPF & ADJnet & Applicable Release Scenario \\
\hline $\begin{array}{l}\text { Noble gases and } \\
\text { Halogens }\end{array}$ & 1.0 & $1.00 \mathrm{E}+00$ & $1.00 \mathrm{E}+00$ & $1.00 \mathrm{E}+00$ & $1.00 \mathrm{E}-01$ & $\begin{array}{l}\text { All materials in the gaseous state can } \\
\text { be transported and inhaled }\end{array}$ \\
Actinides & 1.0 & $5.00 \mathrm{E}-04$ & $5.00 \mathrm{E}-01$ & $1.00 \mathrm{E}+00$ & $2.50 \mathrm{E}-05$ & $\begin{array}{l}\text { Plutonium exposed to thermal stress } \\
\text { (DOE-HDBK-3010-94, p. 4-2) }\end{array}$ \\
U and fission \\
products
\end{tabular}


a zero LPF of $1(\mathrm{LPF}=1.0)$. In the case of TREAT, the two in-series banks of HEPA filters are assumed to be bypassed. For slow-developing accidents occurring in the reactor room, each bank of HEPA filters would be expected to reduce the ST by a factor of 100. For two HEPA filter banks in series, the net reduction would be 10,000 fold. For fast-developing accidents (i.e., puff releases), the F/CS might not capture all of the airborne radionuclides, allowing some unknown fraction to be released without passing through the HEPA filters. Therefore, the HEPA filters are conservatively not assumed to provide mitigation.

- Transport processes consist of advection and dispersion only. Surface roughness is not explicitly accounted for. Plume dispersion follows the model of Markee (Clawson et al. 1989).

- Exposure and dose calculations:

- Collocated workers and facility workers are assumed to be located in the TREAT Reactor control Building, $770 \mathrm{~m}$ from the TREAT Reactor building, for accidents occurring during transient testing at TREAT. In the NEPA-HA, the instantaneously released source was assumed to be transported at a rate of $1.04 \mathrm{~m} / \mathrm{s}$ (about $2.3 \mathrm{mph}$ ). This essentially corresponds to stagnant air conditions. Under stagnant air conditions, air dispersion is negligible, resulting in a consolidated plume and conservatively higher concentrations in air. In the following analyses for accidents occurring at INL, the average wind speed of $4.2 \mathrm{~m} / \mathrm{s}$ is used instead of using the $95^{\text {th }}$ percentile upper confidence value of $1.04 \mathrm{~m} / \mathrm{s}$. The average wind speed was used, because these experiments and subsequent release in the event of an accident would occur during the day when higher wind speeds are the norm. The TED calculation assumes the worker remains at his work location without being evacuated, exposing the collocated worker to the entire ST contained in the plume. The TED is calculated from the peak air concentration and is not averaged over the Gaussian plume.

- Collocated workers are assumed to be located either $100 \mathrm{~m}$ or $300 \mathrm{~m}$ from the site of an accident if transient testing is not in progress at TREAT. The TED calculation assumes the worker remains at his work location without being evacuated, exposing the collocated worker to the entire ST contained in the plume.

- Members of the offsite public are assumed to be located 6,000 $\mathrm{m}$ from the site of the accident at TREAT. The instantaneously released source is assumed to be transported at a rate of $1 \mathrm{~m} / \mathrm{s}$ (about $2.3 \mathrm{mph}$ ) as specified in GDE-10820 (2012). At $1 \mathrm{~m} / \mathrm{s}$, the elapsed time before plume arrival is in excess of 1.6 hours, allowing ample time for INL warning communications to notify members of the public. At the average INL wind speed of $4.2 \mathrm{~m} / \mathrm{s}$, the elapsed time is 24 minutes. The TED calculation assumes the members of the public remains at a fixed location without being evacuated, exposing the hypothetical member of the public to the entire ST contained in the plume.

- In all dose calculations, it is assumed that collocated workers and public receptors are located in the downwind direction of the accident throughout the plume passage. Facility and collocated workers would be located in the TREAT Reactor control building south of the TREAT Reactor building during many of the accident scenarios. The closest access point for members of the public $(6,000 \mathrm{~m})$ is southeast of the TREAT Reactor building (shown in Figure C-1). The primary wind direction during the day is from the southwest (as indicated in Figure A-7). Therefore, it is more likely that the wind would be blowing away from these receptor locations during operations at the TREAT Reactor building. This is not factored into the overall consideration of likelihood provided for each event in the following sections.

\section{F-2.2 Annular Core Research Reactor Facilities}

There were two primary differences introduced between dose assessment approaches adopted for ACRR and TREAT. The first difference was introduced in development of the ST from the MAR. In accident scenarios involving the experiment, both analyses use the bounding inventory (MAR) discussed 
in Appendix E. The MAR for accidents involving the reactor fuel are different for each experiment, but the adjusted ST accounting for the material that becomes airborne or is respirable is different. The analyses provided for ACRR applied guidance provided by NRC Guide 1.1.83 (NRC 2000) versus using DOE-HBK-3010-1994. Applied to the scenarios analyzed, the ST is defined as:

$S T=M A R \times M R F \times P R F$

where:

$\mathrm{MAR}=$ material at risk: the amount of radioactive materials (in grams or curies of activity for each radionuclide) available to be acted on by a given physical stress.

$\mathrm{MRF}=$ matrix release fraction: As defined by the NRC Regulatory Guide 1.1.83 (NRC 2000), the fuel matrix release fraction (MRF) is the fraction of radioisotopes released from the fuel based on the accident impact to the fuel. In Regulatory Guide 1.183, MRFs are expressed in terms of a "Gap Release Phase" and an "Early In-Vessel Phase." The NRC Regulatory Guide 1.183 establishes MRFs for boiling water reactors and pressurized water reactors. It does not provide MRFs for air-cooled reactors such as the TREAT Reactor. Matrix release factors applicable to the low-enriched fuel in the ACRR are shown in Table F-4 and are taken from the regulatory guide.

Table F-4. Regulatory Guide 1.183 matrix release fractions for boiling and pressurized water reactors.

\begin{tabular}{lcccccc}
\hline \multicolumn{1}{c}{ Chemical Group } & \multicolumn{2}{c}{ Boiling Water Reactors } & \multicolumn{3}{c}{ Pressurized Water Reactors } \\
\multicolumn{1}{c}{$\begin{array}{c}\text { Gap } \\
\text { Release } \\
\text { Phase }\end{array}$} & $\begin{array}{c}\text { Early In- } \\
\text { Vessel } \\
\text { Phase }\end{array}$ & Total & $\begin{array}{c}\text { Gap } \\
\text { Release } \\
\text { Phase }\end{array}$ & $\begin{array}{c}\text { Early In- } \\
\text { Vessel } \\
\text { Phase }\end{array}$ & Total \\
\hline Noble Gases (Xe, Kr) & 0.05 & 0.95 & 1.0 & 0.05 & 0.95 & 1.0 \\
Halogens (I, Br) & 0.05 & 0.25 & 0.3 & 0.05 & 0.35 & 0.4 \\
Alkali Metals (Cs, Rb) & 0.05 & 0.20 & 0.25 & 0.05 & 0.25 & 0.3 \\
Tellurium Metals (Te, Sb, Se, Ba, Sr) & 0 & 0.05 & 0.05 & 0.00 & 0.05 & 0.05 \\
Ba, Sr & 0 & 0.02 & 0.02 & 0.00 & 0.02 & 0.02 \\
Noble Metals (Ru, Rh, Pd, Mo, Tc, Co) & 0 & 0.0025 & 0.0025 & 0.00 & 0.0025 & 0.0025 \\
Cerium Group (Ce, Pu, Np) & 0 & 0.0005 & 0.0005 & 0.00 & 0.0005 & 0.0005 \\
Lanthanides (La, Zr, Nd, Eu, Nb, Pm, Pr, & 0 & 0.0002 & 0.0002 & 0.00 & 0.0002 & 0.0002 \\
Sm, Y, Cm, Am) & & & & & & \\
\hline
\end{tabular}

The bounding experiment inventory used for the TREAT and ACRR accident analyses is a mixed oxide (MOX) fuel. Data in existence when Regulatory Guide 1.1.83 was developed suggest MOX fuel and low-enriched uranium fuel have different fission product releases. Therefore, Regulatory Guide 1.183 suggests that the boiling water reactor and pressurized water reactor matrix release fractions may not be applicable to MOX fuel. However, numerical evaluations of $40 \%$ MOX fuel assemblies and low-enriched uranium fuel show that at severe accident fuel temperatures, the volatile fission product releases occur at a similar release rate, regardless of the fuel type (SAND 2008). The study shows that, in general, evaluations of MOX accident progression and STs for low-enriched uranium fuel and MOX fuel are similar (SAND 2008). Therefore, the pressurized water reactors MRFs from Regulatory Guide 1.183 also were applied for the experiment MOX fuel and are considered to be bounding for the release of fission products from MOX fuel.

$\mathrm{LPF}=\mathrm{PRF}=$ pool release fraction (if the radionuclide is postulated to occur in the ACRR pool or the storage pool, a fraction of the material may be retained by the pool water; the pool release fraction is the fraction of material that escapes the pools and is taken as unity for releases occurring outside of the pools. 
is:

The net ST adjustment when Regulatory Guide 1.1.83 was applied to analyses of accidents at ACRR

$A D J_{\text {net }}=M R F \times P R F$

The second difference in the dose assessment approach is introduced in the method of accounting for air dispersion effects. In the ACRR analysis, transport and dose calculations were obtained using the SNL version of the MELCOR accident consequence code system (WinMACCS2-SNL) (McFadden et al. 2007). The basic analytical models of MACCS2 (and WinMACCS2) provide atmospheric transport, dispersion, deposition, and dose calculation for the released inventory. The code accounts for radioactive decay and subsequent buildup of daughter isotopes during transport and dry deposition.

As documented in (Subaiya 2013) the WinMACCS2 code has been used to calculate the resultant dose for a unit curie of a given radionuclide hypothetically released at various SNL/NM locations. These are referred to as radionuclide-specific dose kernels $\left(\mathrm{DK}_{\mathrm{i}}\right)$, and are analogous to a unit response function or value. In addition to being radionuclide dependant, dose kernels are dependent on source-receptor pairs. DKs are based on atmospheric transport conditions for SNL/NM. Using the inventory of each radionuclide (STi), the TED is calculated as follows:

$\operatorname{TED}($ rem $)=\sum_{i} \mathrm{DK}_{\mathrm{i}}\left(\frac{\mathrm{rem}}{\mathrm{Ci}}\right) \times \mathrm{ST}_{\mathrm{i}}(\mathrm{Ci})$

Applied to the analysis of accident scenarios identified in Section F-1.2, the assumptions in this approach include the following:

- ST:

- Appendix E provides the bounding ST as the ATL 7-pin (MARK-III) loop inventory

- $\quad$ The ACRR core inventory includes the FREC-II core.

- Release and transport:

- Accidents were assumed to release radionuclides over a 10-minute period

- Dry deposition to provide a ground shine dose

- Hourly weather data that are specific to the ACRR facility were taken from a 5-year time period to determine applicable 95th percentile meteorological conditions

- $\quad$ MRF and pool release fraction are accident-scenario dependant.

- Dose assessment:

- A breathing rate of 3.33E-4 $\mathrm{m}^{3} / \mathrm{sec}$ was used in accordance with the DOE MACCS2 guidance document DOE-EH-4.2.1.4-MACCS2-Code Guidance (DOE 2004).

- DCFs were taken from ICRP-72, “Age-Dependent Doses from Intakes of Radionuclides," for the public and ICRP-68 for facility workers and collocated workers.

- Plume immersion, groundshine, and inhalation plume passage were considered to occur over 2 hours per DOE-STD-3009.

- No re-suspension inhalation dose for the 24-hour minimum emergency period was included.

- Doses correspond to the centerline dose 95th percentile for whole body pathways (TED).

- Members of the public were assumed to be located at or beyond 1,350 $\mathrm{m}$ from the accident site.

- Collocated workers were assumed to be located $300 \mathrm{~m}$ from the accident site.

\section{F-2.3 Differences in Dose Assessment Assumptions}

Primary differences in the dose assessments provided for ACRR and the TREAT Reactor include the following: 
- Differences in the adjusted (net) ST applied to the experiment MAR. The "net adjustment" to the MAR used to obtain the transportable ST are shown in Equations F-1 and F-3. If it is assumed that both approaches are applied to the same accident scenario and the following:

- ACRR: If releases occur into the air-filled central cavity or into a hot cell or high-bay, the pool release fraction is assigned a value of one

- $\quad$ Building holdup at TREAT is neglected, the LPF would be equal to one

- Damage ratios are assumed to be unity.

Then the net difference in ST would be the difference between the MRF and ARF*RF. For scenarios not involving a fire, the "Gap Release Phase" values in Table F-4 and the "impact or drop" values for ARF and RF shown in Table F-3 would apply. For scenarios involving a fire, the sum of the "Gap Release Phase" and "Early-in-vessel Phase" values shown in Table F-4 and the "Fire Scenario" values shown in Table F-3 would apply.

For both cases, the ST that results from application of the DOE-HDBK-3010-94 approach results in more of the MAR being available for transport. ST differences would be largest for non-fire events involving the release of actinides and some fission products where the NRC recommended values result in more retention in the fuel matrix with less release for transport. In general, the differences in analysis approaches should result in more conservative doses being estimated for Alternative 1 (TREAT), but the relative difference would be scenario and assumption dependent.

- Inclusion of a pool release fraction. The ACRR cooling pool effectively removes most of the activation and fission products from accident emissions that must pass into the pool water prior to being released for environmental transport. The TREAT Reactor is air cooled; therefore, it does not have a cooling water pool. Dose differences between the TREAT and ACRR analyses introduced by pool release fraction are appropriate.

- Delayed versus instantaneous release. Accidents in the TREAT analysis were assumed to result in instantaneous release of the ST for transport, while the ACRR analysis assumed the releases would occur over a 10-minute period. The TREAT dose results will be more conservative because of this assumption.

- Net dispersivity in the transport model. The ACRR analysis included a surface roughness factor that effectively increases the vertical dispersion factor in Equation E-3. The surface roughness factor accounts for additional air mixing that could occur along ground surface as radionuclide-bearing air is transported across the tops of sagebrush at SNL/NM. The analysis conducted for TREAT uses dispersivity functions developed at INL that inherently account for the local surface topology. Therefore, the dose differences introduced by this assumption should be negligible.

- Assumed exposure time. Plume immersion and plume inhalation was limited to 2 hours for the ACRR analysis, but it was not limited in the TREAT analysis. In the TREAT analysis, at the average wind speed of $4.1 \mathrm{~m} / \mathrm{sec}$, the plume centerline would take about 73 seconds to pass beyond $300 \mathrm{~m}$. For public receptors at $6,000 \mathrm{~m}$, it would take about half an hour for the plume centerline to pass by. Therefore, at the wind speeds considered, both approaches would produce the same dose result.

- Worker locations. Locations of collocated workers and members of the public are different at INL and SNL/NM. Therefore, dose differences introduced by these assumptions are appropriate. To facilitate comparison of doses, doses for Alternative 1 (TREAT) are provided at $300 \mathrm{~m}$.

\section{F-3. INTERPRETATION OF DOSE RESULTS}

The potential impacts of a radiological accident on workers and the public can be measured in a number of ways. In this appendix, the measures of consequences used are as follows: 
- Individual dose received by a facility worker, collocated worker, or member of the public. To put the doses provided in subsequent sections into perspective, annual dose limits and annual radiation doses received by average Americans are summarized in Figure F-2. On average, Americans receive a radiation dose of about $0.62 \mathrm{rem}(620 \mathrm{mrem})$ each year. During normal operations, the annual dose limit allowable by DOE for radiation workers is $5 \mathrm{rem}(5,000 \mathrm{mrem})$, and the annual dose limit for members of the public is $0.1 \mathrm{rem}(100 \mathrm{mrem})$.

From the Health Physics Society and International Commission on Radiological Protection, Publication No. 103; 2007:

- $\quad$ 0-5 rem received in a short period or over a long period is safe-we don't expect observable health effects.

- 5-10 rem received in a short time or over a long period is safe-we don't expect observable health effects. At this level, an effect is either nonexistent or too small to observe.

- 10-50 rem received in a short time or over a long period -we don't expect observable health effects, although above 10 rem the chances of getting cancer are slightly increased. We may also see short-term blood cell decreases for doses of about 50 rem received in a matter of minutes.

- 50-100 rem received in a short time will likely cause some observable health effects and received over a long period will increase the chances of getting cancer. Above 50 rem we may see some changes in blood cells, but the blood system quickly recovers.

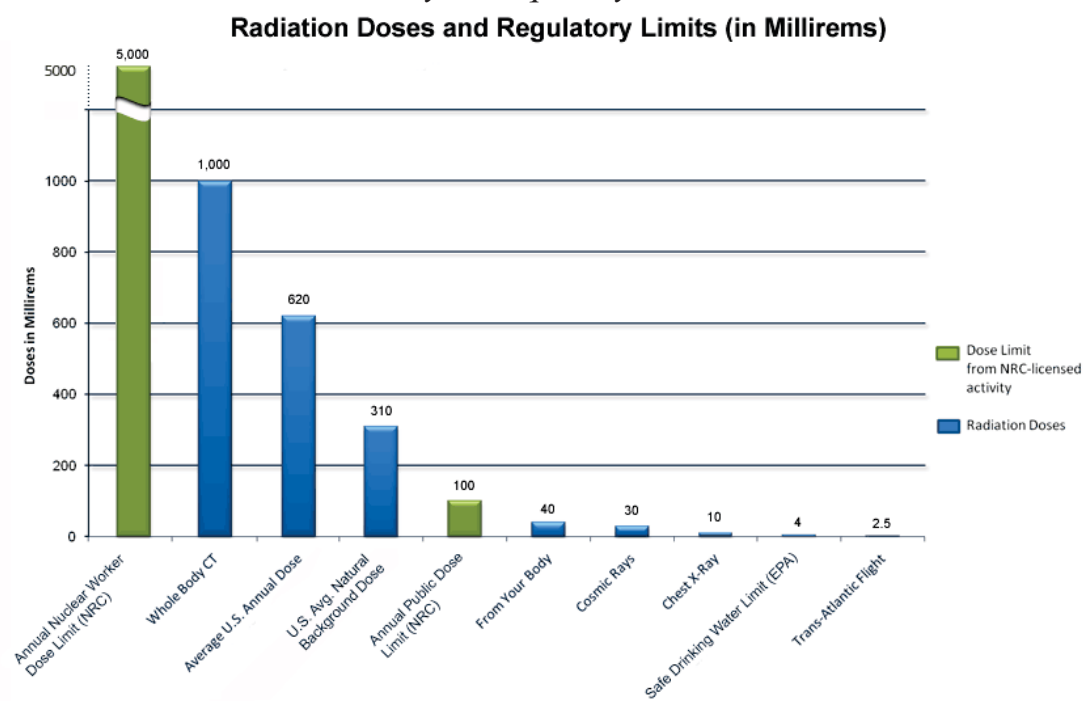

Figure F-2. Radiation doses and regulatory limits.

- Potential of the dose causing a cancer or LCF. According to the Health Physics Society Radiation Benefit and Risk Assessment and International Commission on Radiological Protection, (Publication No. 103 2007):

- The average natural lifetime incidence of cancer in the U.S. is $42 \%-42$ out of 100 people will get cancer in their lifetime. Radiation exposure increases this risk at the estimated rate of $0.17 \%$ per rem of radiation dose, based on the effects observable at high doses.

- A dose of 5 rem increases the chance of getting cancer by $0.85 \%$. For a dose of 5 rem, 43 people out of 100 will get cancer in their lifetime. This is an additional one cancer relative to the average natural lifetime incidence of cancer.

- A dose of $25 \mathrm{rem}$ increases the chance of getting cancer by $4.25 \%$. For a dose of $25 \mathrm{rem}$, 46 out of 100 people will get cancer in their lifetime. This is an additional four cancers relative to the average natural lifetime incidence of cancer. 
- A dose of 100 rem increases the chance of getting a cancer by $17 \%$. For a dose of 100 rem, 59 out of 100 people will get a cancer in their lifetime. This is an additional 17 cancers relative to the average natural lifetime incidence of cancer.

- LCF is a measure of deaths resulting from cancer that became active after a latent period following exposure to radiation. The LCF value corresponds to the risk that cancer will result from the dose sustained. The dose is the consequence. The numbers of radiation-induced LCFs are estimated by multiplying the dose (rem) by health risk conversion factors. The factors most commonly used in recent assessments are 6E-04 LCF per rem (ISCORS 2002). The same factor applies for facility workers, collocated workers, and members of the public.

- Potential for the accident to occur in any given year. Exposure to radiation can only occur if there is an accident involving radioactive materials. In order for a release to occur, precursor events must take place. The calculation of frequency of occurrence takes into account the time at risk and likelihood of the accident's occurrence.

- The following dose consequence analyses include an assessment of preventative measures that would be implemented to keep the accident from occurring or to limit the dose consequences of the event. Identification of the preventative measures allows understanding the event likelihood for each scenario. The likelihood takes into account the conditional probability of each event in the chain of events leading to the potential release.

- The frequency of occurrence is the product of the time-at-risk and event likelihood. For the purposes of providing a summary in the RTT Program's EA, the frequency of event occurrence is assigned to one of the likelihood categories shown in Table F-5.

Table F-5. Likelihood categories assigned to the hazards identified in the preliminary hazards assessment.

\begin{tabular}{llll}
\hline \multicolumn{1}{c}{ Likelihood category } & & Annual Exceedance Probability & \multicolumn{1}{c}{$\begin{array}{c}\text { Estimated Annual Frequency of } \\
\text { Occurrence }\end{array}$} \\
\hline Anticipated & A & $1 / 10$ to $1 / 100$ years & $10^{-2}$ to $10^{-1}$ \\
Unlikely & U & $1 / 100$ to $1 / 10,000$ years & $10^{-4}$ to $10^{-2}$ \\
Extremely Unlikely & EU & $1 / 10,000$ to $1 / 1,000,000$ years & $10^{-6}$ to $10^{-4}$ \\
Beyond Extremely Unlikely & BEU & $<1 / 1,000,000$ years & $<10^{-6}$ \\
\hline
\end{tabular}

- The annual frequency of occurrence shown in Table F-5 is related to the radiological risk evaluation guidelines used at INL to determine the need for safety systems, structures and components (SSCs) or technical safety requirements (TSRs). The cutoff for determining the need for safety features largely corresponds to the EPA recommended emergency planning action guide levels. Additionally, they relate to the published consequences outlined by the Health Physics Society Radiation Benefit and Risk Assessment and International Commission on Radiological Protection, (Publication No. 103 2007). In the following discussions, the conservative dose results are related to these evaluation guidelines to provide an indication of whether or not analysis of additional SSCs or TSRs would be required in order to ensure safety of workers or the public.

Table F-6. Idaho National Laboratory dose evaluation guidelines (from GDE-10820).

\begin{tabular}{lcc}
\hline \multicolumn{1}{c}{ Event Likelihood } & $\begin{array}{c}\text { Collocated and Facility Worker } \\
\text { Consequences }\end{array}$ & Offsite Public Consequences \\
\hline Anticipated $\left(10^{-2}\right.$ to $10^{-1} /$ year $)$ & $5.0 \mathrm{rem}(\mathrm{L})$ & $0.5 \mathrm{rem}(\mathrm{L})$ \\
Unlikely $\left(10^{-4}\right.$ to $10^{-2} /$ year $)$ & $25 \mathrm{rem}(\mathrm{M})$ & $5 \mathrm{rem}(\mathrm{M})$ \\
Extremely unlikely $\left(10^{-6}\right.$ to $10^{-4} /$ year $)$ & $100 \mathrm{rem}(\mathrm{H})$ & $25 \mathrm{rem}(\mathrm{H})$ \\
\hline
\end{tabular}


- Potential for the accident to occur in the lifetime of the RTT Program. As required by DOE guidance for analyzing accidents for NEPA (DOE 2002), the probability that at least one accident occurs over the lifetime of the project is provided. The lifetime of the RTT Program is expected to be 40 years. The probability that at least one accident occurs for each scenario analyzed is computed as:

$P=1-(1-f)^{N W * N Y}$

where:

$\mathrm{P}=$ probability of at least one failure from the nw items over a period of ny years

$\mathrm{F} \quad=$ frequency of failure over a particular period of time (a year in this case)

$\mathrm{NW}=$ number of items that may fail with frequency "f" (assumed to be one in this case)

$\mathrm{NY}=$ number of time periods over which failures can occur (years) (40-year lifecycle).

- Risk that a given dose and LCF are received from any given accident. The risk of an individual receiving a given dose in a year is the dose risk. Dose risk can be viewed as the dose averaged over the time period between accidents of a given type. Low doses are expected for more frequent events because safety features are emplaced to control anticipated events. Higher doses consequences are prevented from occurring frequently by rigorous engineering design. Therefore, high doses typically are associated with a very low probability of occurrence (or frequency). Dose risk and LCF risk are calculated as follows for an individual:

Dose risk $_{i}=D_{i} \times P$

LCF risk r $_{i}=D_{i} \times F \times P$

where:

$\mathrm{R}_{\mathrm{i}}=$ the risk of an individual receiving a dose Di per year

$\mathrm{D}_{\mathrm{i}} \quad=$ the dose in rem to an individual

$\mathrm{P} \quad=$ the probability or frequency of an accident, expressed on a per-year basis

$\mathrm{F}=$ the dose-to-LCF conversion factor, which is $0.0006 \mathrm{LCFs}$ per rem for individuals.

\section{F-4. PREDICTED DOSE IMPACTS FOR ACCIDENTS AT TRANSIENT REACTOR TEST FACILITY}

Postulated events selected as representative, bounding, or unique for transient experiments using TREAT were summarized in Table F-1. A discussion of dose consequences predicted for these scenarios is provided in the following subsections, based on the dose assessment methodology and parameters presented in Section F-1.1.

\section{F-4.1 Hypothesized Reactor Fuel Clad Failure}

A fuel clad failure was determined to be most likely to provide the bounding dose consequence for operation of the TREAT Reactor (INL 2013). The event is postulated to initiate during an unexpected reactivity insertion event, resulting in temperatures that could be high enough to damage the fuel clad, releasing fission products from the TREAT core fuel assemblies.

\section{F-4.1.1 Preventative Measures}

Preventative measures to protect against the possibility of this type of accident are provided by design of the TREAT fuel assembly, reactor mode of operation, reactor control system (RCS), reactor trip system (RTS), and, for defense-in-depth, the F/CS system, including the HEPA filters. An overview of these systems is provided as follows, and the probability of system failure is discussed in Section F-4.1.2. 
- TREAT fuel assembly. The TREAT fuel assembly consists of graphite reflectors, cladded fuel, aluminum gripping fixtures, and alignment pins. Fuel cladding is the outer layer of the fuel rods, providing the barrier between the coolant (air) and the nuclear fuel. TREAT fuel is Zircaloy cladded. The minimum thickness of TREAT fuel cladding has been specified to ensure containment of the fuel under all thermal stress-induced reactor operating conditions.

- TREAT Reactor operation. The TREAT Reactor is operated in a "self-limited" mode in which the total reactivity available to be added rapidly is limited to the amount that will not produce reactor core temperatures high enough to damage the fuel, no matter what reactivity insertion accident might occur coincident with the failure of the reactor scram system to operate properly.

- Negative temperature reactivity coefficients. The maximum steady-state core temperature, assuming the rods could not be reinserted to terminate a transient, is less than $694^{\circ} \mathrm{C}$. At $500^{\circ} \mathrm{C}$, the time required to oxidize 15 mils of cladding is 5,800 hours.

- RCS. TREAT is equipped with a redundant computer-based RCS. The RCS is comprised of three independent sets of control rods and support equipment, providing triple redundant capabilities to limit the total system reactivity. These rods are the compensation/shutdown rods, control/shutdown rods, and transient rods. All three rod banks are used for scram shutdowns initiated by RTS, and all rod banks are designed to a single-failure criterion. The transient, control/shutdown and compensation/shutdown banks are each, independently, capable of providing cold shutdown.

- Transient Rods and Drives: There are eight hydraulically operated control rods used to initiate and control a transient. Separate servo valves control each of the transient drive hydraulic cylinders. Each servo valve receives input from a dedicated controller that, in turn, receives commands from the reactor control system. In the steady-state mode, the hydraulic fluid is supplied by a pump at such a rate that the rod drives can move only slowly, and control is under manual switch command from the control room. When the transient mode is enabled by a key switch, the rods can be moved (reactivity addition and removal) at high speed. In this mode with hydraulic fluid supplied from a precharged accumulator, the control signals are derived from the digital computer-based automatic control system. The transient rods can establish cold shutdown by themselves for most core loadings and hot shutdown for all core loadings. The total reactivity control worth of the eight transient rods is about $9 \%$ and is administratively limited. The administrative limit ensures that TREAT is operated in a self-limited mode. In self-limited operation, the maximum amount of reactivity available in the transient rods is such that, if the available reactivity were rapidly added (as a step), the resulting natural burst would yield a temperature below that of the fuel-assembly damage threshold.

- Control/Shutdown Rod Drives: The operator uses the control/shutdown rods for control during steady-state reactor operation. The total reactivity control worth of the eight control/shutdown rods varies somewhat with core loading, but is calculated to be about $10 \%$. The control/shutdown rods can establish cold shutdown by themselves for all core loadings.

- Compensation/Shutdown Rods and Drives: The compensation/shutdown rods are used in the scram chain as one of three rod shutdown systems, and are also used to compensate for the reactivity worth of the test vehicle. Before any test vehicle or calibration vehicle is removed from the reactor core, the rods will be inserted fully, as will the other control rods. Each of the four compensation/shutdown rod drives in the inner ring moves a single control rod. The total reactivity control worth of these four rods varies somewhat with core loading, but is calculated to be about $10 \%$. The compensation/shutdown rods can establish cold shutdown by themselves for all core loadings. The drives are lead-screw positioned. A pneumatically driven piston is incorporated to scram the rods rapidly downward, and a special high-speed hydraulic latch release mechanism is used for fast response. 
- RTS. The RTS is designed to ensure rapid reactor shutdown or "scram." Reactor scram is the ultimate safety action used to prevent reactor core damage in abnormal or emergency situations, as typically associated with an over-power condition or an under-cooling condition. The scram command produces automatic insertion of the control/ shutdown, compensation/ shutdown, and transient rods. The time between the initial achievement of a high-power or high-energy condition that warrants scram action and removal of power to the latch coils associated with the control rod drives is less than $2 \mathrm{~ms}$ for the least sensitive power and energy ranges. The TREAT RTS is a fast acting, three-channel, hard-wired system comprised of the sensors, signal-conditioning equipment, comparators, and logic units that issue command signals to the RCS to initiate fast insertion of the neutron-absorbing control elements.

- F/CS. Accidents occurring in the TREAT Reactor would release radionuclides into the F/CS (Figure F-3). The air-cooled TREAT Reactor is a small test reactor and the heat generated is low enough to be removed using an air F/CS as opposed to using liquid coolant as required by most commercial reactors. Two blowers operating in parallel, located downstream of the reactor, pull coolant air from the reactor high bay into the reactor core and reflector regions through two fiberglass filtered openings at the top of the reactor shield. After passing through the core, the cooling air passes through two sequential banks of HEPA filters before being discharged out the reactor coolant exhaust stack.

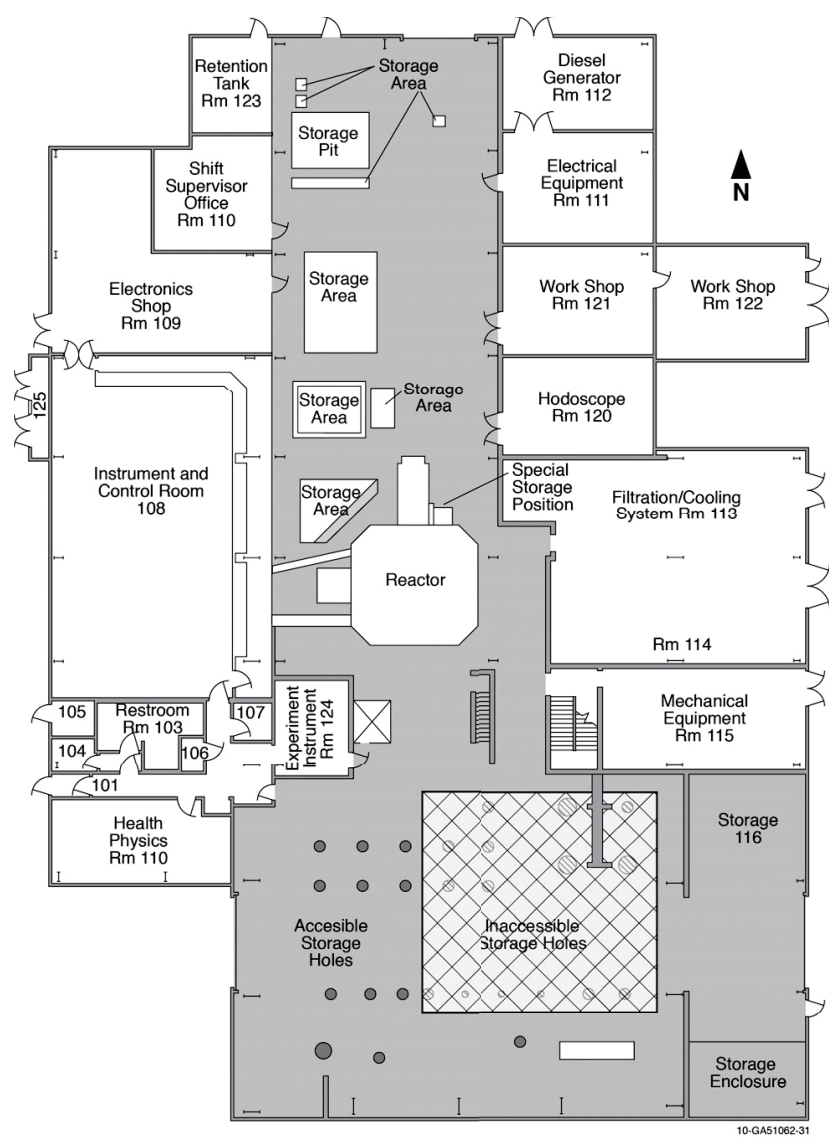

Figure F-3. TREAT Reactor building main floor layout.

The F/CS for TREAT is designed to be highly reliable through use of redundant active components and conservatively designed passive components. The F/CS is designed to entrain and remove radioactive material by first providing subatmospheric pressure in the reactor cavity. Second, the 
F/CS entrains radioactive aerosols on HEPA filters before discharging the filtered effluent up the stack.

To ensure the reliability of the F/CS system, the blowers can be powered from independent power sources. One power source is the normal site electric power; the other is an onsite diesel generator. To maximize reliability, the diesel generator is started and operating before transient testing is initiated. The diesel generator is not required for safe operation, but provides defense-in-depth during transient testing. The NEPA-HA (INL 2013) suggests that neither the cooling function nor the filtration function will be designated safety significant. Therefore, the F/CS provides defense-in-depth, but is not considered to be a safety-significant SSC.

\section{F-4.1.2 Probability of this Type of Accident Occurring}

\section{F-4.1.2.1 Event Occurrence During A Transient}

During a shaped transient test, the reactor operates at 2,950 MJ, producing peak output power of $10,000 \mathrm{MW}$, resulting in peak fuel and clad temperature of $600^{\circ} \mathrm{C}$. During a natural burst transient, the reactor energy output can reach 2,950 MJ, producing peak output power of 16,008 MW, resulting in peak fuel and clad temperature of $600^{\circ} \mathrm{C}$.

This accident scenario is thought to be extremely unlikely (number events $=2.2 \mathrm{E}-6 /$ year) based on the combined preventative measures discussed in Section F-4.1.1 and the probabilistic assessment for this DBA provided in the TREAT final safety analysis report (FSAR 2009). The probabilistic assessment is based on the top-level fault tree shown in Figure F-4. In order for the top event (Event a) to occur, a transient must be attempted that could exceed $600^{\circ} \mathrm{C}$ (Event c) and the rods must fail to stop the transient from occurring (Event $b$ ), so that the probability of Event a is given by:

$P_{a}=P_{b} \times P_{c}$.

Event $\mathbf{b}$ - failure of scram to occur. The rods can fail to scram either because the stop limits are set incorrectly or the scram fails to function because of the trip circuit or the rods fail to operate. Thus, the probability of b occurring is given by:

$P_{b}=P_{e}+P_{d}$.

- Event e-Scram fails to operate. The reliability of the scram circuitry is very high because there are three scrams on period, power, and energy and each circuit is triplicated. In addition, there is a trip on temperature. The first line of defense against a reactor insertion accident is provided by the three period trip circuits. If the initial reactivity was just below the period trip, the three power circuits would be the next defense. If the accident managed to be below the power trip point, the next defense would be the energy trip. If the transient managed to stay below all three trips, then the transient could not result in an accident unless the trips were set wrong (Event $d$, which will be discussed next). The combined likelihood of all nine events occurring is 1E-9.

- Event d - Set all safety limits incorrectly. The stop (safety) limits could be set incorrectly if either faulty rod worth data are entered in the computer or the limits themselves are incorrectly determined. The likelihood of these events occurring is $1 \mathrm{E}-4$.

Event $\mathrm{c}$ - Attempt to run a transient that could result in a temperature over $600^{\circ} \mathrm{C}$. Attempting to run such a transient could be caused by either a program to attempt such a transient (Event $\mathrm{f}$ ), or failure of the computer in such a way as to cause the transient to be run (Event g), or operation of the transient rod drives to insert that much reactivity (Event $h$ ). The event probability is therefore given by:

$P_{c}=P_{f}+P_{g}+P_{h}$.

Probability expression. The probability for this DBA is $1 \mathrm{E}-10$ per final transient computed from the combined expression: 


$$
\begin{gathered}
P_{a}=\left(P_{d}+P_{e}\right) \times\left(P_{i} P_{j}+P_{k} P_{l}+P_{h}\right)= \\
\left(10^{-4}+10^{-9}\right) \times\left(10^{-1} \times 10^{-2}+10^{-4} \times 10^{-4}+10^{-4}\right)
\end{gathered} .
$$

Assuming 34 final transients involving loops will be run per year, the annual probability is 3.7E-06, making the combined events extremely unlikely. For an event frequency of 3.74E-06 per year (probability of one failure per year), there is less than one chance in 6,500 (1.5E-04) of this event occurring in 40 years.

\section{F-4.1.2.2 Event Occurrence During Low-Power or Steady-State Operations}

Low-power and steady-state power output states are used during the calibration phase prior to running a transient and during radiography. During low-power or steady-state operations, the peak power output is $120 \mathrm{~kW}$ with corresponding peak fuel temperatures of approximately $270^{\circ} \mathrm{C}$ (with 180 fuel assemblies). The power and energy deposited in the TREAT reactor is controlled by the amount of reactivity inserted in the core. The amount of reactivity is controlled by the control/shutdown rods, the compensation/shutdown rods, and the transient rods.

During reactor startup, steady-state operation, and the rod-positioning phase prior to initiating a transient, the rods are controlled manually using the manual reactor control system. The total amount of reactivity available to be added rapidly is limited to the amount that will not produce a reactor core temperature high enough to damage the fuel, no matter what reactivity insertion accident might occur. This mode of operation is referred to as the "self-limited" mode, and provides the first level of protection.

The largest reactor fuel temperature rise which can be obtained from the insertion of a given amount of reactivity is from the fastest possible insertion of this reactivity. This type of transient is referred to as a temperature-limited transient. The rate of reactivity insertion is controlled by the hydraulic rod drives. The hydraulic rod drives have two operation ranges, one for slow-speed rod positioning during nontransient operation, and the other for rapid reactivity insertion during transients. In the manual mode, the control computers and the capability for rapid reactivity insertion by the transient rod drives are locked out. Limiting the rod speed and operating the reactor in the self-limited mode ensures the operating temperature remains below the peak temperature of $270^{\circ} \mathrm{C}$ which is well below the melting point of the TREAT Zircaloy cladding $\left(1,800^{\circ} \mathrm{C}\right.$ estimated from the melting point of zirconium which is $1,843^{\circ} \mathrm{C}$ ). At $502^{\circ} \mathrm{C}$, the time required to oxidize 15 mils of cladding is 5,800 hours, providing assurance that the fuel cladding would not be oxidized during steady-state or low-power operations.

Limits on reactivity are controlled by electrical interlocks provided to prevent rod insertion beyond predetermined set points. The probability of exceeding the reactor safety limit (SL) providing protection to $502^{\circ} \mathrm{C}$ is $1 \mathrm{E}-7 / \mathrm{y}$. The $1 \mathrm{E}-7 / \mathrm{y}$ probability of exceedance is a result of redundancy in determining the safety limit for the interlocks. Exceeding $502^{\circ} \mathrm{C}$ would then require overriding or failure of the transient dependent interlock and the core independent interlock. The probability of the transient dependent interlock being set incorrectly or failing is $0.1 / \mathrm{y}$, and the probability of exceeding the core independent interlock incorrectly is $0.01 / \mathrm{yr}$. The combined probability of exceeding the safety limit, and 2 interlock set limits is $1 \mathrm{E}-10 / \mathrm{y}$. Therefore, it is beyond extremely unlikely that high power output could occur when steady-state or low-power operations are intended.

The combination of low fuel and cladding temperatures, limited rod-positioning speed (low hydraulic pressure), lockout of the transient rod drives, and administrative limits on core excess reactivity makes reactor fuel clad failure during low-power and steady-state operations beyond extremely unlikely.

\section{F-4.1.3 Dose Consequences}

Resultant inhalation dose consequences are shown in Table F-7, derived from the dose consequences provided in Table 4 of the NEPA-HA (INL 2013). The values in Table 4 of the NEPA-HA do not consider administrative controls or facility design features in place to limit accident consequences. Administrative controls will include training, evacuation plans and protocols, and the requirement for 
workers to be located in the reactor control building instead of the reactor building during transient experiment operations (about 770-m distance). Locating the workers to the control building increases the $\chi / \mathrm{Q}$ from $4.08 \mathrm{E}-03 \mathrm{~s} / \mathrm{m}^{3}$ at $100 \mathrm{~m}$ to $3.87 \mathrm{e}-04 \mathrm{~s} / \mathrm{m}^{3}$ at $770 \mathrm{~m}$, with a corresponding dose reduction factor of 10.5. Applying the average wind speed at TREAT of $9.4 \mathrm{mph}(4.2 \mathrm{~m} / \mathrm{s}$ ) (Appendix A) reduces the $\chi / \mathrm{Q}$ by an additional factor of 4.2 (Equation E-2).

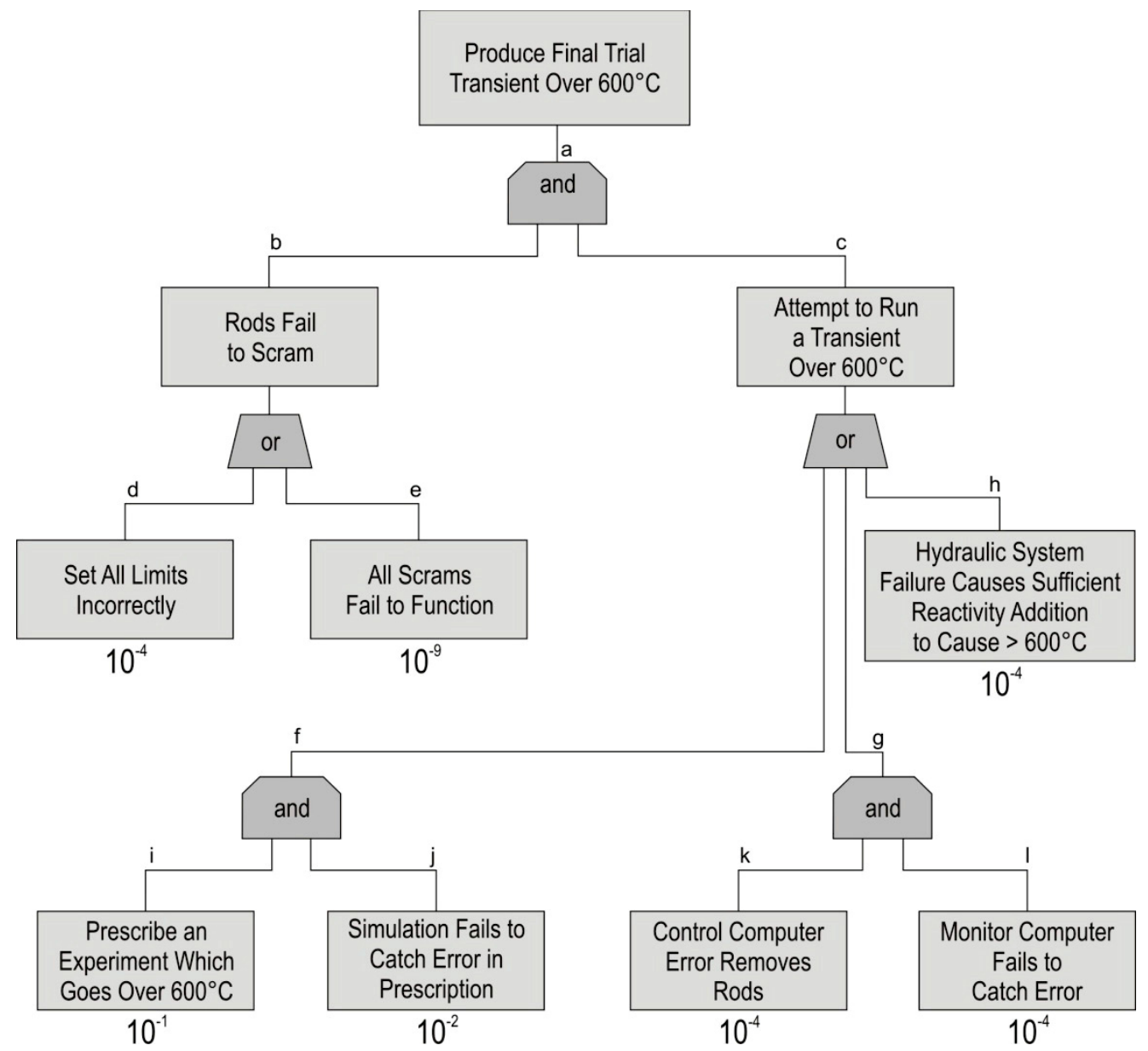

Figure F-4. Fault tree for determining reactor design basis accident probability. Failure likelihoods indicated for each event are expressed as per final transient.

Table F-7. Dose consequences for reactor fuel clad failure.

\begin{tabular}{cccccc}
\hline & $\begin{array}{c}\text { Annual } \\
\text { Frequency } \\
\text { of Occurrence }\end{array}$ & Source & $\begin{array}{c}\text { Facility Worker } \\
\text { (rem) }\end{array}$ & $\begin{array}{c}\text { Collocated Worker } \\
\text { (rem) }\end{array}$ & $\begin{array}{c}\text { Member of the Public }^{3} \\
\text { (rem) }\end{array}$ \\
\hline $\begin{array}{c}\text { 65\% of the } \\
\text { TREAT Reactor }\end{array}$ & $3.7 \mathrm{E}-06$ & CED & 4.1 & 4.1 & 0.21 \\
fuel assemblies & & Cloud Gamma & 2.5 & 2.5 & 0.016 \\
& & Total & 6.5 & 6.5 & 0.24 \\
\hline
\end{tabular}

Notes:

1) The HEPA filters are not SSCs, but are provided at TREAT for defense-in-depth. If the HEPA filters were considered, in the TED calculation, the doses would be reduced four orders of magnitude.

2) Facility workers and collocated workers are assumed located in the TREAT Reactor control building (about $770 \mathrm{~m}$ ) and are not evacuated. This subjects them to the entire plume passage.

3) Offsite members of the public are located $6,000 \mathrm{~m}$ away at the INL boundary and also are subject to the entire plume passage. 
Table F-8. Dose and latent cancer fatality summary for reactor fuel clad failure.

\begin{tabular}{|c|c|c|c|c|c|}
\hline $\begin{array}{c}\text { Probability of } \\
\text { one failure } \\
\text { per year }\end{array}$ & $\begin{array}{c}\text { Probability of } \\
\text { one failure in } \\
40 \text { years }\end{array}$ & Receptor & $\begin{array}{l}\text { Dose } \\
(\mathrm{rem})\end{array}$ & $\begin{array}{c}\text { Dose risk } \\
\text { (rem/yr) }\end{array}$ & $\mathrm{LCF}$ \\
\hline \multirow[t]{3}{*}{ 3.7E-06 } & $1.5 \mathrm{E}-04$ & Facility Worker & 6.5 & $2.4 \mathrm{E}-05$ & $3.9 \mathrm{E}-03$ \\
\hline & & Collocated Worker & 6.5 & $2.4 \mathrm{E}-05$ & $3.9 \mathrm{E}-03$ \\
\hline & & Offsite Member of the Public & 0.24 & $8.8 \mathrm{E}-07$ & $1.4 \mathrm{E}-04$ \\
\hline
\end{tabular}

Design features include the preventative measures discussed in Section F-4.1.1. These primarily serve to reduce the likelihood of the accident occurring in the first place, but, with the exception of the HEPA $\mathrm{F} / \mathrm{CS}$, do not affect dose reduction in case of accident occurrence. The HEPA filters discussed in Section F-4.1.1 provide defense-in-depth, but are not credited in accident scenarios because they are not safety SSCs. Therefore, the results shown in Table F-7 do not reflect the dose reduction that could occur if the HEPA filters are operational during the accident. If they are not damaged, a dose reduction of $1 \mathrm{E}+04$ would be expected.

Values are provided for four collocated worker distances in Table 4 of the NEPA-HA. To account for the administrative controls limiting the location of workers during an experiment, values for a distance of $770 \mathrm{~m}$ were used to obtain the dose consequences. Dose consequences are shown in Table F-7 and are summarized in Table F-8. These tables show the following:

- For members of the public:

- The estimated dose is $0.24 \mathrm{rem}(240 \mathrm{mrem})$. This is less than the annual average 600 -mrem dose received by members of the public from non-DOE facilities (Figure F-2).

- The increased probability of a member of the public getting cancer is $0.04 \%$.

- The risk of an LCF occurring is about 1 in 7,000.

- For facility and collocated workers:

- $\quad$ The estimated dose is 6.5 rem for facility and collocated workers.

- The increased probability of a worker getting cancer is $1.1 \%$.

- The risk of an LCF occurring is about 1 in 250.

Therefore, from this hypothetical accident, all predicted consequences are negligible (Section F-3). In addition, these predicted doses are well below the dose evaluation guidelines used to determine the need for additional protective measures (Table F-6).

The dose and LCF consequences shown in Table F-7 are very conservative in terms of predicted dose and estimated likelihood. The MAR in this accident scenario includes the upgraded TREAT Reactor core as discussed in Section 2 of Appendix E (Section E-2). The initial core inventory and radiologic fission product inventory are both very conservative. The postulated accident is assumed to occur in an area not evacuated by the HEPA F/CS. During transient testing, the F/CS would be expected to remain effective, passing all of the released radionuclides through the HEPA system with a corresponding reduction factor of $1 \mathrm{E}+04$ in dose.

This event is included to provide an indication of the robustness of the TREAT RTS and RCS. The reactor design requires the RTS and RCS to be functional in order to load the reactor either with fuel or an experiment. If the RTS and RCS are not functional, additional reactivity cannot be inserted into the reactor. Therefore, although Section F-4.1.1 assigned a 3.7E-6 system failure likelihood, the likelihood is thought to be more remote. 


\section{F-4.2 Hypothesized Experiment Impact/Drop Accident}

This section provides a summary of the analysis performed in the NEPA-HA (INL 2013) to determine the magnitude of the radiological consequences following a postulated drop or impact to the experiment assembly. In the NEPA-HA, loop impact accidents were analyzed assuming that during loop handling operations an impact on or by the experiment assembly could result from either a failure of the reactor building crane(s) or of the reactor building structures supporting the crane(s). Crane failures can result from structural/mechanical failures, electrical failures, and operator errors; reactor building support structure failures could result from NPH. The INL Site has a warning communications center that provides an early warning of weather phenomena to give adequate time to secure necessary equipment. Therefore, the most likely mode of NPH failure would be associated with earthquakes.

\section{F-4.2.1 Preventative Measures}

Consequences of experiment drop accidents are limited by the structural design of the facility, experiment loop handling equipment; primary and secondary containment designed into the experiment assembly, fuel cladding, radiation detection and fire suppression systems, and the building F/CS system. An overview of the design features provided to limit the potential for this type of accident is provided in the following paragraphs, and the probabilistic analysis of system failure is discussed in Subsection F 4.2.2.

- TREAT facility design. Requirements of DOE-STD-1189 and DOE-STD-1020 include an analysis of SSC failure from natural phenomena, including earthquakes, wind, precipitation, flooding, and so forth. Performance requirements for each are discussed in the following and, if this alternative is selected, the requirements will be met through verification or modification as necessary:

- Seismic design (earthquakes). TREAT has been determined to be a Performance Category (PC)-2 facility based on the preliminary assessment of hazards (INL 2013). For a facility to be classified as PC-2, the unmitigated consequences of seismic hazards must be predicted to fall in the 5 rem $<$ dose $<100$ rem range for collocated workers and 5 rem $<$ dose $<25$ rem for members of the public (DOE-STD-1189-2008, Appendix A, Table A-1).

Consistent with DOE-STD-1189-2008 and the PC-2 categorization, the seismic design category for TREAT is seismic design category-2. Performance requirements for seismic design category-2 facilities are required by DOE-STD-1020 to meet the international building code (IBC 2000). The seismic hazard in IBC (2000) is provided by maps that define the seismic hazard in terms of the maximum considered earthquake ground motions. These maps contain accelerations that are associated with 2,500-year mean return period earthquakes (i.e., an earthquake with a $2 \%$ chance of exceedance in 50 years or likelihood of 4E-4).

- Straight-line wind speeds. In accordance with DOE-STD-1020, the design wind loadings are based on a 96-mph wind, which for INL has a 100-year return period (probability of $1 \mathrm{x}^{-2} 0^{-2} \mathrm{y}^{-1}$ ).

- Snow load. At INL, a snow depth of 26 in. has a 100-year return period and corresponds approximately to a snow load of $13 \mathrm{psf}$. The roof of the east and west low-bay area adjacent to the high-bay area is designed for a 45-psf snow load and the remainder of the roofing for $30 \mathrm{psf}$.

- Flooding. TREAT is located in a topographically closed basin with no permanent surface water features (Appendix A). The grading adjacent to the reactor and control buildings is designed so that surface water will be diverted away from them from any point on their periphery, which is adequate to control surface water based on the flood analysis discussed in Appendix A.

- Brush fires. Hard-scape around the periphery of the buildings will prevent vegetative growth.

- Facility fires. The TREAT Reactor and control buildings are equipped with a fire protection system. Identified deficiencies with the fire protection systems are being tracked for correction prior to resuming TREAT operations (if use of the TREAT facilities is the selected alternative). 
- Experiment-handling equipment. TREAT includes the following:

- 60-ton and 15-ton overhead bridge cranes. A traveling overhead bridge crane with a capacity of 60 tons is provided to service the reactor and experiment loop operations above and south of the reactor. The crane has a 10-ton capacity auxiliary hoist to serve the storage holes and high-bay work areas. The 60 -ton capacity was dictated by the projected weight of some experiment system components; experiment-handling loads governed the choice of the 10-ton auxiliary hoist. The main (60-ton) hoist has a hook travel of $60 \mathrm{ft}$ above the main floor. Hoisting, bridge, and trolley travel speeds are variable to allow precise manipulation of experiment assemblies. The crane has both cab and radio control capabilities, with the latter providing remote control by the operator from any point within the high-bay areas. The radio control system has a unique signal arrangement to prevent its being activated by spurious signals. The radio control does not operate the crane from outside the reactor building; it is fail-safe and it does not cause electrical interference in other reactor building systems, including the reactor control and safety systems. The 15-ton crane services the areas over the reactor and north of the reactor. Interference with the 60-ton crane is prevented by hard-wired electrical interlocks. Like the 60 -ton crane, it is a standard industrial crane. The crane structures will be designated safety-significant SSCs (INL 2013) and will be verified to meet PC-2 standards in conformance with DOE-STD-1020.

- Experiment handling casks. These include a TLHC, and the fuel handling cask. The experiment handling casks are shielded casks used for handling radioactive materials at TREAT. In addition, they are used for transporting these materials between TREAT and MFC. Historically, the TLHC has been a shielded cask that will be used for handling calibration assemblies and Mark-III and single-pin test loop experiments. Its hoisting mechanism was designed to lift the 1,200-lb calibration assembly, and the cask itself was handled by either the 15 -ton or the 60 -ton crane. If it is decided that the TLHC is a safety-significant SSC by the hazards analysis, the design of the new cask will comply with DOE-STD-1020 and DOE-STD-1189-2008.

- Primary and secondary containment. Figure F-5 shows the Mark-III and single-pin test loops illustrating the primary containment of fuel pins in stainless steel tubes and secondary containment of the loop in stainless steel liners. Primary and secondary containment are provided to reduce the likelihood of fuel releases from the experiment in case a drop is significant enough to damage the TLHC or fuel handling cask.

- Fuel cladding. Typical fuel contained in the experiments will be either Zircaloy or Inconel clad. Both materials have high melting points, are dimensionally stable with high thermal stress and fatigue resistance, are corrosion-resistant, and have a low absorption cross-section of thermal neutrons. In some cases, cladding of the experiment fuel is not considered one of the containment systems and is the focus of some of the experiments. Prior to experiments, during experiments not designed to test the performance of fuel clad, and after experiments, the clad is expected to function as a containment system. Given that the experiments could be challenging the fuel cladding, cladding was not considered to be a containment system in the accident analysis.

- Radiation detection system. A new radiation detection system was installed during the latest TREAT upgrade. Its performance will be verified if the restart of the TREAT Reactor is selected as the preferred alternative.

- Filtration and cooling system. The F/CS system includes two banks of HEPA filters in series. The F/CS draws air from the building and exhausts it up the stack. Each bank of filters provides a 100-fold reduction in particulate emissions. The two banks in series reduce emissions by a factor of 10,000 -fold. The F/CS is not likely to be designated a safety-significant SSC in the NEPA-HA (Table 2). A drop accident would most likely release radionuclides into the reactor building (Figure F-5), but a drop could occur in an area less evacuated by the F/CS. Therefore, credit for the $\mathrm{F} / \mathrm{CS}$ is not taken in the calculation of dose consequences. 


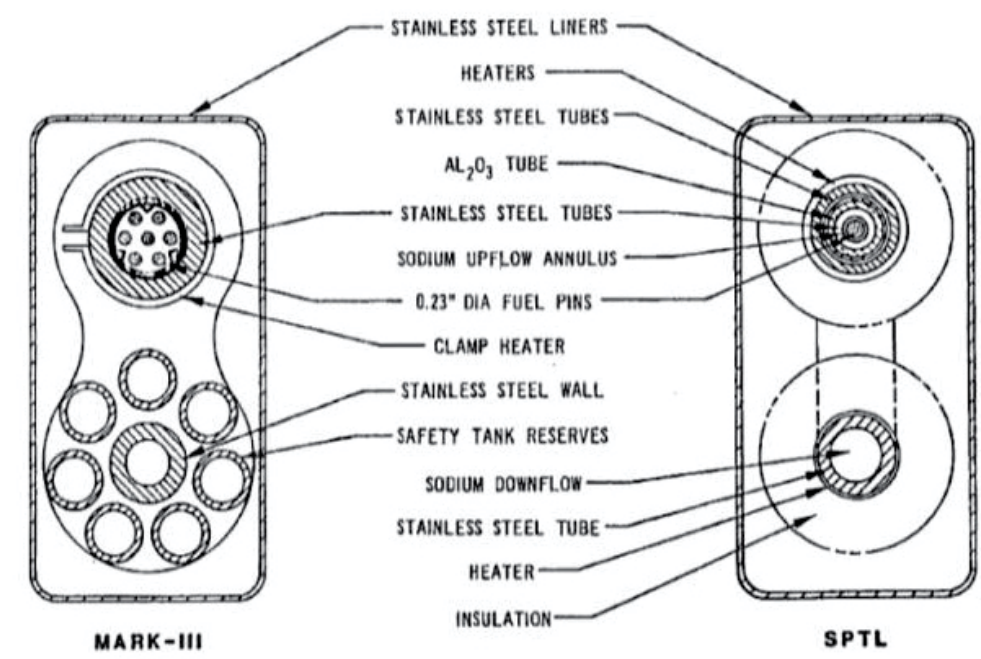

Figure F-5. Mark-III and single-pin test loop showing primary containment of the fuel pins in stainless steel tubes and secondary containment of the loop by stainless steel liners. The fuel clad is not considered to provide containment.

\section{F-4.2.2 Probability of this Type of Accident Occurring}

The frequency of occurrence for a loop impact accident scenario is the product of the time-at-risk and the probability for the accident initiator.

- Time-at-risk: Loop impact accidents can be postulated to occur either before or after exposure to transient operation. Prior to the transient, the fuel pins will be intact and loops (or experiment assemblies) may or may not be handled in the presence of molten sodium. The time-at-risk shown in Table F-9 is based on expert judgment for a mix of experiments, which includes loops containing molten sodium in some of these accidents (Rudolph and Dickerman 1983). The basis provided for the estimated time-at-risk for each case considered is as follows:

- For the cases in which molten sodium is present, the sum of the products of loop handling crane operations per experiment and hours per loop handling crane operation is 4 hours per experiment. Therefore, the total time-at-risk for these accidents (LH-2 and LH-5 in Table F-9) is 136 hours per year ( 0.0155 operating hours per year/hours per year) for a Mark-III loop (20 experiments per year).

- For the case in which molten sodium is not present (accidents LH-3 and LH-6), the sum of the products of loop handling crane operations per experiment and hours per loop handling crane operation is 14.5 hours per experiment. Therefore, the total time-at-risk for this situation is 493 hours per year (0.0562 y/y) for the Mark-III loop.

- For the cases in which the accident occurs after the transient, the pre-irradiated test fuel was assumed dispersed within the sodium inventory of the loop. This sodium will be allowed to solidify; however, because of the decay heat of the fuel, some fraction of the sodium in the region of the test train will remain molten. If the loop is impacted under these circumstances and a containment breach is assumed to result, a sodium fire could be postulated. The sum of the products of loop handling crane operations per experiment and hours per operation for the LH-1 and LH-4 is 20.25 hours per experiment. The total time-at-risk is 405 hours per year $(0.0785 \mathrm{y} / \mathrm{y})$ for the Mark-III loop. 
Table F-9. Estimated loop handling accident frequencies of occurrence.

\begin{tabular}{|c|c|c|c|c|}
\hline Accident & $\begin{array}{l}\text { Molten } \\
\text { Sodium } \\
\text { Present }\end{array}$ & $\begin{array}{c}\text { Initiator } \\
\text { Probability } \\
\left(\mathrm{y}^{-1}\right)\end{array}$ & $\begin{array}{c}\text { Time-at- } \\
\text { Risk } \\
(\mathrm{y} / \mathrm{y})\end{array}$ & $\begin{array}{c}\text { Accident Frequency } \\
\left(\mathrm{y}^{-1}\right) \\
(\mathrm{Col} 3 \times \mathrm{Col} 4)\end{array}$ \\
\hline LH-1 earthquake as experiment is removed post-irradiation & Yes & $4.0 \mathrm{E}-4$ & $7.85 \mathrm{E}-2$ & $3.14 \mathrm{E}-05$ \\
\hline LH-2 earthquake during pre-experiment operations & Yes & $4.0 \mathrm{E}-4$ & $1.55 \mathrm{E}-2$ & $6.21 \mathrm{E}-06$ \\
\hline $\begin{array}{l}\text { LH-3 earthquake during pre-experiment operations involving } \\
\text { a pre-irradiated loop }\end{array}$ & No & $4.0 \mathrm{E}-4$ & $5.62 \mathrm{E}-2$ & $2.25 \mathrm{E}-05$ \\
\hline LH-4 crane failure as experiment is removed post-irradiation & Yes & $3.3 \mathrm{E}-04$ & $7.85 \mathrm{E}-2$ & $2.59 \mathrm{E}-05$ \\
\hline LH-5 crane failure during pre-experiment operations & Yes & $3.3 \mathrm{E}-04$ & $1.55 \mathrm{E}-2$ & $5.12 \mathrm{E}-06$ \\
\hline $\begin{array}{l}\text { LH- } 6 \text { crane failure during pre-experiment operations } \\
\text { involving a pre-irradiated loop }\end{array}$ & No & $3.3 \mathrm{E}-04$ & $5.62 \mathrm{E}-2$ & $1.86 \mathrm{E}-05$ \\
\hline
\end{tabular}

- Seismic initiator: An earthquake producing acceleration in excess of the IBC (2000) design requirements is assumed to be the seismic initiator for a crane load drop. For a PC-2 qualified building, the maximum considered earthquake has probability 4.0E-4/y (i.e., 1/2,500 years). Using the longest time-at-risk value of 7.85E-2 y/y (Table F-9) yields a probability of seismic induced crane failure, resulting in a load drop of 3.14E-5 per operating year. The probability of one seismic initiated event occurring in 40 years is $1.3 \mathrm{E}-03$. For the purpose of determining consequences of radiological release in the following subsection, it is conservatively assumed that the building will not provide holdup of radioactivity for accidents postulated to result from the maximum considered earthquake.

- Nonsiesmic initiator: A risk analysis of three cranes that are functionally equivalent to the 60/10-ton crane that services the high-bay area of the TREAT Reactor building (i.e., the reactor and the south end of the building) was performed during the TREAT upgrade (Blume et al. 1979). Because the 15-ton crane that services the reactor and the north end of the reactor building and the 60/10-ton crane were both built to CMAA-70 standards, it is assumed that the study applies to both cranes. The study indicates that the probability of a load drop resulting from structural/mechanical failures of the crane is $3.7 \mathrm{E}-3 \pm 1.8 \mathrm{E}-3 / \mathrm{y}$, based on 1,336 hours of use per year, corresponding to the total time within a year that the crane is expected to be outside the parked and locked position. The probability that the TREAT crane fails while handling a loop is obtained by adding the failure rate uncertainty to the failure rate mean and scaling by time-at-risk/1336. Using the longest time-at-risk shown in Table F-9 $(7.85 \mathrm{E}-2 \mathrm{y} / \mathrm{y})$ yields the probability that a crane structural or mechanical failure results in a load drop of $2.59 \mathrm{E}-5$ per operating year.

Blume et al. (1979) also provided probabilities of load drop resulting from electrical component failure and from operator error are 1.0E-3 per operating year and 4.0E-3 per operating year, respectively, based on the number of events observed in 1,480 crane-years of operation. This reference notes that because of the sparseness of the data base used to develop the operator error rate, the operator error probability could be higher than the database indicates. However, use of crane and rigger qualification programs and procedures, together with the use of dedicated rigging, would minimize operator errors at TREAT. Therefore, it is assumed that operator error will cause a load drop with a probability of 4.0E-3 per operating year. The total probability of crane failure due to nonseismic causes is the sum of $2.59 \mathrm{E}-5,1.0 \mathrm{E}-3$ and $4.0 \mathrm{E}-3$, resulting in a value of $5.0 \mathrm{E}-3$ failures/operating year, with the total failure probability expected to be dominated by electrical component failure. The probability of one non-seismic initiated event occurring in 40 years of operations is 0.18 .

\section{F-4.2.3 Dose Consequences}

Depending on whether a single-pin experiment or experiment loop assembly is involved and whether a drop accident occurs before or after the experiment transient, barriers (including one of the casks, the experiment secondary vessel, the experiment primary vessel, the security can, or the fuel pin cladding) 
could be compromised. In accordance with NRC guidance (NRC 2003), the dose consequences provided in Table 8 of the NEPA-HA (INL 2013) for this event have been conservatively reduced by a factor of 10 to account for the recommended pin damage ratio of $10 \%$. In addition, the values have been adjusted to account for the average wind speed at TREAT of $9.4 \mathrm{mph}(4.2 \mathrm{~m} / \mathrm{s})$ (Appendix A), reducing the adjusted $\chi / \mathrm{Q}$ by a factor of 4.2 (Equation E-2).

The resultant doses are shown in Table F-10 and the dose risk and risk of LCF are shown in Table F-11. These tables show that the doses for seismic initiated events are expected to be the same as those initiated by operator error or equipment failure. However, the risk of receiving 1 rem per year from a load drop is higher for the non-seismic initiated event and the chance of a LCF occurring also is higher. Therefore, based on the higher consequence event (operator error or equipment failure), the accident consequences can be summarized as follows:

- For members of the public with the accident occurring at TREAT:

- The estimated dose is $0.006 \mathrm{rem}(6 \mathrm{mrem})$. This is much less than the annual average 600 -mrem dose received by members of the public from non-DOE facilities (Figure F-2).

- The increased probability of a member of the public getting cancer is $0.001 \%$.

- The risk of an LCF occurring is less than 1 in 27,500.

- For the collocated workers:

- The estimated dose is 0.21 rem for workers located $100 \mathrm{~m}$ from the site of the accident and 0.062 rem for those located $300 \mathrm{~m}$. It is 0.02 rem for workers located at the TREAT Reactor control building.

- The increased probability of the closest collocated worker getting cancer is $0.04 \%$.

- The risk of an LCF occurring is about 1 in 7,700.

- For facility workers located at the site of the load drop:

- The estimated dose rate is $0.25 \mathrm{rem} /$ minute. They could remain in the building about 100 minutes prior to receiving a dose of $25 \mathrm{rem}$.

- At 25 rem, the increased probability of a worker getting cancer is $4.25 \%$.

- At 25 rem, the rate of an LCF is 0.015 or 1.5 people in 100 .

Table F-10. Dose consequences for experiment assembly drop.

\begin{tabular}{|c|c|c|c|c|c|c|c|}
\hline & \multirow{2}{*}{$\begin{array}{c}\text { Annual } \\
\text { Frequency of } \\
\text { Occurrence }\end{array}$} & \multirow[b]{2}{*}{ Source } & $\begin{array}{c}\text { Facility Worker } \\
\text { (rem/min) }\end{array}$ & \multicolumn{3}{|c|}{ Collocated Workers (rem) } & $\begin{array}{l}\text { Member of the } \\
\text { Public (rem) }\end{array}$ \\
\hline MAR & & & $\begin{array}{l}\text { Located in TREAT } \\
\text { Reactor building }\end{array}$ & $100 \mathrm{~m}$ & $300 \mathrm{~m}$ & $770 \mathrm{~m}$ & $6,000 \mathrm{~m}$ \\
\hline \multirow{3}{*}{$\begin{array}{l}\text { Test loop } \\
\text { inventory }\end{array}$} & \multirow{3}{*}{$\begin{array}{l}\text { Operator error or } \\
\text { equipment } \\
\text { failure: } 5.0 \mathrm{E}-03 \\
\text { Seismic initiated } \\
\text { event: } 3.1 \mathrm{E}-05\end{array}$} & CED & $2.5 \mathrm{E}-01$ & 2.1E01 & $6.2 \mathrm{E}-02$ & $2.0 \mathrm{E}-02$ & $6.0 \mathrm{E}-03$ \\
\hline & & $\begin{array}{l}\text { Cloud } \\
\text { Gamma }\end{array}$ & - & $2.6 \mathrm{E} 06$ & 7.7E-07 & $2.5 \mathrm{E}-07$ & 8.3E-08 \\
\hline & & Total & $\begin{array}{l}0.25 \mathrm{rem} / \mathrm{min}(100 \mathrm{~min} \\
\text { prior to reaching } 25 \mathrm{rem})\end{array}$ & $0.21 \mathrm{rem}$ & $0.062 \mathrm{rem}$ & $0.02 \mathrm{rem}$ & $0.006 \mathrm{rem}$ \\
\hline
\end{tabular}

Notes:

1) Facility workers are assumed to be located in the TREAT Reactor building.

2) Collocated workers are not assumed to be evacuated and are exposed to the entire plume passage.

3) Members of the public are located 6,000 $\mathrm{m}$ away at the nearest INL boundary. Members of the public are assumed to be exposed to the entire plume passage.

4) Facility worker doses are based on a $16,000 \mathrm{~m}^{3}$ building volume.

5) The accident is assumed to occur in a facility area not evacuated by the F/CS; therefore, this accident is not mitigated by the HEPA filtration system provided for defense-in-depth.

6) A damage ratio of $10 \%$ was applied to the unmitigated doses provided in the NEPA-HA (INL 2013) for this scenario. 
Table F-11. Dose and latent cancer fatality summary for experiment assembly drop.

\begin{tabular}{|c|c|c|c|c|c|c|}
\hline & $\begin{array}{l}\text { Probability of } \\
\text { one failure } \\
\text { per year }\end{array}$ & $\begin{array}{c}\text { Probability of } \\
\text { one failure in } \\
40 \text { years }\end{array}$ & Receptor & $\begin{array}{c}\text { Dose } \\
\text { (rem unless } \\
\text { noted) }\end{array}$ & $\begin{array}{c}\text { Dose risk } \\
(\mathrm{rem} / \mathrm{yr})\end{array}$ & $\mathrm{LCF}$ \\
\hline \multicolumn{7}{|c|}{ Operator Error or Equipment Failure } \\
\hline \multirow{5}{*}{\multicolumn{2}{|c|}{$5.0 \mathrm{E}-03$}} & $1.8 \mathrm{E}-01$ & $\begin{array}{l}\text { Facility Worker at TREAT Reactor } \\
\text { building }^{\text {b }}\end{array}$ & $\begin{array}{c}2.5 \mathrm{E}-01 \\
(\mathrm{rem} / \mathrm{min})\end{array}$ & - & $1.5 \mathrm{E}-02^{\mathrm{a}}$ \\
\hline & & & Collocated Worker@100m & $2.1 \mathrm{E}-01$ & $1.0 \mathrm{E}-03$ & $1.3 \mathrm{E}-04$ \\
\hline & & & Collocated Worker@300m & $6.2 \mathrm{E}-02$ & $3.1 \mathrm{E}-04$ & 3.7E-05 \\
\hline & & & Collocated Worker@770m & $2.0 \mathrm{E}-02$ & $9.9 \mathrm{E}-05$ & $1.2 \mathrm{E}-05$ \\
\hline & & & Member of the Public @6,000 m ${ }^{\mathrm{c}}$ & $6.0 \mathrm{E}-03$ & $3.0 \mathrm{E}-05$ & $3.6 \mathrm{E}-06$ \\
\hline \multicolumn{7}{|c|}{ Seismic Initiated Event } \\
\hline \multirow{5}{*}{\multicolumn{2}{|c|}{$3.1 \mathrm{E}-05$}} & $1.3 \mathrm{E}-03$ & $\begin{array}{l}\text { Facility Worker at TREAT Reactor } \\
\text { building }\end{array}$ & $\begin{array}{c}2.5 \mathrm{E}-01 \\
(\mathrm{rem} / \mathrm{min})\end{array}$ & - & $1.5 \mathrm{E}-02^{\mathrm{a}}$ \\
\hline & & & Collocated Worker@100m & $2.1 \mathrm{E}-01$ & $6.6 \mathrm{E}-06$ & $1.3 \mathrm{E}-04$ \\
\hline & & & Collocated Worker@300m & $6.2 \mathrm{E}-02$ & $1.9 \mathrm{E}-06$ & 3.7E-05 \\
\hline & & & Collocated Worker@770m & $2.0 \mathrm{E}-02$ & $6.2 \mathrm{E}-07$ & $1.2 \mathrm{E}-05$ \\
\hline & & & Member of the Public @6,000 m & $6.0 \mathrm{E}-03$ & $1.9 \mathrm{E}-07$ & $3.6 \mathrm{E}-06$ \\
\hline \multicolumn{7}{|c|}{$\begin{array}{l}\text { Assumes a facility worker exposure of } 25 \text { rem and } 6 \mathrm{E}-4 \mathrm{LCF} / \mathrm{rem} \text {; Shaded cells represent the highest dose consequences for workers and } \\
\text { members of the public. } \\
\text { TREAT facility worker doses assume the drop accident occurs in the TREAT Reactor building, MFC facility worker doses assume the } \\
\text { accident occurs in the truck lock at HFEF. } \\
\text { If the accident occurs at TREAT, members of the public are located } 6,000 \mathrm{~m} \text { away at the nearest INL boundary, and if the accident occurs at } \\
\text { MFC, they are at } 5,000 \mathrm{~m} \text {. }\end{array}$} \\
\hline
\end{tabular}

Using the guidance provided by the Health Physics Society (Section F-3), consequences for members of the public and for workers located beyond a distance of $100 \mathrm{~m}$ are negligible. Protection of facility workers will require administrative procedures to limit the exposure time for workers. Based on a 25 rem exposure, there is ample time for facility workers to be evacuated.

The dose consequences shown in Table F-10 are conservative in terms of predicted dose and estimated likelihood:

- Predicted dose:

- Collocated workers in this accident scenario are assumed to be beyond $100 \mathrm{~m}$ from the drop accident. These workers are not assumed to be evacuated; therefore, the doses shown in Table F-10 reflect exposure during the entire plume passage.

- Members of the public are assumed to remain in place for the whole plume passage without being evacuated. The wind is assumed to blow in the direction of the hypothetical receptor.

- ST reduction provided by engineering design of the fuel cladding, loop handling casks, fuel handling casks, primary and secondary containment of the experiment assembly was included explicitly by factoring in a damage ratio of $10 \%$. Drop scenarios considered to be plausible in TREAT will be limited to a few feet and the TLHC or fuel handling cask would be expected to remain intact with minor damage occurring after a drop. After breaching the TLHC, the experiment assembly and fuel cladding also would have to fail prior to releasing radionuclides to the environment. Therefore, it would be unlikely for significant releases to occur from the cask. To account for these protective features, a damage ratio of $10 \%$ was assumed in the calculation of TED. If the effect of a drop considered failure of the TLHC, primary or secondary experiment containment (Figure F-5), or fuel cladding, a reduction in ST could be applied for each layer and the likelihood of this event could be reduced by the probability of breaching each layer. This 
could result in a dose reduction of an additional 10 to 1,000-fold, depending on the number of successive containment layers breached with a similar reduction in event likelihood.

- The postulated drop accident is assumed to occur in an area not evacuated by the HEPA F/CS.

- Estimated likelihood:

- The estimated likelihoods for facility structure and crane failure were based on conservative assumptions. The highest likelihoods of failure were associated with electrical component failure. If restart of the TREAT Reactor is selected as the preferred alternative, the likelihood of failure will be reduced through robust administrative controls, including programs designed to provide and enforce the following:

- Nuclear facility maintenance

- Emergency preparedness plans

- Radiation protection requirements

$\circ$ Hoisting and rigging requirements

- Nuclear criticality safety requirements

- Fire protection

$\circ$ Worker training.

These administrative procedures require pre-job inspections, checklists, multiple observers during transfer operations and crane lifts, and evacuation plans and procedures designed to minimize exposure.

The combination of administrative controls that will be in place will provide multiple points of redundancy, greatly reducing single-point failure modes. In combination with the PC-2 design requirements for safety-significant SSCs, the likelihood of mechanical (design) failure is unlikely and for combinations of design and administrative controls to fail is improbable.

\section{F-4.3 Inadvertent Nuclear Criticality}

Events in this category include violations of mass, geometry, or moderation controls. The NEPA-HA (INL 2013) identifies the need for limits on the facility inventory of fissile material. The double contingency principle applicable to Hazard Category-2 facilities will be satisfied for TREAT through engineering and administrative controls. Further evaluation will be made on the need for additional criticality safety requirements (i.e., specific packaging configurations for high fissile materials) pertaining to TREAT during development of the preliminary DSA to prevent inadvertent nuclear criticality. Therefore, there are no anticipated releases of radioactive material from this category.

\section{F-4.4 External Event}

Events in this category include plane crash, vehicle crash, and adjacent building fire/explosion. Plane crashes at INL are considered to be beyond extremely unlikely due to diversion of air traffic and based on air transportation safety information. Vehicle crashes and adjacent building fire/explosions will not have a significant impact. There is no anticipated release of radioactive material from this category of accidents should they occur.

\section{F-4.5 Hypothesized Reactor Fuel Impact}

As was the case with experiment impact/drop accidents, it is assumed in this scenario that an impact on or by a reactor fuel assembly during fuel-handling operations could result from a failure of the reactor building crane (in this case the 15-ton crane) or of the reactor building structures supporting the crane. The crane failure could occur as a result of structural/mechanical failures due to a seismic event. Natural phenomena other than earthquakes are not considered credible, because operations will be postponed and fuel assemblies secured after warning of their potential occurrence is received. The worst-case accident 
would be the drop of a fuel assembly over the core during insertion or removal, leading to the breach of the dropped assembly and breach of four adjacent fuel assemblies in the core.

\section{F-4.5.1 Preventative Measures}

Measures in place to minimize the likelihood and consequences of this potential accident are provided by TREAT facility design, experiment handling equipment, the fuel handling cask, and the TREAT fuel design as discussed in Sections F-4.2.1 and F-4.2.2. Additional features providing protection against this accident rely on the structure of the reactor itself and could include lift height restrictions in the reactor area.

- Reactor structure. The reactor structure consists of those components that support and encase the core and the reactivity control systems (i.e., core support and alignment components, shielding, permanent graphite reflector, coolant plenums, rotating shield plug, and penetrations for experimental equipment).

- $\quad$ Reactor core. The reactor core is contained in a 3 to 5-ft-thick heavy concrete structure that provides physical support and radiation shielding.

- Grid plate assembly. Beneath the core is a grid plate assembly, which, together with core clamping bars at the top of the core, locates, aligns, and supports the fuel assemblies. The grid plate assembly is supported around its perimeter by a concrete ledge and in its central region by the control rod guide thimbles.

- Control rod guide thimbles. The control rod guide thimbles are embedded in the 3-ft-thick concrete portion of the slab that separates the core cavity from the subpile room below it where the control rod drives are mounted.

- Graphite reflector. The fuel assemblies are surrounded by a permanent graphite reflector that sits on the 4-ft-thick section of the concrete ceiling of the subpile room. The difference between this thickness and the $3-\mathrm{ft}$ thickness of concrete below the core provides the volume for the lower coolant plenum used by the F/CS. The permanent graphite reflector (and its associated thermal column) is surrounded by a concrete structure that provides shielding and support.

- Corbel. A ledge of the concrete structure, called the corbel, extends over the core, providing a load-bearing surface for the rotating shield plug.

- $\quad$ Rotating shield plug. The rotating shield plug consists of three circular steel plates, each 4-in. thick. Movable shield sections in a radial slot in this plug provide for the penetrations needed for fuel loading/unloading operations.

- The upper coolant plenum is formed by a void between the bottom of the rotating shield plug and the top of the fuel assemblies. Removable concrete shield blocks are located above the rotating shield plug.

- Lift height restrictions. Because a high drop of a load might damage the wall, all objects that will be carried over the reactor walls (e.g., loops, reactor fuel assemblies, calibration assemblies, loop and reactor fuel assembly casks, bridge support structure, and top shield structure blocks) could have their lift height above the wall administratively restricted.

\section{F-4.5.2 Probability of this Type of Accident Occurring}

The frequency of occurrence for a fuel assembly handling accident is calculated following the approach given in Section F-4.2.2. The time-at-risk is established for fuel-handling operations during which each of the above initiators can lead to a fuel assembly impact accident.

The annual time-at-risk for a fuel assembly impact accident is based on consideration of all planned fuel-handling operations for adjustment of core loadings. The total time for experiment-related reactor-fuel-assembly-handling operations was estimated to be $680 \mathrm{~h} / \mathrm{y}$. This time includes that required for pre-experiment and calibration operations. To allow for additional fuel changes or other potential fuel 
assembly handling, such as inspection operations or loading to critical, an additional 510 hours (approximately $2 \mathrm{~h} / \mathrm{y}$ per fuel assembly) is assumed. This yields a total time-at-risk of $1,190 \mathrm{~h} / \mathrm{y}(0.13 \mathrm{y} / \mathrm{y})$ for fuel assembly impact accidents.

The frequency of occurrence for a reactor- fuel assembly impact accident scenario is the product of the probability for the accident initiator and the time-at-risk. The earthquake initiator has probability of 4E-04/year, yielding a crane load drop probability of 5.4E-05 /year. The corresponding probability of one event per 40 years of transient testing is 2.2E-3. As with the experiment drop scenario, the total probability of crane failure due to non-seismic causes is 5.0E-3 failures/operating year, yielding a $6.8 \mathrm{E}-4$ frequency of occurrence. The corresponding probability of one event per 40 years of transient testing is 2.7E-02.

\section{F-4.5.3 Dose Consequences}

Dose consequences for this scenario are provided in Table 10 of the NEPA-HA (INL 2013). The doses from Table 10 of the NEPA-HA have been adjusted to account for the average wind speed at TREAT of $9.4 \mathrm{mph}(4.2 \mathrm{~m} / \mathrm{s})$ (Appendix A), reducing the adjusted $\chi / \mathrm{Q}$ by a factor of 4.2 (Equation E-2). The resultant doses are shown in Table F-12 and the dose risk and risk of an LCF occurring are summarized in Table F-13.

Table F-12. Dose consequences for reactor fuel impact.

\begin{tabular}{|c|c|c|c|c|c|c|c|}
\hline \multirow[b]{2}{*}{ MAR } & \multirow[b]{2}{*}{$\begin{array}{c}\text { Annual Frequency } \\
\text { of Occurrence }\end{array}$} & \multirow[b]{2}{*}{ Source } & \multirow[b]{2}{*}{$\begin{array}{l}\text { Facility Worker } \\
(\mathrm{rem} / \mathrm{min})^{1}\end{array}$} & \multicolumn{3}{|c|}{ Collocated Workers ${ }^{2}$ (rem) } & \multirow{2}{*}{$\begin{array}{c}\text { Member } \\
\text { of the } \\
\text { Public } \\
\text { (rem) }\end{array}$} \\
\hline & & & & $100 \mathrm{~m}$ & $300 \mathrm{~m}$ & $770 \mathrm{~m}$ & \\
\hline \multirow{3}{*}{$\begin{array}{l}\text { Five TREAT } \\
\text { Reactor fuel } \\
\text { assemblies }\end{array}$} & \multirow{3}{*}{$\begin{array}{l}\text { Operator error or } \\
\text { equipment failure: } \\
6.8 \mathrm{E}-04 \\
\text { Seismic initiated } \\
\text { event: } 5.4 \mathrm{E}-05\end{array}$} & CED & 3.9 & 3.4 & 0.99 & 0.32 & 0.017 \\
\hline & & $\begin{array}{l}\text { Cloud } \\
\text { Gamma }\end{array}$ & - & 2.1 & 0.61 & 0.2 & 0.0013 \\
\hline & & Total & $\begin{array}{c}3.9 \mathrm{rem} / \mathrm{min} \\
\text { (6.4 min prior to } \\
\text { reaching } 25 \\
\text { rem })\end{array}$ & $5.4 \mathrm{rem}$ & $1.6 \mathrm{rem}$ & $0.51 \mathrm{rem}$ & $0.018 \mathrm{rem}$ \\
\hline \multicolumn{8}{|l|}{ Notes: } \\
\hline \multicolumn{8}{|c|}{ 1) Facility workers are assumed to be located in the TREAT Reactor building. } \\
\hline \multicolumn{8}{|c|}{ Collocated workers are not assumed to be evacuated and are exposed to the entire plume passage. } \\
\hline \multirow{2}{*}{\multicolumn{8}{|c|}{$\begin{array}{l}\text { Offsite members of the public are located } 6,000 \mathrm{~m} \text { or at the nearest INL boundary and are assumed to be exposed to the entire plume passage. } \\
\text { The accident is assumed to occur in a facility area not evacuated by the F/CS; therefore, this accident is not mitigated by the HEPA filtration } \\
\text { system provided for defense-in-depth. }\end{array}$}} \\
\hline & & & & & & & \\
\hline \multicolumn{8}{|c|}{ A damage ratio of $10 \%$ was applied to the unmitigated doses provided in the NEPA-HA (INL 2013) for this scenario. } \\
\hline
\end{tabular}

Based on the higher consequence event (operator error or equipment failure), the accident consequences can be summarized as follows:

- For members of the public:

- The estimated dose is $0.018 \mathrm{rem}(18 \mathrm{mrem})$. This is about $3 \%$ of the annual average 600 -mrem dose received by members of the public from non-DOE facilities (Figure F-2).

- The increased probability of a member of the public getting cancer is $0.003 \%$.

- The risk of an LCF occurring is less than 1 in 93,000.

- For the collocated workers:

- The estimated dose is 5.4 rem for workers located $100 \mathrm{~m}$ from the site of the accident and 1.6 rem for those located $300 \mathrm{~m}$. It is 0.51 rem for workers located at the TREAT Reactor control building.

- The increased probability of the closest collocated worker getting cancer is $0.9 \%$. 
- The risk of an LCF occurring is about 1 in 300.

- For facility workers located in the TREAT Reactor building:

- The estimated dose rate is $3.9 \mathrm{rem} /$ minute. They could remain in the building about 6.5 minutes prior to receiving a dose of $25 \mathrm{rem}$.

- At 25 rem, the increased probability of a worker getting cancer is $4.25 \%$.

- At 25 rem, the rate of an LCF occurrence is 0.015 , or 1.5 people in 100.

Table F-13. Dose and latent cancer fatality summary for reactor fuel impact.

\begin{tabular}{|c|c|c|c|c|c|}
\hline $\begin{array}{l}\text { Probability of One } \\
\text { Failure per Year }\end{array}$ & $\begin{array}{l}\text { Probability of One } \\
\text { Failure in } 40 \text { years }\end{array}$ & Receptor & $\begin{array}{c}\text { Dose } \\
\text { (rem unless } \\
\text { noted) }\end{array}$ & $\begin{array}{l}\text { Dose Risk } \\
\text { (rem/year) }\end{array}$ & $\mathrm{LCF}$ \\
\hline \multicolumn{6}{|c|}{ Operator Error or Equipment Failure } \\
\hline \multirow[t]{5}{*}{$6.8 \mathrm{E}-04$} & 2.7E-02 & $\begin{array}{l}\text { Facility Worker in Treat Reactor } \\
\text { Building }\end{array}$ & $3.9(\mathrm{rem} / \mathrm{min})$ & & $1.5 \mathrm{E}-02 * *$ \\
\hline & & Collocated Worker@100m & 5.4 & $3.7 \mathrm{E}-03$ & $3.3 \mathrm{E}-03$ \\
\hline & & Collocated Worker@300m & 1.6 & $1.1 \mathrm{E}-03$ & $9.6 \mathrm{E}-04$ \\
\hline & & Collocated Worker@770m & 0.5 & $3.5 \mathrm{E}-04$ & 3.1E-04 \\
\hline & & Offsite Member of the Public & 0.02 & $1.2 \mathrm{E}-05$ & $1.1 \mathrm{E}-05$ \\
\hline \multicolumn{6}{|c|}{ Seismic Initiated Event } \\
\hline \multirow[t]{5}{*}{$5.4 \mathrm{E}-05$} & $2.0 \mathrm{E}-03$ & $\begin{array}{l}\text { Facility Worker in Treat Reactor } \\
\text { Building }\end{array}$ & $3.0(\mathrm{rem} / \mathrm{min})$ & & $1.5 \mathrm{E}-02 * *$ \\
\hline & & Collocated Worker@100m & 16 & $3.0 \mathrm{E}-04$ & 3.3E-03 \\
\hline & & Collocated Worker@300m & 4.9 & $8.7 \mathrm{E}-05$ & $9.6 \mathrm{E}-04$ \\
\hline & & Collocated Worker@770m & 1.6 & $2.8 \mathrm{E}-05$ & $3.1 \mathrm{E}-04$ \\
\hline & & Offsite Member of the Public & 0.12 & $9.8 \mathrm{E}-07$ & $1.1 \mathrm{E}-05$ \\
\hline
\end{tabular}

** Assumes a facility worker exposure of 25 rem and 6E-4 LCF/rem.

Using the discussion provided in Section F-3, consequences for members of the public and for workers are negligible. Protection of facility workers could require administrative procedures to limit dose consequences. This could include an emergency response plan or use of personal protection equipment. Based on a 25-rem exposure, there is ample time for workers to be evacuated prior to significant health impact.

\section{F-4.6 Hypothesized Drop of Experiment into the TREAT Reactor}

In this scenario, it is assumed that the experiment is dropped during insertion or removal into the TREAT Reactor. As with a TREAT Reactor fuel insertion accident, this scenario could result from a failure of the reactor building crane or of the reactor building structures supporting the crane during experiment handling operations over the reactor. Requirements for this scenario include (1) the experiment is in or being inserted into the core, (2) the crane is above the core and experiment, and (3) the crane fails. In this scenario, it is unlikely that the experiment would be in the TLHC. Therefore, the barriers protecting the experiment fuel would only consist of the experiment assembly and the fuel cladding.

The unmitigated dose consequences for this scenario were provided in the NEPA-HA in Table 12 based on parameters in Table 11. The MAR in this scenario consists of the radionuclide inventory of five potentially damaged TREAT fuel assemblies, with the fuel assemblies corresponding to the conservative core configuration plus the bounding inventory of the experiment (Appendix E). Parameters used to estimate the ST (Equation E-1) were consistent with a drop scenario and differ from those for an incident, including fire. Fire is not expected to occur in this scenario, based on the following analysis: 
- The total sodium contained in a MARK-III test loop is about $3.3 \mathrm{~kg}(3 \mathrm{~L})$. Before the test loop is removed from the core, the loop sodium is allowed to solidify (freeze) by cooling the test loop below the melting point $\left(97.8^{\circ} \mathrm{C}\right)$. The ignition temperature of sodium in air depends on the area of surface exposed: vapor ignites at room temperature $\left(25^{\circ} \mathrm{C}\right)$; droplets at about $250^{\circ} \mathrm{F}\left(121^{\circ} \mathrm{C}\right)$; an agitated pool at $400^{\circ} \mathrm{F}\left(204^{\circ} \mathrm{C}\right)$. As a result of sample decay heat, some of the sodium near the test fuel region may remain molten, suggesting that much less than $3.3 \mathrm{~kg}$ of sodium would be available to combust.

- For conservatism, the complete oxidation of $3.3 \mathrm{~kg}$ of molten sodium is considered. Given the enthalpy of sodium combustion $(828 \mathrm{~kJ} / \mathrm{mol})$ and the molecular weight $(62 \mathrm{~g} / \mathrm{mol})$, combusting $3.3 \mathrm{~kg}$ of sodium would release about $4.4 \mathrm{E}+07 \mathrm{~J}$.

- Heat sink effects will reduce the temperature of any released sodium. If the molten sodium contacts metallic uranium or steel, the metal-sodium interface temperature will be at or below the sodium melting point. For loop rupture while the experiment is within the reactor, the steel in the experiment assembly and reactor, concrete making up the reactor structure and uranium shielding will provide the heat sink.

- For the purposes of illustration, assume that the bulk temperature of $150^{\circ} \mathrm{C}$ is the temperature at which molten sodium would burn in a pool. This is between the combustion temperature for droplets and an agitated pool.

- The heat capacity of steel is $420 \mathrm{~J} / \mathrm{kg}^{\circ} \mathrm{C}$ and the density is $7.8 \mathrm{E}+03 \mathrm{~kg} / \mathrm{m}^{3}$.

- To raise the temperature from the bulk sodium temperature of $97.8^{\circ} \mathrm{C}$ to $150^{\circ} \mathrm{C}\left(52.2^{\circ} \mathrm{C}\right)$, the required net heat sink capacity would be $6.99 \mathrm{E}+05 \mathrm{~J} /{ }^{\circ} \mathrm{C}$, corresponding to $2,000 \mathrm{~kg}$ of steel after applying the steel heat capacity.

- $\quad 2,000 \mathrm{~kg}$ of steel is equivalent to $0.26 \mathrm{~m}^{3}$, which compared to the steel contained in the experiment assembly or reactor components is very small.

This shows that there is every expectation that any sodium released from the loop would solidify prior to catching fire. Therefore, catching the experiment fuel on fire is simply not likely to occur.

- Catching the reactor fuel or carbon on fire is even more remote given that it is difficult to achieve conditions for self-sustained combustion of graphite (NUREG/CR-4981 1987). If some small portion of the sodium were to catch fire, the reactor fuel fire would be diffusion limited, slowing the release of radionuclides from the fuel and resulting in lower peak air concentrations and ED.

\section{F-4.6.1 Preventative Measures}

Measures in place to minimize the likelihood and consequences of this potential accident are provided by TREAT facility design, experiment handling equipment, the TREAT loop handling cask, and the TREAT fuel design as discussed in Sections F-4.2 and F-4.6. Additional features providing protection against this accident rely on the structure of the reactor itself, requirements to cool the experiment assembly prior to insertion/removal from the reactor and could include use of personal protective equipment and lift height restrictions in the reactor area.

\section{F-4.6.2 Probability of this Type of Accident Occurring}

The frequency of occurrence for an experiment assembly handling accident over the reactor is calculated following the approach given in Section F-4.2.2 and F-4.6. The time-at-risk is established for experiment handling operations during which each of the above initiators can lead to a fuel assembly impact accident.

The annual time-at-risk for a fuel assembly impact accident is based on consideration of all planned experiment handling operations. The total time for experiment-related handling operations was estimated to be $680 \mathrm{~h} / \mathrm{y}$ (Section F-4.2). Of this time, only a small fraction occurs with the experiment assembly over the reactor core. This time is conservatively estimated to be $68 \mathrm{hr} /$ year ( $7.8 \mathrm{E}-3 \mathrm{year} / \mathrm{year})$. The frequency of occurrence for this impact accident scenario is the product of the probability for the accident 
initiator and the time-at-risk. The total probability of crane failure due to non-seismic causes is 5.0E-3 failures/operating year, yielding a 3.9E-5 frequency of occurrence. The corresponding probability of one event per 40 years of transient testing is $1.6 \mathrm{E}-3$.

\section{F-4.6.3 Dose Consequences}

Dose consequences for this scenario are provided in Table 12 of the NEPA-HA (INL 2013). The doses from Table 12 of the NEPA-HA have been adjusted to account for the average wind speed at TREAT of $9.4 \mathrm{mph}(4.2 \mathrm{~m} / \mathrm{s})$ (Appendix A), reducing the adjusted $\chi / \mathrm{Q}$ by a factor of 4.2 (Equation E-2). The resultant doses are shown in Table F-14 and the dose risk and risk of an LCF occurring are summarized in Table F-15.

Table F-14. Dose consequences for the scenario dropping the experiment into the reactor core.

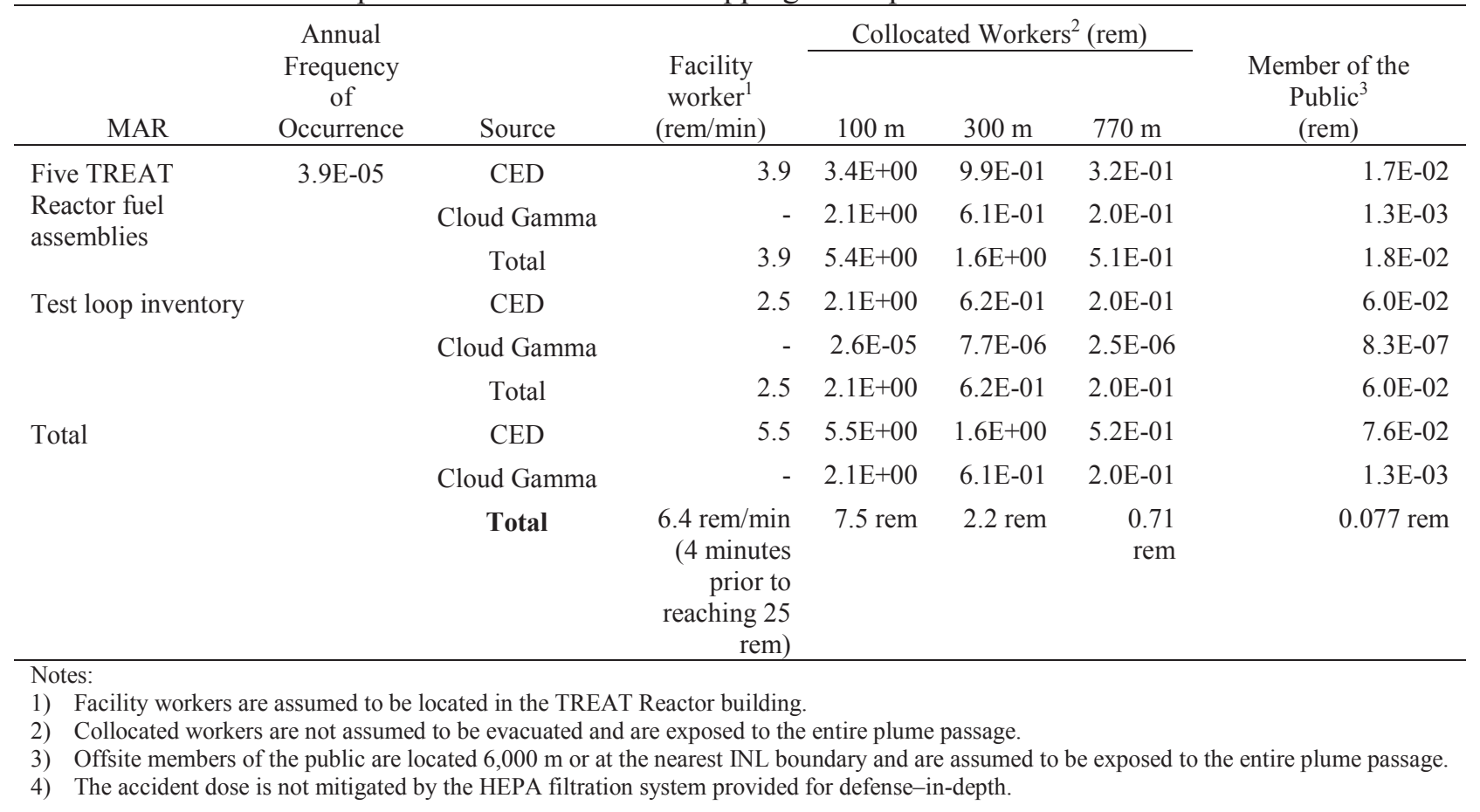

Based on the higher consequence event (operator error or equipment failure), the accident consequences can be summarized as follows:

- For members of the public:

- The estimated dose is $0.077 \mathrm{rem}$ ( $77 \mathrm{mrem})$. This is about $13 \%$ of the annual average 600 -mrem dose received by members of the public from non-DOE facilities (Figure F-2).

- The increased probability of a member of the public getting cancer is $0.01 \%$.

- The risk of an LCF occurring is about 1 in 22,000.

- For the collocated workers:

- The estimated dose is 7.5 rem for workers located $100 \mathrm{~m}$ from the site of the accident and 2.2 rem for those located at $300 \mathrm{~m}$. It is $0.71 \mathrm{rem}$ for workers located at the TREAT Reactor control building.

- The increased probability of the closest collocated worker getting cancer is $1.3 \%$.

- The risk of an LCF occurring is about 1 in 220. 
- For facility workers located in the TREAT Reactor building:

- The estimated dose rate is $6.4 \mathrm{rem} /$ minute. They could remain in the building about 4 minutes prior to receiving a dose of $25 \mathrm{rem}$.

- At 25 rem, the increased probability of a worker getting cancer is $4.25 \%$.

- At 25 rem, the rate of an LCF occurrence is 0.015 , or 1.5 people in 100.

Using the guidance provided by the Health Physics Society (Section F-3), consequences for members of the public and for workers located beyond a distance of $100 \mathrm{~m}$ are negligible. Protection of facility workers and collocated workers closer than $100 \mathrm{~m}$ could require administrative procedures to limit dose consequences. This could include an emergency response plan or use of personal protection equipment. Based on a 25-rem exposure, there is ample time for workers to be evacuated. Therefore, the accident consequences are considered to be negligible.

Table F-15. Dose and latent cancer fatality summary for the scenario of dropping the experiment into the reactor core.

\begin{tabular}{|c|c|c|c|c|c|}
\hline $\begin{array}{l}\text { Probability of } \\
\text { One Failure per } \\
\text { Year }\end{array}$ & $\begin{array}{l}\text { Probability of One } \\
\text { Failure in } 40 \text { Years }\end{array}$ & Receptor & $\begin{array}{c}\text { Dose } \\
\text { (rem unless } \\
\text { noted) }\end{array}$ & $\begin{array}{l}\text { Dose Risk } \\
\text { (rem/yr) }\end{array}$ & LCF \\
\hline \multirow[t]{5}{*}{ 3.9E-05 } & $1.6 \mathrm{E}-03$ & $\begin{array}{l}\text { Facility Worker in TREAT } \\
\text { Reactor building }\end{array}$ & $6.4 \mathrm{rem} / \mathrm{min}$ & & $1.5 \mathrm{E}-02 *$ \\
\hline & & Collocated Worker@100m & 7.5 & $2.9 \mathrm{E}-04$ & $4.5 \mathrm{E}-03$ \\
\hline & & Collocated Worker@300m & 2.25 & $8.7 \mathrm{E}-05$ & $1.3 \mathrm{E}-03$ \\
\hline & & Collocated Worker@770m & 0.71 & $2.8 \mathrm{E}-05$ & 4.3E-04 \\
\hline & & Offsite Member of the Public & 0.077 & $3.0 \mathrm{E}-06$ & $4.6 \mathrm{E}-05$ \\
\hline
\end{tabular}

* Assumes a facility worker exposure of 25 rem and 6E-4 LCF/rem.

\section{F-4.7 Hypothesized Sodium Fire Impacting the Core and Experiment}

This scenario considers the dose consequences that could occur if the experiment assembly fails while it is inserted in the TREAT Reactor. The worst-case failure event would involve the $3 \mathrm{~L}(3.3 \mathrm{~kg})$ of sodium contained in the cooling loops. Contents of the sodium loop are designed to be contained at the maximum expected internal pressure and temperature (ANL 1979a). However, it is possible that over-pressuring the experiment package could occur, initiated by (1) excessive heat, (2) loss of heat rejection capability, and (3) degradation/failure of the sodium loop in the experiment package. It also is possible that an accident could be initiated by an air-sodium reaction within the cooling loops caused by operator error or leaks of sealing surfaces (i.e., ports or flanges) of the experiment package.

Sodium self ignites in air in a range of 100 to $320^{\circ} \mathrm{C}$, depending on the physical circumstances (e.g., small static pool or agitated small pool) (SNL 2010, Berkeley 1972). The maximum operating temperature of the TREAT Reactor is approximately $600^{\circ} \mathrm{C}$. If heat rejection in the experiment package is insufficient, allowing the internal temperature to rise above the self-ignition temperature, the liquid sodium in the cooling loop could burn in the presence of air. The sodium combustion reaction equations provided by Morewitz (1979) are as follows:

Sodium Oxide Reaction: $4 \mathrm{Na}(\mathrm{l})+\mathrm{O}_{2}(\mathrm{~g}) \rightarrow 2 \mathrm{Na}_{2} \mathrm{O}(\mathrm{s})$

Sodium Peroxide Reaction: $2 \mathrm{Na}(\mathrm{l})+\mathrm{O}_{2}(\mathrm{~g}) \rightarrow \mathrm{Na}_{2} \mathrm{O}_{2}$ (s)

Sodium Hydroxide Reaction: $2 \mathrm{Na}(\mathrm{l})+2 \mathrm{H}_{2} \mathrm{O}(\mathrm{g}) \rightarrow 2 \mathrm{NaOH}+\mathrm{H}_{2}$

In the air-cooled TREAT Reactor, minimal water vapor would be expected and the production of sodium hydroxide would be unexpected. The sodium oxide reaction dominates the combustion reaction as most of the sodium reacted with air produces $\mathrm{Na}_{2} \mathrm{O}$. However, the higher energy release is associated with 
the production of sodium peroxide. The amount of sodium oxidized would depend on the availability of air within the sodium loops.

If the molten sodium is retained in the primary containment of the experiment loop, the availability of air would be limited to the amount not purged and replaced with inert gas as the experiment is assembled. Leakage of air into the experiment assembly will not occur because the internal inert gas pressure is higher than atmospheric. Therefore, the amount of sodium oxidized would be small and limited by the availability of air. The oxidation rate would be diffusion limited and would occur over a relatively long time period. It is likely that there would be no radiologic release from either the reactor core or experiment fuel.

If molten sodium is released from the primary containment into the secondary containment and the secondary containment holds, the oxidation process could be more rapid and the experiment assembly could become over pressurized, potentially damaging the fuel in the experiment and the surrounding reactor fuel elements. Release of molten sodium into the reactor cavity would be noted by the sensors and the reactor would be shutdown. Catching the reactor fuel or carbon on fire is unlikely given that it is difficult to achieve conditions for self-sustained combustion of graphite (NUREG/CR-4981 1987). If some small portion of the sodium were to catch fire, the reactor fuel fire would be diffusion limited, slowing the release of radionuclides from the fuel and resulting in lower peak air concentrations and ED.

\section{F-4.7.1 Preventative Measures}

Measures in place to minimize the likelihood and consequences of this potential accident are provided by the engineering design of the MARK-III experiment assembly (ANL 1979a, ANL 1979b) and the engineering and testing requirements of the Guide for Irradiation Experiments in TREAT (1991). The MARK-III Loop experiment system includes the MARK-III Loop and loop support systems as follows:

- The MARK-III Loop is a pressure vessel designed to the requirements of the ASME Boiler and Pressure Vessel Code, Section III, Nuclear Power Plant Components. The primary containment has been designed to not fail during bounding abnormal reactor operations. The secondary enclosure provides a leak tight boundary designed to confine the leakage of sodium and fission gases that might occur as a result of a leak of the primary containment. Design requirements for the primary containment included pressures of $34.5 \mathrm{MPa}$ at $538^{\circ} \mathrm{C}$, proof-tested at pressures of $43.1 \mathrm{MPa}$ and $538^{\circ} \mathrm{C}$. In addition to pressure proof-testing, the loop assembly is required to be leak-tight at a pressure of $331.2 \mathrm{kPa}$. The secondary enclosure is tested to be leak-tight at $13.8 \mathrm{kPa}$. As an additional safety measure, the loop has an expansion tank to ensure over-pressurization of the sodium-containing loops will not occur.

- The loop support systems provide secondary and primary cover gas systems. The secondary enclosure gas system allows purging the annular space between the primary containment and the secondary enclosure with an inert gas. It provides the capability for helium leak checking of the secondary enclosure. The primary cover gas system is provided to allow the loop pressure to be adjusted. It allows capture of contaminated cover gas and sodium vapor that could be inadvertently released to the cover gas system. During operations, inert gas (nitrogen) is circulated at approximately 3 liters/minute through the secondary enclosure and exhausted to the reactor cooling system.

As specified in the Guides for Irradiation Experiments in TREAT (1991), each experimenter is required to show that the design limits of the MARK-III Loop would not be exceeded under accident conditions. If this alternative is selected and transient testing is resumed at TREAT, similar design requirements will be required for all test loops, loop support systems, and experiments conducted under the RTT Program. 


\section{F-4.7.2 Probability of this Type of Accident Occurring}

This accident is thought to be extremely unlikely based on the operating and testing history of the TREAT Reactor and on the design and testing requirements of the experiment assembly. The probability of this event occurring has been estimated for the event occurring in the ACRR and is provided in SNL/NM (2013). Assuming 34 sodium-cooled experiment reactor operations per year, the annual probability has been estimated to be $1.1 \mathrm{e}-2$, making the combined events/failures unlikely. The corresponding probability that one accident of this type will occur during the 40 years of transient testing is 0.36 . Because the event is specific to the experiment, the same likelihood will apply to this scenario if it occurs at TREAT. Assumptions used in the assignment of event failure result in the combined probability expression:

$P_{a}=P_{b} \times P_{c}=\left(P_{d}+P_{h}+P_{i}\right) \times\left(P_{g}+P_{j}+P_{k}\right)$

based on the logic path illustrated in Figure F-6:

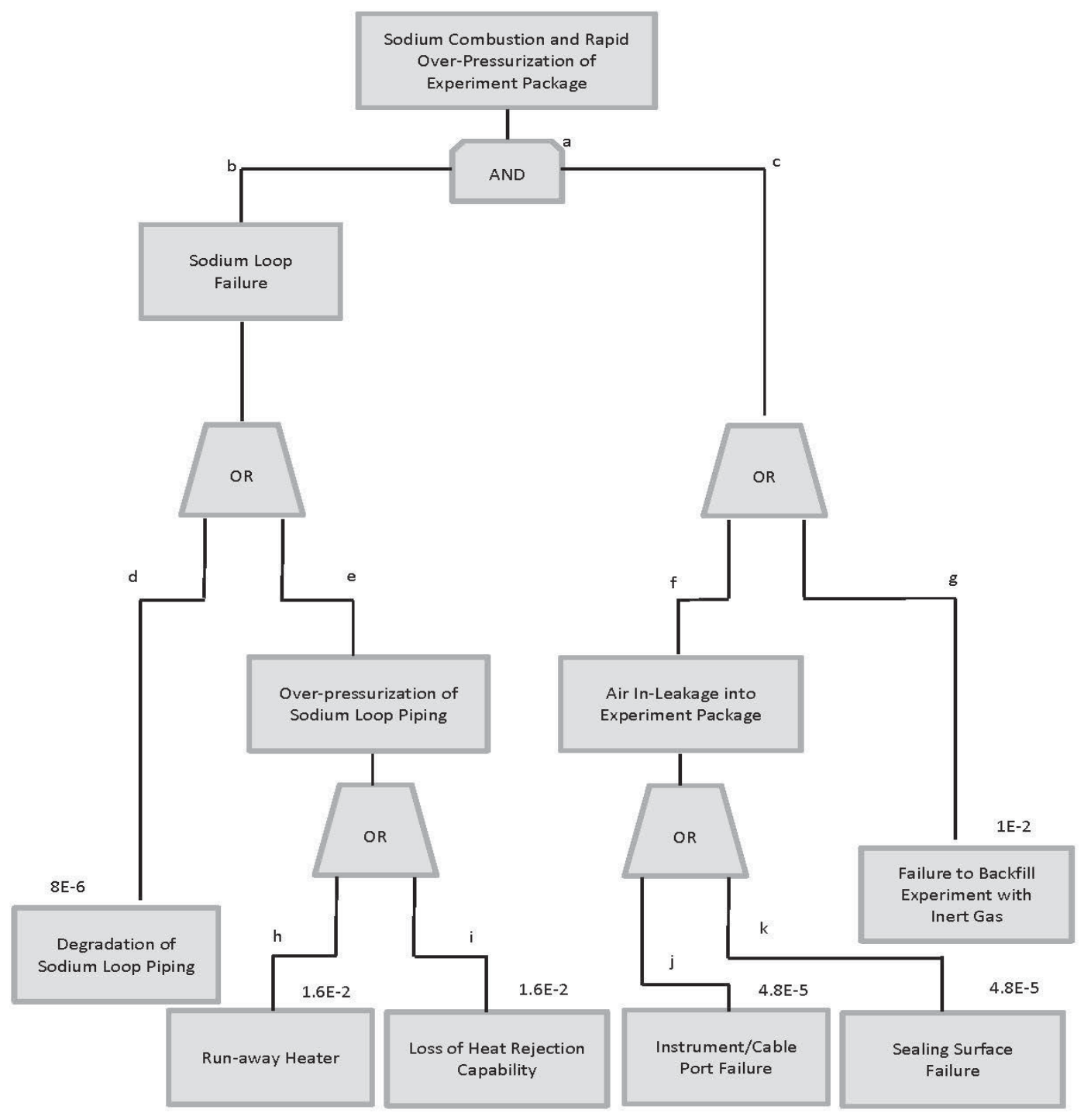

Figure F-6. Fault tree for a sodium loop experiment, resulting in rapid oxidation and damage to the reactor fuel elements. Failure likelihoods indicated for each event are expressed as per final transient (from SNL/NM 2013). 
- Sodium Loop Failure: The sodium loop can fail by degradation or over-pressurization of the sodium loop piping.

- Degradation of Piping: The sodium loop can fail by degradation of piping, which can be represented by the failure rate of pipe joints of 5E-7/hour. Taking into account 8 hours per operation and assuming the use of two pipe joints, this probability is given as $8 \mathrm{E}-6$ per sodium-cooled experiment operation.

- Over-Pressurization of Loop: The sodium loop can fail by over-pressurization of the sodium loop by either runaway heater or loss of heat rejection. These failure rates can be represented by the failure rate of fuses or circuit breakers failing to open of 1E-3/hour. Taking into account 8 hours per operation and assuming the use of two fuses/circuits, these probabilities are given as 1.6E-02 per sodium-cooled experiment operation.

- Air Present in Experiment Package: Air can be present in the experiment package by leaking of ports/sealing surfaces or by failure to backfill with inert gas (i.e., human error).

- Failure to Backfill Air with Inert Gas: Failure to backfill the experiment with inert gas is an error of omission that can be represented by a failure rate of $1 \mathrm{E}-2$ per demand. Considering, the experiment package must be backfilled once per sodium loop experiment operation, the probability of failing to backfill the experiment package with insert gas is provided as $1 \mathrm{E}-2$ per operation.

- Instrument/Cable Port Failure: Air leakage into the experiment package through instrument/cable ports can be represented by the failure probability of gaskets of $3 \mathrm{E}-6 /$ hour. Taking into account 8 hours per operation and assuming two instrument/cable ports, this probability is given as $4.8 \mathrm{E}-5$ per operation.

- Sealing Surface Failure: Air leakage also could occur into the experiment package through o-ring seals or gaskets located at sealing surfaces. This failure can be presented by the failure probability of gaskets of 3E-6/hour, which is higher than that provided for o-rings at 2E-7/hour. Taking into account 8 hours per operation and assuming two sealing surfaces, this failure probability is given by $4.8 \mathrm{E}-5$ per operation.

\section{F-4.7.3 Dose Consequences}

Dose consequences for this scenario are provided in Table 14 of the NEPA-HA (INL 2013). The doses from Table 14 of the NEPA-HA have been adjusted to account for the average wind speed at TREAT of $9.4 \mathrm{mph}(4.2 \mathrm{~m} / \mathrm{s})$ (Appendix A), reducing the adjusted $\chi / \mathrm{Q}$ by a factor of 4.2 (Equation E-2). The resultant doses are shown in Table F-16 and the dose risk and risk of an LCF occurring are summarized in Table F-17. The accident consequences can be summarized as follows:

- For members of the public:

- The estimated dose is $0.027 \mathrm{rem}(27 \mathrm{mrem})$. This is much lower than the annual average 600 -mrem dose received by members of the public from non-DOE facilities (Figure F-2).

- The increased probability of a member of the public getting cancer is $0.005 \%$.

- The risk of an LCF occurring is less than 1 in 62,000.

- For facility and collocated workers:

- Workers would most likely be located in the TREAT Reactor control building during this accident. However, doses are provided for comparison to a similar accident analyzed for ACRR. Workers at ACRR are assumed to be located at $300 \mathrm{~m}$ from the accident site.

- The estimated dose is 0.63 rem for workers located at the TREAT Reactor control building. For comparison to ACRR, it is 2.0 rem for workers located $300 \mathrm{~m}$ from the site of the accident. 
- The increased probability of a worker getting cancer is $0.1 \%$ for workers located in the TREAT Reactor control building. It is $0.34 \%$ at $300 \mathrm{~m}$.

- The risk of an LCF occurring is about 1 2,600 for workers located in the TREAT Reactor control building. It is 1 in 830 at $300 \mathrm{~m}$.

Table F-16. Dose consequences for a sodium fire in the TREAT Reactor.

\begin{tabular}{|c|c|c|c|c|c|c|c|}
\hline \multirow[b]{2}{*}{ MAR } & \multirow{2}{*}{$\begin{array}{c}\text { Annual } \\
\text { Frequency } \\
\text { of } \\
\text { Occurrence } \\
\end{array}$} & \multirow[b]{2}{*}{ Source } & \multirow{2}{*}{$\begin{array}{l}\text { Facility } \\
\text { Worker }^{1} \\
\text { (rem/min) }\end{array}$} & \multicolumn{3}{|c|}{ Collocated Workers ${ }^{2}$ (rem) } & \multirow{2}{*}{$\begin{array}{c}\text { Member } \\
\text { of the } \\
\text { Public } \\
\text { (rem) }\end{array}$} \\
\hline & & & & $100 \mathrm{~m}$ & $300 \mathrm{~m}$ & $770 \mathrm{~m}$ & \\
\hline \multirow{3}{*}{$\begin{array}{l}\text { Six TREAT } \\
\text { Reactor fuel } \\
\text { assemblies }\end{array}$} & \multirow[t]{9}{*}{$1.1 \mathrm{E}-02$} & CED & 3.7E-01 & $4.0 \mathrm{E}+00$ & $1.2 \mathrm{E}+00$ & 3.7E-01 & $2.0 \mathrm{E}-02$ \\
\hline & & $\begin{array}{l}\text { Cloud } \\
\text { Gamma }\end{array}$ & $2.3 \mathrm{E}-01$ & $2.4 \mathrm{E}+00$ & $7.2 \mathrm{E}-01$ & $2.3 \mathrm{E}-01$ & $1.5 \mathrm{E}-03$ \\
\hline & & Total & $6.1 \mathrm{E}-01$ & $6.4 \mathrm{E}+00$ & $1.9 \mathrm{E}+00$ & $6.1 \mathrm{E}-01$ & $2.2 \mathrm{E}-02$ \\
\hline \multirow{3}{*}{$\begin{array}{l}\text { Test loop } \\
\text { inventory }\end{array}$} & & CED & $2.3 \mathrm{E}-02$ & $2.4 \mathrm{E}-01$ & $7.0 \mathrm{E}-02$ & 2.3E-02 & 2.9E-03 \\
\hline & & $\begin{array}{l}\text { Cloud } \\
\text { Gamma }\end{array}$ & $1.3 \mathrm{E}-06$ & $1.4 \mathrm{E}-05$ & $4.0 \mathrm{E}-06$ & $1.3 \mathrm{E}-06$ & 4.3E-07 \\
\hline & & Total & $2.3 \mathrm{E}-02$ & $2.4 \mathrm{E}-01$ & $7.0 \mathrm{E}-02$ & 2.3E-02 & 2.9E-03 \\
\hline \multirow[t]{3}{*}{ Total } & & CED & $4.0 \mathrm{E}-01$ & $4.2 \mathrm{E}+00$ & $1.2 \mathrm{E}+00$ & 4.0E-01 & $2.3 \mathrm{E}-02$ \\
\hline & & $\begin{array}{l}\text { Cloud } \\
\text { Gamma }\end{array}$ & 2.3E-01 & $2.4 \mathrm{E}+00$ & $7.2 \mathrm{E}-01$ & $2.3 \mathrm{E}-01$ & 4.4E-03 \\
\hline & & Total & $0.63 \mathrm{rem} / \mathrm{min}$ & $6.6 \mathrm{rem}$ & $2.0 \mathrm{rem}$ & $0.63 \mathrm{rem}$ & $0.027 \mathrm{rem}$ \\
\hline
\end{tabular}

Notes:

1) Facility workers are assumed to be located in the TREAT Reactor control building.

2) Collocated and facility workers are not assumed to be evacuated and are exposed to the entire plume passage.

3) Offsite members of the public are located 6,000 $\mathrm{m}$ or at the nearest INL boundary and are assumed to be exposed to the entire plume passage.

4) The accident is accident dose is not mitigated by the HEPA filtration system provided for defense-in-depth.

Using the guidance provided by the Health Physics Society (Section F-3), consequences for members of the public and for workers would be negligible.

Table F-17. Dose and latent cancer fatality summary for sodium fire in the TREAT Reactor.

\begin{tabular}{|c|c|c|c|c|c|}
\hline $\begin{array}{l}\text { Probability of One } \\
\text { Failure per Year }\end{array}$ & $\begin{array}{l}\text { Probability of One } \\
\text { Failure in } 40 \text { Years }\end{array}$ & Receptor & $\begin{array}{l}\text { Dose } \\
\text { (rem) }\end{array}$ & $\begin{array}{l}\text { Dose Risk } \\
\text { (rem/year) }\end{array}$ & LCF \\
\hline \multirow[t]{5}{*}{$1.1 \mathrm{E}-02$} & $3.6 \mathrm{E}-01$ & Facility Worker ${ }^{1}$ & 0.63 & - & $1.5 \mathrm{E}-02^{2}$ \\
\hline & & Collocated Worker³@100m & 6.6 & $2.4 \mathrm{E}-02$ & $4.5 \mathrm{E}-03$ \\
\hline & & Collocated Worker³@300m & 2.0 & 7.7E-03 & $1.3 \mathrm{E}-03$ \\
\hline & & Collocated Worker ${ }^{3} @ 770$ m & 0.63 & $3.5 \mathrm{E}-04$ & 4.2E-04 \\
\hline & & Offsite Member of the Public ${ }^{4}$ & 0.027 & $8.1 \mathrm{E}-02$ & $1.9 \mathrm{E}-05$ \\
\hline
\end{tabular}

Notes:

1) Facility workers are assumed to be located in the TREAT Reactor control building.

2) Assumes a facility worker exposure of $25 \mathrm{rem}$ and $6 \mathrm{E}-4 \mathrm{LCF} / \mathrm{rem}$

3) Collocated and facility workers are not assumed to be evacuated and are exposed to the entire plume passage.

4) Offsite members of the public are located 6,000 $\mathrm{m}$ or at the nearest INL boundary and are assumed to be exposed to the entire plume passage.

5) The accident is accident dose is not mitigated by the HEPA filtration system provided for defense-in-depth.

\section{F-4.8 Cask Handling Operations at the Hot Fuel Examination Facility}

Cask receipt and handling operations are routinely performed at HFEF. Cask handling operations within HFEF include receipt of casks into the truck lock (Figure F-1), removal of the cask from the transport vehicle, and handling in the cask tunnel (Figure F-7) in order to load or unload into the decon and main cells (Figure F-1) via the cask tunnel penetrations. Cask handling and movement within HFEF is performed using overhead cranes (40-ton, high-bay area crane and 25-ton truck lock crane) and the cask tunnel cart (Figure F-8). During this evolution, the cask lid remains seated and the closure devices 
(e.g., bolts and fasteners) remain installed. Once placed in the cart, these closure devices and the cask lid are removed so that the cask cavity can be accessed through a cell penetration. Facility area descriptions important to the hazard analysis are as follows:

- High-Bay Area. The $68 \times 154 \mathrm{ft}$ high-bay area (see Figure F-7) extends over the main and decon cells and the truck lock. The high-bay area houses the hot repair area and miscellaneous equipment and storage area. Removable metal covers make up the high-bay area floor over the truck lock and separate the two areas. The area is serviced by the 40-ton, high-bay area crane.

- Truck Lock. A truck lock, about 16 -ft wide $\times 86$-ft long, accommodates receipt of the various materials into the facility through about $14 \times 16$-ft roll-up doors at each end. A 25 -ton bridge crane in the top of the truck lock is used to move loads through a floor hatch into the cask tunnel below. The ceiling of the truck lock consists of metal covers that can be removed for access to the high-bay area. A 29.5-ft-deep cylindrical cask handling pit is located at the north end of the truck lock. The pit is covered with a plug. The truck lock also is accessible to the 40-ton, high-bay area crane, which is used to move loads between the truck lock, the high-bay area, and the cask tunnel.

The risks involved with cask receipt and handling operations include those from direct radiation exposure to the cask and those that could occur if the cask payload were released. Exposure to the cask is expected and calculations will be performed to ensure the provided shielding thickness is sufficient to limit direct radiation exposure rates for the test inventories. In the event that cask integrity is lost due to impact (e.g., drop or mishandling), the payload could be partially or completely ejected from the cask.

A similar event was analyzed for operations occurring at the TREAT facility and is considered an experiment drop or impact event. A radioactive material release could occur due to a cask drop in the facility or a collision with facility walls. The initiator of the event could be equipment failure, operator error, or a seismic event. This event is considered unlikely.

The extent of damage to a dropped cask would be dependent on the cask itself, drop heights, impact surfaces, and other parameters related to material performance. Based on maximum crane hook height and the cask tunnel pit elevation, drop heights of about $90 \mathrm{ft}$ are possible. Although expected to be somewhat less than that associated with a cask drop, the extent of damage to a cask from a collision within the facility also is dependent on various factors. The collision also may be a causal factor in some variation of the cask drop event. This event encompasses the drop of a loaded cask at various locations in the facility. These locations and event variations include the following:

- Truck lock with impact onto truck lock floor

- Truck lock with impact onto service floor or onto cask tunnel cart

- Truck lock collision with east truck wall

- Truck lock collision (interference) between the 25-ton and 40-ton cranes

- High-bay area with impact onto main/decon cell structure

- High-bay area with impact onto floor that penetrates through or into second, operating, and service floors

- High-bay area collision with various walls (e.g., hot repair area and miscellaneous equipment and storage area)

- Cask tipover. 


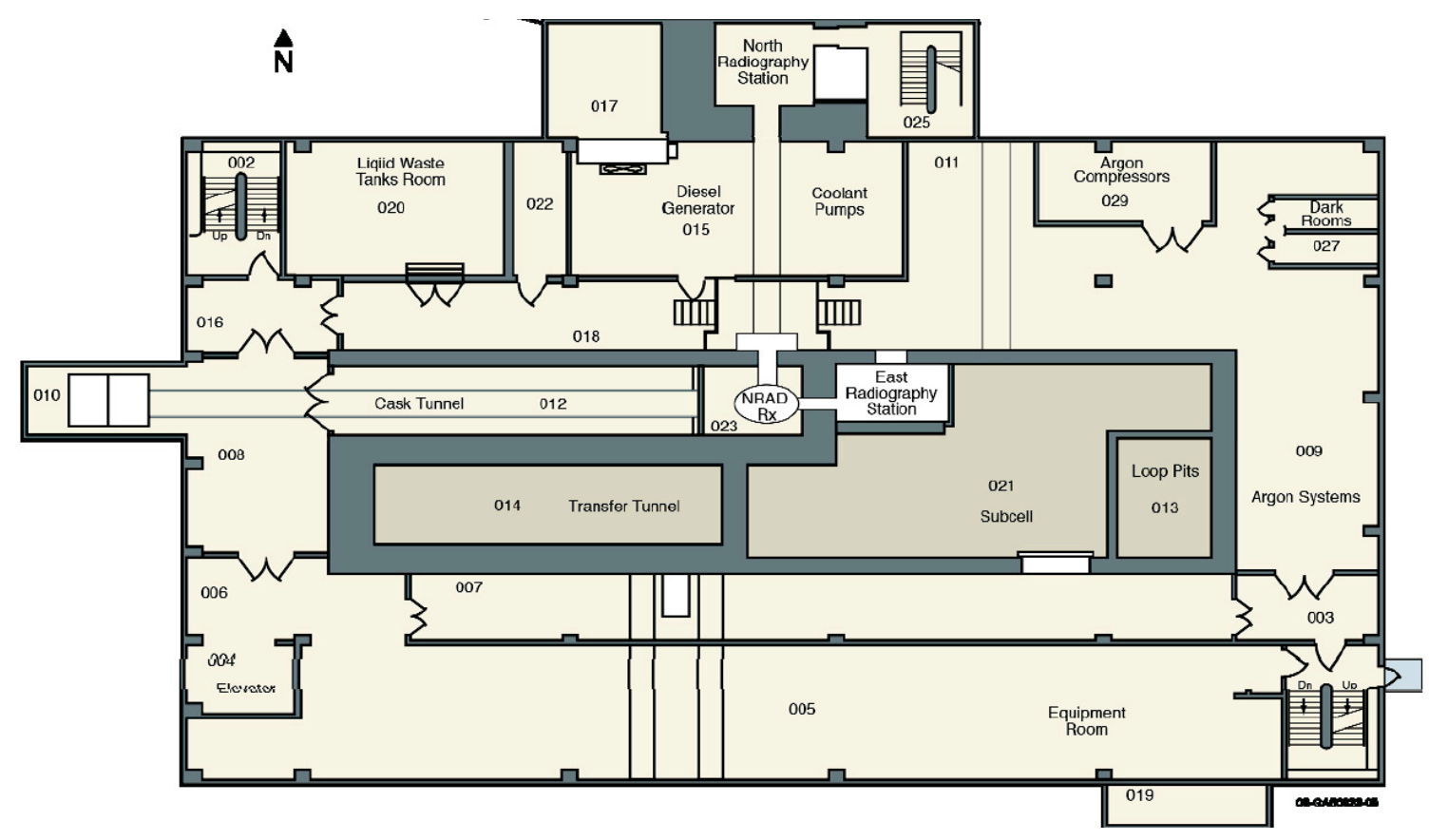

Figure F-7. Hot Fuel Examination Facility service floor layout.

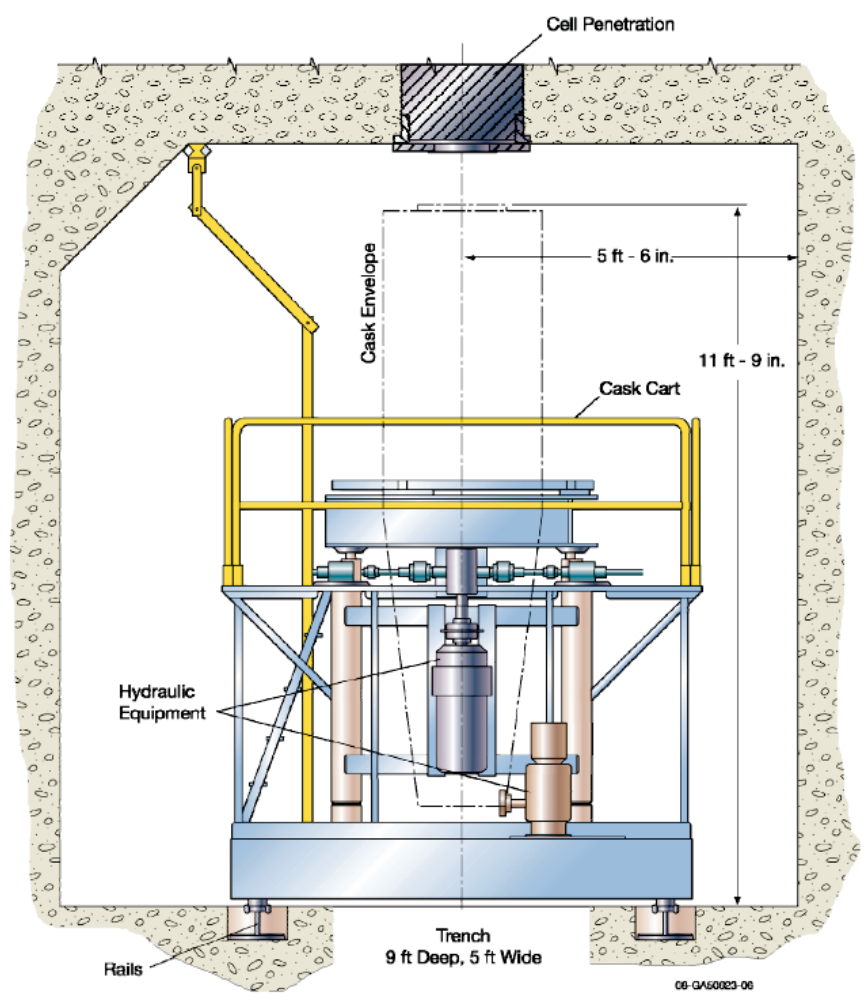

Figure F-8. Cask tunnel and cask cart used to transfer the cask from the transport vehicle to the main hot cells. 


\section{F-4.8.1 Preventative Measures}

The cask is designated a safety-significant SSC that reduces the likelihood that a drop or collision will result in a cask breach and radioactive material release that affects a facility worker. The structural performance (impact resistance) of a cask relative to the safety-significant SSC function is defined in the contractor-approved cask control list (LST-337). The identification of individual casks and the technical basis (referenced analysis) that will demonstrate that the performance criteria are met and maintained will be documented in the same list because the list includes all casks handled at HFEF.

The hoisting and rigging program provides defense-in-depth and serves to protect the cask/payload from unintended interaction with other loads. For example, defining specific load travel paths on either a facility-general or cask-specific basis ensures that drop of a heavy load onto a loaded cask that could result in cask damage and a radioactive material release from the cask are prevented. The potential interference between the 25-ton and 40-ton cranes due to simultaneous operation also has been addressed by the hoisting and rigging program. Consideration of specific load handling circumstances is addressed by the program because some travel paths are necessary to position/locate the cask such that the planned operational evolution can be performed. The program also ensures that heavy load handling (including other casks/components) is not conducted over or near loaded casks to avoid impacts that could result in cask damage and radioactive material release.

\section{F-4.8.2 Probability of this Type of Accident Occurring}

A drop of the loaded cask could occur in the truck lock or high bay and would involve use of the truck lock crane or high-bay area crane. Characteristics of these cranes are as follows:

- Truck Lock Crane-The 25-ton truck lock crane lifts items within the truck lock and between the truck lock and cask tunnel cart. A 25-ton lifting yoke, placed on the hook of the crane, is used as necessary for truck lock load handling. This crane carries a Performance Category- 2 certification.

- High-Bay Area Crane - The 40-ton high-bay area crane use includes the following:

- Transfer of top-opening casks between the truck lock and the cask tunnel cart

- Movement of high-bay area hatch covers and motorized hatch

- Transfer of equipment into or out of the equipment access room in the hot repair area

- $\quad$ Servicing the workstation mockup area in the high-bay area

- $\quad$ Servicing the decon cell hatch cover

- Handling roof hatches in the hot repair and suspect repair rooms

- Backup lifting capability for the main cell, decon cell, and hot repair area equipment normally serviced by other cranes

- Handling of containers (e.g., drums) and equipment in the miscellaneous equipment and storage area.

The high-bay area crane spans the full width of the high-bay area and traverses the length of the building. The trolley is equipped with two 20-ton hooks and one 5-ton hoist. A removable load bar is used to connect the 20 -ton hooks to provide the 40-ton-capacity. This crane carries a PC-2 certification.

Failure of these cranes would proceed in a manner similar to the failure of cranes at TREAT (Section F-4.2.2). Precursor events would include NPHs (e.g., wind, seismic, and flood), operator error, or equipment failure.

- Seismic Initiators. The most likely NPH event would be a seismic event. The designation of the facility structure as a safety-significant SSC prevents this NPH-induced radioactive material release from occurring. The applicable NPH design requirement for a safety-significant SSC whose function is to withstand a seismic event is PC-2. Additional information on INL NPH design criteria, as related 
to performance category, is provided in SAR-400. As discussed in Section 2.4.2 and in Chapter 4 (Section 4.4) of SAR-405, the facility structure has been shown to withstand PC-3 seismic, wind, and snow loads based on a PC-3 analysis. This designation ensures the facility will perform when confronted with events with return periods of one in 2,500 years (i.e., annual exceedance of 4E-4). This makes releases preceded by NPH very unlikely.

- Equipment failure and operator error. The cranes at HFEF are designated PC-2 and are assumed to fail with the recurrence rates analyzed for the cranes that will be used at TREAT.

The frequency of occurrence for a cask drop accident is the product of the time-at-risk and the probability of the accident initiator. The time at risk estimated in Section F-4.2.2 included the total time a cask would be handled at TREAT. This time include pre-irradiation and post-irradiation handling. The time at risk at HFEF is assumed to be similar.

\section{F-4.8.3 Dose Consequences}

Radioactive material release could occur due to drop impact damaging the cask structure sufficiently to release the payload. The payload confinement (typically one or more containers within the cask) also would have to be sufficiently damaged to result in a release of radioactive material. A release could occur in the truck lock, the cask tunnel, or the high-bay area.

The MAR assumed in the cask drop scenario is the bounding inventory identified in Appendix E. Parameters used in the analysis corresponds to the drop scenario evaluated for TREAT (INL 2013). The damage ratio for an event occurring at HFEF (SAR-405) was assumed to be 0.1 , such that only $10 \%$ of the available ST is damaged enough to be released even though the drop is significant enough to fail the cask and inner containers. The ARF and RF values are those applicable to a powder spill as discussed in DOE-HDBK-3010. This is a conservative assumption because most of the materials expected to be transferred to HFEF in casks are in the form of solid metal fuel, cladding hulls, and/or salt pieces rather than powder. The LPF was set at 1.0 to result in an unmitigated analysis and to be consistent with the guidance in DOE-STD-3009-94.

Doses for this event were obtained by scaling the results provided in Section F-4.2.3 by the ratio of TREAT Reactor control building-to-HFEF truck lock volumes for facility workers and by applying the $\chi / \mathrm{Q}$ for a member of the public located at $5,000 \mathrm{~m}$ instead of the value for a member of the public located at $6,000 \mathrm{~m}$.

The resultant doses are shown in Table F-18 and the dose risk and risk of LCF are shown in Table F-19. Based on the higher consequence event (operator error or equipment failure), the accident consequences can be summarized as follows:

- For members of the public with the accident occurring at MFC:

- The estimated dose is 0.007 rem (6 mrem). This is much less than the annual average 600-mrem dose received by members of the public from non-DOE facilities (Figure F-2).

- The increased probability of a member of the public getting cancer is $0.001 \%$.

- The risk of an LCF occurring about 1 in 22,000.

- For the collocated workers:

- The estimated dose is 0.21 rem for workers located $100 \mathrm{~m}$ from the site of the accident and $0.062 \mathrm{rem}$ for those located $300 \mathrm{~m}$.

- The increased probability of the closest collocated worker getting cancer is $0.03 \%$.

- The risk of an LCF occurring is about 1 in 7,700.

- For facility workers located at the site of the load drop: 
- The estimated dose rate is $3.4 \mathrm{rem} /$ minute. They could remain in the building about 7 minutes prior to receiving a dose of $25 \mathrm{rem}$.

- At 25 rem, the increased probability of a worker getting cancer is $4.25 \%$.

- At 25 rem, the rate of an LCF occurrence is 0.015 , or 1.5 people in 100.

Protection of facility workers will require administrative procedures to limit the exposure time for workers. Based on a 25-rem exposure, there is ample time for facility workers to be evacuated.

The dose consequences shown in Table F-18 are based on the following:

- Collocated workers in this accident scenario are assumed to be beyond $100 \mathrm{~m}$ from the drop accident. These workers are not assumed to be evacuated; therefore, the doses shown in Table F-18 reflect exposure during the entire plume passage.

- Members of the public are assumed to remain in place for the whole plume passage without being evacuated. The wind is assumed to blow in the direction of the hypothetical receptor.

- ST reduction provided by engineering design of the fuel cladding, loop handling casks, and fuel handling casks, and primary and secondary containment of the experiment assembly was included explicitly by factoring in a damage ratio of $10 \%$. The TLHC or fuel handling cask would be expected to remain intact with minor damage occurring after a drop. After breaching the TLHC, the experiment assembly and fuel cladding also would have to fail prior to releasing radionuclides to the environment. Therefore, it would be unlikely for significant releases to occur from the cask. To account for these protective features, a damage ratio of $10 \%$ was assumed in the calculation of TED. If the effect of a drop considered failure of the TLHC, primary or secondary experiment containment (Figure F-5), or fuel cladding, a reduction in ST could be applied for each layer and the likelihood of this event could be reduced by the probability of breaching each layer. This could result in a dose reduction of an additional 10 to 1,000-fold, depending on the number of successive containment layers breached with a similar reduction in event likelihood.

- The estimated likelihoods were based on the highest likelihoods of failure of the TREAT crane. The likelihood of crane failure at HFEF will be reduced through robust administrative controls, including programs designed to provide and enforce the following:

- Nuclear facility maintenance

- Emergency preparedness plans

- Radiation protection requirements

- Hoisting and rigging requirements

- Nuclear criticality safety requirements

- Fire protection

$\circ$ Worker training.

These administrative procedures require pre-job inspections, checklists, multiple observers during transfer operations and crane lifts, and evacuation plans and procedures designed to minimize exposure.

The combination of administrative controls that will be in place will provide multiple points of redundancy, greatly reducing single-point failure modes. In combination with the PC-2 design requirements for safety-significant SSCs, the likelihood of mechanical (design) failure is unlikely and for combinations of design and administrative controls to fail is improbable. 
Table F-18. Dose consequences for experiment assembly drop.

\begin{tabular}{|c|c|c|c|c|c|c|c|c|c|}
\hline \multirow[t]{2}{*}{ MAR } & \multirow{2}{*}{$\begin{array}{l}\text { Annual } \\
\text { Frequency of } \\
\text { Occurrence }\end{array}$} & \multirow[t]{2}{*}{ Source } & \multicolumn{2}{|c|}{$\begin{array}{l}\text { Facility Worker }{ }^{1} \\
\quad(\mathrm{rem} / \mathrm{min})\end{array}$} & \multicolumn{3}{|c|}{ Collocated Workers ${ }^{2}$ (rem) } & \multicolumn{2}{|c|}{$\begin{array}{l}\text { Member of the Public } \\
\text { (rem) }\end{array}$} \\
\hline & & & $\begin{array}{l}\text { Occurs in the } \\
\text { TREAT Reactor } \\
\text { building }\end{array}$ & $\begin{array}{l}\text { Occurs at } \\
\text { MFC }\end{array}$ & $100 \mathrm{~m}$ & $300 \mathrm{~m}$ & $770 \mathrm{~m}$ & $\begin{array}{l}\text { Occurs at } \\
\text { MFC } \\
(5,000 \mathrm{~m}) \\
\end{array}$ & $\begin{array}{l}\text { Occurs at } \\
\text { TREAT } \\
(6,000 \mathrm{~m})\end{array}$ \\
\hline \multirow{3}{*}{$\begin{array}{l}\text { Test loop } \\
\text { inventory }\end{array}$} & \multirow{3}{*}{$\begin{array}{l}\text { Operator error } \\
\text { or equipment } \\
\text { failure: } 5.0 \mathrm{E}-03 \\
\text { Seismic initiated } \\
\text { event: } 3.1 \mathrm{E}-05\end{array}$} & CED & $2.5 \mathrm{E}-01$ & 3.4 & 2.1E01 & $6.2 \mathrm{E}-02$ & $2.0 \mathrm{E}-02$ & 7.4E-03 & $6.0 \mathrm{E}-03$ \\
\hline & & $\begin{array}{l}\text { Cloud } \\
\text { Gamma }\end{array}$ & - & - & 2.6Е06 & 7.7E-07 & $2.5 \mathrm{E}-07$ & $1.0 \mathrm{E}-07$ & 8.3E-08 \\
\hline & & Total & $\begin{array}{c}0.25 \mathrm{rem} / \mathrm{min} \\
(100 \mathrm{~min} \text { prior } \\
\text { to reaching } 25 \\
\text { rem })\end{array}$ & $\begin{array}{l}3.4 \mathrm{rem} / \mathrm{min} \\
(7.3 \mathrm{~min} \text { prior } \\
\text { to reaching } \\
25 \mathrm{rem})\end{array}$ & $\begin{array}{l}0.21 \\
\text { rem }\end{array}$ & $\begin{array}{c}0.062 \\
\text { rem }\end{array}$ & $0.02 \mathrm{rem}$ & $0.007 \mathrm{rem}$ & $0.006 \mathrm{rem}$ \\
\hline
\end{tabular}

Notes:

1) At TREAT, facility worker doses are based on $16,000 \mathrm{~m}^{3}$ building volume; the HFEF truck lock volume is $1,161 \mathrm{~m}^{3}$. Doses for the accident at MFC (HFEF) were scaled from the TREAT Reactor building doses.

2) Collocated workers are not assumed to be evacuated and are exposed to the entire plume passage.

3) If the accident occurs at TREAT, members of the public are located 6,000 $\mathrm{m}$ away at the nearest INL boundary, and if the accident occurs at MFC, they are at $5,000 \mathrm{~m}$. Members of the public are assumed to be exposed to the entire plume passage.

4) The accident is assumed to occur in a facility area not evacuated by the F/CS; therefore, this accident is not mitigated by the HEPA filtration system provided for defense-in-depth at either facility.

6) A damage ratio of $10 \%$ was applied to the unmitigated doses provided in the NEPA-HA (INL 2013) for this scenario. 
Table F-19. Dose and latent cancer fatality summary for experiment assembly drop.

\begin{tabular}{|c|c|c|c|c|c|}
\hline $\begin{array}{l}\text { Probability of one } \\
\text { Failure per Year }\end{array}$ & $\begin{array}{l}\text { Probability of One } \\
\text { Failure in } 40 \text { Years }\end{array}$ & Receptor & $\begin{array}{l}\text { Dose } \\
\text { (rem unless } \\
\text { noted) }\end{array}$ & $\begin{array}{l}\text { Dose risk } \\
\text { (rem/year) }\end{array}$ & LCF \\
\hline \multicolumn{6}{|c|}{ Operator Error or Equipment Failure } \\
\hline \multirow[t]{7}{*}{$5.0 \mathrm{E}-03$} & \multirow[t]{7}{*}{$1.8 \mathrm{E}-01$} & $\begin{array}{l}\text { Facility Worker at TREAT Reactor } \\
\text { building }\end{array}$ & $\begin{array}{c}0.25 \\
(\mathrm{rem} / \mathrm{min})\end{array}$ & \multirow[b]{2}{*}{ - } & \multirow{2}{*}{$1.5 \mathrm{E}-02^{\mathrm{a}}$} \\
\hline & & Facility Worker at $\mathrm{MFC}^{\mathrm{b}}$ & $\begin{array}{c}3.4 \\
(\mathrm{rem} / \mathrm{min}) \\
\end{array}$ & & \\
\hline & & Collocated Worker@100m & $2.1 \mathrm{E}-01$ & $1.0 \mathrm{E}-03$ & $1.3 \mathrm{E}-04$ \\
\hline & & Collocated Worker@300m & $6.2 \mathrm{E}-02$ & $3.1 \mathrm{E}-04$ & $3.7 \mathrm{E}-05$ \\
\hline & & Collocated Worker@770m & $2.0 \mathrm{E}-02$ & 9.9E-05 & $1.2 \mathrm{E}-05$ \\
\hline & & Member of the Public @5,000 m ${ }^{\mathrm{c}}$ & $7.4 \mathrm{E}-03$ & $3.7 \mathrm{E}-05$ & $4.5 \mathrm{E}-06$ \\
\hline & & Member of the Public @6,000 m ${ }^{\mathrm{c}}$ & $6.0 \mathrm{E}-03$ & $3.0 \mathrm{E}-05$ & $3.6 \mathrm{E}-06$ \\
\hline \multicolumn{6}{|c|}{ Seismic Initiated Event } \\
\hline \multirow[t]{7}{*}{$3.1 \mathrm{E}-05$} & \multirow[t]{7}{*}{$1.3 \mathrm{E}-03$} & $\begin{array}{l}\text { Facility Worker at TREAT Reactor } \\
\text { building }\end{array}$ & $\begin{array}{c}2.5 \mathrm{E}-01 \\
(\mathrm{rem} / \mathrm{min})\end{array}$ & \multirow[b]{2}{*}{ - } & \multirow{2}{*}{$1.5 \mathrm{E}-02^{\mathrm{a}}$} \\
\hline & & Facility Worker at MFC ${ }^{\mathrm{b}}$ & $\begin{array}{c}3.4 \\
(\mathrm{rem} / \mathrm{min})\end{array}$ & & \\
\hline & & Collocated Worker@100m & $2.1 \mathrm{E}-01$ & $6.6 \mathrm{E}-06$ & $1.3 \mathrm{E}-04$ \\
\hline & & Collocated Worker@300m & $6.2 \mathrm{E}-02$ & $1.9 \mathrm{E}-06$ & 3.7E-05 \\
\hline & & Collocated Worker@770m & $2.0 \mathrm{E}-02$ & $6.2 \mathrm{E}-07$ & $1.2 \mathrm{E}-05$ \\
\hline & & Member of the Public @ $5,000 \mathrm{~m}^{\mathrm{c}}$ & $2.1 \mathrm{E}-03$ & $2.3 \mathrm{E}-07$ & 4.4E-06 \\
\hline & & Member of the Public @6,000 m & $6.0 \mathrm{E}-03$ & $1.9 \mathrm{E}-07$ & $3.6 \mathrm{E}-06$ \\
\hline \multicolumn{6}{|c|}{$\begin{array}{l}\text { a. Assumes a facility worker exposure of } 25 \mathrm{rem} \text { and } 6 \mathrm{E}-4 \mathrm{LCF} / \mathrm{rem} \text {. } \\
\text { b. TREAT facility worker doses assume the drop accident occurs in the TREAT Reactor building, MFC facility worker doses assume the } \\
\text { accident occurs in the truck lock at HFEF. } \\
\text { c. If the accident occurs at TREAT, members of the public are located } 6,000 \mathrm{~m} \text { away at the nearest INL boundary and if the accident occurs at }\end{array}$} \\
\hline
\end{tabular}

\section{F-4.9 Overview of Accident Analysis for Alternative 1 (TREAT)}

Results of the accident analysis conducted for RTT Program operations at INL, including operation of the TREAT Reactor and use of other facilities at INL, are summarized in Table F-20. The analysis was conducted by doing the following:

1. Identifying bounding inventories that would be contained in the experiment assembly and the bounding inventory contained in the TREAT Reactor core with the bounding inventories determined by radiologic dose potential (as opposed to fission potential).

2. Identifying potential accident scenarios that could involve operation of the TREAT Reactor, handling the TREAT Reactor fuel, handling the experiment assembly at TREAT and MFC (closest facility to the INL boundary that would be used), and accident scenarios that could occur during the process of transient testing using the TREAT Reactor.

3. Identifying the chain of events necessary to result in a radiologic release for each accident scenario; determining the probability of occurrence for each event in the chain and the time-at-risk for each event; calculating the annual frequency of occurrence for each accident scenario; and calculating the probability of each accident scenario occurring during the 40-year RTT Program lifetime.

4. Identifying receptor locations for dose calculations. Receptor locations included those for facility workers, collocated workers, and members of the public. 
5. Calculating the acute dose from gamma cloud exposure and inhalation at the receptor locations. Ingestion doses were not computed because, in the event of an accident, contaminated areas would be secured and remediated to prevent food product ingestion. To put the doses provided by the accident analysis into perspective, the guidance provided in Section F-3 should be used.

\section{F-4.9.1 Summary of Radiologic Consequences for Alternative 1 (TREAT)}

The analysis of accident scenarios looked at events that could be caused by a range of NPH (e.g., seismic, wind, and flood), operator errors, and equipment failure. The only credible NPH with the potential of impacting the TREAT Reactor or experiments is an earthquake. The probability that an earthquake could result in damage to key structural features sufficient to cause a radiologic release is on the order of one in 32,000 years. The more likely accident scenarios would be initiated by operator error or equipment failure. The probability that an operator error or equipment failure could cause a radiologic release ranges between 1 chance in 100 years to 1 chance in 25,000 years. The results of the two highest consequence events are shown in Table F-21. The consequences of these events can be summarized as follows:

- Experiment handling event impacting the TREAT Reactor. Higher accident-related doses for workers at TREAT are expected to occur as a result of routine equipment failure or operator error as opposed to being a function of irradiation in the TREAT Reactor. Transient testing requires moving the experiment assembly above the reactor. If the experiment assembly is dropped, there is the remote chance (one in 25,000 years) that fuel from the experiment and from damaged reactor fuel assemblies could be released into the building. The probability of this event occurring once during the 40 -year program lifetime is 0.002 .

During this event, the reactor is not active. It is improbable that dropping an experiment assembly into the reactor would result in a fire or an excursion of the reactor itself. If the drop resulted in a release of gas or particulates from the fuel, facility workers in the building would receive a radiologic dose from the release. In addition, it is assumed that a release occurring in the building would be immediately available to be dispersed and transported downwind from the building. The downwind transport of released radionuclides would first affect workers outside of the building (collocated workers). Eventually, the transported plume would reach the INL boundary, where members of the public could be affected.

Members of the public exposed to this dose would receive 0.077 rem. They would have a $0.01 \%$ chance of getting cancer from this dose and the risk of an LCF occurring is about 1 in 22,000. This dose is calculated for a point on the INL boundary closest to the TREAT Reactor building. Persons located further from the accident site would receive a lower dose.

Collocated workers $300 \mathrm{~m}$ from the TREAT Reactor building could receive a dose of $2.2 \mathrm{rem}$. This could increase their chance of getting cancer by $0.4 \%$. For every 750 workers exposed, one LCF would be expected.

Workers in the building during the accident would receive an estimated dose of $6.4 \mathrm{rem} / \mathrm{minute}$. These workers could remain in the building about 4 minutes before they received a dose of $25 \mathrm{rem}$. Twenty-five rem is the EPA protective action guide value for response persons. At $25 \mathrm{rem}$, there is a $4.25 \%$ increased chance of a facility worker getting cancer, and for every 200 facility workers exposed, three LCFs would be expected. 


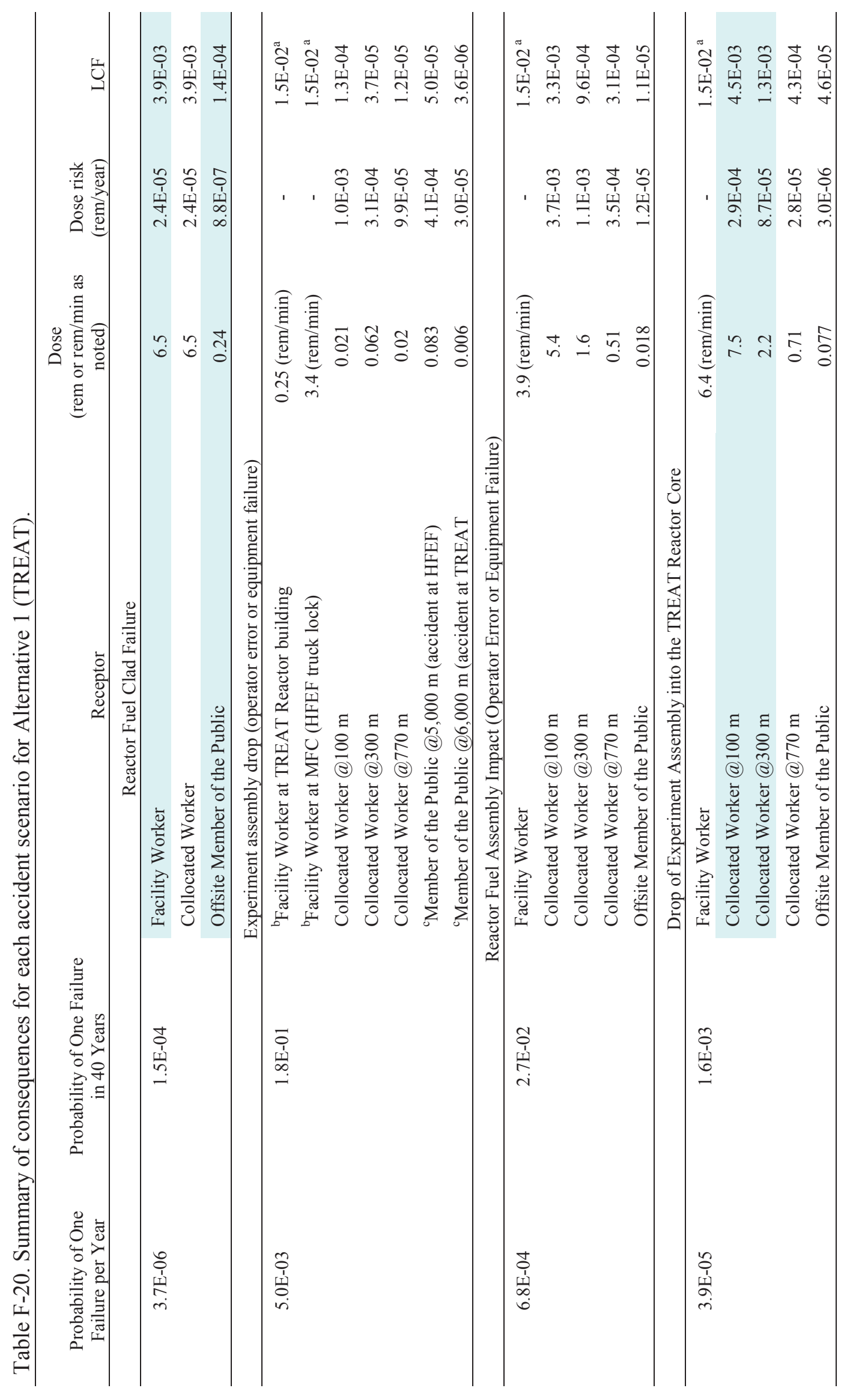




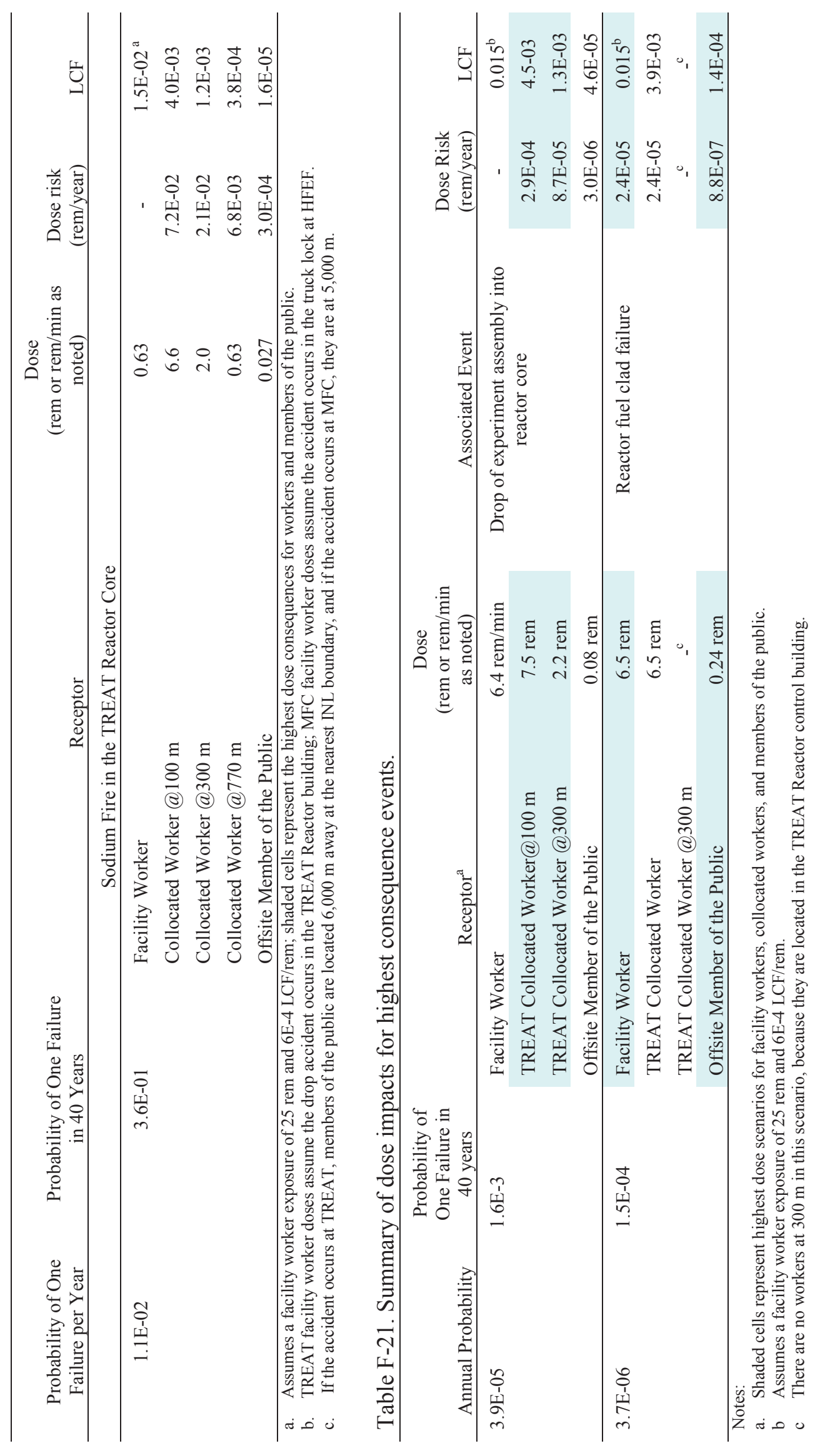


- TREAT Reactor fuel clad failure. The highest dose, increased occurrence of cancer, or risk of LCF (dose consequence), for members of the public could occur if the TREAT Reactor fuel cladding is compromised. The probability that the redundant reactor safety features would fail in any given year is one in 270,000 . The probability that the safety features fail once during the 40 -year transient testing program is 0.00015 . Therefore, this accident is extremely unlikely to occur.

Members of the public at the closest INL boundary could receive a dose of 0.24 rem. This could increase the probability of getting cancer by $0.04 \%$. One LCF in 7,000 exposed persons would be expected.

During transient testing, facility workers and collocated workers are located in the TREAT Reactor control building and approximately $770 \mathrm{~m}$ from the TREAT Reactor building. At this distance, they could be exposed to $6.5 \mathrm{rem}$, resulting in an increased chance of getting cancer of $1.1 \%$. One LCF out of 250 exposed persons could be expected.

The estimated doses and resultant health risks provided in the analysis of accidents are conservative. They are based on a bounding radiologic inventory for the experiments and a very conservative estimate of the TREAT Reactor core radiologic inventory. The dose calculations essentially assume accidents occur outside of a structure (i.e., TREAT Reactor building or HFEF); therefore, they do not credit reductions in radionuclide concentrations that could occur during transport from the site of an accident to the outside environment. Applicable reductions would include particulate filtering by the HEPA filters for some scenarios and adherence to equipment or the facility structure itself for others. The estimated doses do not assume receptors are evacuated. Facility workers and collocated workers are assumed to be unprotected by shielding, respirators, or other personal protective equipment. Additional conservatisms in the dose calculation are discussed for each accident as applicable throughout Appendix F.

Dose, $\mathrm{LCF}$, and cancer consequences for members of the public are negligible for all scenarios. Protection of facility workers and collocated workers would be provided to limit dose consequences. Based on a 25-rem exposure, there is ample time for workers to be evacuated. At 25 rem, there is $4.25 \%$ chance of an exposed worker getting cancer and 1.5E-2 chance of an LCF. Therefore, the accident consequences for workers also are considered to be negligible.

\section{F-5. PREDICTED DOSE IMPACTS FOR ACCIDENTS IN ALTERNATIVE 2 (ACRR)}

Evaluation of accident dose consequences for Alternative 2 (ACRR) must include those that could occur at INL and those that could occur at SNL/NM. Accidents that could occur at INL in this alternative include drop or impact events involving the experiment assembly. These accidents are assumed to occur at MFC and were evaluated in Section F-4.8. The analysis provides facility worker doses for an accident occurring at MFC based on the volume of the HFEF truck lock. Collocated worker doses are independent of any specific facility and the values provided for several different distances apply to this scenario. Members of the public are assumed to be located 5,000 m from MFC at the closest INL boundary. The doses for the drop accident occurring at MFC are provided in Tables F-18 and F-19.

Relevant accident categories evaluated for accidents occurring at SNL/NM include those involving (1) a drop or impact to the experiment, (2) an experiment melt, fire, or engulfing fire, and (3) mechanical failure of the experiment assembly while in the ACRR central cavity. Analyses of these events are provided in the following sections.

\section{F-5.1 Experiment Drop or Impact Accident at the Annular Core Research Reactor}

This accident scenario could involve an irradiated transient experiment assembly that experiences a drop or impact while loading it into or out of the reactor, into a cask, or if it is impacted by a dropped 
heavy load within the ACRR facility or adjacent experiment handling facility. This accident scenario is equivalent to that provided for TREAT in Section F-4.2. The likelihood of this event is assumed to correspond to that provided in Section F-4.2.2, equal to 5.0E-3/year. The dose analysis was conducted by doing the following:

- Scaling facility worker doses at TREAT to the ACRR building air volume. From the ACRR facility DSA (Sandia Report 2008), Section 6.2.2, the reactor room dimensions are 13.4 x $15.8 \times 9.5 \mathrm{~m}$ $\left(2,000 \mathrm{~m}^{3}\right)$, which were added to the penthouse dimensions of $5 \times 13 \times 4.8 \mathrm{~m}$ for a total gross free volume of $2,300 \mathrm{~m}^{3}$. The TREAT Reactor building volume used to estimate worker dose was $16,000 \mathrm{~m}^{3}$, resulting in a TREAT Reactor building vol to ACRR facility reactor room vol of 51 . This value was used with the facility worker dose $(0.21 \mathrm{rem})$ from Table F-10 to obtain the value shown in Table F-22.

- The ACRR facility DSA provides dose kernels at the public receptor distance of 1,350 $\mathrm{m}$ for releases occurring at ground level and for those occurring at stack height. The ground level dose kernels assume the release does not travel through the facility ventilation system, while the stack release is appropriate for events occurring within the ACRR facility in an area ventilated to the stack. For comparison to the TREAT analysis and to include potential releases that may occur in the ACRR hot cell, ground release dose kernels were used.

\section{F-5.1.1 Dose Consequences}

Table F-22 shows the calculated dose for the offsite member of the public located 1,350 $\mathrm{m}$ from ACRR. Table F-23 provides the estimated LCF and dose risk. The accident consequences can be summarized as:

- For members of the public:

- The estimated dose is $0.044 \mathrm{rem}$ (44 mrem). This is much less than the annual average 600 -mrem dose received by members of the public from non-DOE facilities (Figure F-2).

- The increased probability of a member of the public getting cancer is $0.008 \%$.

- The risk of an LCF occurring is 3.6E-06 or about 1 in 275,000.

- For the collocated workers:

- The estimated dose is $0.06 \mathrm{rem}$.

- The increased probability of the closest collocated worker getting cancer is $0.01 \%$.

- The risk of an LCF occurring is about 1 in 27,000.

- For facility workers located at the site of an experiment drop:

- The estimated dose rate is $1.74 \mathrm{rem} /$ minute. They could remain in the building about 14 minutes prior to receiving a dose of $25 \mathrm{rem}$.

- At 25 rem, the increased probability of a worker getting cancer is $4.25 \%$.

- At 25 rem, the rate of an LCF occurrence is 0.015 or 1.5 people in 100.

Using the guidance provided by the Health Physics Society (Section F-3), consequences for members of the public and collocated workers are negligible. Protection of facility workers could require administrative procedures to limit the exposure time for workers or use of personal protection equipment during experiment handling operations, which are not credited in the doses shown in Table F-22. 
Table F-22. Dose consequences for an experiment drop or impact release at SNL/NM.

\begin{tabular}{|c|c|c|c|c|c|}
\hline MAR & $\begin{array}{c}\text { Annual Frequency of } \\
\text { Occurrence }\end{array}$ & Source & $\begin{array}{l}\text { Facility Worker } \\
\text { (rem/min) }\end{array}$ & $\begin{array}{c}\text { Collocated Worker } \\
\text { Located at } 300 \mathrm{~m} \\
(\mathrm{rem})\end{array}$ & $\begin{array}{c}\text { Member of the Public } \\
\text { Located at } 1,350 \mathrm{~m} \\
\text { (rem) }\end{array}$ \\
\hline $\begin{array}{l}\text { Test loop } \\
\text { inventory }\end{array}$ & $5.0 \mathrm{E}-03$ & Total & $\begin{array}{l}1.74 \mathrm{rem} / \mathrm{min} \\
\text { (14 min prior to } \\
\text { reaching } 25 \mathrm{rem})\end{array}$ & $0.062 \mathrm{rem}$ & 4.4E-02 rem \\
\hline
\end{tabular}

Table F-23. Dose and latent cancel fatality summary for experiment assembly drop.

\begin{tabular}{|c|c|c|c|c|c|}
\hline $\begin{array}{l}\text { Probability of One } \\
\text { Failure per Year }\end{array}$ & $\begin{array}{l}\text { Probability of One } \\
\text { Failure in } 40 \text { Years }\end{array}$ & Receptor & $\begin{array}{c}\text { Dose } \\
\text { (rem unless } \\
\text { noted) }\end{array}$ & $\begin{array}{l}\text { Dose Risk } \\
\text { (rem/year) }\end{array}$ & $\mathrm{LCF}$ \\
\hline \multirow[t]{3}{*}{$5.0 \mathrm{E}-03$} & $1.8 \mathrm{E}-01$ & Facility Worker & $\begin{array}{c}1.74 \\
\text { (rem/min) }\end{array}$ & - & $1.5 \mathrm{E}-02^{*}$ \\
\hline & & Collocated Worker@300m & $6.2 \mathrm{E}-02$ & $3.1 \mathrm{E}-04$ & $3.7 \mathrm{E}-05$ \\
\hline & & Offsite Member of the Public & 4.4E-02 & $2.2 \mathrm{E}-04$ & $2.6 \mathrm{E}-05$ \\
\hline
\end{tabular}

\section{F-5.2 Rapid Over-Pressurization of the Sodium-Cooled Experiment}

This accident scenario is similar to the scenario analyzed in Section F-4.7 for TREAT. It is described in SNL/NM (2013). In this accident scenario, it is assumed that a failure of the sodium-cooled experiment could be caused by a combination of high temperature, failure of sodium containment, and the presence of air in the experiment assembly between the primary and secondary experiment containment. The combination would lead to rapid oxidation of the sodium (Equations F-12 through F-14). The analysis supporting the evaluation of this accident at ACRR concludes that the energy and rate of energy production could lead to shrapnel or fragments being released from the experiment assembly and that they could puncture the liner of the central cavity. Puncturing the central cavity would flood the central cavity and would insert large amounts of negative reactivity, shutting down the reactor.

The resultant damage was estimated to include the first three rows of ACRR fuel elements and the fuel contained in the experiments. Damage to fuel contained in the experiment and ACRR would result under impact conditions, which would release radionuclides from the gap between the cladding and fuel. Under the conditions thought to be most representative at ACRR, the oxidation process would occur over tens of minutes and would not transition into the "early-in-vessel" stage of fuel release (Table F4). Because the damage would occur in the ACRR, the ST would be mitigated by the pool water.

\section{F-5.2.1 Preventative Measures}

Preventative measures for this accident scenario are discussed in SNL/NM (2013) and include those provided for the event in Section F-4.7; they are as follows:

- $\quad$ ACRR fuel element design. It is unlikely that the fuel will catch fire after the cladding is breached. The cladding and fuel design will provide diffusion limits on fuel oxidation.

- ACRR pool water: The pool water will be present to scrub most fission products from a release from the reactor core fuel.

- Leak-tight sodium loop and outer experiment containment:

- The sodium loop will be leak tight at the expected maximum temperature/pressure to reduce the frequency of sodium leaking out of the containment loop.

- The outer experiment containment will be leak tight at the expected maximum temperature/pressure to reduce the frequency of air in-leakage into the experiment package.

- Experiment package engineered safety requirements: 
- The sodium heater will be designed to limit power output to reduce the frequency of a runaway heater.

- The experiment package will be designed to withstand overpressure from potential sodium and air reaction to prevent shrapnel from impacting the reactor core fuel.

- Experiment design requirements will reduce excessive energy deposition in the experiment package by ensuring proper heat rejection and ensuring proper experiment planning.

- Prior to insertion of the sodium-cooled experiment package into the central cavity, the experiment will be backfilled with inert gas.

\section{F-5.2.2 Probability of this Type of Accident Occurring}

The probability of this event occurring was provided in SNL/NM (2013) and was discussed in Section F-4.7.2. Assuming 20 sodium-cooled experiment reactor operations per year, the annual probability has been estimated to be 6.4E-3, making the combined events/failures unlikely. Assuming 34 sodium-cooled experiment reactor operations per year, the annual probability is $1.1 \mathrm{E}-2$. The corresponding probability that one accident of this type will occur during the 40 years of transient testing is 0.36 .

\section{F-5.2.3 Dose Consequences}

The doses provided in SNL/NM (2013) for this scenario are shown in Table F-24 and the dose risk and risk of an LCF occurring are summarized in Table F-25. The accident consequences can be summarized as follows:

- For members of the public:

- The estimated dose is $0.077 \mathrm{rem}(77 \mathrm{mrem})$. This is lower than the annual average 600 -mrem dose received by members of the public from non-DOE facilities (Figure F-2).

- The increased probability of a member of the public getting cancer is $0.013 \%$.

- The risk of an LCF occurring is less than 1 in 21,000.

- For collocated workers located at $300 \mathrm{~m}$ from the accident site.

- $\quad$ The estimated dose is $2.98 \mathrm{rem}$.

- The increased probability of a worker getting cancer is $0.5 \%$.

- The risk of an LCF occurring is about 1 in 550.

- For facility workers:

- The facility worker dose is likely dominated by the ACRR fuel contribution (less than 100 rem). The dose rate of $12.9 \mathrm{rem} / \mathrm{min}$ was estimated, assuming it takes workers 10 minutes to evacuate the building.

- At the estimated dose rate of $12.9 \mathrm{rem} / \mathrm{min}$, a worker would have about 2 minutes prior to exceeding 25 rem and would have about 8 minutes prior to exceeding $100 \mathrm{rem}$.

- At 100 rem, the increased probability of a worker getting cancer is $17 \%$.

- At 100 rem, the risk of an LCF occurring is about 1 in 17.

Consequences for members of the public and for collocated workers would be negligible without additional protective measures. Protection of facility workers could be required to mitigate their dose consequences, but protective measures have not been factored into the doses provided in Table F-24. These could include administrative procedures to limit exposure time and use of personal protective equipment when the experiment is in the ACRR central cavity. 
Table F-24. Estimated dose consequences for an over-pressurization of the sodium-bearing experiment loop in the ACRR (from SNL/NM 2013).

\begin{tabular}{|c|c|c|c|}
\hline MAR & $\begin{array}{c}\text { Facility Worker TED } \\
\text { (rem/min) }\end{array}$ & $\begin{array}{l}\text { Collocated Worker TED at } 300 \mathrm{~m} \\
\text { (rem) - Ground Release }\end{array}$ & $\begin{array}{l}\text { Member of the } \\
\text { Public (rem) }\end{array}$ \\
\hline $\begin{array}{l}\text { ACRR fuel (primarily noble gasses } \\
\text { and some halogens) }\end{array}$ & $1.00 \mathrm{E}+01 *$ & $2.73 \mathrm{E}+00 * *$ & $5.96 \mathrm{E}-02$ \\
\hline Experiment fuel (MOX) & $2.93 \mathrm{E}+00$ & $2.50 \mathrm{E}-01$ & $1.75 \mathrm{E}-02$ \\
\hline Total & $12.9 \mathrm{rem} / \mathrm{min}$ & 2.98 & 0.077 \\
\hline \multicolumn{4}{|c|}{$\begin{array}{l}\text { * It was qualitatively estimated that a worker dose equivalent from a release of fission products from one-third of the reactor core ACRR fuel } \\
\text { is less than 100-rem acute. In order to be consistent with the facility worker dose equivalent estimation provided by Alternative } 1 \text {, a dose of } \\
100 \text {-rem acute has been converted to rem per minute. The facility worker exposure time is assumed to be } 600 \text { seconds or } 10 \text { minutes, which } \\
\text { is consistent with the accident release time assumed in the dose kernel dispersion calculations. Because of the nature of the scenario (i.e. } \\
\text { exothermic reaction and shrapnel), the worker would be able to notice the hazardous conditions and would evacuate from the immediate } \\
\text { area. }\end{array}$} \\
\hline \multicolumn{4}{|c|}{$\begin{array}{l}\text { ** The worst case non-involved worker dose equivalent provided from Table F.2-19 of the SNL/NM Site-wide Environmental Impact } \\
\text { Statement (DOE 1999) is } 0.56 \text { rem. The worst case non-involved worker dose equivalent provided was that for an aircraft crash with } \\
\text { collapse of the bridge crane and involved } 10 \% \text { of the core inventory. Because this dose equivalent only involves } 10 \% \text { of the core, it was not } \\
\text { used to estimate worker dose from release of fission products from one-third of reactor core ACRR fuel. The collocated worker dose } \\
\text { equivalent was estimated by scaling the dose kernels for members of the pubic to the collocated worker at } 300 \mathrm{~m} \text { and applying that scaling } \\
\text { factor to the public dose equivalents listed in this table for the ACRR fuel. }\end{array}$} \\
\hline
\end{tabular}

Table F-25. Dose and latent cancer fatality summary for sodium fire in the ACRR.

\begin{tabular}{|c|c|c|c|c|c|}
\hline $\begin{array}{l}\text { Probability of One } \\
\text { Failure per Year }\end{array}$ & $\begin{array}{l}\text { Probability of One } \\
\text { Failure in } 40 \text { Years }\end{array}$ & Receptor & $\begin{array}{c}\text { Dose } \\
\text { (rem unless noted) }\end{array}$ & $\begin{array}{l}\text { Dose Risk } \\
\text { (rem/year) }\end{array}$ & $\mathrm{LCF}$ \\
\hline \multirow[t]{3}{*}{$1.1 \mathrm{E}-02$} & 3.6E-01 & Facility Worker & $\begin{array}{r}<12.9 \mathrm{rem} / \mathrm{min} \\
(2 \text { minutes prior to } \\
\text { reaching } 25 \mathrm{rem})\end{array}$ & - & $1.5 \mathrm{E}-02 *$ \\
\hline & & Collocated Worker@300m & 2.98 & $3.2 \mathrm{E}-02$ & $1.8 \mathrm{E}-03$ \\
\hline & & Offsite Member of the Public & 0.077 & $8.4 \mathrm{E}-04$ & 4.6E-05 \\
\hline
\end{tabular}

\section{F-5.3 Releasing Melted Fuel into the Annular Core Research Reactor Central Cavity}

This scenario assumes melted fuel from the experiment is released into the ACRR central cavity. Release of melted fuel could be caused by equipment failure or human error and can be initiated by excessive energy deposition either by improper experiment package assembly or by erroneous operation of the reactor. Failure to decouple heat from the experiment package could be caused by omitting thermally conductive or nuclear decoupling material within the package. A malfunction of the sodium loop that is used for heat rejection also could allow excessive energy deposition into the experiment package. Excessive energy deposition in conjunction with fielding the experiment package without proper containment may lead to the release of molten MOX fuel.

\section{F-5.3.1 Preventative Measures}

Several preventative measures would reduce the frequency and consequences of this accident. They include the following:

- All experiments at the ACRR facility shall be subjected to the independent safety review process to ensure that experiments are conducted within the parameters evaluated in this analysis.

- Leak-tight inner (i.e., primary) and outer (i.e., secondary) experiment containment will be required:

- The primary and secondary containment prevents the release of experiment MAR from the experiment package. 
- For each unique experiment configuration, calculations estimating the energy deposition and the temperature change of the fissile material must be completed, reviewed, and approved.

- Instrumentation capable of detecting significant increases in the temperature in an experiment package must be installed and operating properly.

- The first operation of such an experiment shall be a low-energy operation to validate the calculated fission energy-coupling factor of the experiment.

\section{F-5.3.2 Probability of this Type of Accident Occurring}

The probability of this event occurring was discussed in SNL/NM (2013), based on the event tree shown in Figure F-9. For a single event, the probability is given by:

$P=P_{a} \times\left[\left(P_{d}+P_{h}+P_{i}\right)+\left(P_{g}+P_{j}+P_{k}\right)\right]$

Using the event probabilities shown in Figure F-9, the combined event probability is 6E-5. Assuming 34 sodium-cooled experiment reactor operations per year, the annual probability is estimated to be $2.04 \mathrm{E}-3$. The corresponding probability that one accident of this type will occur during the 40 years of transient testing is $7.84 \mathrm{E}-2$.

\section{F-5.3.3 Dose Consequences}

The resultant doses are shown in Table F-26 and the dose risk and risk of an LCF occurring are summarized in Table F-27. The accident consequences can be summarized as follows:

- For members of the public:

- The estimated dose is $0.4 \mathrm{rem}$ (400 mrem). This is lower than the annual average 600 -mrem dose received by members of the public from non-DOE facilities (Figure F-2).

- The increased probability of a member of the public getting cancer is $0.07 \%$.

- The risk of an LCF occurring is about 1 in 4,000.

- For collocated workers:

- Workers at ACRR are assumed to be located at $300 \mathrm{~m}$ from the accident site.

- The estimated dose is 3.7 rem.

- The increased probability of a worker getting cancer is $0.6 \%$.

- The risk of an LCF occurring is about 1 in 450.

- For facility workers:

- At the estimated dose rate of $74.7 \mathrm{rem} / \mathrm{min}$, an unprotected (unshielded) facility worker would likely receive at least $25 \mathrm{rem}$. However, at the estimated dose rate, an unprotected (unshielded) facility worker would have 1.3 minutes prior to exceeding a 100-rem dose.

- At 100 rem, the increased probability of a worker getting cancer is $17 \%$.

- At 100 rem, the risk of an LCF occurring is about 1 in 16. 


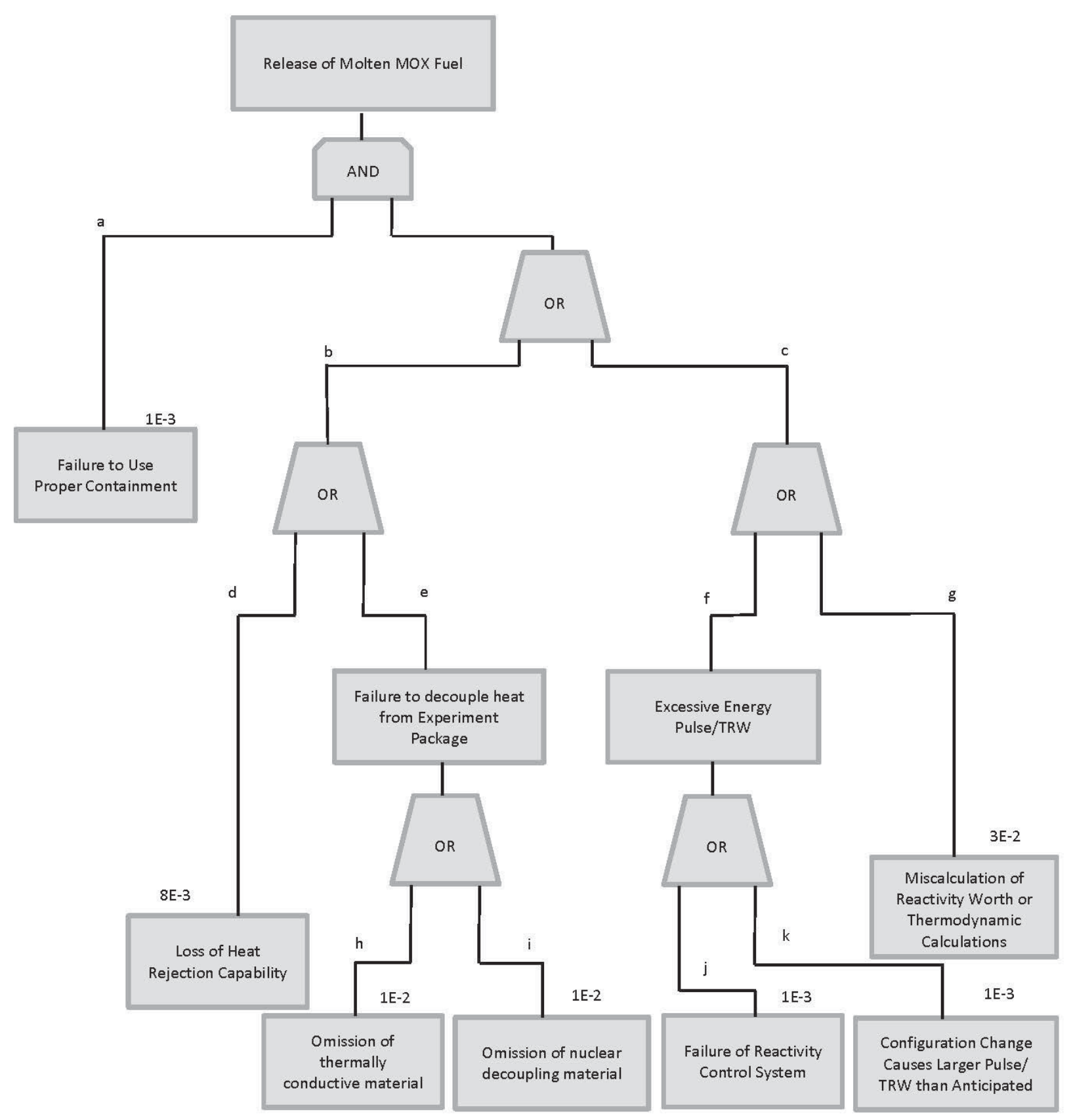

Figure F-9. Fault tree for an inadvertent fuel melt contained in a sodium-cooled experiment while in the ACRR central cavity.

Using the guidance provided by the Health Physics Society (Section F-3), consequences for members of the public and for collocated workers would be negligible without additional protective measures. Protection of facility workers could be required to mitigate their dose consequences. This could include use of administrative procedures requiring relocation of the operators during transient testing (as will be required at TREAT) or use of personal protective equipment during transient testing. Administrative procedures that could be implemented at ACRR have not been factored into the dose estimates provided in Table F-26 and summarized in Table F-27. 
Table F-26. Estimated dose consequences for a fuel melt in the ACRR central cavity (from SNL/NM 2013).

\begin{tabular}{lccc}
\hline MAR & $\begin{array}{c}\text { Facility Worker TED } \\
(\mathrm{rem} / \mathrm{min})\end{array}$ & $\begin{array}{c}\text { Collocated Worker TED at } 300 \mathrm{~m} \text { (rem) }- \\
\text { Ground Release }\end{array}$ & $\begin{array}{c}\text { Member of the Public } \\
\text { (rem) }\end{array}$ \\
\hline $\begin{array}{l}\text { Experiment Fuel } \\
(\mathrm{MOX})\end{array}$ & 74.7 & 3.7 & 0.4 \\
\hline
\end{tabular}

Table F-27. Dose and latent cancer fatality summary for a fuel melt in the ACRR central cavity.

\begin{tabular}{|c|c|c|c|c|c|}
\hline $\begin{array}{l}\text { Probability of one } \\
\text { failure per year }\end{array}$ & $\begin{array}{l}\text { Probability of one } \\
\text { failure in } 40 \text { years }\end{array}$ & Receptor & $\begin{array}{c}\text { Dose } \\
\text { (rem or rem/min as } \\
\text { noted) }\end{array}$ & $\begin{array}{l}\text { Dose Risk } \\
\text { (rem/year) }\end{array}$ & LCF \\
\hline \multirow[t]{3}{*}{$2.0 \mathrm{E}-03$} & $7.8 \mathrm{E}-02$ & Facility Worker & $\begin{array}{c}74.7 \mathrm{rem} / \mathrm{min} \\
\text { (exceeds } 25 \mathrm{rem}) \\
(1.3 \mathrm{~min} \text { prior to } \\
\text { reaching } 100 \mathrm{rem})\end{array}$ & - & $6.0 \mathrm{E}-02 * *$ \\
\hline & & Collocated Worker@300m & 3.7 & 7.6E-03 & $2.2 \mathrm{E}-03$ \\
\hline & & Offsite Member of the Public & 0.4 & $8.2 \mathrm{E}-04$ & $2.4 \mathrm{E}-04$ \\
\hline
\end{tabular}

\section{F-5.4 Summary of Impacts Using the Annular Core Research Reactor Facility}

\section{F-5.4.1 Overview of Accident Analysis for the Annular Core Research Reactor}

The analysis followed the approach used in the analysis of accidents at INL (summarized in Section F-4.9.1).

\section{F-5.4.2 Summary of Radiologic Consequences for Alternative 2 (ACRR)}

Results of the accident analysis conducted for RTT Program operations in Alternative 2 (ACRR) must include those for material handling operations at INL and SNL/NM, in addition to those that could happen as a result of conducting experiments in ACRR. Dose results are summarized in Table F-28.

\section{F-5.4.2.1 Accidents at INL}

Accidents occurring on INL under Alternative 2 (ACRR) would be bounded by experiment drop/impact events occurring at MFC/HFEF. MFC is located about 5,000 $\mathrm{m}$ from the nearest INL boundary. The drop or impact scenario occurring at HFEF was evaluated in Section F.4.8. Results were provided for the distance of 5,000 $\mathrm{m}$ in Tables F-18 and F-19. The results of this accident scenario are summarized as follows:

- For members of the public with the accident occurring at MFC:

- The estimated dose is $0.007 \mathrm{rem}(6 \mathrm{mrem})$. This is much less than the annual average 600 -mrem dose received by members of the public from non-DOE facilities (Figure F-2).

- The increased probability of a member of the public getting cancer is $0.001 \%$.

- The risk of an LCF occurring about 1 in 225,000.

- For the collocated workers:

- The estimated dose is 0.21 rem for workers located $100 \mathrm{~m}$ from the site of the accident and 0.062 rem for those located $300 \mathrm{~m}$.

- The increased probability of the closest collocated worker getting cancer is $0.03 \%$.

- The risk of an LCF occurring is about 1 in 7,700.

- For facility workers located at the site of the load drop: 
- The estimated dose rate is $3.4 \mathrm{rem} /$ minute. They could remain in the building about 7 minutes prior to receiving a dose of $25 \mathrm{rem}$.

- At 25 rem, the increased probability of a worker getting cancer is $4.25 \%$.

- At 25 rem, the rate of an LCF occurrence is 0.015 or 1.5 people in 100.

Consequences for members of the public and for workers located beyond a distance of $100 \mathrm{~m}$ are negligible. Protection of facility workers will require administrative procedures to limit the exposure time for workers. Based on a 25-rem exposure, there is ample time for facility workers to be evacuated.

\section{F-5.4.2.2 Accidents at SNL/NM}

For Alternative 2 (ACRR), the highest consequence event would occur at ACRR and could happen if molten fuel were released from the experiment assembly while inserted in the ACRR central cavity. The results of this highest consequence event are shown in Table F-28 and can be summarized as follows:

- The annual frequency of occurrence for this event is $2 \mathrm{E}-3$ or about once in 500 years. The probability of this event occurring once during the 40-year RTT Program lifetime is about 0.08 . Therefore, this event is unlikely.

- For members of the public:

- The estimated dose is $0.4 \mathrm{rem}(400 \mathrm{mrem})$. This is lower than the annual average 600 -mrem dose received by members of the public from non-DOE facilities (Figure F-2).

- The increased probability of a member of the public getting cancer is $0.07 \%$.

- The risk of an LCF occurring is about 1 in 4,000.

- For collocated workers:

- Workers at ACRR are assumed to be located at $300 \mathrm{~m}$ from the accident site.

- $\quad$ The estimated dose is 3.7 rem.

- The increased probability of a worker getting cancer is $0.6 \%$.

- The risk of an LCF occurring is about 1 in 450.

- For facility workers:

- At the estimated dose rate of $74.7 \mathrm{rem} / \mathrm{min}$, an unprotected (unshielded) a facility worker would likely receive at least $25 \mathrm{rem}$. However, at the estimated dose rate, an unprotected (unshielded) facility worker would have 1.3 minutes prior to exceeding a 100 -rem dose.

- At 100 rem, the increased probability of a worker getting cancer is $17 \%$.

- At 100 rem, the risk of an LCF occurring is about 1 in 16.

Consequences for members of the public and for collocated workers would be negligible without additional protective measures. Protection of facility workers could be required to mitigate their dose consequences. This could include use of administrative procedures requiring relocation of the operators during transient testing (as will be required at TREAT) or use of personal protective equipment during transient testing. Administrative procedures that could be implemented at ACRR have not been factored into the dose estimates provided in Table F-28 and summarized in Table F-29. 


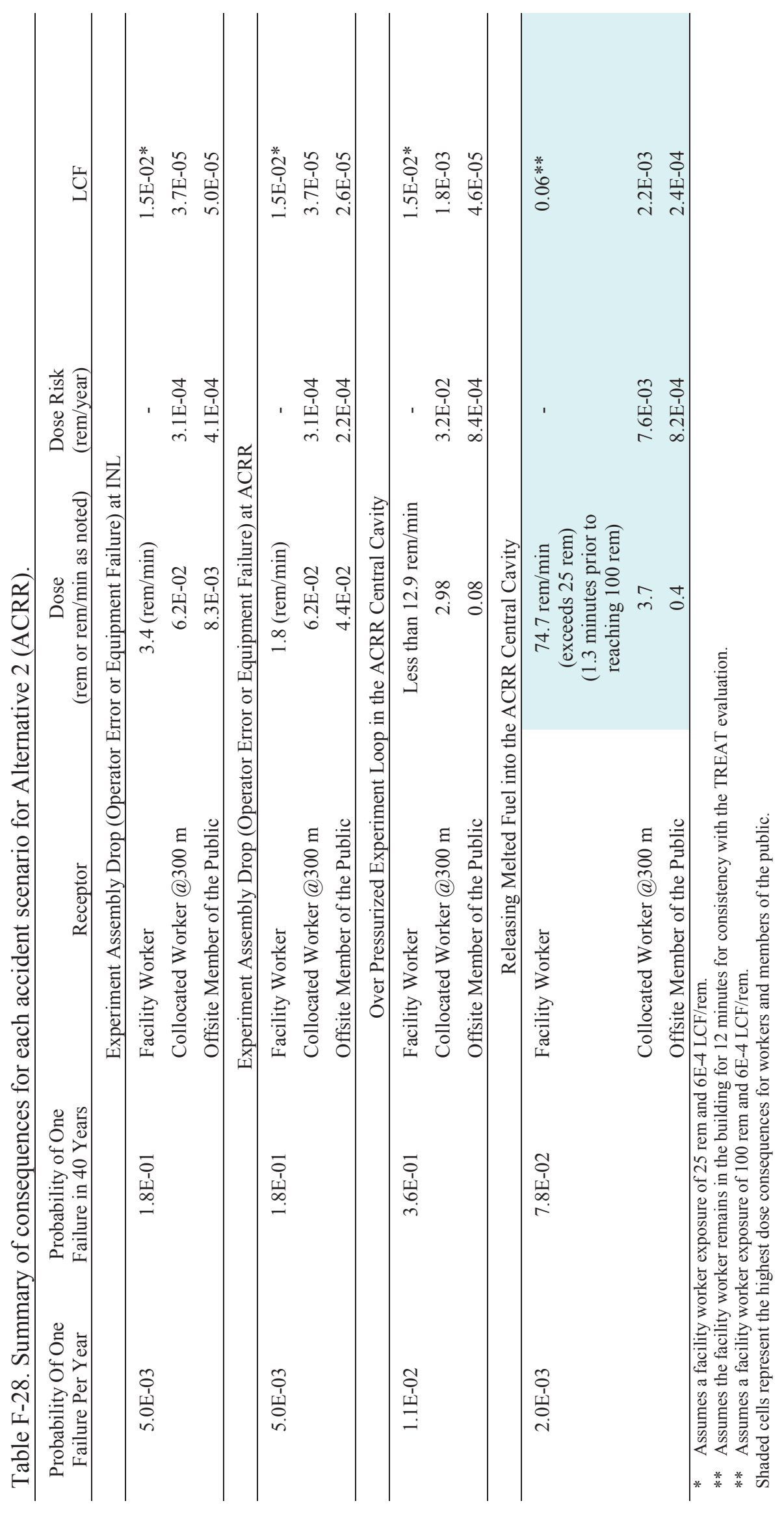




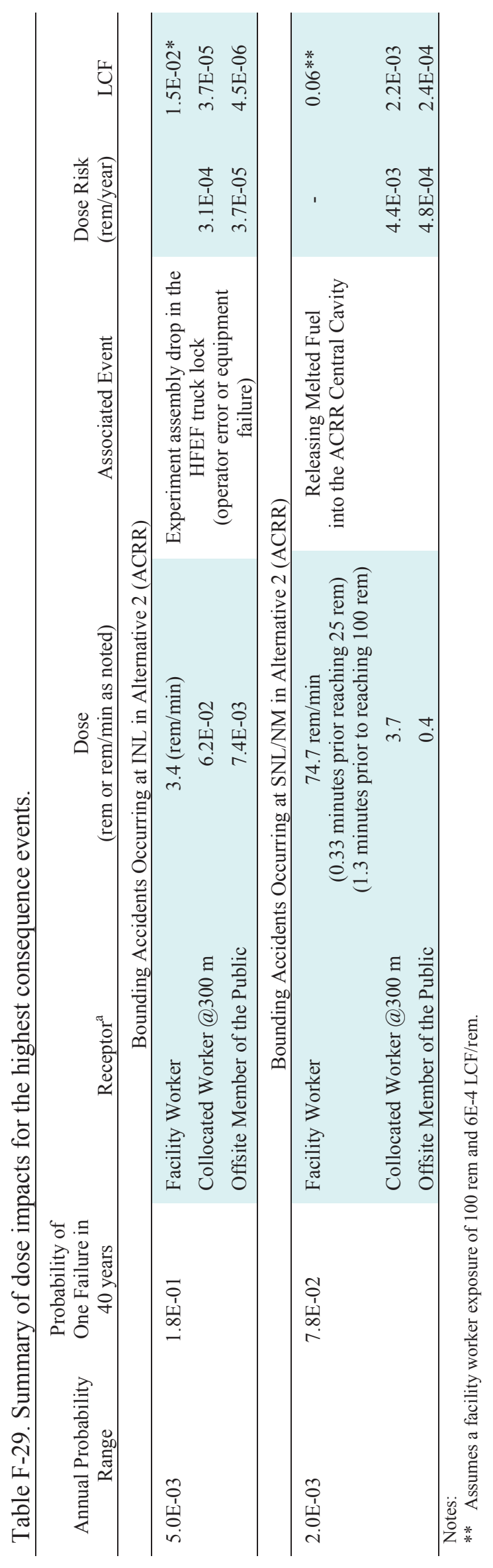

8
1
1 


\section{F-6. REFERENCES}

10 CFR 830, Subpart B, "Nuclear Safety Management," Code of Federal Regulations, Office of the Federal Register.

40 CFR 61, Subpart H, 2010, "National Emission Standards for Emissions of Radionuclides Other than Radon from Department of Energy Facilities," Code of Federal Regulations, Office of the Federal Register, April 2010.

ANL, 1979a, "37-Pin and 7-Pin Advanced TREAT Loop Title II Design Report Prepared for Argonne National Laboratory," Volume I, Prepared by AMETEK, Straza Division and Basic Technology Incorp, December 14, 1981, 8-530230.

ANL, 1979b, "System Design Description for MARK-III Loop Experiment Systems," R0250-1000-SA02, Revision 2, Argonne National Laboratory.

Berkeley, 1972, "Central Electricity Generating Board, Research Department," RD/B/N2412, The Combustion of Liquid Sodium in Air, R. N. Newman, Berkeley Nuclear Laboratories, November 1972.

Blume, John A. and Associates, Engineers, 1979, “A Risk Analysis of the TREAT Upgrade Reactor Building Crane," January 1979, p. 62.

Clawson, K. L., G. E. Start, and N. R. Ricks, 1989, Climatography of the Idaho National Engineering Laboratory, 2nd Edition, DOE/ID-12118, U.S. Department of Commerce, National Oceanic and Atmospheric Administration, Environmental Research Laboratories, Air Resource Laboratory, Field Research Division, Idaho Falls, Idaho.

CMAA-70, "Specifications for Electric Overhead Traveling Cranes," Crane Manufacturer's Association of America.

DOE, 1999, Final Site-Wide Environmental Impact Statement for Sandia National Laboratories/New Mexico, DOE/EIS-0281. U.S. Department of Energy, Albuquerque Operations Office, Albuquerque, New Mexico.

DOE, 2002, "Recommendations for Analyzing Accidents under the National Environmental Policy Act," U.S. Department of Energy, July 2002.

DOE, 2004, "MACCS2 Computer Code Application Guidance for Documented Safety Analysis," U.S. Department of Energy, DOE-EH-4.2.1.4, June 2004.

DOE-HDBK-3010-1994, "Airborne Release Fractions/Rates and Respirable Fractions for Nonreactor Nuclear Facilities,” U.S. Department of Energy, Change Notice No. 1, March 2000.

DOE-STD-3009-94, "Preparation Guide for U.S. Department of Energy Nonreactor Nuclear Facilities documented Safety Analyses," U.S. Department o f Energy, March 2006.

DOE-STD-1189-2008, "Integration of Safety into the Design Process," U.S. Department of Energy, March 2008.

DOE-STD-1020, "Natural Phenomena Hazards Design Evaluation Criteria for Department of Energy Facilities," U.S. Department of Energy, January 2002. 
FSAR, 2009, Transient Reactor Test Facility (TREAT) Final Safety Analysis Report, S3942-0001-YT.

GDE-10820, 2012, “INL Guide to Safety Analysis Methodology,” Revision 0, Idaho National Laboratory, September 2012.

IBC 2000, “International Building Code,” International Code Council, February 2005.

ICRP-68, 1994, "Dose Coefficients for Intakes of Radionuclides by Workers," International Commission on Radiological Protection.

ICRP-72, 1996, “Age-dependent Doses from Intakes of Radionuclides,” International Commission on Radiological Protection.

INL, 2013, National Environmental Policy Act Hazards Assessment of Alternative 1 (TREAT), INL/EXT-13-29496, Revision 0, Idaho National Laboratory.

ISCORS, 2002, "ISCORS Technical Report No. 1, A Method for Estimating Radiation Risk from TEDE," Interagency Steering Committee on Radiation Standards, July 2002.

LST-337, 2013, “Approved Container/Payload List for Inter-Facility Transfer Operations at MFC,” Revision 15, Idaho National Laboratory.

McFadden, K., N. E. Bixler, V. D. Cleary, L. Eubanks, and R. Haaker,, 2007, WinMACCS, a MACCS2 interface for calculating health and economic consequences from accidental release of radioactive materials into the atmosphere, "User's Guide and Reference Manual WinMACCS," Version3, Sigma Software LLC, Sandia National Laboratories, Gram Inc., AQ Safety, Inc.

Morewitz, 1979, "Sodium Spray Fires," in Nuclear Engineering and Design, H. A., Morewitz, 42, 123-135, North-Holland Publishing Company.

NRC, 2000, Alternative Radiological Source Terms for Evaluating Design Basis Accidents at Nuclear Power Reactors, Regulatory Guide 1.183, U.S. Nuclear Regulatory Commission, Washington, D.C., July 2000.

NRC, 2003, “Interim Safety Guide-5,” Attachment, p. 7, Nuclear Regulatory Commission.

NUREG/CR-4981, 1987, “A Safety Assessment of the Use of Graphite in Nuclear Reactors Licensed by the US NRC," Nuclear Regulatory Commission.

Rudolph, R. R. and C. E. Dickerman, "Revised Summary of Times-Risks-Risk for TU Experiment Operations," Memo to Distribution, S3940-S-3-376, January 20, 1983.

SAND, 2008, Assessment of Severe Accident Source Terms in Pressurized-Water Reactors with a 40\% Mixed-Oxide and 60\% Low-Enriched Uranium Core Using MELCOR 1.8.5, SAND2008-6665, Scott. G. Ashbaugh, et al, Sandia National Laboratories, Albuquerque, New Mexico, April 2010.

Sandia Report, 2008, Documented Safety Analysis (DSA) for the Annular Core Research Reactor Facility $(A C R R F)$, SAND2008-5636, Annual Update/CN4, 2001, SER January 11, 2012, IVR April 18, 2012, Sandia National Laboratory, Albuquerque, New Mexico.

SAR-400, 2013, “Chapter 1-Site Characteristics - INL Standardized Safety Analysis Report," SAR-400, Revision 6, May 2013. 
SAR-405, Draft, "Safety Analysis Report for the Hot Fuel Examination Facility," Idaho National Laboratory.

SNL, 2010, Understanding Thermal Consequences of Liquid Sodium Fires, SAND2010-5299C, Tara J. Olivier, John C. Hewson, Thomas K. Blanchat, and Steven P. Nowlen, Sandia National Laboratories, Albuquerque, New Mexico.

SNL/NM, 2013, National Environmental Policy Act Hazards Assessment for the Alternative to Conduct Sodium Cooled Experiments in the Annular Core Research Reactor (ACRR), James J Dahl, P. V. Subaiya, C. D. Carathers, and R. E. Durrer. Sandia National Laboratories, Albuquerque, New Mexico.

Subaiya, 2013, INL (Idaho National Laboratories) Transient Testing Dose Calculations, Calc. No. ACRRF-CAL-016.00, Revision 0, Peter Subaiya, Sandia National Laboratories, Albuquerque, New Mexico, September 2013. 
F-64 


\section{Appendix G}

\section{Assessment of Transportation Impacts}

Primary Contributors

Ruth F. Weiner, Sandia National Laboratories

Cathy Ottinger Farnum, Sandia National Laboratories

Steven Peterson, Oak Ridge National Laboratory 
G-2 


\section{CONTENTS}

G-1. INTRODUCTION G-5

G-1.1 Interpreting Dose Results G-6

G-2. MODELS USED IN THE TRANSPORTATION ANALYSIS …..............................................

G-3. RADIONUCLIDE INVENTORY AND SCREENING ...............................................................

G-4. TRANSPORATION CASKS AND CASK-SPECIFIC PARAMETERS .................................... G-9

G-5. ANALYSIS OF TRANSPORTATION AT THE IDAHO NATIONAL LABORATORY ......... G-10

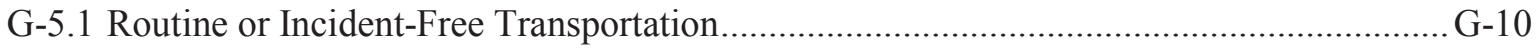

G-5.1.1 Transportation Routes and Route-Specific Parameters.......................................... G-10

G-5.1.2 Results for Routine Transportation at Idaho National Laboratory.......................... G-12

G-5.2 Transportation Accidents at Idaho National Laboratory .................................................. G-12

G-6. ANALYSIS OF IMPACTS FOR TRANSPORTATION BETWEEN THE MATERIALS AND FUELS COMPLEX AND THE ANNULAR CORE RESEARCH REACTOR ................ G-14

G-6.1 Transportation Routes and Route-Specific Parameters.................................................... G-14

G-6.2 Transportation Casks and Cask-Specific Parameters............................................................ G-17

G-6.3 Routine or Incident-Free Transportation.......................................................................... G-18

G-6.3.1 Summary of Incident-Free Transportation Impacts ........................................... G-28

G-6.4 Transportation Impacts Involving an Accident Enroute between the Materials and Fuels Complex and the Annular Core Research Reactor ................................................. G-30

G-6.4.1 Summary of Transportation Impacts Involving an Accident Enroute between the Material and Fuels Complex and Annular Core Research Reactor................. G-40

G-7. NON-RADIOLOGICAL TRANSPORTATION IMPACTS …................................................ G-41

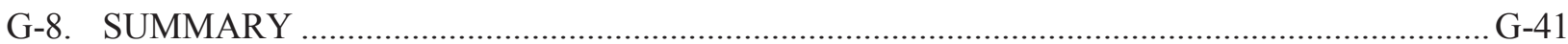

G-8.1 Incident-Free Transportation Results .......................................................................... G-41

G-8.2 Non-Incident-Free Transportation Results.................................................................... G-42

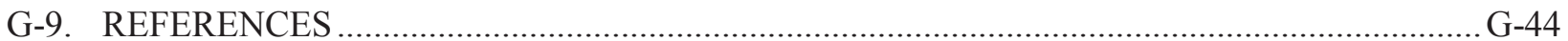


G-4 


\section{Appendix G Assessment of Transportation Impacts}

\section{G-1. INTRODUCTION}

An assessment of the potential impacts from transport of the radiological inventory in the experiments that will be used in the RTT Program is provided in this appendix. The results of this assessment will be used in the NEPA EA for the RTT Program. The EA includes two action alternatives for achieving the proposed action: (1) use of TREAT at the INL Site and (2) use of ACRR, located in TA-V at SNL. Therefore, transportation and handling of the experiment assemblies will be assessed only for (1) transportation on INL and (2) transportation between MFC at INL and ACRR at SNL as explained in Section 2. These paths are illustrated in Figure G-1. At INL, the transport path includes the route from ATR to MFC, then to TREAT, with a return pathway to MFC as indicated by the red arrows. For Alternative 2 (ACRR), the transport path begins at ATR or MFC and then proceeds from MFC to the SNL hot cell, to ACRR, back to the SNL hot cell, and back to MFC as shown by the green connecting arrows. The blue and orange connecting arrows are provided to indicate a transport pathway for experimental components originating at NRC-licensed facilities. Whether the fuel comes from ATR or an NRC-licensed facility, the transport pathways from MFC to either TREAT or the SNL hot cell are the same.

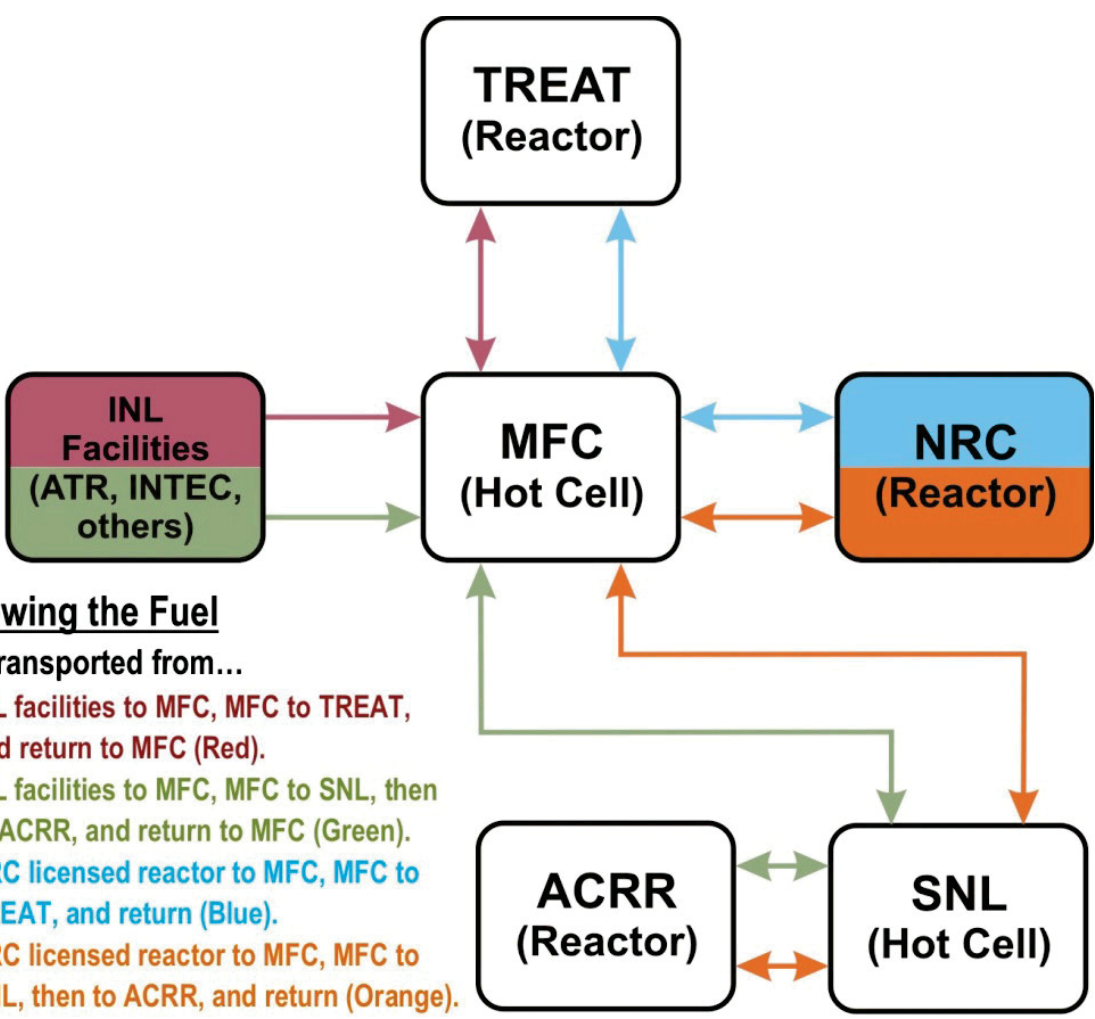

Figure G-1. Transport pathways followed by the experiment fuel and assemblies.

The approach for this transportation and handling impacts analysis follows DOE guidance (DOE 2002a, DOE 2002b, DOE 2004). According to this guidance, both incident-free transportation and transportation accidents should be evaluated for any alternative involving transportation of radioactive and/or hazardous materials. NEPA employs a 'sliding scale' approach that allows the agency to tailor the analysis to the issues involved in the proposed action. 
Collective population risk is defined as the radiological risk associated with routine transportation that results from potential exposure of people to ionizing radiation and is the result of integrating the radiation risk over the area occupied by the population. In the following analyses, the source of the radiation is through exposure that could occur (1) during incident-free transportation to external radiation from the loaded casks, (2) following an incident to external radiation from the loaded cask, or (3) following a severe accident to radioactive material potentially released from the cask. In the case of transportation accidents involving release of radioactive material, the populations in question are those within the dispersion plume footprint. As outlined in the handbook, for routine transportation, all major groups of potentially exposed persons are considered. For transportation-related accidents, dose risk is provided for the general population. The calculations of risk for routine highway transportation include exposures of the following population groups and hypothetical exposure scenarios:

- Persons along the route (offlink population). Collective doses are calculated for all persons residing on each side of a transportation route. The total number of persons within the corridor is calculated separately for each route considered in the assessment. The maximally exposed resident is assumed to live $30 \mathrm{~m}$ (98 ft) from a site entrance route. Shipments pass at an average speed of $24 \mathrm{~km} / \mathrm{h}(15 \mathrm{mph})$, and the unshielded resident is exposed. Cumulative doses are assessed, assuming that the MEI resident is present for $100 \%$ of the shipments. Collective dose is calculated for those residing between 30 and $800 \mathrm{~m}$ from the route.

- Persons sharing the route (onlink population). Collective doses are calculated for all persons in vehicles sharing the transportation route. This group includes persons traveling in the same or the opposite direction.

- Persons at stops. Collective doses are calculated for people who share the stop and may be exposed while a shipment is stopped en route. Collective doses also are calculated for residents near the stop. For truck transportation, these stops include those for refueling, food, and rest.

- Crew members. Collective doses are calculated for truck transportation crew members. Truck crew members are assumed to be occupational radiation workers and would be monitored by a dosimetry program. Therefore, during routine transport, the maximum allowable dose would be $5 \mathrm{rem} / \mathrm{year}$. As an administrative procedure, DOE limits doses to DOE workers to 5 rem/year.

The dose model considers direct external exposure. The doses calculated for the first three population groups are added to yield the collective dose to the public; the dose calculated for the fourth group represents the collective dose to workers. The calculation of routine doses for each exposed population group depends on parameters such as the radiation field strength, source-receptor distance, duration of exposure, vehicular speed, stopping time, traffic density; and route characteristics (such as population density).

Once the ST (i.e., the amount of radioactive material released to the environment) for each accident scenario is determined, the radiological consequences are calculated. The calculations and resulting impacts vary depending on how the radioactive material release is dispersed, what materials are involved, and which receptors are being considered.

\section{G-1.1 Interpreting Dose Results}

The potential impacts of a radiological accident on workers and the public can be measured in a number of ways. In this report, three measures are used. The first measure of consequences is individual dose, expressed in terms of rem for a member of the public or worker and collective dose, expressed in terms of person-rem. The second measure is a post-exposure effect that reflects the likelihood of an LCF for an exposed individual or the expected number of LCFs in a population of exposed individuals. Individual or public exposure to radiation can only occur if there is an accident involving radioactive materials, which leads to the third measure. The third measure of potential accident impacts is referred to 
as risk that takes into account the probability (or frequency) of the accident's occurrence. Risk is the mathematical product of the probability or frequency of accident occurrence and LCF consequences.

Collective dose is a measure of the total amount of radiation exposure to everyone affected by an activity. In the following analyses, collective dose is provided in units of person-rem or person-sieverts (person-Sv). For example, if there are 25 million people in the United States who smoke cigarettes and each of them receives 2 rem from smoking, the collective dose to the U.S. smoking population is 50 million person-rem. Another example of collective dose is to say that the U.S. population receives about 81 million person-rem from natural background radiation because about 270 million people (estimated total U.S. population) receive an average annual exposure of about 300 mrem each from natural sources. The average annual dose rate from natural sources in the United States and Canada is about 311 mrem per year (NCRP 2009), although people in the Rocky Mountain States receive doses about twice as high and Gulf Coast residents receive less. In the smoking example above, the average annual dose rate across the entire U.S. population would be about 185 mrem per year.

Although collective dose is used to express transportation dose effects, the concept of collective dose is not entirely appropriate to determine the numbers of expected health effects from exposing large numbers of people to very small radiation doses. For example, you might predict that, based on the numbers given above, the population of the United States would have about 40,000 fatal cancers from background radiation alone, which is unlikely to be true for a number of reasons. Recently, the International Council on Radiation Protection issued a position statement saying that the use of collective dose for prediction of health effects at low exposure levels is not appropriate. The Health Physics Society also recommends not making risk estimates based on low exposure levels.

LCF is a measure of deaths resulting from cancer that became active after a latent period following exposure to radiation. The LCF value corresponds to the risk that cancer will result from the dose sustained. The dose is the consequence. The numbers of radiation-induced LCFs are estimated by multiplying the dose (person-rem) by health risk conversion factors. The factors most commonly used in recent assessments are 0.0006 LCF per person-rem of exposure for workers and for members of the public (ISCORS 2002).

Risk is calculated as follows:

- For an individual:

$R_{i}=D_{i} \times F \times P$

where:

$\mathrm{R}_{\mathrm{i}}=$ the risk of an LCF for an individual receiving a dose Di in LCFs per year

$\mathrm{D}_{\mathrm{i}} \quad=$ the dose in rem to an individual

$\mathrm{F}=$ the dose-to-LCF conversion factor, which is 0.0006 LCFs per rem for individuals

$\mathrm{P} \quad=$ the probability or frequency of an accident, expressed on a per-year basis.

- For a population:

$R_{p}=D_{p} \times F \times P$

where:

$\mathrm{R}_{\mathrm{p}}=$ the risk of an LCF for a population receiving a dose $\mathrm{D}_{\mathrm{p}}$ in LCFs per year

$\mathrm{D}_{\mathrm{p}}=$ the dose in person-rem to a population

$\mathrm{F}=$ the dose-to-LCF conversion factor, which is $0.0006 \mathrm{LCFs}$ per person-rem for a population

$\mathrm{P} \quad=$ the probability or frequency of an accident, expressed on a per-year basis. 


\section{G-2. MODELS USED IN THE TRANSPORTATION ANALYSIS}

For this analysis, the following models were used:

- TRAGIS. TRAGIS sets routes for the shipment and designates route segments as urban, suburban, or rural so that population densities within 50 miles $(80 \mathrm{~km})$ of the route can be estimated. Two potential transport routes for off-INL transport have been identified for this alternative, each of which may be taken depending on the conditions at the time of transport. The two routes between MFC and ACRR are shown on Figure G-2. Route A is the preferred route because it passes through the least populated areas and is shorter than Route B. Route segment data generated from TRAGIS for the two routes is discussed in Section G-5.1. TRAGIS was not used to define the on-INL transport route shown in Figure G-3.

- RADTRAN. The RADTRAN program calculates individual and collective risks to workers, occupants of vehicles sharing the route, special receptors (e.g., inspectors), and members of the public along each route based on radiological and physical properties of the material being transported. Output from TRAGIS is used as input to RADTRAN to determine the length of the route segments and associated population densities along each route. The dose to crew members along the route, including stops also is calculated. The exposures to members of the pubic in a band, usually within $2,625 \mathrm{ft}(800 \mathrm{~m})$ of the transport link (offlink) are calculated (the off-link dose). Dose to vehicles sharing the transport link (onlink) and at stops also are calculated.

\section{G-3. RADIONUCLIDE INVENTORY AND SCREENING}

To establish the radiation field, this analysis uses the inventory established in Appendix E for the research quantities of radiologic material to be subjected to transient testing. This inventory is assumed to be shipped under both alternatives. For routine or incident free transport, shipments are assumed to be in compliance with allowable limits for exposure from shipping containers of radioactive materials.

As indicated in Appendix E, the primary exposure pathway for relevant accident scenarios involving the experiment inventory is through inhalation and direct exposure with the inhalation dose dominating the TED. This allows using a subset of the radionuclides accounting for the majority of either the plutonium equivalent curie or the $\mathrm{A}_{2}$ value, which is the activity that could be carried in a Type $\mathrm{A}$ package (10 CFR Part 71, Appendix A). To determine the radionuclides contributing to the majority of the dose, the list of radionuclides in the bounding inventory discussed in Appendix E were sorted both according to the plutonium equivalent value and the $\mathrm{A}_{2}$ value. Both sorting methods yielded the same doses when analyzed in RADTRAN and RISKIND. The $\mathrm{A}_{2}$ sort was used as the determining screened inventory because it contained more radionuclides, although most of the radionuclides were the same using either method. The final inventory used in the transportation analysis is provided in Table G-1. It accounts for $99.9 \%$ of the dose screening dose. 
Table G-1. Radionuclides used in the transportation analysis.

\begin{tabular}{|c|c|c|c|c|c|}
\hline Nuclide & $\begin{array}{c}7 \text { pin } \\
\text { MARK-III } \\
\text { (Ci) }\end{array}$ & $\begin{array}{c}\text { ICRP-72 } \\
\text { DCF }\end{array}$ & Nuclide & $\begin{array}{c}7 \text { pin } \\
\text { MARK-III } \\
\text { (Ci) }\end{array}$ & $\begin{array}{c}\text { ICRP-72 } \\
\text { DCF }\end{array}$ \\
\hline Pm-147 & $1.66 \mathrm{E}+03$ & 24.3 & U-237 & $3.03 \mathrm{E}-02$ & $6.29 \mathrm{E}+03$ \\
\hline Ba-137M & $6.05 \mathrm{E}+02$ & $3.59 \mathrm{E}+04$ & $Y-91$ & $1.59 \mathrm{E}+02$ & 8.11 \\
\hline $\mathrm{Pu}-239$ & $2.84 \mathrm{E}+01$ & $1.85 \mathrm{E}+08$ & $\mathrm{H}-3$ & $4.73 \mathrm{E}+00$ & $6.66 \mathrm{E}-03$ \\
\hline $\mathrm{Pu}-241$ & $1.27 \mathrm{E}+03$ & $3.36 \mathrm{E}+06$ & $\mathrm{Nb}-95 \mathrm{M}$ & $3.78 \mathrm{E}+00$ & $2.92 \mathrm{E}+03$ \\
\hline Ce-144 & $3.78 \mathrm{E}+03$ & $1.33 \mathrm{E}+05$ & Sr-89 & $7.38 \mathrm{E}+01$ & $2.26 \mathrm{E}+04$ \\
\hline $\mathrm{Pu}-240$ & $1.74 \mathrm{E}+01$ & $1.85 \mathrm{E}+08$ & $\mathrm{Sb}-125$ & $7.38 \mathrm{E}+01$ & $1.78 \mathrm{E}+04$ \\
\hline $\mathrm{Pu}-238$ & $1.42 \mathrm{E}+01$ & $1.70 \mathrm{E}+08$ & $\mathrm{Am}-242 \mathrm{M}$ & $5.30 \mathrm{E}-02$ & $1.37 \mathrm{E}+08$ \\
\hline Ru-106 & $1.31 \mathrm{E}+03$ & $1.04 \mathrm{E}+05$ & Cs-134 & $3.03 \mathrm{E}+01$ & $3.37 \mathrm{E}+04$ \\
\hline Am-241 & $6.43 \mathrm{E}+00$ & $1.55 \mathrm{E}+08$ & U-236 & $3.59 \mathrm{E}-03$ & $1.18 \mathrm{E}+07$ \\
\hline Sr-90 & $5.11 \mathrm{E}+02$ & 5.41 & Te- $127 \mathrm{~m}$ & $1.38 \mathrm{E}+01$ & $2.74 \mathrm{E}+04$ \\
\hline Y-90 & $5.11 \mathrm{E}+02$ & 5.41 & $\mathrm{Te}-125 \mathrm{M}$ & $1.80 \mathrm{E}+01$ & $1.26 \mathrm{E}+04$ \\
\hline Cs-137 & $6.24 \mathrm{E}+02$ & $3.59 \mathrm{E}+04$ & Te-127 & $1.36 \mathrm{E}+01$ & 13.5 \\
\hline $\mathrm{Cm}-242$ & $7.57 \mathrm{E}+00$ & $1.92 \mathrm{E}+07$ & Eu-155 & $4.73 \mathrm{E}+01$ & $2.55 \mathrm{E}+04$ \\
\hline $\mathrm{Nb}-95$ & $6.43 \mathrm{E}+02$ & 27 & Zr-95 & $3.03 \mathrm{E}+02$ & $1.78 \mathrm{E}+04$ \\
\hline
\end{tabular}

\section{G-4. TRANSPORATION CASKS AND CASK-SPECIFIC PARAMETERS}

The radiological material will be transported between MFC and ACRR using either the GE 2000 (Figure G-2) or BRR cask (package). For transport between ATR and MFC at INL and between MFC and TREAT with either the BRR cask, GE 2000 cask, or the TREAT loop cask HFEF-15 being used. The outer dimensions of the transportation package are the only ones that affect the transportation analysis. For the GE 2000, the length and diameter are $131.5 \mathrm{in},(3.34 \mathrm{~m})$ and $72 \mathrm{in.}(1.83 \mathrm{~m})$, respectively, and for the BRR package, the dimensions are 119.5 in. $(3.035 \mathrm{~m})$ long and $78 \mathrm{in} .(1.98 \mathrm{~m})$ in diameter. The TREAT loop cask is 169.5 in. $(4.3 \mathrm{~m})$ long and 32 in. $(0.81 \mathrm{~m})$ in diameter. For use in transporting the loops, it is assumed the casks would present the profile dimensions shown in Table G-2.

Table G-2. Transportation cask dimensions.

\begin{tabular}{lc}
\hline \multicolumn{1}{c}{ Parameter } & Value \\
\hline Critical dimension (length) & \\
BRR Package & $3.035 \mathrm{~m}$. \\
GE 2000 & $3.340 \mathrm{~m}$ \\
TREAT Loop Cask & $4.3 \mathrm{~m}$ \\
"Crew view" & \\
BRR Package & $3.035 \mathrm{~m}$. \\
GE 2000 & $3.340 \mathrm{~m}$ \\
TREAT Loop Cask & $4.3 \mathrm{~m}$ \\
\hline
\end{tabular}




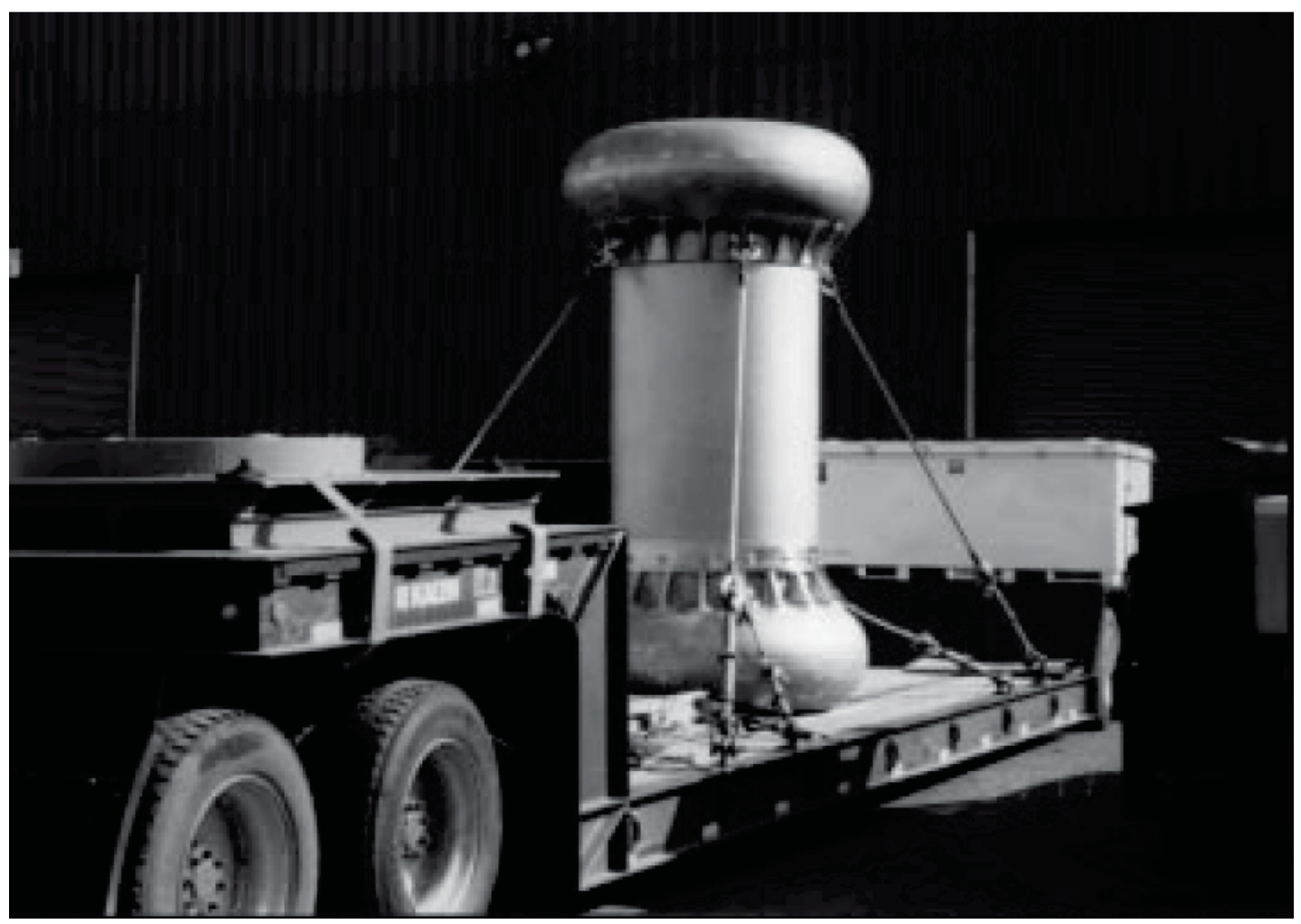

Figure G-2. GE 2000 Type B shipping cask.

\section{G-5. ANALYSIS OF TRANSPORTATION AT THE IDAHO NATIONAL LABORATORY}

Transportation of research quantities of fuel contained in the experiment assemblies will occur at INL between the ATR Complex and MFC and between MFC and TREAT as outlined in Section 2 and shown in Figure G-1. The following subsections evaluate the impacts that could occur during routine handling and transport at INL and during potential accident conditions.

For transport at INL, it is assumed that the public would not be exposed during INL incident-free shipments due to the use of a recently approved multipurpose haul road within the borders of INL to which the public does not have access. For routine handling of the experiment at INL, exposures to workers would be maintained to assure they are within the administratively controlled DOE Occupational Exposure limits of $5 \mathrm{rem} /$ year for radiological workers (DOE 1994). Impacts to the driver, a collocated worker, and the public are evaluated under the TREAT Reactor accident scenario. The accident analysis assumed the accident would occur in an area presenting the shortest distance to the public receptor located either on the INL boundary or in Atomic City; therefore, the predicted impacts would be the same for the RTT Program alternatives using the TREAT Reactor or ACRR.

\section{G-5.1 Routine or Incident-Free Transportation}

The use of TREAT for the RTT Program requires transport from ATR to TREAT. Potential impacts to the public and the crew from routine transport were included in the analysis.

\section{G-5.1.1 Transportation Routes and Route-Specific Parameters}

Transportation impacts were analyzed along the route running between ATR and TREAT. This route is shown in Figure G-3. This route is not publically accessible and access to workers can be limited 
during transportation of the experiment components. The route starts at ATR, passes INTEC, CFA, and MFC before heading north to TREAT. Tables G-3 and G-4 shows the route-dependent and route-independent RADTRAN input values.

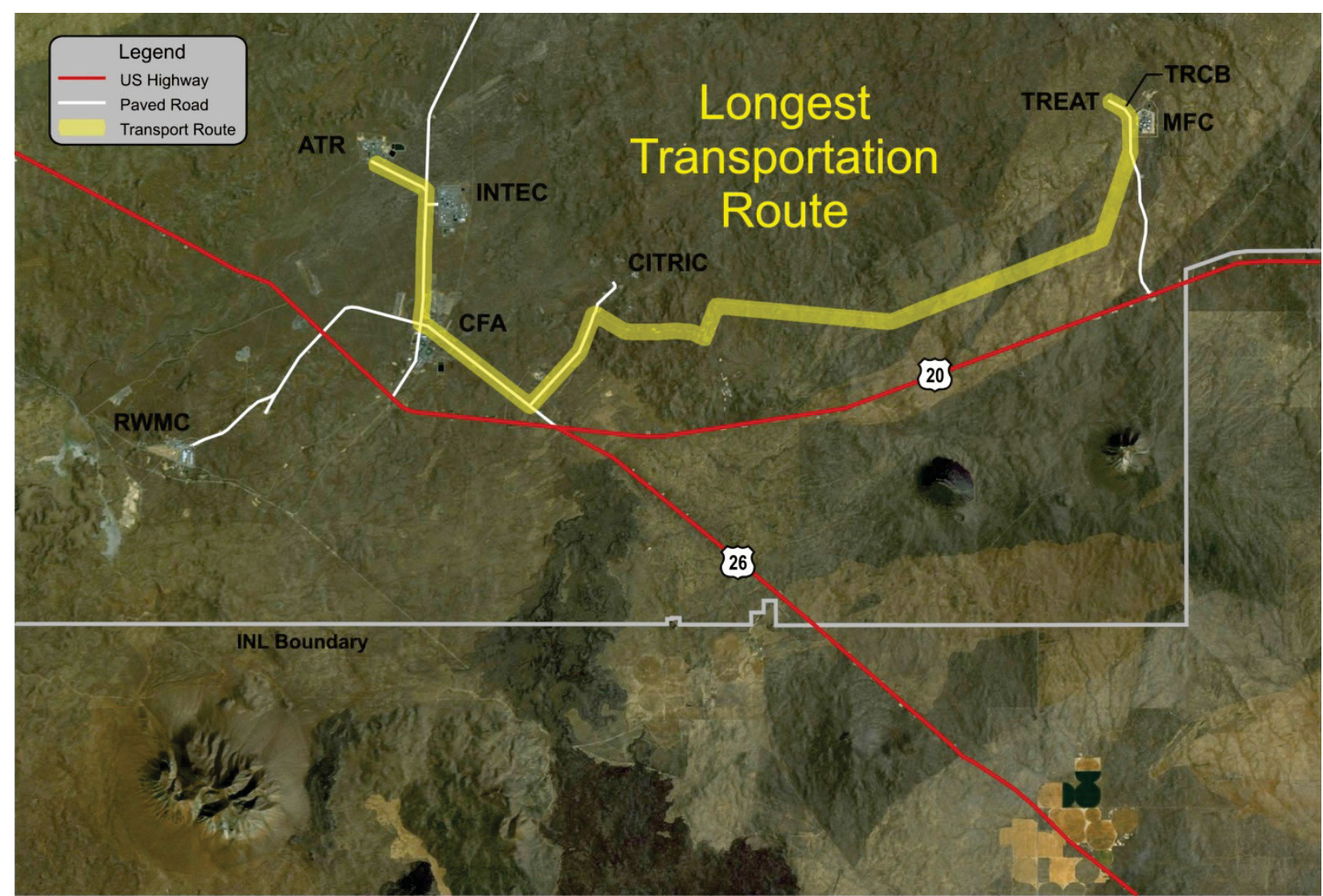

Figure G-3. Transportation route between ATR and HFEF and between HFEF and TREAT Facility (see inset for detail). (All routes are on INL controlled access roads.)

Table G-3. RADTRAN route-dependent input parameters for transport at Idaho National Laboratory.

\begin{tabular}{|c|c|c|c|c|c|c|}
\hline Route & $\begin{array}{l}\text { Route Length } \\
(\mathrm{km})\end{array}$ & ${ }^{\mathrm{a}}$ Persons $/ \mathrm{km}^{2}$ & $\begin{array}{c}\text { Route Speed } \\
(\mathrm{km} / \mathrm{hr})\end{array}$ & Hours $^{\mathrm{b}}$ & Vehicles/hr ${ }^{\mathrm{c}}$ & $\begin{array}{l}\text { Residential } \\
\text { Shielding }^{\mathrm{d}}\end{array}$ \\
\hline ATR - INTEC & 2.68 & $1,136.36$ & $\begin{array}{r}48.28 \\
(30 \mathrm{mph})\end{array}$ & $\begin{array}{l}5.55 \mathrm{E}- \\
02\end{array}$ & 283 & 0.018 \\
\hline INTEC - CFA & 3.71 & 281.25 & 48.28 & $\begin{array}{l}7.68 \mathrm{E}- \\
02\end{array}$ & 283 & 0.870 \\
\hline CFA - MFC & 28 & 441.18 & 48.28 & $\begin{array}{l}5.80 \mathrm{E}- \\
01\end{array}$ & 283 & 0.018 \\
\hline MFC - TREAT & 1.1 & 900 & 48.28 & $\begin{array}{c}2.28 \mathrm{E}- \\
02\end{array}$ & 283 & 0.018 \\
\hline \multicolumn{7}{|c|}{$\begin{array}{l}\text { a. Assumes ATR has } 500 \text { persons and occupies } 0.44 \text { square } \mathrm{km} \text {, CFA has } 450 \text { persons and occupies } 1.6 \text { square km, INTEC has } 750 \text { persons and } \\
\text { occupies } 1.7 \text { square } \mathrm{km} \text {, and MFC has } 900 \text { persons and occupies } 1 \mathrm{square} \mathrm{km} \text {. All people between the facilities are on the route. } \\
\text { b. Total trip time }=0.735 \text { hours. } \\
\text { c. This is the U.S. average vehicle traffic on rural secondary roads (Weiner et al. 2009). If no other vehicles share the road during transport, all } \\
\text { values in this column would be zero. } \\
\text { d. Residential shielding is the fraction of energy that penetrates the shielding and reaches the receptor (e.g., if residential shielding }=0.87,13 \% \text { of the } \\
\text { energy incident on the shielding is absorbed and } 87 \% \text { gets through to the receptor). }\end{array}$} \\
\hline
\end{tabular}


Table G-4. RADTRAN route-independent input parameters for transport at Idaho National Laboratory.

\begin{tabular}{lcc}
\hline & Parameter & Value \\
\hline Dimensions & BRR Cask & \\
External dose rate & $3.04 \mathrm{~m}$ \\
\hline & GE 2000 Cask & $14 \mathrm{mrem} / \mathrm{hr}(100 \%$ gamma $)$ \\
\hline Dimensions & $3.34 \mathrm{~m}$ \\
External dose rate & $14 \mathrm{mrem} / \mathrm{hr}(100 \%$ gamma $)$ \\
Crew & 2 persons \\
Crew shielding factor & 0.32 \\
Band width & $800 \mathrm{~m}$ \\
Inspector/Escort & One person, $3 \mathrm{~m}$ from the cask for 0.735 hours \\
\hline
\end{tabular}

\section{G-5.1.2 Results for Routine Transportation at Idaho National Laboratory}

The collective population dose results are summarized in Table G-5. Radiation doses to the 2-person truck crew, 2-person inspection crew, occupants of facilities (e.g., ATR, INTC, CFA, MFC, and TREAT) along the route, and occupants of vehicles that share the route are provided. Doses for people along the route are based on the population at each facility. Doses for persons sharing the route were computed based on an average number of vehicles per hour based on U.S. average vehicle traffic density on rural secondary roads (Weiner et al. 2009). If there are no persons along the route segment (link), then the value for persons sharing the route would be zero. This is probably the case for the route segment between CFA and MFC.

Doses for both casks are very similar and small. Doses for the TREAT loop handling cask were not computed because the transport vehicle does not conform to a truck configuration, but the doses to the crew and persons on the link would be similar to the other values shown.

Table G-5. Radiation doses (person-rem) to various receptors during routine transportation, one-way from the Advanced Test Reactor to TREAT.

\begin{tabular}{|c|c|c|c|c|c|c|}
\hline \multirow[t]{2}{*}{ Link } & \multicolumn{3}{|c|}{ BRR Cask } & \multicolumn{3}{|c|}{ GE2000 Cask } \\
\hline & Crew & $\begin{array}{l}\text { People Along } \\
\text { Route }\end{array}$ & $\begin{array}{c}\text { People Sharing } \\
\text { Route }\end{array}$ & Crew & $\begin{array}{l}\text { People Along } \\
\text { Route }\end{array}$ & $\begin{array}{c}\text { People Sharing } \\
\text { Route }\end{array}$ \\
\hline ATR-INTEC & $3.54 \mathrm{E}-04$ & $1.03 \mathrm{E}-04$ & $7.70 \mathrm{E}-05$ & 3.97E-04 & $1.16 \mathrm{E}-04$ & 8.64E-05 \\
\hline INTEC-CFA & $4.90 \mathrm{E}-04$ & 4.24E-05 & $1.07 \mathrm{E}-04$ & $5.50 \mathrm{E}-04$ & $4.76 \mathrm{E}-05$ & $1.20 \mathrm{E}-04$ \\
\hline CFA-MFC & $3.69 \mathrm{E}-03$ & $4.18 \mathrm{E}-04$ & 8.04E-04 & 4. $15 \mathrm{E}-03$ & $4.69 \mathrm{E}-04$ & $9.03 \mathrm{E}-04$ \\
\hline MFC-TREAT & $1.45 \mathrm{E}-04$ & $3.35 \mathrm{E}-05$ & $3.16 \mathrm{E}-05$ & $1.63 \mathrm{E}-04$ & $3.76 \mathrm{E}-05$ & $3.55 \mathrm{E}-05$ \\
\hline Totals & $4.68 \mathrm{E}-03$ & $5.97 \mathrm{E}-04$ & $1.02 \mathrm{E}-03$ & $4.72 \mathrm{E}-03$ & $6.10 \mathrm{E}-04$ & $1.03 \mathrm{E}-03$ \\
\hline $\begin{array}{l}\text { Maximum individual dose } \\
\text { (rem) }\end{array}$ & & 3.4E- 07 & & & $3.8 \mathrm{E}-07$ & \\
\hline $\begin{array}{l}\text { Inspector/escort (rem) ( } 3 \mathrm{~m} \\
\text { from cask) }\end{array}$ & & $9.16 \mathrm{E}-03$ & & & $8.64 \mathrm{E}-03$ & \\
\hline
\end{tabular}

\section{G-5.2 Transportation Accidents at Idaho National Laboratory}

After a review of the design criteria used for the shipping casks and of the potential transportation accident scenarios that could occur at INL, it was determined that no credible accident would result in the release of radioactive material from a shipping cask. For transport between ATR and MFC, an unlicensed 
cask or licensed cask similar to the GE-2000 or BRR cask would be used. A Type B cask licensed for highway speeds over public roads is certified to withstand a 9-m drop onto a solid surface with impact at the most damaging point followed by a 1-m drop onto a steel bar. To withstand a potential accident involving a fire, they also are designed to withstand an $800^{\circ} \mathrm{C}$ fire for 30 minutes. These design criteria are in place to minimize the release of radionuclides during potential traffic accidents. For transport between MFC and TREAT, the HFEF-15 cask will likely be used. It was specifically designed to carry the MARK-III loops. It is designed to protect the MARK-III loops under credible drop or impact conditions. On that route, there are no combustible materials that would result in a fire of sufficient duration and intensity to release materials from the cask.

These conditions precluding a traffic accident sufficient to result in a release of radioactivity during transport on INL and include the following:

- Random events caused by other vehicles. On the route that will be followed at INL, the link between ATR, INTEC, and CFA could be traveled by INL workers. On any link, access can be controlled if deemed necessary. The longer route segment between CFA, MFC, and TREAT is a haul road that is designated for non-routine transport. This greatly reduces the potential for random damage to the transport vehicle.

- Drop accidents from a transport at INL are not plausible. On the transportation route, there are no overpasses or other significant height differences. The largest drop height that needs to be considered for design purposes is likely the height of the truck bed, which is on the order of $1 \mathrm{~m}$ and significantly less than the design criteria of $9 \mathrm{~m}$ for Type B casks. The HFEF-15 cask that could be used for transport of the assembled experiment between MFC and ATR has been designed to withstand a drop of $0.5 \mathrm{~m}$. The HFEF-15 cask is likely to be moved using a forklift as it has in the past. The lift height would not exceed the design drop height.

- The speed of the transport carrying the cask can be limited. On the route links between ATR, INTEC, and CFA, the speed of the transport can be limited and the speed of other traffic can be controlled by limiting access during transport. On the INL haul road, the posted speed is less than $30 \mathrm{mph}$. The slower speeds limit the momentum involved in a crash. Transport of experiments contained in the HFEF-15 cask will be limited to about $15 \mathrm{mph}$.

- The cask will be transported by a truck between ATR and MFC. Large trucks are unlikely to experience significant damage by other vehicles on the roadway. The amount of truck fuel can be limited to the amount necessary to make the trip; therefore, the truck will not carry significant combustible materials.

- Casks will be loaded and fixed to the truck or forklift by trained professionals. Safety chains, straps, and binders will be checked prior to use. The limited miles between ATR and MFC or MFC and TREAT will preclude the tie-down system from breaking due to fatigue en route.

- Casks will not be subjected to fire. The casks are designed to withstand extreme heat. An analysis of fuel fire in NUREG 2125 (NRC 2012) (Section 4.2.2) indicates that a gasoline tanker truck carrying 9,000 gallons does not contain enough fuel to produce a fire that can engulf a Type B cask for duration long enough to damage the cask. The regulation of $10 \mathrm{CFR} 71.73$ requires that a Type B cask (like the casks used in this analysis) can withstand a fully engulfing, $800^{\circ} \mathrm{C}$ fire for 30 minutes. Because the trucks will travel short distances on INL, the amount of combustible material available to start a cask fire can be limited. There is no chance of an engulfing fire occurring.

- Accidents, including minor accidents, are not likely to occur more than once in every 100,000 miles on public roadways (NRC 2013). Minor accidents are more unlikely to occur because of the low transport speeds at INL. The total number of miles traveled at INL per year is expected to be less than 1,000. Based on mileage alone, there is very little chance that even a minor accident would occur in any year. 


\section{G-6. ANALYSIS OF IMPACTS FOR TRANSPORTATION BETWEEN THE MATERIALS AND FUELS COMPLEX AND THE ANNULAR CORE RESEARCH REACTOR}

The use of ACRR for the RTT Program requires transport from MFC to ACRR (via the SNL hot cell) as shown in Figure G-1, in addition to transport from ATR at INL to MFC. Potential impacts to the public and the crew from routine transport from MFC to ACRR and potential accidents along the route are included in the analysis. These offsite transportation impacts were analyzed in accordance with the 2002 Resource Handbook on DOE Transportation Risk Assessment (DOE 2002b).

\section{G-6.1 Transportation Routes and Route-Specific Parameters}

Transportation impacts were analyzed along two routes running between MFC and ACRR: (1) the most direct route, which runs through Idaho, Utah, Colorado, and New Mexico; and (2) a longer route, which bypasses Utah. These routes are shown in Figures G-4 and G-5. Tables G-6 and G-7 show the route-dependent RADTRAN input values. The routes, distances, population densities, and rural, suburban, and urban designations were data developed using the code TRAGIS. Re-fueling stops are indicated in Tables G-5 and G-6, based on heavy trucks refueling approximately every $800 \mathrm{~km}$.

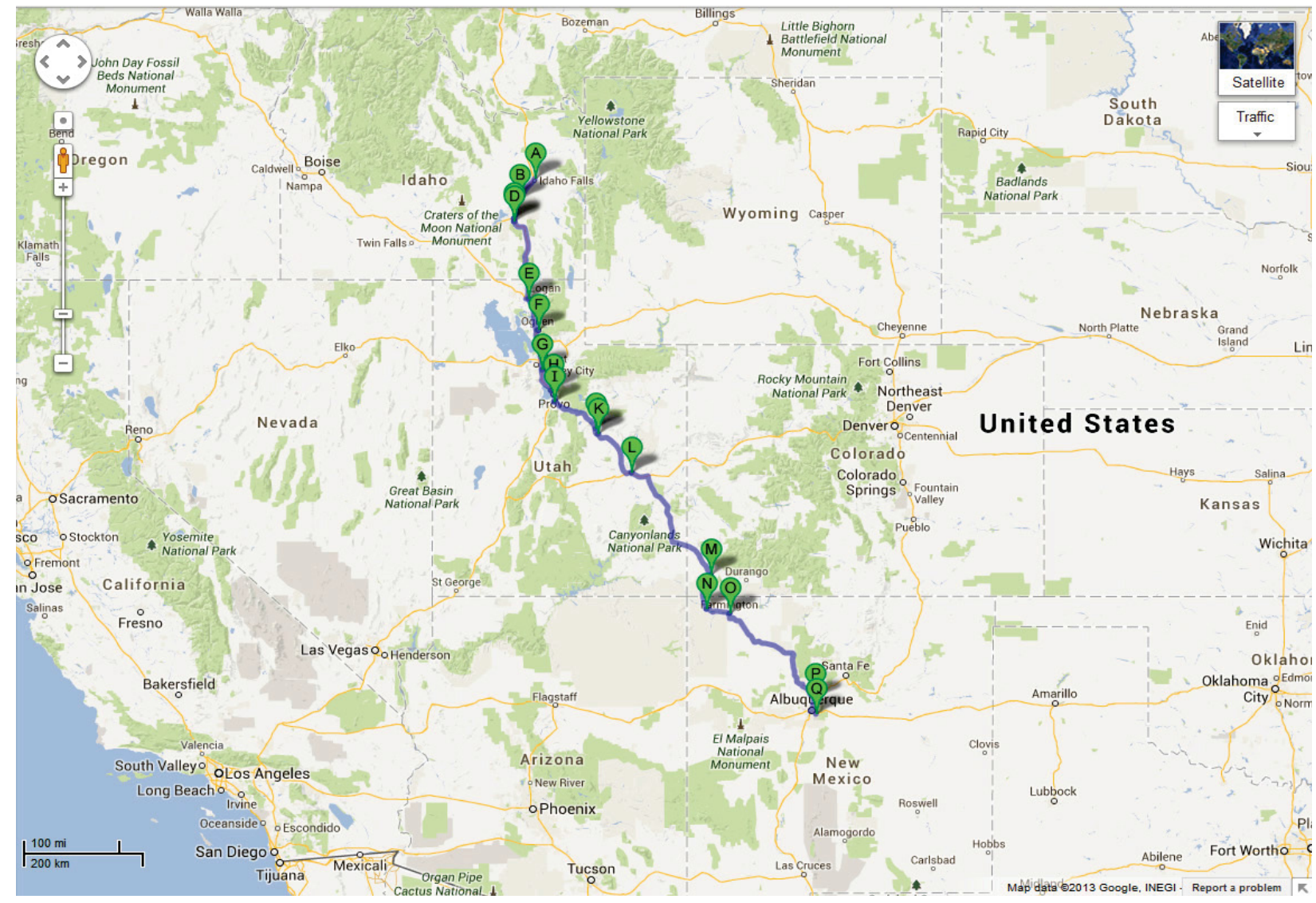

Figure G-4. Map of Route 1 between the INL and SNL/NM. 


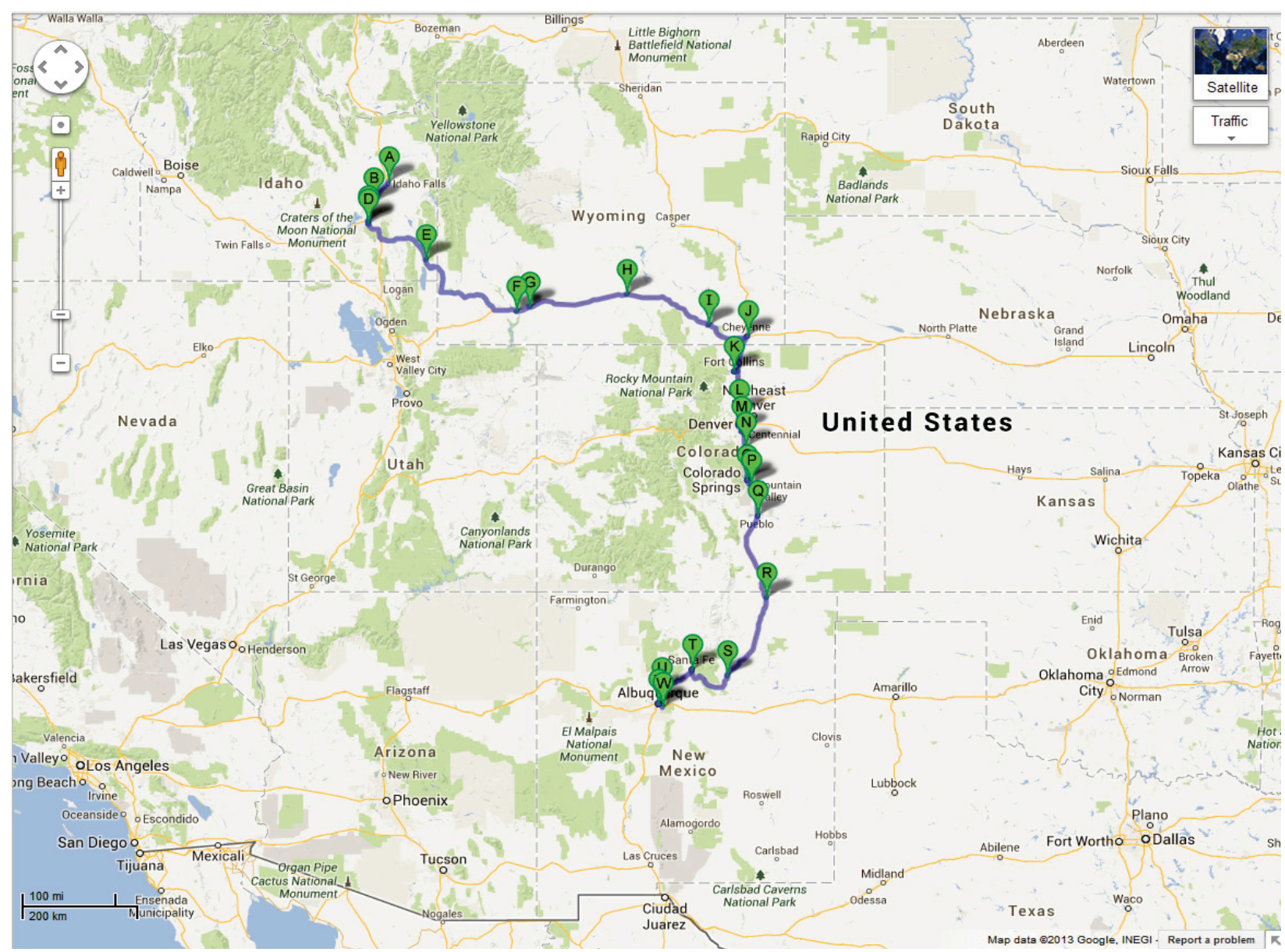

Figure G-5. Map of Route 2 between the INL and SNL/NM. 
Table G-6. RADTRAN route-dependent input values for Route 1.

\begin{tabular}{|c|c|c|c|c|c|c|}
\hline $\begin{array}{c}\text { Route } \\
\text { Number }\end{array}$ & From-To & $\mathrm{R} / \mathrm{S} / \mathrm{U}$ & $\mathrm{km}$ & $\mathrm{km} / \mathrm{hr}$ & Persons $/ \mathrm{km}^{2}$ & $\begin{array}{l}\text { Refueling } \\
\text { Stops }\end{array}$ \\
\hline 1 & Argonne W. to Blackfoot, ID & Rural & 80.79 & 75.74 & 5.23 & \\
\hline 2 & Blackfoot to Chubbuck & Suburban & 33.15 & 103.60 & 18.14 & \\
\hline 3 & Chubbuck to Pocatello & Urban & 8.53 & 102.35 & 424.70 & \\
\hline 4 & Pocatello to Tremonton, UT & Rural & 141.78 & 109.06 & 15.56 & \\
\hline 5 & Tremonton to Ogden W & Suburban & 60.67 & 121.34 & 97.37 & \\
\hline 6 & Ogden W to Midvale & Urban & 69.68 & 101.98 & 536.58 & \\
\hline 7 & Midvale to Orem & Suburban & 45.87 & 105.85 & 559.12 & \\
\hline 8 & Orem to Spanish Fork & Urban & 21.08 & 126.49 & 931.40 & \\
\hline 9 & Spanish Fork to Helper & Rural & 92.05 & 81.22 & 40.48 & \\
\hline 10 & Helper to Price & Suburban & 18.35 & 100.07 & 122.43 & \\
\hline 11 & Price to Green River & Rural & 98.97 & 82.48 & 0.95 & $\mathrm{x}$ \\
\hline 12 & Green River to Cortez, CO & Rural & 270.37 & 84.49 & 9.93 & \\
\hline 13 & Cortez to CEZ Airport & Suburban & 6.12 & 91.73 & 208.28 & \\
\hline 14 & CEZ Airport to Shiprock, NM & Rural & 62.44 & 58.54 & 35.37 & \\
\hline 15 & Shiprock to Farmington & Suburban & 31.22 & 56.77 & 234.82 & \\
\hline 16 & Farmington to Bernalillo & Rural & 264.25 & 83.89 & 31.47 & $\mathrm{x}$ \\
\hline 17 & Bernalillo to 4AC Airport & Rural & 13.20 & 131.97 & 18.00 & \\
\hline 18 & 4AC Airport to Sandia & Urban & 28.00 & 73.05 & 840.23 & \\
\hline
\end{tabular}


Table G-7. RADTRAN route-dependent input values for Route 2.

\begin{tabular}{|c|c|c|c|c|c|c|}
\hline $\begin{array}{c}\text { Route } \\
\text { Number }\end{array}$ & From - To & $\mathrm{R} / \mathrm{S} / \mathrm{U}$ & $\mathrm{km}$ & $\mathrm{km} / \mathrm{hr}$ & Persons $/ \mathrm{km}^{2}$ & $\begin{array}{c}\text { Refueling } \\
\text { Stops }\end{array}$ \\
\hline 1 & Argonne West to Blackfoot, ID & Rural & 80.79 & 78.44 & 5.23 & \\
\hline 2 & Blackfoot to Chubbuck & Suburban & 33.15 & 103.60 & 18.14 & \\
\hline 3 & Chubbuck to Pocatello & Urban & 8.53 & 102.35 & 424.70 & \\
\hline 4 & Pocatello to Montpelier & Rural & 140.34 & 81.75 & 55.31 & \\
\hline 5 & Montpelier to Green River, WY & Rural & 232.71 & 84.11 & 3.22 & \\
\hline 6 & Green River to Rock Springs & Suburban & 121.51 & 121.51 & 43.52 & \\
\hline 7 & Rock Springs to Rawlins W & Rural & 160.77 & 122.11 & 0.07 & \\
\hline 8 & Rawlins W to Rawlins E & Suburban & 6.12 & 122.31 & 168.83 & \\
\hline 9 & Rawlins E to Laramie W & Rural & 154.18 & 121.72 & 8.64 & $\mathrm{x}$ \\
\hline 10 & Laramie $\mathrm{W}$ to Laramie $\mathrm{S}$ & Suburban & 2.25 & 135.19 & 53.26 & \\
\hline 11 & Laramie S to Cheyenne SW & Rural & 74.19 & 123.65 & 8.66 & \\
\hline 12 & Cheyenne SW to Ft. Collins E, CO & Rural & 62.12 & 116.48 & 2.07 & \\
\hline 13 & Ft. Collins E to Northglenn & Suburban & 75.16 & 112.73 & 30.14 & \\
\hline 14 & Northglenn to Greenwood Vlg SE & Urban & 42.33 & 90.70 & $1,245.13$ & \\
\hline 15 & Greenwood Vlg SE to Castle Rock & Suburban & 22.69 & 104.73 & 413.70 & \\
\hline 16 & Castle Rock to Colorado Spgs N & Rural & 53.27 & 118.38 & 206.33 & \\
\hline 17 & Colorado Spgs N to Colorado Spgs S & Urban & 17.06 & 102.35 & 824.56 & \\
\hline 18 & Colorado Spgs S to Security & Suburban & 7.24 & 108.63 & 936.02 & \\
\hline 19 & Security to Pueblo N & Rural & 62.28 & 116.78 & 32.29 & \\
\hline 20 & Pueblo N to Pueblo & Suburban & 2.25 & 135.19 & 534.27 & \\
\hline 21 & Pueblo to Raton, NM & Rural & 174.61 & 121.82 & 87.89 & $\mathrm{x}$ \\
\hline 22 & Raton to Raton S & Suburban & 9.50 & 113.94 & 30.41 & \\
\hline 23 & Raton $\mathrm{S}$ to Las Vegas NE & Rural & 160.45 & 121.86 & 1.96 & \\
\hline 24 & Las Vegas NE to Las Vegas E & Suburban & 2.74 & 164.15 & 43.40 & \\
\hline 25 & Las Vegas E to Santa Fe SE & Rural & 89.48 & 103.25 & 16.11 & \\
\hline 26 & Santa Fe SE to Santa Fe SW & Suburban & 33.47 & 100.42 & 56.54 & \\
\hline 27 & Santa Fe SW to Bernalillo & Rural & 44.10 & 101.76 & 13.41 & \\
\hline 28 & Bernalillo to Albuquerque $\mathrm{E}$ & Suburban & 26.07 & 104.29 & 448.10 & \\
\hline 29 & Albuquerque E to Sandia & Urban & 15.13 & 64.83 & 798.77 & \\
\hline
\end{tabular}

\section{G-6.2 Transportation Casks and Cask-Specific Parameters}

RADTRAN represents radiation exposures and releases from casks using the parameters shown in Figure G-6 and described in Neuhauser et al. (2000) and NRC (2013). In order to estimate radiation doses from routine transportation, the external dose rate $1 \mathrm{~m}$ from the transportation package is modeled as a virtual isotropically radiating sphere at the center of the cask. The dose rate is called the transport index. In 10 CFR 71.04, NRC allows an external dose rate of $10 \mathrm{mrem}(0.1 \mathrm{mSv})$ at $2 \mathrm{~m}$ from the package. This translates, for these packages, to a transport index of $14 \mathrm{mrem} /$ hour. The diameter of the virtual radiation sphere is the longest physical dimension of the cask and can be either a vertical or horizontal dimension. If the package sits vertically, both the virtual diameter and the dimension of the package facing the crew 
cabin (the "crew view") are the long dimension of the package. The RADTRAN model considers the cross-sectional area of the package the same as that of the trailer on which the package sits (i.e., no credit is taken for any offset of the trailer bed).

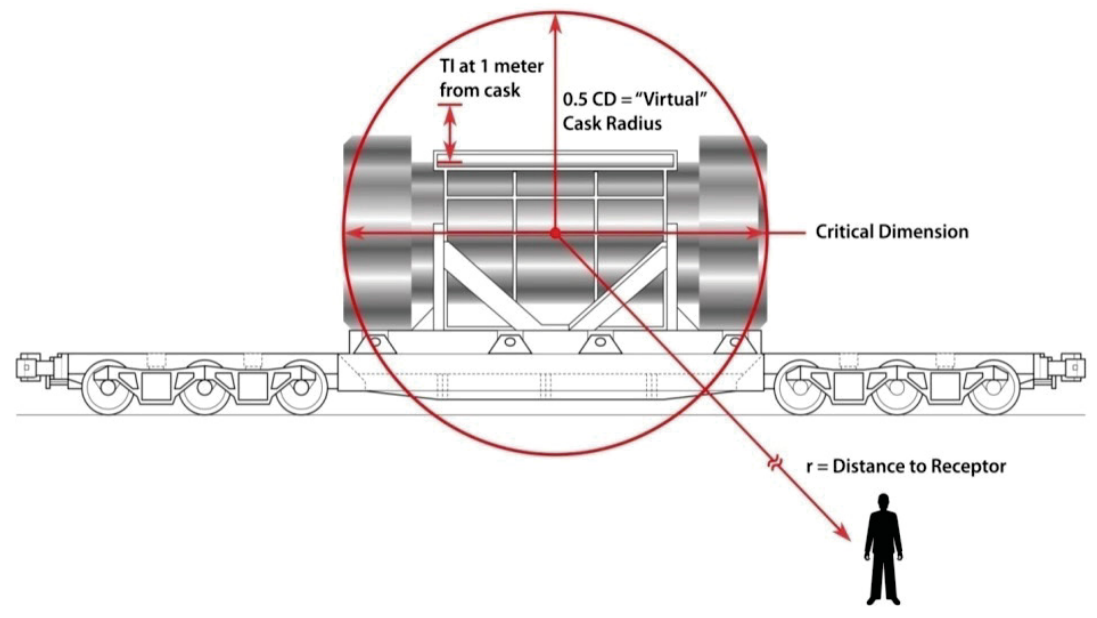

Figure G-6. Basic RADTRAN model for routine transportation (from NRC 2013, Chapter 2).

\section{G-6.3 Routine or Incident-Free Transportation}

Radiation doses to truck crew, members of the public residing along the route, and occupants of vehicles that share the route were modeled. Table G-8 shows inventory and route-independent values (NRC 2013, Appendix B; Weiner et al. 2009). When the truck carrying radioactive material is stopped, the model assumes that any member of the public at the truck stop, the crew member who refuels the truck, and residents of the area surrounding the truck could all be exposed to external radiation from the truck. Figure G-7 provides a diagram of the stop model and Table G-8 also lists the RADTRAN input parameters for the truck stop.

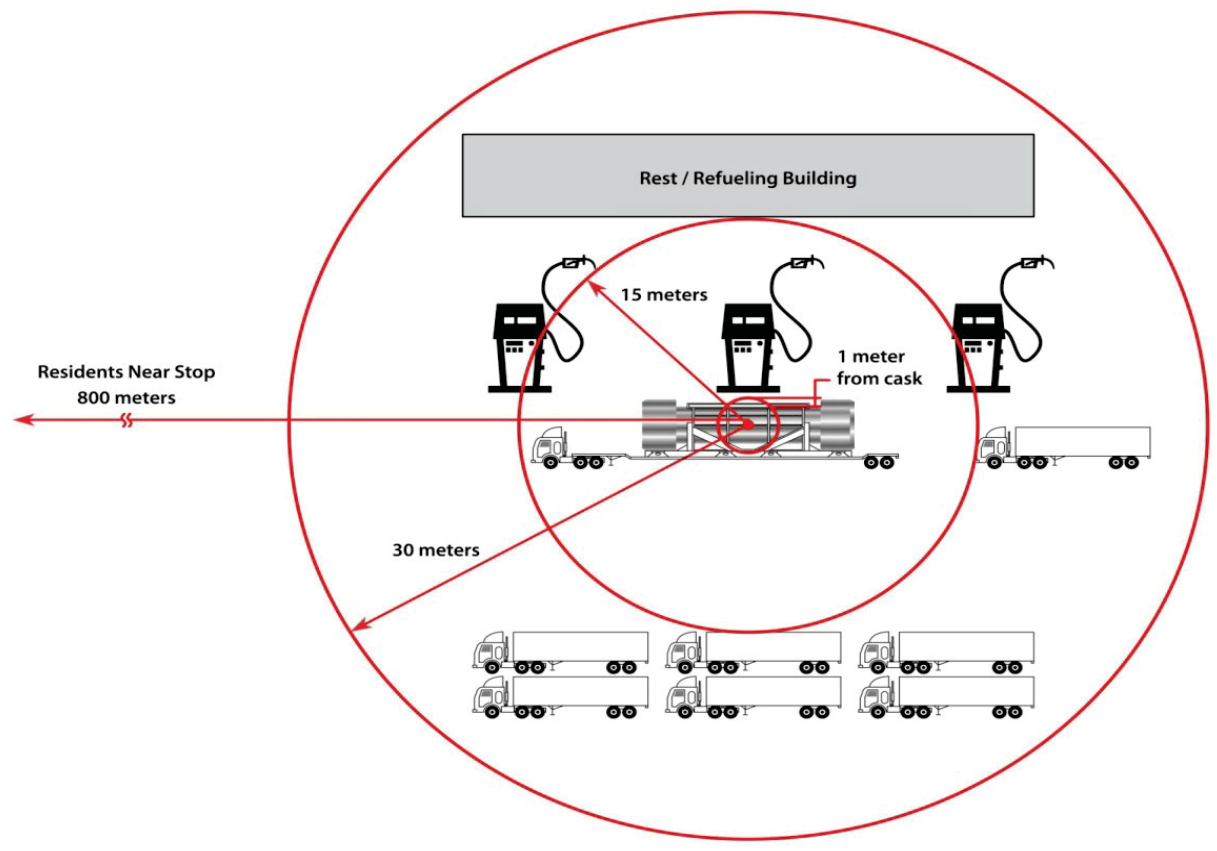

Figure G-7. Truck stop model (from NRC 2013, Appendix B). 
Table G-8. RADTRAN route-independent input values.

\begin{tabular}{|c|c|}
\hline Parameter & Value \\
\hline Gamma fraction of radiation & 1 \\
\hline Neutron fraction of radiation & 0 \\
\hline Number of packages per vehicle & 1 \\
\hline Distance from package to crew cab & $3 \mathrm{~m}$ \\
\hline Crew shielding factor ${ }^{\mathrm{a}}$ & 0.325 \\
\hline Number of crew & 2 \\
\hline \multicolumn{2}{|l|}{ Residential shielding factor } \\
\hline Rural & 1 (no shielding) \\
\hline Suburban & 0.87 \\
\hline Urban & 0.012 \\
\hline Band width for residential population & 30 to $800 \mathrm{~m}$ \\
\hline \multicolumn{2}{|c|}{ Truck Stop Parameters } \\
\hline External dose rate & $14 \mathrm{mrem} / \mathrm{hour}$ \\
\hline Time at stop & 50 minutes $^{\mathrm{a}}$ \\
\hline Average number of people at the stop & $7^{\mathrm{b}}$ \\
\hline Population density around the stop & Route dependent \\
\hline Crew exposed & 2 \\
\hline Crew exposure time & 20 minutes $^{\mathrm{b}}$ \\
\hline \multicolumn{2}{|l|}{ Shielding } \\
\hline Crew and people sharing stop & 1 (no shielding) \\
\hline Residents near stop & Route dependent \\
\hline Approximate distance between stops & $800 \mathrm{~km}$ \\
\hline
\end{tabular}

Tables G-9 through G-11 provide the consequences of exposure to incident-free transportation for each route segment of Route 1 in terms of collective dose expressed as person-rem. Tables G-12 through G-14 provide the consequences of exposure to incident-free transportation for each route segment of Route 2. The collective dose results are summarized in Section G-6.3.1. 


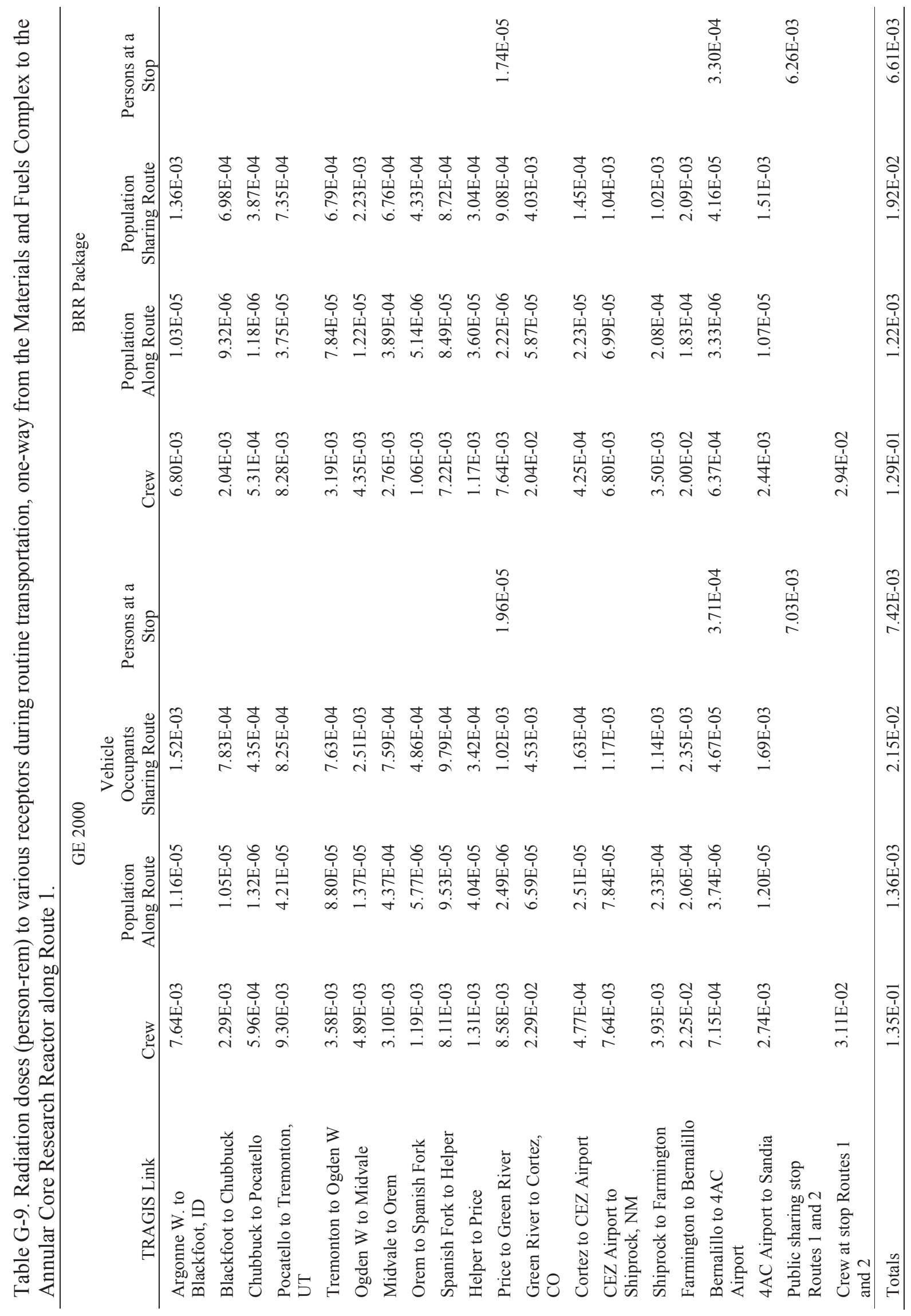




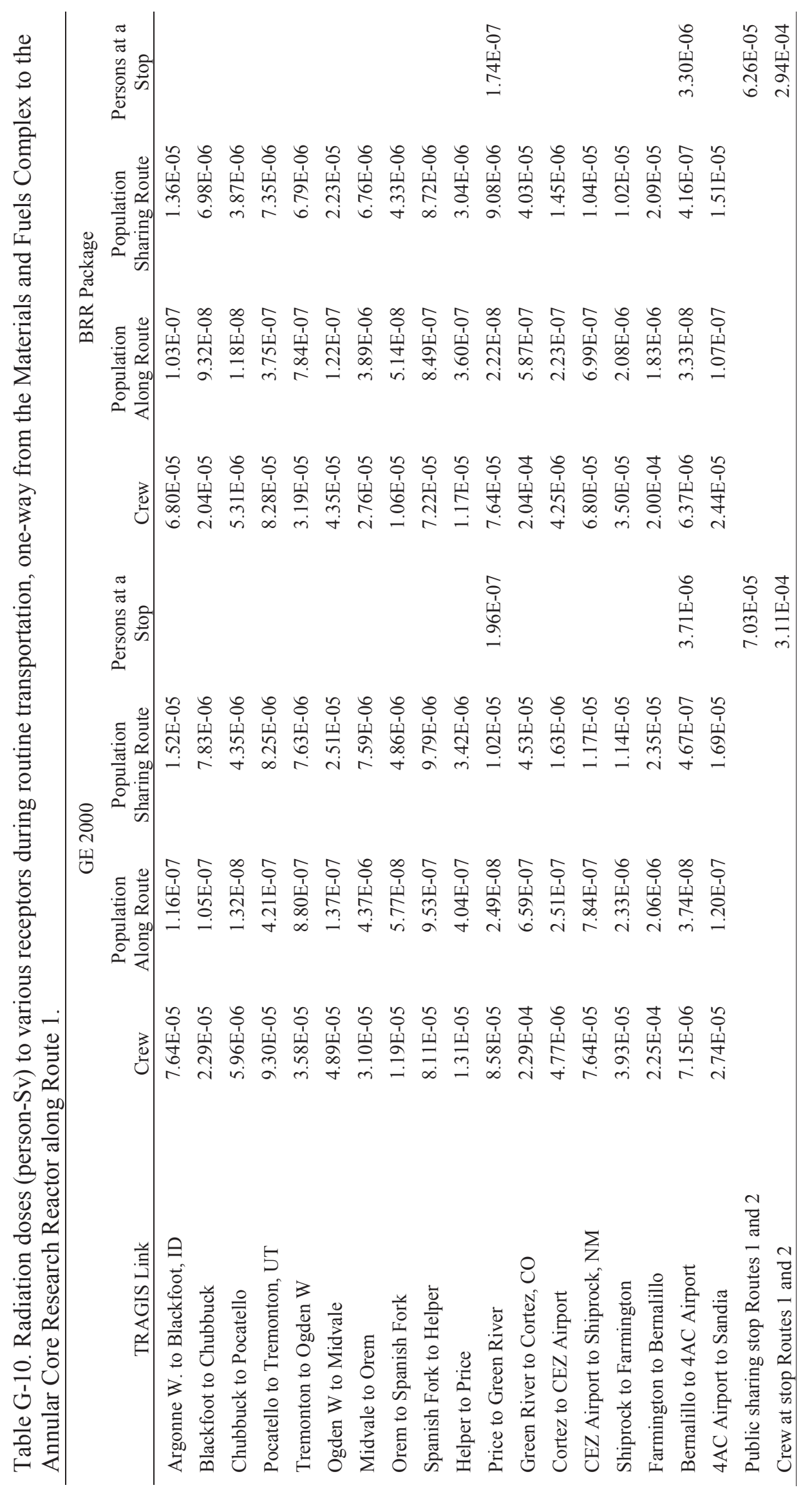




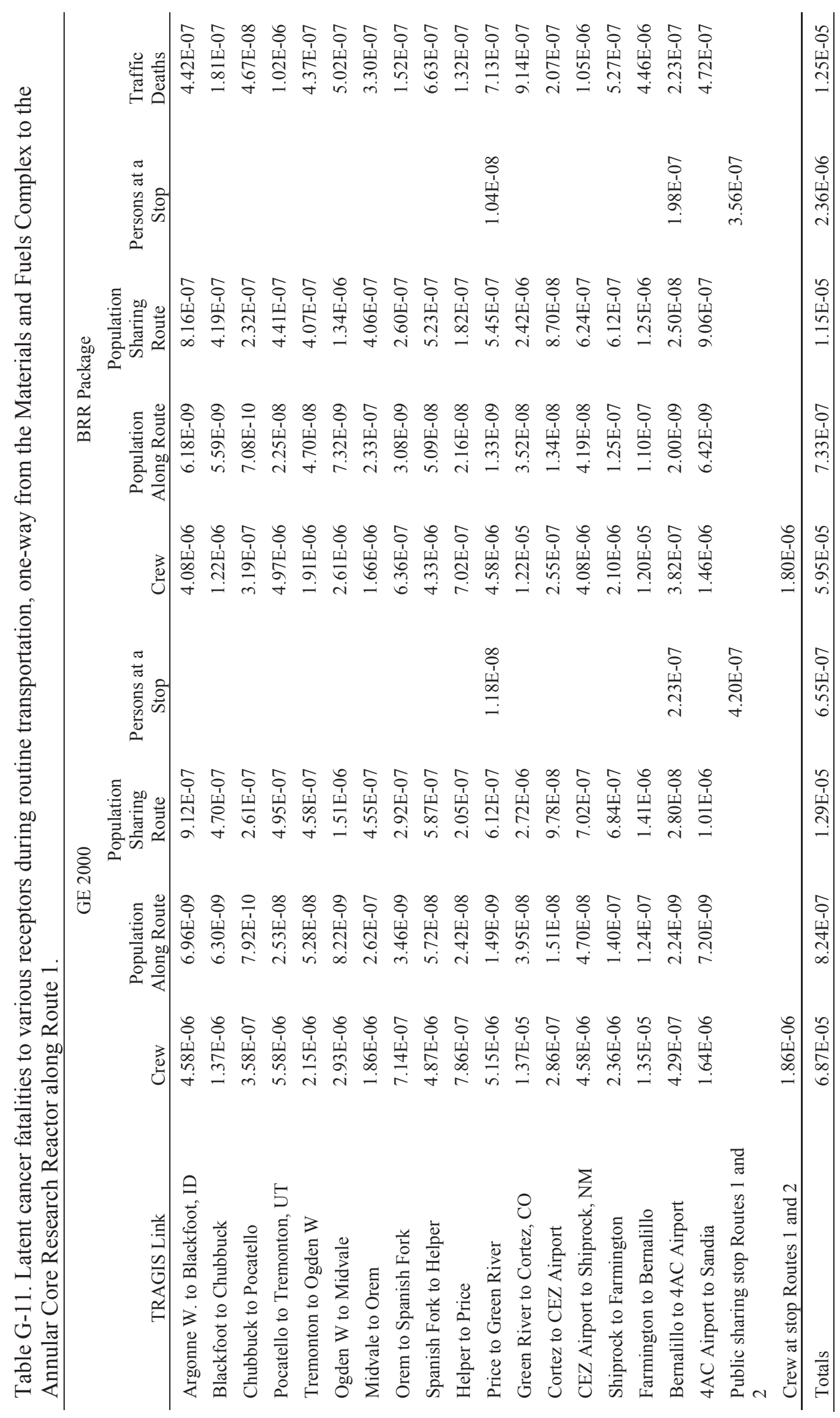




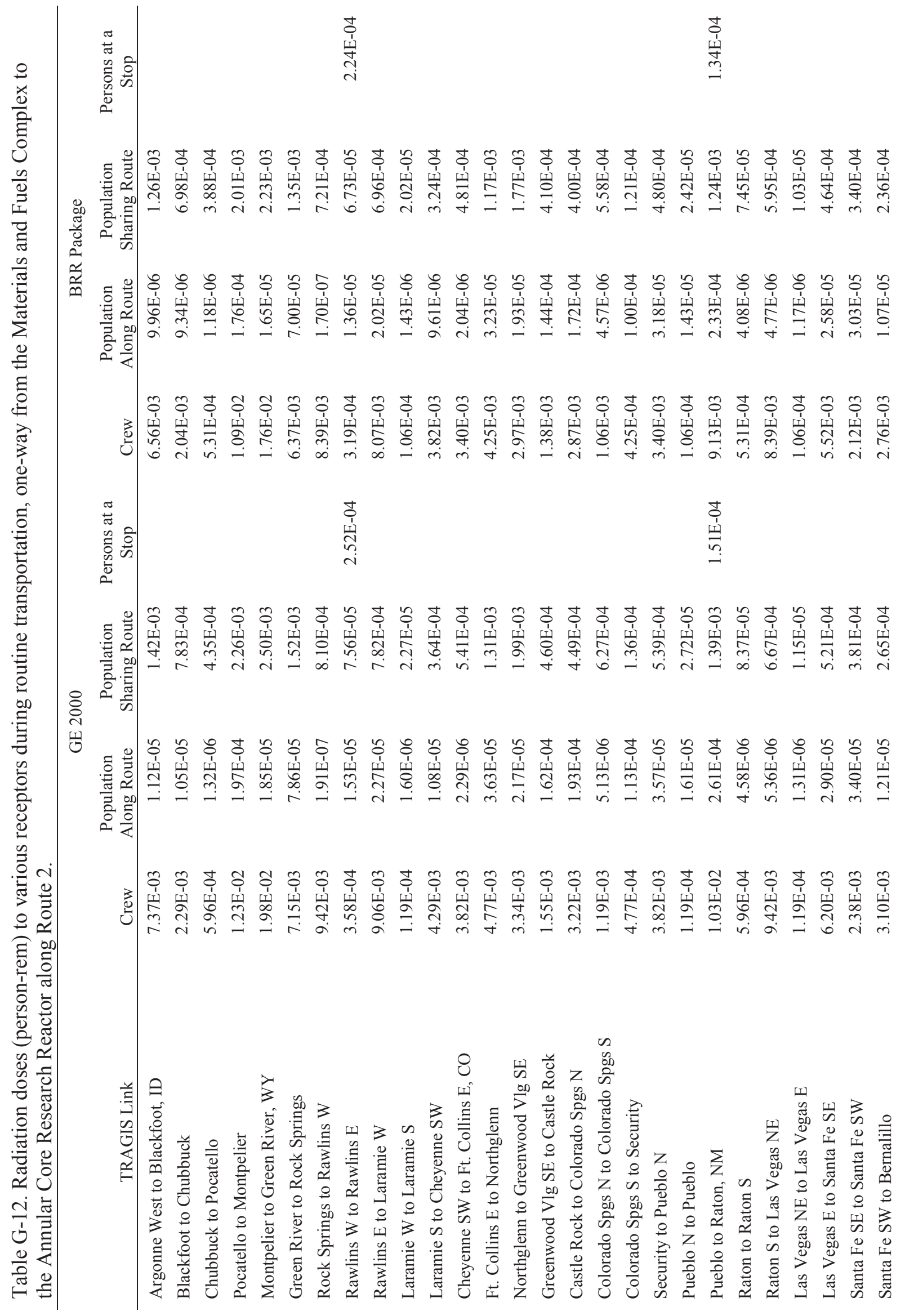




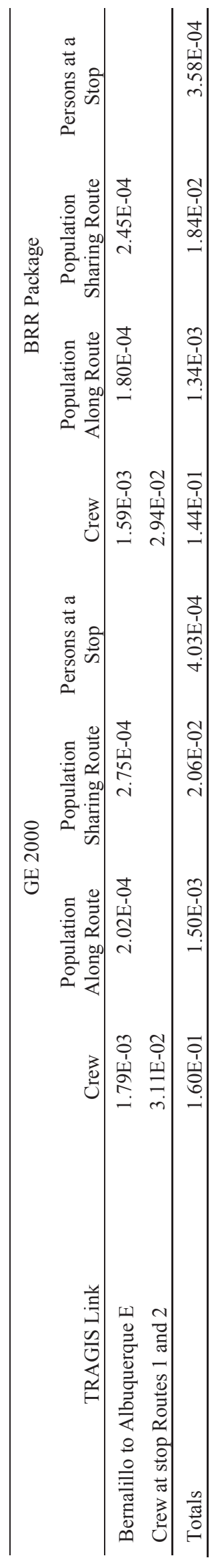

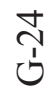




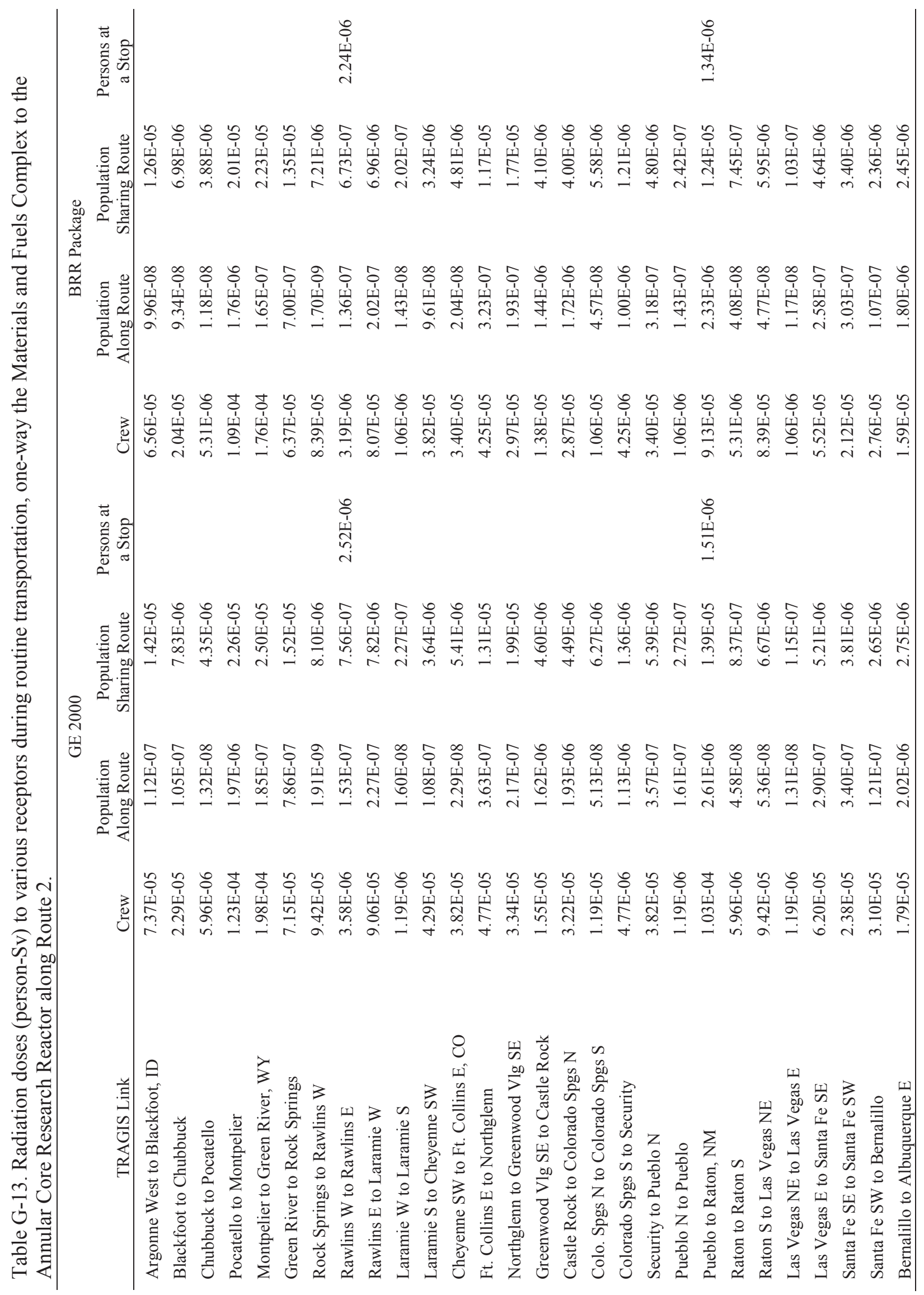




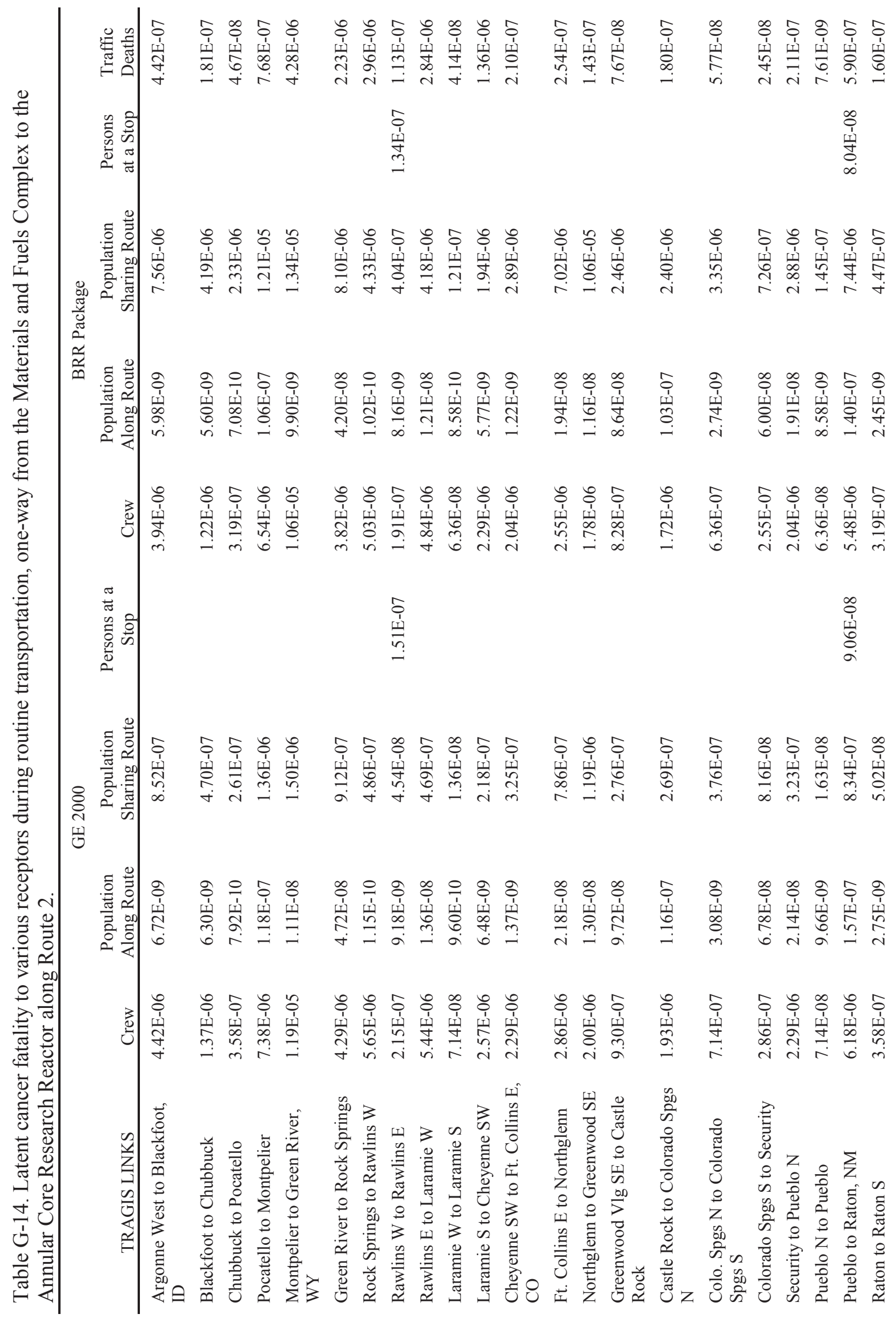




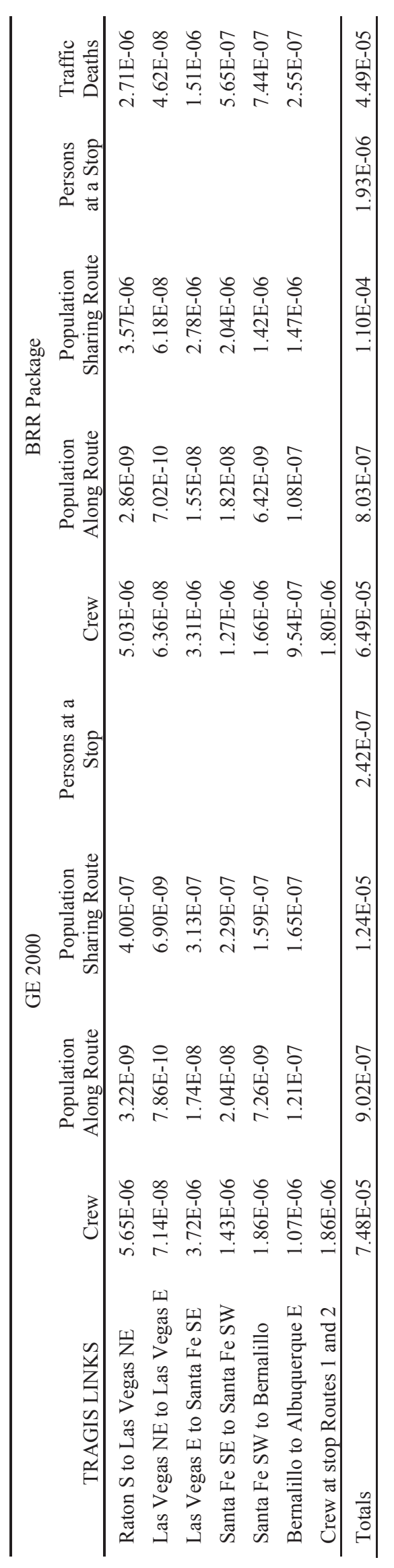

ฟิ 


\section{G-6.3.1 Summary of Incident-Free Transportation Impacts}

Table G-15 provides a summary of the results of the analysis of routine, incident-free transportation in terms of collective dose. The percent of the background dose is shown because background radiation dose is a familiar concept to use as comparison. The value of $311 \mathrm{mrem} / \mathrm{year}(3.1 \mathrm{mSv} / \mathrm{year})$ was used for background (NCRP 2009).

Results are provided for the one-way transport of the package from MFC to ACRR along two different routes. The package would be returned to INL from SNL after irradiation; therefore, the dose per shipment would be twice the values shown in Table G-15 for each shipment. As shown in Table 1 in the main report body, the number of shipments per year will be limited to 20 of the large experiment loops, which also provide the bounding inventory. Therefore, the total annual dose could be 40 times the value in Table G-15.

Observations from the summary and tabular results are as follows for incident free transportation:

- The radiation dose to any receptor from routine transportation of radioactive material depends on the combination of external dose rate and package size; in RADTRAN the latter is an empirical "package shape factor" (NRC 1977; Neuhauser et al. 2000). The difference between doses for the two casks reflects the differences in external dose rate, which itself reflects the differences in the casks' longest dimensions. Doses from the Battelle Energy Alliance research reactor package are slightly smaller than from the GE 2000 package because the Battelle Energy Alliance research reactor package is slightly smaller.

- The collective population dose is a function of population. The source of the radiation is constant for the entire route. Thus, the total population dose for Route 2 is larger than for Route 1, because Route 2 has a larger population than Route 1.

- The radiation dose to the crew depends on the external dose rate and package shape factor, and on the length of the route.

- The dose to the MEI is independently calculated by assuming that the vehicle passes the MEI at the slowest speed it is likely to go, which is $24 \mathrm{~km} /$ hour $(15 \mathrm{mph})$ and that the MEI is $30 \mathrm{~m}$ from the vehicle. The MEI dose is independent of the route. 


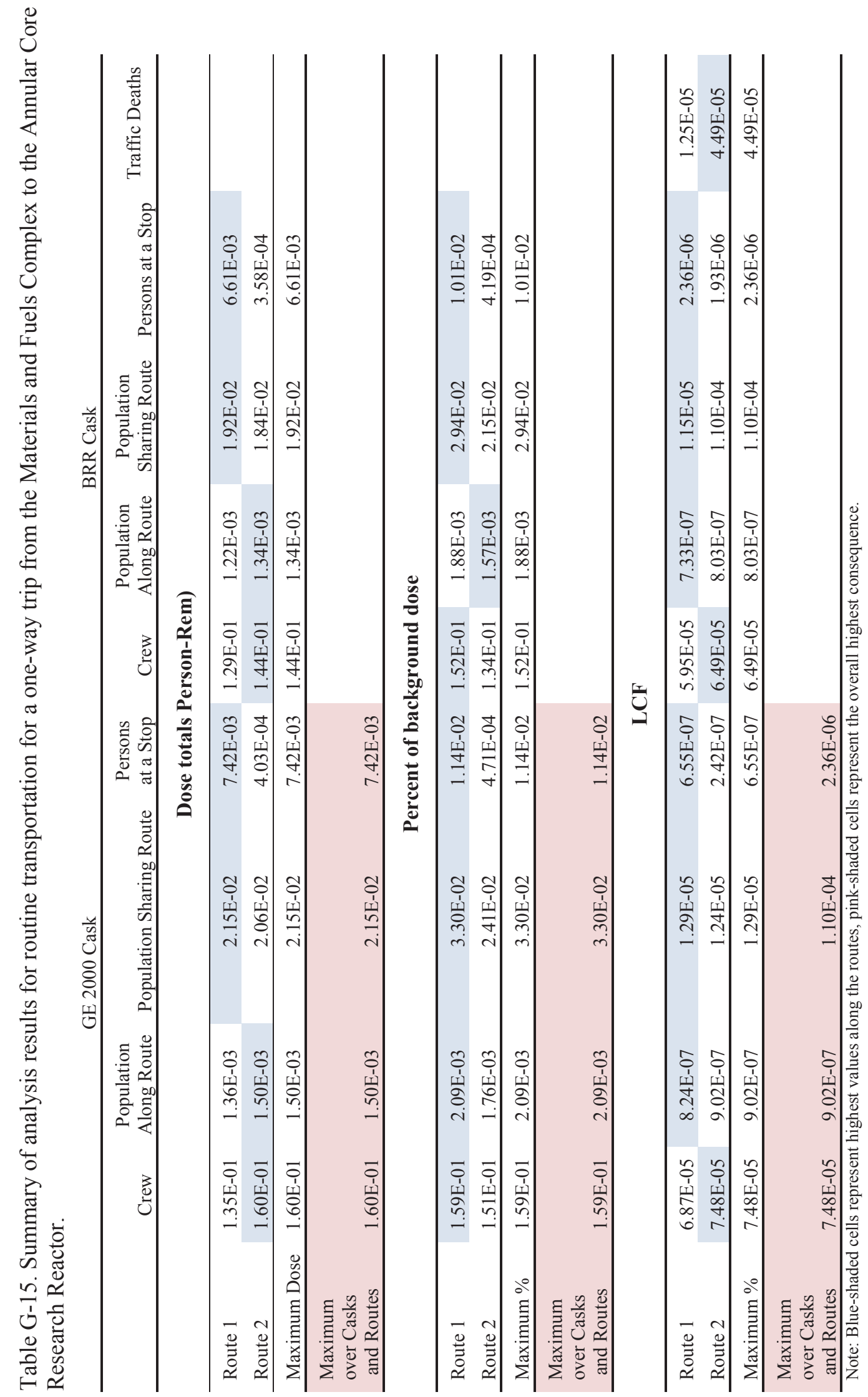




\section{G-6.4 Transportation Impacts Involving an Accident Enroute between the Materials and Fuels Complex and the Annular Core Research Reactor}

The different types of accidents that can interfere with routine transportation of radioactive materials are as follows:

- Accidents in which the spent fuel cask is not damaged or affected.

- Minor traffic accidents (e.g., fender-benders or flat tires), resulting in minor damage to the vehicle.

- Accidents that damage the vehicle or trailer enough so that the vehicle cannot move from the scene of the accident under its own power, but do not result in damage to the spent fuel cask.

- Accidents involving a death or injury, or both, but do not result in damage to the spent fuel cask.

- Accidents in which the spent fuel cask is affected.

- Accidents resulting in the loss of lead gamma shielding or neutron shielding (or both), but no radioactive material is released.

- Accidents in which radioactive material is released.

Accident risk can be expressed as dose risk: a combination of the radiation dose resulting from the accident and the probability of that dose. The units used for accident dose risk are dose units (rem or Sv). Risk is the product of probability and consequence of a particular accident scenario. Therefore, the probability, or likelihood, that a spent fuel cask will be in a specific type of accident is a combination of the following two factors:

- The probability that the vehicle carrying the spent fuel cask will be in an accident.

- The conditional probability that the accident will be a certain type of accident. This is a conditional probability because it depends on the vehicle being in an accident.

The net accident probability is the product of the probability of an accident and the conditional probability of a particular type of accident.

If an accident happens at a particular spot along the route, it is assumed that the vehicle carrying the spent fuel cask stops. Therefore, there can only be one accident for a shipment or on a route; resumption of the shipment is considered a new shipment. RADTRAN calculates and reports collective dose risks for each route segment, because the precise location of the accident cannot be predicted beforehand. The collective dose is different for each route segment because the population is different on each segment. Thus, there is no single or overall accident risk.

The doses and dose risks for a no-release accident are a function of the external dose rate from the cask and are modeled as stops (as shown in Figure G-7). Table G-16 provides the RADTRAN input for no-release accidents. The 10-hour stop is nominal and is based on shippers' estimates of the time needed to either move the cask to another truck or move the vehicle itself. Because the relationship of dose to exposure time is linear, any desired time can be calculated. Inputs specific to the accident analysis are shown in Table G-17.

Conditional probabilities used to determine dose-risk are associated with a set of release fractions, which are surrogates for "accident types." The release fractions depend on the physical/chemical behavior; in the RADTRAN analysis, this devolves to the particle or aerosol size and settling speed. Only aerosol-sized particles can be emitted because the only emissions occur through the cask seals (NRC 2013). Therefore, everything except gases was assumed to have the same settling speed. Tritium is the only gas contributing to $99.9 \%$ of the potential dose in Table G-1. Conditional accident probabilities and release fractions are shown in Table G-18. 
Table G-16. RADTRAN input for no-release accidents.

\begin{tabular}{lc}
\hline \multicolumn{1}{c}{ Parameter } & Value \\
\hline External dose rate & 14 mrem/hour \\
Time at stop & 10 hours \\
Population density around the accident & Route dependent \\
Shielding of residents & Route dependent \\
Area occupied by exposed population & 770 meter annulus \\
Traffic accident rates & Route dependent \\
\hline
\end{tabular}

Table G-17. RADTRAN input for release accident analysis.

\begin{tabular}{lc}
\hline \multicolumn{1}{c}{ Parameter } & Values \\
\hline Accident rate & Route (state) dependent \\
Population density & Route dependent \\
Meteorology & Average weather \\
Particulate deposition rate & $0.01 \mathrm{~m} / \mathrm{sec}$ \\
Cask radionuclide inventory & Table G-1 \\
Aerosol fraction released & 1 \\
Respirable fraction & 0.05 \\
\hline
\end{tabular}

Table G-18. Conditional probabilities and associated release fractions.

\begin{tabular}{rrr}
\hline Conditional Probability $^{\mathrm{a}}$ & Particulate Fraction Released $^{\mathrm{a}}$ & Gas (H-3) Fraction Released $^{\mathrm{a}}$ \\
\hline 0.99999 & 0 & 0 \\
$5.96 \mathrm{E}-12$ & $3.36 \mathrm{E}-06$ & 0.096 \\
$3.57 \mathrm{E}-11$ & $3.36 \mathrm{E}-06$ & 0.096 \\
$1.79 \mathrm{E}-11$ & $3.36 \mathrm{E}-06$ & 0.096 \\
$3.4 \mathrm{E}-10$ & $1.54 \mathrm{E}-09$ & 0.096 \\
\hline
\end{tabular}

a. From NRC 2013, Appendix E.

Tables G-19 through G-26 provide doses and dose risks from a no-release accident and from an accident involving a release of radioactive material for a one-way trip from MFC to ACRR. In deriving these values, it was assumed that an accident can occur on any route segment, but only one accident can happen per trip. The doses and dose risks from an accidental release are the same for both casks, because the model of this type of accident depends only on the radionuclide inventory, which is the same for both casks. 
Table G-19. Population dose risk for two different accident types occurring between the Materials and Fuels Complex and Annular Core Research Reactor along Route 1 using the GE 2000 package.

\begin{tabular}{|c|c|c|c|c|c|c|}
\hline \multirow[b]{2}{*}{ TRAGIS Link } & \multicolumn{3}{|c|}{ No Release, No Loss of Lead Shield } & \multicolumn{3}{|c|}{ Accidental Release } \\
\hline & Person-rem & Person-Sv & LCF & Person-rem & Person-Sv & LCF \\
\hline Argonne W. to Blackfoot, ID & $1.35 \mathrm{E}-08$ & $1.35 \mathrm{E}-10$ & 8.10E-12 & $2.16 \mathrm{E}-17$ & $2.16 \mathrm{E}-19$ & $1.30 \mathrm{E}-20$ \\
\hline Blackfoot to Chubbuck & $1.67 \mathrm{E}-08$ & $1.67 \mathrm{E}-10$ & $1.00 \mathrm{E}-11$ & $3.07 \mathrm{E}-17$ & $3.07 \mathrm{E}-19$ & $1.84 \mathrm{E}-20$ \\
\hline Chubbuck to Pocatello & 2.07E-09 & $2.07 \mathrm{E}-11$ & $1.24 \mathrm{E}-12$ & $5.82 \mathrm{E}-16$ & $5.82 \mathrm{E}-18$ & $3.49 \mathrm{E}-19$ \\
\hline Pocatello to Tremonton, UT & $9.25 \mathrm{E}-08$ & $9.25 \mathrm{E}-10$ & $5.55 \mathrm{E}-11$ & $1.49 \mathrm{E}-16$ & $1.49 \mathrm{E}-18$ & $8.94 \mathrm{E}-20$ \\
\hline Tremonton to Ogden W & $2.16 \mathrm{E}-07$ & $2.16 \mathrm{E}-09$ & $1.29 \mathrm{E}-10$ & $3.97 \mathrm{E}-16$ & $3.97 \mathrm{E}-18$ & $2.38 \mathrm{E}-19$ \\
\hline Ogden W to Midvale & $2.83 \mathrm{E}-08$ & $2.83 \mathrm{E}-10$ & $1.70 \mathrm{E}-11$ & $7.90 \mathrm{E}-15$ & $7.90 \mathrm{E}-17$ & $4.74 \mathrm{E}-18$ \\
\hline Midvale to Orem & $9.36 \mathrm{E}-07$ & $9.36 \mathrm{E}-09$ & $5.62 \mathrm{E}-10$ & $1.72 \mathrm{E}-15$ & $1.72 \mathrm{E}-17$ & $1.03 \mathrm{E}-18$ \\
\hline Orem to Spanish Fork & $1.48 \mathrm{E}-08$ & $1.48 \mathrm{E}-10$ & $8.90 \mathrm{E}-12$ & $4.14 \mathrm{E}-15$ & 4.14E-17 & $2.48 \mathrm{E}-18$ \\
\hline Spanish Fork to Helper & $1.57 \mathrm{E}-07$ & $1.57 \mathrm{E}-09$ & $9.40 \mathrm{E}-11$ & $2.51 \mathrm{E}-16$ & $2.51 \mathrm{E}-18$ & $1.51 \mathrm{E}-19$ \\
\hline Helper to Price & 8.19E-08 & $8.19 \mathrm{E}-10$ & $4.91 \mathrm{E}-11$ & $1.51 \mathrm{E}-16$ & $1.51 \mathrm{E}-18$ & $9.06 \mathrm{E}-20$ \\
\hline Price to Green River & $3.96 \mathrm{E}-09$ & $3.96 \mathrm{E}-11$ & $2.38 \mathrm{E}-12$ & $6.66 \mathrm{E}-18$ & $6.66 \mathrm{E}-20$ & $4.00 \mathrm{E}-21$ \\
\hline Green River to Cortez, CO & $5.28 \mathrm{E}-08$ & $5.28 \mathrm{E}-10$ & $3.17 \mathrm{E}-11$ & $8.48 \mathrm{E}-17$ & $8.48 \mathrm{E}-19$ & $5.09 \mathrm{E}-20$ \\
\hline Cortez to CEZ Airport & $2.19 \mathrm{E}-08$ & $2.19 \mathrm{E}-10$ & $1.31 \mathrm{E}-11$ & $4.02 \mathrm{E}-17$ & $4.02 \mathrm{E}-19$ & $2.41 \mathrm{E}-20$ \\
\hline CEZ Airport to Shiprock, NM & $2.17 \mathrm{E}-07$ & $2.17 \mathrm{E}-09$ & $1.30 \mathrm{E}-10$ & $3.48 \mathrm{E}-16$ & $3.48 \mathrm{E}-18$ & $2.09 \mathrm{E}-19$ \\
\hline Shiprock to Farmington & $6.27 \mathrm{E}-07$ & $6.27 \mathrm{E}-09$ & $3.76 \mathrm{E}-10$ & $1.16 \mathrm{E}-15$ & $1.16 \mathrm{E}-17$ & $6.96 \mathrm{E}-19$ \\
\hline Farmington to Bernalillo & $8.16 \mathrm{E}-07$ & $8.16 \mathrm{E}-09$ & $4.90 \mathrm{E}-10$ & $1.31 \mathrm{E}-15$ & $1.31 \mathrm{E}-17$ & $7.86 \mathrm{E}-19$ \\
\hline Bernalillo to 4AC Airport & 2.34E-08 & $2.34 \mathrm{E}-10$ & $1.40 \mathrm{E}-11$ & $3.74 \mathrm{E}-17$ & $3.74 \mathrm{E}-19$ & $2.24 \mathrm{E}-20$ \\
\hline 4AC Airport to Sandia & 4.17E-08 & $4.17 \mathrm{E}-10$ & $2.50 \mathrm{E}-11$ & $1.16 \mathrm{E}-14$ & $1.16 \mathrm{E}-16$ & $6.96 \mathrm{E}-18$ \\
\hline Maximum value & $9.36 \mathrm{E}-07$ & $9.36 \mathrm{E}-09$ & $5.62 \mathrm{E}-10$ & $1.16 \mathrm{E}-14$ & $1.16 \mathrm{E}-16$ & $6.96 \mathrm{E}-18$ \\
\hline
\end{tabular}


Table G-20. Population dose for two different accident types occurring between the Materials and Fuels Complex and Annular Core Research Reactor along Route 1 using the GE 2000 package.

\begin{tabular}{|c|c|c|c|c|c|c|}
\hline \multirow[b]{2}{*}{ TRAGIS Link } & \multicolumn{3}{|c|}{ No Release, No Loss of Lead Shield } & \multicolumn{3}{|c|}{ Accidental Release } \\
\hline & Person-rem & Person-Sv & LCF & Person-rem & Person-Sv & LCF \\
\hline Argonne W. to Blackfoot, ID & $1.08 \mathrm{E}-04$ & $1.08 \mathrm{E}-06$ & $6.48 \mathrm{E}-08$ & $1.98 \mathrm{E}-04$ & $1.98 \mathrm{E}-06$ & $1.19 \mathrm{E}-07$ \\
\hline Blackfoot to Chubbuck & $3.25 \mathrm{E}-04$ & $3.25 \mathrm{E}-06$ & $1.95 \mathrm{E}-07$ & $6.85 \mathrm{E}-04$ & $6.85 \mathrm{E}-06$ & $4.11 \mathrm{E}-07$ \\
\hline Chubbuck to Pocatello & $1.57 \mathrm{E}-04$ & $1.57 \mathrm{E}-06$ & $9.42 \mathrm{E}-08$ & $5.05 \mathrm{E}-02$ & $5.05 \mathrm{E}-04$ & $3.03 \mathrm{E}-05$ \\
\hline Pocatello to Tremonton, UT & $3.20 \mathrm{E}-04$ & $3.20 \mathrm{E}-06$ & $1.92 \mathrm{E}-07$ & $5.92 \mathrm{E}-04$ & $5.92 \mathrm{E}-06$ & $3.55 \mathrm{E}-07$ \\
\hline Tremonton to Ogden W & $1.74 \mathrm{E}-03$ & $1.74 \mathrm{E}-05$ & $1.04 \mathrm{E}-06$ & $3.68 \mathrm{E}-03$ & $3.68 \mathrm{E}-05$ & $2.21 \mathrm{E}-06$ \\
\hline Ogden W to Midvale & $1.99 \mathrm{E}-04$ & $1.99 \mathrm{E}-06$ & $1.19 \mathrm{E}-07$ & $6.39 \mathrm{E}-02$ & $6.39 \mathrm{E}-04$ & $3.83 \mathrm{E}-05$ \\
\hline Midvale to Orem & $1.00 \mathrm{E}-02$ & $1.00 \mathrm{E}-04$ & $6.00 \mathrm{E}-06$ & $2.11 \mathrm{E}-02$ & $2.11 \mathrm{E}-04$ & $1.27 \mathrm{E}-05$ \\
\hline Orem to Spanish Fork & $3.45 \mathrm{E}-04$ & $3.45 \mathrm{E}-06$ & 2.07E-07 & $1.11 \mathrm{E}-01$ & $1.11 \mathrm{E}-03$ & $6.64 \mathrm{E}-05$ \\
\hline Spanish Fork to Helper & 8.33E-04 & $8.33 \mathrm{E}-06$ & $5.00 \mathrm{E}-07$ & $1.54 \mathrm{E}-03$ & $1.54 \mathrm{E}-05$ & $9.22 \mathrm{E}-07$ \\
\hline Helper to Price & $2.19 \mathrm{E}-03$ & $2.19 \mathrm{E}-05$ & $1.31 \mathrm{E}-06$ & 4.64E-03 & 4.64E-05 & $2.78 \mathrm{E}-06$ \\
\hline Price to Green River & $1.96 \mathrm{E}-05$ & $1.96 \mathrm{E}-07$ & $1.18 \mathrm{E}-08$ & $3.79 \mathrm{E}-05$ & $3.79 \mathrm{E}-07$ & $2.28 \mathrm{E}-08$ \\
\hline Green River to Cortez, CO & $2.04 \mathrm{E}-04$ & $2.04 \mathrm{E}-06$ & $1.22 \mathrm{E}-07$ & $3.76 \mathrm{E}-04$ & $3.76 \mathrm{E}-06$ & $2.26 \mathrm{E}-07$ \\
\hline Cortez to CEZ Airport & $3.73 \mathrm{E}-03$ & $3.73 \mathrm{E}-05$ & $2.24 \mathrm{E}-06$ & $7.89 \mathrm{E}-03$ & $7.89 \mathrm{E}-05$ & 4.73E-06 \\
\hline CEZ Airport to Shiprock, NM & $7.28 \mathrm{E}-04$ & $7.28 \mathrm{E}-06$ & 4.37E-07 & $1.34 \mathrm{E}-03$ & $1.34 \mathrm{E}-05$ & 8.07E-07 \\
\hline Shiprock to Farmington & $4.21 \mathrm{E}-03$ & $4.21 \mathrm{E}-05$ & $2.53 \mathrm{E}-06$ & 8.93E-03 & 8.93E-05 & $5.36 \mathrm{E}-06$ \\
\hline Farmington to Bernalillo & $6.48 \mathrm{E}-04$ & $6.48 \mathrm{E}-06$ & $3.89 \mathrm{E}-07$ & $1.19 \mathrm{E}-03$ & $1.19 \mathrm{E}-05$ & $7.15 \mathrm{E}-07$ \\
\hline Bernalillo to 4AC Airport & $3.71 \mathrm{E}-04$ & $3.71 \mathrm{E}-06$ & $2.23 \mathrm{E}-07$ & $6.80 \mathrm{E}-04$ & $6.80 \mathrm{E}-06$ & 4.08E-07 \\
\hline 4AC Airport to Sandia & $3.11 \mathrm{E}-04$ & $3.11 \mathrm{E}-06$ & $1.87 \mathrm{E}-07$ & $9.96 \mathrm{E}-02$ & $9.96 \mathrm{E}-04$ & $5.98 \mathrm{E}-05$ \\
\hline Maximum & $1.00 \mathrm{E}-02$ & $1.00 \mathrm{E}-04$ & $6.00 \mathrm{E}-06$ & $1.11 \mathrm{E}-01$ & $1.11 \mathrm{E}-03$ & $6.64 \mathrm{E}-05$ \\
\hline
\end{tabular}


Table G-21. Population dose risk for two different accident types occurring between the Materials and Fuels Complex and Annular Core Research Reactor along Route 1 using the Battelle Energy Alliance research reactor package.

\begin{tabular}{|c|c|c|c|c|c|c|}
\hline \multirow[b]{2}{*}{ TRAGIS Link } & \multicolumn{3}{|c|}{ No Release, No Loss of Lead Shield } & \multicolumn{3}{|c|}{ Accidental Release } \\
\hline & Person-rem & Person-Sv & LCF & Person-rem & Person-Sv & LCF \\
\hline Argonne W. to Blackfoot, ID & $1.20 \mathrm{E}-08$ & $1.20 \mathrm{E}-10$ & $6.90 \mathrm{E}-16$ & $2.16 \mathrm{E}-17$ & $2.16 \mathrm{E}-19$ & $1.30 \mathrm{E}-20$ \\
\hline Blackfoot to Chubbuck & $1.49 \mathrm{E}-08$ & $1.49 \mathrm{E}-10$ & $2.58 \mathrm{E}-15$ & $3.07 \mathrm{E}-17$ & 3.07E-19 & $1.84 \mathrm{E}-20$ \\
\hline Chubbuck to Pocatello & $1.85 \mathrm{E}-09$ & $1.85 \mathrm{E}-11$ & $1.55 \mathrm{E}-16$ & $5.82 \mathrm{E}-16$ & $5.82 \mathrm{E}-18$ & $3.49 \mathrm{E}-19$ \\
\hline Pocatello to Tremonton, UT & $8.24 \mathrm{E}-08$ & $8.24 \mathrm{E}-10$ & $1.41 \mathrm{E}-14$ & $1.49 \mathrm{E}-16$ & $1.49 \mathrm{E}-18$ & $8.94 \mathrm{E}-20$ \\
\hline Tremonton to Ogden W & $1.92 \mathrm{E}-07$ & $1.92 \mathrm{E}-09$ & $1.79 \mathrm{E}-13$ & $3.97 \mathrm{E}-16$ & $3.97 \mathrm{E}-18$ & $2.38 \mathrm{E}-19$ \\
\hline Ogden W to Midvale & $2.51 \mathrm{E}-08$ & $2.51 \mathrm{E}-10$ & $2.67 \mathrm{E}-15$ & $7.90 \mathrm{E}-15$ & $7.90 \mathrm{E}-17$ & $4.74 \mathrm{E}-18$ \\
\hline Midvale to Orem & 8.35E-07 & $8.35 \mathrm{E}-09$ & 4.47E-12 & $1.72 \mathrm{E}-15$ & $1.72 \mathrm{E}-17$ & $1.03 \mathrm{E}-18$ \\
\hline Orem to Spanish Fork & $1.32 \mathrm{E}-08$ & $1.32 \mathrm{E}-10$ & $2.43 \mathrm{E}-15$ & 4.14E-15 & 4.14E-17 & $2.48 \mathrm{E}-18$ \\
\hline Spanish Fork to Helper & $1.39 \mathrm{E}-07$ & $1.39 \mathrm{E}-09$ & $6.21 \mathrm{E}-14$ & $2.51 \mathrm{E}-16$ & $2.51 \mathrm{E}-18$ & $1.51 \mathrm{E}-19$ \\
\hline Helper to Price & 7.29E-08 & $7.29 \mathrm{E}-10$ & $8.53 \mathrm{E}-14$ & $1.51 \mathrm{E}-16$ & $1.51 \mathrm{E}-18$ & $9.06 \mathrm{E}-20$ \\
\hline Price to Green River & $3.51 \mathrm{E}-09$ & $3.51 \mathrm{E}-11$ & $3.67 \mathrm{E}-17$ & $6.66 \mathrm{E}-18$ & $6.66 \mathrm{E}-20$ & $4.00 \mathrm{E}-21$ \\
\hline Green River to Cortez, CO & 4.71E-08 & $4.71 \mathrm{E}-10$ & $5.15 \mathrm{E}-15$ & $8.48 \mathrm{E}-17$ & $8.48 \mathrm{E}-19$ & $5.09 \mathrm{E}-20$ \\
\hline Cortez to CEZ Airport & $1.95 \mathrm{E}-08$ & $1.95 \mathrm{E}-10$ & $3.88 \mathrm{E}-14$ & 4.02E-17 & 4.02E-19 & $2.41 \mathrm{E}-20$ \\
\hline CEZ Airport to Shiprock, NM & $1.93 \mathrm{E}-07$ & $1.93 \mathrm{E}-09$ & $7.53 \mathrm{E}-14$ & $3.48 \mathrm{E}-16$ & $3.48 \mathrm{E}-18$ & 2.09E-19 \\
\hline Shiprock to Farmington & $5.59 \mathrm{E}-07$ & $5.59 \mathrm{E}-09$ & $1.26 \mathrm{E}-12$ & $1.16 \mathrm{E}-15$ & $1.16 \mathrm{E}-17$ & $6.96 \mathrm{E}-19$ \\
\hline Farmington to Bernalillo & 7.27E-07 & 7.27E-09 & $2.52 \mathrm{E}-13$ & $1.31 \mathrm{E}-15$ & $1.31 \mathrm{E}-17$ & $7.86 \mathrm{E}-19$ \\
\hline Bernalillo to 4AC Airport & $2.08 \mathrm{E}-08$ & $2.08 \mathrm{E}-10$ & $4.12 \mathrm{E}-15$ & $3.74 \mathrm{E}-17$ & $3.74 \mathrm{E}-19$ & $2.24 \mathrm{E}-20$ \\
\hline 4AC Airport to Sandia & $3.71 \mathrm{E}-08$ & $3.71 \mathrm{E}-10$ & $6.17 \mathrm{E}-15$ & $1.16 \mathrm{E}-14$ & $1.16 \mathrm{E}-16$ & $6.96 \mathrm{E}-18$ \\
\hline Maximum & $8.35 \mathrm{E}-07$ & $8.35 \mathrm{E}-09$ & 4.47E-12 & $1.16 \mathrm{E}-14$ & $1.16 \mathrm{E}-16$ & $6.96 \mathrm{E}-18$ \\
\hline
\end{tabular}


Table G-22. Population dose for two different accident types occurring between the Materials and Fuels Complex and Annular Core Research Reactor along Route 1 using the Battelle Energy Alliance research reactor package.

\begin{tabular}{|c|c|c|c|c|c|c|}
\hline \multirow[b]{2}{*}{ TRAGIS Link } & \multicolumn{3}{|c|}{ No Release, No Loss of Lead Shield } & \multicolumn{3}{|c|}{ Accidental Release } \\
\hline & Person-rem & Person-Sv & LCF & Person-rem & Person-Sv & LCF \\
\hline Argonne W. to Blackfoot, ID & $9.59 \mathrm{E}-05$ & $9.59 \mathrm{E}-07$ & $5.75 \mathrm{E}-08$ & $1.98 \mathrm{E}-04$ & $1.98 \mathrm{E}-06$ & $1.19 \mathrm{E}-07$ \\
\hline Blackfoot to Chubbuck & $2.89 \mathrm{E}-04$ & $2.89 \mathrm{E}-06$ & $1.73 \mathrm{E}-07$ & $6.85 \mathrm{E}-04$ & $6.85 \mathrm{E}-06$ & $4.11 \mathrm{E}-07$ \\
\hline Chubbuck to Pocatello & $1.40 \mathrm{E}-04$ & $1.40 \mathrm{E}-06$ & $8.40 \mathrm{E}-08$ & $5.05 \mathrm{E}-02$ & $5.05 \mathrm{E}-04$ & 3.03E-05 \\
\hline Pocatello to Tremonton, UT & $2.85 \mathrm{E}-04$ & $2.85 \mathrm{E}-06$ & $1.71 \mathrm{E}-07$ & $5.92 \mathrm{E}-04$ & $5.92 \mathrm{E}-06$ & $3.55 \mathrm{E}-07$ \\
\hline Tremonton to Ogden W & $1.55 \mathrm{E}-03$ & $1.55 \mathrm{E}-05$ & $9.30 \mathrm{E}-07$ & $3.68 \mathrm{E}-03$ & $3.68 \mathrm{E}-05$ & $2.21 \mathrm{E}-06$ \\
\hline Ogden W to Midvale & $1.77 \mathrm{E}-04$ & $1.77 \mathrm{E}-06$ & $1.06 \mathrm{E}-07$ & $6.39 \mathrm{E}-02$ & $6.39 \mathrm{E}-04$ & $3.83 \mathrm{E}-05$ \\
\hline Midvale to Orem & 8.92E-03 & $8.92 \mathrm{E}-05$ & $5.35 \mathrm{E}-06$ & 2.11E-02 & $2.11 \mathrm{E}-04$ & $1.27 \mathrm{E}-05$ \\
\hline Orem to Spanish Fork & $3.07 \mathrm{E}-04$ & $3.07 \mathrm{E}-06$ & $1.84 \mathrm{E}-07$ & $1.11 \mathrm{E}-01$ & $1.11 \mathrm{E}-03$ & $6.64 \mathrm{E}-05$ \\
\hline Spanish Fork to Helper & $7.42 \mathrm{E}-04$ & $7.42 \mathrm{E}-06$ & 4.45E-07 & $1.54 \mathrm{E}-03$ & $1.54 \mathrm{E}-05$ & $9.22 \mathrm{E}-07$ \\
\hline Helper to Price & $1.95 \mathrm{E}-03$ & $1.95 \mathrm{E}-05$ & $1.17 \mathrm{E}-06$ & 4.64E-03 & 4.64E-05 & $2.78 \mathrm{E}-06$ \\
\hline Price to Green River & $1.74 \mathrm{E}-05$ & $1.74 \mathrm{E}-07$ & $1.04 \mathrm{E}-08$ & 3.79E-05 & 3.79E-07 & $2.28 \mathrm{E}-08$ \\
\hline Green River to Cortez, CO & $1.82 \mathrm{E}-04$ & $1.82 \mathrm{E}-06$ & $1.09 \mathrm{E}-07$ & $3.76 \mathrm{E}-04$ & $3.76 \mathrm{E}-06$ & $2.26 \mathrm{E}-07$ \\
\hline Cortez to CEZ Airport & $3.32 \mathrm{E}-03$ & $3.32 \mathrm{E}-05$ & $1.99 \mathrm{E}-06$ & 7.89E-03 & 7.89E-05 & 4.73E-06 \\
\hline CEZ Airport to Shiprock, NM & $6.49 \mathrm{E}-04$ & $6.49 \mathrm{E}-06$ & $3.89 \mathrm{E}-07$ & $1.34 \mathrm{E}-03$ & $1.34 \mathrm{E}-05$ & 8.07E-07 \\
\hline Shiprock to Farmington & $3.75 \mathrm{E}-03$ & $3.75 \mathrm{E}-05$ & $2.25 \mathrm{E}-06$ & 8.93E-03 & $8.93 \mathrm{E}-05$ & $5.36 \mathrm{E}-06$ \\
\hline Farmington to Bernalillo & 5.77E-04 & $5.77 \mathrm{E}-06$ & $3.46 \mathrm{E}-07$ & 1.19E-03 & $1.19 \mathrm{E}-05$ & $7.15 \mathrm{E}-07$ \\
\hline Bernalillo to 4AC Airport & $3.30 \mathrm{E}-04$ & $3.30 \mathrm{E}-06$ & $1.98 \mathrm{E}-07$ & $6.80 \mathrm{E}-04$ & $6.80 \mathrm{E}-06$ & 4.08E-07 \\
\hline 4AC Airport to Sandia & $2.77 \mathrm{E}-04$ & $2.77 \mathrm{E}-06$ & $1.66 \mathrm{E}-07$ & $9.96 \mathrm{E}-02$ & $9.96 \mathrm{E}-04$ & $5.98 \mathrm{E}-05$ \\
\hline Maximum & 8.92E-03 & $8.92 \mathrm{E}-05$ & $5.35 \mathrm{E}-06$ & $1.11 \mathrm{E}-01$ & $1.11 \mathrm{E}-03$ & $6.64 \mathrm{E}-05$ \\
\hline
\end{tabular}


Table G-23. Population dose-risk for two different accident types occurring between the Materials and Fuels Complex and Annular Core Research Reactor along Route 2 using the GE 2000 package.

\begin{tabular}{|c|c|c|c|c|c|c|}
\hline \multirow[b]{2}{*}{ TRAGIS Link } & \multicolumn{3}{|c|}{ No Release, No Loss of Lead Shield } & \multicolumn{3}{|c|}{ Accidental Release } \\
\hline & Person-rem & Person-Sv & LCF & Person-rem & Person-Sv & LCF \\
\hline Argonne West to Blackfoot, ID & $1.35 \mathrm{E}-08$ & $1.35 \mathrm{E}-10$ & $8.10 \mathrm{E}-12$ & 4.13E-17 & $4.13 \mathrm{E}-19$ & $2.478 \mathrm{E}-20$ \\
\hline Blackfoot to Chubbuck & $1.67 \mathrm{E}-08$ & $1.67 \mathrm{E}-10$ & $1.00 \mathrm{E}-11$ & $5.88 \mathrm{E}-17$ & $5.88 \mathrm{E}-19$ & $3.528 \mathrm{E}-20$ \\
\hline Chubbuck to Pocatello & 2.07E-09 & $2.07 \mathrm{E}-11$ & $1.24 \mathrm{E}-12$ & $1.11 \mathrm{E}-15$ & $1.11 \mathrm{E}-17$ & $6.66 \mathrm{E}-19$ \\
\hline Pocatello to Montpelier & $2.49 \mathrm{E}-07$ & 2.49E-09 & $1.49 \mathrm{E}-10$ & $7.59 \mathrm{E}-16$ & $7.59 \mathrm{E}-18$ & $4.554 \mathrm{E}-19$ \\
\hline Montpelier to Green River, WY & 8.02E-08 & $8.02 \mathrm{E}-10$ & $4.81 \mathrm{E}-11$ & $2.46 \mathrm{E}-16$ & $2.46 \mathrm{E}-18$ & $1.476 \mathrm{E}-19$ \\
\hline Green River to Rock Springs & 4.94E-07 & 4.94E-09 & $2.96 \mathrm{E}-10$ & $1.74 \mathrm{E}-15$ & $1.74 \mathrm{E}-17$ & $1.044 \mathrm{E}-18$ \\
\hline Rock Springs to Rawlins W & $1.21 \mathrm{E}-09$ & $1.21 \mathrm{E}-11$ & $7.24 \mathrm{E}-13$ & $3.70 \mathrm{E}-18$ & $3.7 \mathrm{E}-20$ & $2.22 \mathrm{E}-21$ \\
\hline Rawlins W to Rawlins E & $9.63 \mathrm{E}-08$ & $9.63 \mathrm{E}-10$ & $5.78 \mathrm{E}-11$ & $3.40 \mathrm{E}-16$ & $3.4 \mathrm{E}-18$ & 2.04E-19 \\
\hline Rawlins E to Laramie W & $1.43 \mathrm{E}-07$ & $1.43 \mathrm{E}-09$ & $8.58 \mathrm{E}-11$ & 4.38E-16 & $4.38 \mathrm{E}-18$ & $2.628 \mathrm{E}-19$ \\
\hline Laramie $\mathrm{W}$ to Laramie $\mathrm{S}$ & $1.12 \mathrm{E}-08$ & $1.12 \mathrm{E}-10$ & $6.70 \mathrm{E}-12$ & $3.94 \mathrm{E}-17$ & $3.94 \mathrm{E}-19$ & 2.364E-20 \\
\hline Laramie S to Cheyenne SW & $6.89 \mathrm{E}-08$ & $6.89 \mathrm{E}-10$ & 4.13E-11 & $2.11 \mathrm{E}-16$ & $2.11 \mathrm{E}-18$ & $1.266 \mathrm{E}-19$ \\
\hline Cheyenne SW to Ft. Collins E, CO & $2.53 \mathrm{E}-09$ & $2.53 \mathrm{E}-11$ & $1.52 \mathrm{E}-12$ & 7.77E-18 & $7.77 \mathrm{E}-20$ & 4.662E-21 \\
\hline Ft. Collins E to Northglenn & $3.89 \mathrm{E}-08$ & $3.89 \mathrm{E}-10$ & $2.33 \mathrm{E}-11$ & $1.37 \mathrm{E}-16$ & $1.37 \mathrm{E}-18$ & $8.22 \mathrm{E}-20$ \\
\hline Northglenn to Greenwood Vlg SE & $1.87 \mathrm{E}-08$ & $1.87 \mathrm{E}-10$ & $1.12 \mathrm{E}-11$ & $1.00 \mathrm{E}-14$ & $1 \mathrm{E}-16$ & $6 \mathrm{E}-18$ \\
\hline Greenwood Vlg SE to Castle Rock & $1.61 \mathrm{E}-07$ & 1.61E-09 & $9.65 \mathrm{E}-11$ & $5.67 \mathrm{E}-16$ & $5.67 \mathrm{E}-18$ & $3.402 \mathrm{E}-19$ \\
\hline Castle Rock to Colorado Spgs N & $2.17 \mathrm{E}-07$ & 2.17E-09 & $1.30 \mathrm{E}-10$ & $6.64 \mathrm{E}-16$ & $6.64 \mathrm{E}-18$ & $3.984 \mathrm{E}-19$ \\
\hline Colorado Spgs N to Colorado Spgs S & 4.99E-09 & 4.99E-11 & 2.99E-12 & $2.67 \mathrm{E}-15$ & $2.67 \mathrm{E}-17$ & $1.602 \mathrm{E}-18$ \\
\hline Colorado Spgs S to Security & $1.17 \mathrm{E}-07$ & $1.17 \mathrm{E}-09$ & $7.00 \mathrm{E}-11$ & 4.10E-16 & 4.1E-18 & $2.46 \mathrm{E}-19$ \\
\hline Security to Pueblo N & $3.97 \mathrm{E}-08$ & $3.97 \mathrm{E}-10$ & $2.38 \mathrm{E}-11$ & $1.22 \mathrm{E}-16$ & $1.22 \mathrm{E}-18$ & 7.32E-20 \\
\hline Pueblo N to Pueblo & $2.07 \mathrm{E}-08$ & $2.07 \mathrm{E}-10$ & $1.24 \mathrm{E}-11$ & 7.27E-17 & 7.27E-19 & 4.362E-20 \\
\hline Pueblo to Raton, NM & $3.02 \mathrm{E}-07$ & $3.02 \mathrm{E}-09$ & $1.81 \mathrm{E}-10$ & $9.28 \mathrm{E}-16$ & $9.28 \mathrm{E}-18$ & $5.568 \mathrm{E}-19$ \\
\hline Raton to Raton $\mathrm{S}$ & $2.47 \mathrm{E}-08$ & $2.47 \mathrm{E}-10$ & $1.48 \mathrm{E}-11$ & $8.71 \mathrm{E}-17$ & $8.71 \mathrm{E}-19$ & $5.226 \mathrm{E}-20$ \\
\hline Raton S to Las Vegas NE & $3.10 \mathrm{E}-08$ & $3.10 \mathrm{E}-10$ & $1.86 \mathrm{E}-11$ & $9.48 \mathrm{E}-17$ & $9.48 \mathrm{E}-19$ & $5.688 \mathrm{E}-20$ \\
\hline Las Vegas NE to Las Vegas E & $1.02 \mathrm{E}-08$ & $1.02 \mathrm{E}-10$ & $6.11 \mathrm{E}-12$ & $3.59 \mathrm{E}-17$ & $3.59 \mathrm{E}-19$ & 2.154E-20 \\
\hline Las Vegas E to Santa Fe SE & $1.42 \mathrm{E}-07$ & $1.42 \mathrm{E}-09$ & $8.53 \mathrm{E}-11$ & $4.35 \mathrm{E}-16$ & $4.35 \mathrm{E}-18$ & $2.61 \mathrm{E}-19$ \\
\hline Santa Fe SE to Santa Fe SW & $1.62 \mathrm{E}-07$ & $1.62 \mathrm{E}-09$ & $9.70 \mathrm{E}-11$ & $5.71 \mathrm{E}-16$ & $5.71 \mathrm{E}-18$ & $3.426 \mathrm{E}-19$ \\
\hline Santa Fe SW to Bernalillo & $5.82 \mathrm{E}-08$ & $5.82 \mathrm{E}-10$ & $3.49 \mathrm{E}-11$ & $1.78 \mathrm{E}-16$ & $1.78 \mathrm{E}-18$ & $1.068 \mathrm{E}-19$ \\
\hline Bernalillo to Albuquerque E & $1.00 \mathrm{E}-06$ & $1.00 \mathrm{E}-08$ & $6.02 \mathrm{E}-10$ & $3.52 \mathrm{E}-15$ & $3.52 \mathrm{E}-17$ & $2.112 \mathrm{E}-18$ \\
\hline Albuquerque E to Sandia & $2.14 \mathrm{E}-08$ & $2.14 \mathrm{E}-10$ & $1.28 \mathrm{E}-11$ & $1.14 \mathrm{E}-14$ & $1.14 \mathrm{E}-16$ & $6.84 \mathrm{E}-18$ \\
\hline Maximum & $1.00 \mathrm{E}-06$ & $1.00 \mathrm{E}-08$ & $6.02 \mathrm{E}-10$ & $1.14 \mathrm{E}-14$ & $1.14 \mathrm{E}-16$ & $6.84 \mathrm{E}-18$ \\
\hline
\end{tabular}


Table G-24. Population dose for two different accident types occurring between the Materials and Fuels Complex and Annular Core Research Reactor along Route 2 using the GE 2000 package.

\begin{tabular}{|c|c|c|c|c|c|c|}
\hline \multirow[b]{2}{*}{ TRAGIS Link } & \multicolumn{3}{|c|}{ No Release, No Loss of Lead Shield } & \multicolumn{3}{|c|}{ Accidental Release } \\
\hline & Person-rem & Person-Sv & LCF & Person-rem & Person-Sv & LCF \\
\hline Argonne West to Blackfoot, ID & $1.08 \mathrm{E}-04$ & $1.08 \mathrm{E}-06$ & $6.48 \mathrm{E}-08$ & 3.79E-04 & $3.79 \mathrm{E}-06$ & 2.27E-07 \\
\hline Blackfoot to Chubbuck & $3.25 \mathrm{E}-04$ & $3.25 \mathrm{E}-06$ & $1.95 \mathrm{E}-07$ & $1.31 \mathrm{E}-03$ & $1.31 \mathrm{E}-05$ & 7.88E-07 \\
\hline Chubbuck to Pocatello & $1.57 \mathrm{E}-04$ & $1.57 \mathrm{E}-06$ & $9.42 \mathrm{E}-08$ & $9.64 \mathrm{E}-02$ & $9.64 \mathrm{E}-04$ & $5.78 \mathrm{E}-05$ \\
\hline Pocatello to Montpelier & $1.14 \mathrm{E}-03$ & $1.14 \mathrm{E}-05$ & $6.84 \mathrm{E}-07$ & 4.01E-03 & $4.01 \mathrm{E}-05$ & $2.40 \mathrm{E}-06$ \\
\hline Montpelier to Green River, WY & $6.63 \mathrm{E}-05$ & $6.63 \mathrm{E}-07$ & $3.98 \mathrm{E}-08$ & 2.33E-04 & $2.33 \mathrm{E}-06$ & $1.40 \mathrm{E}-07$ \\
\hline Green River to Rock Springs & 7.80E-04 & $7.80 \mathrm{E}-06$ & $4.68 \mathrm{E}-07$ & $3.16 \mathrm{E}-03$ & $3.16 \mathrm{E}-05$ & $1.90 \mathrm{E}-06$ \\
\hline Rock Springs to Rawlins W & $1.44 \mathrm{E}-06$ & $1.44 \mathrm{E}-08$ & 8.64E-10 & 5.07E-06 & $5.07 \mathrm{E}-08$ & 3.04E-09 \\
\hline Rawlins W to Rawlins E & $3.02 \mathrm{E}-03$ & $3.02 \mathrm{E}-05$ & $1.81 \mathrm{E}-06$ & $1.23 \mathrm{E}-02$ & $1.23 \mathrm{E}-04$ & 7.37E-06 \\
\hline Rawlins E to Laramie W & $1.78 \mathrm{E}-04$ & $1.78 \mathrm{E}-06$ & $1.07 \mathrm{E}-07$ & $6.27 \mathrm{E}-04$ & $6.27 \mathrm{E}-06$ & $3.76 \mathrm{E}-07$ \\
\hline Laramie $\mathrm{W}$ to Laramie $\mathrm{S}$ & 9.54E-04 & $9.54 \mathrm{E}-06$ & $5.72 \mathrm{E}-07$ & $3.86 \mathrm{E}-03$ & $3.86 \mathrm{E}-05$ & $2.32 \mathrm{E}-06$ \\
\hline Laramie S to Cheyenne SW & $1.78 \mathrm{E}-04$ & $1.78 \mathrm{E}-06$ & $1.07 \mathrm{E}-07$ & $6.29 \mathrm{E}-04$ & $6.29 \mathrm{E}-06$ & 3.77E-07 \\
\hline Cheyenne SW to Ft. Collins E, CO & $4.26 \mathrm{E}-05$ & 4.26E-07 & $2.56 \mathrm{E}-08$ & $1.50 \mathrm{E}-04$ & $1.50 \mathrm{E}-06$ & $9.01 \mathrm{E}-08$ \\
\hline Ft. Collins E to Northglenn & $5.40 \mathrm{E}-04$ & $5.40 \mathrm{E}-06$ & $3.24 \mathrm{E}-07$ & $2.18 \mathrm{E}-03$ & $2.18 \mathrm{E}-05$ & $1.31 \mathrm{E}-06$ \\
\hline Northglenn to Greenwood Vlg SE & $4.61 \mathrm{E}-04$ & 4.61E-06 & $2.77 \mathrm{E}-07$ & $2.83 \mathrm{E}-01$ & $2.83 \mathrm{E}-03$ & $1.70 \mathrm{E}-04$ \\
\hline Greenwood Vlg SE to Castle Rock & $7.41 \mathrm{E}-03$ & $7.41 \mathrm{E}-05$ & $4.45 \mathrm{E}-06$ & $3.00 \mathrm{E}-02$ & $3.00 \mathrm{E}-04$ & $1.80 \mathrm{E}-05$ \\
\hline Castle Rock to Colorado Spgs N & $4.25 \mathrm{E}-03$ & 4.25E-05 & $2.55 \mathrm{E}-06$ & $1.49 \mathrm{E}-02$ & $1.49 \mathrm{E}-04$ & 8.95E-06 \\
\hline Colorado Spgs N to Colorado Spg S & $3.06 \mathrm{E}-04$ & $3.06 \mathrm{E}-06$ & $1.84 \mathrm{E}-07$ & $1.88 \mathrm{E}-01$ & $1.88 \mathrm{E}-03$ & $1.13 \mathrm{E}-04$ \\
\hline Colorado Spgs S to Security & $1.68 \mathrm{E}-02$ & $1.68 \mathrm{E}-04$ & $1.01 \mathrm{E}-05$ & 6.79E-02 & $6.79 \mathrm{E}-04$ & 4.07E-05 \\
\hline Security to Pueblo N & $6.65 \mathrm{E}-04$ & $6.65 \mathrm{E}-06$ & $3.99 \mathrm{E}-07$ & $2.35 \mathrm{E}-03$ & $2.35 \mathrm{E}-05$ & $1.41 \mathrm{E}-06$ \\
\hline Pueblo N to Pueblo & $9.57 \mathrm{E}-03$ & $9.57 \mathrm{E}-05$ & $5.74 \mathrm{E}-06$ & 3.87E-02 & $3.87 \mathrm{E}-04$ & $2.32 \mathrm{E}-05$ \\
\hline Pueblo to Raton, NM & $1.81 \mathrm{E}-03$ & $1.81 \mathrm{E}-05$ & $1.09 \mathrm{E}-06$ & $6.37 \mathrm{E}-03$ & $6.37 \mathrm{E}-05$ & $3.82 \mathrm{E}-06$ \\
\hline Raton to Raton $\mathrm{S}$ & $5.45 \mathrm{E}-04$ & $5.45 \mathrm{E}-06$ & $3.27 \mathrm{E}-07$ & $2.21 \mathrm{E}-03$ & $2.21 \mathrm{E}-05$ & $1.32 \mathrm{E}-06$ \\
\hline Raton S to Las Vegas NE & 4.04E-05 & 4.04E-07 & $2.42 \mathrm{E}-08$ & $1.42 \mathrm{E}-04$ & $1.42 \mathrm{E}-06$ & $8.51 \mathrm{E}-08$ \\
\hline Las Vegas NE to Las Vegas E & 7.77E-04 & 7.77E-06 & 4.66E-07 & $3.15 \mathrm{E}-03$ & $3.15 \mathrm{E}-05$ & $1.89 \mathrm{E}-06$ \\
\hline Las Vegas E to Santa Fe SE & $3.32 \mathrm{E}-04$ & $3.32 \mathrm{E}-06$ & $1.99 \mathrm{E}-07$ & $1.17 \mathrm{E}-03$ & $1.17 \mathrm{E}-05$ & 7.03E-07 \\
\hline Santa Fe SE to Santa Fe SW & $1.01 \mathrm{E}-03$ & $1.01 \mathrm{E}-05$ & $6.06 \mathrm{E}-07$ & 4.10E-03 & 4.10E-05 & $2.46 \mathrm{E}-06$ \\
\hline Santa Fe SW to Bernalillo & $2.76 \mathrm{E}-04$ & $2.76 \mathrm{E}-06$ & $1.66 \mathrm{E}-07$ & $9.70 \mathrm{E}-04$ & $9.70 \mathrm{E}-06$ & $5.82 \mathrm{E}-07$ \\
\hline Bernalillo to Albuquerque E & 8.03E-03 & 8.03E-05 & $4.82 \mathrm{E}-06$ & $3.24 \mathrm{E}-02$ & $3.24 \mathrm{E}-04$ & $1.95 \mathrm{E}-05$ \\
\hline Albuquerque E to Sandia & $2.96 \mathrm{E}-04$ & $2.96 \mathrm{E}-06$ & $1.78 \mathrm{E}-07$ & $1.81 \mathrm{E}-01$ & $1.81 \mathrm{E}-03$ & $1.09 \mathrm{E}-04$ \\
\hline Maximum & $1.68 \mathrm{E}-02$ & $1.68 \mathrm{E}-04$ & $1.01 \mathrm{E}-05$ & $2.83 \mathrm{E}-01$ & $2.83 \mathrm{E}-03$ & $1.70 \mathrm{E}-04$ \\
\hline
\end{tabular}


Table G-25. Population dose risk for two different accident types occurring between the Materials and Fuels Complex and Annular Core Research Reactor along Route 2 using the Battelle Energy Alliance research reactor package.

\begin{tabular}{|c|c|c|c|c|c|c|}
\hline \multirow[b]{2}{*}{ TRAGIS Link } & \multicolumn{3}{|c|}{ No Release, No Loss of Lead Shield } & \multicolumn{3}{|c|}{ Accidental Release } \\
\hline & Person-rem & Person-Sv & $\mathrm{LCF}$ & Person-rem & Person-Sv & LCF \\
\hline Argonne West to Blackfoot, ID & $1.20 \mathrm{E}-08$ & $1.20 \mathrm{E}-10$ & 7.19E-12 & 4.13E-17 & $4.13 \mathrm{E}-19$ & $2.478 \mathrm{E}-20$ \\
\hline Blackfoot to Chubbuck & $1.49 \mathrm{E}-08$ & $1.49 \mathrm{E}-10$ & $8.91 \mathrm{E}-12$ & $5.88 \mathrm{E}-17$ & $5.88 \mathrm{E}-19$ & $3.528 \mathrm{E}-20$ \\
\hline Chubbuck to Pocatello & $1.85 \mathrm{E}-09$ & $1.85 \mathrm{E}-11$ & $1.11 \mathrm{E}-12$ & $1.11 \mathrm{E}-15$ & $1.11 \mathrm{E}-17$ & $6.66 \mathrm{E}-19$ \\
\hline Pocatello to Montpelier & $2.20 \mathrm{E}-07$ & $2.20 \mathrm{E}-09$ & $1.32 \mathrm{E}-10$ & $7.59 \mathrm{E}-16$ & $7.59 \mathrm{E}-18$ & $4.554 \mathrm{E}-19$ \\
\hline Montpelier to Green River, WY & 7.15E-08 & $7.15 \mathrm{E}-10$ & $4.29 \mathrm{E}-11$ & $2.46 \mathrm{E}-16$ & $2.46 \mathrm{E}-18$ & $1.476 \mathrm{E}-19$ \\
\hline Green River to Rock Springs & 4.39E-07 & 4.39E-09 & $2.64 \mathrm{E}-10$ & $1.74 \mathrm{E}-15$ & $1.74 \mathrm{E}-17$ & $1.044 \mathrm{E}-18$ \\
\hline Rock Springs to Rawlins W & 1.07E-09 & $1.07 \mathrm{E}-11$ & $6.44 \mathrm{E}-13$ & $3.70 \mathrm{E}-18$ & 3.7E-20 & $2.22 \mathrm{E}-21$ \\
\hline Rawlins W to Rawlins E & $8.58 \mathrm{E}-08$ & $8.58 \mathrm{E}-10$ & $5.15 \mathrm{E}-11$ & $3.40 \mathrm{E}-16$ & $3.4 \mathrm{E}-18$ & $2.04 \mathrm{E}-19$ \\
\hline Rawlins E to Laramie W & $1.27 \mathrm{E}-07$ & $1.27 \mathrm{E}-09$ & 7.61E-11 & $4.38 \mathrm{E}-16$ & $4.38 \mathrm{E}-18$ & $2.628 \mathrm{E}-19$ \\
\hline Laramie $\mathrm{W}$ to Laramie $\mathrm{S}$ & 9.95E-09 & $9.95 \mathrm{E}-11$ & $5.97 \mathrm{E}-12$ & 3.94E-17 & 3.94E-19 & $2.364 \mathrm{E}-20$ \\
\hline Laramie S to Cheyenne SW & $6.15 \mathrm{E}-08$ & $6.15 \mathrm{E}-10$ & $3.69 \mathrm{E}-11$ & $2.11 \mathrm{E}-16$ & $2.11 \mathrm{E}-18$ & $1.266 \mathrm{E}-19$ \\
\hline $\begin{array}{l}\text { Cheyenne SW to Ft. Collins E, } \\
\text { CO }\end{array}$ & $2.26 \mathrm{E}-09$ & $2.26 \mathrm{E}-11$ & $1.36 \mathrm{E}-12$ & 7.77E-18 & 7.77E-20 & 4.662E-21 \\
\hline Ft. Collins E to Northglenn & $3.46 \mathrm{E}-08$ & $3.46 \mathrm{E}-10$ & $2.08 \mathrm{E}-11$ & $1.37 \mathrm{E}-16$ & $1.37 \mathrm{E}-18$ & $8.22 \mathrm{E}-20$ \\
\hline Northglenn to Greenwood Vlg SE & 1.67E-08 & $1.67 \mathrm{E}-10$ & $1.00 \mathrm{E}-11$ & $1.00 \mathrm{E}-14$ & $1 \mathrm{E}-16$ & $6 \mathrm{E}-18$ \\
\hline $\begin{array}{l}\text { Greenwood Vlg SE to Castle } \\
\text { Rock }\end{array}$ & $1.43 \mathrm{E}-07$ & $1.43 \mathrm{E}-09$ & $8.59 \mathrm{E}-11$ & $5.67 \mathrm{E}-16$ & $5.67 \mathrm{E}-18$ & $3.402 \mathrm{E}-19$ \\
\hline Castle Rock to Colorado Spgs N & $1.93 \mathrm{E}-07$ & $1.93 \mathrm{E}-09$ & $1.16 \mathrm{E}-10$ & $6.64 \mathrm{E}-16$ & $6.64 \mathrm{E}-18$ & $3.984 \mathrm{E}-19$ \\
\hline $\begin{array}{l}\text { Colorado Spgs N to Colorado } \\
\text { Spgs S }\end{array}$ & 4.43E-09 & $4.43 \mathrm{E}-11$ & $2.66 \mathrm{E}-12$ & $2.67 \mathrm{E}-15$ & $2.67 \mathrm{E}-17$ & $1.602 \mathrm{E}-18$ \\
\hline Colorado Spgs S to Security & $1.03 \mathrm{E}-07$ & $1.03 \mathrm{E}-09$ & $6.20 \mathrm{E}-11$ & 4.10E-16 & 4.1E-18 & $2.46 \mathrm{E}-19$ \\
\hline Security to Pueblo N & 3.53E-08 & $3.53 \mathrm{E}-10$ & $2.12 \mathrm{E}-11$ & $1.22 \mathrm{E}-16$ & $1.22 \mathrm{E}-18$ & 7.32E-20 \\
\hline Pueblo N to Pueblo & $1.84 \mathrm{E}-08$ & $1.84 \mathrm{E}-10$ & $1.11 \mathrm{E}-11$ & 7.27E-17 & 7.27E-19 & $4.362 \mathrm{E}-20$ \\
\hline Pueblo to Raton, NM & $2.69 \mathrm{E}-07$ & 2.69E-09 & $1.61 \mathrm{E}-10$ & $9.28 \mathrm{E}-16$ & $9.28 \mathrm{E}-18$ & $5.568 \mathrm{E}-19$ \\
\hline Raton to Raton $\mathrm{S}$ & $2.20 \mathrm{E}-08$ & $2.20 \mathrm{E}-10$ & $1.32 \mathrm{E}-11$ & $8.71 \mathrm{E}-17$ & $8.71 \mathrm{E}-19$ & $5.226 \mathrm{E}-20$ \\
\hline Raton $\mathrm{S}$ to Las Vegas NE & $2.75 \mathrm{E}-08$ & $2.75 \mathrm{E}-10$ & $1.65 \mathrm{E}-11$ & $9.48 \mathrm{E}-17$ & $9.48 \mathrm{E}-19$ & $5.688 \mathrm{E}-20$ \\
\hline Las Vegas NE to Las Vegas E & $9.08 \mathrm{E}-09$ & $9.08 \mathrm{E}-11$ & $5.45 \mathrm{E}-12$ & $3.59 \mathrm{E}-17$ & $3.59 \mathrm{E}-19$ & $2.154 \mathrm{E}-20$ \\
\hline Las Vegas E to Santa Fe SE & $1.26 \mathrm{E}-07$ & $1.26 \mathrm{E}-09$ & $7.58 \mathrm{E}-11$ & 4.35E-16 & 4.35E-18 & $2.61 \mathrm{E}-19$ \\
\hline Santa Fe SE to Santa Fe SW & $1.44 \mathrm{E}-07$ & $1.44 \mathrm{E}-09$ & $8.66 \mathrm{E}-11$ & $5.71 \mathrm{E}-16$ & $5.71 \mathrm{E}-18$ & $3.426 \mathrm{E}-19$ \\
\hline Santa Fe SW to Bernalillo & 5.19E-08 & $5.19 \mathrm{E}-10$ & $3.11 \mathrm{E}-11$ & $1.78 \mathrm{E}-16$ & $1.78 \mathrm{E}-18$ & $1.068 \mathrm{E}-19$ \\
\hline Bernalillo to Albuquerque $\mathrm{E}$ & 8.94E-07 & 8.94E-09 & $5.36 \mathrm{E}-10$ & $3.52 \mathrm{E}-15$ & $3.52 \mathrm{E}-17$ & $2.112 \mathrm{E}-18$ \\
\hline Albuquerque E to Sandia & $1.91 \mathrm{E}-08$ & $1.91 \mathrm{E}-10$ & $1.15 \mathrm{E}-11$ & $1.14 \mathrm{E}-14$ & $1.14 \mathrm{E}-16$ & $6.84 \mathrm{E}-18$ \\
\hline Maximum & $8.94 \mathrm{E}-07$ & 8.94E-09 & $5.36 \mathrm{E}-10$ & $1.14 \mathrm{E}-14$ & $1.14 \mathrm{E}-16$ & $6.84 \mathrm{E}-18$ \\
\hline
\end{tabular}


Table G-26. Population dose for two different accident types occurring between the Materials and Fuels Complex and Annular Core Research Reactor along Route 2 using the Battelle Energy Alliance research reactor package.

\begin{tabular}{|c|c|c|c|c|c|c|}
\hline \multirow[b]{2}{*}{ TRAGIS Link } & \multicolumn{3}{|c|}{ No Release, No Loss of Lead Shield } & \multicolumn{3}{|c|}{ Accidental Release } \\
\hline & Person-rem & Person-Sv & LCF & Person-rem & Person-Sv & LCF \\
\hline Argonne West to Blackfoot, ID & $9.59 \mathrm{E}-05$ & $9.59 \mathrm{E}-07$ & 5.754E-08 & 3.79E-04 & 3.79E-06 & 2.27E-07 \\
\hline Blackfoot to Chubbuck & 2.89E-04 & $2.89 \mathrm{E}-06$ & $1.73 \mathrm{E}-07$ & $1.31 \mathrm{E}-03$ & $1.31 \mathrm{E}-05$ & $7.88 \mathrm{E}-07$ \\
\hline Chubbuck to Pocatello & $1.40 \mathrm{E}-04$ & $1.40 \mathrm{E}-06$ & $8.40 \mathrm{E}-08$ & $9.64 \mathrm{E}-02$ & 9.64E-04 & $5.78 \mathrm{E}-05$ \\
\hline Pocatello to Montpelier & $1.01 \mathrm{E}-03$ & $1.01 \mathrm{E}-05$ & $6.06 \mathrm{E}-07$ & $4.01 \mathrm{E}-03$ & 4.01E-05 & $2.40 \mathrm{E}-06$ \\
\hline Montpelier to Green River, WY & 5.91E-05 & $5.91 \mathrm{E}-07$ & $3.55 \mathrm{E}-08$ & 2.33E-04 & $2.33 \mathrm{E}-06$ & $1.40 \mathrm{E}-07$ \\
\hline Green River to Rock Springs & 6.94E-04 & $6.94 \mathrm{E}-06$ & $4.16 \mathrm{E}-07$ & $3.16 \mathrm{E}-03$ & $3.16 \mathrm{E}-05$ & $1.90 \mathrm{E}-06$ \\
\hline Rock Springs to Rawlins W & $1.28 \mathrm{E}-06$ & $1.28 \mathrm{E}-08$ & $7.68 \mathrm{E}-10$ & $5.07 \mathrm{E}-06$ & $5.07 \mathrm{E}-08$ & 3.04E-09 \\
\hline Rawlins W to Rawlins E & $2.69 \mathrm{E}-03$ & $2.69 \mathrm{E}-05$ & $1.61 \mathrm{E}-06$ & $1.23 \mathrm{E}-02$ & $1.23 \mathrm{E}-04$ & 7.37E-06 \\
\hline Rawlins E to Laramie W & $1.58 \mathrm{E}-04$ & $1.58 \mathrm{E}-06$ & $9.48 \mathrm{E}-08$ & $6.27 \mathrm{E}-04$ & $6.27 \mathrm{E}-06$ & $3.76 \mathrm{E}-07$ \\
\hline Laramie $\mathrm{W}$ to Laramie $\mathrm{S}$ & $8.50 \mathrm{E}-04$ & $8.50 \mathrm{E}-06$ & $5.10 \mathrm{E}-07$ & $3.86 \mathrm{E}-03$ & $3.86 \mathrm{E}-05$ & $2.32 \mathrm{E}-06$ \\
\hline Laramie S to Cheyenne SW & $1.59 \mathrm{E}-04$ & $1.59 \mathrm{E}-06$ & 9.54E-08 & $6.29 \mathrm{E}-04$ & $6.29 \mathrm{E}-06$ & 3.77E-07 \\
\hline $\begin{array}{l}\text { Cheyenne SW to Ft. Collins E, } \\
\mathrm{CO}\end{array}$ & $3.80 \mathrm{E}-05$ & $3.80 \mathrm{E}-07$ & $2.28 \mathrm{E}-08$ & $1.50 \mathrm{E}-04$ & $1.50 \mathrm{E}-06$ & $9.01 \mathrm{E}-08$ \\
\hline Ft. Collins E to Northglenn & 4.81E-04 & $4.81 \mathrm{E}-06$ & $2.89 \mathrm{E}-07$ & $2.18 \mathrm{E}-03$ & $2.18 \mathrm{E}-05$ & $1.31 \mathrm{E}-06$ \\
\hline Northglenn to Greenwood Vlg SE & 4.11E-04 & 4.11E-06 & $2.47 \mathrm{E}-07$ & $2.83 \mathrm{E}-01$ & $2.83 \mathrm{E}-03$ & $1.70 \mathrm{E}-04$ \\
\hline $\begin{array}{l}\text { Greenwood Vlg SE to Castle } \\
\text { Rock }\end{array}$ & $6.60 \mathrm{E}-03$ & $6.60 \mathrm{E}-05$ & $3.96 \mathrm{E}-06$ & $3.00 \mathrm{E}-02$ & $3.00 \mathrm{E}-04$ & $1.80 \mathrm{E}-05$ \\
\hline Castle Rock to Colorado Spgs N & $3.78 \mathrm{E}-03$ & $3.78 \mathrm{E}-05$ & $2.27 \mathrm{E}-06$ & $1.49 \mathrm{E}-02$ & $1.49 \mathrm{E}-04$ & 8.95E-06 \\
\hline $\begin{array}{l}\text { Colorado Spgs N to Colorado } \\
\text { Spgs S }\end{array}$ & $2.72 \mathrm{E}-04$ & $2.72 \mathrm{E}-06$ & $1.63 \mathrm{E}-07$ & $1.88 \mathrm{E}-01$ & $1.88 \mathrm{E}-03$ & $1.13 \mathrm{E}-04$ \\
\hline Colorado Spgs S to Security & $1.49 \mathrm{E}-02$ & $1.49 \mathrm{E}-04$ & $8.94 \mathrm{E}-06$ & $6.79 \mathrm{E}-02$ & $6.79 \mathrm{E}-04$ & 4.07E-05 \\
\hline Security to Pueblo N & 5.92E-04 & 5.92E-06 & $3.55 \mathrm{E}-07$ & $2.35 \mathrm{E}-03$ & $2.35 \mathrm{E}-05$ & $1.41 \mathrm{E}-06$ \\
\hline Pueblo N to Pueblo & 8.53E-03 & $8.53 \mathrm{E}-05$ & $5.12 \mathrm{E}-06$ & $3.87 \mathrm{E}-02$ & $3.87 \mathrm{E}-04$ & $2.32 \mathrm{E}-05$ \\
\hline Pueblo to Raton, NM & $1.61 \mathrm{E}-03$ & $1.61 \mathrm{E}-05$ & $9.66 \mathrm{E}-07$ & $6.37 \mathrm{E}-03$ & $6.37 \mathrm{E}-05$ & $3.82 \mathrm{E}-06$ \\
\hline Raton to Raton $\mathrm{S}$ & 4.85E-04 & 4.85E-06 & $2.91 \mathrm{E}-07$ & $2.21 \mathrm{E}-03$ & $2.21 \mathrm{E}-05$ & $1.32 \mathrm{E}-06$ \\
\hline Raton $\mathrm{S}$ to Las Vegas NE & $3.59 \mathrm{E}-05$ & $3.59 \mathrm{E}-07$ & $2.15 \mathrm{E}-08$ & $1.42 \mathrm{E}-04$ & $1.42 \mathrm{E}-06$ & $8.51 \mathrm{E}-08$ \\
\hline Las Vegas NE to Las Vegas E & $6.93 \mathrm{E}-04$ & $6.93 \mathrm{E}-06$ & $4.16 \mathrm{E}-07$ & $3.15 \mathrm{E}-03$ & $3.15 \mathrm{E}-05$ & $1.89 \mathrm{E}-06$ \\
\hline Las Vegas E to Santa Fe SE & $2.95 \mathrm{E}-04$ & $2.95 \mathrm{E}-06$ & $1.77 \mathrm{E}-07$ & $1.17 \mathrm{E}-03$ & $1.17 \mathrm{E}-05$ & 7.03E-07 \\
\hline Santa Fe SE to Santa Fe SW & $9.02 \mathrm{E}-04$ & $9.02 \mathrm{E}-06$ & $5.41 \mathrm{E}-07$ & 4.10E-03 & 4.10E-05 & $2.46 \mathrm{E}-06$ \\
\hline Santa Fe SW to Bernalillo & $2.46 \mathrm{E}-04$ & $2.46 \mathrm{E}-06$ & $1.48 \mathrm{E}-07$ & $9.70 \mathrm{E}-04$ & $9.70 \mathrm{E}-06$ & $5.82 \mathrm{E}-07$ \\
\hline Bernalillo to Albuquerque E & $7.15 \mathrm{E}-03$ & $7.15 \mathrm{E}-05$ & $4.29 \mathrm{E}-06$ & $3.24 \mathrm{E}-02$ & $3.24 \mathrm{E}-04$ & $1.95 \mathrm{E}-05$ \\
\hline Albuquerque E to Sandia & 2.64E-04 & 2.64E-06 & $1.58 \mathrm{E}-07$ & $1.81 \mathrm{E}-01$ & $1.81 \mathrm{E}-03$ & $1.09 \mathrm{E}-04$ \\
\hline Maximum & $1.49 \mathrm{E}-02$ & $1.49 \mathrm{E}-04$ & $8.94 \mathrm{E}-06$ & $2.83 \mathrm{E}-01$ & $2.83 \mathrm{E}-03$ & $1.70 \mathrm{E}-04$ \\
\hline
\end{tabular}




\section{G-6.4.1 Summary of Transportation Impacts Involving an Accident Enroute between the Material and Fuels Complex and Annular Core Research Reactor}

The dose and dose risk are slightly lower for the Battelle Energy Alliance research reactor cask as explained in Section G-6.3.2 and for Route 1. General observations from the summary and tabular results are as follows for non-incident-free transportation:

- For accidents where there is no release, dose-risks are higher than for accidents involving a release. For accidents severe enough to involve a release from a Type A container, the conditional probability is very low. Therefore, the dose risk is lower than for more routine accidents.

- Although providing health consequences for low-dose exposures and low-likelihood events is not recommended, risk of an LCF is provided and is much less than 1E-06.

- The maximum radiation dose for incidents involving no releases is 16.8 person-mrem. For comparison, the annual average dose per person received by individuals in the United States is 600 mrem with 311 mrem from natural sources.

- The maximum radiation dose for incidents involving a credible release is 1.01E-02 person-mrem, which is much lower than the annual average dose per person received by individuals in the United States.

Table G-27. Summary of accident doses during transport from the Materials and Fuels Complex to the Annular Core Research Reactor.

\begin{tabular}{|c|c|c|c|c|}
\hline \multirow[b]{2}{*}{ Cask } & \multicolumn{2}{|c|}{ No Release, No Loss of Lead Shield } & \multicolumn{2}{|c|}{ Accidental Release } \\
\hline & Person-rem & LCF & Person-rem & LCF \\
\hline \multicolumn{5}{|c|}{ Dose-Risk (person-rem) on Route 1} \\
\hline GE 2000 cask & $9.36 \mathrm{E}-07$ & $5.62 \mathrm{E}-10$ & $1.16 \mathrm{E}-14$ & $6.96 \mathrm{E}-18$ \\
\hline BRR cask & $8.35 \mathrm{E}-07$ & 4.47E-12 & $1.16 \mathrm{E}-14$ & $6.96 \mathrm{E}-18$ \\
\hline \multicolumn{5}{|c|}{ Dose-Risk (person-rem) on Route 2} \\
\hline GE 2000 cask & $1.00 \mathrm{E}-06$ & $6.02 \mathrm{E}-10$ & $1.14 \mathrm{E}-14$ & $6.84 \mathrm{E}-18$ \\
\hline BRR cask & 8.94E-07 & $5.36 \mathrm{E}-10$ & $1.14 \mathrm{E}-14$ & $6.84 \mathrm{E}-18$ \\
\hline Maximum dose- risk-per accident & $1.00 \mathrm{E}-06$ & $6.02 \mathrm{E}-10$ & $1.16 \mathrm{E}-14$ & $6.96 \mathrm{E}-18$ \\
\hline \multicolumn{5}{|c|}{ Dose (person-rem) on Route 1} \\
\hline GE 2000 cask & $1.00 \mathrm{E}-02$ & $6.00 \mathrm{E}-06$ & $1.11 \mathrm{E}-01$ & $6.64 \mathrm{E}-05$ \\
\hline BRR cask & 8.92E-03 & 5.35E-06 & 1.11E-01 & $6.64 \mathrm{E}-05$ \\
\hline \multicolumn{5}{|c|}{ Dose (person-rem) on Route 2} \\
\hline GE 2000 cask & $1.68 \mathrm{E}-02$ & $1.01 \mathrm{E}-05$ & 2.83E-01 & $1.70 \mathrm{E}-04$ \\
\hline BRR cask & 1.49E-02 & 8.94E-06 & 2.83E-01 & 1.70E-04 \\
\hline Maximum dose per accident & $1.68 \mathrm{E}-02$ & $1.01 \mathrm{E}-05$ & 2.83E-01 & 1.70E-04 \\
\hline \multicolumn{5}{|c|}{ Overall Summary (person-rem) } \\
\hline Overall Maximum dose risk per accident & $1.00 \mathrm{E}-06$ & $6.02 \mathrm{E}-10$ & $1.16 \mathrm{E}-14$ & $6.96 \mathrm{E}-18$ \\
\hline Overall Maximum dose per accident & $1.68 \mathrm{E}-02$ & $1.01 \mathrm{E}-05$ & 2.83E-01 & $1.70 \mathrm{E}-04$ \\
\hline
\end{tabular}




\section{G-7. NON-RADIOLOGICAL TRANSPORTATION IMPACTS}

Non-radiological impacts related to transportation for the alternatives using the TREAT Reactor, or ACRR, result simply from transporting any material from one location to another independent of the characteristics of the cargo. The presence or absence of cargo is not a factor in the assessment of these risks. Non-radiological risks are related directly to vehicle emissions (greenhouse gases) and an accident-related fatality. Table G-28 identifies the transportation characteristics for the RTT alternatives and applies documented rates of occurrence or risk factors as appropriate.

Table G-28. Estimated annual emissions and fatalities resulting from shipments.

\begin{tabular}{|c|c|c|c|c|}
\hline Impact Type & Factor & $\begin{array}{c}\text { ATR-MFC-TREAT- } \\
\text { MFC }^{1}\end{array}$ & $\begin{array}{c}\text { ATR-MFC-ACRR } \\
\text { Route } 1^{2} \\
\end{array}$ & $\begin{array}{c}\text { ATR-MFC-ACRR } \\
\text { Route } 2^{2} \\
\end{array}$ \\
\hline Miles/one-way trip (MFC-ARCC) & & & 1,347 & 1,914 \\
\hline Miles/roundtrip & & 25.2 & 2,720 & 3,853 \\
\hline Trips/year & & 34 & 34 & 34 \\
\hline Distance/year & & $\begin{array}{r}857 \mathrm{mi} \\
1,379 \mathrm{~km}\end{array}$ & $\begin{array}{r}92,419 \\
148,730\end{array}$ & $\begin{array}{l}131,010 \\
210,832\end{array}$ \\
\hline Gallons/year & $\begin{array}{r}6.6 \\
\mathrm{mi} / \mathrm{gallo} \\
\mathrm{n}^{3}\end{array}$ & 128.65 & $13,876.70$ & $19,670.99$ \\
\hline Greenhouse gases & $\begin{array}{r}22.2 \\
\mathrm{lb} / \mathrm{gal}^{4}\end{array}$ & 1.43 ton & 154.03 ton & 218.35 ton \\
\hline Accident fatality ${ }^{5}(\# / \mathrm{km})$ & $\begin{array}{r}3.53 \mathrm{E}-3 \\
\text { fatalities/ } \\
\text { accident }\end{array}$ & $1.13 \mathrm{E}-05$ & $1.25 \mathrm{E}-05$ & $2.3 \mathrm{E}-05$ \\
\hline $\begin{array}{l}\text { 1. ATR to MFC }=23.61 \mathrm{mi}, \mathrm{MFC} \text { to TR } \\
\text { 2. ATR to MFC }=23.61 \mathrm{mi}, \mathrm{MFC} \text { to TA } \\
\text { Route } 2 . \\
3 \text { State Transportation Statistics } 2011 . \\
4 \mathrm{www} \text {.eia.gov/tools/faqs/faq.cfm?id=3 }\end{array}$ & $\begin{array}{l}\mathrm{AT}=0.8 \mathrm{mi}, \\
\text { at } \mathrm{SNL}-1 \\
\& \mathrm{t}=11 .\end{array}$ & $\begin{array}{l}\text { tal miles } / \text { trip }=25.2 \mathrm{mi} . \\
46.5 \text { Route } 1,1914 \text { Route }\end{array}$ & tal miles/trip=2,720 fo & oute $1,1,914$ for \\
\hline
\end{tabular}

\section{G-8. SUMMARY}

Dose risk and LCF risk were computed for transport on INL (Section G-5) and transport between MFC and ACRR (Section G-6), assuming transport of the bounding radionuclide inventory discussed in Appendix E. This inventory represents the highest dose potential of any package that would be contained in any of the transient test experiments. It is likely that many of the experiment packages transported in support of transient testing would be smaller in size and would contain less dose-potential.

\section{G-8.1 Incident-Free Transportation Results}

Results presented and discussed in Sections G-5 and G-6 were provided for a single, one-way shipment. To determine an annual dose in person-rem for the 34 experiments to be conducted (shown in Table G-1), these results were multiplied by the number of one-way shipments to obtain the summary results provide in this section.

Routine transportation will have an impact on the crew (2 drivers), inspectors of the shipment, populations along the route (residents or people in facilities), persons sharing the route (other drivers), and persons at stops. For transport at INL, incident-free radiological exposure for two casks is provided in Table G-29. These values represent doses and LCF for 34 roundtrip shipments; therefore, they represent an annual dose. The maximum radiologic exposure regardless of cask is provided in Table G-30. 
Table G-29. Dose summary for routine transportation for 34 roundtrips between the Advanced Test Reactor Complex and TREAT.

\begin{tabular}{|c|c|c|c|c|c|c|}
\hline \multirow[t]{2}{*}{ Link } & \multicolumn{3}{|c|}{ BRR Cask } & \multicolumn{3}{|c|}{ GE2000 Cask } \\
\hline & Crew & $\begin{array}{c}\text { People Along } \\
\text { Route }\end{array}$ & $\begin{array}{c}\text { People Sharing } \\
\text { Route }\end{array}$ & Crew & $\begin{array}{c}\text { People Along } \\
\text { Route }\end{array}$ & $\begin{array}{c}\text { People Sharing } \\
\text { Route }\end{array}$ \\
\hline ATR-INTEC & $2.41 \mathrm{E}-02$ & $7.00 \mathrm{E}-03$ & $5.24 \mathrm{E}-03$ & $2.70 \mathrm{E}-02$ & $7.89 \mathrm{E}-03$ & $5.88 \mathrm{E}-03$ \\
\hline INTEC-CFA & $3.33 \mathrm{E}-02$ & $2.88 \mathrm{E}-03$ & $7.28 \mathrm{E}-03$ & $3.74 \mathrm{E}-02$ & $3.24 \mathrm{E}-03$ & $8.16 \mathrm{E}-03$ \\
\hline CFA-MFC & $2.51 \mathrm{E}-01$ & 2.84E-02 & $5.47 \mathrm{E}-02$ & $2.82 \mathrm{E}-01$ & $3.19 \mathrm{E}-02$ & $6.14 \mathrm{E}-02$ \\
\hline MFC-TREAT & $9.86 \mathrm{E}-03$ & $2.28 \mathrm{E}-03$ & $2.15 \mathrm{E}-03$ & $1.11 \mathrm{E}-02$ & $2.56 \mathrm{E}-03$ & $2.41 \mathrm{E}-03$ \\
\hline Totals & $3.18 \mathrm{E}-01$ & $4.06 \mathrm{E}-02$ & $6.94 \mathrm{E}-02$ & $3.21 \mathrm{E}-01$ & 4.15E-02 & $7.00 \mathrm{E}-02$ \\
\hline $\begin{array}{l}\text { Maximum individual dose } \\
\text { (rem) }\end{array}$ & & $2.31 \mathrm{E}-05$ & & & $2.58 \mathrm{E}-05$ & \\
\hline $\begin{array}{l}\text { Inspector/escort (rem) } \\
\text { ( } 3 \text { m from cask) }\end{array}$ & & $6.23 \mathrm{E}-01$ & & & $5.88 \mathrm{E}-01$ & \\
\hline
\end{tabular}

Table G-30. Summary of analysis results for routine transportation for 34 roundtrips between the Advanced Test Reactor to TREAT.

\begin{tabular}{lcc}
\hline \multicolumn{1}{c}{ Receptor } & Dose (person-rem) & LCF \\
\hline Crew & 0.32 & $1.9 \mathrm{E}-04$ \\
Population Along Route & 0.04 & $2.5 \mathrm{E}-05$ \\
Vehicle Occupants Sharing Route & 0.07 & $4.2 \mathrm{E}-05$ \\
Maximum Individual Dose (rem) & $2.6 \mathrm{E}-05$ & $1.6 \mathrm{E}-08$ \\
Inspector/Escort (rem) & & \\
$(3 \mathrm{~m}$ from cask) & $6.2 \mathrm{E}-01$ & $3.7 \mathrm{E}-04$ \\
\hline
\end{tabular}

For transport from MFC to ACRR, incident-free radiological exposure for both routes and each cask is provided in Table G-31. These values represent doses, percent of background, and LCF for 34 roundtrip shipments; therefore, they represent an annual dose. The maximum radiologic exposure regardless of route and cask is provided in Table G-32.

For either alternative, it is unlikely that the crew would be the same for every shipment and exposure to drivers on INL and traveling between INL and SNL/NM would be maintained within administrative limits for DOE workers of 5 rem/year (DOE 1994).

\section{G-8.2 Non-Incident-Free Transportation Results}

Controlled access, low speeds, robust casks, and limited mileage would preclude accidents severe enough to result in cask releases at INL. Therefore, accident results at INL are not provided.

Table G-33 provides a summary of the estimated annual dose and LCF for non-incident free transportation between MFC and ACRR based on 20-roundtrips per year. Table G-34 provides the summary of estimated annual dose risk and LCF risk. It is extremely unlikely that an LCF would occur as a result of any incident involving an accident during transport of the transient testing experiments. 


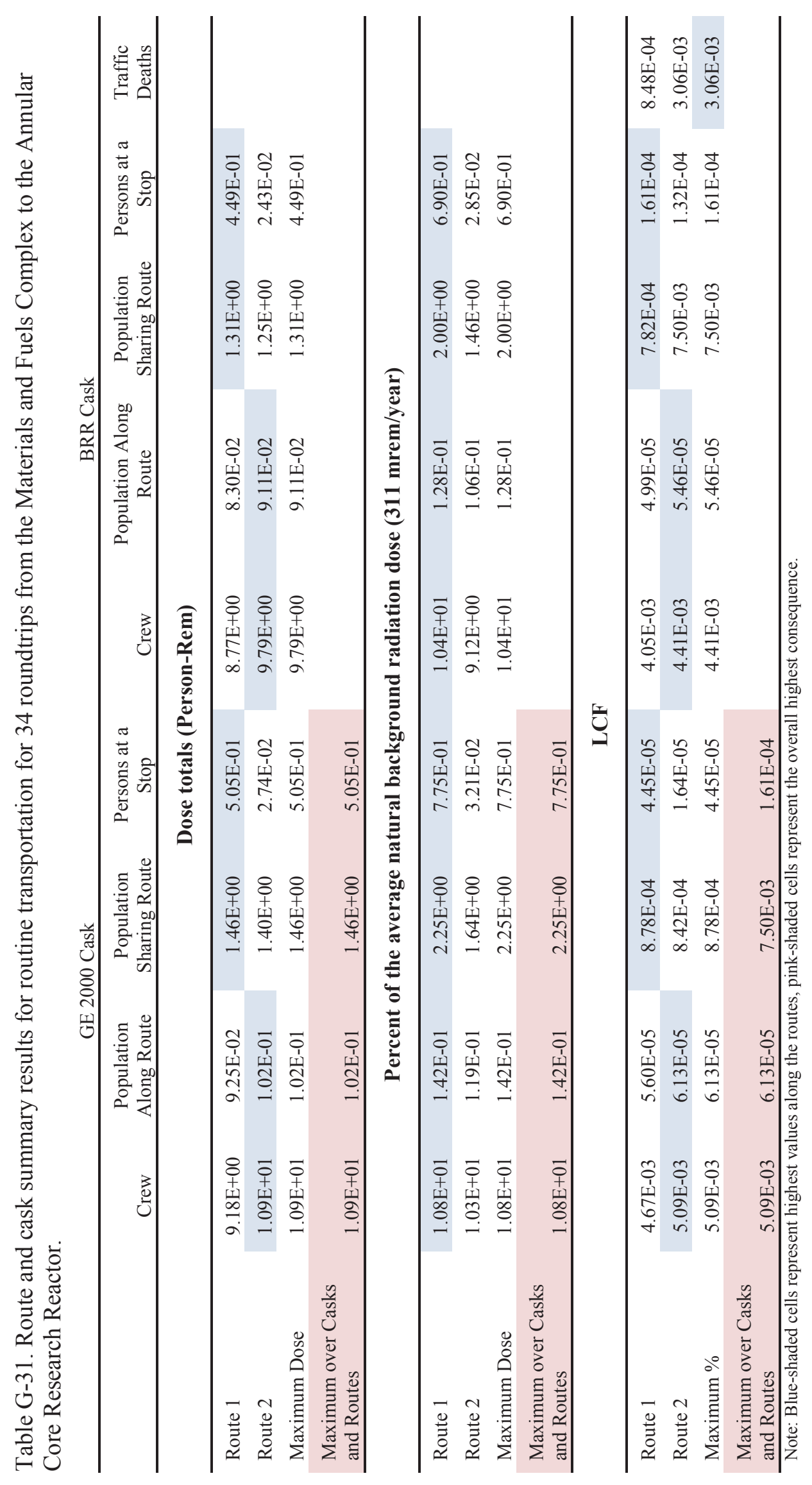

$\stackrel{m}{\forall}$ 
Table G-32. Summary of analysis results for routine transportation for 34 roundtrips from the Materials and Fuels Complex to the Annular Core Research Reactor.

\begin{tabular}{lcc}
\hline \multicolumn{1}{c}{ Receptor } & Dose (person-rem) & LCF \\
\hline Crew & 10.9 & $5.09 \mathrm{E}-03$ \\
Population Along Route (residents) & 0.1 & $6.13 \mathrm{E}-05$ \\
Vehicle Occupants Sharing Route & 1.5 & $7.50 \mathrm{E}-03$ \\
Persons at a Stop & 0.5 & $1.61 \mathrm{E}-04$ \\
\hline
\end{tabular}

Table G-33. Summary results for transportation accidents occurring between the Materials and Fuels Complex and Annular Core Research Reactor.

\begin{tabular}{lccccc}
\hline & \multicolumn{2}{c}{$\begin{array}{c}\text { Accident not Involving a Release from the } \\
\text { Cask or Loss of the Lead Shield }\end{array}$} & \multicolumn{3}{c}{ Accident Involving a Release } \\
& Person-rem & LCF & \multicolumn{2}{c}{ Person-rem } & LCF \\
\hline Overall Maximum dose per accident & $1.68 \mathrm{E}-02$ & $1.01 \mathrm{E}-05$ & $2.83 \mathrm{E}-01$ & $1.70 \mathrm{E}-04$ \\
Overall Maximum dose risk per accident & $1.00 \mathrm{E}-06$ & $6.02 \mathrm{E}-10$ & $1.16 \mathrm{E}-14$ & $6.96 \mathrm{E}-18$ \\
\hline
\end{tabular}

\section{G-9. REFERENCES}

10 CFR 71, "Packaging and Transportation of Radioactive Material," Code of Federal Regulations, Office of the Federal Register.

DOE, 1994, "DOE Radiological Control Manual,” DOE/EH-0256T, Revision 1, U.S. Department of Energy, April 1994.

DOE, 2002a, "Recommendations for Analyzing Accidents Under the National Environmental Policy Act," U.S. Department of Energy Environmental, Safety and Health, Office of NEPA Policy and Compliance.

DOE, 2002b, “A Resource Handbook on DOE Transportation Risk Assessment,” U.S. DOE National Transportation Program, DOE/EM/NTP/HB-01, July 2002.

DOE, 2004, "Recommendations for the Preparation of Environmental Assessments and Environmental Impact Statements, Second Edition,” U.S. Department of Energy Environmental, Safety and Health, Office of NEPA Policy and Compliance, 2004.

ISCORS, 2002, "ISCORS Technical Report No. 1, A Method for Estimating Radiation Risk from TEDE," Interagency Steering Committee on Radiation Standards, July 2002.

Griego, N. R., J. D. Smith, and K. S. Neuhauser, 1996, "Investigation of RADTRAN Stop Model Input Parameters for Truck Stops," Waste Management '96, Tucson, Arizona.

NCRP, 2009, "Ionizing radiation exposure of the Population of the United States," Report 160, National Council on Radiation Protection, Bethesda, MD.

Neuhauser, K. S., F. L. Kanipe, and R. F. Weiner, 2000, “RADTRAN 5, Technical Manual,” Sandia National Laboratories, Albuquerque, New Mexico. 
NRC, 1977, "Final Environmental Statement on the Transportation of Radioactive Material by Air and Other Modes," NUREG-0170, Nuclear Regulatory Commission, Washington, DC.

NRC, 2013, “Spent Fuel Transportation Risk Assessment,” NUREG-2125, Nuclear Regulatory Commission, Washington, DC.

Weiner, R. F., M. L. Dennis, D. Hinojosa, T. J. Heames, J. J. Penisten, M. K. Marincel, and D. M. Osborn, 2009, RadCat 3.0 User Guide, SAND2009-5129P, Sandia National Laboratories, Albuquerque, New Mexico. 